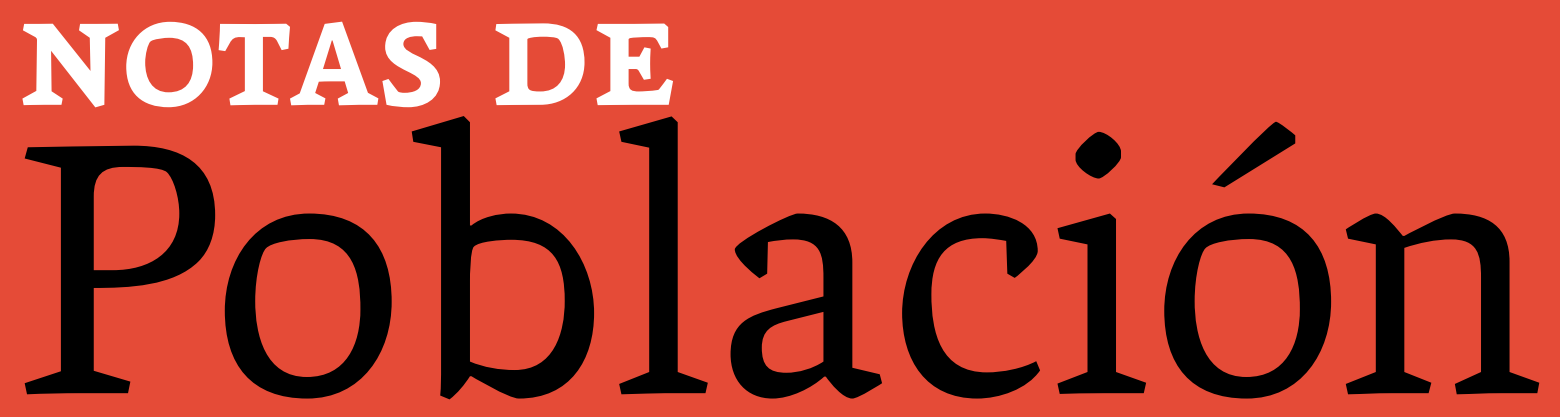

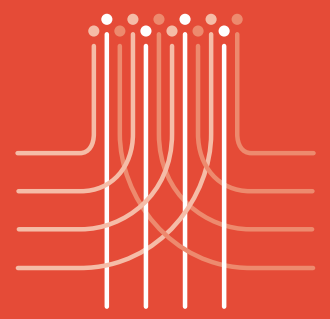

\section{JULIO-DICIEMBRE 2015}

AÑO XLII

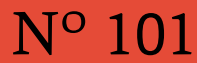

ISSN 0303-1829
Modelo de transición logística aplicado a la población de México

Gerardo Núñez Medina

Proyecciones de la población argentina a lo largo del siglo XXI

\section{Leandro M. González}

Descenso y transición epidemiológica de la mortalidad infantil en América Latina y el Caribe

Alejandro Aguirre, Fortino Vela Peón

Distribución territorial y determinantes de la fecundidad adolescente en Colombia

Víctor Hugo Álvarez Castaño

Los entornos y el envejecimiento en Iberoamérica: análisis a partir de las condiciones de la vivienda

Sagrario Garay Villegas, Verónica Montes de Oca Zavala, Mirna Hebrero Martínez

Del rejuvenecimiento al envejecimiento de la población ¿o viceversa?: Chile en el contexto de América Latina, 1950-2050 Rodrigo Rivero-Cantillano, Jeroen Spijker
Subutilización de las capacidades de los profesionales mexicanos de las ciencias y la tecnología y su vínculo con la migración a los Estados Unidos

\section{Fernando Lozano Ascencio,} Telésforo Ramírez-García

La actitud positiva y el bienestar: un análisis del ciclo vital de la esperanza de vida sana y la esperanza de vida feliz a nivel individual en el Brasil y México

Gilvan R. Guedes, Cristina G. Rodrigues, Luisa P. Terra

El yo y el otro: alteridad próxima en la declaración del color y la raza en preguntas abiertas Kaizô Iwakami Beltrão, Moema De Poli Teixeira 


\section{NOTAS DE}

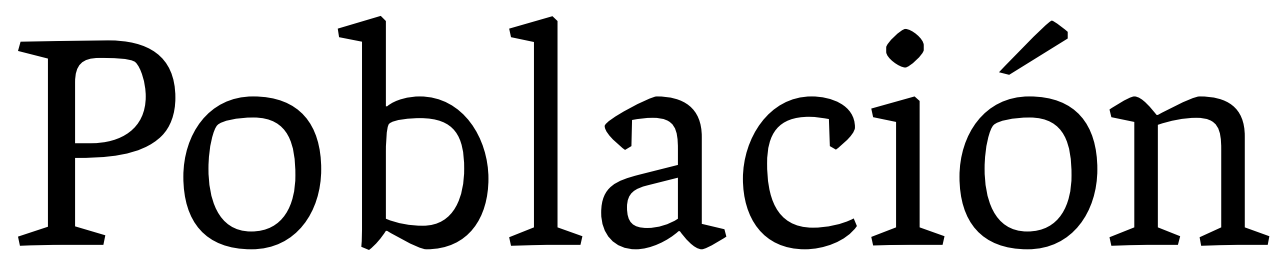

No 101

Santiago, julio-diciembre de 2015

Año XLII

NACIONES UNIDAS 


\author{
Alicia Bárcena \\ Secretaria Ejecutiva \\ Antonio Prado \\ Secretario Ejecutivo Adjunto \\ Dirk Jaspers_Faijer \\ Director del Centro Latinoamericano y Caribeño de Demografía \\ (CELADE)-División de Población de la CEPAL

\section{Ricardo Pérez} \\ Director de la División de Publicaciones y Servicios Web
}

\author{
Comité Editorial \\ Director: Dirk Jaspers_Faijer \\ Coordinador: Jorge Martínez Pizarro \\ Miembros: Enrique González, Leandro Reboiras, Magda Ruiz, Paulo Saad y Orly Winer \\ Secretaria: María Ester Novoa
}

Todos los miembros del Comité Editorial pertenecen al CELADE-División de Población de la CEPAL.

Redacción y administración: casilla 179-D, Santiago, Chile. E-mail: CELADE-NotasDePoblacion@cepal.org.

La revista Notas de Población es una publicación del Centro Latinoamericano y Caribeño de Demografía (CELADE)-División de Población de la CEPAL, cuyo propósito principal es la difusión de investigaciones y estudios de población sobre América Latina y el Caribe, aun cuando recibe con particular interés artículos de especialistas de fuera de la región y, en algunos casos, contribuciones que se refieren a otras regiones del mundo. Se publica dos veces al año, con una orientación interdisciplinaria, por lo que acoge tanto artículos sobre demografía propiamente tal como otros que aborden las relaciones entre las tendencias demográficas y los fenómenos económicos, sociales y biológicos. Las opiniones expresadas en esta revista son responsabilidad de los autores, y pueden no coincidir con las del Centro Latinoamericano y Caribeño de Demografía (CELADE)-División de Población de la CEPAL.

La revista Notas de Población está indizada en Citas Latinoamericanas en Ciencias Sociales y Humanidades (CLASE) y en el Sistema Regional de Información en Línea para Revistas Científicas de América Latina, el Caribe, España y Portugal (LATINDEX). 


\section{Consejo Editorial}

\begin{tabular}{|c|}
\hline Nombre \\
\hline Antonio Aja Díaz \\
\hline Juan Carlos Alfonso Fraga \\
\hline José Luis Ávila Martínez \\
\hline Guiomar Bay \\
\hline Wanda Cabella \\
\hline Anna Cabré Pla \\
\hline Francisco Cáceres \\
\hline Juan José Calvo \\
\hline Alejandro I. Canales \\
\hline Suzana Cavenaghi \\
\hline Dora E. Celton \\
\hline Marcela Cerruti \\
\hline Mirna Cunningham \\
\hline Fabiana del Popolo \\
\hline Mariachiara Di Cesare \\
\hline Andreu Domingo Valls \\
\hline Albert Esteve \\
\hline Carmen Elisa Florez Nieto \\
\hline Anitza Freitez \\
\hline Silvia Elena Giorguli Saucedo \\
\hline Daniela González \\
\hline Alejandro Guillén García \\
\hline Martín Hopenhayn \\
\hline Sandra Huenchuan \\
\hline Dina Li Suárez \\
\hline Fernando Lozano Ascencio \\
\hline Cássio Maldonado Turra \\
\hline Robert McCaa \\
\hline Tim Miller \\
\hline Abelardo Morales \\
\hline Irene Palma Calderón \\
\hline Enrique Peláez \\
\hline Héctor Pérez Brignoli \\
\hline José Marcos Pinto da Cunha \\
\hline Joseph E. Potter \\
\hline Jorge Rodríguez Vignoli \\
\hline Laura Rodríguez Wong \\
\hline Luis Rosero-Bixby \\
\hline Susana Schkolnik \\
\hline Alejandra Silva \\
\hline Zulma Sosa Portillo \\
\hline Andras Uthoff \\
\hline Miguel Villa \\
\hline Brenda Yépez Martínez \\
\hline
\end{tabular}

Afiliación institucional

Universidad de La Habana

Oficina Nacional de Estadística e Información

Universidad Nacional Autónoma de México

CELADE-División de Población de la CEPAL

Universidad de la República

Universidad Autónoma de Barcelona

Oficina Nacional de Estadística

Universidad de la República

Universidad de Guadalajara

Instituto Brasileño de Geografía y Estadística

Universidad Nacional de Córdoba

Centro de Estudios de Población

Centro para la Autonomía y Desarrollo de los Pueblos Indígenas CELADE-División de Población de la CEPAL

Imperial College London

Universidad Autónoma de Barcelona

Universidad Autónoma de Barcelona

Universidad del Rosario

Universidad Católica Andres Bello

El Colegio de México

CELADE-División de Población de la CEPAL

Universidad de Cuenca

Consultor independiente

CELADE-División de Población de la CEPAL

Consultora independiente

Universidad Nacional Autónoma de México

Universidad Federal de Minas Gerais

Universidad de Minnesota

CELADE-División de Población de la CEPAL

Facultad Latinoamericana de Ciencias Sociales (FLACSO)

Instituto Centroamericano de Estudios Sociales y Desarrollo

Universidad Nacional de Córdoba

Universidad de Costa Rica

Universidad Estadual de Campinas

Universidad de Texas en Austin

CELADE-División de Población de la CEPAL

Universidad Federal de Minas Gerais

Universidad de California en Berkeley

Consultora independiente

CELADE-División de Población de la CEPAL

Instituto Nacional de Desarrollo Rural y de la Tierra

Consultor independiente

Consultor independiente

Universidad Central de Venezuela

El Colegio de México

\section{País/organización}

Cuba

Cuba

México

CEPAL

Uruguay

España

República Dominicana

Uruguay

México

Brasil

Argentina

Argentina

Nicaragua

CEPAL

Reino Unido

España

España

Colombia

República Bolivariana de Venezuela

México

CEPAL

Ecuador

Chile

CEPAL

Perú

México

Brasil

Estados Unidos

CEPAL

Costa Rica

Guatemala

Argentina

Costa Rica

Brasil

Estados Unidos

CEPAL

Brasil

Estados Unidos

Chile

CEPAL

Paraguay

Chile

Chile

República Bolivariana de Venezuela México 
Los límites y los nombres que figuran en los mapas de esta publicación no implican su apoyo o aceptación oficial por las Naciones Unidas.

Publicación de las Naciones Unidas

ISBN: 978-92-1-121902-9 (versión impresa)

ISBN: 978-92-1-057231-6 (versión pdf)

ISBN: 978-92-1-358019-6 (versión ePub)

$N^{\circ}$ de venta: S.15.II.G.14

LC/G.2651-P

Copyright (๑) Naciones Unidas, 2015

Todos los derechos reservados.

Impreso en Naciones Unidas, Santiago

S.15-00721

Esta publicación debe citarse como: Comisión Económica para América Latina y el Caribe (CEPAL), Notas de Población, N 101, (LC/G.2651-P), Santiago de Chile, 2015

La autorización para reproducir total o parcialmente esta obra debe solicitarse al Secretario de la Junta de Publicaciones, Sede de las Naciones Unidas, Nueva York 10017, Estados Unidos. Los Estados miembros y sus instituciones gubernamentales pueden reproducir esta obra sin autorización previa. Solo se les solicita que mencionen la fuente e informen a las Naciones Unidas de tal reproduccción. 


\section{Índice}

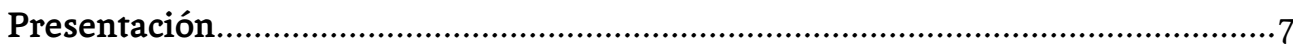

Modelo de transición logística aplicado a la población de México ...........................11

Gerardo Núñez Medina

Proyecciones de la población argentina a lo largo del siglo XXI .37

Leandro M. González

Descenso y transición epidemiológica de la mortalidad infantil

en América Latina y el Caribe

Alejandro Aguirre, Fortino Vela Peón

Distribución territorial y determinantes de la fecundidad adolescente

en Colombia

Víctor Hugo Álvarez Castaño

Los entornos y el envejecimiento en Iberoamérica: análisis a partir de

las condiciones de la vivienda

Sagrario Garay Villegas, Verónica Montes de Oca Zavala,

Mirna Hebrero Martínez

Del rejuvenecimiento al envejecimiento de la población ¿o viceversa?:

Chile en el contexto de América Latina, 1950-2050

Rodrigo Rivero-Cantillano, Jeroen Spijker

Subutilización de las capacidades de los profesionales mexicanos

de las ciencias y la tecnología y su vínculo con la migración

a los Estados Unidos.

Fernando Lozano Ascencio, Telésforo Ramírez-García

La actitud positiva y el bienestar: un análisis del ciclo vital de la esperanza de vida sana y la esperanza de vida feliz a nivel individual en el Brasil y México.

Gilvan R. Guedes, Cristina G. Rodrigues, Luisa P. Terra

El yo y el otro: alteridad próxima en la declaración del color y la raza en preguntas abiertas

Kaizô Iwakami Beltrão, Moema De Poli Teixeira 



\section{Presentación}

Llega a los lectores la edición número 101 de Notas de Población, que contiene nueve artículos sobre temas de gran actualidad y relevancia futura en el campo de la investigación sociodemográfica en América Latina y el Caribe. La variada gama de asuntos que se abordan en la presente edición empieza con la aplicación del modelo de transición logística y las proyecciones de población, pasando por el análisis de la transición epidemiológica de la mortalidad infantil en América Latina y los determinantes de la fecundidad adolescente y su relación con la distribución territorial. Continúa con el envejecimiento, su relación con las condiciones de la vivienda, la migración calificada y el análisis del ciclo vital de las personas en relación con una esperanza de vida sana. Concluye con la percepción de la alteridad en la declaración del color y la raza en la encuesta de empleo del Brasil.

Coincidiendo con el reciente lanzamiento de la edición 2015 de World Population Prospects por parte de la División de Población del Departamento de Asuntos Económicos y Sociales (DAES) de las Naciones Unidas, el presente número de Notas se inicia con dos artículos sobre proyecciones de la población. El primero de ellos, "Modelo de transición logística aplicado a la población de México", de Gerardo Núñez Medina, contiene una propuesta metodológica orientada a acotar el límite máximo que puede alcanzar una población en las proyecciones de largo plazo. En el segundo artículo, "Proyecciones de la población argentina a lo largo del siglo XXI", Leandro González presenta un esbozo de los posibles escenarios que podría seguir la población argentina a lo largo del siglo XXI, de acuerdo a la dinámica demográfica reciente. Sobre la base de la población censada en el año 2010, propone cuatro escenarios demográficos a partir de diversos niveles futuros de fecundidad.

También en el plano metodológico, y combinando el análisis de un problema prioritario, el siguiente trabajo, "Descenso y transición epidemiológica de la mortalidad infantil en América Latina y el Caribe", de Alejandro Aguirre y Fortino Vela-Peón, se propone dar respuesta a algunos interrogantes sobre la medición adecuada de la mortalidad infantil en América Latina, la confiabilidad de las estadísticas vitales para estimar la tasa de mortalidad infantil y la utilidad de las estadísticas vitales para el conocimiento del perfil epidemiológico de dicha mortalidad. Mediante la comparación de las estimaciones obtenidas por el método de Brass con las que se obtienen directamente de las estadísticas vitales, los autores analizan la pertinencia de la utilización de esta técnica indirecta para contar con estimaciones confiables de la mortalidad infantil en la región.

Los artículos que siguen vinculan los temas de fecundidad adolescente y envejecimiento, respectivamente, con el de territorio. En "Distribución territorial y determinantes de la fecundidad adolescente en Colombia", Víctor Hugo Álvarez Castaño explora el uso inédito del registro de nacimientos como fuente primaria para describir el grado y el patrón de 
la fecundidad adolescente en niveles geográficos y grupos de edad más desagregados, complementado con una revisión analítica de los determinantes próximos que influyen en posibles diferencias regionales. Por su parte, en el artículo "Los entornos y el envejecimiento en Iberoamérica: análisis a partir de las condiciones de la vivienda", de Sagrario Garay Villegas, Verónica Montes de Oca Zavala y Mirna Hebrero Martínez, las autoras llaman la atención sobre la relevancia que tienen las condiciones de la vivienda, el acceso a los servicios públicos y la configuración física y social de los entornos en los cuales reside la población adulta mayor a la hora de analizar los desafíos que plantea el envejecimiento demográfico. En este marco, el artículo propone la exploración de las características de la vivienda y el acceso a servicios públicos de la población adulta mayor en países seleccionados de la región iberoamericana.

A continuación, Rodrigo Rivero-Cantillano y Jeroen Spijker, en el artículo "Del rejuvenecimiento al envejecimiento de la población ¿o viceversa?: Chile en el contexto de América Latina, 1950-2050", proponen un nuevo enfoque para analizar el envejecimiento demográfico - que denominan "la perspectiva prospectiva" - y lo aplican al caso de la población de Chile. Dicho enfoque considera las mejoras en la esperanza de vida para calcular la edad umbral de la vejez como alternativa al uso de una edad fija, como es los 60065 años.

El tema de la migración internacional se aborda en el artículo de Fernando Lozano Ascencio y Telésforo Ramírez-García, "Subutilización de las capacidades de los profesionales mexicanos de las ciencias y la tecnología y su vínculo con la migración a los Estados Unidos". Sobre la base de la información proporcionada por la Encuesta Nacional de Ocupación y Empleo (ENOE) de México, y de la American Community Survey (ACS) de los Estados Unidos, los autores analizan el problema de la subutilización de las capacidades de la población de profesionales mexicanos, tanto en su país de origen como en aquel país de destino, con énfasis en aquellos formados en las áreas de ciencias, tecnología, ingenierías y matemáticas (CTIM).

Ya en el campo del envejecimiento, el siguiente artículo aborda una temática menos usual en la investigación, desarrollando una metodología novedosa que introduce la dimensión actitudinal en relación con los conceptos de "esperanza de vida sana" y "esperanza de vida feliz". En efecto, el artículo de Gilvan Guedes, Cristina Rodrigues y Luisa Terra, "La actitud positiva y el bienestar: un análisis del ciclo vital de la esperanza de vida sana y la esperanza de vida feliz a nivel individual en el Brasil y México", aporta un análisis comparado para las poblaciones de México y el Brasil sobre la relación entre una actitud positiva y el tiempo de vida restante saludable y feliz en el ciclo de vida individual.

Por último, y en el plano del diseño y afinación de encuestas para la captación de características sociodemográficas de los distintos grupos étnicos de la población, el artículo que cierra la presente edición de Notas de Población es "El yo y el otro: la alteridad próxima en la declaración del color y la raza en preguntas abiertas. El caso de la Encuesta Mensual de Empleo del Instituto Brasileño de Geografía y Estadística", de Kaizô Iwakami Beltrão y Moema De Poli Teixeira. Reconociendo el hecho de que en las encuestas domiciliarias 
una de las principales limitaciones radica en que un único informante responde por los demás residentes, los autores se proponen comparar, a través del Suplemento de Color y Origen de la Encuesta Mensual de Empleo del Instituto Brasileño de Geografía y Estadística (IBGE), las respuestas a las preguntas abiertas y cerradas sobre color y raza discriminando el informante.

Comité Editorial de Notas de Población 



\title{
Modelo de transición logística aplicado a la población de México
}

\author{
Gerardo Núñez Medina1
}

Recibido: 12/06/2015

Aceptado: 15/07/2015

\section{Resumen}

El método de proyección de población propuesto se origina en la necesidad de acotar el límite máximo que puede alcanzar una población en proyecciones a largo plazo. Para lograr dicho objetivo, se tiene en cuenta la información sobre el tamaño de la población total proyectada por el modelo de crecimiento logístico en la estimación de la estructura por edad y sexo, en cada paso de la proyección realizada mediante el método de cohorte-componente.

Además de analizar la evolución del crecimiento logístico que deberá seguir la población total, el modelo propuesto incorpora la tendencia establecida por la teoría de la transición demográfica en relación al descenso de las tasas de mortalidad y fecundidad. En particular, se modifica la dirección de la deriva empleada para la proyección de las tasas específicas de mortalidad y fecundidad establecidas en el modelo de Lee-Carter, de conformidad con la tendencia histórica y las proyecciones futuras dictadas por la teoría de la transición demográfica.

Palabras clave: proyección; cohorte-componente; transición; largo plazo.

Doctor en Demografía por la Universidad Autónoma de Barcelona, Maestro en Ingeniería por la Universidad Nacional Autónoma de México, Maestro en Demografía por El Colegio de México, Director de Investigación y Evaluación del Consejo de Investigación y Evaluación de la Política Social del Estado de Chiapas. Correo electrónico: gerardo.nm1@gmail.com. 


\begin{abstract}
The population projection method proposed is a response to the need to specify the maximum population limit in long-range projections. To this end, each stage of the cohort-component method projection uses age and sex structure estimates for the total population projected by the logistic growth model.

In addition to analysing the evolution of logistic growth for the total population, the model incorporates the negative trend in mortality and fertility rates described by demographic transition theory. In particular, the direction of the drift used to project specific mortality and fertility rates established in the Lee-Carter model are modified, in line with historical trends and future projections suggested by demographic transition theory.
\end{abstract}

Keywords: population projection; cohort component; transition; long-range.

\title{
Résumé
}

La méthode de projection de la population proposée répond à la nécessité de préciser la limite supérieure que peut atteindre une population dans les projections à long terme.

Pour ce faire, il faut tenir compte de l'information relative à la taille de la population totale projetée par le modèle de croissance logistique dans l'estimation de la structure par âge et par sexe, à chaque étape de la projection réalisée moyennant la méthode de composante cohorte.

Le modèle proposé ne se limite pas à analyser l'évolution de la croissance logistique que devra suivre la population totale; il incorpore également la tendance établie par la théorie de la transition démographique par rapport à la diminution des taux de mortalité et de fécondité. II modifie en particulier le sens de la dérive utilisée pour la projection des taux spécifiques de mortalité et de fécondité tels qu'ils ont été établis dans le modèle de Lee-Carter, conformément à la tendance historique et aux projections futures résultant de la théorie de la transition démographique.

Mots clés: projection de la population; composante cohorte; transition; long terme. 


\section{Introducción}

La proyección de población constituye un insumo básico en la planificación que realizan muchas áreas estratégicas de ámbitos tanto públicos como privados, e involucra sectores que van desde la economía, la educación y la salud, hasta el turismo y la recreación. En consecuencia, es fundamental contar con proyecciones de población que coadyuven al proceso de toma de decisiones.

En la actualidad, la mayor parte de las proyecciones de población se realizan mediante técnicas basadas en variaciones del método de proyección cohorte-componente (Partida, 2008). Dichas variaciones han surgido a partir de cambios en la forma de modelar y proyectar las tasas de mortalidad y fecundidad y, en menor medida, de migración. Las nuevas formas de proyección incorporan modelos estocásticos clásicos o bayesianos que proyectan el comportamiento de las tasas de crecimiento natural y social, que luego se integran a la ecuación de balance demográfico. Entre las más importantes se encuentran: las distintas variantes del método de Lee-Carter (Lee y Carter, 1992), el análisis de datos funcionales propuesto por Hyndman y Ullah (2007) y diferentes aproximaciones bayesianas (Hoeting y otros, 2012) que hacen uso del método de cohorte-componente.

Los métodos para la proyección de la población se dividen en dos grandes categorías: los que proyectan la población total y los que proyectan la estructura por edad y sexo. Ambos tipos funcionan de manera independiente, de modo que una proyección no aporta explícitamente información a la otra. Así, podría suponerse que proyectar la población total es un proceso completamente independiente del desarrollo de una proyección de la estructura por edad, como si la evolución de la estructura por edad no afectara en modo alguno el volumen de población total o viceversa.

En este sentido, se propone la elaboración de un método de proyección que reúna información sobre la evolución de la población total mediante el ajuste de un modelo de crecimiento logístico, al método de cohorte-componente, con lo que se busca obtener estimaciones más robustas y confiables en horizontes de proyección a largo plazo. Para que la tendencia de crecimiento logístico no se rompa, es necesario adecuar la evolución de las tasas de mortalidad, fecundidad y migración al comportamiento de la tasa de crecimiento poblacional.

La forma en que se proyecta la evolución de las tasas de cambio demográfico, en el caso del método de Lee-Carter, se basa en modelos autorregresivos integrados de media móvil (ARIMA) con deriva. Ese tipo de metodología incorpora información histórica de la evolución de las tasas, lo que permite que la deriva capture su ritmo del cambio (Ordorica, 2004). Sin embargo, debido a que no incorpora ningún límite (inferior o superior) sobre la evolución de la deriva, y por lo tanto, de las tasas, resulta poco útil intentar hacer predicciones a largo plazo.

A mediados del siglo XIX se postuló la teoría de la transición demográfica como un esquema general utilizado para explicar la evolución de las tasas de mortalidad y fecundidad, 
a partir de la generalización de observaciones de diversas poblaciones europeas desde inicios del siglo XIX hasta mediados del siglo XX. Este conocimiento puede incorporarse a las metodologías de proyección de población, pues captura la pauta de las tasas de mortalidad y fecundidad durante largos períodos de tiempo, lo que permite proyectar su evolución a largo plazo con un modelo simple de extrapolación.

El término cohorte-componente de transición logística se origina en de la información proveniente de la teoría de la transición demográfica y la aplicación del modelo logístico para elaborar una variante del método de Lee-Carter. La variante de Lee-Carter surge al modificar la deriva, suponiendo que la evolución de las tasas seguirá la tendencia marcada por la teoría de la transición demográfica y que la tasa de crecimiento de la población total seguirá un comportamiento logístico.

Una de las grandes ventajas de la metodología propuesta estriba en que, cuando no se posee información sobre la evolución futura de las tasas de migración, estas pueden estimarse como la diferencia de la tasa de crecimiento de población total proyectada por la curva logística y las tasas de crecimiento natural proyectadas por el método de cohortecomponente, sobre la base de la teoría de la transición demográfica. Este método puede aplicarse siempre y cuando no se disponga de información sobre la evolución de flujos migratorios, o se sospeche de cambios importantes en el sentido o la estructura de la migración, que no puedan cuantificarse de algún modo con anticipación.

\section{A. Antecedentes}

El método de cohorte-componente para la proyección de población, uno de los más utilizados a nivel mundial, consiste en proyectar la población en intervalos de tamaño $\Delta t$. Para ello, se envejece la población de base en $\Delta t$ - años y se agregan los nacimientos que se espera ocurran durante el lapso $\Delta t$. Luego deben restarse las defunciones previstas en el mismo período de tiempo en las edades pronosticadas. Por último, debe descontarse el saldo neto migratorio en el patrón de edad modelado en el período señalado. El proceso se repite hasta que $\Delta t$ alcance el horizonte de proyección deseado.

Los insumos básicos son, desde luego, la población de base y las tasas específicas de mortalidad, fecundidad y migración proyectadas en cada $\Delta t$. Las tasas proyectadas pueden estimarse por medio de extrapolaciones de tendencias históricas, modelos estructurales o técnicas de simulación. En este artículo se pondrá a prueba una técnica de extrapolación que seguirá la tendencia marcada por la teoría de la transición demográfica.

Muchos autores han tomado el trabajo desarrollado por Lee y Carter (1992) como punto de referencia clave para elaborar diferentes modelos estadístico-demográficos que tienen por objeto proyectar la evolución de las tasas de mortalidad, fecundidad y migración. 
El principio fundamental del método de Lee-Carter consiste precisamente en extrapolar las tendencias de las tasas de mortalidad, con la finalidad de proyectar su comportamiento durante largos períodos, tomando como base para su estimación datos provenientes de largas series históricas. Sin embargo, el método puede presentar desviaciones en la dirección de las tasas proyectadas, a largo plazo, debido a la presencia de observaciones aberrantes. Esta situación obliga, en algunos casos, a modificar la longitud del período de datos ajustados, con la finalidad de mejorar las estimaciones.

El modelo de Lee-Carter incorpora las tendencias estructurales observadas en los patrones de mortalidad a lo largo de casi un siglo, lo que confiere gran relevancia a los datos pasados, con efectos importantes en predicciones de corto plazo. Básicamente, extrapola la tendencia histórica de las tasas, ignorando los cambios en los patrones más recientes, situación que a largo plazo provoca incrementos desmesurados de la magnitud de las tasas.

La premisa básica del modelo es que existe una relación lineal entre el logaritmo de las tasas específicas de mortalidad $m_{x, t}$, el tiempo $t$ y la edad $x$.

Del modelo se deriva un sistema de ecuaciones aplicable a las edades y el tiempo, cuya solución proporciona una serie de valores para los parámetros $\left\{a_{x}\right\},\left\{b_{x}\right\}$ y $\left\{k_{t}\right\}$. En Li y Lee (2005), puede encontrarse una descripción exhaustiva sobre el planteamiento teórico y las distintas formas de solución del modelo de Lee-Carter.

La crítica principal al modelo de Lee-Carter es que los parámetros $a_{x}$ y $b_{x}$ dependen solo de la edad, mientras que la predicción de valores futuros de las distintas tasas se basa únicamente en el parámetro $k_{t}$, lo que equivale a admitir que no existe interacción alguna entre la edad y el tiempo.

Por su parte, la teoría de la transición demográfica marca la pauta general del comportamiento a largo plazo de las tasas de crecimiento natural. Hace referencia al cambio de un régimen de alta mortalidad y fecundidad en sociedades pretransicionales hacia uno de baja mortalidad y fecundidad en sociedades postransicionales (Chesnais, 1986), como se indica en el gráfico 1. El proceso de transición se ha dividido en tres etapas:

i) durante la primera etapa, los niveles de mortalidad comienzan a descender y los niveles de fecundidad permanecen altos y estables;

ii) en la segunda, se inicia el descenso de la fecundidad al tiempo que la mortalidad continúa reduciéndose, y

iii) en la tercera, la mortalidad y la fecundidad se estabilizan al alcanzar niveles bajos y estables.

En general, el régimen pretransicional presenta bajas tasas de crecimiento demográfico debido a la combinación de tasas de fecundidad altas y estables y tasas de mortalidad altas, pero no estables. Entretanto, el régimen postransicional presenta también bajas tasas de crecimiento, originadas por la interacción de tasas de mortalidad bajas y estables y tasas de fecundidad bajas, pero no estables (MacInnes y Pérez-Díaz, 2008). 
Gráfico 1

México: evolución de las tasas de crecimiento natural, 1895-2100

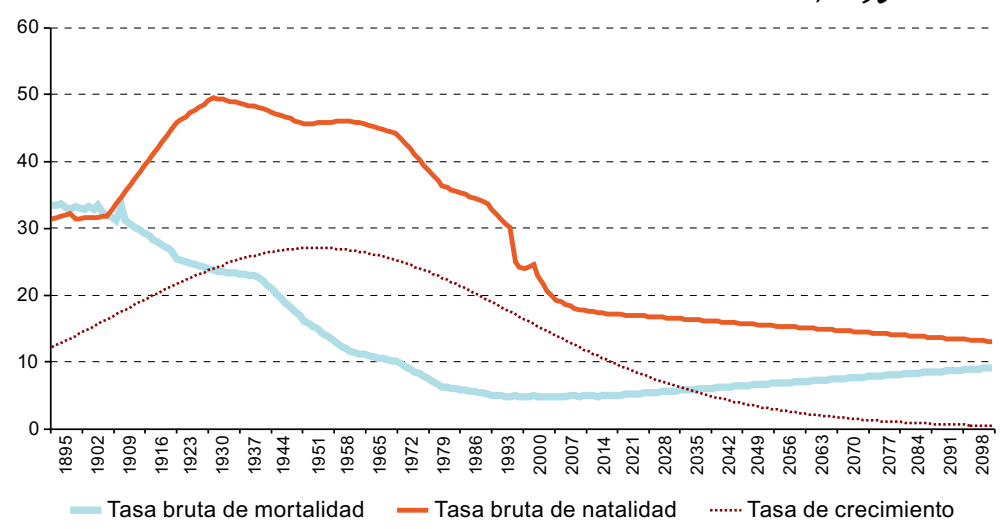

Fuente: Elaboración propia, sobre la base de datos del Instituto Nacional de Estadística y Geografía (INEGI).

La teoría de la transición es, hasta la fecha, una de las teorías demográficas más completas. Por una parte, se basa en evidencia empírica sobre el comportamiento de variables demográficas mensurables $\mathrm{y}$, aunque los países no transiten homogéneamente por los estadios establecidos, no cabe duda de que finalmente se observa el comportamiento pronosticado. Por otra parte, otras teorías demográficas la complementan y enriquecen al aportar explicaciones sobre los comportamientos observados.

La teoría de la transición demográfica proporcionó por primera vez la estructura necesaria para hacer generalizaciones empíricas sobre el comportamiento y las tendencias de las tasas de mortalidad y fecundidad, que se incorporarán al modelo de proyección de población propuesto mediante una variación del modelo de Lee-Carter.

En este punto, es necesario señalar que la teoría de la transición demográfica no hace ninguna referencia explícita sobre la forma de evolución de las tasas de migración, que se elaboró para poblaciones cerradas. Sin embargo, es de esperarse que durante la segunda etapa de transición, en la que se observarán los mayores incrementos de población, se presenten importantes flujos de emigración.

Una de las modificaciones más exitosas del método de Lee-Carter fue propuesta por Hyndman y Ullah (2007). Dicha variante combina ideas de suavización no paramétrica, regresión por componentes principales y análisis de datos funcionales para predecir el comportamiento de las tasas específicas de mortalidad, fecundidad y migración, de conformidad con los siguientes supuestos:

i) la mortalidad es una función de la edad y, con arreglo a esa suposición, se estiman las tasas de mortalidad a partir de métodos de suavización no paramétricos;

ii) se estima un conjunto de componentes del tipo $\left(k_{t}, b_{x}\right)$ más extenso, y

iii) se usan métodos generales de series de tiempo para predecir la evolución de las tasas. 
Así, Hyndman y Ullah (Hyndman, Booth y Yasmeen, 2013) presentan un método capaz de suavizar las tasas demográficas por edad e integrar, a la vez, más de un componente principal al permitir el uso de modelos generales basados en series temporales más generales que las del modelo ARIMA. Si bien estas modificaciones permiten tener un mayor control sobre el pronóstico de las tasas, no logran acotar su descenso a largo plazo.

Las ventajas del método de Hyndman-Ullah consisten en que su aplicación asegura pronósticos para tasas masculinas y femeninas que no divergen en el tiempo. El método suaviza los datos históricos mediante el uso de la función spline y utiliza modelos de series de tiempo ARIMA y ARFIMA (basadas en el modelo autorregresivo de media móvil integrado fraccionalmente), ambos proporcionados por el paquete Demography desarrollado por Hyndman en lenguaje R (Hyndman, y Khandakar, 2008).

\section{B. Datos}

Se presenta una aplicación del método propuesto para la población de México, con un horizonte de proyección de 90 años. Los datos utilizados para la proyección de población total corresponden a los años censales dentro del período 1790-2010, la disponibilidad de información sobre la evolución de las tasas de mortalidad y fecundidad se reduce a algunos años del período comprendido entre 1895 y 2010, mientras que la información histórica referente a la estructura por edad y sexo está disponible únicamente respecto de los años censales del período 1990-2010. En todos los casos, la información se puede encontrar en la página de Internet del Instituto Nacional de Estadística y Geografía (INEGI).

Por otra parte, la información referente a las estadísticas vitales, tales como nacimientos y defunciones, puede obtenerse de forma anual en relación con el período 1979-2012, respecto de las defunciones, y 1984-2012 respecto de los nacimientos. En ambos casos, la información se encuentra disponible en la página del Sistema Nacional de Información en Salud (SINAIS).

Las tasas específicas de mortalidad, fecundidad y migración se estimaron respecto del período 1990-2010, con las correcciones mínimas para utilizarlas en la proyección de población 2011-2100, y se presentan a continuación.

\section{Población total}

La proyección de la población total se ajustó a los datos reportados por los diferentes censos y conteos de población mexicanos desde 1790. La curva logística estimada permite obtener la población total del período comprendido entre los años 2011 y 2100, según se observa en el gráfico 2, donde se aprecia además una línea de tendencia con datos sin ajustar de la población total registrada en los censos de población de México desde 1790 hasta 2010. 
Gráfico 2

México: ajuste de la curva logística a la población, 1790-2150

(En millones de habitantes)

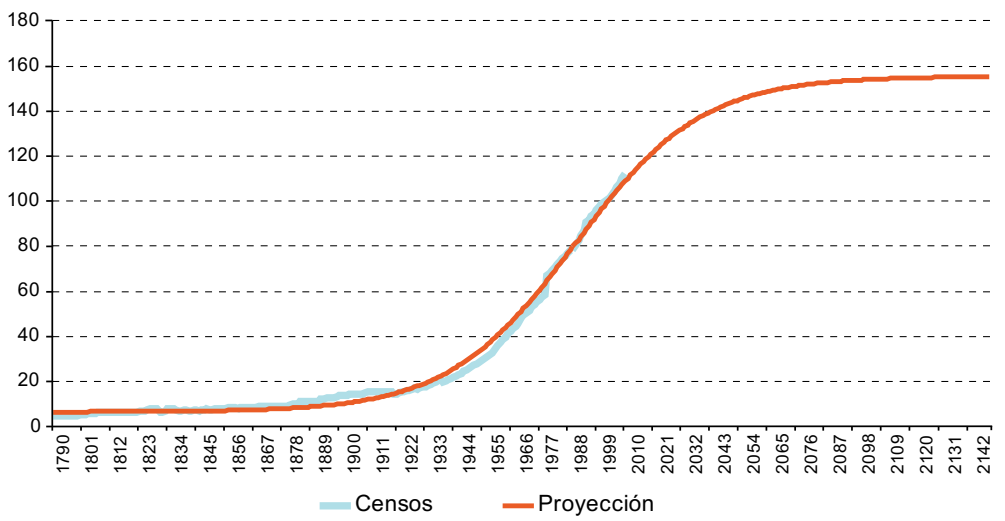

Fuente: Elaboración propia, sobre la base de datos del Instituto Nacional de Estadística y Geografía (INEGI).

Es importante señalar que la población de México parece alcanzar su límite de crecimiento alrededor de los 155 millones de habitantes, lo que ocurriría poco después de 2090 (véase el gráfico 2). Sin embargo, se espera que la población crezca a tasas menores al $1 \%$ a partir de 2018 , e inferiores al $0,1 \%$ a partir de 2080 .

\section{Tasas de mortalidad}

La estimación de las tasas específicas de mortalidad (TEM) por año en el período de 1990 a 2010 comprende la corrección e interpolación de la estructura por edad y sexo de las poblaciones censales correspondientes a los años 1990, 1995, 2000, 2005 y 2010, así como la corrección por preferencia de dígitos de las defunciones recopiladas por la Oficina del Registro Civil en el período 1989-2011.

Las tasas estimadas presentan tendencias de mortalidad aceptables para todas las edades, a excepción de la mortalidad infantil, que muestra altos niveles de subregistro, por lo que fue necesario estimarla de forma independiente con un método indirecto.

Puede decirse que los niveles de mortalidad en México comienzan a descender desde principios del siglo XX, cuando se inicia el proceso de transición demográfica. La reducción de los niveles de mortalidad tiene como consecuencia inmediata el incremento del tamaño de la población mediante dos elementos: un mayor número de nacimientos debido a la mayor sobrevivencia de mujeres en edad fértil, y una mayor esperanza de vida. Los gráficos 3 y 4 muestran el comportamiento de las TEM en relación con hombres y mujeres, respectivamente, de 1990 a 2010, con curvas que representan el descenso de los niveles de mortalidad en el tiempo. 
Gráfico 3

México: tasas específicas de mortalidad masculina, 1990-2010

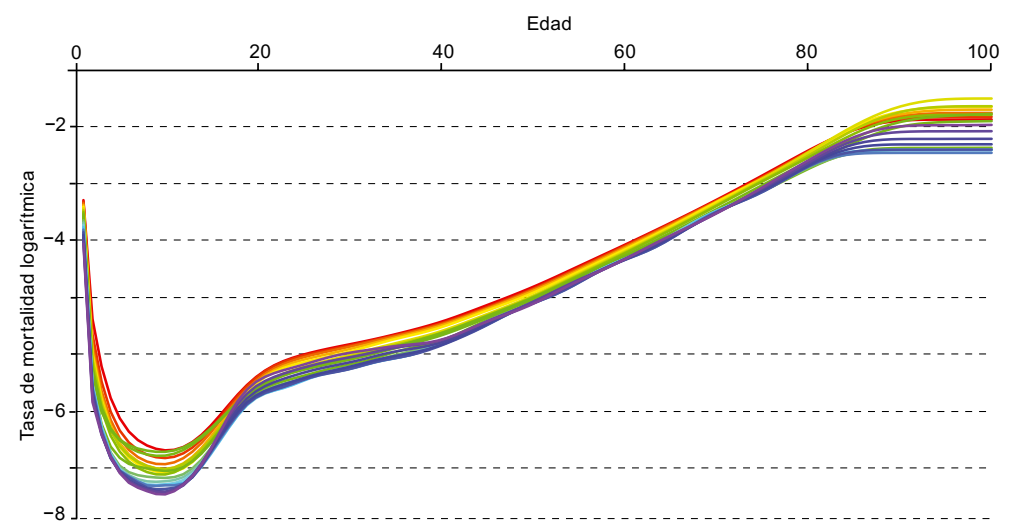

Fuente: Elaboración propia, sobre la base de datos del Instituto Nacional de Estadística y Geografía (INEGI).

Gráfico 4

México: tasas específicas de mortalidad femenina, 1990-2010

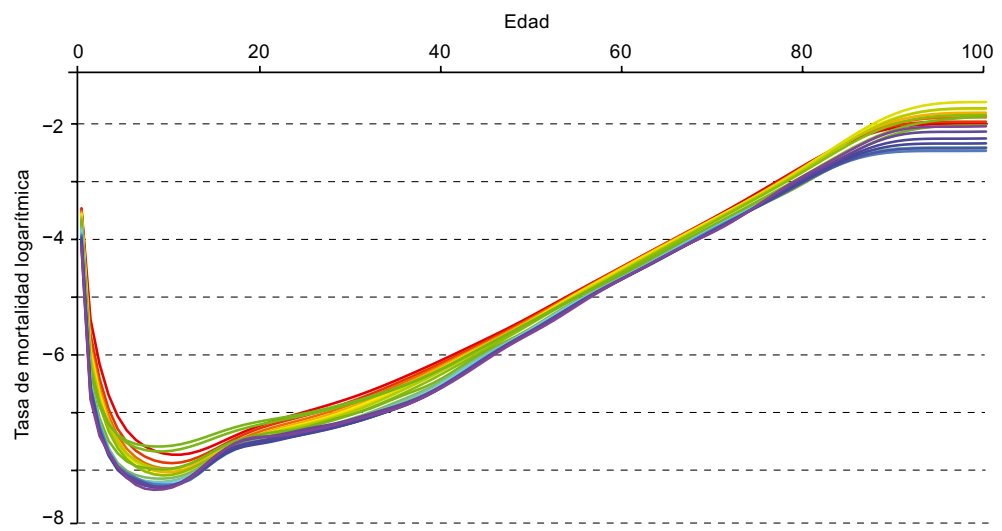

Fuente: Elaboración propia, sobre la base de datos del Instituto Nacional de Estadística y Geografía (INEGI).

A lo largo del período estudiado puede observarse, en el gráfico 5, una reducción paulatina de la tasa de mortalidad infantil, así como de la diferencia entre las tasas observadas y corregidas, situación que puede asociarse con mejoras en la calidad de la información captada por los censos y estadísticas vitales, lo que a la postre derivará en la convergencia entre las estimaciones directas, obtenidas de estadísticas vitales, y las estimaciones obtenidas mediante métodos indirectos (Aguirre y Vela, 2012). 
Gráfico 5

México: proyección de las tasas de mortalidad infantil, 1976-2100

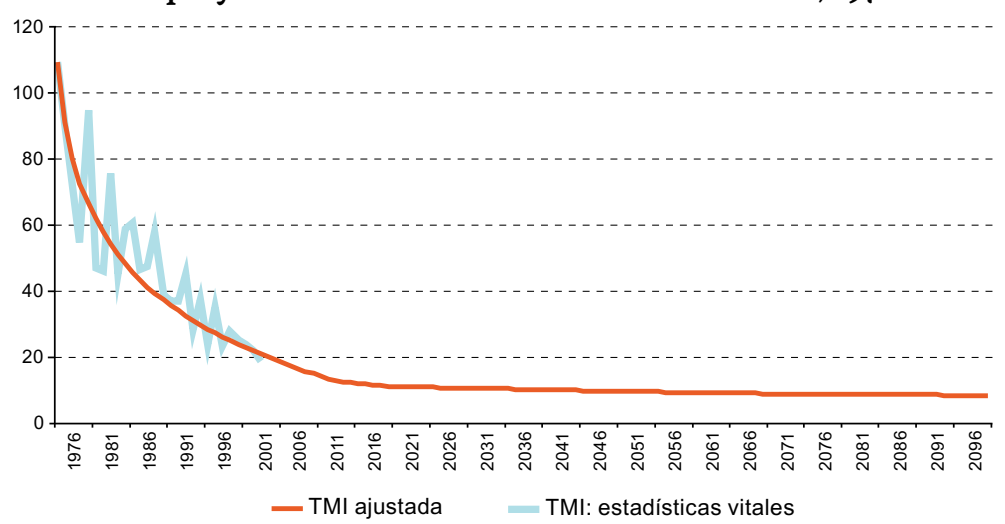

Fuente: Elaboración propia, sobre la base de datos del Instituto Nacional de Estadística y Geografía (INEGI).

\section{Estimación indirecta de las tasas de mortalidad infantil}

La mortalidad infantil es un insumo básico para estimar y proyectar los niveles generales de mortalidad. Sin embargo, en países donde no se cuenta con sistemas confiables de registro de defunciones, existe un importante nivel de subenumeración de defunciones de menores de cinco años en general, y de un año en particular, lo que hace inviable el uso de métodos de estimación directos para el cálculo de las tasas de mortalidad infantil.

El método indirecto empleado para estimar los niveles de mortalidad infantil, a partir del número de hijos nacidos vivos e hijos fallecidos por edad de las madres, es una variante del método elaborado por W. Brass (Trussell, 1975). La variante elaborada por Griffith Feeney (Feeney, 1980) permite asignar una fecha a la incidencia de la mortalidad infantil, por lo que la aplicación sucesiva del método a diferentes censos arroja estimaciones repetidas en fechas muy cercanas. Esta característica permite interpolar una curva cuya tendencia modela y proyecta los niveles de mortalidad infantil. En el gráfico 5 se observa la aplicación del método propuesto por Feeney a los distintos censos y conteos de población mexicanos, así como la curva que interpola las estimaciones obtenidas sobre distintos momentos.

\section{Tasas de fecundidad}

Las tasas específicas de fecundidad de México correspondientes al período 1990-2010 se estimaron de manera directa (como el cociente de los nacimientos de mujeres entre $a$ y $a+n$ años y el total de mujeres entre $a y a+n$, años de edad, donde $a$ marca el inicio de la edad reproductiva y $a+n$ marca el final). Sin embargo, en algunos casos, el nivel de la curva debió corregirse debido al subregistro de nacimientos observado en distintos años. 
Para ajustar el nivel de las tasas específicas se utilizó la tendencia histórica proyectada de la tasa global de fecundidad (TGF). La información sobre los niveles históricos de la TGF se obtuvo de la página del INEGI, mientras que su evolución se proyectó empleando una función de tipo logarítmico. La evolución de la TGF puede observarse en el gráfico 6, mientras que las tasas específicas de fecundidad ajustadas y suavizadas, correspondientes a los años 1990 a 2010, se presentan en el gráfico 7, donde las curvas que corresponden a fecundidades más altas son cercanas a la década de 1990 y las curvas que se refieren a fecundidades más bajas son más próximas al año 2000.

Gráfico 6

México: evolución y proyección de la tasa global de fecundidad, 1895-2100

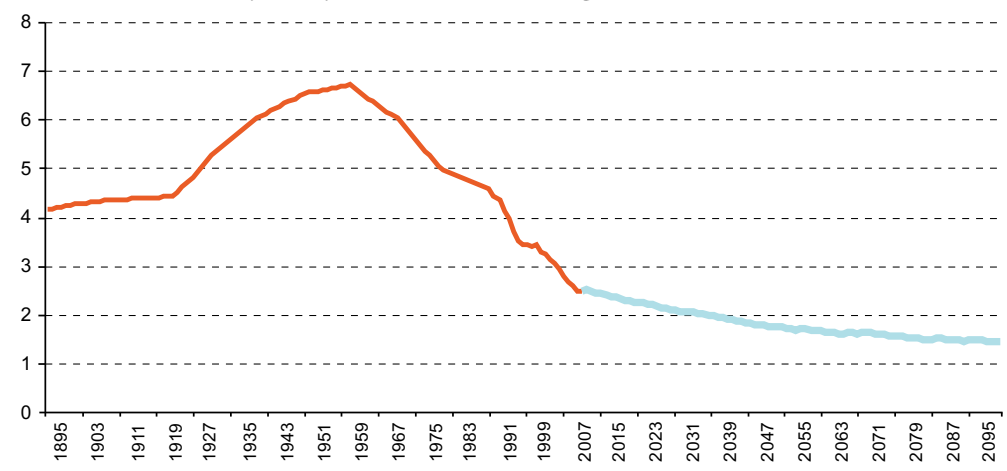

_TGF según el INEGI_ _TGF proyectada

Fuente: Elaboración propia, sobre la base de datos del Instituto Nacional de Estadística y Geografía (INEGI).

Gráfico 7

México: tasas específicas de fecundidad, 1990-2010

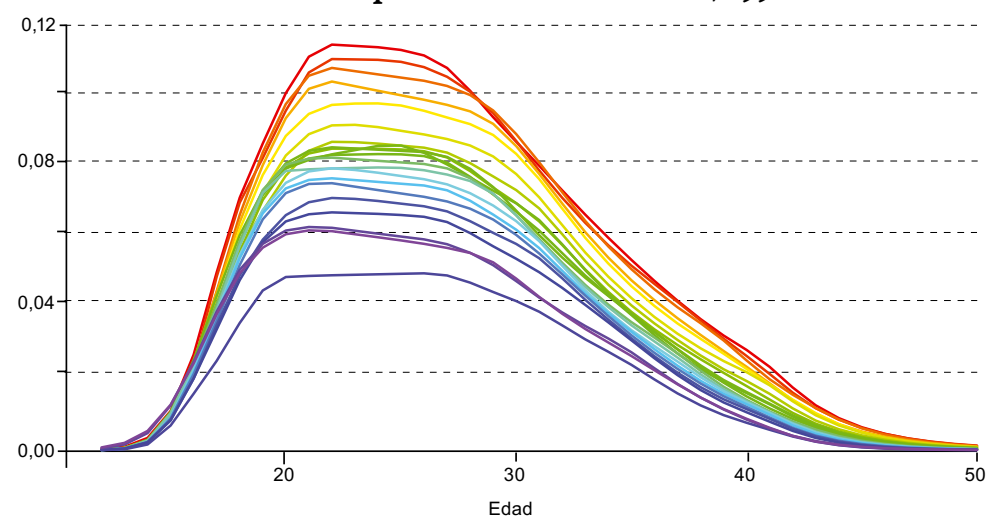

Fuente: Elaboración propia, sobre la base de datos del Instituto Nacional de Estadística y Geografía (INEGI).

Con relación al comportamiento de la tasa global de fecundidad, es importante señalar que desde finales de la década de 1960 se inició en México el descenso de la fecundidad, lo 
que marcó, a su vez, el inicio de la segunda etapa de la transición demográfica. El declive toma como punto de partida tasas globales de fecundidad superiores a los 6 hijos por mujer, en los años sesenta, y evoluciona hasta alcanzar niveles de 2,4 hijos al año en 2014.

\section{Tasas de migración}

Uno de los aspectos más difíciles de modelar durante el proceso de proyección de poblaciones es el referente a la estimación de patrones migratorios. En general, puede atribuirse a que los modelos demográficos de tipo teórico parten del supuesto de que las poblaciones son cerradas a la migración, lo que se suma, sin lugar a dudas, a la naturaleza cambiante de los flujos, tanto en dirección e intensidad como en su composición por edad.

Las estimaciones relativas al comportamiento de los flujos migratorios internacionales se realizaron con datos censales, a partir de la pregunta sobre el país de residencia durante los últimos cinco años. Es importante señalar que la estimación directa de flujos migratorios suele presentar problemas asociados a la omisión diferencial por edad y sexo, además de importantes niveles de subregistro, sobre todo en los casos donde emigra el grupo familiar completo. En general, los saldos netos migratorios son negativos durante todo el período ajustado (1990-2010).

En el gráfico 8 se muestran las tasas específicas de emigración. Las curvas de color más oscuro corresponden a los años 2000 a 2005 y las de color más claro a los de 2006 a 2010. Por su parte, el comportamiento de tasas específicas de inmigración muestra un descenso continuado entre 1990 y 2010, como se muestra en el gráfico 9 . Conviene resaltar que el patrón por edad, tanto de emigrantes como de inmigrantes, es muy joven. La edad media no rebasa los 25 años en ambos casos y el pico esperado para la edad de retiro es apenas notorio, alrededor de los 85 años.

Gráfico 8

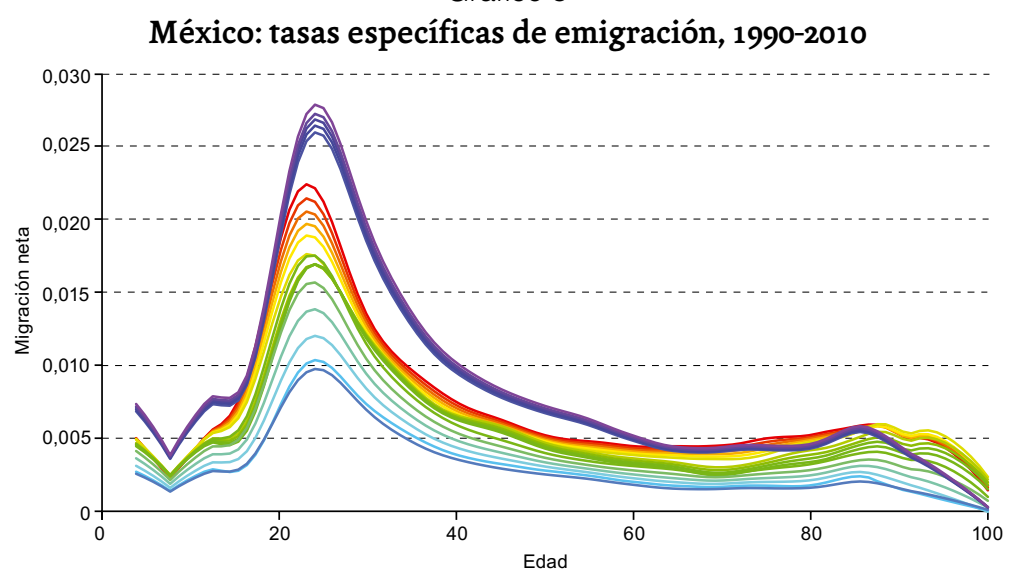

Fuente: Elaboración propia, sobre la base de datos del Instituto Nacional de Estadística y Geografía (INEGI). 
Gráfico 9

México: tasas específicas de inmigración, 1990-2010

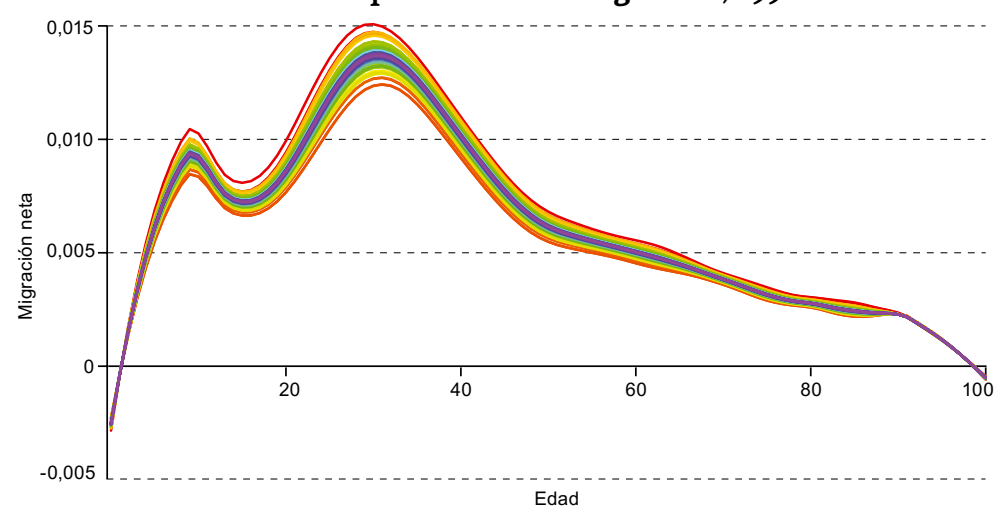

Fuente: Elaboración propia, sobre la base de datos del Instituto Nacional de Estadística y Geografía (INEGI).

\section{Metodología}

La metodología general propuesta se basa en el método de cohorte-componente, que permite realizar la proyección de las tasas específicas de mortalidad y fecundidad con una variante del método de Lee-Carter, y el crecimiento de la población se acota mediante la utilización de una proyección logística de población total. Para ello, se hace uso del método de ajuste presentado por Poveda y Manrique (2007), en el que se propone una metodología de ajuste del modelo logístico de 12 pasos. El resultado final se presenta en el gráfico 2.

Para lograr que la población total proyectada por el método de cohorte-componente corresponda a la población proyectada por la curva logística, es necesario imponer condiciones sobre los límites inferior y superior de las tasas de mortalidad y fecundidad, además de utilizar el residuo de ambas poblaciones (cohorte-componente y curva logística) como saldo neto migratorio de la proyección. Es decir, las tasas específicas de migración ajustan su nivel residual observado, pero conservan el patrón histórico.

La teoría de la transición demográfica hace referencia al cambio de un régimen poblacional con tasas de mortalidad y fecundidad altas y estables, en sociedades tradicionales, hacia un régimen de mortalidad y fecundidad con tasas bajas y estables, en sociedades modernas. Cada etapa de la transición marca un ritmo de evolución diferente en el descenso de las tasas de mortalidad y fecundidad, lo que puede captarse adecuadamente con un modelo logístico. La validez de la teoría de transición demográfica se ha demostrado de forma empírica en relación con diferentes países en desarrollo (Chesnais, 1986). 
A pesar de las diferencias percibidas en los contextos y en los ritmos de descenso de las tasas de mortalidad y fecundidad, ha sido posible observar el tránsito por cada una de las diferentes etapas postuladas.

Puesto que la evolución histórica de las tasas brutas de mortalidad y natalidad parece seguir una tendencia logística (que puede observarse en el gráfico 1), se ha optado por ajustar y extrapolar su tendencia empleando una ecuación de tipo logarítmico. De ese modo, proyectar la evolución histórica de las tasas de mortalidad y fecundidad es un ejercicio más o menos simple, en tanto puede modelarse el camino descrito por la teoría de la transición demográfica.

Las tasas de mortalidad y fecundidad pueden modelarse y proyectarse mediante el coeficiente $k_{t}$ del método de Lee-Carter (García y Ordorica, 2012), representado por la ecuación:

$$
\ln \left(m_{x t}\right)=a_{x}+b_{x} k_{t}+e_{x t}
$$

donde

$a_{x}$ es el promedio de las $m_{x}$ a lo largo del tiempo $t$

$b_{x}$ es el primer componente principal que capta el cambio en la edad

$k_{t}$ es el primer componente principal que capta el cambio en el tiempo

$e_{x t}$ es el residual

En general, se utiliza la descomposición de valores propios y se imponen los requisitos:

$$
\sum_{t} k_{t}=0 \quad y \quad \sum_{x=0}^{\omega} b_{x}=1
$$

El método se elaboró básicamente para ajustar tasas de mortalidad.

Una vez modificada la evolución de las tasas de mortalidad y fecundidad, el algoritmo para la implementación del método de proyección de cohorte-componente de transición logística quedará establecido como:

i) La población total a alcanzar se estima a partir de la curva:

$$
N_{\log }(\mathrm{t})=K_{0}+\frac{L}{1+K_{1} e^{-b t}}
$$

donde $K_{1}=K e^{a b / c}$ y $B=b / c$. Los parámetros se determinan por mínimos cuadrados, empleando el método de ajuste elaborado en (Poveda y Manrique, 2007).

ii) Se aplica el método de Lee-Carter, representado como:

$$
\ln \left(m_{x, t}\right)=a_{x}+b_{x} k_{t}+\varepsilon_{x, t}
$$

donde $\mathrm{m}_{x, t}$ representa la tasa de mortalidad a edad $x$ en el año $t$. $k_{t}$ es el índice de intensidad de mortalidad a lo largo del tiempo. Entretanto, $a_{x}$ es el patrón promedio de mortalidad por edad y $b_{x}$ modela la velocidad relativa de cambio de las tasas correspondientes a cada edad. 
iii) Una vez ajustado el modelo, los coeficientes $b_{t, k}$ obtenidos se extrapolan utilizando una caminata aleatoria con dirección para proyectar el comportamiento de las tasas, de este modo:

$$
b_{t, k}=b_{t-1, k}+d_{t}+e_{t}
$$

donde $d_{k}$ es el parámetro de dirección, que mide el cambio promedio anual de las tasas, y se calcula como:

$$
d_{t}=\frac{s m_{t}-s m_{t-1}}{s m_{t}}
$$

donde $s m_{t}$ es la suma de las tasas específicas de mortalidad al año $t$ y dichas tasas se estiman mediante una curva de tipo logístico que extrapola el comportamiento histórico de las tasas y sigue el comportamiento decreciente establecido según la teoría de la transición demográfica (véase el gráfico 2).

iv) La proyección de las tasas específicas de mortalidad se obtiene a partir de la extrapolación de $k_{t}$, manteniendo fijos los valores de $a_{x}$ y $b_{x}$, a partir de la ecuación:

$$
m_{x, t+1}=a_{x}+b_{x} k_{t+1}
$$

v) La proyección de las tasas de fecundidad se realiza de la misma manera que la de las tasas de mortalidad. Una vez proyectadas, se estima la población total antes de la migración como:

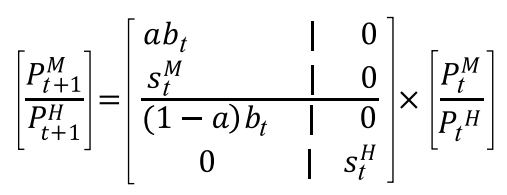

donde

$$
\begin{gathered}
s_{t}^{k}=\frac{1-0.5\left(m_{x, t}^{k}\right)}{1+0.5\left(m_{x+1, t}^{k}\right)} \\
b_{t}=\frac{1}{1+0.5 m_{0, t}} \times \frac{\left[f_{t}(x)+s_{t}^{k} f_{t}(x+1)\right]}{2}
\end{gathered}
$$

$a=\frac{1}{2.05}$ es la proporción esperada de mujeres en la población.

vi) El cálculo de las tasas de migración se realiza considerando el residuo entre la población $P_{t+1}$ y la población $N_{\log }(t+1)$. Si la población total estimada está por arriba de la población logística, se incrementan las tasas de emigración hasta ajustar la población esperada. En caso contrario, se incrementan las tasas de inmigración, por un factor de ajuste que permita igualar ambas poblaciones. 
vii) La proyección se realiza por el método de componentes demográficos, combinando las distintas cohortes, a partir de:

$$
\left[\frac{P_{t+1}^{M}}{P_{t+1}^{H}}\right]=\left[\begin{array}{llr}
a b_{t} & 0 \\
s_{t}^{M} & 0 \\
\hline(1-a) b_{t} & 0 \\
0 & s_{t}^{H}
\end{array}\right] \times\left[\frac{P_{t}^{H M}}{P_{t}^{H}}\right]+\left[\frac{I_{t}^{M}}{I_{t}^{H}}\right]
$$

donde, una vez más:

$$
s_{t}^{k}=\frac{1-0.5\left(m_{x t}^{k}+\eta_{x t}^{k}\right)}{1+0.5\left(m_{x+1, t}^{k}+\eta_{x+1, t}^{k}\right)}
$$

representa la tasa de sobrevivencia (la probabilidad de llegar con vida al año $t+1$, dado que se sobrevivió al año t), considerando las tasas de mortalidad de los emigrantes $\eta_{x t}^{k}$, es decir, el total de inmigrantes $I_{t}$ al año $t$. $a$ y $b_{t}$ se estiman de la misma forma que antes.

El modelo propuesto aplicado a la población de México utiliza un $\Delta t$ igual a un año calendario, con un horizonte de proyección de 90 años. Los resultados de la aplicación del modelo se presentan a continuación.

En el gráfico 10 se muestra el patrón medio de las tasas específicas de mortalidad de hombres, mujeres y población total, estimadas con el método de Lee-Carter en relación con el período 1990 a 2010. El gráfico 11 captura el cambio por edad (parámetro $b_{x}$ ), lo que arroja un importante nivel de subregistro de mortalidad durante el primer año de vida. En el gráfico 12 se muestra el cambio de los niveles de mortalidad en el tiempo (parámetro $k_{t}$ ), con lo que se hace evidente que a partir de 2006 ha habido un incremento de los niveles de mortalidad en México.

México: parámetro $a_{x}$ de mortalidad ajustado, 1990-2010

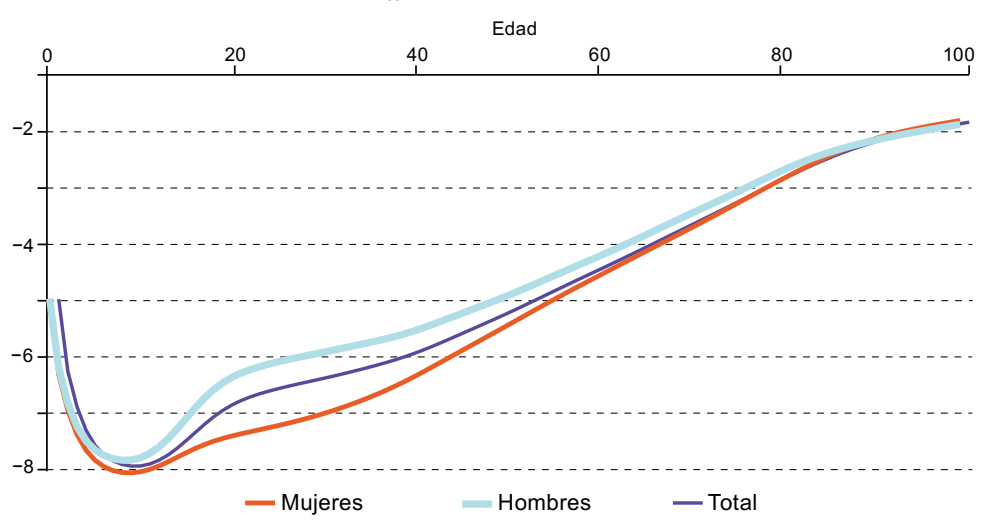

Fuente: Elaboración propia, sobre la base de datos del Instituto Nacional de Estadística y Geografía (INEGI). 


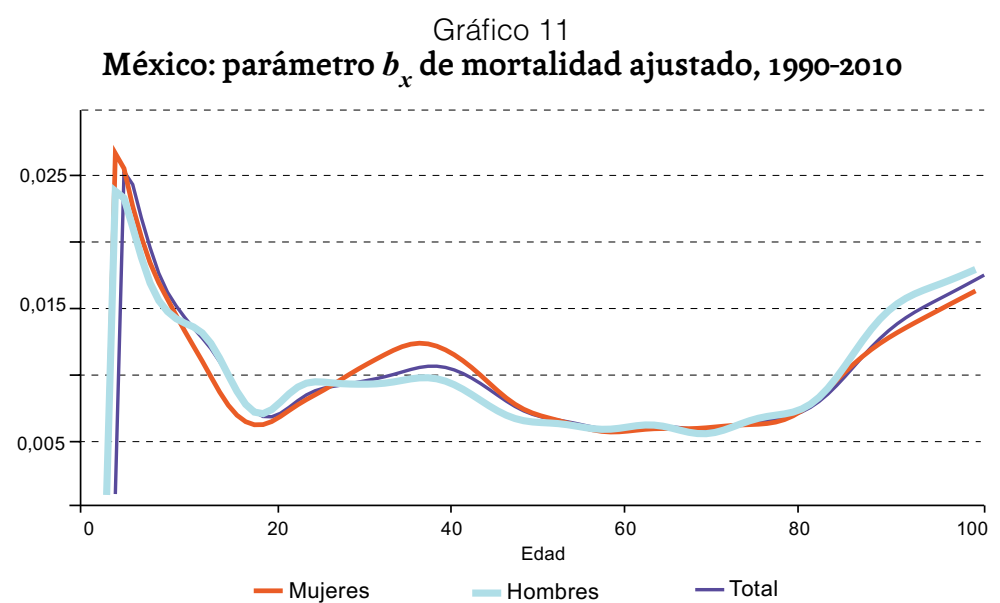

Fuente: Elaboración propia, sobre la base de datos del Instituto Nacional de Estadística y Geografía (INEGI).

Gráfico 12

México: parámetro de mortalidad $\boldsymbol{k}_{t}$ ajustado, 1990-2010

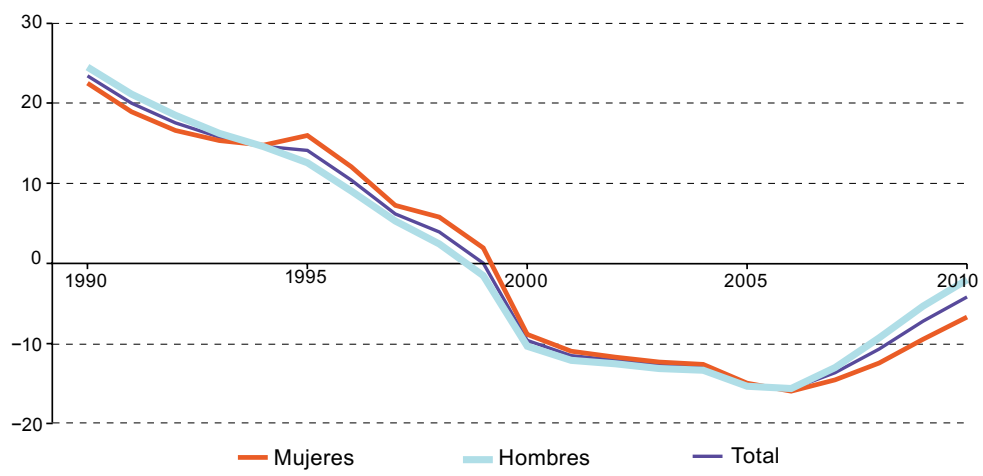

Fuente: Elaboración propia, sobre la base de datos del Instituto Nacional de Estadística y Geografía (INEGI).

\section{Resultados}

La aplicación del método de transición logística responde al esquema metodológico propuesto. Para comenzar, se ajustó la población del censo de México en 2010 a fin de construir la población de base de la proyección. Se prorrateó, de modo uniforme, la población de edad no especificada y se corrigió la preferencia de dígitos utilizando el método de promedios móviles ponderados. Por último, el resultado se interpoló al 1 de enero del año referido y la población de base se conformó por un total de 112,4 millones de personas.

El parámetro $a_{x}$ representa el nivel medio de la mortalidad observado históricamente, ya que se estima como el promedio del logaritmo de las tasas de mortalidad a lo largo del tiempo. Como se puede observar en el gráfico 12, este parámetro toma la forma clásica de 
una curva de mortalidad, con su tradicional dibujo de tubo de cañería y con los niveles de mortalidad masculinos superiores a los femeninos en casi todas las edades.

El parámetro $b_{x}$ refleja los niveles de intensidad de la mortalidad por edad. En el caso de la población mexicana, el parámetro indica que la intensidad de la mortalidad será especialmente alta al nacer y durante las edades que se corresponden con la adolescencia, o sea, entre los 16 y 22 años (véase el gráfico 13).

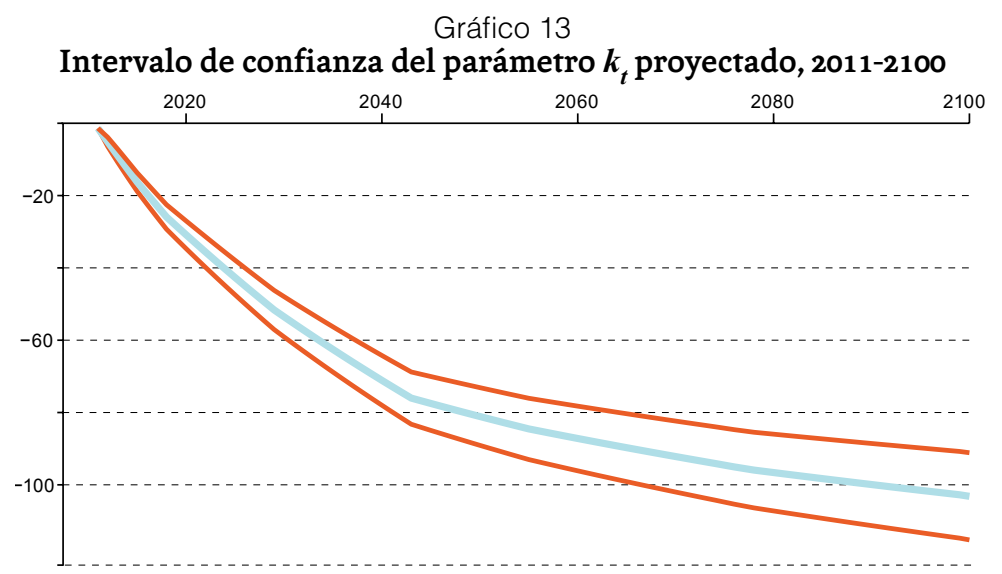

Fuente: Elaboración propia, sobre la base de datos del Instituto Nacional de Estadística y Geografía (INEGI).

Gráfico 14

México: tasa global de fecundidad proyectada, 2011-2100

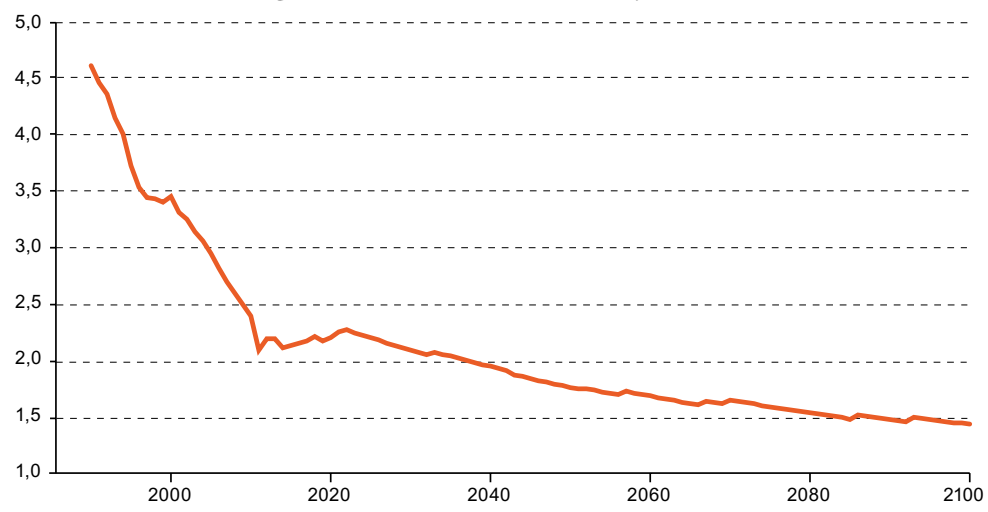

Fuente: Elaboración propia, sobre la base de datos del Instituto Nacional de Estadística y Geografía (INEGI).

El parámetro $k_{t}$ modela la intensidad de la mortalidad a lo largo del tiempo, por lo que marca la tendencia seguida por las tasas y permite extrapolar su futuro. La tendencia del índice $k_{t}$ muestra que el valor obtenido en el período 1990-2010, previo al pronosticado, presenta un comportamiento que se rompe. Hasta 2006, se marcaba un claro descenso de la mortalidad, mientras que, a partir de dicho año, pueden observarse importantes 
incrementos, lo que podría atribuirse al inicio de la guerra contra el narcotráfico iniciada por el gobierno de México. De esta forma, las metodologías de Lee-Carter y Hyndman-Ullah se enfrentan al problema de decidir a qué observaciones le asignan mayor peso relativo con la finalidad de obtener proyecciones coherentes. Ese dilema se resuelve al utilizar la dirección establecida por los patrones de comportamiento teóricos a largo plazo, dados por la teoría de la transición demográfica.

En el gráfico 15 se muestran los valores pronosticados de $k_{t}$ así como los intervalos de predicción al $95 \%$ de confianza estimados a partir de la función forecast del paquete Demography, disponible en lenguaje $\mathrm{R}$ y modificado mediante la deriva propuesta. Se puede observar que el comportamiento del parámetro indica una clara reducción en la intensidad de la mortalidad al avanzar el tiempo, este efecto se debe al cambio de la deriva y tiene importantes efectos sobre la proyección de los niveles de mortalidad y fecundidad a largo plazo.

Gráfico 15

México: saldo neto migratorio proyectado, 2011-2100

(En habitantes)

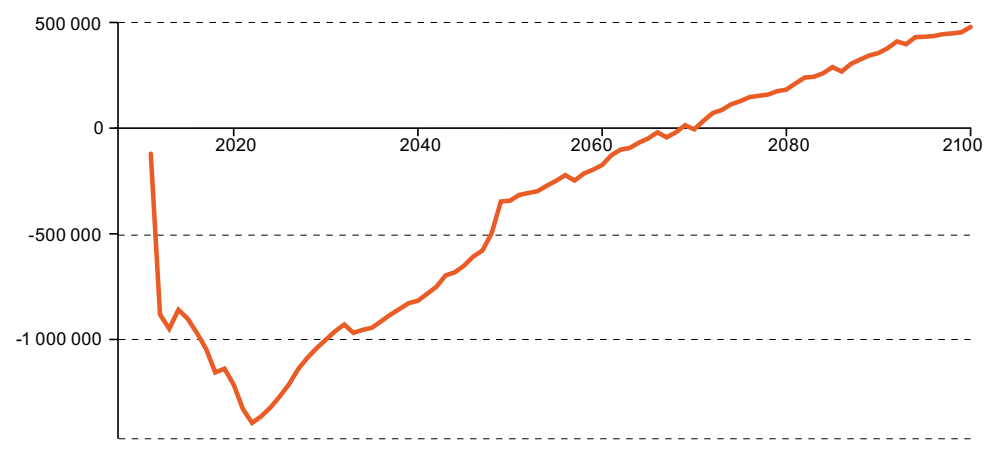

Fuente: Elaboración propia, sobre la base de datos del Instituto Nacional de Estadística y Geografía (INEGI).

Durante los próximos años, México continuará registrando descensos moderados de sus niveles de mortalidad y fecundidad. Esto se debe a que se encuentra en la fase final de la segunda etapa de la transición demográfica (CONAPO, 2007). La pirámide de población actual da cuenta de que México es un país con una estructura por edades sumamente joven. El porcentaje de población de personas con 65 años o más es inferior al 7\%.

La paulatina reducción de los niveles de mortalidad tendrá, entre otras consecuencias, el incremento del porcentaje de población envejecida, que alcanzará en 2050 el 18\% del total de la población, que a su vez llegará a los 144,1 millones de habitantes.

Las tasas de fecundidad se reducirán de los 2,4 hijos por mujer, observados en el año 2014, hasta niveles de 1,4 hijos al año 2100, con arreglo a pronósticos establecidos por la curva ajustada para la TGF y la proyección realizada (véase el gráfico 16). Según esos 
pronósticos, se espera que en 2020 nazcan 2,2 millones de menores, y 1,1 millones para 2100, lo que supondrá un descenso de más de un 40\% en el número de nacimientos.

Gráfico 16

México: tasa de crecimiento proyectada, 1990-2100

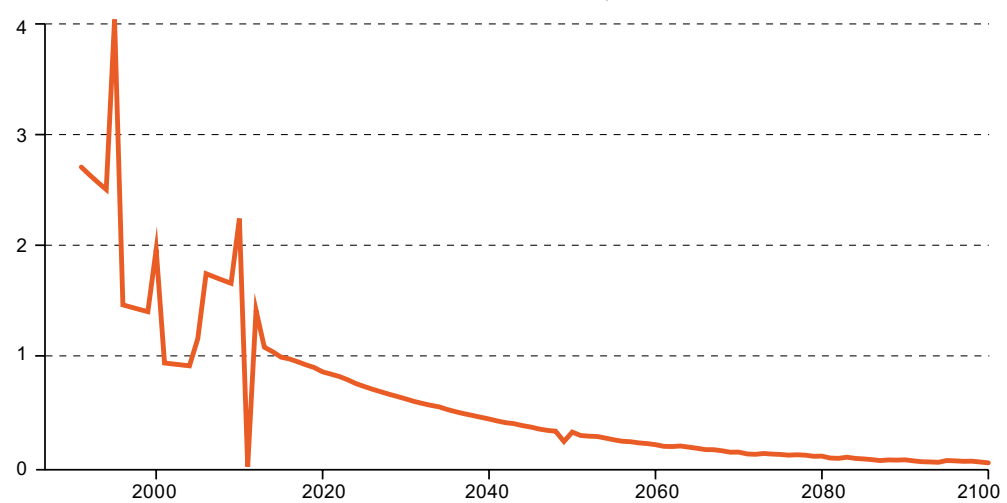

Fuente: Elaboración propia, sobre la base de datos del Instituto Nacional de Estadística y Geografía (INEGI).

Gráfico 17

México: esperanza de vida proyectada, 1990-2100

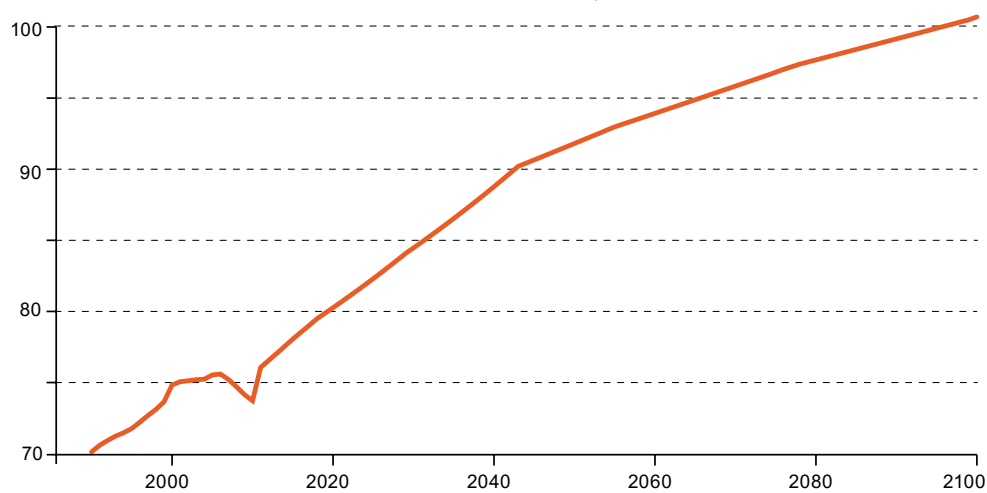

Fuente: Elaboración propia, sobre la base de datos del Instituto Nacional de Estadística y Geografía (INEGI)

Aunque en los gráficos 10 y 11 se muestra el patrón migratorio clásico, es probable que las estimaciones realizadas contengan algunos sesgos producidos por deficiencias propias de la captación de información. Las tasas se estimaron con información de los flujos captados por la pregunta de lugar de residencia en el censo anterior, lo que puede ocasionar importantes niveles de subregistro, en especial cuando el grupo familiar completo emigra. No obstante, según cifras proyectadas, se esperan reducciones sostenidas de los flujos de emigración a largo plazo (véase el gráfico 15), pues el saldo neto migratorio comenzará a ser positivo a partir de la década de 2070. 
Según se muestra en el gráfico 16, la evolución de las tasas de crecimiento de la población de México atestigua el paso de la transición demográfica. La inestabilidad observada durante la última década del siglo XX y la primera del XXI es producto del desfase entre los descensos de la mortalidad y la fecundidad, y de las variaciones en los flujos migratorios registrados durante el período en cuestión. Alrededor de 2050, se puede observar un quiebre o alteración en la tendencia provocada como efecto inercial de las fluctuaciones pasadas.

Una vez establecidos los supuestos básicos del modelo, y al no contar con información actualizada sobre el comportamiento de las tasas de migración, se decidió emplear el patrón promedio de inmigración y emigración como estándar para ajustar los niveles de migración en el sentido establecido por el punto vi) de la metodología propuesta. Como se observa en el gráfico 15, los saldos netos migratorios de México durante el período 2011-2100 resultan de dibujar el efecto de la transición demográfica sobre los niveles esperados de población que se espera será expulsada o atraída hacia México en el período señalado. De contar con tasas específicas de inmigración y emigración para el período de proyección, estas deberán ajustarse a los niveles esperados que permitan alcanzar la población total fijada en cada período de proyección por el modelo logístico, lo que tal vez llegue a alterar la tendencia de la mortalidad y la fecundidad.

Una vez realizada la proyección, la población total estimada por el método de cohorte-componente presenta el comportamiento esperado, como puede observarse en el gráfico 18. Las estructuras por edad y sexo proyectadas pueden verse en sus respectivas pirámides poblacionales, donde se observa el envejecimiento paulatino de la población debido al descenso de las tasas de fecundidad, el descenso del nivel de mortalidad y el incremento de la esperanza de vida al nacer.

\section{Gráfico 18}

México: estimaciones y proyecciones de población del CELADE-División de Población de la CEPAL y el Consejo Nacional de Población y método de transición logística, 1950-2100

(En millones de habitantes)

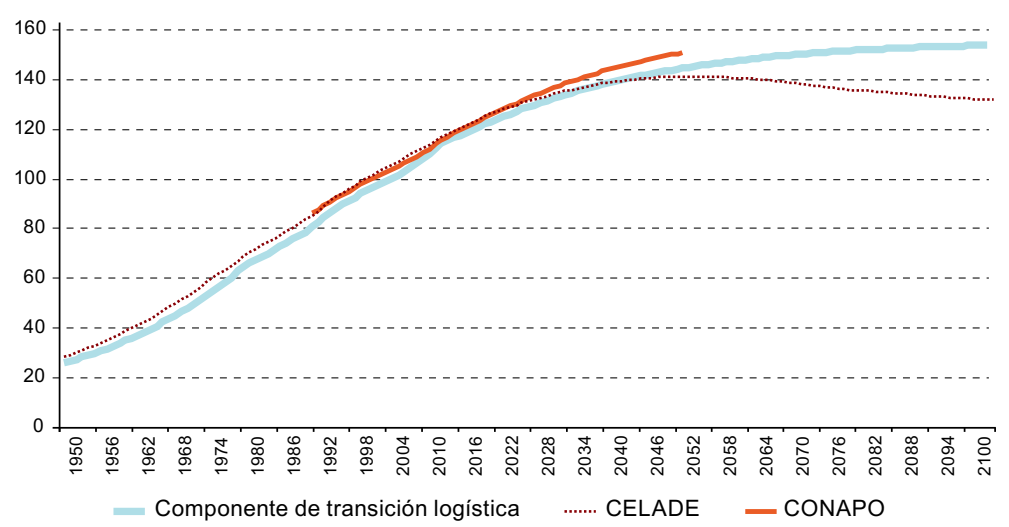

Fuente: Elaboración propia, sobre la base de datos del Instituto Nacional de Estadística y Geografía (INEGI). 
Gráfico 19

México: proyección de la estructura y sexo por edad, 2015, 2050, 2075 y 2100

A. 2015
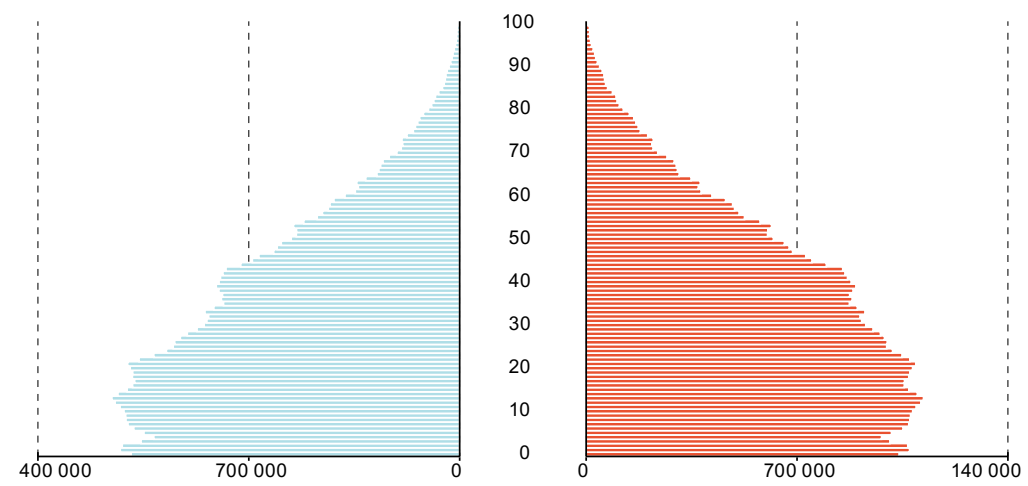

B. 2050
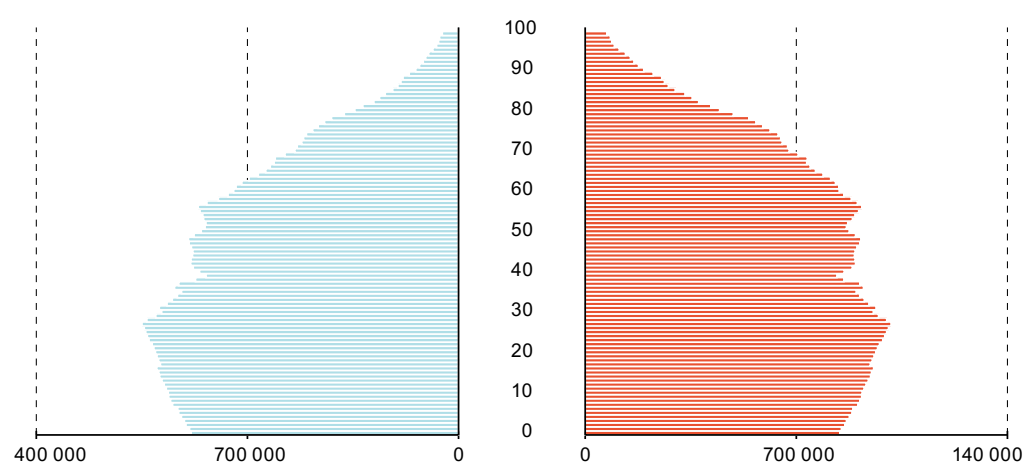

C. 2075

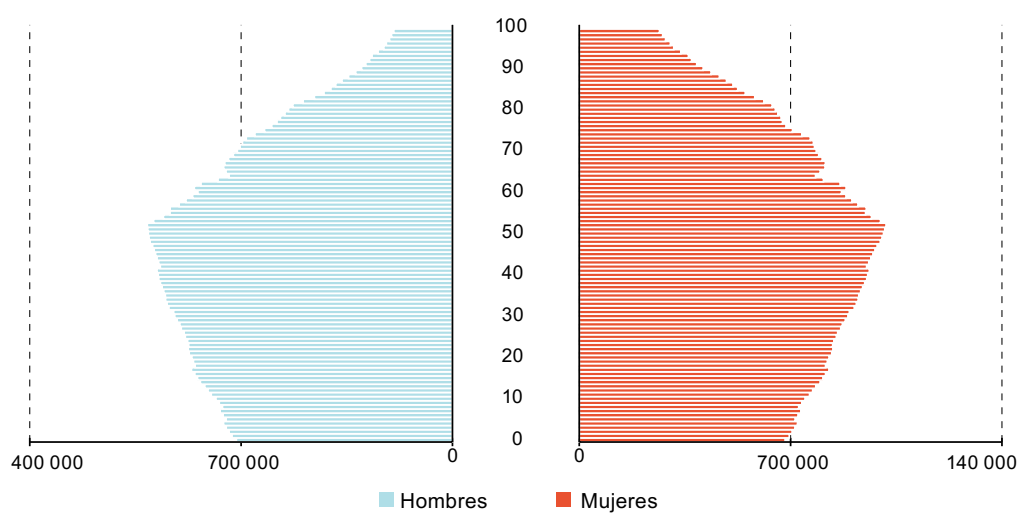


Gráfico 19 (conclusión)

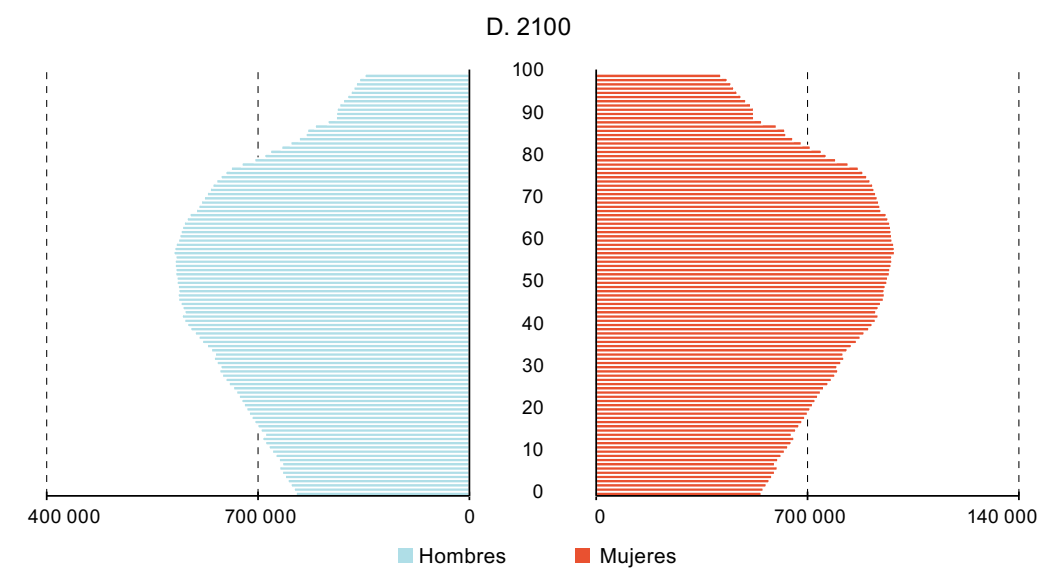

Fuente: Elaboración propia, sobre la base de cifras proyectadas por el método de transición logística..

De mantenerse el descenso de las tasas específicas de mortalidad, se espera que la esperanza de vida al nacer alcance un máximo de 100,5 años a nivel nacional, lo que implica un incremento de 24,7 años durante el período de proyección. Esto daría por resultado una estructura poblacional envejecida con una edad mediana de 48 años y una proporción de población envejecida de 65 años o más, equivalente al 32\% de la población total.

\section{E. Conclusiones}

En 1992, Lee y Carter describieron un método estocástico basado en una aproximación de cohorte-componente con la finalidad de estimar y pronosticar las tasas de mortalidad por edad. Desde entonces, se han elaborado una gran cantidad de variantes, la mayor parte orientadas a la recuperación y posterior extrapolación de los efectos del pasado. La aproximación propuesta en este trabajo busca recuperar los efectos del pasado, al incorporar una tendencia futura esperada y fundamentada en la teoría de la transición demográfica.

De esta forma, el modelo de transición logística propuesto permite proyectar la evolución de las tasas de mortalidad y fecundidad a largo plazo, al tomar como fundamento las tendencias marcadas en las distintas etapas definidas por la teoría de la transición demográfica. Un punto importante a destacar del modelo es el hecho de que impone un límite máximo al crecimiento de la población proyectada, lo que permite fijar horizontes de proyección de larga temporalidad.

Otro aspecto importante del trabajo, aunque no es propio del método propuesto, es que se incorporan estimaciones indirectas de mortalidad infantil, realizadas a partir de datos censales, a la vez que se hace una proyección estable de dichas estimaciones. Esto contribuye a dar mayor certidumbre a los pronósticos sobre mortalidad general, pues permite mejorar las estimaciones de la esperanza de vida a lo largo de todo el período proyectado. Los métodos de estimación indirectos de mortalidad infantil pueden consultarse con mayor detalle en Aguirre y Vela (2012). 
Entre las principales desventajas del método propuesto cabe señalar que ignora las variaciones observadas en las tasas, tanto de mortalidad como de fecundidad, ocurridas en períodos recientes, ya que se concentra en seguir la tendencia histórica de las series y alcanzar el límite preestablecido por el marco teórico. Otra desventaja importante del método es la asociada a la restricción impuesta sobre la estructura y los niveles de migración, ya que genera un conflicto entre la velocidad de crecimiento de la población y el límite de población máximo permitido.

Es decir, los niveles de migración (inmigración y emigración) en cada paso de la proyección se estiman como residuo entre la población total proyectada por el método de cohorte-componente y la población total máxima permitida por la proyección logística. Una vez conocido el residuo, se estiman las tasas de migración, conservando la estructura de las tasas estimadas y ajustando el nivel de acuerdo al total esperado.

Además, es importante señalar que los resultados de la aplicación en el caso de México parecen ser bastante alentadores, en el sentido de que presentan estimaciones consistentes para todos los indicadores demográficos expuestos en la sección de resultados. En particular, la tasa de crecimiento de la población alcanza niveles bajos y estables a partir de 2080, la tasa global de fecundidad disminuye por debajo del reemplazo a partir de 2030 y la esperanza de vida permanece acotada en valores menores a 100 años.

La transición demográfica permite describir y también "predecir" los cambios en materia de natalidad y mortalidad, a partir de generalizaciones sobre la dinámica demográfica de sociedades europeas desde el siglo XVIII. El equilibrio demográfico pretransicional comienza con un lento descenso de la mortalidad, acompañado por aumentos sostenidos de la esperanza de vida, principalmente a consecuencia del descenso de la mortalidad infantil. Luego comienza un proceso de reducción de la natalidad, paralelo al descenso de la mortalidad. El desfase temporal entre el descenso de las tasas brutas de mortalidad y natalidad provoca un incremento de población (en poblaciones cerradas). Por último, las tasas de natalidad y mortalidad alcanzan niveles relativamente bajos y estables, lo que lleva a una reducción de la tasa de crecimiento natural.

Una de las principales ventajas del uso del método de transición logística consiste en que permite emplear las predicciones de natalidad y mortalidad propuestas por la teoría de la transición demográfica e integrarlas de forma explícita en la metodología, ajustando su nivel y ritmo de cambio a largo plazo (véase el gráfico 1). Es decir, la tasa de crecimiento natural se estima como la diferencia entre la tasa bruta de natalidad y la tasa bruta de mortalidad, suponiendo una población cerrada. La migración se integra, mediante el saldo neto migratorio, como el residuo de la población total proyectada por la curva logística (en $t+1)$ y la población total proyectada con la metodología propuesta, que será la suma de la estructura por edad y sexo de la población llevada al momento $t+1$, utilizando únicamente la tasa de crecimiento natural. Según ese criterio, el saldo migratorio es resultado de la interacción del crecimiento natural y un límite máximo hipotético impuesto sobre el crecimiento de la población. 
Los resultados de la aplicación del método de transición logística, en relación con la población total, pueden verse en el gráfico 18. Allí se muestran las proyecciones del Consejo Nacional de Población (CONAPO, 2015) correspondientes al período 2010-2050 y del Centro Latinoamericano y Caribeño de Demografía (CELADE)-División de Población de la CEPAL (CEPAL, 2015) correspondientes al período 1950-2100. Las diferencias más palpables ocurren a largo plazo, donde el modelo propuesto sigue la tendencia establecida por la curva de crecimiento logística. Por otra parte, es importante señalar que tanto el CELADE-División de Población de la CEPAL como el CONAPO comienzan la proyección con una población de base corregida en 2010 de 114 y 115 millones de personas, respectivamente (mientras que la población censada en 2010 ascendió a 112 millones, según cifras oficiales del INEGI). Esa diferencia es notoria en el nivel de todas las proyecciones, no así en la tendencia a mediano plazo (2010-2040). Por último, el método de transición logística ha permitido modelar la evolución histórica de las tasas brutas de mortalidad y natalidad mediante el método de LeeCarter, a la vez que ha incorporado una variación en la dirección de la deriva, para permitir que ambas tasas sigan la tendencia evolutiva marcada por la transición demográfica.

\section{Bibliografía}

Alders, M., N. Keilman y H. Cruijsen (2007), "Assumptions for long-term stochastic population forecasts in 18 European countries", European Journal of Population, vol. 23, № 1.

Aguirre, Alejandro y Fortino Vela-Peón (2012), "La mortalidad infantil en México, 2010", Papeles de Población, vol. $18, \mathrm{~N}^{\circ} 73$.

Bates, J. M. y C. W. J. Granger (1969), "The combination of forecasts", Operational Research Quarterly, vol. $20, \mathrm{~N}^{\circ} 4$.

CEPAL (Comisión Económica para América Latina y el Caribe) (2015), "Estimaciones y proyecciones de población a largo plazo 1950-2100" [en línea] http://www.cepal.org/celade/proyecciones/basedatos_ bd.htm [fecha de consulta: 19 de julio de 2015].

Chesnais, J.C. (1986), "La transition démographique. Étapes, formes, implications économiques", Cahiers de l'INED, París, PUF.

Claeskens, G. y N. L. Hjort (2008), Model Selection and Model Averaging, Cambridge, Cambridge University Press.

CONAPO (Consejo Nacional de Población) (2015), "Proyecciones de población 2010-2050, para la República Mexicana" [en línea] http://www.conapo.gob.mx/es/CONAPO/Proyecciones_Datos [fecha de consulta: 19 de junio de 2015].

_ (2007), Estimación infantil para México, entidades federativas y los municipios. Nota metodológica, Ciudad de México.

Feeney, Griffith (1980), "Estimating infant mortality trends from child survivorship data", Population Studies, vol. 34, $\mathrm{N}^{\circ}$, Londres.

García Guerrero, V. M. y M. Ordorica Mellado (2012), “Proyección estocástica de la mortalidad mexicana por medio del método de Lee-Carter", Estudios Demográficos y Urbanos, vol. 27, № 2, mayo-agosto. 
Hoeting, J. A. y otros (1999), "Bayesian model averaging", Statistical Science, vol. 14, No 4 .

Hyndman, R. J. y S. Ullah (2007), "Robust forecasting of mortality and fertility rates: a functional data approach", Computational Statistics and Data Analysis, vol. 51, $\mathrm{N}^{\circ} 10$.

Hyndman, R. J. y Y. Khandakar (2008), "Automatic time series forecasting: the forecast package for R", Journal of Statistical Software, vol. 27, $\mathrm{N}^{\circ} 3$.

Hyndman, R. J., H. Booth y F. Yasmeen (2013), "Coherent mortality forecasting: the product-ratio method with functional time series models", Demography, vol. 50, $\mathrm{N}^{\circ} 1$.

Lee, R. D. y L. R. Carter (1992), "Modeling and forecasting U.S. mortality", Journal of the American Statistical Association, vol. 87, $\mathrm{N}^{\circ} 419$

Li, N. y R. Lee (2005), "Coherent mortality forecasts for a group of populations: an extension of the Lee-Carter method", Demography, vol. 42, $\mathrm{N}^{\circ} 3$.

MacInnes, John y Julio Pérez-Díaz (2008), "La tercera revolución de la modernidad: la revolución reproductiva", Revista Española de Investigaciones Sociológicas, $\mathrm{N}^{\circ} 122$.

Newton, M. A. y A. E. Raftery (1994), "Approximate Bayesian inference with the weighted likelihood bootstrap", Journal of the Royal Statistical Society, Series B, vol. 56, No 1.

Ordorica Mellado, M. (2004), "Pronóstico de las defunciones por medio de los modelos autorregresivos integrados de promedios móviles", Papeles de Población, $\mathrm{N}^{\circ} 42$.

Partida, V. (2008), Proyecciones de la población de México, de las entidades federativas, de los municipios y de las localidades, 2005-2050. Documento metodológico, Ciudad de México, Consejo Nacional de Población (CONAPO).

Poveda, Gabriel y Jorge Manrique (2007), "Aplicación de la curva logística a los censos de la ciudad de Medellín", Ecos de Economía, [S.l.], vol. 11, N²5.

Preston, S., P. Heuveline y M. Guillot (2000), Demography: Measuring and modeling population processes, Londres, Blackwell Publishers.

Trussell, James (1975), "A re-estimation of the multiplying factors for the Brass technique for determining childhood survivorship rates", Population Studies, vol. 29, № 1 . 


\title{
Proyecciones de la población argentina a lo largo del siglo XXI
}

\author{
Leandro M. González¹
}

Recibido: 25/06/2015

Aceptado: 16/07/2015

\section{Resumen}

Se presenta un esbozo de los escenarios que podría seguir la población argentina a lo largo del siglo XXI, de acuerdo a la dinámica demográfica reciente. A partir de la población censada en 2010 se proponen cuatro escenarios demográficos, con diversos niveles futuros de fecundidad. La población argentina tendrá un crecimiento moderado durante el siglo XXI, y no volverá a duplicarse como ocurrió en la segunda mitad del siglo XX. De acuerdo a la hipótesis media de fecundidad, se llegaría aproximadamente a 56,8 millones de habitantes durante el presente siglo y luego esa cifra comenzaría a reducirse gradualmente hasta poco menos de 54 millones en 2100, con un incremento relativo máximo del $39 \%$ de la población inicial. Se destaca el proceso sostenido de envejecimiento en que se encuentra la población y que, según las proyecciones ensayadas, provocará una notable transformación de la estructura demográfica actual.

Palabras clave: proyección; Argentina; envejecimiento; fecundidad; mortalidad; migración; censo.

\section{Abstract}

This paper outlines possible population scenarios for Argentina over the course of the twenty-first century, based on recent population dynamics. Four demographic scenarios, with varying future fertility rates, are hypothesized from the 2010 population

\footnotetext{
Licenciado en Ciencia Política, Magíster y Doctor en Demografía, Investigador del Centro de Investigaciones y Estudios sobre Cultura y Sociedad (CIECS) - Consejo Nacional de Investigaciones Científicas y Técnicas (CONICET) y docente del Centro de Estudios Avanzados (CEA) de la Universidad Nacional de Córdoba (Argentina). Correo electrónico: leandrogonzalez@yahoo.com.ar.
} 
census. Argentina's population will increase slightly during the twenty-first century, but it will not double as it did in the second half of the twentieth century. In the mean fertility hypothesis, the population will reach approximately 56.8 million in this century before starting to fall gradually to just under 54 million in 2100 , with a relative increase on the initial population size peaking at $39 \%$. Steady population ageing will lead, according to projections, to a notable shift in the current population structure.

Keywords: population projection; Argentina; ageing; fertility; mortality; migration; census.

\section{Résumé}

Cette étude dresse une ébauche des scénarios que pourrait suivre la population argentine durant le XXle siècle, à la lumière de la dynamique démographique récente. À partir de la population recensée en 2010, l'auteur propose quatre scénarios démographiques, sur la base de différents niveaux futurs de fécondité. La population argentine va enregistrer une croissance modérée durant le XXle siècle et ne doublera pas comme ce fut le cas dans la deuxième moitié du XXe siècle. Conformément à l'hypothèse moyenne de fécondité, cette population atteindrait 56,8 millions d'habitants environ au cours de ce siècle, chiffre qui va ensuite commencer à diminuer progressivement pour atteindre moins de 54 millions en 2100, soit une augmentation relative maximale de $39 \%$ de la population initiale. Cette étude fait ressortir le processus soutenu de vieillissement de la population qui, selon les projections utilisées, se traduira par une transformation substantielle de la structure démographique actuelle.

Mots clés: projection de la population; Argentine; vieillissement; fécondité; mortalité; migration; recensement. 


\section{Introducción}

En este artículo se presenta un esbozo de los escenarios que podría seguir la población argentina en el siglo XXI, con arreglo a la dinámica demográfica de los años recientes. Si bien apenas ha transcurrido una década y media desde el comienzo del siglo, las técnicas de proyecciones de población permiten ensayar diferentes hipótesis a largo plazo a fin de anticiparse a los problemas y oportunidades que podrían materializarse como consecuencia de los cambios de las variables demográficas fundamentales. Gracias a las posibilidades que ofrecen los programas informáticos, se pueden realizar simulaciones de diversos escenarios poblacionales sobre la base de diferentes niveles de fecundidad, mortalidad y migración, lo que permite ilustrar los posibles impactos en la magnitud y composición de una población determinada.

Tradicionalmente, los ejercicios de proyecciones se han elaborado para obtener posibles escenarios futuros sobre una población determinada, a fin de ofrecer elementos de juicio útiles para la planificación de políticas públicas y la gestión privada. Durante décadas, numerosos organismos públicos nacionales e internacionales han realizado investigaciones que han producido numerosas proyecciones demográficas, sobre todo respecto de poblaciones nacionales, a diferentes plazos de tiempo en el futuro. El Centro Latinoamericano y Caribeño de Demografía (CELADE)-División de Población de la CEPAL, la División de Población de las Naciones Unidas y la Oficina del Censo de los Estados Unidos son las principales instituciones que han producido proyecciones periódicas a mediano y largo plazo para distintos países. En especial, el CELADE-División de Población de la CEPAL colabora con las oficinas nacionales de estadísticas de América Latina para definir sus propias proyecciones demográficas.

En este documento se presentan las proyecciones demográficas realizadas por los autores a partir de escenarios imaginados sobre la base del análisis de la trayectoria de la población argentina en las últimas décadas. Se hace especial énfasis en los registros de estadísticas vitales del período 2010-1013, y se intenta comparar los resultados con los publicados por las instituciones antes citadas, a fin de detectar coincidencias y diferencias que ayuden a ilustrar el impacto de las variables demográficas en la evolución futura de la población argentina.

\section{A. Antecedentes}

En un trabajo reciente, Rafael Rofman (2007) analizó la historia de las proyecciones demográficas ensayadas respecto de la población argentina y realizó un ejercicio de simulación hasta el año 2300. Expresó acertadamente el modo adecuado de considerar e interpretar las proyecciones de población:

"Ejercicios de simulación que, utilizando supuestos razonables, pueden generar escenarios probables en el largo plazo, pero sin valor de certeza. (...) El objetivo de estos escenarios no es predictivo (como no debería ser en ningún caso el de cualquier proyección 
publicada) sino de simulación, con la idea de mostrar qué pasaría si determinados supuestos se verifican en el futuro". (...)

"Si se consideran las proyecciones como el resultado esperable en el caso de que una determinada combinación de procesos sociales ocurra, su utilidad para la comprensión de las tendencias poblacionales y las necesarias políticas públicas que respondan a ellas será muy alta, ya que permitirá plantear estrategias de mediano plazo que, por supuesto, deberán adaptarse a medida que la realidad verifique o desmienta los escenarios desarrollados" (Rofman, 2007, págs. 604 y 607).

Rofman realiza ejercicios de proyección de la población argentina a muy largo plazo (hasta 2300), basándose en las proyecciones elaboradas por el Instituto Nacional de Estadística y Censos (INDEC) y el CELADE-División de Población de la CEPAL hasta 2050. Para ello, define cuatro escenarios basados en diferentes niveles de fecundidad: i) un escenario "alto" que supone una tasa global de fecundidad constante de 2,35 hijos por mujer a partir de 2050; ii) un escenario "medio", con una fecundidad que desciende a 1,85 y progresivamente converge en 2,1 hijos por mujer en 2100, y iii) un escenario "bajo", con una fecundidad constante de 1,35 hijos por mujer a partir de 2050. Rofman afirma que para el año 2300 la diferencia de un hijo en la fecundidad puede producir resultados muy diferentes entre el escenario alto y el bajo: 331 y 3,5 millones respectivamente. Hacia 2100, la proyección media arroja una población total aproximada de 50 millones de habitantes (Rofman, 2007, págs. 613 a 615).

Rofman también ensaya diferentes hipótesis con diversos niveles de mortalidad. Define así un escenario de mortalidad alta en que las esperanzas de vida se estabilizan en los valores observados en 2005 (71,6 años en el caso de los hombres nacidos en ese año). Otro escenario de mortalidad media supone un avance de la esperanza de vida al ritmo actual, que llegaría a 98 años en 2300. Finalmente, calcula un escenario de mortalidad baja, con una esperanza de vida masculina que llegaría a casi 118 años. Las poblaciones proyectadas hasta 2300 difieren mucho menos que en el caso de los escenarios de fecundidad: se llegaría a 101 millones con el escenario de baja mortalidad, frente a los 56 millones que se obtendrían con mortalidad alta. El autor señala que, a muy largo plazo, una diferencia del $74 \%$ en la tasa global de fecundidad podría producir una diferencia del $9.300 \%$ en la población final, mientras que una diferencia del $65 \%$ en la esperanza de vida generaría un cambio del $80 \%$ en la población (Rofman, 2007, págs. 613 a 616).

Por su parte, la División de Población de las Naciones Unidas realiza proyecciones de población de todos los países del mundo hasta el año 2100 y publica revisiones cada dos años. La metodología empleada consta principalmente de la aplicación de modelos jerárquicos bayesianos para la estimación probabilística de los niveles futuros de fecundidad y mortalidad, lo que permite obtener intervalos de confianza y diversos escenarios. En el caso de la Argentina, la Revisión 2015 proyecta, de acuerdo a la variante media de fecundidad, que la población total alcanzará los 55,4 millones en 2050, llegará a un máximo de 59,131 millones en 2084 y descenderá a 58,6 millones en 2100. La tasa global de fecundidad estimada descendería de 2,27 hijos por mujer en la actualidad a 1,84 en 2100. La esperanza de vida masculina al nacer llegaría en 2100 a 86,48 años y la femenina, a 90,46 años. La tasa 
de mortalidad infantil descendería a 5 por cada 1.000 nacidos vivos en 2050 y a 3 por cada 1.000 en 2100 (Naciones Unidas, 2015).

El CELADE-División de Población de la CEPAL publica también sus proyecciones demográficas de los países de América Latina. Según su Revisión 2013, la población argentina alcanzaría los 50 millones de habitantes en 2050, hasta un máximo de 50,389 millones en 2059, para luego descender a 44,3 millones en 2100. En esa proyección, la tasa global de fecundidad en 2010-2015 es de 2,2 hijos por mujer, y desciende a 1,7 en 2050 y a 1,6 en el período 2075-2090, para finalizar en 1,7 en la última década del siglo. La esperanza de vida al nacer llegaría en 2095-2100 a 82,1 años en el caso de los varones y a 88,6 años en el de las mujeres. La mortalidad infantil se estima en 6,2 por cada 1.000 nacidos vivos en $2050-2055$ y 3,3 por cada 1.000 en 2095-2100 (CEPAL, 2013a).

A continuación se consigna la proyección demográfica realizada por la Oficina del Censo de los Estados Unidos, que prevé 53,5 millones de habitantes para 2050. Se estima que entonces la esperanza de vida al nacer de la población masculina alcanzará los 79 años, y los 85,4 años en el caso de la población femenina. En cuanto a la mortalidad infantil, se prevé que descienda de 11,1 por cada 1.000 nacidos vivos en 2010 a 4,8 por cada 1.000 en 2050. Por otra parte, se calcula que habrá un descenso de la fecundidad, de 2,33 hijos por mujer en la actualidad a 1,84 en 2050 (Oficina del Censo, 2013).

Finalmente, se reseña la proyección oficial realizada por el INDEC, que abarca el período 2010-2040. El INDEC proyecta una población total de 52,8 millones de habitantes para 2040. Según la proyección oficial, se estima inicialmente una fecundidad de 2,41 hijos por mujer en 2010, pero esa cifra se reduciría a 1,98 en 2040. En lo que respecta a la mortalidad, para 2040 se prevé una esperanza de vida al nacer de 78,44 años en el caso de los varones y de 84,72 años en el de las mujeres. Por su parte, la tasa de mortalidad infantil descendería a lo largo del período de 11,77 a 4,99 por cada 1.000 nacidos vivos (INDEC, 2013).

\section{B. Metodología}

Las proyecciones demográficas son técnicas que permiten estimar la población que reside en una zona y un momento determinados. El procedimiento más usual es el método de los componentes, que permite realizar una simulación del cambio de una población de acuerdo a sus componentes de crecimiento, según la lógica de un diagrama de Lexis. Este método sigue a cada cohorte de personas de la misma edad a lo largo de su vida, tomando en cuenta la influencia que tienen en ella la mortalidad, la fecundidad y la migración. Comienza con la población de base por edad y sexo, la población en cada edad específica en un período posterior está dada por las tasas de mortalidad y de migración a las que se expondrá esta población a lo largo de su vida; y las tasas de fecundidad determinan los nacimientos y el inicio de las nuevas cohortes. El procedimiento completo se repite para cada año del período de proyección, lo que da como resultado la población proyectada por edad y sexo por año calendario (Arriaga, 2001, págs. 309 y 310). 
En este trabajo se emplea el programa RUPEX desarrollado por la Oficina del Censo de los Estados Unidos (Arriaga, 2001). Esa herramienta permite incorporar los registros de nacimientos por sexo de los nacidos y edad de las madres, así como las defunciones por sexo y edad, además de saldos de migrantes por sexo y edad. De esta manera se pueden aprovechar los registros de estadísticas vitales disponibles hasta 2013, para luego incorporar diferentes hipótesis de mortalidad, fecundidad y migración hasta 2100.

A partir de la población censada en 2010 se proponen cuatro escenarios demográficos, con arreglo a diversos niveles futuros de fecundidad. Dado que la fecundidad es la variable más influyente en la magnitud y composición etaria de una población, en condiciones normales de crecimiento, se proponen cuatro valores posibles a largo plazo que se combinan con una hipótesis única de mortalidad y migración. En el caso de la mortalidad, la estimación futura del nivel general es más sencilla debido a la regularidad que experimenta a lo largo de la serie histórica de datos disponibles. La migración, por su parte, es el componente demográfico más difícil de estimar y proyectar hacia el futuro, y tiende a ser menos influyente en las grandes poblaciones, salvo que se produzcan movimientos masivos de migrantes que no puedan preverse de antemano.

\section{Población de base}

La población de base de la proyección se define a partir de la población residente censada en 2010, ajustada por la omisión por sexo y edad, que alcanza los 40.901 .296 habitantes. El INDEC calculó la omisión general en un $2 \%$, desglosada por sexo y grandes grupos etarios. La distribución etaria de la población se ajustó de la siguiente manera:

- La población menor de cinco años se obtuvo a partir de un diagrama de Lexis con la información de nacimientos y defunciones registrados durante el quinquenio 2005-2010

- A pesar de que los índices de preferencia de dígitos fueron bajos en el censo de 2010 (1,02 el índice de Whipple y 1,6 el de Myers), se calcularon promedios móviles de las edades simples de la población de cinco años y más, a fin de suavizar la distribución etaria.

- Se realizó un ajuste por omisión censal, aplicando los porcentajes de omisión calculados por grandes grupos etarios ${ }^{3}$.

- Se realizó un ajuste por fecha de realización del censo (del 27 de octubre al 1 de julio de 2010), mediante interpolación exponencial y empleando la tasa de crecimiento intercensal de 2001-2010.

\footnotetext{
Para este ajuste se supone que las estadísticas vitales son completas. Más adelante se especifica el grado de omisión de los registros.

3 En referencia a la población masculina se calcularon los siguientes porcentajes de omisión censal: el 4,7\% en el caso de los menores de 15 años, el 1,8\% en el grupo de 15 a 64 años y el 1,4\% en el caso de los mayores de 64 años. En el caso de la población femenina, los porcentajes fueron: el 3,1\% en el caso de las menores de 15 años y el 1,1\% en el de las mayores de 14 años (INDEC, 2013, pág. 12).
} 


\section{Mortalidad}

En relación con el período comprendido entre 2009 y 2013 se emplean las defunciones por sexo y grupos etarios publicadas por el Ministerio de Salud de la Argentina. En estos registros de estadísticas vitales es necesario introducir algunos ajustes correspondientes a la declaración del sexo y edad de los fallecidos. En los casos sin información, se distribuyen proporcionalmente, en cada sexo por separado, las defunciones sin edad especificada entre las defunciones con edad registrada. En las defunciones de menores de un año también se ajustan proporcionalmente los casos en que no se registró el sexo de los fallecidos, teniendo en cuenta los casos con sexo registrado. A continuación se calculan los promedios trianuales de los fallecimientos por edad y sexo, a fin de reducir el efecto de las oscilaciones aleatorias entre años calendarios. Por último, se utiliza el programa RUPEX para ajustar las distribuciones promediadas al promedio de fallecidos totales registrados por trienio, a fin de incorporar las defunciones que no tienen consignado el sexo de las personas fallecidas.

Se aclara que no se realizan correcciones por omisión de registro de defunciones o nacimientos, ni de inscripción tardía de estos últimos, dado que los registros de estadísticas vitales tienen un grado elevado de cobertura o integridad (Fernández y otros, 2008). La Dirección de Estadísticas e Información de Salud (DEIS) menciona en sus anuarios que los problemas de omisión se limitan a determinadas áreas geográficas. La omisión de nacimientos estaría por debajo del $3 \%$, y se han implementado medidas para mejorar los registros, como la gratuidad de la inscripción del recién nacido desde 2003 (DEIS, 2011, págs. 2 y 3 ).

Para los años posteriores a 2013, se realiza una extrapolación logística de las esperanzas de vida al nacer por sexo, mediante la planilla EoLOGST del paquete PAS (Arriaga, 2001, pág. 389). Se incorporaron las esperanzas de vida calculadas por el INDEC en el período 1950-2009 y los valores obtenidos en el período 2010-2013 a partir de las estadísticas vitales publicadas por el Ministerio de Salud. Además, el programa requiere el establecimiento de valores asintóticos inferiores ( 25 años) y superiores por sexo, a cuyo efecto se tomaron como referencia las esperanzas de vida proyectadas por la División de Población de las Naciones Unidas para 2100 y se fijaron arbitrariamente en 86 años en el caso del sexo masculino y 91 años en el del femenino.

De esa manera queda definida una única hipótesis de mortalidad, en la que las esperanzas de vida de 2010 a 2013 se derivan directamente de los registros de defunciones y, a partir de 2014, se extrapolan logísticamente. Se obtienen así esperanzas de vida al nacer, en 2100, de 82,23 años en el caso de los varones y de 88,07 años en el de las mujeres. En comparación con las esperanzas de vida empleadas por la División de Población de las Naciones Unidas, los valores obtenidos en este trabajo al final del período resultan inferiores en tres años en el caso de los varones y en dos años en el caso de las mujeres. En relación con el mismo año, las proyecciones del CELADE se aproximan más a los valores aquí calculados. Si se compara con las esperanzas de vida empleadas por la Oficina del Censo de los Estados Unidos para 2050, los valores obtenidos resultan inferiores en un año en ambos sexos. 


\section{Fecundidad}

En el caso de la fecundidad se combinan también los registros de nacimientos publicados por el Ministerio de Salud y los valores estimados hacia el futuro. Los registros de nacimientos del período 2009-2013 se ajustan cuando no se cuenta con declaración del sexo del recién nacido y se desconoce la edad de las madres. En ambos casos se distribuyeron proporcionalmente a los nacimientos con sexo declarado y a las edades registradas de otras madres. De igual manera que con las defunciones, las distribuciones anuales de nacimientos corregidos de la forma señalada se ajustaron al promedio trianual de nacimientos totales registrados con el fin de reducir el efecto de las oscilaciones aleatorias en los registros y de los registros tardíos.

El nivel y estructura de fecundidad general durante el período 2010-2013 se deriva de los registros de nacimientos. A partir de 2014, y ante la incertidumbre acerca de la evolución del nivel de fecundidad en un plazo tan largo, se proponen cuatro hipótesis diferentes:

i) Hipótesis "constante": Se mantiene el mismo nivel de fecundidad de 2013 hasta el final del período proyectado, equivalente a una tasa global de 2,3 hijos por mujer. La estructura de la fecundidad de 2013 es dilatada, con leve predominio del grupo etario de las mujeres de 20 a 24 años. Esa estructura etaria se modificará gradualmente hacia una estructura envejecida en 2100 , con una cúspide en las edades de 30 a 34 años ${ }^{4}$. Con ese fin se emplea la estructura de fecundidad observada en la Ciudad Autónoma de Buenos Aires en 2013, que presenta esa característica. Si bien este escenario es improbable, se utiliza con el fin de ensayar un marco de crecimiento máximo donde solo envejece la estructura de la fecundidad.

ii) Hipótesis "alta": la tasa global de fecundidad descenderá gradualmente de 2,3 hijos por mujer a 2,05 en 2050, y se mantendrá constante hasta 2100. La estructura de la fecundidad envejecerá de la misma manera que en la hipótesis anterior. Así, se supone un descenso suave de la fecundidad general hasta alcanzar el nivel de reemplazo a mitad de siglo, de manera que no se produzca un descenso de la población de carácter vegetativo a largo plazo.

iii) Hipótesis "media": la tasa global de fecundidad descenderá gradualmente de 2,3 hijos por mujer en 2013 a 1,7 en 2100, y la estructura de la fecundidad envejecerá de la misma manera que en las hipótesis anteriores. Ello representa un descenso moderado a lo largo del siglo hacia niveles por debajo del reemplazo. Este escenario se asemeja a los supuestos de evolución de los niveles de fecundidad calculados por el CELADE, en cuya proyección se estipula un descenso de 2,25 hijos por mujer en 2005-2010 a 1,62 en 2080-2085 y 1,71 al finalizar el período, en 2095-2100. Respecto a las cifras proyectadas por la Oficina del Censo, la fecundidad de 2010 es muy semejante a la utilizada aquí $(2,3)$, pero la tasa global estimada para $2050(1,84)$ se encuentra entre las hipótesis media y baja de este trabajo.

$4 \quad$ El programa RUPEX cambia gradualmente las estructuras de la fecundidad mediante una interpolación lineal de las tasas específicas al comienzo y al final del período proyectado. 
iv) Hipótesis "baja": la tasa global de fecundidad descenderá gradualmente desde el valor observado en 2013 a 1,3 hijos por mujer, y la estructura de la fecundidad envejecerá de la misma manera que en las hipótesis anteriores. Así, se supone un fuerte descenso de la fecundidad a lo largo del presente siglo.

Para determinar los valores intermedios de la tasa global de fecundidad entre $2014 \mathrm{y}$ 2100 se realizó una extrapolación logística mediante la planilla TFRLGST del paquete PAS (Arriaga, 2001, págs. 397 a 401). Estos escenarios difieren de los planteados por la División de Población de las Naciones Unidas, ya que en sus hipótesis se inicia el período con valores de fecundidad distintos al calculado aquí, utilizando un nivel mínimo hacia el quinquenio 2065-2070, que luego asciende levemente hasta 2100.

De esa manera se obtienen cuatro proyecciones distintas que solo varían en el nivel de la fecundidad general, ya que pequeñas modificaciones de esa variable pueden producir importantes diferencias en la magnitud y composición etaria de una población. Las simulaciones representan cuatro escenarios distintos que podría seguir la población argentina a lo largo del siglo XXI, partiendo de un mismo supuesto de mortalidad y migración.

\section{Migración}

El programa RUPEX requiere la incorporación de una hipótesis de saldo migratorio anual discriminado por edad y sexo. Como no se dispone de registros anuales de migrantes, se estima en primer lugar el nivel general de la migración internacional tomando como base el saldo migratorio del período 2002-2010, mediante el procedimiento de la ecuación compensadora5. De esta manera, el saldo migratorio es igual a la diferencia entre el crecimiento demográfico total (calculado a partir de las poblaciones interpoladas exponencialmente al 1 de enero de 2011 y de 2002) y el crecimiento vegetativo (obtenido por la diferencia entre los nacimientos y defunciones registrados entre los años 2002 y 2010) ${ }^{6}$. El saldo migratorio anual de la Argentina en ese período fue de -9.216 migrantes anuales, lo que equivale a una tasa neta media de -0,2 migrantes por cada 1.000 habitantes.

Dada la imposibilidad de contar con la medición completa de la estructura etaria de los migrantes internacionales en todos los destinos del mundo, se adopta la población relativa de los inmigrantes recientes en España, por ser este uno de los destinos principales de los argentinos que emigran (OIM, 2012, págs. 44 a 48; Novick, 2007, pág. 31)7. La estructura etaria de los emigrantes de la Argentina se aplica proporcionalmente al saldo migratorio anual.

5 Se calcula el saldo migratorio correspondiente al período comprendido entre los años calendarios 2002 y 2010 completos, por su cercanía con las fechas de los dos últimos censos de población (17 de noviembre de 2001 y 27 de octubre de 2010). La consideración de años calendarios completos, en lugar de períodos intercensales exactos, permite aprovechar los eventos vitales registrados en esos años para el cálculo indirecto de los saldos migratorios.

6 En el cálculo del saldo migratorio se tuvo en cuenta la omisión general de cada censo de población: un 2,75\% en 2001 y un $2 \%$ en 2010 (INDEC, 2004, pág. 6; INDEC, 2013, pág. 9).

7 Población por sexo y edad censada en España en 2011, que en 2001 residía en Centroamérica, América del Sur o el Caribe (INE, 2015). Los emigrantes menores de diez años se estimaron proporcionalmente a las mujeres inmigrantes en España, según la relación niños-mujeres en edad fértil observada en el censo argentino de 2010. 
Los cuatro escenarios de proyección propuestos incorporan como única hipótesis de migración un saldo inicial de -9.216 migrantes, equivalente al saldo del período de referencia, que se irá reduciendo gradualmente hasta hacerse nulo en 2050 y se mantendrá así hasta $2100^{8}$. Se adopta ese criterio por la incertidumbre inherente a los movimientos migratorios y se supone que la migración reciente tendrá un efecto inercial que poco a poco irá desapareciendo.

La hipótesis de migración planteada difiere un tanto de la estimación hecha por el CELADE, en la que se calcula una emigración anual de -21.000 personas durante el período 2010-2015, que irá descendiendo gradualmente hasta volverse nula en 2035. Las Naciones Unidas también prevén un saldo migratorio negativo, desde una tasa neta de -0,5 por cada 1.000 en 2010-2020 (equivalente a -20.000 emigrantes anuales), que disminuye gradualmente hasta volverse nula en el período 2095-2100. La Oficina del Censo de los Estados Unidos no incluye estimaciones del nivel de migración, por lo que estipula un saldo migratorio nulo durante todo el período de la proyección.

\section{Resultados}

En primer lugar se presentan los resultados obtenidos en los cuatro escenarios demográficos propuestos. En el gráfico 1 se muestra la población total proyectada de acuerdo a las cuatro hipótesis diferentes de fecundidad, mientras que en el cuadro 1 se consignan los principales resultados. Las diferentes proyecciones desarrolladas cuentan con la misma población de base en 2010 (40.901.296 habitantes) y se diferencian solo las diferentes hipótesis de fecundidad.

\section{Gráfico 1}

\section{Argentina: población total proyectada de acuerdo a diferentes niveles de fecundidad, 2010-2100}

(En millones de habitantes)

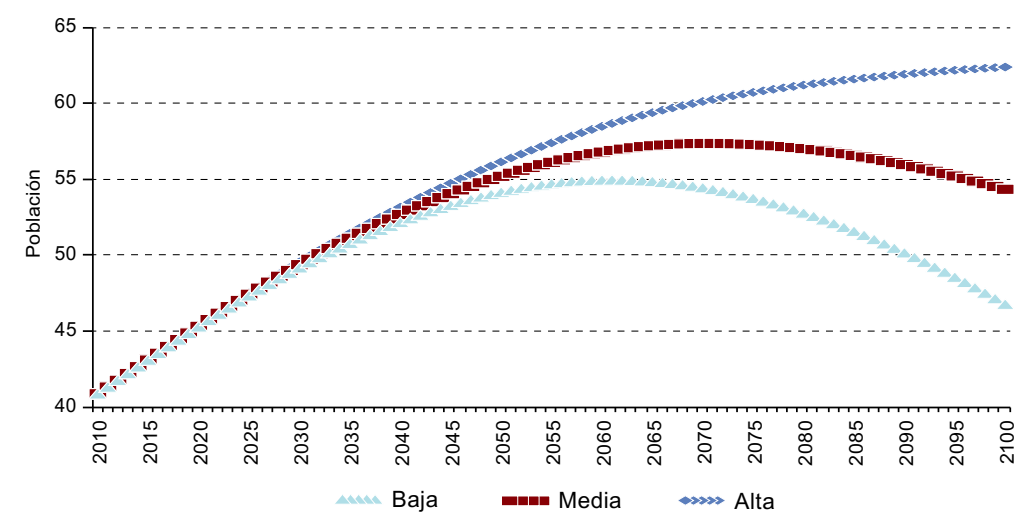

Fuente: Elaboración propia sobre la base de Instituto Nacional de Estadística y Censos (INDEC), Censo Nacional de Población 2010 y Ministerio de Salud de la Nación, estadísticas vitales.

$8 \quad$ El programa RUPEX interpola linealmente el saldo migratorio por sexo y edad entre el año base y el saldo nulo previsto para 2050. 
Cuadro 1

Argentina: principales resultados de la proyección de la población de acuerdo a diferentes niveles de fecundidad, 2010-2100

\begin{tabular}{lrrrr}
\hline & \multicolumn{4}{c}{ Hipótesis de fecundidad } \\
\cline { 2 - 5 } & Constante & \multicolumn{1}{c}{ Alta } & \multicolumn{1}{c}{ Media } & \multicolumn{1}{c}{ Baja } \\
\hline Población en 2100 & 73405733 & 61789542 & 53940533 & 46571190 \\
\hline Población máxima & 73405766 & 61789542 & 56811690 & 54425705 \\
\hline Año de población máxima & 2100 & 2100 & 2071 & 2061 \\
\hline $\begin{array}{l}\text { Incremento máximo respecto a 2010 } \\
\begin{array}{l}\text { Incremento máximo respecto a 2010 } \\
\text { (en porcentajes) }\end{array}\end{array} \quad 32504470$ & 20888246 & 15910394 & 13524409 \\
\hline
\end{tabular}

Fuente: Elaboración propia, sobre la base de Instituto Nacional de Estadística y Censos (INDEC), Censo Nacional de Población 2010 y Ministerio de Salud de la Nación, estadísticas vitales.

En el gráfico 1 se puede observar una importante cercanía de los cuatro escenarios demográficos hasta 2030, aproximadamente. A partir de entonces, los diferentes niveles de fecundidad se hacen visibles en términos de población absoluta. Como es lógico, el escenario de fecundidad constante da como resultado la población más numerosa para 2100, con 73,4 millones de habitantes y un importante potencial de crecimiento futuro. Ese perfil demográfico es muy poco probable debido a la tendencia natural al descenso de la fecundidad observada en las poblaciones. Aun así, resulta interesante contar con un ensayo de lo que podría considerarse un incremento poblacional máximo a partir del estado de la población argentina actual.

El siguiente escenario, de fecundidad alta, produce un crecimiento demográfico bastante inferior a la proyección anterior, con una población de 61,8 millones para 2100. Ya que esa hipótesis de fecundidad estipula una tasa de reemplazo fija, a lo largo del siglo XXII la población tendería a estabilizarse si el nivel de mortalidad también llegara a una meseta. El crecimiento relativo hacia finales de este siglo alcanzaría el 51\% de la población inicial.

Los escenarios de fecundidad media y baja muestran un incremento transitorio de la población total hasta un año determinado, pero luego comienza a registrarse un descenso. La proyección con fecundidad media alcanzaría una población máxima de 56,8 millones de habitantes hacia 2071 (momento de crecimiento igual a o), para luego comenzar un suave descenso y culminar el siglo con poco menos de 54 millones. El incremento relativo máximo llegaría al 39\% de la población inicial. El descenso de la población se produciría como consecuencia directa de la caída de la fecundidad por debajo del nivel de reemplazo a partir de 2036, que provocaría a mediano plazo un menor número de nacimientos con respecto a las defunciones.

El escenario de baja fecundidad, por su parte, produce un incremento de la población hasta un máximo de 54,4 millones de habitantes en 2061, para luego descender de manera marcada hasta terminar el siglo con 46,6 millones. El incremento relativo máximo alcanzaría al 33\% de la población inicial. La fecundidad caería por debajo del nivel de reemplazo hacia 2030. Al igual que en el escenario anterior, la tendencia decreciente continuaría durante el siglo próximo si no se corrigiera el nivel de fecundidad futura. 
Debido a la disparidad de resultados que arrojan los diferentes escenarios se recomienda, por lo general, adoptar la proyección media como la variante más probable, aunque no se tengan elementos ciertos que hagan suponer el cumplimiento efectivo de las hipótesis elaboradas para este escenario. Por razones prácticas, aquí se presentan los resultados más relevantes de la proyección media a fin de ilustrar el cambio demográfico de la población argentina proyectado para este siglo, teniendo en cuenta que puede representar una "media aproximada" de los escenarios más probables en el futuro.

En primer lugar se comparan los resultados obtenidos por la proyección de la hipótesis media de fecundidad con las proyecciones vigentes de los autores y organismos citados anteriormente. Como puede apreciarse en el cuadro 2, la proyección aquí ensayada arroja resultados cercanos a los de las Naciones Unidas, el INDEC y la Oficina del Censo de los Estados Unidos para 2040, ya que al comienzo los niveles de fecundidad son semejantes y el período de cálculo, más acotado. A medida que se alejan en el tiempo, las diferencias se incrementan en relación con lo informado por los distintos organismos. La proyección media supera en 1,1 millones a la de la Oficina del Censo y es menor en 0,8 millones a la de las Naciones Unidas en 2050. Para fin de siglo, las diferencias llegan a 4 millones respecto a Rofman y las Naciones Unidas, y superan en 9,6 millones la proyección del CELADE. Resulta evidente que las diferencias radican principalmente en las distintas hipótesis en que se basan las estimaciones, pero también en que el nivel de fecundidad aplicado en este trabajo supone una disminución más lenta a lo largo del siglo que la mayoría de las proyecciones citadas.

\section{Cuadro 2}

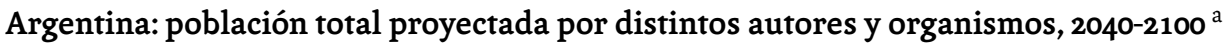

(En millones de habitantes)

\begin{tabular}{lrrr}
\hline Referencia bibliográfica & 2040 & 2050 & 2100 \\
\hline Rofman (2007) & - & - & 50,0 \\
\hline División de Población de las Naciones Unidas (2015) & 52,7 & 55,4 & 58,6 \\
\hline CELADE-División de Población de la CEPAL (2013) & 48,8 & 50,0 & 44,3 \\
\hline Oficina del Censo de los Estados Unidos (2013) & 51,6 & 53,5 & - \\
\hline INDEC (2013) & 52,8 & - & - \\
\hline Propia (fecundidad media) & 52,2 & 54,6 & 53,9 \\
\hline
\end{tabular}

Fuente: Elaboración propia, sobre la base de R. Rofman, "Perspectivas de la población en el siglo XXI: los segundos doscientos años", Población y bienestar en la Argentina del primero al segundo Centenario. Una historia del siglo XX, Susana Torrado (comp.), Buenos Aires, Edhasa, 2007; Naciones Unidas, "World Population Prospects: The 2015 Revision, Key Findings and Advance Tables", Working Paper, $N^{\circ}$ ESA/P/WP.241, División de Población, 2015 [en línea] http://esa.un.org/unpd/wpp/;Comisión Económica para América Latina y el Caribe (CEPAL), "Proyecciones de largo plazo. Revisión 2013", Santiago, CELADE-División de Población de la CEPAL, 2013 [en línea] http://www.cepal.org/celade/ proyecciones/basedatos_BD.htm [fecha de consulta: 16 de junio de 2015]; Oficina del Censo de los Estados Unidos, "International Programs", Washington, D.C., 2013 [en línea] http://www.census.gov/ population/international/data/idb/ informationGateway.php [fecha de consulta: 16 de junio de 2015; e Instituto Nacional de Estadística y Censos (INDEC) de la Argentina "Estimaciones y proyecciones de población 2010-2014: total del país", serie Análisis Demográfico, № 35, Buenos Aires, 2013 [en línea] http://www.indec.gov.ar/ bajarPublicacion.asp?idc=3C0A5260A490C6F182A1E47FA9F48BE11638666F F2DD424D0109EFA2423522697D9046924A86E2FD.

a Las proyecciones citadas difieren en cuanto la población de base utilizada y sus hipótesis de fecundidad, mortalidad y migración. 
En segundo lugar, se destaca el proceso sostenido de envejecimiento en que se encuentra la población argentina y que, de acuerdo a la proyección media, provocará una notable transformación de la estructura por sexo y edad. A pesar de que el número absoluto de habitantes no crecería de manera importante (la población ya no volvería a duplicarse como en la segunda mitad del siglo XX), el cambio más notable se verificaría en la distribución por edades.

Las pirámides de población (véase el gráfico 2) muestran claramente que el proceso de envejecimiento ya está presente en 2010. Hacia 2050, la población argentina mostrará un fuerte incremento de la población adulta y anciana de ambos sexos, mientras que la población joven e infantil disminuirá de manera lenta pero constante. Al final del siglo, el mayor incremento se verificará por encima de los 50 años, sobre todo en la población femenina, y se constatará una importante reducción de la población menor de dicha edad. Como consecuencia de ese proceso, la edad mediana aumentará de 29,5 a 46,7 años (véase el cuadro 3) y la primera mitad del siglo sería el período de incremento más rápido (casi nueve años en total).

\section{Gráfico 2}

Argentina: pirámides de población proyectadas de acuerdo a la hipótesis de fecundidad media, 2010, 2050 y 2100

(En miles de habitantes)

A. 2010
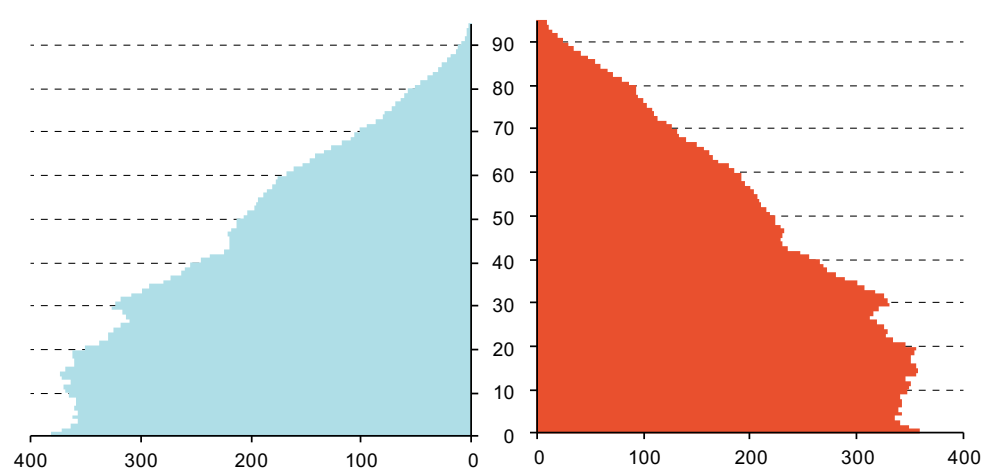

B. 2050
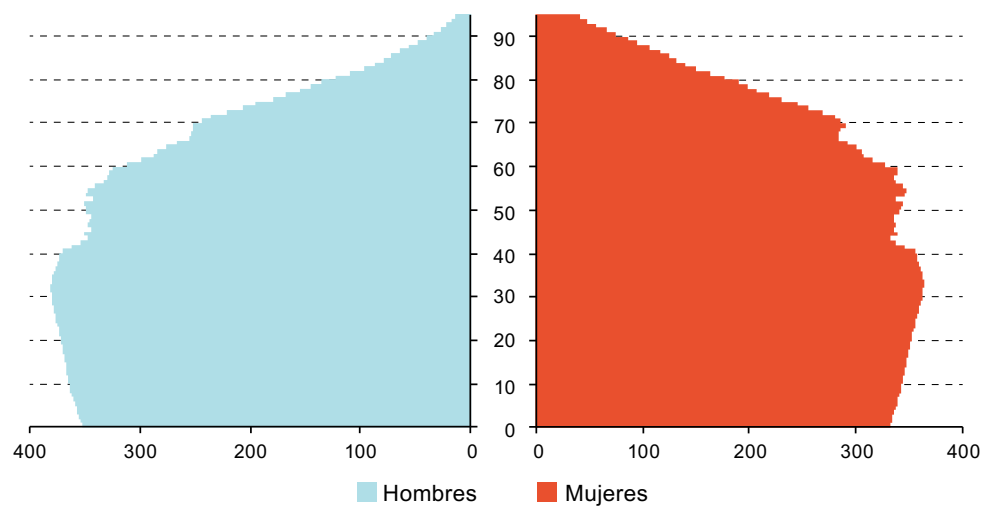
Gráfico 2 (conclusión)

C. 2100
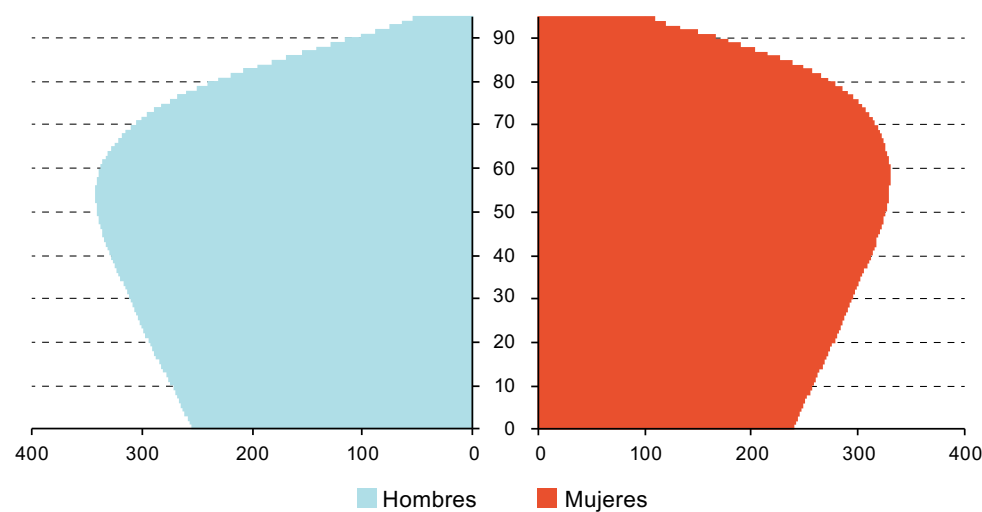

Fuente: Elaboración propia, sobre la base de Instituto Nacional de Estadística y Censos (INDEC), Censo Nacional de Población 2010 y Ministerio de Salud de la Nación, estadísticas vitales.

Cuadro 3

\section{Argentina: principales resultados de la proyección de la población de acuerdo} a la hipótesis de fecundidad media, 2010-2100

\begin{tabular}{|c|c|c|c|c|c|}
\hline & 2010 & 2025 & 2050 & 2075 & 2100 \\
\hline $\begin{array}{l}\text { Población total } \\
\text { (en habitantes) }\end{array}$ & 40901296 & 47124100 & 54621288 & 56750779 & 53940533 \\
\hline $\begin{array}{l}\text { Población masculina } \\
\text { (en habitantes) }\end{array}$ & 20015341 & 23177715 & 26967210 & 28053682 & 26664030 \\
\hline $\begin{array}{l}\text { Población femenina } \\
\text { (en habitantes) }\end{array}$ & 20885955 & 23946385 & 27654078 & 28697097 & 27276503 \\
\hline Índice de masculinidad ${ }^{a}$ & 95,8 & 96,8 & 97,5 & 97,8 & 97,8 \\
\hline Edad mediana (en años) & 29,5 & 32,7 & 38,3 & 43,2 & 46,7 \\
\hline $\begin{array}{l}\text { Tasa anual de crecimiento } \\
\text { (en porcentajes) }\end{array}$ & 10,9 & 0,8 & 0,4 & $-0,1$ & $-0,3$ \\
\hline Nacimientos & 753185 & 738942 & 679091 & 589192 & 495351 \\
\hline Tasa global de fecundidad ${ }^{\mathrm{b}}$ & 2,37 & 2,16 & 1,92 & 1,78 & 1,7 \\
\hline Defunciones & 314062 & 345582 & 472530 & 620055 & 675376 \\
\hline $\begin{array}{l}\text { Esperanza de vida, varones } \\
\text { (en años) }\end{array}$ & 72,21 & 74,68 & 78,01 & 80,47 & 82,23 \\
\hline $\begin{array}{l}\text { Esperanza de vida, mujeres } \\
\text { (en años) }\end{array}$ & 78,76 & 81,37 & 84,42 & 86,58 & 88,07 \\
\hline $\begin{array}{l}\text { Brecha de esperanzas } \\
\text { de vida }^{c}\end{array}$ & 6,55 & 6,69 & 6,41 & 6,11 & 5,84 \\
\hline Tasa de mortalidad infantil d & 12,0 & 8,0 & 5,1 & 3,6 & 2,8 \\
\hline $\begin{array}{l}\text { Migrantes anuales } \\
\text { (en habitantes) }\end{array}$ & -9217 & -5761 & 0 & 0 & 0 \\
\hline $\begin{array}{l}\text { Población de } 0 \text { a } 14 \text { años } \\
\text { (en habitantes) }\end{array}$ & 10682901 & 11118573 & 10403033 & 9204072 & 7812521 \\
\hline
\end{tabular}


Cuadro 3 (conclusión)

\begin{tabular}{|c|c|c|c|c|c|}
\hline & 2010 & 2025 & 2050 & 2075 & 2100 \\
\hline $\begin{array}{l}\text { Población de } 0 \text { a } 14 \text { años } \\
\text { (en porcentajes) }\end{array}$ & 26,1 & 23,6 & 19,0 & 16,2 & 14,5 \\
\hline $\begin{array}{l}\text { Población de } 15 \text { a } 24 \text { años } \\
\text { (en habitantes) }\end{array}$ & 6914499 & 7014108 & 7167778 & 6582034 & 5676920 \\
\hline $\begin{array}{l}\text { Población de } 15 \text { a } 24 \text { años } \\
\text { (en porcentajes) }\end{array}$ & 16,9 & 14,9 & 13,1 & 11,6 & 10,5 \\
\hline $\begin{array}{l}\text { Población de } 25 \text { a } 64 \text { años } \\
\text { (en habitantes) }\end{array}$ & 19165020 & 23282409 & 27525094 & 27815960 & 25546997 \\
\hline $\begin{array}{l}\text { Población de } 25 \text { a } 64 \text { años } \\
\text { (en porcentajes) }\end{array}$ & 46,9 & 49,4 & 50,4 & 49,0 & 47,4 \\
\hline $\begin{array}{l}\text { Población de } 65 \text { a } 79 \text { años } \\
\text { (en habitantes) }\end{array}$ & 3134916 & 4370981 & 6886129 & 8383337 & 8886759 \\
\hline $\begin{array}{l}\text { Población de } 65 \text { a } 79 \text { años } \\
\text { (en porcentajes) }\end{array}$ & 7,7 & 9,3 & 12,6 & 14,8 & 16,5 \\
\hline $\begin{array}{l}\text { Población de } 80 \text { años y más } \\
\text { (en habitantes) }\end{array}$ & 1003960 & 1338029 & 2639254 & 4765376 & 6017336 \\
\hline $\begin{array}{l}\text { Población de } 80 \text { años y más } \\
\text { (en porcentajes) }\end{array}$ & 2,5 & 2,8 & 4,8 & 8,4 & 11,2 \\
\hline Tasa de dependencia total $^{\mathrm{e}}$ & 56,8 & 55,5 & 57,4 & 65,0 & 72,8 \\
\hline Tasa de dependencia, niños $^{f}$ & 41,0 & 36,7 & 30,0 & 26,8 & 25,0 \\
\hline $\begin{array}{l}\text { Tasa de dependencia, } \\
\text { ancianos } 9\end{array}$ & 15,9 & 18,8 & 27,5 & 38,2 & 47,7 \\
\hline
\end{tabular}

Fuente: Elaboración propia, sobre la base de Instituto Nacional de Estadística y Censos (INDEC), Censo Nacional de Población 2010 y Ministerio de Salud de la Nación, estadísticas vitales.

a Población masculina cada 100 mujeres.

b Hijos por mujer.

c Diferencia entre las esperanzas de vida femenina y la masculina, expresada en años de vida.

d Por cada 1.000 nacidos vivos.

e Razón entre la población menor de 15 años y mayor de 64 sobre la población de 15 a 64 años, por 100.

f Razón entre la población menor de 15 años sobre la población de 15 a 64 años, por 100.

g Razón entre la población mayor de 64 años sobre la población de 15 a 64 años, por 100.

En el gráfico 3 se puede apreciar la distribución relativa de la población por grandes grupos etarios. Se observa que la población menor de 15 años (pasiva en razón de su edad) descenderá más rápidamente en la primera mitad del siglo, y se reducirá a un $15 \%$ de la población total hacia 2100 . El grupo de 15 a 24 años (que es potencialmente activo por su edad pero transitoriamente pasivo por razones de estudio) experimentará un descenso más leve que el grupo anterior, aunque su mayor reducción también se producirá antes de 2050. La población activa (de 25 a 64 años) mostrará un incremento desde 2010 hasta un largo período de relativa estabilidad en 2025-2075, pero descenderá levemente al final del período estudiado. La tercera edad (de 65 a 79 años) duplicará su participación relativa a lo largo del siglo, creciendo sobre todo en el período 2025-2050. La cuarta edad (80 años y más) será el segmento de crecimiento relativo más vertiginoso, desde el 2,5\% en 2010 hasta el $11 \%$ a fin de siglo. Si se considera a la población anciana en conjunto (65 años y más), se pasará de un 10\% inicial al $28 \%$ final, lo que implica casi la triplicación de la población relativa en edades ancianas y un incremento de 3,6 veces en términos absolutos (de 4 a 15 millones). 


\section{Gráfico 3}

\section{Argentina: población relativa por grandes grupos de edad, proyectada de acuerdo a la hipótesis de fecundidad media, 2010-2100}

(En porcentajes)

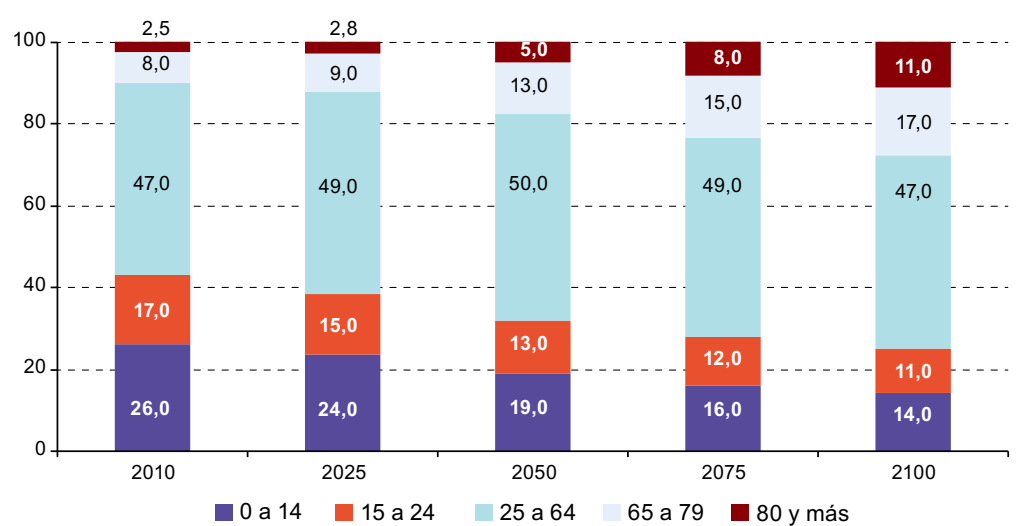

Fuente: Elaboración propia, sobre la base de Instituto Nacional de Estadística y Censos (INDEC), Censo Nacional de Población 2010 y Ministerio de Salud de la Nación, estadísticas vitales.

La relación entre activos y pasivos, expresada a partir de las tasas de dependencia, muestra que el incremento de la población activa conducirá al descenso transitorio de la tasa de dependencia total. Hacia 2035 terminaría el llamado "bono demográfico" . A partir de entonces crecería nuevamente la tasa. Ese proceso sería resultado del descenso continuo de la dependencia de los niños (de 41 a 25 por cada 100 activos en 2100) y, sobre todo, del marcado aumento de la dependencia de los ancianos (de 16 a 48 por cada 100 activos).

En tercer lugar, la distribución de la población por sexos (índice de masculinidad) se modificaría muy poco en la primera mitad del siglo a favor del sexo masculino, y quedaría prácticamente estable hasta 2100 . De todas maneras, la población femenina seguirá siendo mayoritaria, con una diferencia aproximada de 650.000 mujeres.

En cuarto lugar, y en relación a la fecundidad, se verifica un temprano incremento de los nacimientos durante la segunda década del siglo, que luego disminuirá paulatinamente durante el resto del período considerado. En 2013 se registraron 754.603 nacimientos y, en caso de verificarse la hipótesis de fecundidad prevista en este escenario (descenso continuo de 2,3 hijos por mujer en 2011 a 1,7 en 2100 y envejecimiento del calendario

9 El concepto del "bono demográfico" se define como el período de tiempo en que disminuye transitoriamente la relación de dependencia total, por efecto del descenso de la fecundidad (caída de la población menor de 15 años), hasta que vuelve a incrementarse por efecto del envejecimiento (incremento de la población de 65 años y más). Se argumenta que durante ese tiempo la sociedad puede disponer de ahorros provenientes de la menor demanda de los niños, que pueden aprovecharse en inversiones productivas o reasignarse a beneficios sociales, antes que la relación de dependencia vuelva a incrementarse por el peso creciente de la población mayor. Esa visión es criticada por no considerar la capacidad real de creación de puestos de trabajo de los países en desarrollo, acorde a la mayor demanda de población adulta joven y a la alta volatilidad de sus economías nacionales (Chackiel, 2004, págs. 63 y 64; CEPAL, 2005, págs. 12 a 14). 
de la fecundidad), el número máximo de nacimientos se produciría en 2016, con aproximadamente 756.000 niños. Hacia fines de siglo los nacimientos anuales serían de alrededor de 500.000. Siguiendo ese supuesto de fecundidad, la tasa global caería por debajo del nivel de reemplazo hacia 2036, pero de todos modos los nacimientos superarán el número total de defunciones hasta 2071.

En quinto lugar, en caso de verificarse la hipótesis de mortalidad definida en estas simulaciones, las personas de ambos sexos registrarían un importante incremento de la esperanza de vida a lo largo del siglo. La esperanza de vida de la población masculina aumentaría en diez años, hasta alcanzar los 82,23 años en 2100. La de la población femenina aumentaría en poco más de nueve años, hasta llegar a 88,07 años al final del período. La brecha entre ambos sexos se acortaría de 6,6 a 5,8 años, siempre a favor de la población femenina. El número absoluto de fallecimientos crecería de manera continua, desde 326.197 en 2013 hasta alrededor de 675.000 a fin de siglo.

Por su parte, las tasas de mortalidad infantil mostrarían un fuerte descenso, de 10,9 por cada 1.000 nacidos vivos en 2013 a 2,8 en 2100, debido al alto incremento de la esperanza de vida al nacer. Cabe advertir que se trata de estimaciones a largo plazo cuya validez queda en el terreno de la especulación propia de un ejercicio de simulación, como sucede con toda proyección demográfica. No es posible prever cuáles serán los avances futuros de la medicina o los hábitos personales que puedan tener un efecto favorable sobre la expansión de la vida. Por lo tanto, estos indicadores de mortalidad solo son válidos como conjeturas, siempre y cuando se acepten los supuestos sobre los que se construyeron.

Por último, la migración que se ha asumido para estas proyecciones solo muestra un descenso continuo desde los -9.217 migrantes iniciales hasta volverse nula en 2050. Su baja magnitud actual no tiene una influencia importante en la evolución cuantitativa de la población argentina, salvo que en el futuro se produzcan eventos migratorios relevantes que no puedan preverse de antemano.

\section{Conclusiones}

Las proyecciones presentadas en este trabajo representan ejercicios de simulación de escenarios hipotéticos en que la evolución de la población depende exclusivamente de la validez de los supuestos definidos. Se definieron cuatro escenarios posibles a partir de diferentes niveles de fecundidad, como variable que representa el principal factor de cambio demográfico y cuyo valor futuro resulta una incógnita.

Los cuatro escenarios ensayados muestran que la población argentina tendrá un crecimiento moderado durante este siglo y no volverá a duplicarse como en la segunda mitad del siglo XX. El máximo crecimiento ensayado, si se mantiene constante el nivel de fecundidad de 2013 , llega a 73,4 millones en 2100 . No obstante, su materialización parece improbable dada la tendencia al descenso de la fecundidad registrada en las últimas tres 
décadas. Con mayor margen de probabilidad se presenta el escenario de alta fecundidad, que sería de 61,8 millones de habitantes en 2100, un 51\% superior a la población censada en 2010. Si se verificaran valores medios de fecundidad, la población llegaría a un total aproximado de 56,8 millones durante el presente siglo y comenzaría a reducirse gradualmente. Estos resultados divergen de las proyecciones realizadas por otros autores y organismos, principalmente por las diferentes hipótesis de evolución demográfica planteadas en cada ejercicio.

Más allá del incremento de la población total, el fenómeno predominante será el marcado envejecimiento que sufrirá su estructura etaria. Las pirámides del escenario de fecundidad media muestran con claridad la expansión progresiva de la población adulta y anciana, acompañada por la reducción de la población joven e infantil. Ello representará un serio desafío para el financiamiento de los sistemas de salud y seguridad social a mediano plazo, además de impactar en la constitución y organización doméstica de las familias. Si bien el "bono demográfico" se extendería hasta 2035, el empobrecimiento de la población tras la crisis económica de 2001-2002 y la persistente informalidad del empleo limitan seriamente las ventajas transitorias que ofrece la disminución actual de las tasas de dependencia.

Las simulaciones aquí ensayadas no agotan en absoluto los posibles escenarios respecto de la evolución de la población argentina. Se podrían modificar los supuestos de fecundidad en descenso continuo por etapas de recuperación o incremento, así como diversos niveles de mortalidad y migración. Para ello, es necesario hacer un seguimiento de los nuevos registros de estadísticas vitales que se publican y consultar las nuevas metodologías que se están desarrollando en diversos centros de investigación y, de ese modo, obtener una mejor estimación de la fecundidad y mortalidad futuras.

Queda pendiente la desagregación por provincias de las proyecciones de la población nacional, a fin de mostrar el peso relativo de las distintas regiones y las diversas dinámicas demográficas que se verifican en el interior del país. Con todo, es de esperar que este ejercicio ayude a reflexionar sobre los posibles escenarios demográficos y aporte elementos de juicio para una mejor planificación de las políticas públicas, así como para la gestión privada. 


\section{Bibliografía}

Arriaga, Eduardo (2001), El análisis de la población con microcomputadoras, Córdoba, Facultad de Ciencias Económicas de la Universidad Nacional de Córdoba.

CEPAL (Comisión Económica para América Latina y el Caribe) (2013a), Observatorio Demográfico 2013 (LC/G.2615-P), Santiago [en línea] http://www.cepal.org/sites/default/files/publication/files/ observatoriodemografico2013.pdf.

_ (2013b), "Proyecciones de largo plazo. Revisión 2013", Santiago, [en línea] http://www.cepal.org/ celade/proyecciones/basedatos_BD.htm [fecha de consulta: 16 de junio de 2015].

(2005), "Dinámica demográfica y desarrollo en América Latina y el Caribe", serie Población y Desarrollo, $\mathrm{N}^{\circ} 58$ (LC/L.2235-P), Santiago, Centro Latinoamericano y Caribeño de Demografía (CELADE) - División de Población de la CEPAL.

Chackiel, Juan (2004), "La dinámica demográfica en América Latina", serie Población y Desarrollo, $\mathrm{N}^{\circ} 52$ (LC/L.2127-P), Santiago, Centro Latinoamericano y Caribeño de Demografía (CELADE)-División de Población de la CEPAL.

DEIS (Dirección de Estadísticas e Información de Salud) (2009-2014), "Estadísticas VitalesInformación Básica" [en línea], Buenos Aires, Ministerio de Salud de la Nación, serie 5 - años 2009-2013 [en línea] www.deis.gov.ar.

Fernández y otros (2008), Omisión de registro de nacimientos y muertes infantiles. Magnitud, desigualdades y causas, Buenos Aires, Organización Panamericana de la Salud (OPS)/Ministerio de Salud de la Nación.

INDEC (Instituto Nacional de Estadística y Censos) (2013), "Estimaciones y proyecciones de población 2010-2014: total del país", serie Análisis Demográfico, No 35, Buenos Aires [en línea] http://www. indec.gov.ar/bajarPublicacion.asp? idc $=3$ CoA 5260A490C6F182A1E47FA9F48BE11638666FF2DD 424 Do109EFA2423522697D9046924A86E2FD .

(2010), "Censo Nacional de Población, Hogares y Viviendas 2010", Buenos Aires [en línea] http://www.censo2010.indec.gov.ar/.

_(2004), "Estimaciones y proyecciones de población. Total del país. 1950-2015", serie Análisis Demográfico, $\mathrm{N}^{\circ} 30$, Buenos Aires.

INE (Instituto Nacional de Estadística) (2015), Censo de Población y Viviendas 2011. Resultados Detallados, Madrid, [en línea], http://www.ine.es/censos2011_datos/cen11_datos_resultados.htm\#

Naciones Unidas (2015), "World Population Prospects: The 2015 Revision, Key Findings and Advance Tables", Working Paper, No ESA/P/WP.241, División de Población [en línea] http://esa.un.org/ unpd/wpp/.

Novick, Susana (2007), Sur-Norte. Estudios sobre la emigración reciente de argentinos, Buenos Aires, Editorial Catálogos/Universidad de Buenos Aires.

Oficina del Censo de los Estados Unidos (2013), "International Programs", Washington, D.C., Departamento de Comercio de los Estados Unidos [en línea] http://www.census.gov/population/ international/data/idb/informationGateway.php [fecha de consulta: 16 de junio de 2015].

OIM (Organización Internacional para las Migraciones (2012), Perfil migratorio de Argentina 2102, Buenos Aires [en línea] http://argentina.iom.int/ro/sites/default/files/publicaciones/PERFIL MIGRATORIO_DE_ARGENTINA2012.pdf.

Rofman, Rafael (2007), "Perspectivas de la población en el siglo XXI: los segundos doscientos años", Población y bienestar en la Argentina del primero al segundo Centenario. Una historia del siglo XX, Susana Torrado (comp.), Buenos Aires, Ed. Edhasa, tomo II. 


\section{Anexo A1}

Cuadro A1.1

Argentina: población proyectada de acuerdo a la hipótesis media de fecundidad, 2010-2100

(En habitantes)

\begin{tabular}{|c|c|c|c|}
\hline \multirow{2}{*}{ Edad } & Total & Varones & Mujeres \\
\hline & \multicolumn{3}{|c|}{ Población de 2010} \\
\hline Total & 40901296 & 20015341 & 20885955 \\
\hline 0 a 4 & 3562911 & 1834929 & 1727982 \\
\hline 5 a 9 & 3511894 & 1798886 & 1713008 \\
\hline 10 a 14 & 3608096 & 1846671 & 1761425 \\
\hline 15 a 19 & 3579447 & 1811467 & 1767980 \\
\hline 20 a 24 & 3335052 & 1671314 & 1663738 \\
\hline 25 a 29 & 3183956 & 1584574 & 1599382 \\
\hline 30 a 34 & 3123217 & 1540872 & 1582345 \\
\hline 35 a 39 & 2705752 & 1329788 & 1375964 \\
\hline 40 a 44 & 2341985 & 1145322 & 1196663 \\
\hline 45 a 49 & 2221179 & 1083310 & 1137869 \\
\hline 50 a 54 & 2057698 & 996834 & 1060864 \\
\hline 55 a 59 & 1894349 & 908580 & 985769 \\
\hline 60 a 64 & 1636884 & 771387 & 865497 \\
\hline 65 a 69 & 1306685 & 595351 & 711334 \\
\hline 70 a 74 & 1020323 & 441610 & 578713 \\
\hline 75 a 79 & 807908 & 323810 & 484098 \\
\hline 80 a 84 & 568591 & 203002 & 365589 \\
\hline 85 a 89 & 302085 & 94337 & 207748 \\
\hline 90 a 94 & 104556 & 27260 & 77296 \\
\hline \multirow[t]{2}{*}{95 o más } & 28728 & 6037 & 22691 \\
\hline & \multicolumn{3}{|c|}{ Población de 2025} \\
\hline Total & 47124100 & 23177715 & 23946385 \\
\hline 0 a 4 & 3689491 & 1897303 & 1792188 \\
\hline $5 a 9$ & 3724750 & 1915014 & 1809736 \\
\hline 10 a 14 & 3704332 & 1906221 & 1798111 \\
\hline 15 a 19 & 3536349 & 1819234 & 1717115 \\
\hline 20 a 24 & 3477759 & 1776023 & 1701736 \\
\hline 25 a 29 & 3558948 & 1811863 & 1747085 \\
\hline 30 a 34 & 3520100 & 1769994 & 1750106 \\
\hline 35 a 39 & 3272105 & 1629549 & 1642556 \\
\hline 40 a 44 & 3111782 & 1538940 & 1572842 \\
\hline 45 a 49 & 3030874 & 1483686 & 1547188 \\
\hline 50 a 54 & 2590787 & 1258611 & 1332176 \\
\hline 55 a 59 & 2192864 & 1052102 & 1140762 \\
\hline 60 a 64 & 2004949 & 946496 & 1058453 \\
\hline 65 a 69 & 1755742 & 805673 & 950069 \\
\hline 70 a 74 & 1485933 & 653517 & 832416 \\
\hline 75 a 79 & 1129306 & 465594 & 663712 \\
\hline 80 a 84 & 731813 & 271302 & 460511 \\
\hline 85 a 89 & 391447 & 124587 & 266860 \\
\hline 90 a 94 & 157455 & 39990 & 117465 \\
\hline 95 o más & 57314 & 12016 & 45298 \\
\hline
\end{tabular}


Cuadro A1.1 (continuación)

\begin{tabular}{|c|c|c|c|}
\hline \multirow{2}{*}{ Edad } & Total & Varones & Mujeres \\
\hline & \multicolumn{3}{|c|}{ Población de 2050} \\
\hline Total & 54621288 & 26967210 & 27654078 \\
\hline 0 a 4 & 3412557 & 1755685 & 1656872 \\
\hline 5 a 9 & 3471641 & 1785774 & 1685867 \\
\hline 10 a 14 & 3518835 & 1809666 & 1709169 \\
\hline 15 a 19 & 3561171 & 1830330 & 1730841 \\
\hline 20 a 24 & 3606607 & 1850862 & 1755745 \\
\hline 25 a 29 & 3651647 & 1870550 & 1781097 \\
\hline 30 a 34 & 3678358 & 1881153 & 1797205 \\
\hline 35 a 39 & 3643980 & 1862411 & 1781569 \\
\hline 40 a 44 & 3461406 & 1766384 & 1695022 \\
\hline 45 a 49 & 3381060 & 1711092 & 1669968 \\
\hline 50 a 54 & 3418919 & 1720772 & 1698147 \\
\hline 55 a 59 & 3313031 & 1637186 & 1675845 \\
\hline 60 a 64 & 2976693 & 1440139 & 1536554 \\
\hline 65 a 69 & 2680716 & 1263232 & 1417484 \\
\hline 70 a 74 & 2404429 & 1088662 & 1315767 \\
\hline 75 a 79 & 1800984 & 772094 & 1028890 \\
\hline 80 a 84 & 1237927 & 487261 & 750666 \\
\hline 85 a 89 & 797680 & 276314 & 521366 \\
\hline 90 a 94 & 396385 & 112407 & 283978 \\
\hline \multirow[t]{2}{*}{95 o más } & 207262 & 45236 & 162026 \\
\hline & \multicolumn{3}{|c|}{ Población de 2075} \\
\hline Total & 56750779 & 28053682 & 28697097 \\
\hline 0 a 4 & 2977200 & 1532129 & 1445071 \\
\hline 5 a 9 & 3065819 & 1577580 & 1488239 \\
\hline 10 a 14 & 3161053 & 1626348 & 1534705 \\
\hline 15 a 19 & 3252052 & 1672503 & 1579549 \\
\hline 20 a 24 & 3329982 & 1710740 & 1619242 \\
\hline 25 a 29 & 3393192 & 1740938 & 1652254 \\
\hline 30 a 34 & 3446092 & 1765998 & 1680094 \\
\hline 35 a 39 & 3483464 & 1782848 & 1700616 \\
\hline 40 a 44 & 3512613 & 1794946 & 1717667 \\
\hline 45 a 49 & 3538453 & 1803983 & 1734470 \\
\hline 50 a 54 & 3547670 & 1802151 & 1745519 \\
\hline 55 a 59 & 3512858 & 1773913 & 1738945 \\
\hline 60 a 64 & 3381618 & 1691694 & 1689924 \\
\hline 65 a 69 & 3070697 & 1512202 & 1558495 \\
\hline 70 a 74 & 2792731 & 1333324 & 1459407 \\
\hline 75 a 79 & 2519909 & 1154041 & 1365868 \\
\hline 80 a 84 & 2042912 & 866467 & 1176445 \\
\hline 85 a 89 & 1380391 & 523922 & 856469 \\
\hline 90 a 94 & 786078 & 251781 & 534297 \\
\hline 95 o más & 555995 & 136174 & 419821 \\
\hline
\end{tabular}


Cuadro A1.1 (conclusión)

\begin{tabular}{|c|c|c|c|}
\hline \multirow{2}{*}{ Edad } & Total & Varones & Mujeres \\
\hline & \multicolumn{3}{|c|}{ Población de 2100} \\
\hline Total & 53940533 & 26664030 & 27276503 \\
\hline 0 a 4 & 2514043 & 1293978 & 1220065 \\
\hline 5 a 9 & 2602072 & 1339217 & 1262855 \\
\hline 10 a 14 & 2696406 & 1387634 & 1308772 \\
\hline 15 a 19 & 2793880 & 1437387 & 1356493 \\
\hline 20 a 24 & 2883040 & 1482048 & 1400992 \\
\hline 25 a 29 & 2964509 & 1522419 & 1442090 \\
\hline 30 a 34 & 3048786 & 1564358 & 1484428 \\
\hline 35 a 39 & 3136940 & 1608088 & 1528852 \\
\hline 40 a 44 & 3217696 & 1647659 & 1570037 \\
\hline 45 a 49 & 3279691 & 1676571 & 1603120 \\
\hline 50 a 54 & 3313720 & 1689413 & 1624307 \\
\hline 55 a 59 & 3315960 & 1682813 & 1633147 \\
\hline 60 a 64 & 3269695 & 1645338 & 1624357 \\
\hline 65 a 69 & 3169877 & 1574314 & 1595563 \\
\hline 70 a 74 & 2999559 & 1459821 & 1539738 \\
\hline 75 a 79 & 2717323 & 1279230 & 1438093 \\
\hline 80 a 84 & 2292003 & 1023091 & 1268912 \\
\hline 85 a 89 & 1713783 & 704531 & 1009252 \\
\hline 90 a 94 & 1053591 & 380330 & 673261 \\
\hline 95 o más & 957959 & 265790 & 692169 \\
\hline
\end{tabular}

Fuente: Elaboración propia, sobre la base de Instituto Nacional de Estadística y Censos (INDEC), Censo Nacional de Población 2010 y Ministerio de Salud de la Nación, estadísticas vitales. 


\title{
Descenso y transición epidemiológica de la mortalidad infantil en América Latina y el Caribe
}

\author{
Alejandro Aguirre ${ }^{1}$ \\ Fortino Vela Peón ${ }^{2}$
}

Recibido: 27/05/2015

Aceptado: 10/08/2015

\section{Resumen}

En décadas recientes, América Latina ha logrado importantes avances en la reducción de la mortalidad infantil, tanto desde el punto de vista cuantitativo como cualitativo. Por una parte, los niveles de la tasa de mortalidad infantil (TMI) han descendido en la mayoría de los países a menos de 30 defunciones por 1.000 nacidos vivos, y en algunos otros son similares a las del mundo desarrollado. Además, se ha ido modificando el perfil de causas de la mortalidad infantil: las infecciones intestinales y las respiratorias pierden terreno ante las afecciones perinatales y las anomalías congénitas. En este trabajo se analiza la situación (nivel y perfil epidemiológico) de la mortalidad infantil en varios países de la región utilizando datos de las estadísticas vitales e información censal preveniente de la plataforma Integrated Public Use Microdata Series, International (IPUMS).

Palabras clave: mortalidad infantil, estimación indirecta, Brass, transición epidemiológica, América Latina, IPUMS.

1 Profesor-Investigador de El Colegio de México, Doctor en Demografía Médica por la Escuela de Higiene y Medicina Tropical de la Universidad de Londres. Sus principales áreas de investigación son: mortalidad infantil, mortalidad materna y mortalidad por causas. Correo electrónico: aguirre@colmex.mx.

2 Profesor-Investigador en el Departamento de Producción Económica de la Universidad Autónoma Metropolitana Xochimilco (UAMX). Sus principales áreas de investigación son: mercado laboral, mortalidad y población y desarrollo. Correo electrónico: fvela@correo.xoc.uam.mx. 


\begin{abstract}
In recent decades, Latin America has made significant progress in reducing infant mortality, from in both quantitative and qualitative terms. The infant mortality rate (IMR) has fallen to fewer than 30 deaths per 1,000 live births in most of the countries, and in some comes close to developed-country rates. The causes of infant mortality have also changed - deaths are increasingly the result of perinatal conditions and congenital malformations rather than intestinal and respiratory infections. This paper analyses infant mortality (rates and epidemiological profile) in several countries of the region using vital statistics and census data taken from the international Integrated Public Use Microdata Series (IPUMS).
\end{abstract}

Keywords: infant mortality; indirect estimation; Brass; epidemiological transition; Latin America; Integrated Public Use Microdata Series (IPUMS).

\title{
Résumé
}

Au cours des dernières décennies, des progrès substantiels ont été accomplis en Amérique latine dans la réduction de la mortalité infantile, à la fois en termes quantitatifs et qualitatifs. D'une part, les niveaux du taux de mortalité infantile (TMI) sont tombés, dans la majorité des pays, à moins de 30 décès sur 1000 nés vivants et, dans certains pays, sont proches des taux observés dans le monde développé. De plus, le profil des causes de la mortalité infantile a également évolué : les infections intestinales et les infections respiratoires perdent du terrain face aux affections périnatales et aux anomalies congénitales. Dans cette étude, l'auteur analyse la situation (niveau et profil épidémiologique) de la mortalité infantile dans plusieurs pays de la région, sur la base des données des statistiques vitales et de l'information censitaire issue de la plateforme Integrated Public Use Microdata Series, International (IPUMS).

Mots clés: mortalité infantile, estimation indirecte, Brass, transition épidémiologique, Amérique latine, IPUMS. 


\section{Introducción}

En décadas recientes, América Latina ha logrado importantes avances en la reducción de la mortalidad infantil, tanto desde el punto de vista cuantitativo como cualitativo. Por una parte, los niveles de la tasa de mortalidad infantil (TMI) han descendido en la mayoría de los países a menos de 30 defunciones por 1.000 nacidos vivos, y en algunos otros son similares a las del mundo desarrollado. Además, se ha ido modificando el perfil de las causas de la mortalidad infantil: las infecciones intestinales y las respiratorias pierden terreno ante las afecciones perinatales y las anomalías congénitas. Lo anterior se evidencia en la literatura sobre el tema. En este sentido, Ahmad y otros (2000), considerando un total de 120 países en el período 1950-2000, tanto desarrollados como no desarrollados, señalan una clara tendencia descendente de la TMI. En el caso de América Latina y el Caribe, los autores resumen sus hallazgos mostrando una caída de este indicador de 140 a 38 defunciones de niños menores de 1 año por cada 1.000 nacidos vivos en el período comprendido entre 1955 y 1990, considerando que esta reducción inicialmente fue lenta, más pronunciada a partir de la década de 1970 y se atenuó a finales de la década de 1990. De igual manera, Aguirre (2009) muestra que, en el caso de México en particular, cuando se considera el perfil epidemiológico de la mortalidad infantil existe evidencia de una transformación de las causas de muerte, que en 1980 fueron, en orden de importancia, las afecciones perinatales, las infecciones intestinales, las infecciones respiratorias y las anomalías congénitas, mientras que en $2005 \mathrm{su}$ orden fue el siguiente: afecciones perinatales, anomalías congénitas, infecciones respiratorias e infecciones intestinales. Como se verá más adelante, transformaciones similares ocurrieron en prácticamente todos los países de América Latina y el Caribe.

Para contar con un panorama completo, tanto de los niveles como de las causas de la mortalidad en general y la infantil en particular, se requiere de la información más precisa posible que permita identificar los cambios en ambas dimensiones. Sin lugar a dudas, los sistemas de información demográfica han observado mejoras tanto en la cobertura como en la calidad de los datos en casi todo los países de la región. Por lo tanto, cabe evaluar la utilidad de seguir utilizando métodos indirectos para la estimación de la mortalidad infantil. En este sentido, resulta de interés comparar la estimación derivada de la aplicación de métodos indirectos a la información censal con la que se obtiene directamente sobre la base de las estadísticas vitales, a fin de conocer si a lo largo del tiempo se observa cierta convergencia en estos dos tipos de cálculo. De ocurrir la convergencia, se evidenciaría la pérdida de utilidad de los métodos indirectos.

A partir de lo anterior, este trabajo tiene como propósito dar respuesta a las siguientes interrogantes: ¿se mide adecuadamente la mortalidad infantil?; ¿las estadísticas vitales son una fuente confiable para estimar la TMI o todavía es necesario emplear la técnica de Brass para contar con estimaciones fidedignas?, y ¿qué utilidad tienen las estadísticas vitales para el conocimiento del perfil epidemiológico de la mortalidad infantil? A tal fin, este artículo se encuentra organizado de la siguiente manera: en primer lugar, se analiza la pertinencia 
de continuar utilizando la técnica indirecta de Brass y Coale (1968), que consiste en dividir el número de hijos nacidos vivos por el número de hijos sobrevivientes, para contar con estimaciones confiables de la mortalidad infantil. Para esto se comparan las estimaciones obtenidas mediante esta metodología con las que se obtienen directamente de las estadísticas vitales. Si bien hay más fuentes de información en los países de la región, a fin de lograr resultados comparables ${ }^{3}$, las estimaciones indirectas que se presentan en este trabajo se obtuvieron aplicando el método de Brass exclusivamente a la información de los censos contenidos en las bases de datos de Integrated Public Use Microdata Series (IPUMS) en los que se realizaron preguntas sobre hijos nacidos vivos y sobrevivientes. Los países considerados fueron los siguientes: Argentina, Bolivia (Estado Plurinacional de), Brasil, Chile, Colombia, Costa Rica, Ecuador, El Salvador, Jamaica, México, Nicaragua, Panamá, Perú y Uruguay. El único criterio para su inclusión fue la disponibilidad de la información en IPUMS. En cuanto a las causas de muerte, se analiza la evolución de los primeros cuatro grupos de causas en el marco de la transición epidemiológica de la mortalidad infantil de estos mismos países 4 . En este caso, se emplearon las estadísticas vitales tal y como los países las reportan a la Organización Mundial de la Salud (OMS)5.

\section{A. Niveles de mortalidad infantil en América Latina y el Caribe}

William Brass (Brass y Coale, 1968) desarrolló el método indirecto de hijos nacidos vivos e hijos sobrevivientes para estimar la mortalidad infantil y juvenil, que ha permitido conocer de manera más fidedigna los niveles reales de la mortalidad infantil de unas tres cuartas partes de la población mundial. Este método consiste en utilizar información (generalmente censal, aunque puede provenir de encuestas) del total de hijos nacidos vivos y los sobrevivientes de estos que han tenido las mujeres durante toda su vida, hasta el momento en que son entrevistadas. La información se clasifica por la edad de la madre. Se espera que entre mayor sea la mujer, sus hijos sean (en promedio) mayores, que hayan estado expuestos al riesgo de muerte durante un período más largo y que, por ende, la proporción de hijos fallecidos aumente con la edad de la mujer. El método se basa en la similitud de los valores de las proporciones de hijos fallecidos, según la edad de la madre, en grupos quinquenales del período reproductivo (es decir, del grupo de mujeres de 15 a 19 años al grupo de 45 a 49 años) y las probabilidades de fallecer entre el nacimiento y las edades de $1,2,3,5,10,15$ y 20 años, respectivamente.

Según la formulación original de Brass, el método está basado en varios supuestos de los cuales ninguno llega a cumplirse plenamente en cualquier población, y cuya violación,

3 Es importante señalar que una de las características de la información de IPUMS consiste en que las bases de datos han sido previamente armonizadas, de modo que es posible su comparación directa.

4 A excepción del Estado Plurinacional de Bolivia, país sobre el cual no fue posible obtener la información pertinente.

5 Esta información se encuentra disponible públicamente [en línea] http://apps.who.int/whosis/database/mort/table2. 
de una u otra manera, no llega a producir sesgos muy importantes en la mayoría de los casos. En general, la metodología produce - en las poblaciones con datos incompletosestimaciones más cercanas a la realidad en comparación con las subestimaciones que ofrecen las estadísticas vitales. A continuación se enuncian los supuestos y una breve explicación de por qué, salvo excepciones, su no cumplimiento no afecta de manera considerable las estimaciones.

- Hay una fecundidad constante. Aunque las cohortes quinquenales en determinado momento censal tengan diferentes niveles de fecundidad, en última instancia el método se basa en el cociente de hijos fallecidos respecto de los hijos nacidos vivos, que no se ve afectado por el nivel de fecundidad de cada cohorte en particular.

- Existe una mortalidad constante. Este supuesto se cumplía en las poblaciones africanas a mediados del siglo pasado, con las que Brass y Coale (1968) trabajaron originalmente. Dado que había una mortalidad constante, el método estimaba la mortalidad de la población en estudio. La aplicación del método fue extendiéndose a otras regiones del mundo en desarrollo y permitió obtener estimaciones razonables de la mortalidad infantil en el último cuarto del siglo pasado de países donde habita alrededor de las tres cuartas partes de la población mundial, como ya se señaló. Sin embargo, en algunas de estas regiones la mortalidad infantil se encontraba en descenso. Posteriormente se fueron desarrollando algunas variantes del método original entre las que destacan las de Sullivan (1972), Trussell (1975) y Feeney (1980). Este último introdujo - considerando cambios en la mortalidad- la ubicación en el tiempo de las estimaciones de cada uno de los grupos quinquenales de edad de las mujeres de quienes se obtiene la información de hijos nacidos vivos e hijos sobrevivientes. De esta manera, lo que en la propuesta original podría considerarse como una limitación, con las adaptaciones de Feeney se convirtió en una virtud del método, ya que permite obtener estimaciones en varios momentos y así conocer las tendencias del indicador.

- Hay independencia entre la mortalidad de los niños y la edad de la madre. La mortalidad de los hijos depende, entre otras variables, de la edad de la madre. Los hijos de las mujeres muy jóvenes están más expuestos al riesgo de morir. Esto se debe a razones tanto biológicas como socioculturales. Por una parte, algunas de estas mujeres aún no terminan su propio desarrollo cuando ya están ejerciendo la maternidad, lo que compromete la sobrevivencia de sus hijos (y la propia). Por otra parte, puede ser que no estén preparadas de manera óptima para el cuidado del infante. Esto resulta más notorio para los hijos nacidos vivos de madres de 15 a 19 años. Sin embargo, en los demás grupos de edad el supuesto no se separa demasiado de la realidad. El incumplimiento de este supuesto se subsana al eliminar las estimaciones de mortalidad infantil que provienen de las mujeres más jóvenes, como se detalla más adelante.

- Hay independencia entre la mortalidad de los niños y la mortalidad de la madre. Un niño huérfano experimenta una mayor probabilidad de morir ante la falta de atención y de cuidados que una madre podría proporcionarle. El caso extremo sucede cuando la madre fallece al momento de dar a luz, con lo que el infante se ve privado de la 
lactancia materna, la que además de constituir un valioso alimento lo protege contra infecciones. Afortunadamente, la mortalidad materna es un evento relativamente raro, y aun la mortalidad de las mujeres en edad fértil es baja; por lo tanto, no hay tantos huérfanos y, por ende, el no cumplimiento de este supuesto no tiene una repercusión mayor en las estimaciones.

- La población está cerrada a la migración. La información que utiliza el método de Brass refleja la experiencia de mortalidad de los hijos de las informantes en cualquier momento del pasado. Así, una mujer puede estar informando en el lugar donde es censada la mortalidad (o sobrevivencia) de sus hijos ocurrida en un lugar en donde residió con anterioridad. Este sesgo será importante en la medida en que exista un diferencial considerable entre la localidad de origen y la de destino de quien haya migrado. Entre mayor sea la escala geográfica considerada, habrá menos movimientos migratorios y, por tanto, la suposición no produce distorsiones que afecten de manera significativa los resultados obtenidos. En cambio, entre menor sea la escala geográfica analizada, puede haber un mayor efecto del no cumplimiento del supuesto. Tratándose de poblaciones nacionales, resulta difícil que el supuesto afecte demasiado las estimaciones que se producen con el método.

Como se señaló, los supuestos no llegan a cumplirse cabalmente, por lo que las estimaciones no pueden tener una exactitud absoluta. Sin embargo, producen estimaciones de la mortalidad infantojuvenil más cercanas a la realidad en poblaciones en las que las estadísticas vitales son deficientes.

Para este trabajo se utilizó el programa de estimación de la mortalidad infantil por microcomputadora (QFIVE), desarrollado por la División de Población de las Naciones Unidas. Este programa se sustenta en la variante de Trussell (1975) del método de hijos nacidos vivos y sobrevivientes, y produce resultados acordes con los cuatro modelos de las tablas regionales de mortalidad de Coale y Demeny (1966), y con los cinco patrones de mortalidad de las tablas de las Naciones Unidas para países en desarrollo (1982). En un primer panel de resultados, QFIVE produce la serie de las probabilidades de morir entre el nacimiento y la edad exacta $\mathrm{x}(\mathrm{q}(\mathrm{x}))$ para los valores de $\mathrm{x}$ de $1,2,3,5,10,15 \mathrm{y}$ 20 años, derivados respectivamente de la información acerca de la sobrevivencia de los hijos que suministran las mujeres de los grupos etarios 15-19, 20-24, 25-29, 30-34, 35-39, 40-44 y 45-49 años, respectivamente (véase el cuadro 1). Estas probabilidades van acompañadas de su ubicación en el tiempo, expresado en años antes del censo. Cuanto mayores son las mujeres, habrán tenido (en promedio) a sus hijos antes. En el cuadro 1 se presenta el ejemplo del Brasil en 1980.

Por otra parte, las tablas de vida modelo permiten, para un cierto patrón y nivel de mortalidad, establecer otros parámetros de la tabla correspondiente. Así, es posible obtener otros parámetros de la mortalidad a partir de la estimaciones originales de las $\mathrm{q}(\mathrm{x})$. Es decir, QFIVE produce tres paneles adicionales de resultados con las $\mathrm{q}(1)$, las ${ }_{4} \mathrm{q}_{1}$ y las $\mathrm{q}(5)$ que corresponden al nivel de mortalidad de cada $\mathrm{g}(\mathrm{x})$ (véase el cuadro 2). En estos paneles el tiempo de las estimaciones se establece en años calendario. 


\section{Cuadro 1}

Brasil: listado del panel 1 de resultados del programa QFIVE sobre las probabilidades de morir entre el nacimiento y la edad exacta $\mathrm{x}$ bajo el método de Brass

de hijos nacidos vivos e hijos sobrevivientes, junio de 1980

\begin{tabular}{|c|c|c|c|c|c|c|c|c|c|c|c|c|}
\hline \multirow{3}{*}{$\begin{array}{l}\text { Grupo de edad } \\
\text { de la madre } \\
\text { (en años) }\end{array}$} & \multicolumn{2}{|c|}{$\begin{array}{l}\text { Número promedio } \\
\text { de hijos }\end{array}$} & \multirow{3}{*}{$\begin{array}{c}\begin{array}{c}\text { Proporción } \\
\text { de hijos }\end{array} \\
\text { Fallecidos }\end{array}$} & \multicolumn{9}{|c|}{$\begin{array}{l}\text { Modelos de Coale y Demeny } \\
\text { (ecuaciones de Trussell) }\end{array}$} \\
\hline & \multirow{2}{*}{ Nacidos vivos } & \multirow{2}{*}{ Sobrevivientes } & & \multirow{2}{*}{ Edad $x$} & \multicolumn{2}{|c|}{ Norte } & \multicolumn{2}{|c|}{ Sur } & \multicolumn{2}{|c|}{ Este } & \multicolumn{2}{|c|}{ Oeste } \\
\hline & & & & & $q(x)$ & $t(x)$ & $q(x)$ & $t(x)$ & $q(x)$ & $t(x)$ & $q(x)$ & $t(x)$ \\
\hline $15-19$ & 0,146 & 0,129 & 0,116 & 1 & 0,121 & $(1,0)$ & 0,117 & $(1,0)$ & 0,125 & $(1,0)$ & 0,124 & $(1,0)$ \\
\hline $20-24$ & 0,906 & 0,812 & 0,104 & 2 & 0,104 & $(2,3)$ & 0,109 & $(2,3)$ & 0,109 & $(2,4)$ & 0,109 & $(2,3)$ \\
\hline $25-29$ & 1,905 & 1,706 & 0,104 & 3 & 0,099 & $(4,1)$ & 0,106 & $(4,2)$ & 0,105 & $(4,3)$ & 0,104 & $(4,3)$ \\
\hline $30-34$ & 2,960 & 2,623 & 0,114 & 5 & 0,112 & $(6,3)$ & 0,116 & $(6,5)$ & 0,114 & $(6,7)$ & 0,114 & $(6,6)$ \\
\hline $35-39$ & 3,967 & 3,457 & 0,129 & 10 & 0,135 & $(8,7)$ & 0,134 & $(9,1)$ & 0,132 & $(9,3)$ & 0,132 & $(9,1)$ \\
\hline $40-44$ & 4,664 & 3,988 & 0,145 & 15 & 0,150 & $(11,3)$ & 0,147 & $(11,9)$ & 0,147 & $(12,2)$ & 0,147 & $(11,8)$ \\
\hline $45-49$ & 4,979 & 4,196 & 0,157 & 20 & 0,159 & $(14,2)$ & 0,158 & $(15,1)$ & 0,158 & $(15,4)$ & 0,158 & $(14,8)$ \\
\hline
\end{tabular}

Fuente: Elaboración propia.

Cuadro 2

Brasil: listado del panel 2 de resultados del programa QFIVE sobre q(1), 4q1 y q(5), según diferentes patrones y niveles de mortalidad infantil, mediante el método de Brass de hijos nacidos vivos e hijos sobrevivientes, 1980

\begin{tabular}{|c|c|c|c|c|c|c|c|c|}
\hline \multirow{3}{*}{$\begin{array}{l}\text { Edad de } \\
\text { la mujer }\end{array}$} & \multicolumn{8}{|c|}{ Modelos de Coale y Demeny } \\
\hline & \multicolumn{2}{|c|}{ Norte } & \multicolumn{2}{|c|}{ Sur } & \multicolumn{2}{|c|}{ Este } & \multicolumn{2}{|c|}{ Oeste } \\
\hline & $\begin{array}{l}\text { Fecha de } \\
\text { referencia }^{a}\end{array}$ & q & $\begin{array}{l}\text { Fecha de } \\
\text { referencia }^{a}\end{array}$ & q & $\begin{array}{l}\text { Fecha de } \\
\text { referencia }^{a}\end{array}$ & q & $\begin{array}{l}\text { Fecha de } \\
\text { referencia }\end{array}$ & $q$ \\
\hline \multicolumn{9}{|c|}{ Tasa de mortalidad infantil: $\mathrm{q}(1)$} \\
\hline $15-19$ & 1979,4 & 0,121 & 1979,4 & 0,117 & 1979,4 & 0,125 & 1979,4 & 0,124 \\
\hline $20-24$ & 1978,2 & 0,084 & 1978,2 & 0,090 & 1978,1 & 0,095 & 1978,1 & 0,090 \\
\hline $25-29$ & 1976,4 & 0,072 & 1976,3 & 0,083 & 1976,1 & 0,087 & 1976,2 & 0,080 \\
\hline $30-34$ & 1974,2 & 0,071 & 1973,9 & 0,085 & 1973,8 & 0,089 & 1973,9 & 0,081 \\
\hline $35-39$ & 1971,8 & 0,074 & 1971,4 & 0,091 & 1971,1 & 0,096 & 1971,4 & 0,085 \\
\hline $40-44$ & 1969,1 & 0,076 & 1968,5 & 0,095 & 1968,3 & 0,101 & 1968,6 & 0,089 \\
\hline $45-49$ & 1966,2 & 0,074 & 1965,4 & 0,096 & 1965,0 & 0,102 & 1965,7 & 0,088 \\
\hline \multicolumn{9}{|c|}{ Probabilidad de morir entre las edades de 1 a 5 años: $4 q 1$} \\
\hline $15-19$ & 1979,4 & 0,094 & 1979,4 & 0,072 & 1979,4 & 0,046 & 1979,4 & 0,067 \\
\hline $20-24$ & 1978,2 & 0,055 & 1978,2 & 0,039 & 1978,1 & 0,030 & 1978,1 & 0,042 \\
\hline $25-29$ & 1976,4 & 0,045 & 1976,3 & 0,032 & 1976,1 & 0,026 & 1976,2 & 0,035 \\
\hline $30-34$ & 1974,2 & 0,044 & 1973,9 & 0,034 & 1973,8 & 0,027 & 1973,9 & 0,036 \\
\hline $35-39$ & 1971,8 & 0,046 & 1971,4 & 0,040 & 1971,1 & 0,031 & 1971,4 & 0,039 \\
\hline $40-44$ & 1969,1 & 0,048 & 1968,5 & 0,044 & 1968,3 & 0,033 & 1968,6 & 0,041 \\
\hline $45-49$ & 1966,2 & 0,046 & 1965,4 & 0,045 & 1965,0 & 0,034 & 1965,7 & 0,040 \\
\hline \multicolumn{9}{|c|}{ Probabilidad de morir a la edad de 5 años: $\mathrm{q}(5)$} \\
\hline $15-19$ & 1979,4 & 0,203 & 1979,4 & 0,181 & 1979,4 & 0,165 & 1979,4 & 0,183 \\
\hline $20-24$ & 1978,2 & 0,134 & 1978,2 & 0,125 & 1978,1 & 0,122 & 1978,1 & 0,128 \\
\hline $25-29$ & 1976,4 & 0,114 & 1976,3 & 0,112 & 1976,1 & 0,111 & 1976,2 & 0,113 \\
\hline 30-34 & 1974,2 & 0,112 & 1973,9 & 0,116 & 1973,8 & 0,114 & 1973,9 & 0,114 \\
\hline 35-39 & 1971,8 & 0,117 & 1971,4 & 0,127 & 1971,1 & 0,123 & 1971,4 & 0,121 \\
\hline $40-44$ & 1969,1 & 0,120 & 1968,5 & 0,135 & 1968,3 & 0,131 & 1968,6 & 0,127 \\
\hline $45-49$ & 1966,2 & 0,117 & 1965,4 & 0,137 & 1965,0 & 0,132 & 1965,7 & 0,125 \\
\hline
\end{tabular}

Fuente: Elaboración propia.

a La fecha de referencia se considera como una variable continua. Por ejemplo, la cifra 1965,0 se refiere al inicio de ese año, es decir, el 1 de enero de 1965. Cada decimal representa 36,5 días, esto es, aproximadamente un mes y una semana. 
En el segundo panel se muestran los resultados en términos de la mortalidad infantil, datos que más interesan para nuestros propósitos, ya que permiten observar la tendencia de la q(1) en un período de aproximadamente 15 años antes del censo. Estas estimaciones con su ubicación temporal son el insumo para proyectar la tendencia de la TMI hasta el momento de cada censo. Las proyecciones se realizaron ajustando una curva exponencial negativa, dado que el ritmo de descenso de la mortalidad es cada vez más lento. Este tipo de curva además asegura que no se alcanzan valores negativos aun en el caso de una caída pronunciada de la TMI. Por otra parte, existe el cuarto supuesto aludido anteriormente, referido a la independencia del nivel de la mortalidad de los niños y la edad de la madre. En los hechos, los hijos de las mujeres muy jóvenes experimentan una mortalidad mayor. Esto se ve reflejado en el repunte de la tendencia de la mortalidad infantil en la estimación derivada de los datos de las mujeres de 15 a 19 años de edad. Para superar esta situación, resulta más conveniente ignorar esta última estimación del ajuste que se hace para la proyección. El procedimiento se muestra en el gráfico 1 aplicado al caso del Brasil en el período 1964-1980.

\section{Gráfico 1}

Brasil: estimaciones de la tasa de mortalidad infantil $(\mathrm{q}(1))$ utilizando el modelo Oeste y la variante de Trussell del método de Brass, 1964-1980

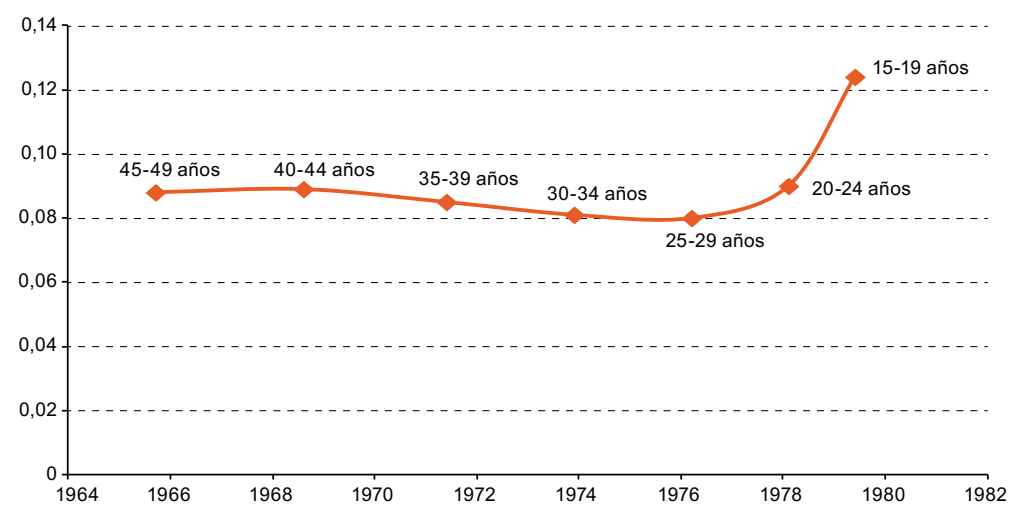

Fuente: Elaboración propia.

Este procedimiento se repitió 43 veces - para cada uno de los censos disponibles en la base de datos de IPUMS-. Finalmente, se tomaron las estimaciones derivadas de las estadísticas vitales de cada país y año (o la más cercana disponible) a fin de comparar las estimaciones de mortalidad infantil directas con las indirectas de las mismas poblaciones y en los mismos años.

Se utilizaron todas las bases de datos disponibles de IPUMS sobre países latinoamericanos en que hay información de hijos nacidos vivos y sobrevivientes. Algunas pueden parecer relativamente antiguas; sin embargo, dado que uno de los objetivos de este trabajo es analizar la transición de la mortalidad, consideramos indispensable incluirlas junto con los resultados más recientes. 
De los supuestos de la formulación original del método de Brass, uno de los que más claramente quedan desestimados para muchos países es el de la mortalidad constante. El programa QFIVE produce estimaciones que tienen un momento de referencia en el pasado reciente: las estimaciones derivadas de datos de las mujeres que se encuentran en los siete grupos quinquenales (entre los 15 y los 49 años de edad) se ubican en los 15 años previos al censo. Así, es posible observar las tendencias recientes de la mortalidad infantil.

A partir de cada una de estas fuentes de información se obtuvo una estimación de la TMI para cada uno de los países en los años de levantamiento censal. Se procedió entonces de la siguiente manera. En primer lugar, se aplicó el programa QFIVE a la información de hijos nacidos vivos e hijos sobrevivientes por grupo quinquenal de edad de las mujeres (15-19 a 45-49 años) correspondiente a cada censo disponible en IPUMS en el que se hicieron las preguntas sobre hijos nacidos vivos y sobrevivientes. El QFIVE produjo siete estimaciones de la TMI con su ubicación en el tiempo (aproximadamente desde 15 hasta 1,5 años antes de cada censo). Con esas estimaciones, se proyectó la tendencia de la TMI hasta el momento de cada censo.

Como se señaló anteriormente, existe una mortalidad diferencial por edad de la madre. Los hijos de las mujeres de 15 a 19 años experimentan una sobremortalidad, por lo tanto, la estimación derivada de este grupo de edad fue eliminada de la proyección, ya que rompe con la tendencia que se observa en las estimaciones correspondientes a los otros seis grupos de edad (20-24 a 45-49 años).

Dado que en general la mortalidad disminuye a un ritmo cada vez más lento, y para garantizar que la proyección no produjera cifras negativas, se ajustó en cada caso una curva exponencial negativa para la proyección. En algunos casos en particular, tal vez podría haberse realizado un ajuste mejor, pero se prefirió utilizar un protocolo estándar en todas las proyecciones de la TMI. En efecto, la curva logística en contados casos ofreció un mejor ajuste con un mayor coeficiente de correlación. Por ejemplo, en el caso del Brasil, de los cinco censos utilizados, solo en el de 1991 fue mejor el ajuste obtenido con la curva logística que con la exponencial negativa, como se muestra en el cuadro 3.

Cuadro 3

Brasil: coeficientes de correlación correspondientes a los ajustes exponencial negativo y logístico

\begin{tabular}{lcc}
\hline Año & Ajuste exponencial & Ajuste logístico \\
\hline 1960 & 0,7552 & $-0,7549$ \\
\hline 1970 & $-0,2381$ & $-0,2379$ \\
\hline 1980 & $-0,3270$ & $-0,3262$ \\
\hline 1991 & $-0,9915$ & $-0,9917$ \\
\hline 2000 & $-0,9881$ & $-0,9850$ \\
\hline
\end{tabular}

Fuente: Elaboración propia. 


\section{B. La calidad de la información de IPUMS}

El conjunto de bases de datos de IPUMS comprende más de 150 censos realizados en poco más de 50 países a lo largo de medio siglo (de 1960 a 2010). Se trata de muestras de los microdatos que han sido armonizados en la mayoría de las variables para facilitar, entre otras cosas, su comparación. Para este trabajo se utilizaron las bases de datos de los países de América Latina y el Caribe en los que se indagó sobre hijos nacidos vivos y sobrevivientes, un total de 43 censos de 14 países de la región (véase el cuadro 4).

En todo censo se captan una serie de variables y esta información puede tener distintos grados de calidad. Existen formas de evaluar la calidad de la información en ciertos aspectos. Las más conocidas son las que se refieren a la declaración de la edad, como los índices de Whipple y de Myers.

La calidad de las series de hijos nacidos vivos y sobrevivientes puede evaluarse comparando las estimaciones que produce el método de Brass, por una parte, con las tendencias obtenidas de los censos y, por la otra, con las estimaciones derivadas de las estadísticas vitales. La primera prueba se fundamenta en el hecho de que, salvo excepciones, la mortalidad tiene una tendencia descendente. Así, se espera que la serie de estimaciones censales de la TMI siga esta tendencia esperada, lo que ocurre en la mayoría de los países analizados en este trabajo. Sin embargo, hay casos como el de Nicaragua, donde las estimaciones indirectas arrojan una TMI de 129 por 1.000 en 1971,80 por 1.000 en 1975 y 146 por 1.000 en 2005 . Resulta poco plausible que esta sea la tendencia real, a pesar de las turbulencias políticas por las que atravesó ese país. Otro caso es el de Chile, donde la TMI habría aumentado de 11 por 1.000 a 19 por 1.000 entre 1992 y 2002. En el Estado Plurinacional de Bolivia, las cifras son de 168,62 y 83 defunciones por 1.000 para 1976, 1992 y 2001, respectivamente. En este último caso, según Villarroel (2012), el aparente aumento de la mortalidad infantil de 1992 a 2001 se debe a la forma en que se realizaron las preguntas en cada uno de los censos de esos años: mientras en 1992 se hicieron preguntas acerca de los hijos nacidos vivos y los hijos sobrevivientes, en 2001 se indagó sobre los hijos nacidos vivos, los hijos sobrevivientes y explícitamente sobre los hijos fallecidos. Esta última pregunta permitió recuperar información de hijos fallecidos que de otra manera se habría perdido por confusión del entrevistador o la entrevistada. Por ello resulta más confiable la estimación correspondiente al año 2001 que la de 1992.

La técnica de hijos nacidos vivos e hijos sobrevivientes fue elaborada por Brass para contar con estimaciones más confiables de la TMI en poblaciones con datos deficientes. Esto significa que las estimaciones indirectas corrigen hacia arriba las estimaciones directas a partir de las estadísticas vitales. La segunda forma de evaluar consiste en comparar las estimaciones directas con las indirectas. Si las primeras son mayores que las segundas, es probable que las segundas estén por debajo de la realidad. Por ejemplo, en el caso del Estado Plurinacional de Bolivia, la estimación indirecta ubica a la TMI de 1992 en 62 por 1.000 , en tanto que con la directa se obtiene 72 por 1.000, pero la situación fue distinta en 1976 y en 2001, es decir, en estos últimos años la estimación directa no fue superior a la indirecta (véase el cuadro 4). Lo mismo ocurre con Chile, con estimaciones de 11 (indirecta) y 14 (directa) por 1.000 en 1992, y con Colombia, cuyas estimaciones arrojan un resultado de 37 (indirecta) y 50 (directa) por 1.000 en 1985. 


\section{Cuadro 4}

\section{América Latina y el Caribe (países seleccionados): tasas de mortalidad infantil derivadas de censos de población y estadísticas vitales}

\begin{tabular}{|c|c|c|c|c|c|}
\hline País & Año & Según censos & $\begin{array}{c}\text { Según estadísticas } \\
\text { vitales }^{\mathrm{a}}\end{array}$ & Diferencia & $\begin{array}{c}\text { Diferencia } \\
\text { (en porcentajes) }\end{array}$ \\
\hline \multirow{3}{*}{ Argentina } & 1970 & 69 & 59 & 10 & 14 \\
\hline & 1980 & 44 & 33 & 11 & 25 \\
\hline & 1991 & 21 & 25 & -4 & -19 \\
\hline \multirow{3}{*}{$\begin{array}{l}\text { Bolivia (Estado } \\
\text { Plurinacional de) }\end{array}$} & 1976 & 168 & $138^{b}$ & & \\
\hline & 1992 & 62 & 72 & -10 & -17 \\
\hline & 2001 & 83 & 61 & 22 & 27 \\
\hline \multirow{5}{*}{ Brasil } & 1960 & 145 & 70 & 75 & 52 \\
\hline & 1970 & 109 & $79^{b}$ & & \\
\hline & 1980 & 83 & 62 & 21 & 25 \\
\hline & 1991 & 44 & 35 & 9 & 21 \\
\hline & 2000 & 27 & 20 & 7 & 25 \\
\hline \multirow{4}{*}{ Chile } & 1970 & 86 & 79 & 7 & 8 \\
\hline & 1982 & 44 & 24 & 20 & 45 \\
\hline & 1992 & 11 & 14 & -3 & -28 \\
\hline & 2002 & 19 & 8 & 11 & 57 \\
\hline \multirow{4}{*}{ Colombia } & 1973 & 74 & 53 & 21 & 29 \\
\hline & 1985 & 37 & $50^{c}$ & $\ldots$ & $\ldots$ \\
\hline & 1993 & 38 & 37 & 1 & 2 \\
\hline & 2005 & 37 & 16 & 21 & 56 \\
\hline \multirow{3}{*}{ Costa Rica } & 1973 & 64 & 45 & 19 & \\
\hline & 1984 & 21 & 19 & 2 & 9 \\
\hline & 2000 & 14 & 10 & 4 & 27 \\
\hline \multirow{4}{*}{ Ecuador } & 1974 & 102 & 76 & 26 & 25 \\
\hline & 1982 & 77 & 61 & 16 & 21 \\
\hline & 1990 & 60 & 40 & 20 & 33 \\
\hline & 2001 & 26 & 25 & 1 & 3 \\
\hline \multirow[t]{2}{*}{ El Salvador } & 1992 & 31 & & $46^{d}$ & $\ldots$ \\
\hline & 2007 & 30 & 9 & 21 & 70 \\
\hline \multirow{2}{*}{ Jamaica } & 1982 & 26 & 21 & 5 & 19 \\
\hline & 2002 & 27 & 18 & 9 & 33 \\
\hline \multirow{3}{*}{ México } & 1990 & 36 & 24 & 12 & 33 \\
\hline & 2000 & 33 & 14 & 19 & 58 \\
\hline & 2005 & 19 & & 19 & 100 \\
\hline \multirow{3}{*}{ Nicaragua } & 1971 & 129 & 45 & 84 & 65 \\
\hline & 1975 & 80 & 46 & 34 & 42.5 \\
\hline & 2005 & 146 & & 146 & 100 \\
\hline \multirow{2}{*}{ Panamá } & 1980 & 62 & 22 & 40 & 65 \\
\hline & 1990 & 25 & $25^{d}$ & $\ldots$ & $\ldots$ \\
\hline \multirow{2}{*}{ Perú } & 1993 & 50 & 75 & -25 & -49 \\
\hline & 2003 & 22 & 20 & 2 & 9 \\
\hline \multirow{3}{*}{ Uruguay } & 1975 & 55 & 49 & 6 & $\ldots$ \\
\hline & 1985 & 36 & $28^{e}$ & 8 & 22 \\
\hline & 1995 & 27 & $\ldots$ & & $\ldots$ \\
\hline
\end{tabular}

Fuente: Elaboración propia, sobre la base de Minnesota Population Center, "Integrated Public Use Microdata Series, International: Version 6.1", 2011 [base de datos en línea], Minneapolis, University of Minnesota; IPUMS; y Naciones Unidas, Demographic Yearbook, varios años [en línea] http://unstats.un.org/unsd/demographic/ products/dyb/2000_round.htm.

a Las estimaciones basadas en las estadísticas vitales se calcularon directamente a partir de las cifras de defunciones infantiles y de nacimientos publicados en las ediciones de Naciones Unidas, Demographic Yearbook.

b La cifra corresponde a 1978.

c La cifra corresponde a 1983.

d La cifra corresponde a 1993.

e La cifra corresponde a 1986. 
La conclusión de los párrafos anteriores es que no se puede confiar ciegamente en que las estimaciones indirectas de la mortalidad infantil vayan invariablemente a producir buenos resultados, si bien en la mayoría de los casos permiten obtener una estimación de la TMI más cercana a la realidad.

En la diversidad de países analizados (14) y en el horizonte temporal considerado (desde 1960 en el Brasil hasta 2005 en Colombia, México y Nicaragua) existe un amplio abanico de situaciones en lo que respecta a la cobertura de las estadísticas vitales. En este artículo solo se señala como un indicio de la subestimación de la TMI la diferencia entre las estimaciones indirectas y las directas.

\section{Transición epidemiológica de la mortalidad infantil en América Latina y el Caribe}

El presente análisis de la evolución de la mortalidad infantil y sus perspectivas se llevó a cabo en el marco de la transición epidemiológica de la mortalidad infantil. Omran (1971) definió la transición epidemiológica de la mortalidad (en todas las edades) como el paso de una situación en la que predominan las enfermedades infectocontagiosas a otra en la que los padecimientos crónicodegenerativos se convierten en las principales causas de muerte. Pero ¿qué acontece con la mortalidad infantil?

Por definición, la mortalidad infantil es la que ocurre en el primer año de vida. Un año suele ser (salvo excepciones) un período demasiado corto para desarrollar una enfermedad crónicodegenerativa. No obstante, el descenso de la mortalidad infantil va acompañado de una drástica modificación del patrón de causas de muerte.

Para analizar la transición epidemiológica de la mortalidad infantil, las causas de muerte se pueden agrupar según el grado de dificultad para evitarlas (Aguirre, 2009). De menor a mayor grado, la clasificación sería la siguiente: i) enfermedades inmunoprevenibles, ii) enfermedades diarreicas agudas, iii) infecciones respiratorias agudas, iv) afecciones perinatales y v) anomalías congénitas.

Esto grupos de causas provocan más de dos tercios de las defunciones infantiles registradas en los países de la región.

El grupo de causas en el que es más fácil abatir la mortalidad es el de las enfermedades inmunoprevenibles. Con la aplicación de una o varias dosis de vacunas, es posible evitar estas enfermedades en la mayoría de los casos. Entre los padecimientos contra los que se protege a los niños con vacunas figuran la tuberculosis, la poliomielitis, la difteria, la tos ferina, el tétanos y el sarampión. En muchos casos, las defunciones causadas por enfermedades inmunoprevenibles pueden evitarse aun cuando no haya un sustancial mejoramiento en las demás condiciones de vida de la población. 
Las enfermedades diarreicas pueden prevenirse con medidas de saneamiento ambiental, como suministro de agua potable y establecimiento de redes de alcantarillado. Esto requiere de inversiones en infraestructura. Sin embargo, incluso sin estas medidas puede evitarse, si no la morbilidad, sí la mortalidad por enfermedad diarreica aguda de una manera relativamente fácil con la terapia de hidratación oral. Desde la aplicación de esta terapia, desarrollada por el Centro Internacional de Investigaciones sobre Enfermedades Diarreicas en Bangladesh en 1968, el número de defunciones por enfermedad diarreica aguda ha disminuido considerablemente aun en poblaciones donde, por el rezago económico, se carece de infraestructura sanitaria básica.

Para las infecciones respiratorias agudas no existe una prevención similar a las vacunas o la terapia de hidratación oral. Sin embargo, muchas defunciones por esta causa pueden evitarse con una serie de medidas de atención primaria de salud, tanto en el hogar como en centros sanitarios. El punto clave parece ser la oportuna identificación de los casos que se agravan, así como su adecuada referencia a los centros de salud.

Para evitar defunciones por afecciones originadas en el período perinatal, se requieren medidas más costosas, como una adecuada atención prenatal y atención (de preferencia médica) durante el parto. Esto implica contar con una infraestructura hospitalaria y con recursos humanos capacitados, elementos asociados al desarrollo económico.

Finalmente, las anomalías congénitas son condiciones no solamente difíciles de evitar, sino también, en ocasiones, de detectar, por lo que es poco lo que en este campo puede hacerse para disminuir la mortalidad infantil. Entre las medidas que pueden tomarse en este sentido, y que ya se aplican en algunos países desarrollados, se encuentra la detección mediante tecnología avanzada (por ejemplo, imágenes de ultrasonido) de malformaciones del feto. Si después se procede a la interrupción del embarazo, se logra bajar la mortalidad infantil de manera un tanto artificial, evitando el nacimiento y la muerte por una anomalía congénita. Esto reduce la TMI, ya que disminuye en la misma cantidad su numerador (defunciones infantiles) y su denominador (nacimientos).

Para analizar las causas de muerte es inevitable el uso de estadísticas vitales, ya que las otras fuentes de información que permiten corregir su nivel no captan las causas de defunción. Es posible que el patrón epidemiológico que revelan las estadísticas vitales distorsione la distribución real de las causas de defunción. Se podría pensar que, dado que el subregistro es mayor en zonas rurales, y que las enfermedades diarreicas y las infecciones respiratorias agudas son más frecuentes en este medio, en el patrón epidemiológico derivado de las estadísticas vitales estas causas estarían subrepresentadas. No obstante, el subregistro de defunciones infantiles también tiende a concentrarse en la mortalidad neonatal y en general en las edades más jóvenes. En este tramo de edades es frecuente la mortalidad por afecciones perinatales. Así, se produce un subregistro en al menos tres de los grupos de causas de muerte, con lo cual la distorsión deja de ser tan marcada. En otras palabras, hay un subregistro de defunciones por enfermedades diarreicas agudas, 
infecciones respiratorias agudas y afecciones perinatales, por lo que el subregistro queda repartido entre ellas.

Durante la transición epidemiológica de la mortalidad infantil, los grupos de causas de muerte van cambiando de posición según el orden de importancia. Se pueden identificar seis etapas de la transición, que van desde el predominio de las enfermedades diarreicas agudas hasta el predominio de las anomalías congénitas (véase el cuadro 5).

Cuadro 5

Evolución de las principales de causas de muerte en la transición epidemiológica de la mortalidad infantil

\begin{tabular}{cllll}
\hline \multirow{2}{*}{ Etapa } & \multicolumn{4}{c}{ Causas } \\
\cline { 2 - 4 } & Primera & Segunda & Tercera & Cuarta \\
\hline I & $\begin{array}{l}\text { Enfermedad } \\
\text { diarreica aguda }\end{array}$ & $\begin{array}{l}\text { Infección } \\
\text { respiratoria aguda }\end{array}$ & $\begin{array}{l}\text { Enfermedad } \\
\text { inmunoprevenible }\end{array}$ & Afección perinatal \\
\hline III & $\begin{array}{l}\text { Enfermedad } \\
\text { diarreica aguda }\end{array}$ & $\begin{array}{l}\text { Infección } \\
\text { respiratoria aguda }\end{array}$ & Afección perinatal & Anomalía congénita \\
\hline IV & Afección perinatal & $\begin{array}{l}\text { Enfermedad } \\
\text { diarreica aguda }\end{array}$ & $\begin{array}{l}\text { Infección } \\
\text { respiratoria aguda }\end{array}$ & Anomalía congénita \\
\hline V & Afección perinatal & Anomalía congénita & $\begin{array}{l}\text { Infección } \\
\text { respiratoria aguda }\end{array}$ & $\begin{array}{l}\text { Enfermedad } \\
\text { diarreica aguda }\end{array}$ \\
\hline VI & Afección perinatal & Anomalía congénita & & \\
\hline
\end{tabular}

Fuente: Alejandro Aguirre, "La mortalidad infantil y la mortalidad materna en el siglo XXI", Papeles de Población, vol. 15, № 61, Toluca, Universidad Autónoma del Estado de México, 2009, pág. 82.

México, por ejemplo, se encuentra en la cuarta etapa de la transición epidemiológica de la mortalidad infantil. Es decir, las principales causas de muerte en orden jerárquico son: i) afecciones originadas en el período perinatal, ii) anomalías congénitas, iii) infecciones respiratorias agudas y iv) enfermedades diarreicas agudas (Aguirre, 2009).

Cabe destacar que durante la quinta etapa de la transición, las afecciones perinatales y las anomalías congénitas se mantienen en las dos primeras posiciones, aunque en niveles inferiores, en tanto que las infecciones respiratorias agudas y las enfermedades diarreicas agudas bajan a tal grado que dejan de figurar entre las primeras cinco causas de mortalidad infantil. Esta es la situación que prevalece en la mayoría de los países desarrollados, donde la tasa de mortalidad infantil es de 10 muertes por 1.000 o menos, nivel al que la región aspira a llegar cuanto antes. Entre las causas de mortalidad infantil que ascienden del tercero al quinto lugar figuran los accidentes, el síndrome de muerte infantil súbita, las enfermedades del sistema nervioso y las deficiencias de la nutrición. 


\section{Resultados}

En el cuadro 4 se presentan las estimaciones realizadas con el método de hijos nacidos vivos e hijos sobrevivientes y el cálculo directo del cociente de defunciones de niños menores de 1 año entre el total de hijos nacidos vivos reportados en las estadísticas vitales en diferentes años del período 1960-2005. Tanto las estimaciones directas como las indirectas muestran una clara tendencia descendente de la mortalidad infantil en todos los países analizados, aunque en niveles distintos (salvo algunas inconsistencias señaladas en la sección B, observadas en Bolivia (Estado Plurinacional de), Chile y Nicaragua). Por ejemplo, en el caso del Ecuador, en 1974 la estimación indirecta de la TMI es de 102 por 1.000 mientras que la directa es de 76 por 1.000 en ese mismo año; para 2001 estas cifras fueron, respectivamente, de 26 por 1.000 y 25 por 1.000 . Como se puede apreciar, salvo cinco excepciones (Argentina (1991), Bolivia (Estado Plurinacional de) (1992), Chile (1992), Colombia (1985) y Perú (1993)), las estimaciones indirectas en todos los años y países considerados superan las estimaciones directas, lo que estaría indicando un grado mayor o menor de subestimación. Al calcular estas diferencias en términos absolutos y relativos, se puede señalar que los datos de 1960 del Brasil presentan la mayor la diferencia en términos absolutos (75 por 1.000). En términos relativos, los datos de El Salvador de 2007 son los que presentan la mayor diferencia, de un 70\%, seguidos por los de Panamá correspondientes a 1980, de un $65 \%$. El patrón esperado es que tanto las diferencias absolutas como las relativas fuesen disminuyendo en el tiempo, como ocurre en el Brasil entre 1960 y 2000, lo que implicaría de alguna forma la convergencia entre las estimaciones directas e indirectas debida a una mejora en la calidad de las estadísticas vitales.

Sin embargo, dadas las persistentes diferencias entre las estimaciones, sería prematuro afirmar que los métodos indirectos resultan innecesarios para la estimación de la TMI en la región. Esto se hace más patente al estudiar subpoblaciones de un país donde la calidad de la información es todavía más deficiente.

Considerando razonables la mayoría de las estimaciones indirectas, se corrobora el descenso de la tasa de mortalidad infantil en la región, a diferentes niveles: de 168 a 83 por 1.000 en un cuarto de siglo en el Estado Plurinacional de Bolivia; de 145 a 27 por 1.000 entre 1960 y 2000 en el Brasil; de 55 a 27 por 1.000 en el Uruguay entre 1975 y 1995, y de 69 a 21 por 1.000 en la Argentina entre 1970 y 1991.

En el cuadro 6 se muestra su evolución de la transición epidemiológica de la mortalidad infantil en los países de América Latina y el Caribe en el período de 1980 a 2005. El análisis se basó solo en los datos provenientes de las estadísticas vitales, si bien se tiene en cuenta que la calidad de la información sobre las causas de muerte no es homogénea entre países y períodos. Sin embargo, como se ha mencionado anteriormente, se espera que la distorsión en el patrón epidemiológico de la mortalidad infantil no sea tan acentuada, dado que el subregistro afecta a por lo menos tres grupos de causas de muerte (enfermedades diarreicas agudas, infecciones respiratorias agudas y afecciones perinatales). 
Cuadro 6

América Latina y el Caribe (países seleccionados): principales causas de muerte infantil y etapa de la transición epidemiológica

\begin{tabular}{|c|c|c|c|c|c|c|}
\hline \multirow{2}{*}{ País } & \multirow{2}{*}{ Año } & \multicolumn{4}{|c|}{ Causa de muerte } & \multirow{2}{*}{ Etapa } \\
\hline & & Primera & Segunda & Tercera & Cuarta & \\
\hline \multirow{4}{*}{ Argentina } & 1980 & $\begin{array}{l}\text { Afección } \\
\text { perinatal }\end{array}$ & $\begin{array}{l}\text { Anomalía } \\
\text { congénita }\end{array}$ & $\begin{array}{l}\text { Infección } \\
\text { respiratoria aguda }\end{array}$ & $\begin{array}{l}\text { Enfermedad } \\
\text { diarreica aguda }\end{array}$ & 4 \\
\hline & 1986 & $\begin{array}{l}\text { Afección } \\
\text { perinatal }\end{array}$ & $\begin{array}{l}\text { Anomalía } \\
\text { congénita }\end{array}$ & $\begin{array}{l}\text { Infección } \\
\text { respiratoria aguda }\end{array}$ & $\begin{array}{l}\text { Enfermedad } \\
\text { diarreica aguda }\end{array}$ & 4 \\
\hline & 1990 & $\begin{array}{l}\text { Afección } \\
\text { perinatal }\end{array}$ & $\begin{array}{l}\text { Anomalía } \\
\text { congénita }\end{array}$ & $\begin{array}{l}\text { Infección } \\
\text { respiratoria aguda }\end{array}$ & $\begin{array}{l}\text { Enfermedad } \\
\text { diarreica aguda }\end{array}$ & 4 \\
\hline & 2003 & $\begin{array}{l}\text { Afección } \\
\text { perinatal }\end{array}$ & $\begin{array}{l}\text { Anomalía } \\
\text { congénita }\end{array}$ & $\begin{array}{l}\text { Infección } \\
\text { respiratoria aguda }\end{array}$ & $\begin{array}{l}\text { Enfermedad } \\
\text { diarreica aguda }\end{array}$ & 4 \\
\hline \multirow{4}{*}{ Brasil } & 1980 & $\begin{array}{l}\text { Afección } \\
\text { perinatal }\end{array}$ & $\begin{array}{l}\text { Enfermedad } \\
\text { diarreica aguda }\end{array}$ & $\begin{array}{l}\text { Infección } \\
\text { respiratoria aguda }\end{array}$ & $\begin{array}{l}\text { Anomalía } \\
\text { congénita }\end{array}$ & 3 \\
\hline & 1991 & $\begin{array}{l}\text { Afección } \\
\text { perinatal }\end{array}$ & $\begin{array}{l}\text { Enfermedad } \\
\text { diarreica aguda }\end{array}$ & $\begin{array}{l}\text { Infección } \\
\text { respiratoria aguda }\end{array}$ & $\begin{array}{l}\text { Anomalía c } \\
\text { ongénita }\end{array}$ & 3 \\
\hline & 2000 & $\begin{array}{l}\text { Afección } \\
\text { perinatal }\end{array}$ & $\begin{array}{l}\text { Anomalía } \\
\text { congénita }\end{array}$ & $\begin{array}{l}\text { Infección } \\
\text { respiratoria aguda }\end{array}$ & $\begin{array}{l}\text { Enfermedad } \\
\text { diarreica aguda }\end{array}$ & 4 \\
\hline & 2004 & $\begin{array}{l}\text { Afección } \\
\text { perinatal }\end{array}$ & $\begin{array}{l}\text { Anomalía } \\
\text { congénita }\end{array}$ & $\begin{array}{l}\text { Infección } \\
\text { respiratoria aguda }\end{array}$ & $\begin{array}{l}\text { Enfermedad } \\
\text { diarreica aguda }\end{array}$ & 4 \\
\hline \multirow{3}{*}{ Chile } & 1982 & $\begin{array}{l}\text { Afección } \\
\text { perinatal }\end{array}$ & $\begin{array}{l}\text { Anomalía } \\
\text { congénita }\end{array}$ & $\begin{array}{l}\text { Infección } \\
\text { respiratoria aguda }\end{array}$ & $\begin{array}{l}\text { Enfermedad } \\
\text { diarreica aguda }\end{array}$ & 4 \\
\hline & 1992 & $\begin{array}{l}\text { Afección } \\
\text { perinatal }\end{array}$ & $\begin{array}{l}\text { Anomalía } \\
\text { congénita }\end{array}$ & $\begin{array}{l}\text { Infección } \\
\text { respiratoria aguda }\end{array}$ & $\begin{array}{l}\text { Enfermedad } \\
\text { diarreica aguda }\end{array}$ & 4 \\
\hline & 2002 & $\begin{array}{l}\text { Afección } \\
\text { perinatal }\end{array}$ & $\begin{array}{l}\text { Anomalía } \\
\text { congénita }\end{array}$ & $\begin{array}{l}\text { Infección } \\
\text { respiratoria aguda }\end{array}$ & $\begin{array}{l}\text { Enfermedad } \\
\text { diarreica aguda }\end{array}$ & 4 \\
\hline \multirow{3}{*}{ Colombia } & 1984 & $\begin{array}{l}\text { Afección } \\
\text { perinatal }\end{array}$ & $\begin{array}{l}\text { Enfermedad } \\
\text { diarreica aguda }\end{array}$ & $\begin{array}{l}\text { Infección } \\
\text { respiratoria aguda }\end{array}$ & $\begin{array}{l}\text { Anomalía } \\
\text { congénita }\end{array}$ & 3 \\
\hline & 1997 & $\begin{array}{l}\text { Afección } \\
\text { perinatal }\end{array}$ & $\begin{array}{l}\text { Anomalía } \\
\text { congénita }\end{array}$ & $\begin{array}{l}\text { Infección } \\
\text { respiratoria aguda }\end{array}$ & $\begin{array}{l}\text { Enfermedad } \\
\text { diarreica aguda }\end{array}$ & 4 \\
\hline & 2005 & $\begin{array}{l}\text { Afección } \\
\text { perinatal }\end{array}$ & $\begin{array}{l}\text { Anomalía } \\
\text { congénita }\end{array}$ & $\begin{array}{l}\text { Infección } \\
\text { respiratoria aguda }\end{array}$ & $\begin{array}{l}\text { Enfermedad } \\
\text { diarreica aguda }\end{array}$ & 4 \\
\hline \multirow{3}{*}{ Costa Rica } & 1984 & $\begin{array}{l}\text { Afección } \\
\text { perinatal }\end{array}$ & $\begin{array}{l}\text { Anomalía } \\
\text { congénita }\end{array}$ & $\begin{array}{l}\text { Infección } \\
\text { respiratoria aguda }\end{array}$ & $\begin{array}{l}\text { Enfermedad } \\
\text { diarreica aguda }\end{array}$ & 4 \\
\hline & 2000 & $\begin{array}{l}\text { Afección } \\
\text { perinatal }\end{array}$ & $\begin{array}{l}\text { Anomalía } \\
\text { congénita }\end{array}$ & $\begin{array}{l}\text { Infección } \\
\text { respiratoria aguda }\end{array}$ & $\begin{array}{l}\text { Enfermedad } \\
\text { diarreica aguda }\end{array}$ & 4 \\
\hline & 2005 & $\begin{array}{l}\text { Afección } \\
\text { perinatal }\end{array}$ & $\begin{array}{l}\text { Anomalía } \\
\text { congénita }\end{array}$ & $\begin{array}{l}\text { Infección } \\
\text { respiratoria aguda }\end{array}$ & $\begin{array}{l}\text { Enfermedad } \\
\text { diarreica aguda }\end{array}$ & 4 \\
\hline \multirow{4}{*}{ Ecuador } & 1984 & $\begin{array}{l}\text { Afección } \\
\text { perinatal }\end{array}$ & $\begin{array}{l}\text { Enfermedad } \\
\text { diarreica aguda }\end{array}$ & $\begin{array}{l}\text { Infección } \\
\text { respiratoria aguda }\end{array}$ & $\begin{array}{l}\text { Anomalía } \\
\text { congénita }\end{array}$ & 3 \\
\hline & 1991 & $\begin{array}{l}\text { Afección } \\
\text { perinatal }\end{array}$ & $\begin{array}{l}\text { Enfermedad } \\
\text { diarreica aguda }\end{array}$ & $\begin{array}{l}\text { Infección } \\
\text { respiratoria aguda }\end{array}$ & $\begin{array}{l}\text { Anomalía } \\
\text { congénita }\end{array}$ & 3 \\
\hline & 2001 & $\begin{array}{l}\text { Afección } \\
\text { perinatal }\end{array}$ & $\begin{array}{l}\text { Infección } \\
\text { respiratoria aguda }\end{array}$ & Anomalía congénita & $\begin{array}{l}\text { Enfermedad } \\
\text { diarreica aguda }\end{array}$ & $3 / 4$ \\
\hline & 2005 & $\begin{array}{l}\text { Afección } \\
\text { perinatal }\end{array}$ & $\begin{array}{l}\text { Anomalía } \\
\text { congénita }\end{array}$ & $\begin{array}{l}\text { Infección } \\
\text { respiratoria aguda }\end{array}$ & $\begin{array}{l}\text { Enfermedad } \\
\text { diarreica aguda }\end{array}$ & 4 \\
\hline \multirow{2}{*}{ El Salvador } & 1984 & $\begin{array}{l}\text { Afección } \\
\text { perinatal }\end{array}$ & $\begin{array}{l}\text { Enfermedad } \\
\text { diarreica aguda }\end{array}$ & $\begin{array}{l}\text { Infección } \\
\text { respiratoria aguda }\end{array}$ & $\begin{array}{l}\text { Anomalía } \\
\text { congénita }\end{array}$ & 3 \\
\hline & 1999 & $\begin{array}{l}\text { Afección } \\
\text { perinatal }\end{array}$ & $\begin{array}{l}\text { Anomalía } \\
\text { congénita }\end{array}$ & $\begin{array}{l}\text { Infección } \\
\text { respiratoria aguda }\end{array}$ & $\begin{array}{l}\text { Enfermedad } \\
\text { diarreica aguda }\end{array}$ & 4 \\
\hline
\end{tabular}


Cuadro 6 (conclusión)

\begin{tabular}{|c|c|c|c|c|c|c|}
\hline \multirow{2}{*}{ País } & \multirow{2}{*}{ Año } & \multicolumn{4}{|c|}{ Causa de muerte } & \multirow{2}{*}{ Etapa } \\
\hline & & Primera & Segunda & Tercera & Cuarta & \\
\hline \multirow{2}{*}{ Jamaica } & 1982 & $\begin{array}{l}\text { Afección } \\
\text { perinatal }\end{array}$ & $\begin{array}{l}\text { Enfermedad } \\
\text { diarreica aguda }\end{array}$ & $\begin{array}{l}\text { Infección } \\
\text { respiratoria aguda }\end{array}$ & $\begin{array}{l}\text { Anomalía } \\
\text { congénita }\end{array}$ & 3 \\
\hline & 1991 & $\begin{array}{l}\text { Afección } \\
\text { perinatal }\end{array}$ & $\begin{array}{l}\text { Enfermedad } \\
\text { diarreica aguda }\end{array}$ & Anomalía congénita & $\begin{array}{l}\text { Infección } \\
\text { respiratoria aguda }\end{array}$ & $3 / 4$ \\
\hline \multirow{3}{*}{ México } & 1988 & $\begin{array}{l}\text { Afección } \\
\text { perinatal }\end{array}$ & $\begin{array}{l}\text { Enfermedad } \\
\text { diarreica aguda }\end{array}$ & $\begin{array}{l}\text { Infección } \\
\text { respiratoria aguda }\end{array}$ & $\begin{array}{l}\text { Anomalía } \\
\text { congénita }\end{array}$ & 3 \\
\hline & 2000 & $\begin{array}{l}\text { Afección } \\
\text { perinatal }\end{array}$ & $\begin{array}{l}\text { Anomalía } \\
\text { congénita }\end{array}$ & $\begin{array}{l}\text { Infección } \\
\text { respiratoria aguda }\end{array}$ & $\begin{array}{l}\text { Enfermedad } \\
\text { diarreica aguda }\end{array}$ & 4 \\
\hline & 2005 & $\begin{array}{l}\text { Afección } \\
\text { perinatal }\end{array}$ & $\begin{array}{l}\text { Anomalía } \\
\text { congénita }\end{array}$ & $\begin{array}{l}\text { Infección } \\
\text { respiratoria aguda }\end{array}$ & $\begin{array}{l}\text { Enfermedad } \\
\text { diarreica aguda }\end{array}$ & 4 \\
\hline Nicaragua & 1998 & $\begin{array}{l}\text { Afección } \\
\text { perinatal }\end{array}$ & $\begin{array}{l}\text { Infección } \\
\text { respiratoria aguda }\end{array}$ & $\begin{array}{l}\text { Enfermedad } \\
\text { diarreica aguda }\end{array}$ & $\begin{array}{l}\text { Anomalía } \\
\text { congénita }\end{array}$ & 3 \\
\hline \multirow{3}{*}{ Panamá } & 1980 & $\begin{array}{l}\text { Afección } \\
\text { perinatal }\end{array}$ & $\begin{array}{l}\text { Anomalía } \\
\text { congénita }\end{array}$ & $\begin{array}{l}\text { Enfermedad } \\
\text { diarreica aguda }\end{array}$ & $\begin{array}{l}\text { Infección } \\
\text { respiratoria aguda }\end{array}$ & 4 \\
\hline & 1989 & $\begin{array}{l}\text { Afección } \\
\text { perinatal }\end{array}$ & $\begin{array}{l}\text { Anomalía } \\
\text { congénita }\end{array}$ & $\begin{array}{l}\text { Enfermedad } \\
\text { diarreica aguda }\end{array}$ & $\begin{array}{l}\text { Infección } \\
\text { respiratoria aguda }\end{array}$ & 4 \\
\hline & 2004 & $\begin{array}{l}\text { Afección } \\
\text { perinatal }\end{array}$ & $\begin{array}{l}\text { Anomalía } \\
\text { congénita }\end{array}$ & $\begin{array}{l}\text { Infección } \\
\text { respiratoria aguda }\end{array}$ & $\begin{array}{l}\text { Enfermedad } \\
\text { diarreica aguda }\end{array}$ & 4 \\
\hline \multirow{2}{*}{ Perú } & 1992 & $\begin{array}{l}\text { Afección } \\
\text { perinatal }\end{array}$ & $\begin{array}{l}\text { Infección } \\
\text { respiratoria aguda }\end{array}$ & $\begin{array}{l}\text { Enfermedad } \\
\text { diarreica aguda }\end{array}$ & $\begin{array}{l}\text { Anomalía } \\
\text { congénita }\end{array}$ & 3 \\
\hline & 2000 & $\begin{array}{l}\text { Afección } \\
\text { perinatal }\end{array}$ & $\begin{array}{l}\text { Infección } \\
\text { respiratoria aguda }\end{array}$ & Anomalía congénita & $\begin{array}{l}\text { Anomalía } \\
\text { congénita }\end{array}$ & $3 / 4$ \\
\hline \multirow{3}{*}{ Uruguay } & 1980 & $\begin{array}{l}\text { Afección } \\
\text { perinatal }\end{array}$ & $\begin{array}{l}\text { Anomalía } \\
\text { congénita }\end{array}$ & $\begin{array}{l}\text { Enfermedad } \\
\text { diarreica aguda }\end{array}$ & $\begin{array}{l}\text { Infección } \\
\text { respiratoria aguda }\end{array}$ & 4 \\
\hline & 1987 & $\begin{array}{l}\text { Afección } \\
\text { perinatal }\end{array}$ & $\begin{array}{l}\text { Anomalía } \\
\text { congénita }\end{array}$ & & & $4 / 5$ \\
\hline & 2004 & $\begin{array}{l}\text { Afección } \\
\text { perinatal }\end{array}$ & $\begin{array}{l}\text { Anomalía } \\
\text { congénita }\end{array}$ & & & 5 \\
\hline
\end{tabular}

Fuente: Elaboración propia, sobre la base de datos de la Organización Mundial de la Salud (OMS) [en línea] http://apps.who.int/whosis/database/mort; y de la Organización Panamericana de la Salud (OPS), LaS Condiciones de Salud en las Américas, varios años.

Un primer resultado es que todos los países analizados han dejado atrás la primera y segunda etapa de la transición epidemiológica. En el Estado Plurinacional de Bolivia dejan de registrarse más de la mitad de las defunciones infantiles (Villarroel, 2012); sin embargo, es posible que este país se encuentre en la tercera etapa de la transición con los mayores rezagos de la región. Nicaragua, por su parte, en el umbral del siglo XXI, aún se encontraba en la tercera etapa. Con un mejor desempeño, el Brasil, Colombia, el Ecuador, El Salvador y México pasaron de la tercera a la cuarta etapa, es decir que hubo una disminución considerable de la participación relativa de las enfermedades diarreicas agudas y las infecciones respiratorias agudas. Chile, Costa Rica y Panamá desde los años ochenta se encuentran en la cuarta etapa de la transición. Sin que el país hubiera llegado de lleno a la quinta etapa, en 1992, los accidentes, el síndrome de muerte súbita y las enfermedades 
del sistema nervioso en Chile habían desplazado a las enfermedades diarreicas agudas al séptimo lugar entre las causas de mortalidad infantil, aunque las infecciones respiratorias agudas permanecían en el tercer lugar; esto significa que el país se encontraba en un punto intermedio entre la cuarta y la quinta etapa de la transición. También en un punto intermedio, pero entre la tercera y la cuarta etapa, se encontraban Jamaica en 1991, el Perú en 2000 y el Ecuador en 2001, si bien este último llegó a la cuarta etapa en 2005.

Además, Chile, Colombia y México, hacia 2005 se encontraban en una posición intermedia entre la cuarta y la quinta etapa de la transición al haber logrado ubicar la mortalidad por infecciones intestinales por debajo del cuarto lugar entre las causas de defunciones de niños menores de 1 año.

Finalmente, el Uruguay es uno de los países que se ha mantenido a la vanguardia tanto en los niveles de mortalidad infantil como en el patrón de causas. En 1980 se encontraba en la cuarta etapa de la transición; en 1987 alcanzó un punto intermedio entre la cuarta y la quinta etapas, ya que las infecciones respiratorias agudas aún se encontraban en el cuarto lugar (si bien las enfermedades diarreicas agudas se ubicaron alrededor del séptimo lugar). Para el año 2004, el Uruguay ya había accedido a la quinta etapa de la transición epidemiológica, dado que ni las enfermedades diarreicas agudas ni las infecciones respiratorias agudas figuraban entre las primeras cinco causas de mortalidad infantil, alcanzando así un perfil epidemiológico propio de los países desarrollados.

\section{E. Conclusiones}

En resumen, el análisis presentado en este artículo permite responder a las preguntas originalmente planteadas. En lo que respecta a la medición de la mortalidad infantil por medio de las estadísticas vitales, en algunos países de la región se observan subestimaciones de diferente magnitud, por lo que es necesario continuar empleando métodos indirectos de estimación, como la técnica de Brass, para contar con estimaciones más fidedignas. Esto se hace más patente cuando se realizan estudios a nivel subnacional. Además, cabe destacar la utilidad de las estadísticas vitales para el conocimiento del perfil epidemiológico de la mortalidad infantil, ya que, a diferencia de los censos y las encuestas, captan las causas de muerte, lo que las convierte en una fuente de información invaluable. En efecto, cuando en los censos se pregunta acerca de hijos nacidos vivos e hijos sobrevivientes, no se consignan las causas de los decesos de los niños fallecidos. Tampoco sucede así en las encuestas demográficas, que registran las muertes, pero no escudriñan las causas que las provocaron. 


\section{Bibliografía}

Aguirre, Alejandro (2009), "La mortalidad infantil y la mortalidad materna en el siglo XXI", Papeles de Población, vol. 15, N 61, Toluca, Universidad Autónoma del Estado de México.

Aguirre, Alejandro y Fortino Vela (2012), "La mortalidad infantil en México, 2010", Papeles de Población, vol. 18, $\mathrm{N}^{\circ} 73$, Toluca, Universidad Autónoma del Estado de México.

Ahmad, Omar B. y otros (2000), "The decline in child mortality: a reappraisal", Bulletin of the World Health Organization, vol. 78(10).

Brass, William y A.J. Coale (1968), "Methods of analysis and estimation", The Demography of Tropical Africa, W. Brass y otros (eds.), Princeton University Press.

Coale, A.J. y P. Demeny (1966), Regional Model Life Tables and Stable Populations, Princeton, Nueva Jersey.

Feeney, G. (1980), "Estimating infant mortality trends from child survivorship data", Populations Studies, vol. XXXIV, $\mathrm{N}^{\circ} 1$, Londres.

Minnesota Population Center (2011), "Integrated Public Use Microdata Series, International: Version 6.1" [base de datos en línea], Minneapolis, University of Minnesota.

Naciones Unidas (varios años), Demographic Yearbook [en línea] http://unstats.un.org/unsd/ demographic/products/dyb/2000_round.htm.

(1982), Tablas Modelo de Mortalidad para Países en Desarrollo (ST/ESA/Ser.A/77), Nueva York.

(s/f), QFIVE: Microcomputer Program for Child Mortality Estimation [en línea] http://www.un.org/esa/ population/pubsarchive/catalogue/catdbs.htm\#l.

Omran, A. (1971), "The epidemiologic transition. A theory of the epidemiology of population change", Milbank Memorial Fund Quarterly, vol. XLIX, $\mathrm{N}^{\circ} 4$.

OPS (Organización Panamericana de la Salud) (varios años), Las Condiciones de Salud en las Américas, vol. I y vol. II, Washington, D.C.

Sullivan, J.M. (1972), "Models for the Estimation of the Probability of Dying between Birth and Exact Ages of Early Childhood", Population Studies, vol. 26, № 1.

Trussell, J.T. (1975), "A re-estimation of the multiplying factors for the brass technique for determining childhood survivorship rates", Population Studies, vol. XXIX, $\mathrm{N}^{\circ}$ 1, Londres.

Villarroel, C. (2012), "Estimación indirecta de la mortalidad en Bolivia con base en información censal 1992-2001", tesis de Maestría en Demografía, El Colegio de México. 



\title{
Distribución territorial y determinantes de la fecundidad adolescente en Colombia
}

\author{
Víctor Hugo Álvarez Castaño1
}

Recibido: 26/06/2015

Aceptado: 29/07/2015

\section{Resumen}

La ocurrencia de embarazos a temprana edad en Colombia se reconoce hoy como un fenómeno sociosanitario problemático, visibilizado en las últimas dos décadas a partir del aumento creciente de los índices de fecundidad adolescente medidos en encuestas poblacionales. En este artículo se explora el uso inédito del registro de nacimientos como fuente primaria para describir el grado y el patrón de la fecundidad adolescente en niveles geográficos y grupos de edad más desagregados, complementado con una revisión analítica de los determinantes próximos que influyen en posibles diferencias regionales. Las estadísticas vitales del período 1998-2009 revelan niveles altos de fecundidad adolescente con tendencias ligeramente decrecientes a nivel nacional y regional, pero resistentes a la baja en las regiones costeras, proclives al aumento. Se concluye que es necesario integrar distintas fuentes y métodos de medición y profundizar el análisis del contexto para orientar mejor la gestión de políticas públicas de prevención o reducción de la fecundidad adolescente en las regiones, dada la diversidad del país.

Palabras clave: nacimientos, fecundidad, fecundidad adolescente, determinantes próximos, estadísticas vitales, encuestas nacionales de demografía y salud, ENDS.

Médico Epidemiólogo-Demógrafo del Ministerio de Salud y Protección Social de Colombia. Correo electrónico: valvarez@minsalud.gov.co. 


\begin{abstract}
The occurrence of early pregnancies in Colombia is currently recognized as a problematic socio-medical phenomenon, as has become evident in the increasing rates of adolescent fertility measured in population surveys in the past two decades. This article explores the unprecedented use of birth registration as the primary source to describe the level and pattern of adolescent fertility by geographical area and more disaggregated age groups, complemented by an analytical review of the proximate determinants that influence potential regional differences. Vital statistics for 1998-2009 reveal high levels of adolescent fertility, decreasing slightly at the national and regional levels, but less prone to decline in coastal areas, where they are tending to rise. We conclude that different sources and measurement methods should be integrated, and a more thoroughgoing analysis conducted of the context, in order to better guide the management of public policies for prevention or reduction of fertility in the regions, given Colombia's diversity.
\end{abstract}

Keywords: birth, fertility, adolescent fertility, proximate determinants, vital statistics, national demographic and health surveys.

\title{
Résumé
}

Les grossesses précoces en Colombie sont aujourd'hui reconnues comme un phénomène socio sanitaire problématique dont rend compte l'augmentation croissante des taux de fécondité chez les adolescentes mesurés dans les enquêtes démographiques au cours des deux dernières décennies. Dans cet article, l'auteur analyse l'utilisation inédite du registre des naissances comme source primaire permettant de décrire le degré et le modèle de fécondité adolescente à des niveaux géographiques et pour des groupes d'âge plus désagrégés, complétés par une révision analytique des déterminants proches ayant une influence sur d'éventuelles différences régionales. Les statistiques vitales de la période 1998-2009 font état de niveaux élevés de fécondité adolescente, qui montrent des tendances légèrement à la baisse à l'échelle nationale et régionale, mais qui résistent à la diminution dans les régions côtières où elles ont tendance à augmenter. Les conclusions de cette analyse sont qu'il convient d'intégrer différentes sources et méthodes de mesure et de renforcer l'analyse du contexte afin de mieux orienter la gestion des politiques publiques de prévention ou réduction de la fécondité adolescente dans la région, compte tenu de la diversité existant dans le pays.

Mots clés: naissances; fécondité; fécondité adolescente; déterminants proches; statistiques vitales; enquêtes nationales de démographie et de santé; ENDS. 


\section{Introducción}

Elcrecimientodela fecundidad adolescente es uno delos cambios demográficos másnotables observados en Colombia durante las últimas cuatro décadas. Mientras la fecundidad general de mujeres en edad fértil, de 15 a 49 años, disminuye de manera sostenida acercándose cada vez más al nivel de reemplazo, con un índice sintético de fecundidad de 2,1 en 2010 (Profamilia, 2011), las tasas de fecundidad adolescente oscilan entre la reducción observada entre los años 1970 y 1990 - de 99 a 70 nacidos vivos por cada 1.000 mujeres de 15 a 19 años y un aumento creciente - con tasas de 85,90 y 84 nacidos vivos por cada 1.000 mujeres en los años 2000, 2005 y 2010, respectivamente-, que contribuye cada vez más a la fecundidad total, la que ascendió de un $7 \%$ en 1970 a un $12 \%$ en 1990 , un $16 \%$ en 2000 y un $19 \%$ en 2010.

Las encuestas nacionales de demografía y salud (ENDS) realizadas en Colombia en 1990, 1995, 2000, 2005 y $2010^{2}$ muestran un aumento de la proporción de adolescentes con hijos y una disminución de la edad a la cual tienen su primer hijo (Profamilia, 2011). Este incremento de la fecundidad adolescente se expresa en una mayor proporción de madres solteras, un menor número de uniones, el inicio más temprano de relaciones sexuales y diferencias notables de embarazo no deseado entre adolescentes según nivel socioeconómico, destacándose la importancia de los factores contextuales vinculados a la falta de oportunidades sociales y económicas. Los estudios elaborados en el país sobre determinantes del embarazo en adolescentes revelan que la deserción escolar y la pobreza son condiciones previas y no consecuencias del embarazo, aunque una gran proporción de adolescentes pobres abandona los estudios a raíz de esa situación (Flórez y Soto, 2006, 2013), truncando su trayectoria educativa en la mayoría de casos y reforzando el círculo vicioso de la pobreza.

Sin embargo, en análisis recientes de los niveles y tendencias de la fecundidad total en Colombia, elaborados a partir de estimaciones basadas en el método de hijos propios aplicado a datos censales y de las ENDS, se plantea una posible sobreestimación de la fecundidad adolescente y se afirma que, de hecho, esta tiende a mantenerse en un nivel estable o a aumentar levemente en algunas regiones (Verhulst, 2012). Por otra parte, poco se sabe sobre las diferencias de la fecundidad adolescente en unidades territoriales más pequeñas que las grandes subregiones y el nivel nacional; tampoco queda claro si sus contextos y determinantes afectan por igual a todos los subgrupos de edad que comprende la adolescencia ni cuáles son sus patrones geográficos y temporales.

En este trabajo se describen las intensidades y tendencias de la fecundidad adolescente a nivel de departamentos en Colombia, a partir de los registros de estadísticas vitales en el período comprendido entre 1998 y 2009, y los determinantes clave de la fecundidad asociados a la maternidad temprana entre las adolescentes colombianas que explicarían las diferencias territoriales, sobre la base de las ENDS.

2. Encuestas de Demografía y Salud (DHS) [en línea] www.measuredhs.com. 
Colombia no escapa a las marcadas inequidades sociales presentes en la región latinoamericana, y exhibe una maternidad adolescente heterogénea entre los grupos socioeconómicos, que afecta más a los menos favorecidos debido al alto grado de desigualdad derivado de diferencias en la distribución del ingreso, el nivel educativo de las mujeres y el acceso a servicios anticonceptivos equitativos y suficientes para un efectivo control de la fecundidad (Profamilia, 2011). El aumento de la fecundidad adolescente debido a la incidencia del crecimiento en los grupos más pobres, con predominio de las adolescentes urbanas y escolarizadas, ha sido señalado por varios autores (Flórez y Núñez, 2002; Bay, Del Popolo y Ferrando, 2003; Chackiel, 2004; Di Cesare y Rodríguez, 2006; Flórez y Soto, 2006; Henao, 2007; Rodríguez, 2008).

El análisis de determinantes de la fecundidad adolescente en este trabajo parte del marco conceptual desarrollado por diferentes autores (Freedman, Davis y Blake, 1967; Bongaarts, 1978; Simmons, 1985) para explicar los vínculos entre la fecundidad y sus determinantes próximos y distales. De acuerdo con este enfoque, las condiciones socioeconómicas y contextuales actúan sobre la fecundidad solo por medio de determinantes próximos, que incluyen factores relacionados con la exposición al riesgo de embarazo —edad de inicio de relaciones sexuales, matrimonio, unión-, la anticoncepción, el aborto y la infertilidad posparto (Flórez, 2005; Profamilia, 2011). Sobre la base de este modelo explicativo y del orden jerárquico de relaciones de causa y efecto, las variables que más influyen en la exposición a un embarazo en la adolescencia son el inicio de la actividad sexual, la nupcialidad y el uso de métodos anticonceptivos, conocidos como determinantes próximos, cuyo grado de intensidad está en función inversa a la edad de aparición. Los determinantes próximos, a su vez, están condicionados por un primer conjunto de características individuales de las adolescentes, como la escolaridad o el nivel educativo, la ocupación, el uso del tiempo libre y el ocio, y el acceso al sistema de salud. Un segundo conjunto de determinantes tiene que ver con el contexto del hogar, como la estructura familiar, las condiciones socioeconómicas de la familia a la que pertenece, la supervisión parental del comportamiento, el clima educativo familiar y otros. Un tercer conjunto, constituido por determinantes más distales, comprende los factores socioculturales y contextuales del entorno en que crecen los jóvenes, definidos por valores y normas sociales relativas al matrimonio, las relaciones sexuales, la pareja y el amor, entre otras cosas; también forman parte del contexto general la pertenencia étnica, el credo religioso y el círculo de amigos, pares y vecinos, así como el entorno sociopolítico representado por la institucionalidad, las políticas y las acciones gubernamentales.

De todos estos factores y consecuentemente con el carácter etiológico de los determinantes y los mecanismos mediante los cuales actúan, en el marco conceptual de este trabajo se enfatiza la influencia que ejercen los determinantes próximos de la fecundidad en el comportamiento reproductivo de las adolescentes, como una primera aproximación al marco con que debería abordarse el fenómeno desde la perspectiva de la salud pública. 


\section{A. Datos, fuentes y métodos}

Los datos utilizados en esta investigación proceden de la explotación inédita de microdatos del registro de nacimientos de la serie de estadísticas vitales 1998-2009, de los datos agregados de la población censada en 2005, suministrados por el Departamento Administrativo Nacional de Estadística (DANE) de Colombia, y de la serie de ENDS quinquenales de 1995-2010, estandarizadas y suministradas por MEASURE DHS.

Los registros de nacimientos se homogenizaron en una única serie tras homologar algunas variables cuyos diseños de ficheros anuales diferían y descartar aquellas que, por completitud, congruencia o calidad, no eran útiles. Los datos básicos extraídos fueron la edad, el estado civil, el nivel educativo y el lugar de residencia (departamento, municipio y área urbana o rural) de la madre; la edad y el nivel educativo del padre, y el mes y año de nacimiento, el orden de nacimiento, el tiempo de gestación, el peso y la talla del recién nacido.

Dado que el registro de nacidos vivos trae consigo problemas de cobertura y calidad diversos según la entidad territorial, el análisis se realizó con los datos brutos y ajustados por subregistro a partir de factores de corrección originados en las estimaciones de cobertura establecidas en el censo de 2005, con el único propósito de comparar el nivel de fecundidad con las otras fuentes de indicadores. El procedimiento de ajuste consistió en la aplicación del índice departamental de cabalidad del registro de nacimientos de 2005, estimado por el DANE (2007a), a toda la serie de nacimientos en estudio, asumiendo que este índice es el más confiable por haber sido estimado utilizando diversas fuentes y una metodología estandarizada (no explícita en el documento de referencia); para este efecto, el número de nacimientos se multiplicó por el inverso del índice de cabalidad.

Para el cálculo de las tasas, se utilizaron como denominadores las proyecciones de población estimadas por el DANE en el proceso de conciliación censal de 2005 de todos los municipios del país. Los datos de población disponibles están desagregados por edades simples hasta los 24 años y refieren al 30 de junio de cada año calendario proyectado, desde 1985 hasta 2020.

Los indicadores empleados fueron las tasas de fecundidad medidas como tasas específicas de fecundidad por edad $\left(f_{x}\right)$, para caracterizar la estructura de la fecundidad, y la edad media a la maternidad, definida como la media de edad a la que las adolescentes tienen sus hijos ponderada por la tasa de fecundidad específica de mujeres de 10 a 19 años, con la cual se mide de manera directa el calendario de la maternidad, sensible a la edad de entrada en la vida reproductiva, al intervalo entre nacimientos y al nivel de fecundidad. Estos indicadores se calcularon a partir de los datos de las estadísticas vitales a escala de departamentos, tanto por edades simples como por subgrupos etarios adolescentes (10 a 14,15 a 17 y 18 a 19 años), dado que los ajustes por subregistro solo se aplicaron hasta ese nivel. 
Las encuestas nacionales de demografía y salud del período 1995-2010 fueron la fuente utilizada para el análisis de los factores determinantes de la fecundidad adolescente, por tratarse de estudios basados en muestras poblacionales que permiten diferenciar a las adolescentes que habían sido madres o estaban embarazadas al momento de la encuesta y las que aún no eran madres. A partir de esta fuente, se ejecutaron análisis de regresión logística con el fin de determinar la relación de diversos factores con la fecundidad en adolescentes usando como variables dicotómicas dependientes "tiene hijos nacidos vivos (sí/no)", que incluye solo a las mujeres que informaron tener hijos nacidos vivos, y "fecundidad adolescente", que incluye a aquellas con hijos nacidos vivos y a las que estaban embarazadas al momento de la encuesta o que informaron haber tenido un aborto. El análisis multivariado se llevó a cabo de acuerdo con el modelo conceptual de determinantes mencionado y se centró principalmente en establecer las variables que podrían explicar las diferencias a lo largo del tiempo en los distintos cortes transversales del período 1995-2010 y en las seis regiones en que está dividido el país.

\section{B. Resultados}

\section{Evaluación de las fuentes}

El primer resultado importante es la homogeneidad y completitud del registro de nacimientos per se, al menos en variables esenciales, que lo convierten en la mejor fuente de datos para el análisis de la natalidad y la fecundidad en los ámbitos nacional y departamental, pese al subregistro diferencial existente en los niveles subnacionales. Las tasas de fecundidad obtenidas usando las estadísticas vitales como fuente primaria, con las correcciones adecuadas, muestran una notable concordancia con las tasas calculadas por medio de las ENDS, lo que corrobora la utilidad de las encuestas como referencia para evaluar la cobertura de las estadísticas vitales. En el gráfico 1 se muestra la yuxtaposición casi perfecta del índice sintético de fecundidad (ISF) estimado para todas las mujeres en edad fértil sobre la base de las ENDS y de las estadísticas vitales ajustadas. Esto no ocurre con las estimaciones de la fecundidad adolescente, que evidencian resultados discordantes entre las fuentes, incluso entre las mismas encuestas, salvo en algunos pocos puntos en el tiempo en que se yuxtaponen las estimaciones de las ENDS de 1995 y 2000.

En primer término, se observa que los niveles de fecundidad son más altos en cada encuesta, lo que sugiere - como lo han descrito varios autores (Flórez y Soto, 2006; Profamilia, 2011) - un aumento de la fecundidad adolescente, que se contrapone a una tendencia hacia el descenso de la fecundidad estimada que se observa en cada una de las encuestas. En la literatura relacionada, se ha documentado que tales discordancias pueden deberse a varios efectos, que se aplican a las ENDS aquí tratadas, como la distorsión de la estructura por edades, debida a déficits de cobertura de la encuesta o a la mala declaración por parte del jefe de hogar de la edad de la madre o de los niños, usualmente 
con desplazamiento de los nacimientos hacia atrás; por otra parte, se debe considerar el efecto del muestreo por la variabilidad aleatoria propia del proceso o por sesgos de selección que se pueden introducir en un tipo de muestreo complejo como el utilizado en las ENDS o por tamaños insuficientes.

\section{Gráfico 1}

\section{Colombia: evolución de la fecundidad, 1980-2010}

A. Comparación del índice sintético de fecundidad según encuestas nacionales de demografía y salud (ENDS) y estadísticas vitales ${ }^{a}$

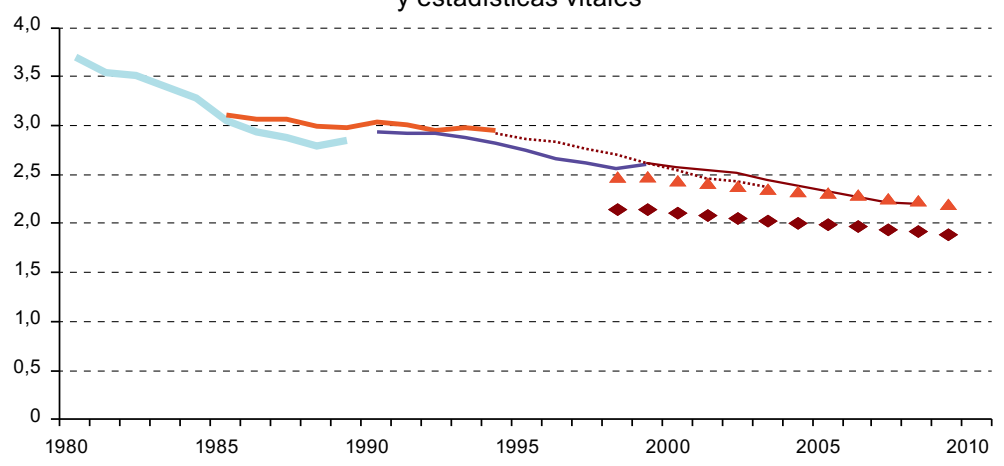

B. Tasa específica de fecundidad adolescente según encuestas nacionales de demografía y salud (ENDS) y estadísticas vitales ${ }^{\mathrm{b}}$

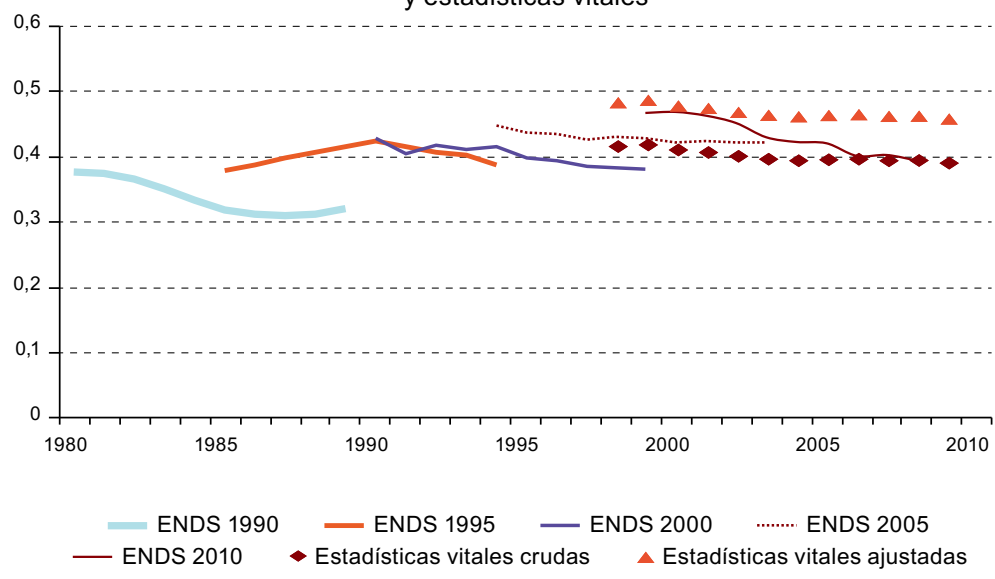

Fuente: Elaboración propia, sobre la base de las encuestas nacionales de demografía y salud (ENDS); y Departamento Administrativo Nacional de Estadística (DANE), Estadísticas vitales.

a Corresponde al grupo etario de 10 a 49 años.

b Corresponde al grupo etario de 10 a 19 años. 


\section{Indicadores a nivel nacional y regional}

Los indicadores básicos de natalidad y fecundidad se presentan por niveles nacional, regional y departamental, dando cuenta de su evolución anual en el período 1998-2009. En general, el número total de nacimientos y de madres adolescentes se mantiene constante, sin ninguna correlación cuando aumenta o disminuye uno u otro. En el cuadro 1, se observa que la tasa bruta de natalidad y la tasa general de fecundidad estimada de todas las mujeres en edad fértil y las adolescentes muestran una tendencia a un decremento paulatino y sostenido de alrededor del 10\% en promedio entre 1998 y 2009, con mayor variación del indicador entre las adolescentes. En cambio, resulta notable la mayor proporción de nacimientos de madres adolescentes respecto del total de nacimientos, creciente a lo largo del período, con un incremento de alrededor del 5\%.

Cuadro 1

Colombia: natalidad y fecundidad, 1998-2009

\begin{tabular}{lcccccc}
\hline Año & $\begin{array}{c}\text { Total de } \\
\text { nacimientos }\end{array}$ & $\begin{array}{c}\text { Nacimientos } \\
\text { de madres } \\
\text { adolescentes }\end{array}$ & $\begin{array}{c}\text { Tasa bruta } \\
\text { de natalidad }\end{array}$ & $\begin{array}{c}\text { Tasa general } \\
\text { de fecundidad }\end{array}$ & $\begin{array}{c}\text { Nacimientos de } \\
\text { madres adolescentes } \\
\text { (en porcentajes) }\end{array}$ \\
\hline 1998 & 831932 & 181248 & 21,2 & 67,2 & 94,8 & 21,8 \\
\hline 1999 & 863254 & 191074 & 21,7 & 68,7 & 98,9 & 22,1 \\
\hline 2000 & 849543 & 188925 & 21,1 & 66,6 & 96,7 & 22,2 \\
\hline 2001 & 838982 & 187018 & 20,6 & 64,9 & 94,7 & 22,3 \\
\hline 2002 & 811983 & 180246 & 19,6 & 61,9 & 90,4 & 22,2 \\
\hline 2003 & 824769 & 183735 & 19,7 & 62,1 & 91,4 & 22,3 \\
\hline 2005 & 840920 & 188748 & 19,8 & 62,5 & 93,1 & 22,4 \\
\hline 2006 & 831746 & 189116 & 19,6 & 61,6 & 92,5 & 22,5 \\
\hline 2007 & 824435 & 193221 & 18,8 & 60,4 & 92,7 & 23,0 \\
\hline 2008 & 831613 & 195840 & 18,7 & 59,3 & 92,5 & 23,4 \\
\hline
\end{tabular}

Fuente: Elaboración propia con datos ajustados, sobre la base de Departamento Administrativo Nacional de Estadística (DANE), Estadísticas vitales.

Como era de esperar, la fecundidad específica de las adolescentes difiere por subgrupos de edad, observándose una mayor fecundidad en el subgrupo de mayor edad (18 a 19 años), que contribuye con más del 60\% de los nacimientos de madres adolescentes, seguido del grupo de 15 a 17 años, que aporta un poco más del 35\% (véase el cuadro 2). La reducción de la fecundidad adolescente durante el período se debe al crecimiento negativo de la fecundidad en mujeres de 18 a 19 años, que registra una caída del $11 \%$, mientras que en las adolescentes de 15 a 17 años la tasa permanece constante y en menores de 14 años tiene una tendencia creciente de un $24 \%$. Asimismo, en la última década, el peso de la fecundidad adolescente ha crecido dos puntos porcentuales, del $18,5 \%$ al $20,5 \%$, mientras que la edad media de la maternidad adolescente al primer nacimiento se mantiene constante a nivel nacional, alrededor de los 17,9 años. 
Cuadro 2

Colombia: fecundidad por subgrupos etarios de adolescentes ${ }^{\text {a }}, 1998-2009$

\begin{tabular}{lccccc}
\hline Año & $f 10-14$ & $f 15-17$ & $f 18-19$ & $\begin{array}{c}\text { Edad media a } \\
\text { la maternidad } \\
\text { (en años) }\end{array}$ & $\begin{array}{c}f \text { 15-19/índice sintético } \\
\text { de fecundidad (ISF) } \\
\text { (en porcentajes) }\end{array}$ \\
\hline 1998 & 2,8 & 67,2 & 130,5 & 17,9 & 18,5 \\
\hline 1999 & 3,1 & 70,3 & 135,2 & 17,9 & 18,9 \\
\hline 2000 & 3,2 & 70,1 & 129,6 & 17,9 & 18,9 \\
\hline 2001 & 3,1 & 69,3 & 125,8 & 17,9 & 19,1 \\
\hline 2002 & 3,1 & 66,5 & 119,2 & 17,9 & 19,1 \\
\hline 2004 & 3,2 & 66,8 & 120,8 & 17,9 & 19,2 \\
\hline 2005 & 3,4 & 68,3 & 122,6 & 17,9 & 19,5 \\
\hline 2006 & 3,5 & 68,4 & 120,3 & 17,9 & 19,6 \\
\hline 2008 & 3,5 & 69,1 & 119,8 & 17,8 & 20,0 \\
\hline 2009 & 3,6 & 69,2 & 119,0 & 17,8 & 20,4 \\
\hline
\end{tabular}

Fuente: Elaboración propia, sobre la base de Departamento Administrativo Nacional de Estadística (DANE), Estadísticas vitales.

a Corresponde al grupo etario de 10 a 19 años.

Las tasas específicas de fecundidad adolescente por edades simples se expresan en el número de nacimientos por cada 1.000 adolescentes a nivel nacional por cada uno de los años del período observado (véase el cuadro 3), y en las regiones se consideran tres años de referencia (véase el cuadro 4).

Cuadro 3

Colombia: tasas nacionales específicas de fecundidad adolescente por edades simples, $1998-2009^{\text {a }}$

(En tasas por 1.000)

\begin{tabular}{cccccccccccc}
\hline Año & \multicolumn{10}{c}{ Edades } \\
\cline { 2 - 13 } & 10 años & 11 años & 12 años & 13 años & 14 años & 15 años & 16 años & 17 años & 18 años & 19 años 15 a 19 años \\
\hline 1998 & 0,0 & 0,1 & 0,4 & 2,4 & 11,7 & 33,5 & 65,9 & 103,4 & 127,4 & 133,6 & 91,8 \\
\hline 1999 & 0,0 & 0,1 & 0,4 & 2,6 & 12,8 & 35,3 & 70,4 & 106,5 & 127,0 & 143,4 & 95,6 \\
\hline 2000 & 0,0 & 0,1 & 0,4 & 2,6 & 13,1 & 36,8 & 69,0 & 105,7 & 122,9 & 136,4 & 93,2 \\
\hline 2001 & 0,0 & 0,0 & 0,4 & 2,7 & 12,9 & 36,5 & 71,0 & 101,4 & 119,1 & 132,6 & 91,3 \\
\hline 2002 & 0,0 & 0,1 & 0,4 & 2,7 & 12,7 & 35,1 & 65,9 & 99,6 & 111,8 & 126,7 & 87,1 \\
\hline 2003 & 0,0 & 0,0 & 0,4 & 2,8 & 13,1 & 35,4 & 67,0 & 99,1 & 117,2 & 124,5 & 87,9 \\
\hline 2004 & 0,0 & 0,1 & 0,5 & 3,0 & 13,5 & 37,4 & 68,2 & 100,3 & 115,3 & 130,0 & 89,5 \\
\hline 2005 & 0,0 & 0,1 & 0,5 & 3,0 & 14,2 & 37,6 & 69,4 & 99,2 & 113,7 & 127,1 & 88,7 \\
\hline 2006 & 0,0 & 0,1 & 0,4 & 3,2 & 14,0 & 38,2 & 70,0 & 99,9 & 114,0 & 125,6 & 88,9 \\
\hline 2007 & 0,0 & 0,1 & 0,5 & 3,2 & 14,2 & 37,4 & 71,3 & 99,7 & 114,4 & 123,6 & 88,7 \\
\hline 2008 & 0,0 & 0,1 & 0,6 & 3,4 & 14,8 & 38,7 & 69,9 & 99,4 & 113,4 & 125,8 & 88,9 \\
\hline 2009 & 0,0 & 0,1 & 0,6 & 3,5 & 14,5 & 37,8 & 68,3 & 96,2 & 109,9 & 124,1 & 86,8 \\
\hline
\end{tabular}

Fuente: Elaboración propia, sobre la base de Departamento Administrativo Nacional de Estadística (DANE), Estadísticas vitales.

a Corresponde al grupo etario de 10 a 19 años. 
Cuadro 4

Colombia: tasas específicas de fecundidad adolescente por edades simples a nivel regional a 1998,2005 y 2009

(En tasas por 1.000)

\section{Edades}

Año 10 años 11 años 12 años 13 años 14 años 15 años 16 años 17 años 18 años 19 años 15 a 19 años Región Orinoquia/Amazonia

\begin{tabular}{llllllllllll}
\hline 1998 & 0,0 & 0,0 & 1,0 & 5,3 & 21,7 & 51,7 & 92,0 & 133,0 & 158,4 & 146,8 & 114,8 \\
\hline 2005 & 0,1 & 0,1 & 1,0 & 6,4 & 25,6 & 58,3 & 93,1 & 127,0 & 135,8 & 156,0 & 112,2 \\
\hline 2009 & 0,0 & 0,1 & 1,1 & 6,7 & 23,6 & 52,8 & 85,5 & 113,0 & 120,0 & 135,5 & 100,4
\end{tabular}

Región Atlántica

\begin{tabular}{rrrrrrrrrrrr}
\hline 1998 & 0,0 & 0,1 & 0,4 & 2,1 & 10,6 & 32,8 & 61,4 & 96,1 & 124,6 & 129,5 & 87,7 \\
\hline 2005 & 0,0 & 0,0 & 0,4 & 3,0 & 16,2 & 42,8 & 78,0 & 113,7 & 127,5 & 147,4 & 100,8 \\
\hline 2009 & 0,1 & 0,2 & 0,7 & 4,6 & 17,5 & 45,1 & 78,7 & 114,0 & 133,8 & 152,8 & 104,0
\end{tabular}

Región Pacífica

\begin{tabular}{rllllllllllll}
\hline 1998 & 0,0 & 0,0 & 0,4 & 2,0 & 11,8 & 31,0 & 63,6 & 100,1 & 121,5 & 127,2 & 87,6 & \\
\hline 2005 & 0,0 & 0,1 & 0,5 & 3,8 & 15,9 & 40,9 & 74,1 & 102,0 & 115,2 & 123,2 & 90,4 & \\
\hline 2009 & 0,0 & 0,1 & 0,8 & 3,6 & 14,9 & 38,6 & 69,5 & 91,7 & 105,3 & 113,4 & 83,3 & \\
\hline
\end{tabular}

Región Oriental

\begin{tabular}{rrrrrrrrrrrrr}
\hline 1998 & 0,0 & 0,1 & 0,4 & 2,1 & 10,2 & 29,1 & 59,7 & 99,7 & 123,7 & 130,3 & 87,2 & \\
\hline 2005 & 0,0 & 0,1 & 0,4 & 2,1 & 10,3 & 29,2 & 54,9 & 85,6 & 106,5 & 121,6 & 78,5 & \\
\hline 2009 & 0,0 & 0,1 & 0,3 & 2,2 & 10,8 & 30,3 & 58,5 & 87,0 & 98,5 & 118,3 & 77,9 &
\end{tabular}

\begin{tabular}{rlllllllllll}
\hline \multicolumn{10}{c}{ Región Central } \\
\hline 1998 & 0,0 & 0,1 & 0,4 & 3,0 & 14,7 & 41,5 & 81,2 & 123,4 & 149,7 & 150,7 & 108,1 \\
\hline 2005 & 0,0 & 0,1 & 0,6 & 3,8 & 15,7 & 40,8 & 75,4 & 101,2 & 114,2 & 126,7 & 90,9 \\
\hline 2009 & 0,0 & 0,1 & 0,5 & 3,8 & 16,1 & 40,1 & 70,1 & 95,1 & 107,9 & 113,8 & 85,2 \\
\hline
\end{tabular}

Región de Bogotá

\begin{tabular}{rlllllllllll}
\hline 1998 & 0,0 & 0,0 & 0,4 & 1,8 & 7,9 & 26,2 & 54,0 & 87,2 & 104,8 & 122,9 & 79,0 \\
\hline 2005 & 0,0 & 0,0 & 0,2 & 1,1 & 7,9 & 24,5 & 51,1 & 79,4 & 93,5 & 103,2 & 70,6 \\
\hline 2009 & 0,0 & 0,1 & 0,2 & 1,8 & 8,8 & 26,8 & 54,9 & 83,3 & 94,0 & 114,9 & 74,7 \\
\hline
\end{tabular}

Fuente: Elaboración propia, sobre la base de Departamento Administrativo Nacional de Estadística (DANE), Estadísticas vitales.

a Corresponde al grupo etario de 10 a 19 años.

Durante el período observado, las tasas específicas de fecundidad de adolescentes de 15 a 19 años muestran un descenso del 5,7\% en el conjunto nacional, al que contribuyen todas las regiones con excepción de la Atlántica, la que muestra un incremento del 15,6\%. Los descensos son más notables en la región centro-oriental del país, debido a la reducción de la fecundidad de las mujeres de 18 a 19 años, que oscila entre un $14 \%$ en la región Pacífica, un $17 \%$ en la Oriental, un $20 \%$ en Amazonia-Orinoquia y un $36 \%$ en la región Central, si bien en esta última también se destaca la reducción del 20\% de la fecundidad en el grupo de 15 a 17 años. En síntesis, el descenso de la fecundidad adolescente a nivel nacional se debe a la disminución de un 11,6\% de la fecundidad de adolescentes de 18 a 19 años. 
Al contrario de lo observado en adolescentes mayores, llama la atención el constante aumento de la fecundidad en niñas menores de 14 años en todas las regiones, que alcanza el $24 \%$ en el país, registrándose los crecimientos máximos en las regiones Atlántica (44\%) y Pacífica (28\%) y el mínimo en las regiones Oriental (8\%) y Bogotá (4\%). En la franja de edad de 15 a 17 años, las regiones Atlántica y Pacífica muestran incrementos de fecundidad adolescente del $20 \%$ y el $3 \%$, respectivamente. Estas dos regiones corresponden a las zonas costeras, donde se concentra aproximadamente el 70\% de la población afrocolombiana y una alta proporción de población indígena33; además, con excepción del Valle del Cauca, en estas regiones se encuentran los departamentos con los indicadores socioeconómicos más bajos. La situación de fecundidad por edades simples a nivel regional se resume en el gráfico 2, donde se resalta la diferencia de comportamiento de las regiones costeras, especialmente la Atlántica, donde todos los grupos por edades simples presentan un crecimiento positivo constante de las tasas específicas de fecundidad, seguida por la región Pacífica, donde se observan incrementos en la fecundidad de las niñas menores de 17 años.

Gráfico 2

Colombia: variación de las tasas específicas de fecundidad $(f x)$ en adolescentes por edades simples y regiones, 1998-2009

(En porcentajes)

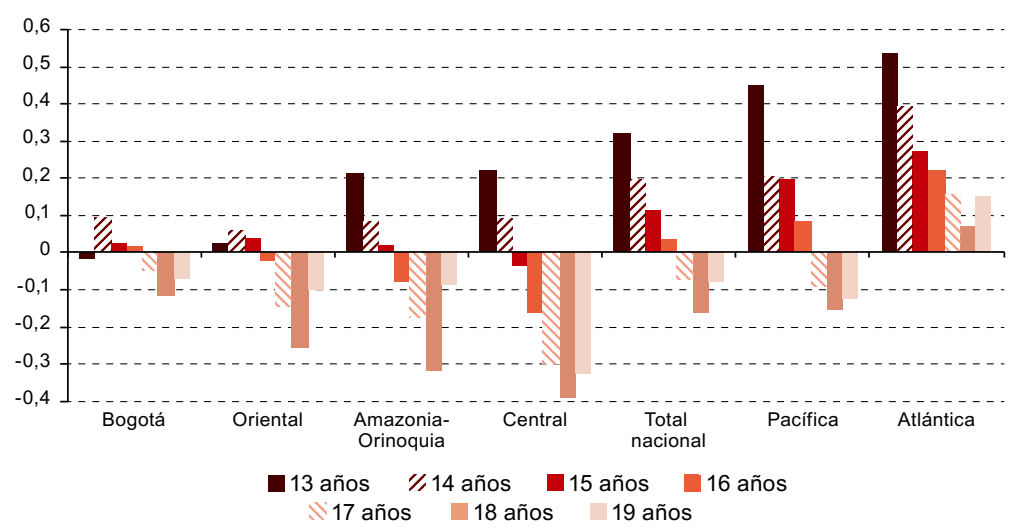

Fuente: Elaboración propia.

En resumen, el crecimiento de la fecundidad adolescente a nivel nacional y en la mayoría de las regiones se observa en los grupos menores de 17 años, con excepción de la región Central, en la que solo se registra aumento en las menores de 15 años.

3 Los departamentos de La Guajira y Córdoba (región Atlántica), Cauca y Nariño (región Pacífica) concentran el 59,8\% del total de la población indígena nacional (DANE, 2007b). 


\section{Indicadores a nivel departamental}

Las tasas departamentales de fecundidad específicas por edades simples y agrupadas muestran diferencias notables que dan cuenta de la variabilidad presente dentro de la misma región a la que pertenecen, lo que indica la heterogeneidad de estas divisiones regionales. En el cuadro 5 se comparan las tasas departamentales de fecundidad adolescente por grupos de edad de los años 1998 y 2009, ordenadas de mayor a menor y por regiones, según la tasa específica de fecundidad de las adolescentes de 15 a 19 años en 2009, resaltándose en negrita las que están por encima de la tasa nacional. Los departamentos de las regiones costeras son los que más se apartan de la tendencia descrita para el nivel nacional, siendo Magdalena, Bolívar, Sucre y Cesar, en la región Atlántica, y Nariño y Chocó, en la región Pacífica, los departamentos donde la fecundidad adolescente se incrementa en todos los subgrupos de edad. Asimismo, se observa que, a pesar del aparente rejuvenecimiento de la fecundidad adolescente, en ninguna de las regiones se evidencian cambios sustanciales de la edad media a la maternidad, que se mantiene alrededor de los 17,9 años, registrándose el promedio menor en la AmazoniaOrinoquia (17,7 años) y el mayor en Bogotá (18,0 años).

\section{Los determinantes próximos y los factores de contexto}

En el análisis de los determinantes próximos de la fecundidad adolescente se tuvo en cuenta solamente a la población expuesta al riesgo de tener hijos, es decir, a adolescentes de 15 a 19 años que ya habían iniciado su vida sexual, incluidas las niñas de 13 y 14 años encuestadas en 2005 y 2010. Los determinantes próximos se definieron como variables dicotómicas, de la siguiente manera:

i) la variable continua "edad al inicio de las relaciones sexuales" fue transformada en variable dicotómica clasificatoria de las adolescentes que han tenido relaciones sexuales antes de los 15 años, aplicando el criterio de que esa es la edad media a la primera relación en todo el conjunto, e incorporando a las que no han iniciado su vida sexual antes de los 15 años como grupo de referencia;

ii) la variable "número de hijos que tenía cuando usó anticonceptivos por primera vez" se recodificó como antecedente de uso (grupo de referencia) y no uso de anticoncepción antes del primer embarazo, $\mathrm{y}$

iii) la variable "intervalo entre la primera unión y el primer nacimiento (en meses)" se recodificó en la variable "estado conyugal: unida o no unida antes del primer embarazo", incluyendo como no unidas (grupo de referencia) a las adolescentes con intervalo negativo más las que tienen menos de nueve meses de intervalo y las nunca unidas, dejando en el grupo de exposición a aquellas con un intervalo superior a los nueve meses entre la primera unión y el primer nacimiento. 


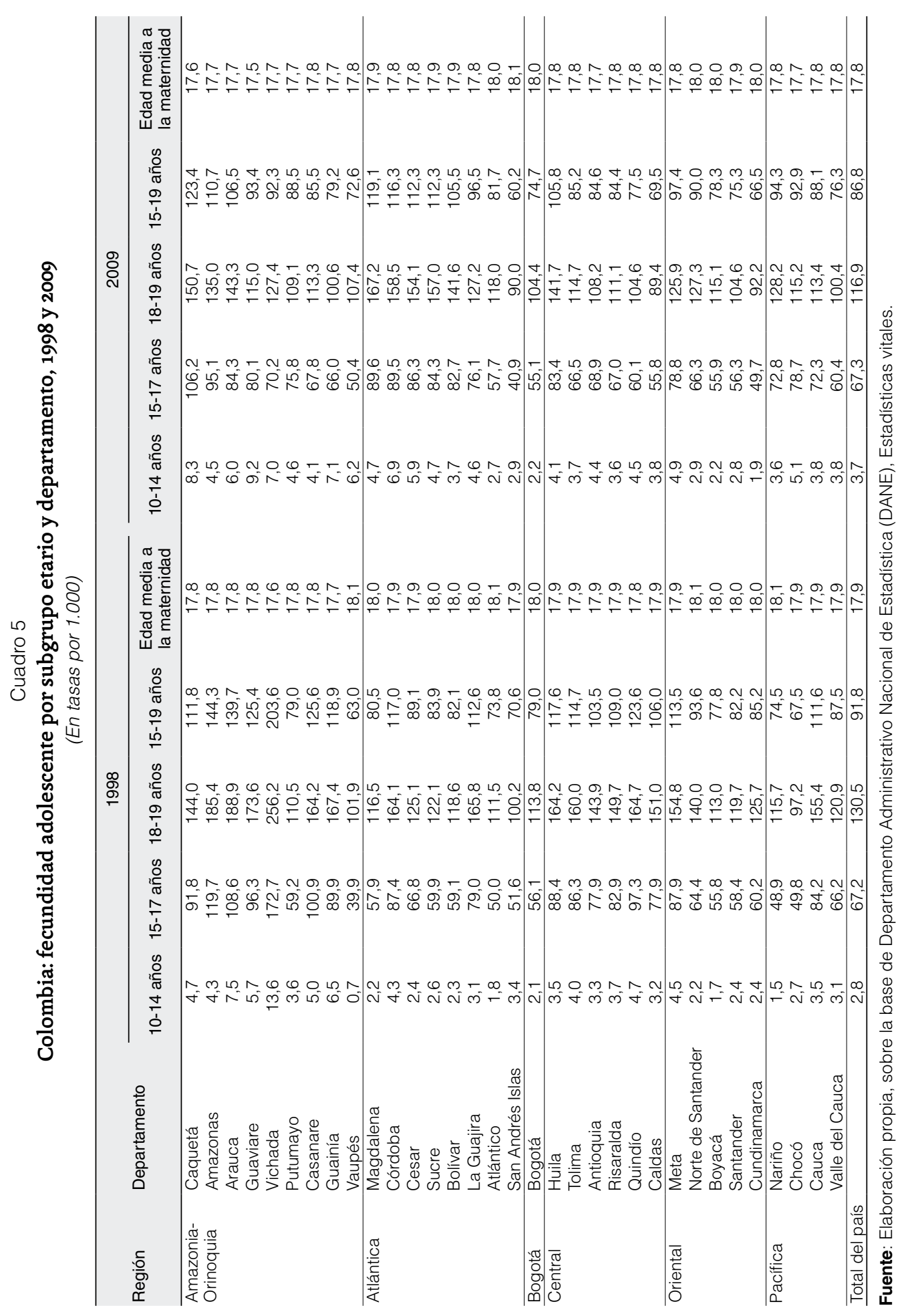


En el cuadro 6 se resumen todas las variables independientes empleadas en este análisis, cuya variable dependiente dicotómica es tener o no hijos en la edad de la adolescencia, destacándose la importante fuerza asociativa de casi todas las variables consideradas, con excepción de la región de residencia y el conocimiento sobre el período de riesgo de embarazo durante el ciclo ovulatorio.

Cuadro 6

Colombia: determinantes de la fecundidad adolescente, 1995-2010

\begin{tabular}{|c|c|c|c|c|c|}
\hline \multirow[t]{2}{*}{ Variables categóricas } & \multirow[t]{2}{*}{ Categoría de referencia } & \multirow[t]{2}{*}{ Significación } & \multirow{2}{*}{$\begin{array}{l}\text { Razón de } \\
\text { probabilidades } \\
(\operatorname{Exp}(\mathrm{B}))\end{array}$} & \multicolumn{2}{|c|}{$\begin{array}{l}\text { Intervalo de confianza } \\
\text { del } 95 \% \text { para la razón } \\
\text { de probabilidades }\end{array}$} \\
\hline & & & & $\begin{array}{l}\text { Límite } \\
\text { inferior }\end{array}$ & $\begin{array}{l}\text { Límite } \\
\text { superior }\end{array}$ \\
\hline \multicolumn{6}{|c|}{ Determinantes próximos } \\
\hline $\begin{array}{l}\text { Relaciones sexuales antes de los } \\
15 \text { años: sí }\end{array}$ & No antes de los 15 años & 0,000 & 2,280 & 2,083 & 2,495 \\
\hline Unión previa al embarazo: sí & $\begin{array}{l}\text { No unida antes del primer } \\
\text { embarazo }\end{array}$ & 0,000 & 2,337 & 2,126 & 2,569 \\
\hline $\begin{array}{l}\text { Uso de anticonceptivos antes del } \\
\text { primer embarazo: no }\end{array}$ & $\begin{array}{l}\text { Sí, usaba anticonceptivos } \\
\text { antes }\end{array}$ & 0,000 & 5,854 & 5,288 & 6,481 \\
\hline \multicolumn{6}{|c|}{ Determinantes del contexto individual } \\
\hline Grupo de edad (1): 16 a 17 años & 13 a 15 años & 0,000 & 2,368 & 1,966 & 2,852 \\
\hline Grupo de edad (2): 18 a 19 años & 13 a 15 años & 0,000 & 4,927 & 4,128 & 5,882 \\
\hline Educación (1): básica primaria & Básica secundaria & 0,011 & 0,887 & 0,808 & 0,973 \\
\hline $\begin{array}{l}\text { Educación (2): primaria incompleta/ } \\
\text { sin educación }\end{array}$ & Básica secundaria & 0,000 & 2,511 & 2,208 & 2,854 \\
\hline Conoce el ciclo ovulatorio: no & Sí, conoce el ciclo ovulatorio & 0,230 & 1,053 & 0,968 & 1,144 \\
\hline \multicolumn{6}{|c|}{ Determinantes del contexto familiar } \\
\hline Edad de los padres: 25 a 39 años & 40 años y más & 0,000 & 1,558 & 1,430 & 1,698 \\
\hline Tipo de familia (1): extensa & Nuclear & 0,000 & 2,492 & 2,178 & 2,851 \\
\hline Tipo de familia (2): otro tipo & Nuclear & 0,038 & 0,814 & 0,621 & 1,067 \\
\hline Riqueza (1): más pobre & Más rico & 0,000 & 4,254 & 3,562 & 5,081 \\
\hline Riqueza (2): pobre & Más rico & 0,000 & 3,635 & 3,049 & 4,333 \\
\hline Riqueza (3): medio & Más rico & 0,000 & 2,233 & 1,865 & 2,673 \\
\hline Riqueza (4): rico & Más rico & 0,000 & 1,446 & 1,196 & 1,747 \\
\hline \multicolumn{6}{|c|}{ Determinantes del contexto sociocultural y ambiental } \\
\hline Región (1): Atlántica & Bogotá & 0,402 & 1,054 & 0,932 & 1,191 \\
\hline Región (2): Oriental & Bogotá & 0,763 & 0,980 & 0,861 & 1,116 \\
\hline Región (3): Central & Bogotá & 0,116 & 1,100 & 0,977 & 1,238 \\
\hline Región (4): Pacífica & Bogotá & 0,056 & 1,134 & 0,997 & 1,289 \\
\hline Región (5): Amazonia-Orinoquia & Bogotá & 0,005 & 1,476 & 1,126 & 1,935 \\
\hline Área rural & Área urbana & 0,000 & 1,878 & 1,707 & 2,067 \\
\hline Región/área (1): rural & Área urbana & 0,000 & 1,635 & 1,505 & 1,776 \\
\hline Región/área (2): Bogotá & Área urbana & 0,132 & 1,086 & 0,976 & 1,209 \\
\hline Etnia (1): indígena/rom/raizal & Otro & 0,008 & 1,392 & 1,091 & 1,776 \\
\hline $\begin{array}{l}\text { Etnia (2): afrodescendiente/ } \\
\text { palenquero }\end{array}$ & Otro & 0,000 & 1,380 & 1,176 & 1,619 \\
\hline
\end{tabular}

Fuente: Elaboración propia.

Los determinantes próximos considerados (edad de inicio de relaciones sexuales, estado conyugal y uso de anticonceptivos antes de tener hijos o haber quedado embarazada) muestran un fuerte efecto sobre la probabilidad de ser madre adolescente o haber estado 
alguna vez embarazada antes de los 20 años de edad; especialmente el uso de anticonceptivos antes de tener el primer embarazo tiene un efecto negativo sobre la probabilidad de ser madre adolescente. Le siguen con un alto nivel de asociación los determinantes de contexto representados por la educación de la madre, el tipo de hogar y el nivel de riqueza del hogar. El resto de las variables muestran un nivel moderado de asociación con el resultado; no obstante, todas fueron consideradas en los diferentes modelos de análisis de regresión logística que se describen a continuación.

En primer término, el modelo que considera solo los determinantes próximos evidencia una fuerza de asociación constante ya vista en el análisis univariado, donde se resalta nuevamente que el mayor efecto sobre la probabilidad de ser madre adolescente lo ejerce el antecedente de uso de anticonceptivos antes de un primer embarazo (véase el cuadro 7).

Cuadro 7

Colombia: modelo de determinantes próximos de fecundidad, 1995-2010

\begin{tabular}{|c|c|c|c|c|c|}
\hline \multirow{2}{*}{ Variable } & \multirow{2}{*}{ Coeficiente B } & \multirow{2}{*}{ Significación } & \multirow{2}{*}{$\begin{array}{l}\text { Razón de } \\
\text { probabilidades }\end{array}$} & \multicolumn{2}{|c|}{$\begin{array}{l}\text { Intervalo de confianza del } 95 \% \\
\text { para la razón de probabilidades }\end{array}$} \\
\hline & & & & Límite inferior & Límite superior \\
\hline $\begin{array}{l}\text { Relaciones sexuales } \\
\text { antes de los } 15 \text { años: sí }\end{array}$ & 0,571 & 0,000 & 1,769 & 1,603 & 1,953 \\
\hline $\begin{array}{l}\text { Unión previa al } \\
\text { embarazo: sí }\end{array}$ & 1,535 & 0,000 & 4,640 & 4,161 & 5,173 \\
\hline $\begin{array}{l}\text { Uso de anticonceptivos } \\
\text { antes del primer } \\
\text { embarazo: no }\end{array}$ & 1,626 & 0,000 & 5,082 & 4,535 & 5,695 \\
\hline Constante & $-1,079$ & 0,000 & 0,340 & & \\
\hline \multicolumn{6}{|c|}{$\begin{array}{l}\text { n: } 10.110 \\
\text { Casos pronosticados: } 72,3 \% \\
\text { R² de Nagelkerke: } 0,273\end{array}$} \\
\hline
\end{tabular}

Fuente: Elaboración propia.

Se observa el efecto negativo de iniciar relaciones sexuales a temprana edad, con un riesgo de embarazo casi dos veces mayor entre quienes han iniciado su vida sexual antes de los 15 años con respecto a las que la han iniciado después, lo que resulta lógico por el aumento del período de exposición. El estado conyugal de unión legal o consensual antes de tener un primer embarazo o hijos también tiene un efecto positivo en la probabilidad de ser madre adolescente, que cuadriplica el riesgo con relación a aquellas que no han entrado en unión, lo que tiene un significado notable teniendo en cuenta que en el cómputo de la variable no se incluye a las adolescentes que se unieron después de estar embarazadas y ratifica la significativa diferencia proporcional de adolescentes unidas que no han tenido hijos (12\%) frente a las unidas con hijos (42\%). El no uso de anticonceptivos antes de tener un primer embarazo o hijos tiene un efecto positivo cinco veces mayor que su uso, lo que confirma el efecto protector de la anticoncepción, ya evidente al comparar la proporción de adolescentes usuarias de anticonceptivos que no tienen hijos (63\%) con las no usuarias 
con hijos nacidos vivos o embarazos (77\%). Es importante señalar que cuando se usan las variables "alguna vez unida/nunca unida" y "usa/no usa anticonceptivos", sin tener en cuenta el tiempo de exposición de la población al riesgo - es decir, el inicio de la actividad sexual-, los resultados son discordantes o contrarios a lo esperado.

El conjunto de estas tres variables explican el $27 \%$ de la probabilidad de ser madre adolescente, porcentaje que aumenta al 35\% con la inclusión de la variable de la edad, indicando el importante efecto de esta sobre la variable de resultado y los determinantes próximos. En el cuadro 8 se contrastan los efectos cuando se usa la edad como variable continua y en forma categórica, así como el efecto sinérgico que ejerce sobre la variable del inicio de la actividad sexual antes de los 15 años.

Cuadro 8

Colombia: modelo de determinantes próximos de fecundidad que incluyen la edad de la madre, 1995-2010

\begin{tabular}{|c|c|c|c|c|c|}
\hline \multirow{3}{*}{ Variable } & \multirow{2}{*}{ Coeficiente B } & \multirow{2}{*}{ Significación } & \multirow{2}{*}{$\begin{array}{l}\text { Razón de } \\
\text { probabilidades }\end{array}$} & \multicolumn{2}{|c|}{$\begin{array}{l}\text { Intervalo de confianza del } 95 \% \\
\text { para la razón de probabilidades }\end{array}$} \\
\hline & & & & Límite inferior & Límite superior \\
\hline & \multicolumn{5}{|c|}{ Modelo de determinantes próximos con la edad como variable continua } \\
\hline $\begin{array}{l}\text { Relaciones sexuales antes de } \\
\text { los } 15 \text { años: sí }\end{array}$ & 1,296 & 0,000 & 3,655 & 3,235 & 4,129 \\
\hline Unión previa al embarazo: sí & 1,516 & 0,000 & 4,553 & 4,065 & 5,099 \\
\hline $\begin{array}{l}\text { Uso de anticonceptivos antes } \\
\text { del primer embarazo: no }\end{array}$ & 1,668 & 0,000 & 5,299 & 4,704 & 5,970 \\
\hline Edad & 0,480 & 0,000 & 1,616 & 1,555 & 1,680 \\
\hline Constante & $-9,667$ & 0,000 & 0,000 & & \\
\hline
\end{tabular}

n: 10.110

Casos pronosticados: $73,9 \%$

$\mathrm{R}^{2}$ de Nagelkerke: 0,345

Modelo de determinantes próximos con la edad como variable categórica

\begin{tabular}{|c|c|c|c|c|c|}
\hline $\begin{array}{l}\text { Relaciones sexuales antes de } \\
\text { los } 15 \text { años: sí }\end{array}$ & 1,273 & 0,000 & 3,570 & 3,159 & 4,035 \\
\hline Unión previa al embarazo: sí & 1,524 & 0,000 & 4,589 & 4,099 & 5,137 \\
\hline $\begin{array}{l}\text { Uso de anticonceptivos antes } \\
\text { del primer embarazo: no }\end{array}$ & 1,679 & 0,000 & 5,363 & 4,761 & 6,040 \\
\hline $\begin{array}{l}\text { Grupo de edad: } 16 \text { a } 17 \text { años } \\
\text { (ref: } 13 \text { a } 15 \text { años) }\end{array}$ & 1,252 & 0,000 & 3,496 & 2,924 & 4,180 \\
\hline $\begin{array}{l}\text { Grupo de edad: } 18 \text { a } 19 \text { años } \\
\text { (ref.: } 13 \text { a } 15 \text { años) }\end{array}$ & 2,049 & 0,000 & 7,759 & 6,462 & 9,316 \\
\hline
\end{tabular}

$\mathrm{n}: 10.110$

Casos pronosticados: $73,0 \%$

$\mathrm{R}^{2}$ de Nagelkerke: 0,340

Fuente: Elaboración propia. 
El efecto de la edad sobre la probabilidad de ser madre muestra que el riesgo casi se triplica cuando las adolescentes pasan del grupo de edad de 13 a 15 años a los grupos de 16 a 17 y de 18 a 19 años, lo que corrobora su condición de variable determinante de la variación de la fecundidad.

Las probabilidades de tener o no hijos durante la adolescencia, considerando el efecto positivo y negativo de la exposición a estos tres determinantes próximos, se representan en el gráfico 3, donde puede observarse su variación con el incremento de la edad. Las líneas continuas representan las probabilidades estimadas con la ecuación logística (1) cuando todos los factores de exposición están presentes $(\mathrm{Y}=1)$ o ausentes $(\mathrm{Y}=0)$, en contraste con las respectivas proporciones observadas en la muestra estudiada, representadas por puntos, que, no obstante su dispersión en las adolescentes de 15 años y menos, sugiere una elevada verosimilitud del modelo.

\footnotetext{
e $\left(-9,667+1,296^{*}\right.$ Relaciones sexuales antes de los 15 años +

1,516 *Unión previa al primer embarazo+1,688*

$\mathrm{P}(\mathrm{Y}=1)=\frac{\text { No uso de anticonceptivos }+0,480 * \text { Edad })}{1+\mathrm{e}(-9,667+1,296 * \text { Relaciones sexuales antes de los } 15 \text { años }+}$

1,516 *Unión previa al primerembarazo+1,688*

No uso de anticonceptivos+o,480*Edad)
}

\section{Gráfico 3}

\section{Colombia: probabilidades de maternidad adolescente} según determinantes próximos, 1995-2010

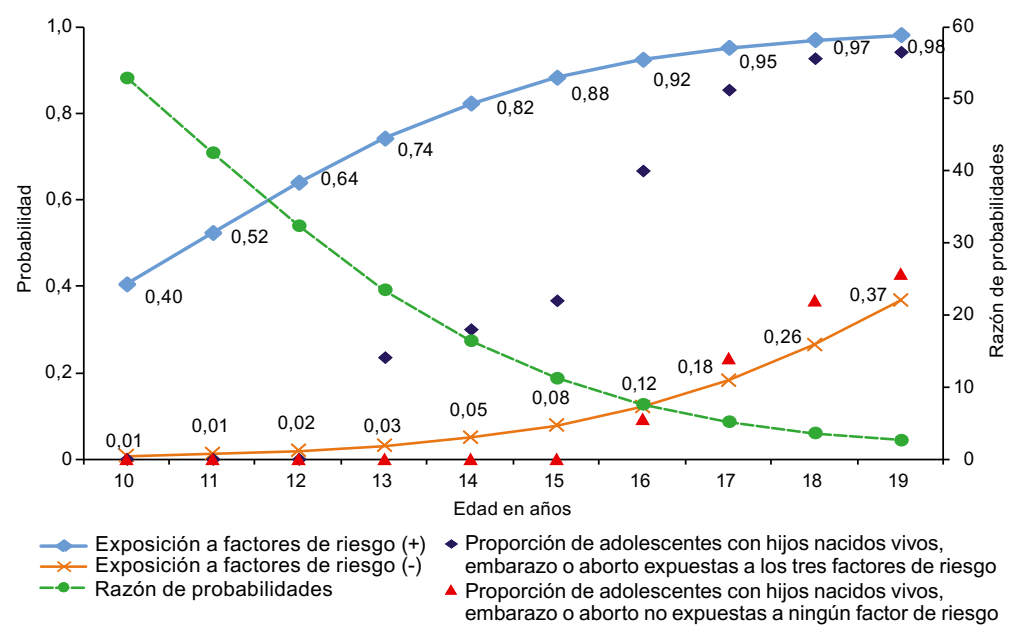

Fuente: Elaboración propia.

En tanto, la línea discontinua representa la razón de probabilidades entre las adolescentes expuestas o no a los determinantes próximos, indicando el alto impacto del cambio de estas variables a menor edad; mientras que una niña de 10 años expuesta a 
estos factores tiene un riesgo 53 veces mayor de tener un embarazo adolescente que una no expuesta, entre adolescentes de 19 años expuestas, el riesgo es apenas dos veces y media más alto que cuando no están expuestas.

El modelo que incluye todas las variables contextuales, sin determinantes próximos, muestra que el nivel educativo es el factor que ejerce de manera más consistente un efecto negativo mucho más marcado sobre la probabilidad de ser madre cuando la adolescente supera el nivel más bajo de educación (primaria incompleta o sin educación) y alcanza la básica primaria (primaria completa y parte de la secundaria) y la básica secundaria (secundaria completa y superior), donde se supone que recibió educación sobre su salud reproductiva y tuvo mayor acceso a información sexual idónea. El conocimiento sobre el ciclo ovulatorio y los métodos anticonceptivos, tan extendido entre las jóvenes, no ejerce el efecto negativo esperado, indicando que la calidad de la información o su influencia en la toma de decisiones sobre el comportamiento sexual no son las más adecuadas, como lo corroboran los hallazgos de las ENDS.

En cuanto al entorno familiar, la variable "edad de los padres", sin distinguir si se trata del padre, la madre o ambos, sugiere una asociación significativa entre la edad temprana y la probabilidad de que sus hijas sean madres adolescentes, con un efecto moderado que se mantiene en todos los modelos examinados. El nivel socioeconómico de los hogares, medido por el índice de riqueza (variable disponible en las dos encuestas más recientes), muestra los efectos negativos muy significativos que tiene cada nivel sobre la probabilidad de ser madre adolescente, con un riesgo entre las adolescentes pobres que duplica con creces el riesgo que corren aquellas que viven en hogares de nivel socioeconómico medio y alto. Dos variables con significancia relevante no se consideraron en la modelación final por estar disponibles solo para 2010: el tipo de familia, que mostró un efecto negativo significativo si la adolescente no cuenta con una familia nuclear bien estructurada, y la etnia, que mostró diferencias de riesgo entre indígenas y afrocolombianas comparadas con adolescentes de otro tipo étnico. No obstante la relevancia de la mayoría de los determinantes socioeconómicos y culturales examinados, los modelos con distintas combinaciones de dichas variables dan cuenta de modificaciones del efecto que sugieren la influencia cambiante de una variable modulada por las otras, lo que hace difícil determinar su contribución como covariable explicativa. Más aún, dado que la mayoría de las variables socioeconómicas y contextuales se refieren al momento de la encuesta y no a momentos anteriores al embarazo, no se puede establecer su condición precedente y, por tanto, no resulta clara su influencia en la relación causa-efecto.

En la localización geográfica de la madre adolescente, se combinó la región con el área para evitar distorsiones del efecto de residencia por tratar estas variables de forma separada. Las diferencias del efecto mostraron la incidencia que tiene la residencia rural en una mayor probabilidad de ser madre adolescente. El modelo final de las variables de contexto, que se presentan en el cuadro 9, incluyó la variable combinada "región/área", distinguiendo entre la zona urbana de cada región como categoría de referencia para contrastar con su zona rural respectiva, y Bogotá como región netamente urbana. 
Cuadro 9

Colombia: modelos logísticos de factores contextuales de la fecundidad, 1995-2010

\begin{tabular}{|c|c|c|c|c|c|}
\hline \multirow{3}{*}{ Variable } & \multirow{2}{*}{ Coeficiente B } & \multirow{2}{*}{ Significación } & \multirow{2}{*}{$\begin{array}{l}\text { Razón de } \\
\text { probabilidades }\end{array}$} & \multicolumn{2}{|c|}{$\begin{array}{l}\text { Intervalo de confianza del } 95 \% \\
\text { para la razón de probabilidades }\end{array}$} \\
\hline & & & & Límite inferior & Límite superior \\
\hline & \multicolumn{5}{|c|}{ Modelo de determinantes de contexto sin determinantes próximos } \\
\hline $\begin{array}{l}\text { Educación (1): básica primaria } \\
\text { (ref.: básica secundaria) }\end{array}$ & 0,604 & 0,000 & 1,830 & 1,651 & 2,029 \\
\hline $\begin{array}{l}\text { Educación (2): primaria } \\
\text { incompleta/sin educación } \\
\text { (ref.: básica secundaria) }\end{array}$ & 1,423 & 0,000 & 4,148 & 3,433 & 5,013 \\
\hline $\begin{array}{l}\text { Conoce ciclo ovulatorio (1): } \\
\text { no (ref.: sí, conoce) }\end{array}$ & 0,107 & 0,036 & 1,113 & 1,007 & 1,231 \\
\hline $\begin{array}{l}\text { Edad de los padres (1): } 25 \text { a } \\
39 \text { años (ref.: } 40 \text { años y más) }\end{array}$ & 0,276 & 0,000 & 1,317 & 1,195 & 1,452 \\
\hline $\begin{array}{l}\text { Región/área (1): rural } \\
\text { (ref.: urbana) }\end{array}$ & 0,459 & 0,000 & 1,583 & 1,417 & 1,768 \\
\hline \multirow[t]{2}{*}{$\begin{array}{l}\text { Región/área (2): Bogotá } \\
\text { (ref.: urbana) }\end{array}$} & 0,125 & 0,053 & 1,134 & 0,998 & 1,288 \\
\hline & \multicolumn{5}{|c|}{ Modelo de determinantes próximos con índice de riqueza } \\
\hline $\begin{array}{l}\text { Educación (1): básica primaria } \\
\text { (ref.: básica secundaria) }\end{array}$ & 0,418 & 0,000 & 1,519 & 1,354 & 1,703 \\
\hline $\begin{array}{l}\text { Educación (2): primaria } \\
\text { incompleta/sin educación } \\
\text { (ref.: básica secundaria) }\end{array}$ & 1,193 & 0,000 & 3,296 & 2,620 & 4,146 \\
\hline $\begin{array}{l}\text { Conoce el ciclo ovulatorio (1): } \\
\text { no (ref.: sí, conoce) }\end{array}$ & 0,001 & 0,989 & 1,001 & 0,894 & 1,121 \\
\hline $\begin{array}{l}\text { Edad de los padres (1): } 25 \text { a } \\
39 \text { años (ref.: } 40 \text { años y más) }\end{array}$ & 0,207 & 0,000 & 1,230 & 1,103 & 1,371 \\
\hline $\begin{array}{l}\text { Región/área (1): rural } \\
\text { (ref.: urbana) }\end{array}$ & $-0,100$ & 0,231 & 0,905 & 0,769 & 1,065 \\
\hline $\begin{array}{l}\text { Región/área (2): Bogotá } \\
\text { (ref.: urbana) }\end{array}$ & 0,467 & 0,000 & 1,595 & 1,379 & 1,846 \\
\hline $\begin{array}{l}\text { Índice de riqueza (1): más } \\
\text { pobre (ref.: más rico) }\end{array}$ & 1,318 & 0,000 & 3,734 & 2,970 & 4,695 \\
\hline $\begin{array}{l}\text { Índice de riqueza (2): pobre } \\
\text { (ref.: más rico) }\end{array}$ & 1,082 & 0,000 & 2,949 & 2,442 & 3,562 \\
\hline $\begin{array}{l}\text { Índice de riqueza (3): medio } \\
\text { (ref.: más rico) }\end{array}$ & 0,635 & 0,000 & 1,886 & 1,585 & 2,244 \\
\hline $\begin{array}{l}\text { Índice de riqueza (4): rico } \\
\text { (ref.: más rico) }\end{array}$ & 0,291 & 0,001 & 1,338 & 1,124 & 1,591 \\
\hline $\begin{array}{l}\text { n: } 7.385 \\
\text { Casos pronosticados: } 63,6 \% \\
\text { R}^{2} \text { de Nagelkerke: 0,109 }\end{array}$ & & & & & \\
\hline
\end{tabular}

Fuente: Elaboración propia. 
Con todos los determinantes próximos y las variables de contexto significativas con valores de $\mathrm{p}$ inferiores a 0,05 , se describen dos modelos más sintéticos que resumen la influencia que estas variables explicativas ejercen sobre la probabilidad de ser madre adolescente, uno sin el índice de riqueza y otro que lo incluye (véase el cuadro 10).

Llama la atención que ambos modelos explican el 36\% y el 37\%, respectivamente, de la probabilidad de ser madre adolescente, cifra no muy alejada de la obtenida con el modelo básico elaborado solo con los determinantes próximos y la edad (35\%). En cualquiera de los modelos finales, se observa que los principales factores que afectan la probabilidad de ser madre adolescente son el uso de anticonceptivos y la mayor exposición al riesgo de embarazo con el inicio temprano de la actividad sexual y la vida en pareja. En ninguno de los modelos finales, la inclusión de las variables "edad de los padres" y "área" agregan valor, evidenciando la dilución de su efecto; igualmente, la variable "índice de riqueza", pese al gradiente de riesgo significativo que muestra, no mejora la capacidad del modelo para explicar las relaciones. Lo anterior sugiere que, en términos predictivos, aunque todas las variables ayudan a la caracterización del fenómeno, son los determinantes próximos los factores que más inciden en la variación del riesgo de la fecundidad en adolescentes, brindando un modelo simple, efectivo y no saturado que integra la compleja trama con que contribuyen los distintos determinantes socioeconómicos contextuales de manera indirecta a través de los determinantes próximos. Sin apartarse de la importancia que tienen estos últimos en la variación de los efectos, cabe destacar que los datos provenientes de estudios observacionales de corte, como las encuestas de demografía y salud, brindan limitadas posibilidades de analizar relaciones ciertas de causa y efecto e interacciones entre las covariables socioeconómicas de interés, dado el diseño y las muestras.

Cuadro 10

Colombia: modelos logísticos finales con y sin índice de riqueza, 1995-2010

\begin{tabular}{|c|c|c|c|c|c|}
\hline \multirow{3}{*}{ Variable } & \multirow{2}{*}{ Coeficiente B } & \multirow{2}{*}{ Significación } & \multirow{2}{*}{$\begin{array}{l}\text { Razón de } \\
\text { probabilidades }\end{array}$} & \multicolumn{2}{|c|}{$\begin{array}{l}\text { Intervalo de confianza del } 95 \% \\
\text { para la razón de probabilidades }\end{array}$} \\
\hline & & & & Límite inferior & Límite superior \\
\hline & \multicolumn{5}{|c|}{ Modelo final sin índice de riqueza } \\
\hline $\begin{array}{l}\text { Relaciones sexuales antes } \\
\text { de los } 15 \text { años: sí }\end{array}$ & 1,198 & 0,000 & 3,315 & 2,902 & 3,786 \\
\hline Unión previa al embarazo: sí & 1,361 & 0,000 & 3,899 & 3,416 & 4,451 \\
\hline $\begin{array}{l}\text { Uso de anticonceptivos antes } \\
\text { del primer embarazo: no }\end{array}$ & 1,394 & 0,000 & 4,032 & 3,532 & 4,603 \\
\hline Edad & 0,599 & 0,000 & 1,820 & 1,739 & 1,905 \\
\hline $\begin{array}{l}\text { Educación (1): básica primaria } \\
\text { (ref.: básica secundaria) }\end{array}$ & 0,899 & 0,000 & 2,458 & 2,163 & 2,793 \\
\hline $\begin{array}{l}\text { Educación (2): primaria } \\
\text { incompleta/sin educación } \\
\text { (ref.: básica secundaria) }\end{array}$ & 1,091 & 0,000 & 2,976 & 2,361 & 3,752 \\
\hline $\begin{array}{l}\text { Edad de los padres (1): } 25 \text { a } \\
39 \text { años (ref.: } 40 \text { años y más) }\end{array}$ & 0,151 & 0,009 & 1,163 & 1,038 & 1,304 \\
\hline $\begin{array}{l}\text { Región/área (1): rural } \\
\text { (ref.: urbana) }\end{array}$ & 0,274 & 0,000 & 1,315 & 1,155 & 1,497 \\
\hline $\begin{array}{l}\text { Región/área (2): Bogotá } \\
\text { (ref.: urbana) }\end{array}$ & 0,259 & 0,000 & 1,296 & 1,123 & 1,495 \\
\hline Constante & $-12,462$ & 0,000 & 0,000 & & \\
\hline $\begin{array}{l}\text { n: } 8.686 \\
\text { Casos pronosticados: } 74,4 \% \\
\mathrm{R}^{2} \text { de Nagelkerke: } 0,361\end{array}$ & & & & & \\
\hline
\end{tabular}


Cuadro 10 (conclusión)

\begin{tabular}{|c|c|c|c|c|c|}
\hline \multirow{3}{*}{ Variable } & \multirow{2}{*}{ Coeficiente B } & \multirow{2}{*}{ Significación } & \multirow{2}{*}{$\begin{array}{l}\text { Razón de } \\
\text { probabilidades }\end{array}$} & \multicolumn{2}{|c|}{$\begin{array}{l}\text { Intervalo de confianza del } 95 \% \\
\text { para la razón de probabilidades }\end{array}$} \\
\hline & & & & Límite inferior & Límite superior \\
\hline & \multicolumn{5}{|c|}{ Modelo final con índice de riqueza } \\
\hline $\begin{array}{l}\text { Relaciones sexuales antes } \\
\text { de los } 15 \text { años: sí }\end{array}$ & 1,211 & 0,000 & 3,356 & 2,901 & 3,883 \\
\hline Unión previa al embarazo: sí & 1,311 & 0,000 & 3,712 & 3,198 & 4,308 \\
\hline $\begin{array}{l}\text { Uso de anticonceptivos antes } \\
\text { del primer embarazo: no }\end{array}$ & 1,438 & 0,000 & 4,214 & 3,619 & 4,907 \\
\hline Edad & 0,611 & 0,000 & 1,842 & 1,752 & 1,937 \\
\hline $\begin{array}{l}\text { Educación (1): básica primaria } \\
\text { (ref.: básica secundaria) }\end{array}$ & 0,803 & 0,000 & 2,231 & 1,934 & 2,575 \\
\hline $\begin{array}{l}\text { Educación (2): primaria } \\
\text { incompleta/sin educación } \\
\text { (ref.: básica secundaria) }\end{array}$ & 1,014 & 0,000 & 2,756 & 2,080 & 3,651 \\
\hline $\begin{array}{l}\text { Edad de los padres (1): } 25 \text { a } \\
39 \text { años (ref.: } 40 \text { años y más) }\end{array}$ & 0,096 & 0,136 & 1,101 & 0,970 & 1,249 \\
\hline $\begin{array}{l}\text { Región/área (1): rural } \\
\text { (ref.: urbana) }\end{array}$ & $-0,105$ & 0,279 & 0,901 & 0,745 & 1,089 \\
\hline $\begin{array}{l}\text { Región/área (2): Bogotá } \\
\text { (ref.: urbana) }\end{array}$ & 0,546 & 0,000 & 1,726 & 1,468 & 2,030 \\
\hline $\begin{array}{l}\text { Índice de riqueza (1): más } \\
\text { pobre (ref.: más rico) }\end{array}$ & 0,864 & 0,000 & 2,372 & 1,825 & 3,084 \\
\hline $\begin{array}{l}\text { Índice de riqueza (2): pobre } \\
\text { (ref.: más rico) }\end{array}$ & 0,850 & 0,000 & 2,340 & 1,892 & 2,893 \\
\hline $\begin{array}{l}\text { Índice de riqueza (3): medio } \\
\text { (ref.: más rico) }\end{array}$ & 0,545 & 0,000 & 1,724 & 1,421 & 2,092 \\
\hline $\begin{array}{l}\text { Índice de riqueza (4): rico } \\
\text { (ref.: más rico) }\end{array}$ & 0,154 & 0,119 & 1,166 & 0,961 & 1,415 \\
\hline Constante & $-13,041$ & 0,000 & 0,000 & & \\
\hline $\begin{array}{l}\text { n: } 7.385 \\
\text { Casos pronosticados: } 7.385 \\
\mathrm{R}^{2} \text { de Nagelkerke: } 0,372\end{array}$ & & & & & \\
\hline
\end{tabular}

Fuente: Elaboración propia.

Sobre la base de los resultados obtenidos, se aplicó el modelo simplificado al análisis segmentado por año de encuesta para dilucidar si los niveles de riesgo cambiaban a lo largo del período observado, y luego se realizó el análisis separadamente por regiones para examinar si estas mismas variables podrían explicar las diferencias regionales de la probabilidad de ser madre adolescente en función de los niveles de riesgo. Las razones de la disparidad se presentan en el cuadro 11.

La comparación de la razón de probabilidades de todo el conjunto de variables no revela diferencias evolutivas sustanciales a lo largo del período que comprende las últimas cuatro encuestas quinquenales, excepto por la marcada diferencia del riesgo asociado al no uso de anticonceptivos en 2010 , que podría estar indicando la mayor relevancia que tiene esta variable en la explicación de las diferencias del efecto sobre la probabilidad de ser madre adolescente hoy. Un mayor número de variables significativas podría deberse al tamaño de la muestra de la ENDS 2010, que duplica la de 2005 y cuadruplica las de 1995 y 2000. 
Cuadro 11

Colombia: razón de probabilidades de los determinantes próximos y contextuales significativos estimados según año de la encuesta nacional de demografía y salud (ENDS), 1995-2010

\begin{tabular}{|c|c|c|c|c|}
\hline \multirow{2}{*}{ Variable } & \multicolumn{4}{|c|}{ Año de la ENDS } \\
\hline & 1995 & 2000 & 2005 & 2010 \\
\hline Relaciones sexuales antes de los 15 años: sí & $2,65^{\star}$ & $3,59^{*}$ & $4,39^{*}$ & $2,71^{*}$ \\
\hline Unión previa al embarazo: sí & $3,86^{*}$ & $3,45^{\star}$ & $3,57^{*}$ & $4,39^{*}$ \\
\hline $\begin{array}{l}\text { Uso de anticonceptivos antes del } \\
\text { primer embarazo: no }\end{array}$ & $3,76^{\star}$ & $2,92^{*}$ & $2,81^{*}$ & $6,55^{*}$ \\
\hline Edad & $1,65^{\star}$ & $1,80^{*}$ & $1,90^{*}$ & $1,79^{*}$ \\
\hline Educación (1): básica primaria (ref.: básica secundaria) & 2,39 * & $2,35^{\star}$ & $2,62^{*}$ & $2,37^{\star}$ \\
\hline Educación (2): primaria incompleta/sin educación & $1,87(\mathrm{NS})$ & $3,33^{*}$ & $3,37^{\star}$ & $3,10^{*}$ \\
\hline Edad de los padres (1): 25 a 39 años & $1,43(\mathrm{NS})$ & 1,34 (NS) & 1,01 (NS) & $1,24^{*}$ \\
\hline Región/área (1): rural (ref: urbana) & $1,52(\mathrm{NS})$ & 1,41 (NS) & 1,19 (NS) & $1,39^{*}$ \\
\hline Región/área (2): Bogotá (ref: urbana) & 1,06 (NS) & $0,63(\mathrm{NS})$ & $1,66^{*}$ & $1,31^{*}$ \\
\hline Tamaño de las muestras & 533 & 768 & 2906 & 4479 \\
\hline $\mathrm{R}^{2}$ de Nagelkerke & 0,338 & 0,341 & 0,354 & 0,370 \\
\hline
\end{tabular}

Fuente: Elaboración propia.

Nota: *: significativo $p<0,05$

NS: no significativo.

El mismo análisis aplicado a las regiones utilizando todo el conjunto acumulado de información de las encuestas, dado que no ostenta diferencias temporales, se resume en el cuadro 12, donde se ponen de relieve diferentes niveles de riesgo para un mismo determinante en las regiones; lo anterior se basa en el concepto de que las razones de probabilidades significativas controladas por las demás variables representan la magnitud del riesgo (véanse el cuadro 12 y el gráfico 4).

\section{Cuadro 12}

Colombia: razón de probabilidades de determinantes próximos y contextuales de la fecundidad adolescente según región geográfica, 1995-2010

\begin{tabular}{|c|c|c|c|c|c|c|}
\hline Región & Bogotá & Atlántica & Oriental & Central & Pacífica & $\begin{array}{l}\text { Amazonia/ } \\
\text { Orinoquia }\end{array}$ \\
\hline $\begin{array}{l}\text { Relaciones sexuales antes } \\
\text { de los } 15 \text { años: sí }\end{array}$ & $2,71^{\star *}$ & $3,41^{\star \star}$ & $4,42^{\star \star}$ & $3,30^{* *}$ & $3,25^{\star \star}$ & $6,79^{\star *}$ \\
\hline Unión previa al embarazo: sí & $6,41^{\star *}$ & $2,72^{* *}$ & $4,14^{\star \star}$ & $4,61^{\star *}$ & $3,68^{* *}$ & 2,55 (NS) \\
\hline $\begin{array}{l}\text { Uso de anticonceptivos antes } \\
\text { del primer embarazo: no }\end{array}$ & $2,75^{\star *}$ & $3,26^{\star \star}$ & $4,21^{\star *}$ & $4,15^{\star *}$ & $6,92^{\star *}$ & $4,43^{* *}$ \\
\hline Edad & $1,82^{\star \star}$ & $1,76^{\star *}$ & $1,98^{\star \star}$ & $1,72^{\star *}$ & $1,96^{\star \star}$ & $2,15^{\star \star}$ \\
\hline $\begin{array}{l}\text { Educación (1): básica primaria } \\
\text { (ref: secundaria) }\end{array}$ & $2,50^{\star \star}$ & $2,95^{\star \star}$ & $2,61^{\star *}$ & $2,41^{\star *}$ & $2,14^{\star *}$ & 2,05 (NS) \\
\hline $\begin{array}{l}\text { Educación (2): primaria } \\
\text { incompleta/sin educación }\end{array}$ & 2,41 (NS) & $3,33^{\star *}$ & $3,48^{\star *}$ & $2,79^{\star *}$ & $3,05^{\star \star}$ & 1,77 (NS) \\
\hline Edad de los padres (1): 25 a 39 años & $1,11(\mathrm{NS})$ & $1,21(\mathrm{NS})$ & 1,24 (NS) & 0,98 (NS) & $1,42^{\star \star}$ & 0,98 (NS) \\
\hline Área rural (ref: urbana) & 0,03 (NS) & 0,93 (NS) & $1,75^{\star \star}$ & 1,25 (NS) & $1,43^{* *}$ & $1,32(\mathrm{NS})$ \\
\hline Tamaño de las muestras & 601 & 1713 & 1162 & 2316 & 1415 & 1443 \\
\hline $\mathrm{R}^{2}$ de Nagelkerke & 0,280 & 0,345 & 0,398 & 0,351 & 0,406 & 0,435 \\
\hline
\end{tabular}

Fuente: Elaboración propia.

Nota: $\quad * *$ : significativo $p<0,05$

NS: no significativo. 
Gráfico 4

Colombia: probabilidad de maternidad adolescente por regiones y años de edad, 1995-2010

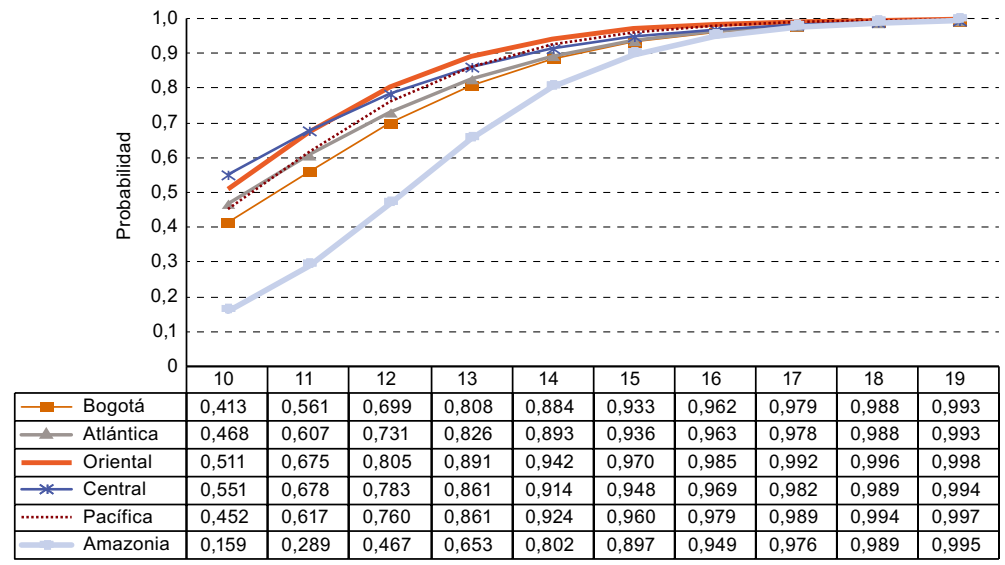

Fuente: Elaboración propia

Con este modelo, las probabilidades de ser madre adolescente teniendo todos los factores de exposición considerados (determinantes próximos y contextuales) difieren entre las regiones solamente para las edades menores de 15 años, lo que da como resultado que las regiones Central y Oriental son aquellas donde las adolescentes tienen mayor probabilidad de ser madres a más temprana edad, en contraste con Bogotá, que presenta la menor probabilidad, con diferencias de alrededor de 10 puntos porcentuales (véase el gráfico 4). La región amazónica presenta un resultado paradójico, dado que se intuye que en ella la probabilidad de ser madre adolescente en edades tempranas debería ser más alta, teniendo en cuenta un contexto sociocultural que empíricamente ha mostrado mayor precocidad en el inicio de relaciones sexuales y, por ende, mayor exposición al embarazo adolescente.

En el gráfico 5 se visualiza el peso diferencial que tienen los factores más determinantes de la fecundidad adolescente en las regiones de Colombia, evidenciando variaciones presentes en los diferentes contextos socioculturales y ambientales. En general, se podría decir que en Bogotá el principal factor es la exposición al embarazo ocasionada por el establecimiento de uniones conyugales estables o no estables, a juzgar por la menor proporción de adolescentes unidas antes del primer embarazo que tiene hijos, mientras que, por ejemplo, en el caso de la región Atlántica, la proporción de adolescentes con hijos que se han unido antes del primer embarazo es similar a la de las que no se han unido. Este resultado podría significar que, en la medida en que la unión no matrimonial sea un comportamiento más frecuente, dada la tolerancia social a la unión consensual en el país y la facilidad para deshacer tal tipo de unión, se podría esperar la generalización de este comportamiento y la pérdida de sensibilidad de esta variable, que ya no sería un factor determinante próximo. En el gráfico 5 se observa que el uso de anticonceptivos es el factor crítico en la región Pacífica, donde ciertamente se registran no solo grandes problemas de cobertura sanitaria, sino también niveles bajos de los indicadores socioeconómicos y educativos, hecho aunado al predominio de la cultura afroamericana e indígena de la región, lo que podría dar origen a las diferencias de comportamiento. Asimismo, llama la atención que, en los departamentos de la Amazonia-Orinoquia, donde hay un predominio de población indígena y colonos, el factor determinante sea la precocidad en el inicio de las relaciones sexuales. 


\section{Gráfico 5}

\section{Colombia: razón de probabilidades de maternidad adolescente según determinantes clave, por regiones, 1995-2010}

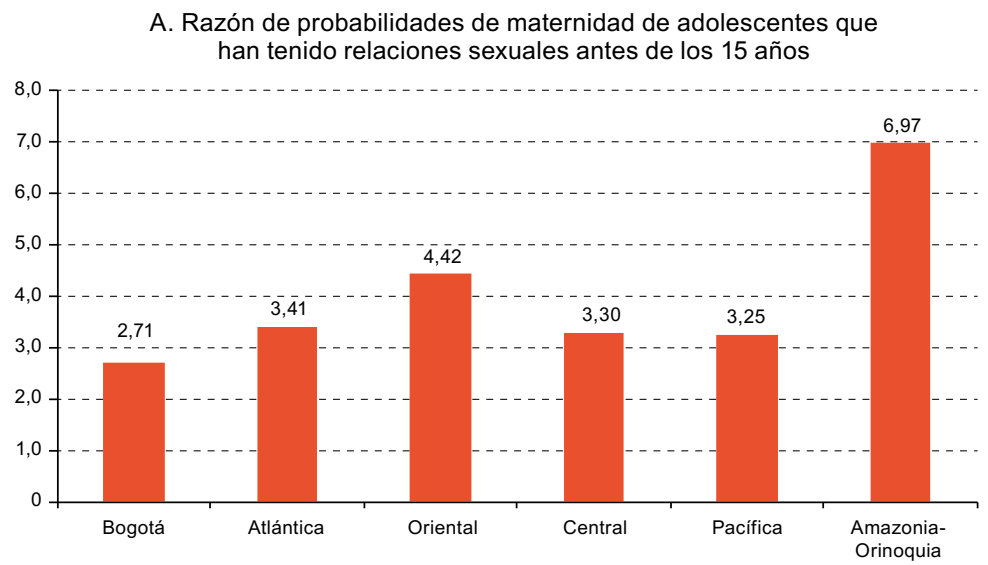

B. Razón de probabilidades de maternidad de adolescentes que han estado en unión conyugal antes del primer embarazo

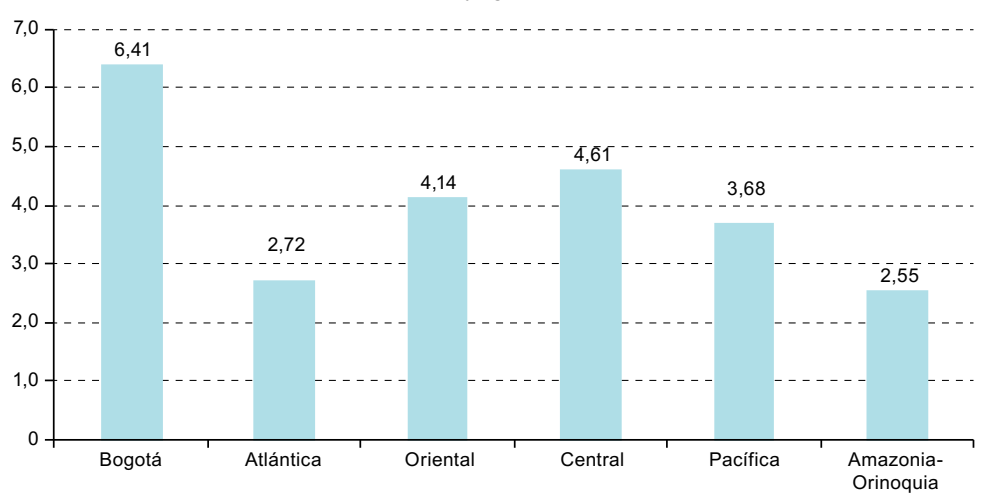

C. Razón de probabilidades de maternidad de adolescentes que no usaban anticonceptivos antes del primer embarazo

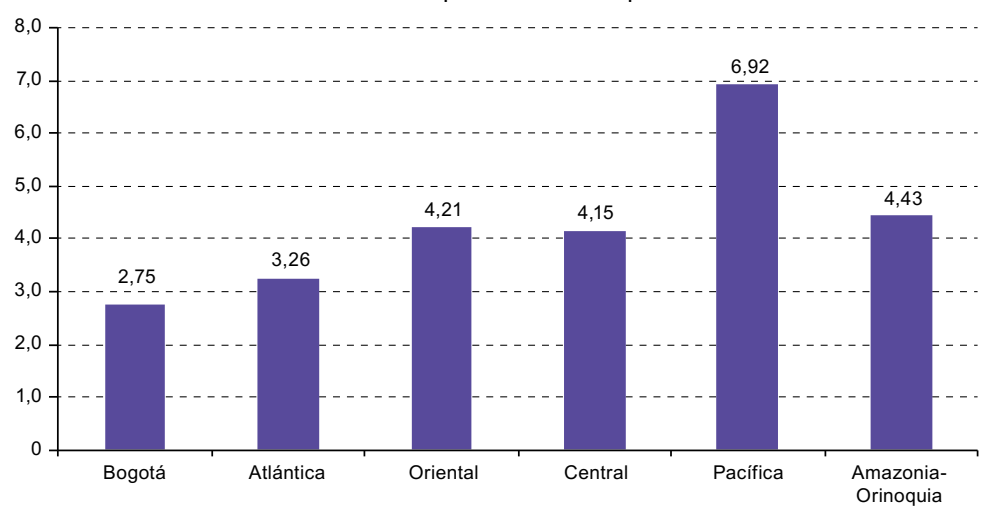


Gráfico 5 (conclusión)

D. Razón de probabilidades de maternidad adolescente según nivel educativo, tomando como referencia la educación básica secundaria

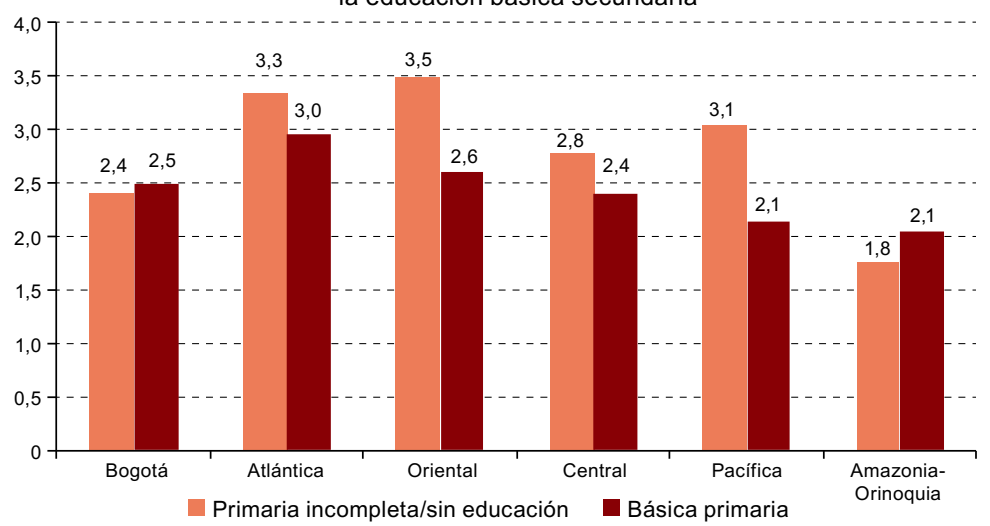

E. Razón de probabilidades de maternidad de adolescentes

hijas de padres jóvenes ( 25 a 39 años), tomando como referencia a padres de 40 años y más

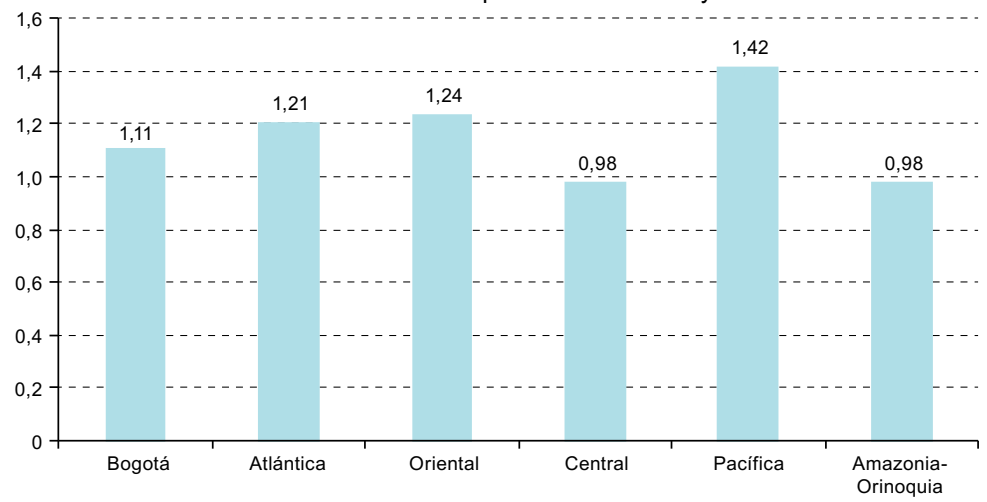

F. Razón de probabilidades de maternidad de adolescentes que residen en zonas rurales, tomando como referencia la zona urbana y Bogotá

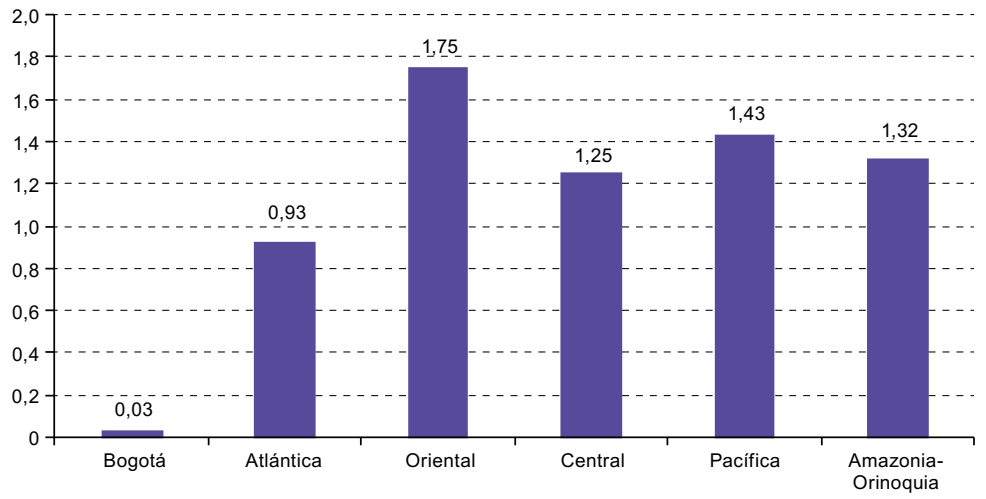

Fuente: Elaboración propia. 


\section{Discusión y conclusiones}

En este artículo se efectuó una revisión de los patrones, niveles y determinantes clave de la fecundidad adolescente en Colombia en la entrada al siglo XXI, haciendo uso de diversas fuentes de información, principalmente de la explotación inédita de su fuente primaria: los registros de nacimientos. Mientras que las ENDS muestran un aparente incremento de la fecundidad adolescente entre 1990 y 2005, seguido de un leve descenso en 2010, la serie de estadísticas vitales de 1998 a 2010 revela niveles altos de este indicador, con tendencias ligeramente decrecientes a nivel nacional y regional, pero con resistencia a la baja en las regiones costeras e incluso proclives al aumento en algunos departamentos de las regiones Atlántica y Pacífica.

Cuando se sigue la trayectoria de las tasas de fecundidad estimadas en las ENDS, se observa un aumento del nivel de las mediciones de período. Las tasas se calcularon para los tres años anteriores a la recolección de los datos y suelen estar afectadas por la mala declaración de edad de los niños y las mujeres; esto ocasiona un desplazamiento de la edad y finalmente una subestimación o sobreestimación de las tasas, como señala Verhulst (2012). Otras razones podrían también causar una distorsión al interpretar las tasas resultantes, si se tiene en cuenta que no solo se ha ampliado el tamaño de la muestra, sino también el límite inferior del rango de edad de las mujeres entrevistadas, de 15 años en 2000 a 13 años en 2005 y 2010; además, se cuenta con procedimientos más estandarizados y controlados, y hay menos tabúes acerca del tema y una mayor disposición de las entrevistadas a responder, lo que sugiere un mejor registro.

El uso de las estadísticas vitales como fuente para las estimaciones directas, corregidas con factores de ajuste definidos con múltiples métodos, permite obtener mediciones de fecundidad concordantes con otros resultados que dan cuenta de la coherencia de las fuentes, por lo que su comparación permanente debería utilizarse como estrategia de evaluación para obtener mejores estimaciones.

En 2010 , la fecundidad adolescente representó el 20,5\% de la fecundidad total del país y el $33,6 \%$ de los nacimientos, cifras que, contrastadas con la proporción de adolescentes, del $34,5 \%$ del total de las mujeres colombianas en edad fértil (10 a 49 años), no resultan extrañas, tratándose de una población joven con una pirámide poblacional ensanchada en las edades de adolescentes y adultos jóvenes (cerca de 4,3 millones de niñas y adolescentes de 10 a 19 años). Según los diversos estudios conducidos por el DANE sobre la base de los datos censales, la fecundidad ha venido evolucionando de una cúspide dilatada (mayor fecundidad en mujeres de 20 a 29 años) en 1985 a una temprana (mayor fecundidad en mujeres de 20 a 24) en 2005. Asimismo, la fecundidad adolescente a nivel nacional pasó del $11,8 \%$ en 1985 al 16,1\% en 1993 y al 19,4\% en 2005; lo mismo ocurre con la edad media de la fecundidad, que se vuelve más temprana, pasando de 27,24 años en el quinquenio 1985-1990 a 26,63 en el período 2000-2005. 
Indudablemente, como se muestra en los resultados descritos, los diferenciales se observan tanto entre las regiones como entre los departamentos que las componen; los estudios poscensales revelan aparentes cambios de las estructuras poblacionales que dan cuenta de la variedad de estadios de la transición demográfica en la que se encuentran los departamentos. El resultado más notable es la tendencia generalizada al aumento de la fecundidad en las edades menores y la reducción en las edades tardías de la adolescencia, exceptuando las regiones costeras, donde las tasas se mantienen en todos los grupos de edad con tendencias a un incremento moderado pero constante del orden del $5 \%$ anual; por otra parte, las regiones Central y Oriental experimentan los descensos más marcados. Muchas características de tipo sociocultural podrían dar origen a estas diferencias regionales; sin embargo, la composición de las regiones es demasiado heterogénea para intentar hacer esta caracterización a menor escala, más allá de lo descrito, sin caer en falacias ecológicas. Esto se debe a la diversidad interna de las regiones y aun dentro de un mismo departamento y a que los indicadores no discriminan adecuadamente la heterogénea composición territorial del país.

No obstante, los modelos logísticos revelan que la fecundidad no es homogénea por grupos socioeconómicos y que los sectores más pobres tienen una mayor incidencia de embarazos en la adolescencia, como se ha descrito en estudios previos. Las diferencias son tangibles según la condición de ser pobre o rico, pero no resulta claro si los excesos de fecundidad de una región pueden atribuirse a su mayor nivel de pobreza con respecto a otra. La misma situación se observa cuando se examina la incidencia del nivel educativo o la pertenencia étnica de las adolescentes en la probabilidad de ser madres; las diferencias son marcadas entre las adolescentes sin ninguna educación o que no han terminado la primaria comparadas con aquellas que al menos completaron estudios primarios o han realizado estudios secundarios parciales o completos; pero la estrecha relación entre el nivel educativo y el socioeconómico da lugar a ambigüedades en la interpretación de su real efecto en la fecundidad por región y sugiere que otros factores, como los proyectos de vida, el uso del tiempo, las percepciones y los imaginarios culturales puedan tener interacciones más relevantes (Hoffman, 1998; Lawlor y Shaw, 2002; Kirchengast, 2009). En el caso de la etnia, es posible que, por efecto de la concentración de la población de determinados grupos étnicos en algunos territorios, no se puedan explicar las diferencias regionales.

En lo que respecta a los determinantes de la fecundidad adolescente, los modelos logísticos confirman que los tres determinantes próximos explican por sí solos las probabilidades de ser o no madres si las adolescentes están expuestas a los factores definidos como de riesgo de embarazo. El efecto negativo del inicio de las relaciones sexuales a edad más temprana sobre la probabilidad de ser madre adolescente mostró el alto significado de este determinante no solo por el hecho de incidir directamente en la fecundidad, sino por la importante modificación del efecto, que se acentúa cuando se introducen otros determinantes de contexto, como el nivel educativo y el nivel socioeconómico, lo que no ocurre con los otros determinantes. Esto podría significar que más importante que la propia edad de iniciación sexual son los factores que inducen a esa 
iniciación temprana, los cuales ameritan ser estudiados en profundidad (Flórez y Soto, 2013). Al respecto, algunos autores se refieren a las brechas entre el comportamiento sexual de la juventud, hoy más liberal y aceptada por la sociedad, y las habilidades para la vida con que cuenta el adolescente para un adecuado manejo de su sexualidad y la prevención del embarazo. Un razonamiento parecido podría aplicarse al estado conyugal, en el sentido de que la unión marital previa al primer embarazo estaría asociada al conjunto de comportamientos concomitantes que adoptan los adolescentes cuando deciden establecer una unión formal -legal o consensual-, que son diferentes en el caso de tener una pareja sexual pero sin reconocimiento de una unión.

El uso de anticonceptivos antes del primer embarazo es el determinante más notable de los determinantes próximos. En todos los modelos, es el determinante de mayor efecto, lo que conduce a plantear que quizá sea la clave para incidir en la fecundidad adolescente, aunque no propiamente por la vía educativa, donde se observó falta de concordancia entre el nivel educativo y el conocimiento que tienen las adolescentes sobre su período de riesgo de embarazo. Si bien este tema está fuera del alcance de este análisis, se sabe que su influencia tiene que ver más con el acceso a la anticoncepción combinado con el conocimiento y el adecuado uso de los métodos anticonceptivos, como se demostró en varios estudios en que se analiza el impacto de la anticoncepción en la fecundidad (Santelli y Melnikas, 2010).

El modelo demográfico de determinantes de la fecundidad aquí tratado muestra que los determinantes distales por sí solos no explican directamente las tendencias si no son operados por la vía de los determinantes próximos que definen la conducta de los adolescentes. Asimismo, aunque las condiciones sociales, económicas y culturales son esenciales en la formación de los adolescentes para la toma de decisiones reproductivas, como variables independientes en un modelo no son suficientes para explicar los cambios en el riesgo de embarazo, debido a que su influencia está a su vez determinada por múltiples interacciones dinámicas entre sí que dificultan su simplificación. Dado que estas variables se miden en el mismo momento sin tener en cuenta una línea de tiempo, la precedencia de estos factores es un supuesto teórico cuya interpretación es limitada, teniendo en cuenta la escasa posibilidad de efectuar análisis desagregados. En cambio, sí resulta muy contundente la explicación a partir de modelos simples basados en los determinantes próximos, como el uso de la anticoncepción, el que se relaciona con políticas públicas de educación sexual y acceso a métodos anticonceptivos diferenciales en todas las regiones.

De lo que antecede se deriva que la cuantificación y el análisis de determinantes a macronivel requieren ser llevados a cabo a micronivel, habida cuenta del reconocimiento del fenómeno de la fecundidad adolescente como un hecho no aleatorio, sino determinado por factores distribuidos de manera desigual en la población que se reproducen en contextos concretos y delimitados. Asimismo, se requiere profundizar los enfoques metodológicos y analíticos, no solo para comprender el fenómeno desde la perspectiva de los ciclos de vida y los efectos de las cohortes, que tienen su propia historia, sino también para predecir las trayectorias y tendencias futuras de la fecundidad y así brindar un mejor apoyo a las políticas públicas. 


\section{Bibliografía}

Bay, G., F. Del Popolo y D. Ferrando (2003), “Determinantes próximos de la fecundidad: una aplicación a países latinoamericanos", serie Población y Desarrollo, $\mathrm{N}^{\circ} 43$ (LC/L.1953-P), Santiago, Comisión Económica para América Latina y el Caribe (CEPAL).

Bongaarts, J. (1978), "A framework for analyzing the proximate determinants of fertility", Population and Development Review, vol. $4, \mathrm{~N}^{\circ} 1$.

Chackiel, J. (2004), "La dinámica demográfica en América Latina", serie Población y Desarrollo, $\mathrm{N}^{\circ} 52$ (LC/L.2127-P), Santiago, Comisión Económica para América Latina y el Caribe (CEPAL).

DANE (Departamento Administrativo Nacional de Estadística de Colombia) (2007a), Conciliación censal 1985-2005. Estudios de fecundidad, proyecciones de población, Bogotá.

(2007b), Colombia una nación multicultural: su diversidad étnica, Bogotá, Dirección de Censos y Demografía.

Di Cesare, M. y J. Rodríguez (2006), "Análisis micro de los determinantes de la fecundidad adolescente en Brasil y Colombia", Papeles de Población, vol. 48, Universidad Autónoma del Estado de México.

Flórez, C.E. (2005), "Socioeconomic and contextual determinants of reproductive activity among adolescent women in Colombia", Pan American Journal of Public Health, vol. 18, N ${ }^{\circ}$ 6, Washington, D.C., Organización Panamericana de la Salud (OPS).

Flórez, C.E. y J. Núñez (2002), "Teenage childbearing in Latin American countries", Documento CEDE 2002-01, edición electrónica, Bogotá, Universidad de los Andes.

Flórez, C.E. y V. Soto (2006), "Fecundidad adolescente y desigualdad en Colombia", Notas de Población, № 83 (LC/G.2340-P), Santiago, Comisión Económica para América Latina y el Caribe (CEPAL).

(2013), "Factores protectores y factores de riesgo del embarazo adolescente en Colombia", serie de Estudios a Profundidad Encuesta Nacional de Demografía y Salud -ENDS-1990/2010, Bogotá.

Freedman, R., K. Davis y J. Blake (1967), Factores sociológicos de la fecundidad, Ciudad de México, Gráfica Panamericana.

Henao Escobar, J. (2007), "Fecundidad adolescente, género y desarrollo: evidencias de la investigación", Territorios, $\mathrm{N}^{\circ} 16-17$, Bogotá, Universidad del Rosario.

Hoffman, S. D. (1998), "Teenage childbearing is not so bad after all... or is it? A review of the new literature", Family Planning Perspectives, vol. $30, \mathrm{~N}^{\circ} 5$, Nueva York, Guttmacher Institute.

Kirchengast, S. (2009), "Teenage-pregnancies. A biomedical and a sociocultural approach to a current problem", Current Women's Health Reviews, vol. 5, $\mathrm{N}^{\circ}$ 1, Bentham Science Publishers.

Lawlor, D.A. y M. Shaw (2002), "Too much too young? Teenage pregnancy is not a public health problem", International Journal of Epidemiology, vol. 31, $\mathrm{N}^{\circ} 3$, Bristol, IEA Publications.

Measure DHS Project (Monitoring and Evaluation to Assess and Use Results Demographic and Health Survey) (2012), "Data Archives", The DHS Program at ICF Macro International Inc. Calverton, Maryland USA.

Profamilia (2011), Encuesta Nacional de Demografía y Salud (ENDS) 2010, Bogotá, Ministerio de Salud y Protección Social/Instituto Colombiano de Bienestar Familiar (ICBF)/Agencia de los Estados Unidos para el Desarrollo Internacional (USAID).

Rodríguez Vignoli, J. (2008), "Reproducción en la adolescencia en América Latina y el Caribe: ¿una anomalía a escala mundial?", documento presentado en el Tercer Congreso de la Asociación Latinoamericana de Población (ALAP), Córdoba.

Santelli, J.S. y A.J. Melnikas (2010), "Teen fertility in transition: Recent and historic trends in the United States", Annual Review of Public Health, vol. 2010, $\mathrm{N}^{\circ} 31$.

Simmons, G.B. (1985), "Theories of fertility", Fertility in Developing Countries: An economic perspective on research and policy issues, G.M. Farooq y G.B. Simmons (eds.), Nueva York, St. Martin's Press.

Verhulst, A. (2012), "Estimación de la fecundidad a partir de las Encuestas Nacionales de Demografía y Salud", RevistaIBde Información Básica Estadística, Bogotá, Centro Andino de Altos Estudios (CANDANE). 



\title{
Los entornos y el envejecimiento en Iberoamérica: análisis a partir de las condiciones de la vivienda ${ }^{1}$
}

\author{
Sagrario Garay Villegas ${ }^{2}$ \\ Verónica Montes de Oca Zavala ${ }^{3}$ \\ Mirna Hebrero Martínez ${ }^{4}$
}

Recibido: 26/06/2015

Aceptado: 04/08/2015

\section{Resumen}

El envejecimiento demográfico implica desafíos que, por lo regular, se centran en los regímenes de pensiones y sistemas de salud. Sin embargo, en la vida diaria existen dimensiones igual de importantes, como las condiciones de la vivienda, el acceso a servicios públicos y la configuración física y social de los entornos en los que reside la población adulta mayor. En los trabajos relativos a esta temática, se ha mostrado que la seguridad dentro de las viviendas puede ser un factor de protección de la salud al

Investigación realizada gracias al Programa de Apoyo a Proyectos de Investigación e Innovación Tecnológica (PAPIIT) de la Universidad Nacional Autónoma de México (UNAM), proyecto clave: IG300414. Las autoras agradecen a Vicente Rodríguez-Rodríguez, investigador del Instituto de Economía, Geografía y Demografía (IEGD) del Consejo Superior de Investigaciones Científicas (CSIC), por el procesamiento de los datos del Censo de Población y Vivienda 2011 de España.

2 Profesora Investigadora de la Facultad de Trabajo Social y Desarrollo Humano de la Universidad Autónoma de Nuevo León; Licenciada y Maestra en Economía por la Universidad Autónoma Metropolitana (UAM); Doctora en Estudios de Población por El Colegio de México. Correo electrónico: sgarayv@gmail.com.

3 Investigadora Titular del Instituto de Investigaciones Sociales de la Universidad Nacional Autónoma de México (UNAM); Coordinadora del Seminario Universitario Interdisciplinario sobre Envejecimiento y Vejez (SUIEV); Licenciada en Sociología por la UNAM; Maestra en Demografía y Doctora en Ciencias Sociales con especialidad en Población por El Colegio de México. Correo electrónico: vmoiis@gmail.com.

4 Directora de Evaluación de los Servicios de Salud de la Dirección General de Evaluación del Desempeño de la Secretaría de Salud de México; Licenciada en Actuaría por la UNAM; maestría en Demografía y doctorado en Estudios de Población por El Colegio de México. Correo electrónico: mhebrero@hotmail.com. 
disminuir accidentes y reducir el estrés, hechos que pueden garantizar la calidad de vida a cualquier edad. Bajo esa lógica, el objetivo principal de este artículo es explorar las características de la vivienda y el acceso a servicios públicos de la población adulta mayor en la región iberoamericana. Se seleccionó a algunos países de América Latina que se encuentran en etapas intermedias y avanzadas de la transición demográfica, y a España, que presenta una transición demográfica avanzada y comparte una raigambre cultural con algunos de los países seleccionados.

Palabras clave: personas mayores, vivienda, servicios, habitabilidad y equipamiento.

\begin{abstract}
The challenges usually associated with an ageing population are the financial burdens of pensions and on health services. However, there are equally important daily considerations, such as housing conditions, access to public services and the physical and social environment in which older persons live. Studies on this subject have shown that safety at home can protect health by reducing the number of accidents and lowering stress, which can add to quality of life at any age. Accordingly, this article explores aspects of housing and access to public services for the older population in Latin America. We selected Latin American countries that are at intermediate or advanced stages of the demographic transition, and Spain, which is advanced in the demographic transition and shares cultural roots with some of the countries selected.
\end{abstract}

Keywords: older persons; housing; services; habitability; equipment.

\title{
Résumé
}

Le vieillissement démographique implique des défis qui sont généralement centrés sur le régime des pensions et les systèmes de santé. II existe pourtant, dans la vie quotidienne, des aspects tout aussi importants comme les conditions du logement, l'accès aux services publics et les paramètres physiques et sociaux du contexte dans lequel vit la population de personnes âgées. Les études menées dans ce domaine ont démontré que la sécurité dans les logements peut constituer un facteur de protection de la santé, car elle réduit les accidents et le stress, ce qui peut garantir la qualité de vie à n'importe quel âge. Suivant cette logique, l'objectif principal de cet article est d'étudier les caractéristiques du logement et l'accès aux services publics de la part de la population de personnes âgées dans la région ibéro-américaine. Pour ce faire, l'auteur a choisi plusieurs pays d'Amérique latine se trouvant dans des étapes intermédiaires et avancées de la transition démographique, et l'Espagne qui présente une transition démographique avancée et des caractéristiques culturelles communes avec certains des pays choisis.

Mots clés: personnes âgées, logement, services, habitabilité et équipement. 


\section{Introducción}

En América Latina y el Caribe, los niveles de fecundidad y mortalidad se han reducido en los últimos 50 años. La fecundidad se ubica por debajo de la media mundial, mientras que la reducción de la mortalidad se ha traducido en un incremento de la esperanza de vida al nacer de casi 22 años, pasando de 51,4 años en el período 1950-1955 a 74 años en 2012 (CEPAL, 2009) $)^{5}$.

Lo anterior ha diversificado los escenarios sociales y demográficos de los países latinoamericanos. Algunos se encuentran en una etapa de envejecimiento demográfico avanzado o muy avanzado (Argentina, Brasil, Chile, Costa Rica, Cuba y Uruguay), otros en etapa moderada (Colombia, Ecuador, El Salvador, Honduras, México, Nicaragua, Panamá, Paraguay, Perú, República Dominicana y Venezuela (República Bolivariana de)) y otros en un estado incipiente (Guatemala, Haití y Bolivia (Estado Plurinacional de)) (Red de Envejecimiento de ALAP, 2012).

El cambio demográfico de los países latinoamericanos ha traído consigo diversas implicaciones sociales y económicas, entre las que se encuentran las transformaciones en la organización y composición familiar, las transferencias intergeneracionales de los recursos, los servicios de salud, las redes de apoyo familiares y no familiares, la participación económica de la población adulta mayor y sus condiciones de vida, vivienda y salud, entre otras (CELADE, 2006; Garay y Montes de Oca, 2011). Este conjunto de temáticas forman parte del análisis de los entornos físicos y sociales. El estudio de los entornos como parte de la calidad de vida de las personas mayores ha sido un tema por demás relevante en los últimos años, indicándose que los entornos propicios se refieren a las condiciones socioculturales $\mathrm{y}$ ambientales que permiten un envejecimiento digno y seguro en la comunidad de origen (CELADE, 2006, pág.13).

Como una forma de aproximarse al estudio de los entornos, en este artículo se analizan las condiciones de vivienda y el acceso a servicios básicos de la población adulta mayor en la región, dado que ambas condiciones suelen ser muy distintas para estas personas y esto incidirá en su bienestar y calidad de vida (Contreras, 1992; Szalachman, 2000; De Vos, Solís y Montes de Oca, 2004) $)^{6}$. En el análisis se incluirán diversos países de la región iberoamericana; España se encuentra en una etapa más avanzada de transición demográfica y la transformación de sus entornos se manifiesta en los datos recabados y disponibles en su censo de población.

5 Al respecto véanse también los sitios web del Banco Mundial [en línea] www.bancomundial.org y de la CEPAL [en línea] www.cepal.org.

6 La edad seleccionada de la población adulta mayor como indicador general y comparable entre los países fue de 60 años o más. 


\section{A. Los entornos y ambientes en contextos de envejecimiento y la calidad de vida}

La discusión sobre los ambientes físicos, urbanos y rurales se ha establecido desde los años ochenta en países más desarrollados y ha considerado la interacción de las personas con su ambiente físico y social, admitiendo la importancia de la vivienda, el transporte, los servicios sociales y los arreglos residenciales (familiares o institucionales) (Committee on Aging Society, 1985). El debate ha integrado el concepto de envejecimiento, unido al de discapacidad y calidad de vida de las personas adultas mayores (Soldo y Longino, 1985; Wachs, 1985; Struyk, 1985; Morgan, 1985; Rojo y otros, 2014).

Recientemente, se ha indicado que la calidad de vida está compuesta por dimensiones que refieren a valores objetivos y subjetivos de las personas. Esto se debe a que el concepto incluye elementos como el estado físico y psicológico, las relaciones y creencias personales, las características del ambiente residencial y las condiciones económicas, de vivienda y entorno (OMS, 1995; Osorio, Torrejón y Vogel, 2008; Flores y otros, 2011). Además, en los estudios sobre el tema se ha avanzado en la medición de la calidad de vida en la vejez y en el análisis de sus implicaciones. Entre los aspectos que destacan en esta temática, están los ambientes residenciales, que pueden traducirse como el estado de la vivienda, el barrio y los vecinos, elementos que inciden en el bienestar subjetivo de la población adulta mayor (Rojo y otros, 2001 y 2002).

El análisis de los entornos residenciales en la vejez ha tenido auge en países europeos, entre ellos España, en donde se han realizado estudios en que se analiza la importancia de estos componentes en la percepción de la calidad de vida. Al respecto, se muestra que existen variaciones en la importancia que tienen los entornos residenciales como parámetros de satisfacción y que el sexo y el número de personas adultas mayores en el hogar son dimensiones de gran poder predictor de la satisfacción residencial (Rojo y otros, 2001; Fernández-Mayoralas, Rojo y Rojo, 2004).

Por su parte, en países con un proceso de planeación urbana en desarrollo, como los latinoamericanos, el entorno físico y social de la población adulta mayor es un aspecto poco analizado (CELADE, 2006). Los análisis efectuados se asocian generalmente con las características internas de la vivienda en donde habita esta población, con el contexto de los hogares o con las redes de apoyo familiares y no familiares como elementos que inciden en su calidad de vida (Guzmán, Huenchuan y Montes de Oca, 2003).

\section{Entornos y vivienda}

El concepto de entorno considera tanto los espacios físicos (la vivienda, el barrio, la localidad) como las relaciones interpersonales con la comunidad y la familia (CELADE, 2006). Desde hace varias décadas, España incluye en sus censos de población información 
sobre los espacios ${ }^{7}$. Sin embargo, en el resto de los países analizados, la información no contiene todos estos aspectos, de modo que no es posible realizar un análisis comparativo; por ello los entornos harán referencia a los servicios con los que cuenta la población adulta mayor y a las características de la vivienda y el equipamiento ${ }^{8}$.

En el presente análisis los entornos se estudian solo a partir de las condiciones de la vivienda. Una de las características que se analizan es la disponibilidad de servicios que deberían ser accesibles para la población y que forman parte de condiciones sociosanitarias requeridas para mantener cierta calidad de vida; también se contemplan los aspectos materiales y físicos de la vivienda, así como la disponibilidad de equipamiento. Las variables consideradas en cada caso se presentan en el cuadro 1.

Cuadro 1

Variables consideradas para el análisis de condiciones de vivienda de la población adulta mayor

\begin{tabular}{ll}
\hline Disponibilidad de servicios & Condiciones de habitabilidad y equipamiento \\
\hline Servicios públicos & Características espaciales y materiales \\
& de la vivienda \\
\hline - Electricidad & - Régimen de propiedad \\
- Agua entubada & - Material de pisos, paredes y techo \\
- Desagüe o drenaje & - Número de cuartos \\
- Combustible & - Índice de hacinamiento \\
- Eliminación de basura & - Cocina \\
& - Baño \\
\hline Disponibilidad de tecnologías de la información & Equipamiento de la vivienda \\
y las comunicaciones (TIC) & \\
\hline - Teléfono fijo & - Refrigerador \\
- Celular & - Lavadora \\
- Computadora & - Televisor \\
- Internet & - Radio \\
& - Calentador de agua \\
& - Calefacción \\
& - Aire acondicionado \\
\hline
\end{tabular}

Fuente: Elaboración propia.

\section{B. Fuentes de datos}

En este artículo se utilizan los datos disponibles en la plataforma Integrated Public Use Microdata Series, International (IPUMS)9 , la que concentra censos de población de la mayoría de los países del mundo y ha logrado generar variables comparables entre países. IPUMS es un proyecto que, poco a poco, ha incorporado a nuevos países y que depende

\footnotetext{
7 Por ejemplo, en algunas fuentes de datos españolas se considera el espacio disponible en las viviendas en términos de metros. Este dato, junto con el número de personas en el hogar, permite conocer la cantidad de metros disponibles por persona en cada vivienda (Rojo y otros, 2001; Fernández-Mayoralas, Rojo y Pozo, 2002).

8 Por vivienda se entiende el espacio físico en donde residen las personas.

9 Véase [en línea] https://international.ipums.org/.
} 
del apoyo de las instituciones generadoras de información de cada país. Dado que en la plataforma solo hay datos recientes sobre la Argentina (2010), el Brasil (2010), el Ecuador (2010) y México (2010), también se recurrió a la consulta de los censos de población y vivienda de otros países, como Costa Rica (2011), España (2011) y el Uruguay (2011).

La elección de los países latinoamericanos se basó en que no todos cuentan con información reciente y, en los casos en que sí se tienen datos actualizados, no fue posible acceder a los microdatos o consultar los tabulados. Se ha incluido a España porque es un país donde existe una preocupación notoria sobre los entornos de la población adulta mayor, tema que está presente en sus encuestas y que vale la pena comparar con los países latinoamericanos.

Sin duda, los censos de población son una fuente de información confiable con la que es posible efectuar un ejercicio comparativo entre países con las variables disponibles. Evidentemente, como se observa en el cuadro 2 (donde las casillas coloreadas indican la disponibilidad de datos), las variables consideradas no se captan en todos los países, pero las que se logran reunir permiten distinguir la diversidad de condiciones en materia de vivienda y servicios básicos que se presentan en los correspondientes contextos.

\section{Cuadro 2}

América Latina (países seleccionados) y España: disponibilidad de datos sobre variables de condiciones de vivienda de la población adulta mayor

\begin{tabular}{|c|c|c|c|c|c|c|c|}
\hline Variables & Argentina & Brasil & Costa Rica & Ecuador & España & México & Uruguay \\
\hline \multicolumn{8}{|l|}{ Electricidad } \\
\hline \multicolumn{8}{|l|}{ Agua } \\
\hline \multicolumn{8}{|l|}{ Drenaje } \\
\hline \multicolumn{8}{|l|}{ Combustible para cocinar } \\
\hline \multicolumn{8}{|l|}{ Eliminación de basura } \\
\hline \multicolumn{8}{|l|}{ Teléfono fijo } \\
\hline \multicolumn{8}{|l|}{ Celular } \\
\hline \multicolumn{8}{|l|}{ Computadora } \\
\hline \multicolumn{8}{|l|}{ Internet } \\
\hline \multicolumn{8}{|l|}{ Propiedad de la vivienda } \\
\hline \multicolumn{8}{|l|}{ Material del piso } \\
\hline \multicolumn{8}{|l|}{ Material de las paredes } \\
\hline \multicolumn{8}{|l|}{ Material del techo } \\
\hline \multicolumn{8}{|l|}{ Hacinamiento } \\
\hline \multicolumn{8}{|l|}{ Cocina } \\
\hline \multicolumn{8}{|l|}{ Baño } \\
\hline Equipamiento en la vivienda & & & & & & & \\
\hline
\end{tabular}

Fuente: Elaboración propia. 


\section{Características de la población adulta mayor analizada en los países seleccionados}

De los países seleccionados, la Argentina y el Uruguay cuentan con una proporción más alta de población adulta mayor en contextos urbanos, mientras que en el Ecuador cerca de la mitad de la población adulta mayor reside en localidades rurales. La composición por sexo en los distintos países mantiene un comportamiento similar: las mujeres representan un porcentaje más elevado en todos los casos, debido a su mayor esperanza de vida (véase el cuadro 3 ).

Cuadro 3

América Latina (países seleccionados) y España: distribución porcentual de la población adulta mayor según características sociodemográficas

\begin{tabular}{|c|c|c|c|c|c|c|c|}
\hline Variables seleccionadas & $\begin{array}{c}\text { Argentina } \\
(2010)\end{array}$ & $\begin{array}{l}\text { Brasil } \\
(2010)\end{array}$ & $\begin{array}{c}\text { Costa Rica } \\
(2011)\end{array}$ & $\begin{array}{c}\text { Ecuador } \\
(2010)\end{array}$ & $\begin{array}{c}\text { España } \\
\text { (2011) }\end{array}$ & $\begin{array}{l}\text { México } \\
(2010)\end{array}$ & $\begin{array}{c}\text { Uruguay } \\
\text { (2011) }\end{array}$ \\
\hline \multicolumn{8}{|l|}{ Tipo de localidad } \\
\hline Rural & 8,1 & 15,9 & 24,8 & 41,2 & 24,9 & 26,2 & 5,4 \\
\hline Urbana $^{a}$ & 91,9 & 84,1 & 75,2 & 58,8 & 75,1 & 73,8 & 94,6 \\
\hline \multicolumn{8}{|l|}{ Sexo } \\
\hline Hombres & 42,7 & 44,5 & 46,8 & 48,0 & 44,3 & 46,7 & 41,3 \\
\hline Mujeres & 57,3 & 55,5 & 53,2 & 52,0 & 55,7 & 53,3 & 58,7 \\
\hline \multicolumn{8}{|l|}{ Grupos de edad } \\
\hline 60-64 años & 28,7 & 31,6 & 30,6 & 29,8 & 23,6 & 30,7 & 24,5 \\
\hline 65-69 años & 22,8 & 23,5 & 23,0 & 24,2 & 20,9 & 23,1 & 21,4 \\
\hline 70-74 años & 17,8 & 18,2 & 17,4 & 17,9 & 16,5 & 18,8 & 18,3 \\
\hline 75-79 años & 14,0 & 12,5 & 12,6 & 12,3 & 17,2 & 12,4 & 15,2 \\
\hline 80 años o más & 16,7 & 14,2 & 16,4 & 15,8 & 21,9 & 15,0 & 20,5 \\
\hline \multicolumn{8}{|l|}{ Estado conyugal } \\
\hline Soltero(a) & $\ldots$ & 5,5 & 12,2 & 10,2 & 7,6 & 6,4 & 14,3 \\
\hline Casado(a)/unido(a) & $\ldots$ & 56,2 & 57,6 & 59,0 & 64,2 & 59,6 & 6,3 \\
\hline Divorciado(a)/separado(a) & $\ldots$ & 12,7 & 10,7 & 8,8 & 3,1 & 7,3 & 21,4 \\
\hline Viudo(a) & $\ldots$ & 25,6 & 19,5 & 22,0 & 24,0 & 26,8 & 58,0 \\
\hline
\end{tabular}

Fuente: Elaboración propia, sobre la base de datos de IPUMS International, Censo de Población y Viviendas 2011(España), X Censo Nacional de Población y VI de Vivienda 2011 (Costa Rica), Censo de Población y Vivienda 2011 (Uruguay).

a La definición de urbano varía significativamente entre países. En algunos casos, se basa en la cantidad de población (Costa Rica y México) y en otros, en una clasificación administrativa (Brasil y Ecuador).

Los países que tienen mayor concentración de personas con 80 años y más son España y el Uruguay, donde representan un poco más del $20 \%$ de la población adulta mayor, lo que refleja un proceso de envejecimiento más avanzado en comparación con los otros países (véase el cuadro 3).

El alargamiento de la esperanza de vida ha traído consigo un mayor número de personas viudas y una extensión de la vida conyugal que puede incrementar las separaciones o los divorcios, dado que se tienen matrimonios de primeras y segundas nupcias. En la mayoría de los países, la condición conyugal que predomina es la de casado(a) o unido(a); destaca el caso del Uruguay, que presenta la mayor proporción de personas viudas (véase el cuadro 3 ). 


\section{Condiciones de las viviendas de la población adulta mayor en los países seleccionados}

\section{Disponibilidad de servicios}

Los entornos de las personas mayores se analizaron a través de los servicios que poseen en la vivienda y del acceso a tecnologías de la información, pues estos constituyen indicadores del contexto en el que residen. En los países seleccionados, se observa que la mayoría cuenta con servicio de electricidad (véase el cuadro 4); sin embargo, no ocurre lo mismo con el agua entubada: países como el Ecuador y México tienen porcentajes importantes de población adulta mayor que no recibe este servicio básico (véase el cuadro 5).

Cuadro 4

América Latina (países seleccionados): disponibilidad de electricidad en las viviendas donde reside la población adulta mayor

\begin{tabular}{lccccc}
\hline Disponibilidad de electricidad & $\begin{array}{c}\text { Brasil } \\
(\mathbf{2 0 1 0})\end{array}$ & $\begin{array}{c}\text { Costa Rica } \\
(\mathbf{2 0 1 1})\end{array}$ & $\begin{array}{c}\text { Ecuador } \\
(\mathbf{2 0 1 0})\end{array}$ & $\begin{array}{c}\text { México } \\
(\mathbf{2 0 1 0})\end{array}$ & $\begin{array}{c}\text { Uruguay } \\
(\mathbf{2 0 1 1})\end{array}$ \\
\hline Sí & 98,4 & 99,0 & 95,4 & 94,9 & 96,9 \\
\hline No & 1,6 & 1,0 & 4,6 & 4,5 & 0,7 \\
\hline No especificado & $\ldots$ & $\ldots$ & $\ldots$ & 0,6 & 2,4 \\
\hline Total & 100,0 & 100,0 & 100,0 & 100,0 & 100,0 \\
\hline
\end{tabular}

Fuente: Elaboración propia, sobre la base de datos de IPUMS International, X Censo Nacional de Población y VI de Vivienda 2011 (Costa Rica), Censo de Población y Vivienda 2011 (Uruguay).

\section{Cuadro 5}

América Latina (países seleccionados) y España: disponibilidad de agua en las viviendas donde reside la población adulta mayor

\begin{tabular}{lccccccc}
\hline Disponibilidad de agua & $\begin{array}{c}\text { Argentina } \\
(\mathbf{2 0 1 0})\end{array}$ & $\begin{array}{c}\text { Brasil } \\
(\mathbf{2 0 1 0})\end{array}$ & $\begin{array}{c}\text { Costa Rica } \\
(\mathbf{2 0 1 1})\end{array}$ & $\begin{array}{c}\text { Ecuador } \\
(\mathbf{2 0 1 0})\end{array}$ & $\begin{array}{c}\text { España } \\
(\mathbf{2 0 1 1})\end{array}$ & $\begin{array}{c}\text { México } \\
(\mathbf{2 0 1 0})\end{array}$ & $\begin{array}{c}\text { Uruguay } \\
(\mathbf{2 0 1 1})\end{array}$ \\
\hline $\begin{array}{l}\text { Entubada dentro } \\
\text { de la vivienda }\end{array}$ & 92,7 & 89,4 & 98,0 & 61,4 & 99,8 & 52,1 & 96,3 \\
\hline $\begin{array}{l}\text { Entubada dentro del } \\
\text { edificio o terreno }\end{array}$ & 6,0 & 3,7 & $\ldots$ & 20,9 & $\ldots$ & 30,2 & $\ldots$ \\
\hline $\begin{array}{l}\text { Entubada fuera de la } \\
\text { vivienda, edificio o terreno }\end{array}$ & $\ldots$ & $\ldots$ & $\ldots$ & 3,9 & $\ldots$ & $\ldots$ & 1,4 \\
\hline $\begin{array}{l}\text { Acceso a agua } \\
\text { entubada pública }\end{array}$ & $\ldots$ & $\ldots$ & $\ldots$ & & $\ldots$ & 2,4 & $\ldots$ \\
\hline $\begin{array}{l}\text { Sin agua entubada } \\
\text { No especificado }\end{array}$ & 1,4 & 6,9 & 2,0 & 13,8 & 0,2 & 15,0 & 1,3 \\
\hline Total & $\ldots$ & $\ldots$ & $\ldots$ & & $\ldots$ & 0,4 & 1,1 \\
\hline
\end{tabular}

Fuente: Elaboración propia, sobre la base de datos de IPUMS International, X Censo Nacional de Población y VI de Vivienda 2011 (Costa Rica), Censo de Población y Vivienda 2011 (Uruguay). 
Otro indicador de los servicios sociosanitarios es la existencia de drenaje o desagüe. En el caso de la población adulta mayor, llama la atención el alto porcentaje de personas en el Brasil, el Ecuador y México que no cuentan con drenaje. En cambio, en el caso de Costa Rica, destaca el alto porcentaje de viviendas que poseen fosa séptica. España es el que presenta el mayor porcentaje de viviendas con población adulta mayor que posee desagüe a la red pública (véase el cuadro 6). La carencia de este servicio y del agua es de gran importancia, dado que puede traducirse en una deficiencia de las condiciones de higiene y propiciar problemas de salud.

Cuadro 6

América Latina (países seleccionados) y España: disponibilidad de drenaje o desagüe en las viviendas donde reside la población adulta mayor

\begin{tabular}{lrrrrrrr}
\hline Tipo de drenaje & $\begin{array}{c}\text { Argentina } \\
(\mathbf{2 0 1 0})\end{array}$ & $\begin{array}{c}\text { Brasil } \\
(\mathbf{2 0 1 0})\end{array}$ & $\begin{array}{c}\text { Costa Rica } \\
(\mathbf{2 0 1 1})\end{array}$ & $\begin{array}{c}\text { Ecuador } \\
(\mathbf{2 0 1 0})\end{array}$ & $\begin{array}{c}\text { España } \\
(\mathbf{2 0 1 1})\end{array}$ & $\begin{array}{c}\text { México } \\
(\mathbf{2 0 1 0})\end{array}$ & $\begin{array}{c}\text { Uruguay } \\
(\mathbf{2 0 1 1})\end{array}$ \\
\hline Sistema de drenaje público & 59,9 & 48,0 & 25,6 & 54,4 & 93,4 & 47,2 & 62,1 \\
\hline Fosa séptica & 23,9 & 12,3 & 70,8 & 21,3 & $\ldots$ & 26,5 & 35,0 \\
\hline Sin drenaje & 16,2 & 39,6 & 3,5 & 24,3 & 0,3 & 25,4 & 0,4 \\
\hline No especificado & $\ldots$ & $\ldots$ & $\ldots$ & $\ldots$ & 6,3 & 0,9 & 2,4 \\
\hline Total & 100,0 & 100,0 & 100,0 & 100,0 & 100,0 & 100,0 & 100,0 \\
\hline
\end{tabular}

Fuente: Elaboración propia, sobre la base de datos de IPUMS International, Censo de Población y Viviendas 2011 (España), X Censo Nacional de Población y VI de Vivienda 2011 (Costa Rica), Censo de Población y Vivienda 2011 (Uruguay).

La disposición de gas entubado como principal combustible para cocinar predomina en la Argentina y el gas de cilindro en el Ecuador y el Uruguay. En México, un alto porcentaje de la población adulta mayor declaró usar madera como combustible para cocinar (42,2\%) (véase el cuadro 7). En el caso de España, en el censo de 2011 se preguntó sobre la disponibilidad de gas en el edificio donde residen las personas, a lo que un $49 \%$ de la población adulta mayor respondió no disponer de gas.

Cuadro 7

América Latina (países seleccionados): combustible empleado para cocinar en las viviendas donde reside la población adulta mayor

\begin{tabular}{lcccr}
\hline Tipo de combustible & $\begin{array}{c}\text { Argentina } \\
(\mathbf{2 0 1 0 )}\end{array}$ & $\begin{array}{c}\text { Ecuador } \\
(\mathbf{2 0 1 0 )}\end{array}$ & $\begin{array}{c}\text { México } \\
(\mathbf{2 0 1 0})\end{array}$ & $\begin{array}{c}\text { Uruguay } \\
(\mathbf{2 0 1 1})\end{array}$ \\
\hline Ninguno & $\ldots$ & 1,3 & $\ldots$ & 0,5 \\
\hline Electricidad & 0,2 & 0,6 & 2,2 & 5,8 \\
\hline Gas entubado & 66,9 & 0,2 & 54,5 & 8,4 \\
\hline Gas de tanque o bote & 30,5 & 85,8 & 42,2 & $\ldots$ \\
\hline Madera & $\ldots$ & $\ldots$ & 0,6 & 3,0 \\
\hline Otro & 2,5 & 12,1 & 0,5 & 2,4 \\
\hline No especificado & $\ldots$ & $\ldots$ & 100,0 & 100,0 \\
\hline Total & 100,0 & 100,0 & & \\
\hline
\end{tabular}

Fuente: Elaboración propia, sobre la base de datos de IPUMS International, Censo de Población y Vivienda 2011 (Uruguay). 
En relación con la eliminación de basura, se observa que, la mayoría de los países sobre los que se dispone de información cuentan con servicio de recolección de basura, aunque es elevada la proporción de personas que recurren a la quema (véase el cuadro 8). Nuevamente se observa un problema de servicios que la población resuelve de un modo que sin duda acarrea problemas ambientales y que además afecta las vías respiratorias.

Cuadro 8

\section{América Latina (países seleccionados): población adulta mayor} según servicio de eliminación de basura

(En porcentajes)

\begin{tabular}{lccc}
\hline Eliminación de basura & Brasil (2010) & Ecuador (2010) & México (2010) \\
\hline Recolectada directamente en el hogar o vivienda & 79,5 & 72,6 & 76,8 \\
\hline $\begin{array}{l}\text { Recolectada indirectamente de un contenedor } \\
\text { de basura o depósito }\end{array}$ & 6,4 & $\ldots$ & 3,2 \\
\hline Quema & 10,4 & 17,5 & 17,3 \\
\hline Arrojada en otros sitios o enterrada ${ }^{a}$ & 3,6 & 9,9 & 2,7 \\
\hline
\end{tabular}

Fuente: Elaboración propia, sobre la base de datos de IPUMS International.

a Incluye las categorías de enterrar, tirar en la calle, en baldíos, barrancas, grietas, ríos, lagos, océanos o lagunas, u otra forma de eliminación.

Sobre las tecnologías de la información y las comunicaciones (TIC) para la población adulta mayor, el servicio de mayor disponibilidad y presencia es el del teléfono fijo, sobre todo en España. En la Argentina, el Brasil y el Uruguay, un alto porcentaje de los adultos mayores reporta contar con teléfono celular. El teléfono fijo ha demostrado ser una herramienta que permite mantener la comunicación y las relaciones afectivas entre las personas mayores y sus familiares, pues en ocasiones la distancia física no permite visitas continuas (FernándezMayoralas, Rojo y Pozo, 2002). El tener computadora e Internet en el hogar no es un aspecto que destaque entre esta población; el más alto porcentaje de disponibilidad de computadora se observa en la Argentina y el de Internet, en España (véase el gráfico 1).

\section{Gráfico 1}

\section{América Latina (países seleccionados) y España: disponibilidad de tecnologías de la información y las comunicaciones (TIC) para la población adulta mayor}

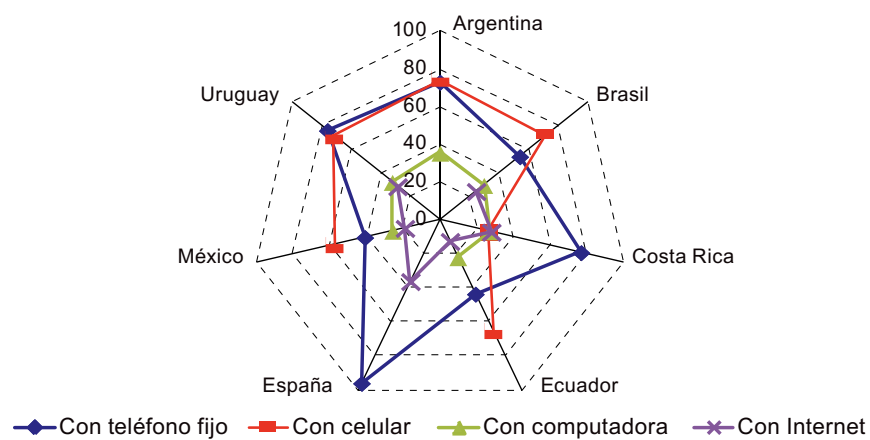

Fuente: Elaboración propia, sobre la base de datos de IPUMS International, Censo de Población y Viviendas 2011 (España), X Censo Nacional de Población y VI de Vivienda 2011 (Costa Rica), Censo de Población y Vivienda 2011 (Uruguay). 


\section{Condiciones de habitabilidad y equipamiento de la vivienda}

Uno de los aspectos señalados como factor de seguridad económica y de apoyo en la vejez es la tenencia de activos. Entre estos, la propiedad de la vivienda es uno de los más importantes, pues podría propiciar la recepción de apoyos de la descendencia, ya sea incorporándose al hogar de los padres u prestando alguna colaboración con la finalidad de heredar la propiedad (Fernández-Mayoralas, Rojo y Pozo, 2002). En los distintos países analizados, gran parte de la población adulta mayor es propietaria de su vivienda, condición que no varía demasiado por sexo y grupo de edad (véase el cuadro 9).

Cuadro 9

América Latina (países seleccionados) y España: población de 60 años o más con vivienda propia

(En porcentajes)

\begin{tabular}{|c|c|c|c|c|c|c|c|c|}
\hline \multirow[b]{2}{*}{ Países } & \multicolumn{2}{|c|}{ Sexo } & \multicolumn{5}{|c|}{ Grupos de edad } & \multirow[b]{2}{*}{ Total } \\
\hline & Hombres & Mujeres & $\begin{array}{l}60-64 \\
\text { años }\end{array}$ & $\begin{array}{c}65-69 \\
\text { años }\end{array}$ & $\begin{array}{l}70-74 \\
\text { años }\end{array}$ & $\begin{array}{l}75-79 \\
\text { años }\end{array}$ & $\begin{array}{l}80 \text { años } \\
\text { o más }\end{array}$ & \\
\hline Argentina (2010) & 86,2 & 87,0 & 85,0 & 86,7 & 87,4 & 87,7 & 87,5 & 86,6 \\
\hline Brasil (2010) & 86,0 & 86,0 & 85,3 & 86,5 & 86,9 & 86,6 & 85,1 & 86,0 \\
\hline Costa Rica (2011) & 84,8 & 86,7 & 84,8 & 85,7 & 86,4 & 86,5 & 86,8 & 85,8 \\
\hline Ecuador (2010) & 81,3 & 81,3 & 80,7 & 81,8 & 81,7 & 81,9 & 80,4 & 81,3 \\
\hline España (2011) & 87,6 & 86,5 & 88,1 & 89,0 & 87,2 & 86,1 & 84,4 & 86,9 \\
\hline México (2010) & 88,5 & 88,1 & 87,3 & 88,7 & 89,0 & 89,1 & 88,5 & 88,3 \\
\hline Uruguay (2011) & 70,9 & 71,8 & 69,0 & 70,8 & 72,0 & 73,2 & 73,5 & 71,5 \\
\hline
\end{tabular}

Fuente: Elaboración propia, sobre la base de datos de IPUMS International, Censo de Población y Viviendas 2011 (España), X Censo Nacional de Población y VI de Vivienda 2011 (Costa Rica), Censo de Población y Vivienda 2011 (Uruguay).

Las condiciones materiales de la vivienda han sido generalmente tomadas como un indicador de calidad de vida de las personas. Entre los países con información disponible, destaca el caso del Uruguay, donde la población adulta mayor cuenta con mejores condiciones de vivienda en comparación con los otros países, pues gran parte de ella cuenta con piso de mosaico u otra terminación, paredes de ladrillo, cemento o bloques de hormigón y techos de mampostería, concreto o arcilla. En el caso del Ecuador y México, llama la atención el porcentaje de personas cuyas viviendas tienen piso de tierra, superior al resto de los países; de igual forma, las paredes edificadas con un material diferente al ladrillo, el cemento o los bloques de hormigón es relevante en estos dos países. El material del techo de las viviendas varía en los países seleccionados; por ejemplo, en la Argentina predomina el techo de mosaico, arcilla o piedra plana y la hoja de metal, mientras que en el Ecuador una alta proporción de personas cuentan con techo de hoja de metal, y en México y el Uruguay, con techo de mampostería, concreto o arcilla (véase el cuadro 10). 
Cuadro 10

América Latina (países seleccionados): población con 60 años o más según materiales de la vivienda

(En porcentajes)

\begin{tabular}{|c|c|c|c|c|c|c|}
\hline Materiales de la vivienda & $\begin{array}{l}\text { Argentina } \\
(2010)\end{array}$ & $\begin{array}{l}\text { Brasil } \\
(2010)\end{array}$ & $\begin{array}{l}\text { Costa Rica } \\
(2011)\end{array}$ & $\begin{array}{l}\text { Ecuador } \\
\text { (2010) }\end{array}$ & $\begin{array}{l}\text { México } \\
(2010)\end{array}$ & $\begin{array}{l}\text { Uruguay } \\
(2011)\end{array}$ \\
\hline \multicolumn{7}{|l|}{ Material del piso } \\
\hline Ninguno (tierra) & 2,0 & $\ldots$ & 1,3 & 9,5 & 12,3 & 0,4 \\
\hline Cemento o ladrillo & 13,3 & $\ldots$ & 19,9 & 31,7 & 64,5 & 13,4 \\
\hline Madera & $\ldots$ & $\ldots$ & 8,2 & 20,1 & $\ldots$ & $\ldots$ \\
\hline Mosaico u otra terminación & 84,7 & $\ldots$ & 70,6 & 38,2 & 22,8 & 86,2 \\
\hline \multicolumn{7}{|l|}{ Material de las paredes } \\
\hline $\begin{array}{l}\text { Ladrillo, cemento o bloque de } \\
\text { hormigón }\end{array}$ & & 87,3 & & 75,1 & 64,6 & 98,3 \\
\hline Adobe & $\ldots$ & $\ldots$ & $\ldots$ & 10,4 & 22,3 & 0,2 \\
\hline Otro material & $\ldots$ & 12,0 & $\ldots$ & 14,1 & 12,6 & 1,5 \\
\hline \multicolumn{7}{|l|}{ Material del techo } \\
\hline Mampostería, concreto o arcilla & $\ldots$ & $\ldots$ & $\ldots$ & 25,3 & 49,9 & 64,2 \\
\hline Mosaico, arcilla o piedra plana & 35,0 & $\ldots$ & $\ldots$ & 14,8 & 9,8 & $\ldots$ \\
\hline Yeso laminado o plástico & 2,2 & $\ldots$ & $\ldots$ & $\ldots$ & $\ldots$ & 34,6 \\
\hline Cubierta de asfalto o laminada & 20,2 & $\ldots$ & 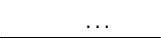 & ... & $\ldots$ & \\
\hline Teja o arcilla & 10,5 & $\ldots$ & - & $\ldots$ & $\ldots$ & $\ldots$ \\
\hline Asbesto & -- & $\ldots$ & $\ldots$ & 16,0 & 7,8 & $\ldots$ \\
\hline Hoja de metal & 29,3 & $\ldots$ & $\ldots$ & 41,9 & 25,6 & $\ldots$ \\
\hline Madera, caña o paja & 1,4 & $\ldots$ & $\ldots$ & 1,2 & 3,0 & 0,7 \\
\hline Material de desecho & $\ldots$ & $\ldots$ & $\ldots$ & $\ldots$ & 0,1 & 0,1 \\
\hline Cartón & 0,5 & $\ldots$ & $\ldots$ & $\ldots$ & 3,2 & $\ldots$ \\
\hline No especificado & 0,9 & & & 0,2 & $\ldots$ & 0,5 \\
\hline
\end{tabular}

Fuente: Elaboración propia, sobre la base de datos de IPUMS International, X Censo Nacional de Población y VI de Vivienda 2011 (Costa Rica), Censo de Población y Vivienda 2011 (Uruguay).

Las condiciones dentro de la vivienda muestran algunas particularidades. En el caso del número de cuartos, la población adulta mayor de la Argentina se ubica principalmente en viviendas con tres y cuatro cuartos (56,4\%); en el Brasil y Costa Rica, se concentra principalmente en viviendas con cinco y seis cuartos (43,6\% y 47,6\%); en el Ecuador y México, predominan las viviendas entre dos y cuatro cuartos $(63,4 \%$ y $68,2 \%)$, y en España, las de cuatro y cinco cuartos (56\%). El número de cuartos es un indicador general del tamaño de la vivienda y del hogar $u$ hogares que lo habitan, pero no da cuenta de la presencia o ausencia de hacinamiento. Para ello se calculó el índice de hacinamiento, observándose que los mayores porcentajes de hacinamiento medio y crítico se presentan en el Ecuador y México (véase el cuadro 11).

Otro aspecto relacionado con las condiciones de la vivienda se refiere a las comodidades que ofrece, es decir, la existencia de cocina y baño. Respecto de la cocina, no existe información sobre todos los países seleccionados, pero en aquellos de los que se tienen datos (Ecuador, México y Uruguay) se observa que la mayoría de la población 
cuenta con cocina en su vivienda, siendo ligeramente menores los porcentajes de México y el Ecuador en comparación con el Uruguay (véase el cuadro 12). El tipo de baño varía entre países, pero la ausencia de cuarto de baño en la vivienda se registra en mayor proporción en el Ecuador y México, y en menor medida en la Argentina y el Uruguay (véase el cuadro 13).

Cuadro 11

América Latina (países seleccionados): nivel de hacinamiento de las viviendas donde reside la población adulta mayor

(En porcentajes)

\begin{tabular}{lcccc}
\hline Índice de hacinamiento $^{\text {a }}$ & Argentina (2010) & Brasil (2010) & Ecuador (2010) & México (2010) \\
\hline Sin hacinamiento & 93,1 & 91,3 & 75,3 & 73,3 \\
\hline Hacinamiento medio & 6,3 & 7,9 & 16,1 & 20,7 \\
\hline Hacinamiento crítico & 0,6 & 0,8 & 8,6 & 6,0 \\
\hline Total & 100,0 & 100,0 & 100,0 & 100,0 \\
\hline
\end{tabular}

Fuente: Elaboración propia, sobre la base de datos de IPUMS International.

a El índice de hacinamiento resulta de la división del número de personas por el número de dormitorios. La clasificación es la siguiente: 2,4 y menos, sin hacinamiento; 2,5 a 4,9, hacinamiento medio; 5 y más, hacinamiento crítico. Cuando la vivienda no tiene dormitorios, el hacinamiento se considera crítico.

Cuadro 12

América Latina (países seleccionados): disponibilidad de cocina en las viviendas donde reside la población adulta mayor

(En porcentajes)

\begin{tabular}{lccc}
\hline Disponibilidad & Ecuador (2010) & México (2010) & Uruguay (2011) \\
\hline Sin cocina & 12,7 & 11,4 & 4,4 \\
\hline Con cocina & 87,3 & 87,8 & 93,2 \\
\hline Cocina compartida con otro hogar & $\ldots$ & $\ldots$ & $\ldots$ \\
\hline No especificado & $\ldots$ & 0,8 & 2,4 \\
\hline Total & 100,0 & 100,0 & 100,0 \\
\hline
\end{tabular}

Fuente: Elaboración propia, sobre la base de datos de IPUMS International, Censo de Población y Vivienda 2011 (Uruguay).

\section{Cuadro 13}

América Latina (países seleccionados): disponibilidad de baño en las viviendas donde reside la población adulta mayor

(En porcentajes)

\begin{tabular}{lcccr}
\hline Disponibilidad & Argentina (2010) & Ecuador (2010) & México (2010) & Uruguay (2011) \\
\hline Sin baño & 1,5 & 7,7 & 8,0 & 1,0 \\
\hline Con baño & 92,4 & 92,3 & 44,7 & 99,0 \\
\hline No especificado & 6,1 & $\ldots$ & 50,0 & $\ldots$ \\
\hline Total & 100,0 & 100,0 & 100,0 & 100,0 \\
\hline
\end{tabular}

Fuente: Elaboración propia, sobre la base de datos de IPUMS International, Censo de Población y Vivienda 2011 (Uruguay). 
Contar con cierto equipamiento en la vivienda puede hacer la diferencia entre tener dotaciones necesarias y de confort. De acuerdo con Fernández-Mayorales, Rojo y Pozo (2002), las primeras hacen referencia, entre otras cosas, a la disponibilidad de calefacción ${ }^{10}$ y agua caliente; las segundas incluyen la tenencia de refrigerador, dos o más duchas y dos o más retretes. En los países seleccionados se hace referencia solo a algunas de las mencionadas dotaciones; por ejemplo, se encuentra que el tener refrigerador es predominante en la mayor parte de los países (Argentina, Brasil, México y Uruguay), pero eso no ocurre con el hecho de tener lavadora, que representa una mayor proporción en México comparada con el Brasil. El tener agua caliente hace referencia a contar con calentador de agua: solo en el Uruguay, cerca del $90 \%$ de la población adulta mayor posee este equipamiento en la vivienda. El televisor es un artículo que tiene gran presencia en la mayoría de los países seleccionados, siendo el Brasil y el Uruguay los que registran la mayor proporción. La disposición de calefacción y aire acondicionado solo está presente en España y el Uruguay, siendo la primera uno de los equipamientos que reflejan mayores porcentajes en España (véase el cuadro 14).

Cuadro 14

América Latina (países seleccionados) y España: población adulta mayor que cuenta con algún tipo de equipamiento en la vivienda

(En porcentajes)

\begin{tabular}{lc}
\hline Argentina (2010) & \\
\hline Refrigerador & 97,1 \\
\hline Brasil (2010) & 49,3 \\
\hline Lavadora & 94,5 \\
\hline Refrigerador & 94,1 \\
\hline Televisor & 82,8 \\
\hline Radio & 12,0 \\
\hline Costa Rica (2011) & 91,4 \\
\hline Agua caliente & 33,8 \\
\hline Televisor & 88,0 \\
\hline España (2011) & 50,5 \\
\hline Agua caliente & 66,3 \\
\hline Calefacción & 82,7 \\
\hline México (2010) & 89,6 \\
\hline Agua caliente & 78,1 \\
\hline Lavadora & \\
\hline Refrigerador & 88,1 \\
\hline Televisor & 87,5 \\
\hline Radio & 92,8 \\
\hline Uruguay (2011) & 8,3 \\
\hline Agua caliente & 94,3 \\
\hline Calefacción & 92,5 \\
\hline Refrigerador & \\
\hline Secadora de ropa & \\
\hline Televisor & \\
\hline Radio & \\
\hline & \\
\hline
\end{tabular}

Fuente: Elaboración propia, sobre la base de IPUMS International, Censo de Población y Viviendas 2011 (España), X Censo Nacional de Población y VI de Vivienda 2011 (Costa Rica), Censo de Población y Vivienda 2011 (Uruguay).

a Se incluye solo la información disponible de cada país.

10 La calefacción, según Fernández-Mayoralas, Rojo y Pozo (2002), es una dotación necesaria para mantener cierta calidad de vida, sobre todo para las personas mayores residentes en climas fríos (incluso no extremos), pues la ausencia de este equipamiento puede generar problemas serios de salud en esta población. 


\section{E. Conclusiones y discusión}

El panorama mostrado corresponde a las características de habitabilidad de las viviendas en donde reside la población adulta mayor, que forman parte de las condiciones mínimas que deben reunir. Los datos presentados indican que en España las viviendas de la población adulta mayor cuentan con servicios básicos, condiciones materiales adecuadas y el equipamiento necesario; sin embargo, en algunos países latinoamericanos, como el Brasil, el Ecuador y México, aún se observan serios rezagos en el acceso a servicios básicos (agua entubada y drenaje) y las condiciones materiales y de equipamiento de la vivienda no son las mejores. Esto representa un reto importante para el análisis de los entornos físicos y sociales, pues no se puede avanzar en este sentido si las necesidades más básicas no están cubiertas.

El análisis comparado ha permitido evidenciar que en la mayoría de los países analizados las condiciones de una vivienda digna y sus carencias en materia de servicios continúan siendo un tema presente, dada la heterogeneidad y desigualdad social que existe. Por otro lado, la disponibilidad de información de España permite ver la falta de datos de los países de la región, lo que valdría la pena solucionar en futuros esfuerzos por tratar el tema en los países latinoamericanos.

Como parte del estudio del entorno residencial y la calidad de vida de las personas mayores, en el censo de población y en algunas encuestas a hogares de España se han contemplado dimensiones de gran importancia sobre la vivienda, como la superficie útil, el tipo de vivienda, el tipo de edificio, el número de pisos, el año de construcción, el estado del edificio, la disponibilidad de ascensor, la accesibilidad, la disponibilidad de garaje, el número de baños y otras. Además, se han incluido aspectos relacionados con el equipamiento, por ejemplo, la disponibilidad de calefacción, el tipo de calefacción, el tendido telefónico y la disponibilidad de agua caliente, entre otros. Estas temáticas incorporadas en las fuentes de datos españolas han mostrado ser de gran utilidad en el análisis del entorno residencial de las personas mayores, pues permiten contar con un panorama más amplio sobre las dotaciones y el ambiente en el cual se desenvuelven. Asimismo, se ha señalado la importancia de considerar el espacio disponible en las viviendas, dado que, cuando reside un mayor número de miembros en el hogar, el número de metros por personas de la vivienda se reduce (Rojo y otros, 2001; Fernández-Mayoralas, Rojo y Pozo, 2002). Estos son solo algunos ejemplos de la importancia que tienen algunos temas para ampliar la visión de habitabilidad de la vivienda en las encuestas latinoamericanas.

Cabe agregar que, cuando se analizan las viviendas de la población adulta mayor, se debe considerar la accesibilidad para facilitar el desempeño de actividades básicas en el interior y en el entorno próximo (CELADE, 2006). Esto incluye el estudio de las adecuaciones que se hacen en algunas viviendas cuando la población adulta mayor presenta alguna limitación para realizar las actividades básicas de la vida diaria.

Otro aspecto a considerar en futuros estudios es la percepción y los significados que atribuyen las personas mayores a su vivienda y barrio, así como sus preferencias por 
residir en cierto lugar y el bienestar o el conflicto derivados de su entorno residencial. Las investigaciones han demostrado la importancia que tiene para las personas mayores envejecer en casa, a pesar de las limitaciones físicas que puedan tener (Rojo y otros, 2001; INGEMA s/f), de ahí la relevancia de no perder de vista esta temática.

Por último, no hay que dejar de lado que dentro de los entornos físicos también se deben tener en cuenta las características de los elementos externos de la vivienda, como determinantes socioambientales de la calidad de vida en la vejez, por ejemplo, la seguridad peatonal, la accesibilidad de las calles, la cercanía a las áreas de desperdicios o industrias tóxicas, y la seguridad del transporte público. Si bien estos elementos pueden captarse en los censos o encuestas, también pueden ser rastreados mediante estudios cualitativos que analicen en profundidad los entornos físicos y sociales con una perspectiva objetiva y subjetiva.

\section{Bibliografía}

CELADE (Centro Latinoamericano y Caribeño de Demografía-División de Población de la CEPAL) (2006), "Manual sobre indicadores de calidad de vida en la vejez" (LC/W.113), Santiago, Comisión Económica para América Latina y el Caribe (CEPAL).

CEPAL (Comisión Económica para América Latina y el Caribe) (2009), "Proyección de población", Observatorio Demográfico, $\mathrm{N}^{\circ} 7$ (LC/G.2414-P), Santiago.

Committee on an Aging Society (1985), The Social and Built Environment in an Older Society, National Academies Press.

Contreras de Lehr, E. (1992), "Aging and family support in Mexico", Family Support for the Elderly: The international experience, H.L. Kendig, A. Hashimoto y L.C. Coppard (eds.), Nueva York, Oxford University Press.

De Vos, S., P. Solís y V. Montes de Oca (2004), "Receipt of assistance and extended family residence among elderly men in Mexico", International Journal of Aging and Human Development, vol. $58, \mathrm{~N}^{\circ} 1$.

Fernández-Mayoralas, G., F. Rojo y E. Pozo (2002), "El entorno residencial de los mayores en Madrid", Estudios Geográficos, vol. LXIII, No $248 / 249$.

Fernández-Mayoralas, G., F. Rojo y J.M. Rojo (2004), "Components of the residential environment and socio-demographic characteristics of the elderly", Journal of Housing for the Elderly, vol. 18, № 1.

Flores, M. E. y otros (2011), "Concepto de la calidad de vida en relación con el adulto mayor", Condiciones sociales y calidad de vida en el adulto mayor. Experiencias de México, Chile y Colombia, M. E. Flores, M. G. Vega y G. J. González (coords.), Universidad de Guadalajara.

Garay, S. y V. Montes de Oca (2011), "La vejez en México: una mirada general sobre la situación socioeconómica y familiar de los hombres y mujeres adultos mayores", Perspectivas Sociales/Social Perspectives, vol. 13, $\mathrm{N}^{\circ} 1$.

Garay, S., V. Montes de Oca y J. Guillén (2014), "Social support and social networks among the elderly in Mexico: Updating the discussion on reciprocity", Journal of Population Ageing, vol. 7, $\mathrm{N}^{\circ} 2$.

Guzmán, J. M., S. Huenchuan y V. Montes de Oca (2003), "Marco conceptual sobre redes de apoyo social de las personas mayores", Redes de apoyo social de las personas mayores en América Latina y el Caribe, serie Seminarios y Conferencias, No 30 (LC/L.1995-P), Santiago, Comisión Económica para América Latina y el Caribe (CEPAL). 
INGEMA (Instituto Gerontológico Matia) (s/f), "Envejecimiento, vivienda y entorno. Informe de la investigación cualitativa" [en línea] http://www.tecnologiasocial.org/upload/files/Housing Cualitativo_final.pdf.

López, A. (2001), El perfil sociodemográfico de los hogares en México 1970-1997, México, D.F., Consejo Nacional de Población (CONAPO).

Montes de Oca, V. y otros (2014), "Living arrangements and aging in Mexico: Changes in households, poverty and regions, 1992-2009", International Journal of Social Science Studies, vol. 2, No 4.

Morgan, J. N. (1985), "The relation of housing and living arrangements to the productivity of older people", The Social and Built Environment in an Older Society, Committee on an Aging Society, National Academies Press.

Oliveira, O. de (1988), "Unidades domésticas y familias censales", DEMOS, Carta Demográfica sobre México, $1988, \mathrm{~N}^{\circ} 1$.

OMS (Organización Mundial de la Salud) (1995), "The World Health Organization Quality of Life Assessment (WHO-QOL). Position paper from the World Health Organization", Social Science and Medicine, $\mathrm{N}^{\mathrm{O}} 10$.

Osorio, P., M.J. Torrejón y N. Vogel (2008), “Aproximación a un concepto de calidad de vida en la vejez. Escuchando a las personas", Revista de Psicología, vol. XVII, $\mathrm{N}^{\circ} 1$.

Quilodrán, J. (2011), "Los cambios en la familia vistos desde la demografía: una breve reflexión", Parejas conyugales en transformación, J. Quilodrán (coord.), México, El Colegio de México.

Red de Envejecimiento de ALAP (2012), "Envejecimiento poblacional y condiciones de vida de los adultos mayores. La situación paraguaya en la perspectiva latinoamericana", Perspectivas Sociales/ Social Perspectives, vol. 14, $\mathrm{N}^{\circ} 2$.

Rojo, F. y otros (2014), "La vivienda como elemento del entorno residencial", Argentina, Españay México: panorámica sociodemográfica comparada, Documento de Trabajo, F. Rojo y otros, Departamento de Población, Instituto de Economía, Geografía y Demografía del Consejo Superior de Investigaciones Científicas (CSIC) [en línea] http://envejecimiento.csic.es/documentos/documentos/DptoPoblenvejecimiento-enfoques-argentina-espana-mexico-02-2015.pdf.

(2002), Envejecer en casa: la satisfacción residencial de los mayores en Madrid como indicador de su calidad de vida, Consejo Superior de Investigación Científica.

(2001), "Ageing in place: Predictors of the residential satisfaction of elderly", Social Indicators Research, $\mathrm{N}^{\circ} 54$.

Soldo, B. y C.F. Longino Jr. (1985), "Social and physical environments for the vulnerable aged", The Social and Built Environment in an Older Society, Committee on an Aging Society, National Academies Press.

Struyk, R. J. (1985), "Current and emerging issues in housing environments for the elderly", The Social and Built Environment in an Older Society, Committee on an Aging Society, National Academies Press.

Varley, A. y M. Blasco (2001), “¿Cosechan lo que siembran? Mujeres ancianas, vivienda y relaciones familiares en el México urbano", Procesos sociales, población y familia. Alternativas teóricas y empíricas en las investigaciones sobre vida doméstica, C. Gomes, México, D.F., Facultad Latinoamericana de Ciencias Sociales (FLACSO)/Miguel Ángel Porrúa.

Wachs, M. (1985), "The role of transportation in the social integration of the aged", The Social and Built Environment in an Older Society, Committee on an Aging Society, National Academies Press. 



\title{
Del rejuvenecimiento al envejecimiento de la población ¿o viceversa?: Chile en el contexto de América Latina, 1950-2050
}

\author{
Rodrigo Rivero-Cantillano ${ }^{1}$ \\ Jeroen Spijker²
}

\section{Resumen}

En este trabajo se propone un nuevo enfoque para analizar el envejecimiento demográfico, la prospectiva, que considera las mejoras en la esperanza de vida para calcular la edad umbral de la vejez, como alternativa al uso de una edad fija como los 60 o 65 años. El objetivo es, en primer lugar, describir los factores del envejecimiento en Chile. En segundo lugar, ofrecer una nueva perspectiva del envejecimiento desde 1950 hasta 2050. Por último, analizar el envejecimiento del país en el mismo período dentro del contexto de América Latina bajo esta nueva perspectiva. Si se piensa en la vejez no solo en términos de los años vividos, sino también en términos de los años que quedan por vivir, el resultado es una población mayor de 65 años que ha rejuvenecido

\footnotetext{
Estudiante del Programa de Doctorado en Historia Económica del Departamento de Historia e Instituciones Económicas de la Universidad de Barcelona (España). Becario del programa Formación de Capital Humano Avanzado, Becas Chile, CONICYT. Correo electrónico: rodrigoriverocn@gmail.com.

2 Doctor en Ciencias Espaciales (especialización en Demografía), Universidad de Groningen (Países Bajos). Actualmente es investigador del Centro de Estudios Demográficos de la Universidad de Barcelona en el marco del programa Ramón y Cajal (RYC-2013-14851), financiado por el Ministerio de Economía y Competitividad de España. El trabajo también se enmarca en el proyecto I+D-Retos “¿Con quién viviré y quien me cuidará?” (CSO201460113-R), codirigido por Spijker y financiado por el mismo Ministerio. Correo electrónico: jspijker@ced.uab.es.
} 
en términos prospectivos, debido a las mejoras de la esperanza de vida en edades avanzadas; por lo tanto, la edad adquiere un nuevo significado.

Palabras clave: envejecimiento, esperanza de vida, edad prospectiva, edad mediana prospectiva, tasa de dependencia de personas mayores prospectiva.

\begin{abstract}
This paper presents a new approach to analysing population ageing, the prospective approach, which considers improvements in life expectancy to calculate the threshold for old age, as an alternative to using a fixed age, such as 60 or 65 years. The paper, first of all, describes the main factors behind ageing in Chile. Secondly, it offers a new perspective on ageing over the period 1950-2050. Lastly, it analyses ageing in Chile over the same period, in the context of Latin America, from this new perspective. Considering old age not only in terms of years lived, but also in terms of years left to live, yields a rejuvenated over-65 population, in prospective terms, as a result of improved life expectancy in old age. Age therefore on a changed meaning.
\end{abstract}

Keywords: aging; life expectancy; prospective age; average prospective age; prospective old age dependency ratio

\title{
Résumé
}

Dans cette étude, les auteurs proposent une nouvelle approche pour analyser le vieillissement démographique, à savoir la prospective qui tient compte des améliorations dans l'espérance de vie pour calculer l'âge considéré comme seuil de la vieillesse comme alternative à l'utilisation d'un âge fixe comme 60 ou 65 ans. L'objectif consiste d'abord à décrire les facteurs du vieillissement au Chili. II s'agit ensuite de présenter une nouvelle perspective du vieillissement de 1950 à 2050, et finalement d'analyser le vieillissement du pays au cours de la même période dans le contexte de l'Amérique latine et dans le cadre de cette nouvelle perspective. Considérant la vieillesse non seulement en termes d'années vécues, mais aussi en termes d'années qui restent à vivre, le résultat est une population de plus de 65 ans qui a rajeuni en termes prospectifs en raison de l'amélioration de l'espérance de vie à l'âge avancé, ce qui donne à l'âge un nouveau sens.

Mots clés: vieillissement, espérance de vie, âge prospectif, âge moyen prospectif, taux prospectif de dépendance des personnes âgées. 


\section{Introducción}

El envejecimiento demográfico consiste en un cambio, en términos relativos, de la estructura por edades de la población, que fundamentalmente se traduce en un aumento del porcentaje de personas en edad avanzada (Díaz, 1998). A diferencia del envejecimiento biológico que experimentan las personas, el envejecimiento demográfico es reversible, dando espacio a períodos de rejuvenecimiento ${ }^{3}$. En la actualidad, el envejecimiento es una dinámica generalizada entre los países más desarrollados, y se espera que en el futuro se extienda a nivel global. En consecuencia, en las últimas décadas el envejecimiento ha dominado el debate en torno a la relación entre la estructura de la población y sus implicancias sociales y económicas.

El análisis del envejecimiento de la población se ha realizado habitualmente sobre la base de la dimensión cronológica de la edad, es decir, con un enfoque retrospectivo, que considera el número de años vividos desde el nacimiento. En este trabajo se propone una visión complementaria, la dimensión prospectiva, que considera las mejoras en la esperanza de vida, las que dan un nuevo significado a la edad cronológica. Sobre la base de este enfoque, se obtiene una nueva imagen del envejecimiento, más proporcional y a la vez coherente con los grandes avances producidos en la esperanza de vida a edades avanzadas durante las últimas décadas. Además, viene a satisfacer la necesidad de considerar el envejecimiento no solo en términos de los años vividos, sino también de los años que quedan por vivir.

El objetivo de este trabajo es, en primer lugar, describir los factores que originaron el envejecimiento en Chile. En segundo lugar, ofrecer una nueva perspectiva de este fenómeno que contemple las mejoras en la esperanza de vida desde 1950 hasta 2050. Por último, se analizará el envejecimiento de la población del país dentro del contexto de América Latina bajo esta nueva perspectiva y en el mismo período.

\section{A. El envejecimiento en la literatura}

El cambio en la estructura de edades de la población ha dominado el debate sobre las consecuencias sociales y económicas de la transición demográfica ${ }^{4}$. El trabajo seminal de Coale y Hoover (1958) fue seguido por Leff (1969), Gupta (1971), Goldberger (1973), Kelley (1973) y Arthur y McNicoll (1977), y retomado en los años noventa por Higgins y Williamson (1997), Andersson (2001), Lindh y Malmberg (1999), Brander y Dowrick (1994), Bloom y Williamson (1998), Bloom, Canning y Sevilla (2003) y Reher (2011). El envejecimiento es el término que sintetiza los cambios en la distribución por edades de la población hacia las

3 Especialmente en momentos de rápido crecimiento de la población causado por un incremento del número de nacimientos o de la inmigración. En este sentido, cabe destacar en la región los casos de la Argentina, Cuba y el Uruguay, donde las corriente migratorias han influido en el cambio de la estructura demográfica (Villa y Rivadeneira, 2000).

4 Véase Notestein (1945), Chesnais (1986), Weeks (1984). Sobre la transición demográfica en América Latina, véase Ortega Ordóñez y Villamarín Martínez (2010). 
edades más avanzadas (Gavrilov y Heuveline 2003), los que tienen determinados efectos sobre la sociedad (Bongaarts, 2004; Doyle y otros, 2009; Bloom, Canning y Fink, 2010; Wolf y Amirkhanyan, 2010; Spijker y MacInnes, 2013).

A diferencia de los países más desarrollados y al igual que en la mayor parte de América Latina ${ }^{5}$, en Chile el envejecimiento es un tema reciente. La mayoría de los países poseen en la actualidad una estructura poblacional joven, aunque envejecen rápidamente, por lo que este fenómeno se ha convertido en una preocupación a mediano plazo ${ }^{6}$.

Pese a la elocuencia del concepto de envejecimiento, su definición implica una gran complejidad. Generalmente, los 65 años es la edad que las sociedades con algún tipo de sistema de bienestar han fijado como la frontera legal entre el fin de la adultez y el inicio de la vejez. Se ha considerado como la edad a partir de la cual los trabajadores activos pueden retirarse del mercado de trabajo, pudiendo obtener una retribución económica por el tiempo que les quede de vida, independientemente de su esperanza de vida?

También en la academia se suele utilizar una edad fija como los 60065 años como umbral de envejecimiento, por ejemplo, para estimar la carga demográfica de la población mayor en las finanzas públicas o transferencias sociales (Chackiel, 2000; Rosero-Bixby y Jiménez, 2012), sin considerar la heterogeneidad de la población mayor ni el aumento de la esperanza de vida, lo que hace cuestionar la comparabilidad entre dos personas de la misma edad en dos momentos distintos del tiempo (Desjardins y Légeré 1984).

Como alternativa, el concepto de envejecimiento se ha redefinido, mezclando dos dimensiones de la edad: la cronológica o retrospectiva, que corresponde a los años vividos desde el nacimiento, y la prospectiva, basada en la esperanza de vida de las personas. Entre los trabajos que han sentado las bases de esta nueva perspectiva están los de Ryder (1975) y Sanderson y Scherbov $(2005,2007$ y 2010), que toman en consideración las mejoras de las expectativas de vida para elaborar nuevos enfoques sobre el envejecimiento.

\section{B. Metodología}

Sanderson y Scherbov (2007 y 2010) proponen un nuevo enfoque para medir la edad: la orientación hacia el futuro (forward-looking). El punto central de esta nueva perspectiva es establecer la existencia de dos edades diferentes para cada persona. Por un lado, la edad cronológica o retrospectiva, es decir, el número de años que cada persona ha vivido. En este sentido, todos aquellos que tengan la misma edad han vivido el mismo número de años. Por

Salvo el Uruguay (véase Solari (1957)).

6 Véase Chesnais (1990), Chackiel (2000, 2004a y 2004b), Del Popolo (2001), Guzmán (2001), Rivadeneira y Villa (2000), Lee y Donehower (2010), Leiva (2010), Rosero-Bixby y Jiménez (2011), Saravia (2012) y, en relación con Chile, Domínguez (1987), Meza (2003), Villa y González (2004) Huenchuan y otros (2007), Cerda (2008), Donoso y Carvajal (2009), Villalón y Vera (2012).

7 Véase el artículo 26 del Convenio núm. 102 sobre la seguridad social de la Organización Internacional del Trabajo (OIT) de 1952. 
otro lado, la edad prospectiva, con una perspectiva de futuro, que implica que todos aquellos con la misma edad prospectiva tienen por delante la misma expectativa de años por vivir.

En el diagrama 1 se muestra el modo de calcular la edad prospectiva. El panel de la izquierda contiene dos columnas de la tabla de mortalidad para una persona de edad a en determinado año, que recibe el nombre de año índice. En la primera columna se incluye la edad de la persona y en la segunda se muestra la esperanza de vida a esa edad, también en el año índice. El panel de la derecha contiene las mismas dos columnas de las tablas de mortalidad, pero están presentadas en el sentido opuesto, haciendo un efecto de espejo. La tercera columna contiene la misma esperanza de vida de a, pero esta vez en la tabla de mortalidad del año estándar ${ }^{8}$. Por último, la cuarta columna contiene la edad exacta en que en el año estándar poseía la misma esperanza de vida que en la segunda columna. La edad prospectiva de una persona con edad a en el año índice es la edad en el año estándar denotada con A. Entonces, la esperanza de vida restante de la persona de edad a en el año índice es la misma que una persona de edad A en el año estándar (Sanderson y Scherbov, 2007).

\section{Diagrama 1}

\section{Determinación de la edad prospectiva}

Tabla de mortalidad del año índice

\begin{tabular}{|c|c|}
\hline $\begin{array}{c}\text { Edad } \\
\text { retrospectiva }\end{array}$ & $\begin{array}{c}\text { Esperanza de } \\
\text { vida restante }\end{array}$ \\
\hline$a$ & $E V R_{a}^{\text {indice }}$ \\
\hline
\end{tabular}

Tabla de mortalidad del año estándar

\begin{tabular}{|c|c|}
\hline $\begin{array}{c}\text { Esperanza de } \\
\text { vida restante }\end{array}$ & Edad prospectiva \\
\hline$E V R_{A}^{\text {estándar }}$ & $A$ \\
\hline
\end{tabular}

Fuente: W. Sanderson y S. Scherbov, "A new perspective on population aging", Demographic Research, vol. 16, № 2, 2007.

Aplicando esta nueva perspectiva, se obtienen nuevos indicadores para medir el envejecimiento en Chile, desde 1950 hasta la actualidad, pudiéndose proyectar la tendencia hasta 2050.

En este sentido, la tasa de dependencia de las personas mayores (TDM) se define como el cociente entre la población que ha llegado a la vejez, es decir, de 65 años y más, y la población considerada activa, que generalmente abarca a las personas de 16 a 64 años? Por otro lado, sobre la base del enfoque prospectivo, se obtiene la tasa de dependencia de las personas mayores prospectiva (TDMP), que tiene por numerador la suma de hombres y mujeres (estimada por separado, como indica la fórmula) que poseen una esperanza de vida de 15 años y menos, en lugar del total de personas de 65 años y más, como sucede con la tasa de dependencia tradicional (Sanderson y Scherbov, 2007). Para obtener la tasa de

8 En este trabajo, el año estándar corresponde al período 2000-2005 de las tablas abreviadas de mortalidad publicadas en CEPAL (2004), el trabajo más actualizado que cuenta con tablas abreviadas de mortalidad desde mediados del siglo XX.

$9 \operatorname{TDM}=\left(\frac{\sum_{\text {s población } 65+}}{\sum_{\mathrm{s} \text { población } 16-64}}\right) * 100$ 
dependencia prospectiva, se divide el numerador por el número de hombres y mujeres que tengan 16 años o más de edad y una esperanza de vida superior a 15 años ${ }^{10}$.

$$
\mathrm{TDMP}=\left(\frac{\sum_{\text {s población } E V \leq 15}}{\sum_{\mathrm{s} \text { población }>15 \& \sum_{\mathrm{s}} \text { población } E V>15}}\right) * 100
$$

De esta forma, se integra el enfoque prospectivo en el indicador de envejecimiento por excelencia: la proporción de personas dependientes mayores por cada persona activa ${ }^{11}$.

\section{Factores demográficos de envejecimiento en la transición demográfica chilena}

Desde una perspectiva demográfica, las primeras décadas del siglo XX en Chile fueron una continuación del siglo anterior. Los altos niveles de natalidad eran compensados por los altos niveles de mortalidad, coincidiendo con el típico esquema antiguo o premoderno de crecimiento. En las décadas de 1930 y 1960 tuvieron lugar dos puntos de inflexión en la historia demográfica del país. El primero corresponde a la consolidación de la transición de la mortalidad y el segundo marca el inicio del declive de las tasas de natalidad y el comienzo de la transición de la fecundidad.

Tanto el rejuvenecimiento como el envejecimiento son dinámicas que tienen lugar dentro del proceso de transición demográfica (Chackiel, 2004a). Primero, la combinación de una drástica reducción de la mortalidad a edades tempranas con un aumento de la fecundidad dio lugar al rejuvenecimiento de la población chilena. Luego, tras la década de

10 Alternativamente, se puede escoger como denominador una edad mínima de 20 años en lugar de 16, para ajustar el retraso en la entrada al mercado laboral como consecuencia de la expansión educativa

$$
\left(\mathrm{TDMP}=\left(\frac{\sum_{\mathrm{s} \text { población } E V \leq 15}}{\left(\text { población } \geq 20 \text { \& } \sum \text { s población } E V>15\right.}\right) * 100\right)
$$

11 Para realizar el análisis de los cambios demográficos en Chile, se empleó la información de dos fuentes, la División de Población de las Naciones Unidas y el Centro Latinoamericano y Caribeño de Demografía (CELADE)-División de Población de la CEPAL. De la primera se obtuvieron las estimaciones de población, la estructura por edad entre 1950 y 2010 y las proyecciones hasta 2050. Se optó por esta fuente porque publica estimaciones de la población para edades simples anuales desde 1950 hasta 2100 , necesarias para calcular los indicadores de envejecimiento, como la edad que corresponde a una esperanza de vida de 15 años. En cambio, los datos del CELADE-División de Población de la CEPAL están expresados en edades quinquenales para años quinquenales (véanse más detalles [en línea] http://esa.un.org/ wpp/cepal.org/celade/proyecciones/basedatos_BD.htm). Para las estimaciones de la esperanza de vida, se utilizaron las tablas abreviadas de mortalidad del CELADE-División de Población de la CEPAL del período comprendido entre los quinquenios 1950-1955 y 2005-2010 publicadas por la CEPAL (2004) y las tablas abreviadas de mortalidad de la División de Población de las Naciones Unidas del período 2010-2050. Para esta última elección, se tuvo en cuenta el carácter moderado de la fuente frente a las proyecciones del CELADE-División de Población de la CEPAL, la Superintendencia de Pensiones y la Superintendencia de Valores de Seguros (SVS) (véase [en línea] http://www.svs.cl/portal/prensa/604/ w3-article-20463.html), estas últimas las menos conservadoras. Por ejemplo, entre los períodos 1950-1955 y 2005-2010, aunque el CELADE-División de Población de la CEPAL y la División de Población de las Naciones Unidas coinciden en la estimación de esperanza de vida, la proyección para los hombres chilenos de 65 años de edad del período 20102015 es de 17,3 años según el primero y de 17,9 años según la segunda, y para 2020-2025 es de 17,84 y 19,11 años, respectivamente. En cambio, para la SVS, la esperanza de vida masculina a los 65 años de edad en 2016 es de 20,6 años. Una subestimación de esperanza de vida conlleva menos personas a edades avanzadas, por lo cual las proyecciones del CELADE-División de Población de la CEPAL se desestimaron al ser las más conservadoras. 
1970, la confluencia de un notable descenso de la mortalidad a edades avanzadas y un aún más marcado descenso de la fecundidad dio paso al incipiente proceso de envejecimiento, que se ha intensificado con el pasar de los años.

\section{Cambios en la fecundidad}

Desde mediados del siglo XX se observan dos tendencias significativas de cambio de la fecundidad. Primero, entre 1950 y 1960 , la tasa global de fecundidad experimenta un crecimiento de 4,9 a 5,5 hijos por mujer en edad fértil. Posteriormente, a partir de la década de 1960, la transición de fecundidad hizo bajar rápidamente la tasa de fecundidad global, que decayó a 2,2 hijos hacia finales del siglo XX, para situarse por debajo del nivel de reemplazo desde el inicio del siglo XXI, lo que equivale a una reducción del $66 \%$ en casi 40 años.

Los cambios de la tendencia de la fecundidad han tenido un impacto importante en el crecimiento de la población joven. Entre los censos de 1952 y 1960, la población joven de o a 15 años alcanzó su mayor ritmo de crecimiento, con una tasa intercensal del 3,2\% anual, frente al $2,4 \%$ que exhibía el total de la población en el mismo período. Tras este período de rápido crecimiento, se redujo significativamente el ritmo de crecimiento de la población joven, cediendo protagonismo a otros grupos.

El impacto de la fecundidad en la estructura de la población puede apreciarse en el índice de Friz, el que, tras un breve rejuvenecimiento, da paso al envejecimiento ${ }^{12}$ (véase el gráfico 1).

Gráfico 1

Chile: índice de Friz y tasa global de fecundidad, 1950-2015

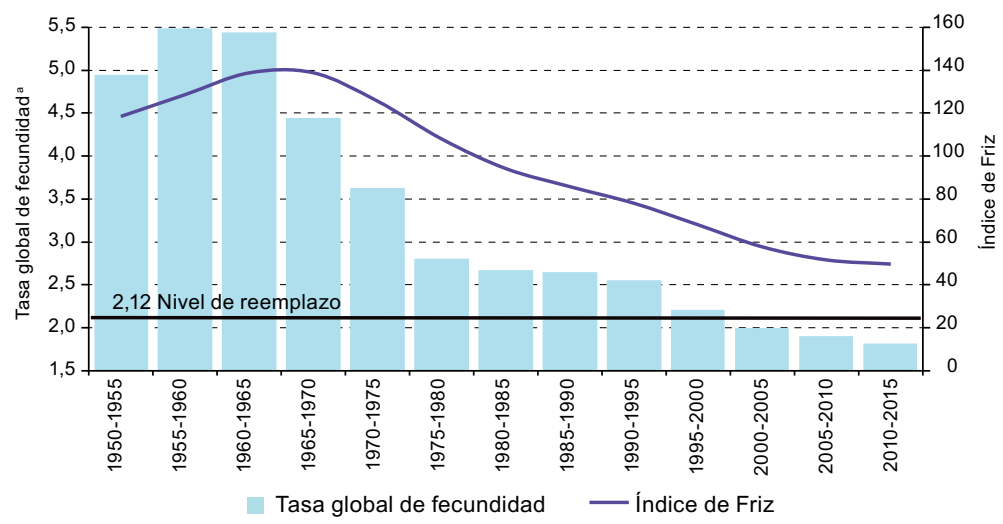

Fuente: Elaboración propia, sobre la base de Comisión Económica para América Latina y el Caribe (CEPAL), "América Latina: estimaciones y proyecciones de población a largo plazo 1950-2100: Revisión 2013", Centro Latinoamericano y Caribeño de Demografía (CELADE)-División de Población de la CEPAL, 2013 [en línea] http://www.cepal.org/celade/proyecciones/basedatos_bd.htm [fecha de consulta: 16 de junio de 2015].

a Expresada en número de hijos por mujer.

12 El índice de Friz hace referencia al grupo de población de 30 a 49 años en relación porcentual con la de o a 19 años. Este indicador permite señalar, a través de tres umbrales, la condición de una población como joven, madura o envejecida. Los límites de esta proporción son de 160 para la población joven y de 60 para la población envejecida (Ortiz y Mendoza, 2008). 
En el futuro se espera que la fecundidad siga disminuyendo, intensificando el proceso de envejecimiento, y que la población de 65 años y más adquiera un mayor protagonismo en la estructura de edad de la población chilena.

\section{El descenso de la mortalidad: ganancias en años de vida y longevidad}

El descenso de la mortalidad desde la década de 1930 hasta hoy ha sido constante. Sin embargo, a lo largo del tiempo se han producido cambios importantes en el perfil de los fallecimientos, que han influido en el impacto de la mortalidad sobre la estructura de edad en el largo plazo.

Desde el comienzo de la transición de la mortalidad, el descenso de las muertes entre los recién nacidos elevó considerablemente la esperanza de vida al nacer, la que pasó de 39 a 78 años entre los censos de 1930 y 2002 . La mortalidad infantil tal vez sea la más sensible a la mejora de las condiciones sanitarias, educativas o de bienestar material en el conjunto de la población. Pese a los avances en estos aspectos, durante gran parte del siglo XX, sobrevivir al primer año de vida era el primer desafío para muchos chilenos; la tasa de mortalidad infantil en Chile en el año 1932 alcanzaba las 235 muertes por cada 1.000 nacidos vivos, la segunda más alta de los 80 países sobre los que se cuenta con registros disponibles de ese año (Naciones Unidas, 1948). El impacto de la puesta en marcha de políticas de salud pública es elocuente (Meza, 2003): la tasa de mortalidad infantil pasó de 261 muertes por 1.000 nacidos vivos en 1934 a 78 muertes por 1.000 nacidos vivos en 1970 (Naciones Unidas, 1948 y 1974).

La descomposición de la esperanza de vida por edades nos revela cómo contribuyen las mejoras de las expectativas de vida a distintas edades al mejoramiento de la esperanza de vida total. En este sentido, puede observarse que el patrón de ganancias de esperanza de vida por edades ha cambiado considerablemente a lo largo del tiempo, pasando desde un esquema dominado principalmente por la mortalidad infantil hacia otro en que las contribuciones se concentran en edades avanzadas (véase el gráfico 2).

Hasta la década de 1980, los mayores aportes en años al aumento de la esperanza de vida provenían de los más jóvenes. Entre 1950 y mediados de la década de 1980, solo entre los menores de 15 años se ganaron 9,5 años de los 17,4 ganados entre todas las edades en ese mismo período. La rápida reducción de las tasas de mortalidad, pero sobre todo de las elevadas tasas de mortalidad infantil en cohortes cada vez más numerosas, permitió una gran ganancia en un corto tiempo. A partir de la década de 1980 las ganancias han sido cada vez más reducidas y ha cambiado el perfil de los grupos con mayores aportaciones, que pasan primero a las edades intermedias y, con la llegada del nuevo siglo, se hacen cada vez más importantes en los grupos de edades avanzadas.

Las ganancias en años de esperanza de vida son producto de la acumulación transversal de años vividos en todas las edades. En este sentido, será el declive de los altos niveles de mortalidad infantil lo que hará que los grupos de edades infantiles tengan un mayor peso en la acumulación de ganancias de años de vida, contribuyendo al rejuvenecimiento demográfico previo a la década de 1970. Durante las décadas de 1970 y 1980, de forma 
incipiente pero consolidada a partir de la década de 1990, la combinación de bajas tasas de mortalidad y fecundidad, y una mayor esperanza de vida entre las personas de 65 años y más dieron paso al proceso de envejecimiento de la población chilena (véase el cuadro 1).

Gráfico 2

Chile: ganancias en esperanza de vida por grupos de edad y sexo, década de 1950 a década de 2000

(En años)
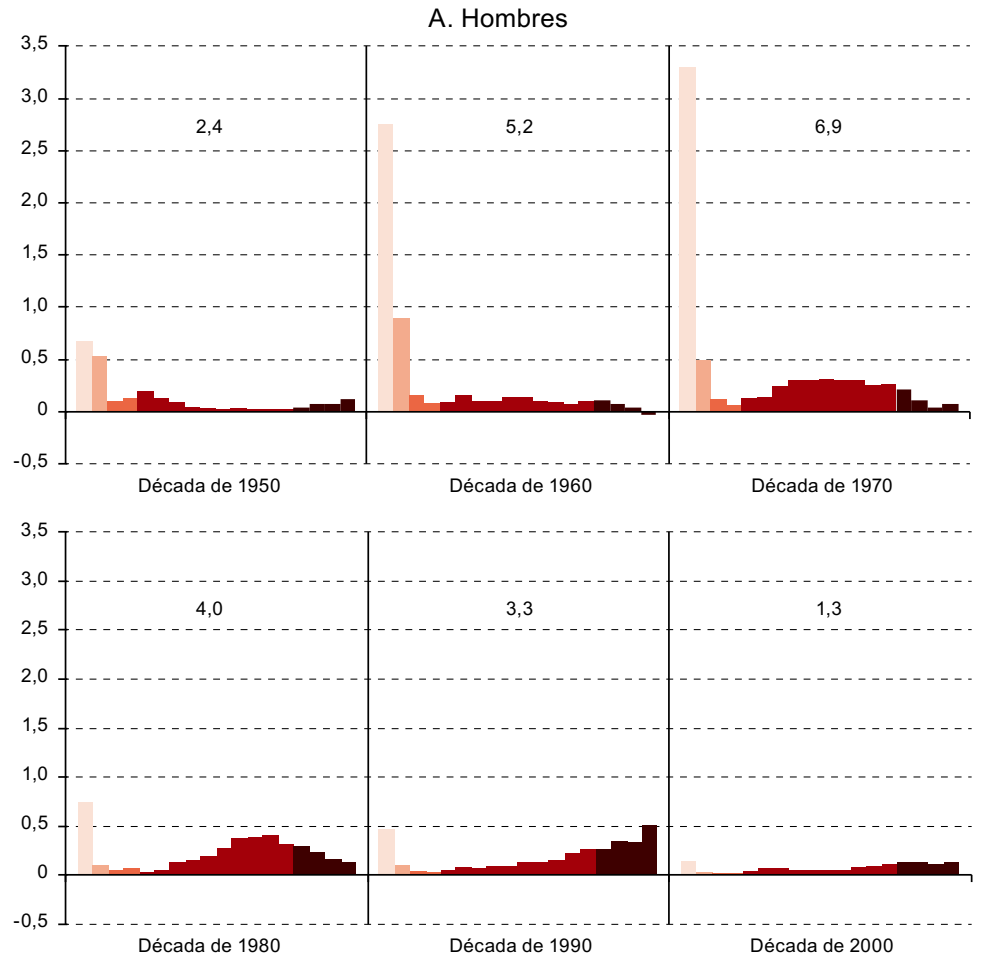

B. Mujeres

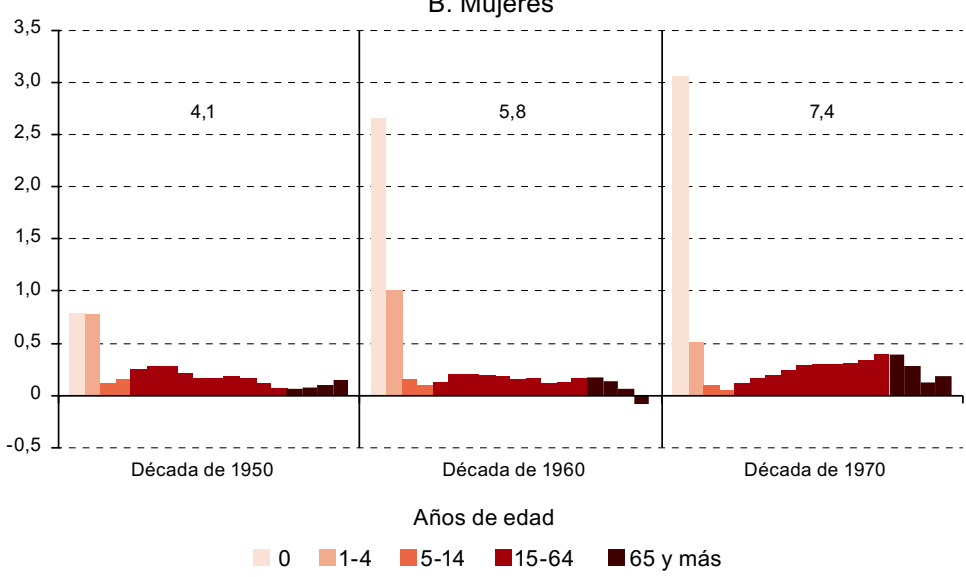


Gráfico 2 (conclusión)

\section{B. Mujeres}

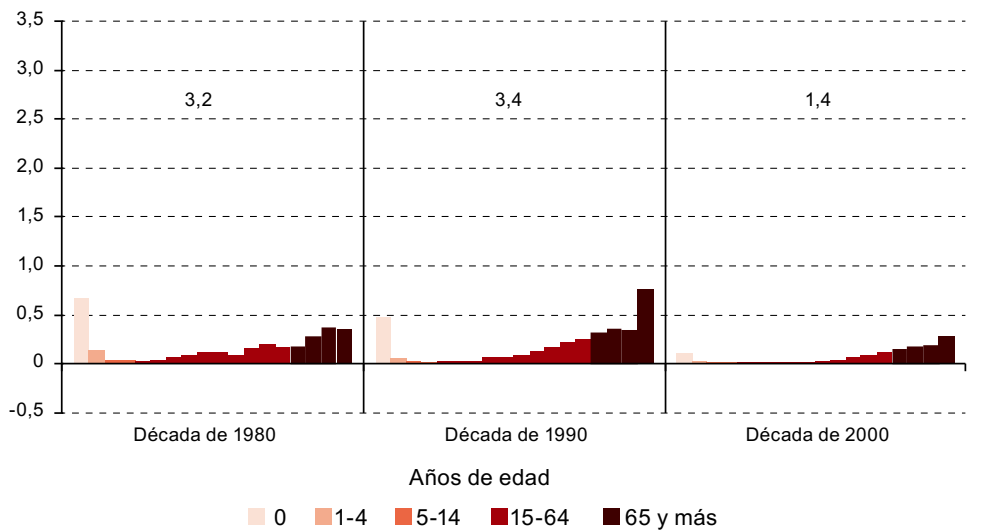

Fuente: Elaboración propia, sobre la base de Comisión Económica para América Latina y el Caribe (CEPAL), "Tablas de mortalidad", Observatorio Demográfico, No 74 (LC/G.2257-P), Santiago, 2004.

Cuadro 1

Chile: evolución de la esperanza de vida a diferentes edades, 1950-2015

(En años de edad)

\begin{tabular}{|c|c|c|c|c|c|c|c|c|c|c|}
\hline Edad & & $\begin{array}{l}1950- \\
1955\end{array}$ & $\begin{array}{l}1960- \\
1965\end{array}$ & $\begin{array}{l}1970- \\
1975\end{array}$ & $\begin{array}{l}1980- \\
1985\end{array}$ & $\begin{array}{l}1990- \\
1995\end{array}$ & $\begin{array}{l}2000- \\
2005\end{array}$ & $\begin{array}{l}2010- \\
2015\end{array}$ & $\begin{array}{c}\text { Diferencia } \\
\text { absoluta, } \\
1950-2015\end{array}$ & $\begin{array}{c}\text { Diferencia } \\
\text { relativa, } \\
\text { 1950-2015 } \\
\text { (en porcentajes) }\end{array}$ \\
\hline \multirow{4}{*}{0} & Hombre & 52,9 & 55,3 & 60,5 & 67,4 & 71,5 & 74,8 & 76,1 & 23,2 & 43,9 \\
\hline & Mujer & 56,8 & 61,0 & 66,8 & 74,2 & 77,4 & 80,8 & 82,8 & 26,0 & 45,9 \\
\hline & Diferencia absoluta & 3,9 & 5,7 & 6,3 & 6,8 & 5,9 & 6,0 & 6,7 & 2,8 & 73,1 \\
\hline & $\begin{array}{l}\text { Diferencia relativa } \\
\text { (en porcentajes) }\end{array}$ & 7,3 & 10,3 & 10,5 & 10,1 & 8,3 & 8,0 & 8,8 & & \\
\hline \multirow{4}{*}{40} & Hombre & 28,5 & 29,1 & 30,0 & 32,1 & 34,9 & 37,4 & 38,3 & 9,8 & 34,5 \\
\hline & Mujer & 31,8 & 33,3 & 34,5 & 37,5 & 39,5 & 42,2 & 43,4 & 11,7 & 36,7 \\
\hline & Diferencia absoluta & 3,3 & 4,2 & 4,5 & 5,3 & 4,6 & 4,8 & 5,1 & 1,8 & 55,8 \\
\hline & $\begin{array}{l}\text { Diferencia relativa } \\
\text { (en porcentajes) }\end{array}$ & 11,4 & 14,4 & 15,2 & 16,6 & 13,1 & 12,9 & 13,3 & & \\
\hline \multirow{4}{*}{65} & Hombre & 11,8 & 12,4 & 12,8 & 13,6 & 14,8 & 16,7 & 17,3 & 5,6 & 47,4 \\
\hline & Mujer & 13,7 & 14,5 & 15,0 & 16,4 & 17,8 & 19,9 & 20,8 & 7,1 & 52,2 \\
\hline & Diferencia absoluta & 1,9 & 2,1 & 2,1 & 2,8 & 3,0 & 3,2 & 3,5 & 1,6 & 81,8 \\
\hline & $\begin{array}{l}\text { Diferencia relativa } \\
\text { (en porcentajes) }\end{array}$ & 16,3 & 16,7 & 16,7 & 20,6 & 20,6 & 19,2 & 20,1 & & \\
\hline
\end{tabular}

Fuente: Elaboración propia, sobre la base de Comisión Económica para América Latina y el Caribe (CEPAL), "Tablas de mortalidad", Observatorio Demográfico, No 74 (LC/G.2257-P), Santiago, 2004.

En este sentido, el proceso de envejecimiento se ve reflejado en el descenso de la proporción de jóvenes desde 1970, superior al 40\%, y en la aceleración del aumento de la proporción de personas de 65 años y más desde los años noventa (véase el cuadro 2).

Los cambios de la estructura de la población desde 1970 se pueden apreciar de mejor forma a partir de una pirámide de población (véase el gráfico 3 ). 
Cuadro 2

Chile: evolución de la estructura de la población por grupos de edad, 1950-2015

(En porcentajes del total)

\begin{tabular}{lrrrrrrrrr}
\hline Grupo de edad & $\begin{array}{c}1950- \\
1955\end{array}$ & $\begin{array}{c}1960- \\
1965\end{array}$ & $\begin{array}{c}1970- \\
1975\end{array}$ & $\begin{array}{c}1980- \\
1985\end{array}$ & $\begin{array}{c}1990- \\
1995\end{array}$ & $\begin{array}{c}2000- \\
2005\end{array}$ & $\begin{array}{c}2010- \\
2015\end{array}$ & $\begin{array}{c}\text { Diferencia } \\
\text { absoluta, } \\
1950-2015\end{array}$ & $\begin{array}{c}\text { Diferencia } \\
\text { relativa, } \\
1950-2015\end{array}$ \\
\hline 0 a 15 años & 39,2 & 41,9 & 40,3 & 34,1 & 31,5 & 28,0 & 22,9 & $-16,4$ & $-41,7$ \\
\hline 16 a 64 años & 56,4 & 53,2 & 54,4 & 60,2 & 62,1 & 64,4 & 67,3 & 10,9 & 19,4 \\
\hline 65 años y más & 4,4 & 4,9 & 5,2 & 5,7 & 6,4 & 7,7 & 9,8 & 5,4 & 123,8 \\
\hline
\end{tabular}

Fuente: Elaboración propia, sobre la base de Comisión Económica para América Latina y el Caribe (CEPAL), "América Latina: estimaciones y proyecciones de población a largo plazo 1950-2100: Revisión 2013", Centro Latinoamericano y Caribeño de Demografía (CELADE)-División de Población de la CEPAL, 2013 [en línea] http://www.cepal.org/celade/proyecciones/basedatos_bd.htm [fecha de consulta: 16 de junio de 2015].

\section{Gráfico 3}

\section{Chile: pirámide de población, 1972 y $2012^{\text {a }}$}

(En porcentajes y años de edad)

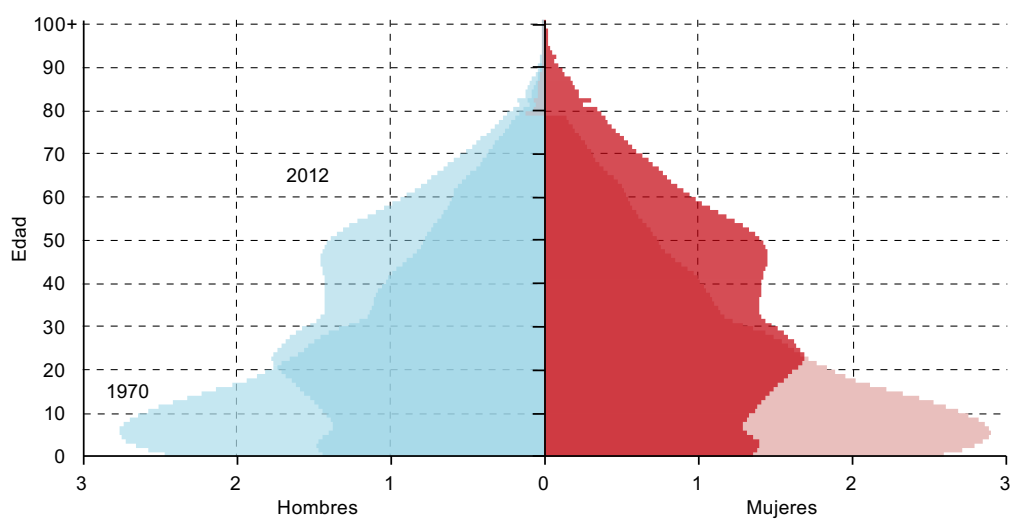

Fuente: Elaboración propia; año 1970: Instituto Nacional de Estadísticas de Chile (INE), XIV Censo de Población y III de Vivienda. Total país, Santiago, 1970, y Naciones Unidas, "World Population Prospects: The 2012 Revision", 2013 [en línea] http://esa.un.org/wpp; año 2012: INE, "Actualización de población 2002-2012 y proyecciones 2013-2020", 2014 [en línea] http://www.ine.cl/canales/chile_estadistico/familias/demograficas_vitales.php.

a A fin de solucionar el problema de la preferencia de edades terminadas en ciertos dígitos (age heaping), se aplicó la estructura de edad de la población de 1970 publicada en Naciones Unidas, "World Population Prospects: The 2012 Revision", 2013.

Tanto el rejuvenecimiento como el envejecimiento han sido procesos habituales en las distintas experiencias de transición demográfica; no obstante, a diferencia de lo ocurrido en los países precursores, la velocidad y la intensidad de ambos procesos han tendido a ser mayores entre los países seguidores y recientes ${ }^{13}$. Por otro lado, en todos los casos estas dinámicas llevan consigo importantes desafíos sociales y económicos, por lo que su intensidad se relaciona directamente con la magnitud de los desafíos que plantean.

13 David Reher (2004) establece cuatro categorías de países en función del momento de inicio de la transición de la fecundidad: los precursores, donde se inició antes de 1935, los seguidores, donde comenzó entre 1950 y 1964; los rezagados, países en que la transición tuvo lugar entre 1965 y 1979, y los recientes, donde el cambio ocurrió a partir de 1980. Chile es el único país de la región que se encuentra entre los seguidores. La mayoría de los países latinoamericanos se encuentran entre las categorías de rezagados y recientes. 


\section{Resultados}

\section{El envejecimiento en los indicadores}

La vejez es una etapa más de la vida del ser humano. A lo largo del tiempo, ha sido interpretada de muchas formas dependiendo del contexto social, cultural, simbólico o incluso económico en el que se analice (Parkin, 2003).

Por su parte, el envejecimiento demográfico es un fenómeno relativamente nuevo en la historia de la humanidad, pues, pese a que hoy en día es normal llegar a la vejez, en el pasado ha sido privilegio de una minoría. Por esta razón, es ahora, dada la envergadura y la amplia difusión que actualmente tiene el envejecimiento, cuando existen mayores expectativas en la sociedad.

La forma más simple de analizar el proceso de envejecimiento es observando la evolución estadística de la población a partir de cierta edad aceptada como el umbral a partir del cual se llega a la vejez (Chande, 2000). No obstante, recientemente se han abierto nuevas interpretaciones del proceso de envejecimiento que relativizan la forma de definir este umbral, entregando una imagen complementaria a la tradicional.

\section{a) Las dimensiones de la edad}

En la historia de Chile, nunca la población de 65 años y más había alcanzado una proporción tan grande como en la actualidad. Este aumento obedece a la continua mejora de la esperanza de vida. Si en los años cincuenta la esperanza de vida a los 65 años era de 11,8 años entre los hombres y de 13,7 años entre las mujeres, al iniciarse el siglo XXI alcanzó los 16,7 años entre los hombres y los 19,9 años entre las mujeres. Un hecho importante asociado a estos cambios es que se tiende a pensar que dos personas con la misma edad cronológica se comportan de igual manera, sin que importe el momento de la historia del que se trate. Sin embargo, los significativos avances producidos en la esperanza de vida han tenido importantes efectos sobre la percepción de la edad; por ejemplo, no significa lo mismo tener 65 años en 1950 que en 2015.

Así como las variables financieras se ajustan por la inflación, la edad puede ajustarse por la esperanza de vida (Sanderson y Scherbov, 2010). De esta manera, la edad de las personas y, por extensión, la de una población se componen de dos dimensiones; por un lado, la cronológica, es decir, el número de años vividos desde el nacimiento, que también recibe el nombre de retrospectiva, y por otro lado, la prospectiva, los años que quedan por vivir (Sanderson y Scherbov, 2007). Por ejemplo, teniendo en cuenta la dimensión prospectiva, un hombre de 28,7 años en el período 2000-2005 (año estándar) será equivalente a un hombre de 20,8 años en 1975-1980, pues ambos poseen virtualmente la misma esperanza de vida (respectivamente, 47,9 y 47,8 años), en otras palabras, la misma edad prospectiva. 
En el gráfico 4 se muestra la edad mediana de la población chilena entre 1950 y 2050, y la edad mediana prospectiva. La primera fue de 21,6 años para los hombres y de 22,5 años para las mujeres a mediados del siglo XX y experimentó un declive hasta casi los 19 y 20 años, respectivamente, en la década de 1960. Esta tendencia se invierte en la década de 1970, cuando registra un incremento sostenido hasta alcanzar los 29 y 30 años, respectivamente, al iniciarse el siglo XXI, proceso que se espera siga su curso.

Gráfico 4

Chile: edad mediana y edad mediana prospectiva de la población, 1950-2050

(En años)

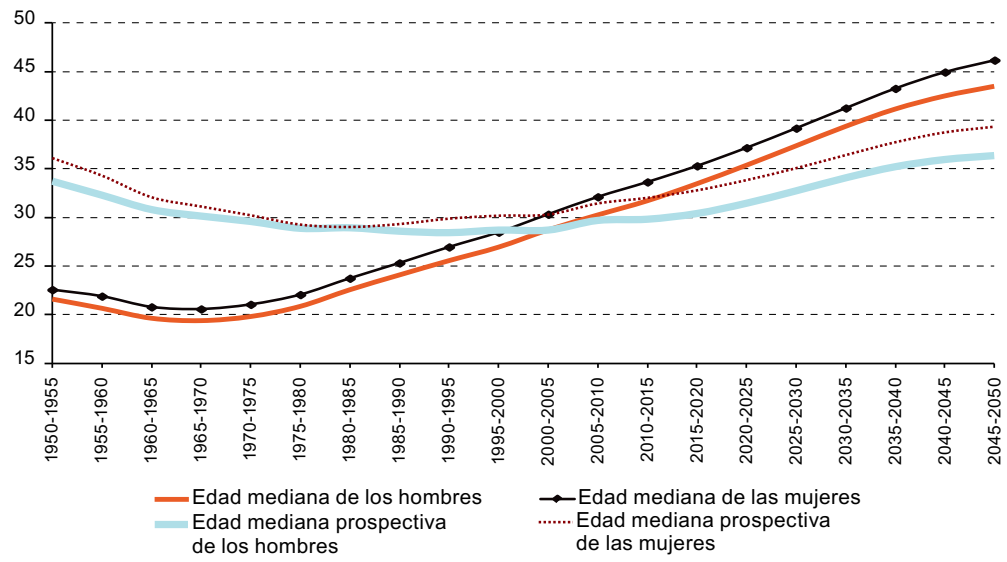

Fuente: Elaboración propia, sobre la base de Comisión Económica para América Latina y el Caribe (CEPAL), "Tablas de mortalidad", Observatorio Demográfico, No 74 (LC/G.2257-P), Santiago, 2004; y Naciones Unidas, "World Population Prospects: The 2012 Revision", 2013 [en línea] http://esa.un.org/wpp.

La edad mediana prospectiva proporciona una historia diferente del envejecimiento. Usando el quinquenio 2000-2005 como año estándar, se obtiene que la edad mediana prospectiva en el quinquenio $1950-1955$ fue de 34 años para los hombres y 36 para las mujeres, muy superior a las edades medianas respectivas. Por otro lado, este indicador descendió desde el período 1950-1955 hasta el período 1975-1980, para luego mantenerse sin grandes cambios hasta principios del siglo XXI, cuando comenzó a crecer.

Las diferencias observadas entre la edad mediana y edad mediana prospectiva se deben a que en esta última están comprendidas las mejoras en las expectativas de vida, que hacen rejuvenecer a la población chilena desde un punto de vista prospectivo. Incluso se puede afirmar que, una vez ajustada la edad por las mejoras en la esperanza de vida, la población chilena es hoy más joven que a mediados del siglo XX.

i) La edad como el umbral de la vejez

Desde un punto de vista demográfico y laboral, se considera que la vejez comienza a partir de una edad específica. A partir de mediados del siglo XX, con el desarrollo de los sistemas de seguridad social, se ha identificado el umbral del envejecimiento con la edad 
de retiro de la actividad económica, siendo los 65 años la edad límite en que las personas quedan habilitadas para ejercer el derecho a la jubilación ${ }^{14}$.

Este umbral es, sin duda, la construcción social de una categoría adscriptiva. Corresponde a una delimitación estadística y arbitraria, que no puede contemplar la multidimensionalidad de un estado que depende de muchos factores, en los que la edad por sí sola nada significa (Desjardins y Légaré, 1984; Chackiel, 2000; Aranibar, 2001). No obstante, es el criterio utilizado por la mayoría de los seguros sociales del mundo para definir la edad a partir de la cual se tiene acceso a los sistemas de prestaciones por vejez ${ }^{15}$.

De esta manera, la vejez ha adquirido una interpretación por un lado cronológica, la de los años vividos, y por otro lado económica, el fin de la vida activa y el paso a la vida dependiente. Sobre la base de esta perspectiva, desde mediados del siglo XX Chile ha venido experimentando, junto con el proceso de envejecimiento demográfico, un crecimiento constante de la población de 65 años y más, tanto en cifras absolutas como en proporción de la población total. De la mano de las mejoras en la esperanza de vida, sobre todo a edades avanzadas, y de la baja de la fecundidad, a partir de la década de 1950 creció la proporción de personas de 65 años y más sobre el total de la población, pasando del 4,4\% del total en 19501955 al 9,8\% en 2010-2015 (véase el cuadro 2).

Empero, como se vio anteriormente, desde que la esperanza de vida se ha convertido en el factor principal del envejecimiento de la población, la edad en el sentido cronológico ha perdido su relevancia para medir la carga demográfica asociada a la vejez. Su principal falencia es que no toma en cuenta las mejoras en la esperanza de vida, atribuyendo la misma condición de vejez a dos personas de la misma edad en dos momentos distintos sin considerar el contexto histórico y demográfico.

ii) El umbral móvil: la nueva imagen del envejecimiento

Siguiendo a Sanderson y Scherbov (2005 y 2007), se establece un umbral de envejecimiento móvil a partir de aquella edad exacta a la que las personas cuentan con una esperanza de vida de 15 años o menos. Este será el nuevo umbral de envejecimiento, que no siempre serán los 65 años de edad, como sucede con el umbral fijo (Spijker y MacInnes, 2013).

Con una perspectiva de largo plazo, es posible notar el cambio del umbral de envejecimiento. El umbral móvil, es decir, aquella edad en que la esperanza de vida alcanzaba los 15 años, se mantuvo por debajo del umbral fijo desde mediados del siglo XX hasta el inicio del siglo XXI, pasando de 61 años en 1950-1955 a 71 años en 2010-2015. Se espera que en el futuro cercano el umbral de envejecimiento se acerque a los 76 años de edad (véase gráfico 5).

14 En Chile, en la década de 1920 comenzaron a funcionar la Caja del Seguro Obrero Obligatorio, la Caja de Previsión de Empleados Particulares y la Caja de Empleados Públicos, instituciones que aseguraban la jubilación a partir de los 65 años de edad. En el caso específico de las obreras y empleadas, la edad se rebajó a 60 años. Este sistema persistió, con ciertas modificaciones, hasta inicios de la década de 1980.

15 Véase el artículo 26 del Convenio núm. 102 sobre la seguridad social de la OIT de 1952. 
Gráfico 5

Chile: umbral móvil de la edad exacta a los 15 años de esperanza de vida, 1950-2050

(En años de edad)

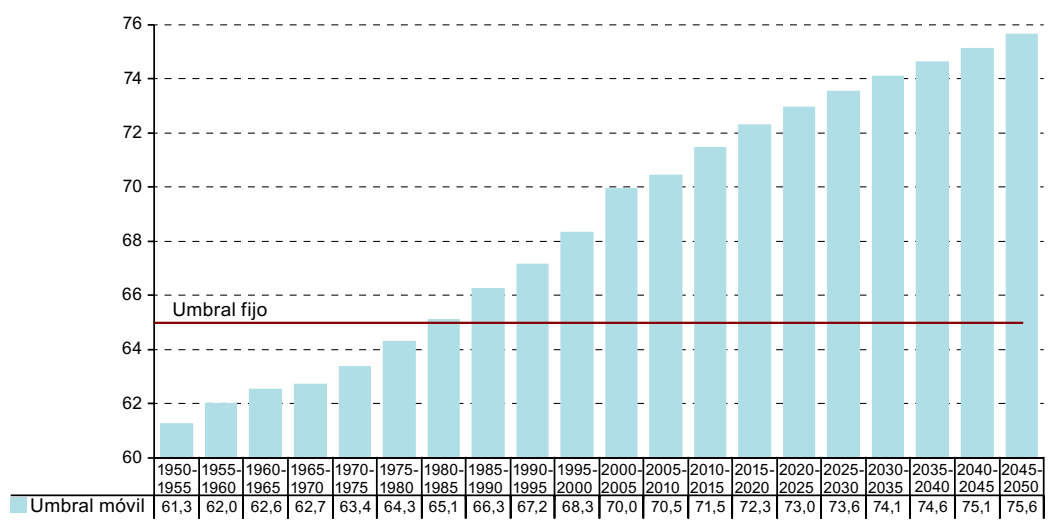

Fuente: Elaboración propia, sobre la base de Comisión Económica para América Latina y el Caribe (CEPAL), "Tablas de mortalidad", Observatorio Demográfico, No 74 (LC/G.2257-P), Santiago, 2004; y "América Latina: estimaciones y proyecciones de población a largo plazo 1950-2100: Revisión 2013", Centro Latinoamericano y Caribeño de Demografía (CELADE)-División de Población de la CEPAL, 2013 [en línea] http://www.cepal.org/celade/proyecciones/basedatos_bd.htm.

\section{El cálculo de la población dependiente}

La tasa de dependencia demográfica constituyeunimportante indicador de las transformaciones producidas en la estructura de la población a lo largo de la transición demográfica, que pueden abarcar la proporción de niños, el retiro de la vida activa o la mayor proporción de ancianos. Tradicionalmente, los grupos de activos y pasivos se definieron teniendo en consideración la dimensión retrospectiva de la edad. No obstante, como ya se mencionó, esta conceptualización de los comportamientos de la población no ha tenido en cuenta las mejoras en la esperanza de vida a lo largo de la transición demográfica, que originan importantes cambios en los comportamientos de las personas (Sanderson y Scherbov, 2007). Por ejemplo, muchas personas mayores de 65 años actualmente prolongan su vida activa más allá de aquel umbral, mientras que a mediados del siglo XX la proporción de personas que alcanzaba este umbral era reducida. Por otro lado, los jóvenes, que cuentan con una expectativa de vida mayor que las generaciones pasadas, retrasan su entrada a la vida activa, con el fin de obtener una carrera profesional que les provea mayores rentas en el futuro. De manera que, incorporando el enfoque prospectivo de la edad, se posible comprender de mejor forma los cambios de la estructura de edad, las dinámicas de rejuvenecimiento y envejecimiento, y sus potenciales efectos demográficos, sociales y económicos a lo largo de la transición demográfica.

\section{a) La tasa de dependencia prospectiva de las personas mayores}

A la hora de contabilizar a la población de mayores dependientes, es decir, aquella que ha cruzado el umbral de la vejez, con una perspectiva de largo plazo se comprueba la existencia de importantes saldos entre los dos umbrales (véase el cuadro 3 ). 
Cuadro 3

Chile: saldos en el umbral móvil a con respecto al umbral fijo ${ }^{\mathrm{b}}, 1950-2050$

\begin{tabular}{lrrrrr}
\hline Quinquenio & Años & $\begin{array}{c}\text { Número de } \\
\text { personas }\end{array}$ & Quinquenio & Años & $\begin{array}{c}\text { Número de } \\
\text { personas }\end{array}$ \\
\hline $1950-1955$ & $-3,7$ & 121092 & $2000-2005$ & 5,0 & -396602 \\
\hline $1955-1960$ & $-3,0$ & 110081 & $2005-2010$ & 5,5 & -504275 \\
\hline $1960-1965$ & $-2,4$ & 96994 & $2010-2015$ & 6,5 & -720146 \\
\hline $1965-1970$ & $-2,3$ & 96605 & $2015-2020$ & 7,3 & -935514 \\
\hline $1970-1975$ & $-1,6$ & 79331 & $2020-2025$ & 8,0 & -1238243 \\
\hline $1975-1980$ & $-0,7$ & 33742 & $2025-2030$ & 8,6 & -1636779 \\
\hline $1980-1985$ & 0,1 & 7348 & $2030-2035$ & 9,1 & -1953469 \\
\hline $1985-1990$ & 1,3 & -72489 & $2035-2040$ & 9,6 & -2099789 \\
\hline $1990-1995$ & 2,2 & -146858 & $2040-2045$ & 10,1 & -2166609 \\
\hline $1995-2000$ & 3,3 & -251214 & $2045-2050$ & 10,6 & -2269769 \\
\hline
\end{tabular}

Fuente: Elaboración propia, sobre la base de Comisión Económica para América Latina y el Caribe (CEPAL), "Tablas de mortalidad", Observatorio Demográfico, № 74 (LC/G.2257-P), Santiago, 2004; y Naciones Unidas, "World Population Prospects: The 2012 Revision", 2013 [en línea] http://esa.un.org/wpp.

a Población con una esperanza de vida inferior a 15 años.

b Población mayor de 64 años.

Entre 1950 y 1980, el saldo en años es negativo y el umbral fijo se sitúa por sobre el umbral móvil. Sin embargo, las mejoras en la esperanza de vida de los adultos mayores han elevado de forma constante el umbral móvil de envejecimiento, superando el umbral fijo desde principios de los años ochenta. De tal manera, cuando el umbral móvil se sitúe por debajo del umbral fijo, se sumará toda la población que no captura el umbral fijo; y cuando el umbral móvil se sitúe por sobre el umbral fijo, se restará toda la población de 65 años y más con una esperanza de vida superior a 15 años.

Utilizando el umbral de envejecimiento móvil, la imagen del envejecimiento cambia significativamente. En este sentido, la TDMP experimenta un declive sostenido entre 1960 y 2010. Esta tendencia a la baja surge de las mejoras de la esperanza de vida en edades avanzadas, que ejercen una influencia directa sobre el aumento del umbral móvil. Se espera que en el futuro la proporción de TDMP aumente, no obstante, las diferencias entre las previsiones de TDM y TDMP son significativas (véase el gráfico 6).

La tasa de dependencia de las personas mayores medida de la manera tradicional, es decir, con el umbral de envejecimiento fijo, muestra una tendencia de envejecimiento más o menos estable desde 1950 hasta la década de 1990, (8 a 10 personas mayores de 65 años por cada 100 personas en edad laboral) punto en que acelera su ritmo y que concuerda con la mejora de la esperanza de vida a edades avanzadas y la entrada de cohortes más pequeñas en la edad de trabajar. De esta manera, la TDM empieza a crecer de forma acelerada a partir de 2010, cuando las cohortes más grandes - aquellas nacidas entre 1945 y 1960-cumplen 65 años (alcanzando un 13\% en el período 2005-2010 y estimándose que llegará al 39\% en el período 2045-2050). 
Gráfico 6

Chile: tasa de dependencia de las personas mayores (TDM) y tasa de dependencia de las personas mayores prospectiva (TDMP), 1950-2050

(En número de dependientes por cada 100 personas en edad laboral)

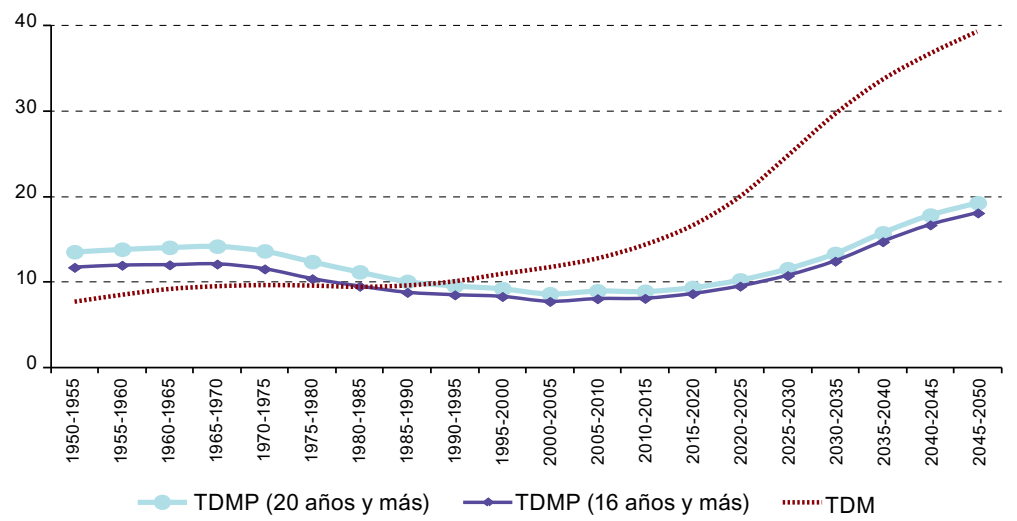

Fuente: Elaboración propia, sobre la base de Comisión Económica para América Latina y el Caribe (CEPAL), "Tablas de mortalidad", Observatorio Demográfico, № 74 (LC/G.2257-P), Santiago, 2004; y Naciones Unidas, "World Population Prospects: The 2012 Revision", 2013 [en línea] http://esa.un.org/wpp.

Llama poderosamente la atención la discrepancia de los niveles y las tendencias de ambos indicadores desde mediados del siglo XX según se sigan con la tasa de dependencia o con la tasa prospectiva. Entre los períodos 1950-1955 y 1970-1975, la TDMP es más elevada que la TDM, debido a que el umbral móvil contabiliza como dependientes a aquellas personas que, aunque no alcancen los 65 años, cuentan con una esperanza de vida de 15 años o menos. De esta manera, gracias a la TDMP se puede comprobar que la dependencia por vejez fue muy superior en el pasado, debido a la menor esperanza de vida de los adultos mayores. En cuanto a la tendencia, el contraste es significativo. Mientras que la TDMP muestra un descenso sostenido desde la década de 1970 hasta los primeros años del siglo XXI, la TDM muestra una trayectoria inversa, creciendo con fuerza desde mediados de los años ochenta. Si bien se espera que en el futuro ambas tasas experimenten una tendencia alcista, los niveles esperados son mucho más preocupantes en el caso de la TDM.

\section{Chile en el contexto de América Latina}

Siguiendo el esquema de Reher (2004), Chile es el único país de la región que se encuentra en la categoría de seguidores. La mayoría de los países latinoamericanos se ubican entre las categorías de rezagados y recientes, es decir que comenzaron su transición de fecundidad durante la segunda mitad de la década de 1960 o incluso durante la década de 1980. En conjunto, estos países concentran gran parte de la población de la región; por lo tanto, a escala regional, el envejecimiento es una preocupación relativamente nueva, cuya atención se centra en el medio plazo, dada la rapidez que ha mostrado el proceso en las últimas décadas. 
En la región existen poblaciones más envejecidas que la de Chile y coinciden con aquellos países que han disfrutado de un mayor nivel de desarrollo histórico. La Argentina y el Uruguay, los dos únicos casos latinoamericanos entre los precursores, son dos ejemplos emblemáticos de poblaciones con un nivel de envejecimiento siempre comparable con los países europeos y situados por encima del promedio latinoamericano, incluido el de Chile.

De forma general, a través de la edad mediana, podemos observar dos escenarios a escala regional. Primero, entre los años cincuenta y setenta existió una marcada divergencia entre los precursores - que envejecían a un ritmo moderado- y el resto de los países de la región - que pasaban por una dinámica de rejuvenecimiento- ${ }^{16}$. El segundo escenario surge a partir de la década de 1970: a medida que el envejecimiento comenzó a extenderse de forma paulatina en la región, tuvo lugar la actual convergencia de países rezagados y recientes con los precursores.

En estos dos escenarios subyace la existencia de dos grupos de países claramente marcados. El primero, entre los que se encuentra Chile, está formado por aquellos cuya edad mediana se situaba, entre 1950 y 1955, en torno al promedio de la región o sobre él, que convergen rápidamente con los precursores a partir de la década de 1970 (véase el gráfico $7 \mathrm{~A}$ ). El segundo grupo corresponde a los países que se situaban por debajo del promedio regional de la edad mediana, que prolongan su rejuvenecimiento hasta la década de 1980, convergiendo más tardíamente (véase el gráfico 7B).

En términos estructurales, los cambios más grandes se han producido en aquellos países que han pasado de un intenso rejuvenecimiento a un rápido envejecimiento en pocos años.

\section{Gráfico 7}

América Latina: edad mediana de la población, 1950-2050

(En años)

A. Países cuya edad mediana se ubica en torno al promedio de la región o lo supera

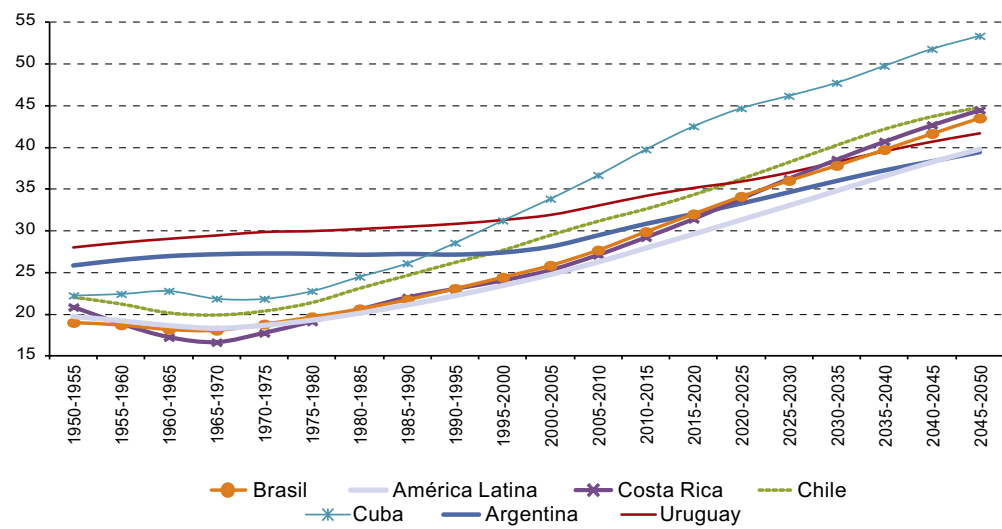

16 Sobre este último, aunque su intensidad y duración tuvieron un comportamiento variado en los distintos países, se trató de una tendencia generalizada e hizo decrecer el promedio de la edad mediana de la población latinoamericana de 19,7 años en 1950-1955 a 18,3 años en 1965-1970. 
Gráfico 7 (conclusión)

B. Países cuya edad mediana se ubica por debajo del promedio de la región

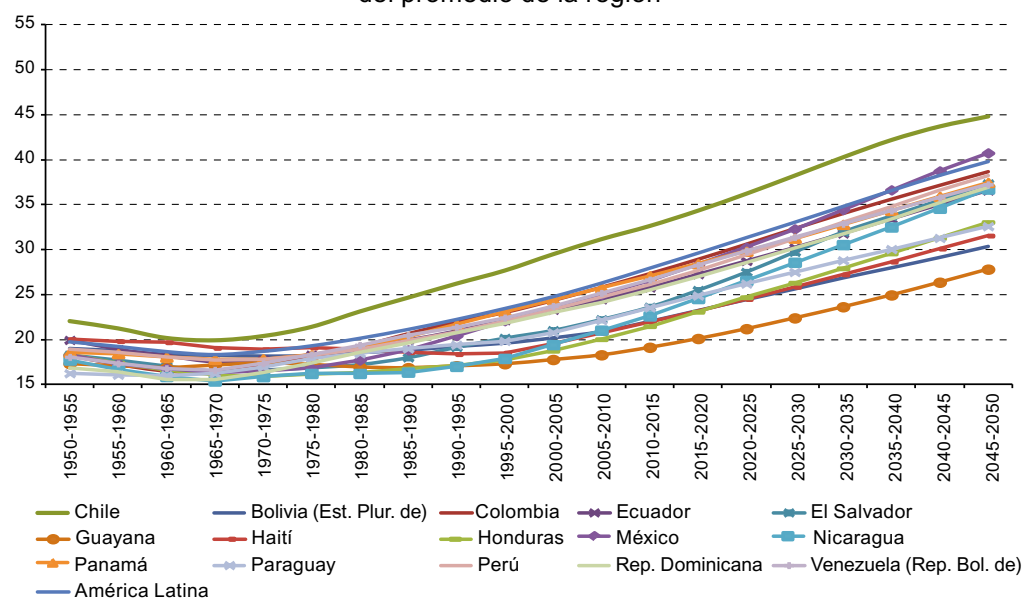

Fuente: Elaboración propia, sobre la base de Comisión Económica para América Latina y el Caribe (CEPAL), "Tablas de mortalidad", Observatorio Demográfico, No 74 (LC/G.2257-P), Santiago, 2004; y Naciones Unidas, "World Population Prospects: The 2012 Revision", 2013 [en línea] http://esa.un.org/wpp.

\section{a) El envejecimiento de América Latina con enfoque prospectivo}

En América Latina la transición demográfica se transformó en una dinámica generalizada durante las últimas décadas del siglo XX. La experiencia de la región se caracteriza por su rapidez, ya que pasó en pocos años de una transición incipiente a una fase avanzada (Chakiel, 2004).

En el cuadro 4 se muestra el cambio de la estructura de la población de los países latinoamericanos a través de la edad mediana y la edad mediana prospectiva ${ }^{17}$. La población masculina del Paraguay fue la más joven de la región a mediados del siglo XX, con una edad mediana de tan solo 15,5 años, mientras que, en el caso de las mujeres, la República Dominicana cuenta con las mujeres más jóvenes, con una edad mediana de 16,7 en el mismo período. En términos de edad mediana prospectiva, el Paraguay poseía la edad más baja de la región en ambos sexos, de 19,0 años para los hombres y 21,2 años para las mujeres. A lo largo del siglo XX, el aumento de ambas edades fue lento, lo que posiciona al Paraguay entre los países más jóvenes de la región aún en la actualidad, junto con el Estado Plurinacional de Bolivia y los países centroamericanos.

Calculadas sobre la base de las tablas abreviadas de mortalidad elaboradas y publicadas por la CEPAL (2004); corresponden a tablas de período. 


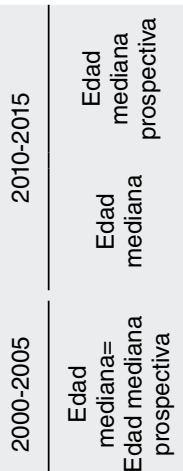

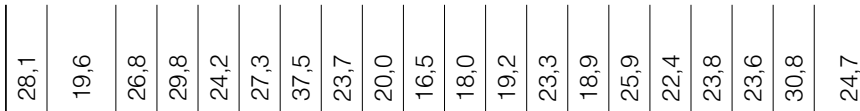

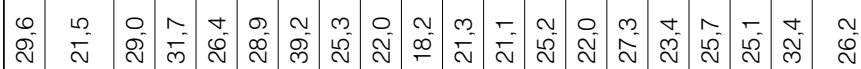
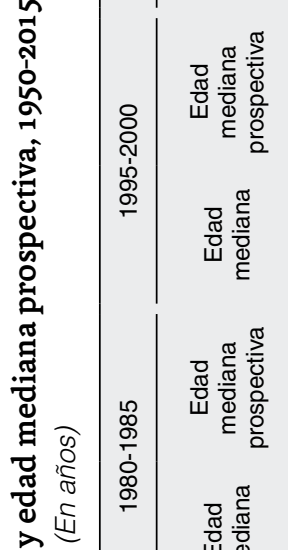

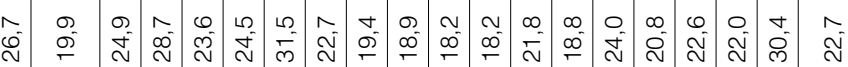

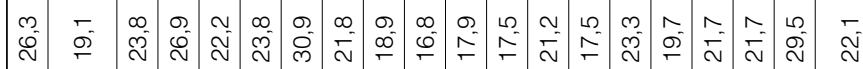

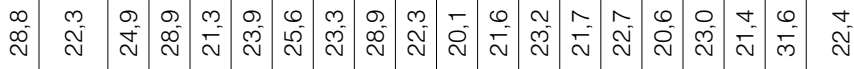

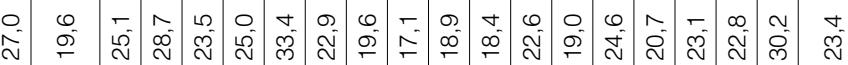

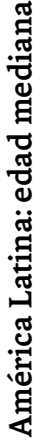

ए

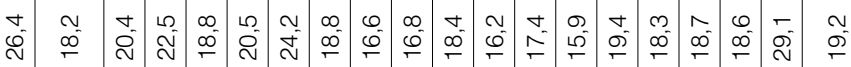

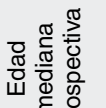

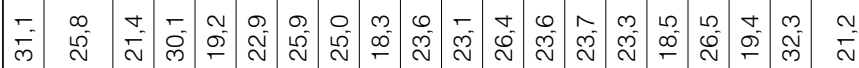

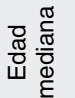

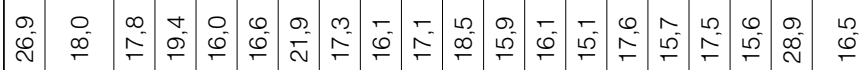

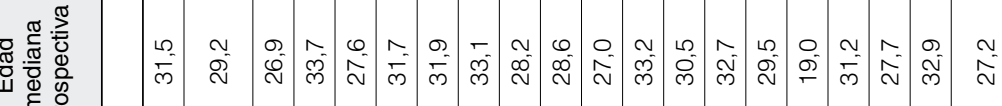

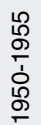

흐

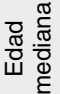

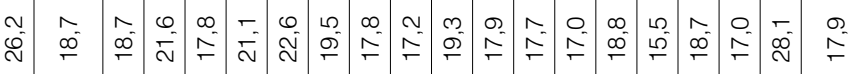

$\frac{\sqrt{0}}{\frac{\pi}{0}} \frac{\pi}{\frac{\pi}{0}}$

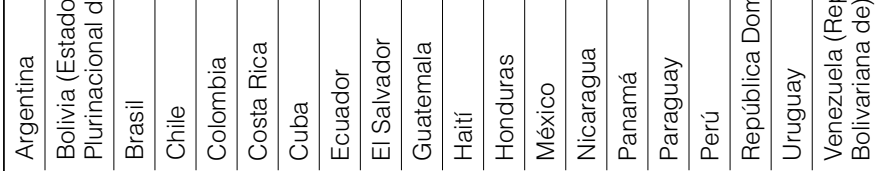




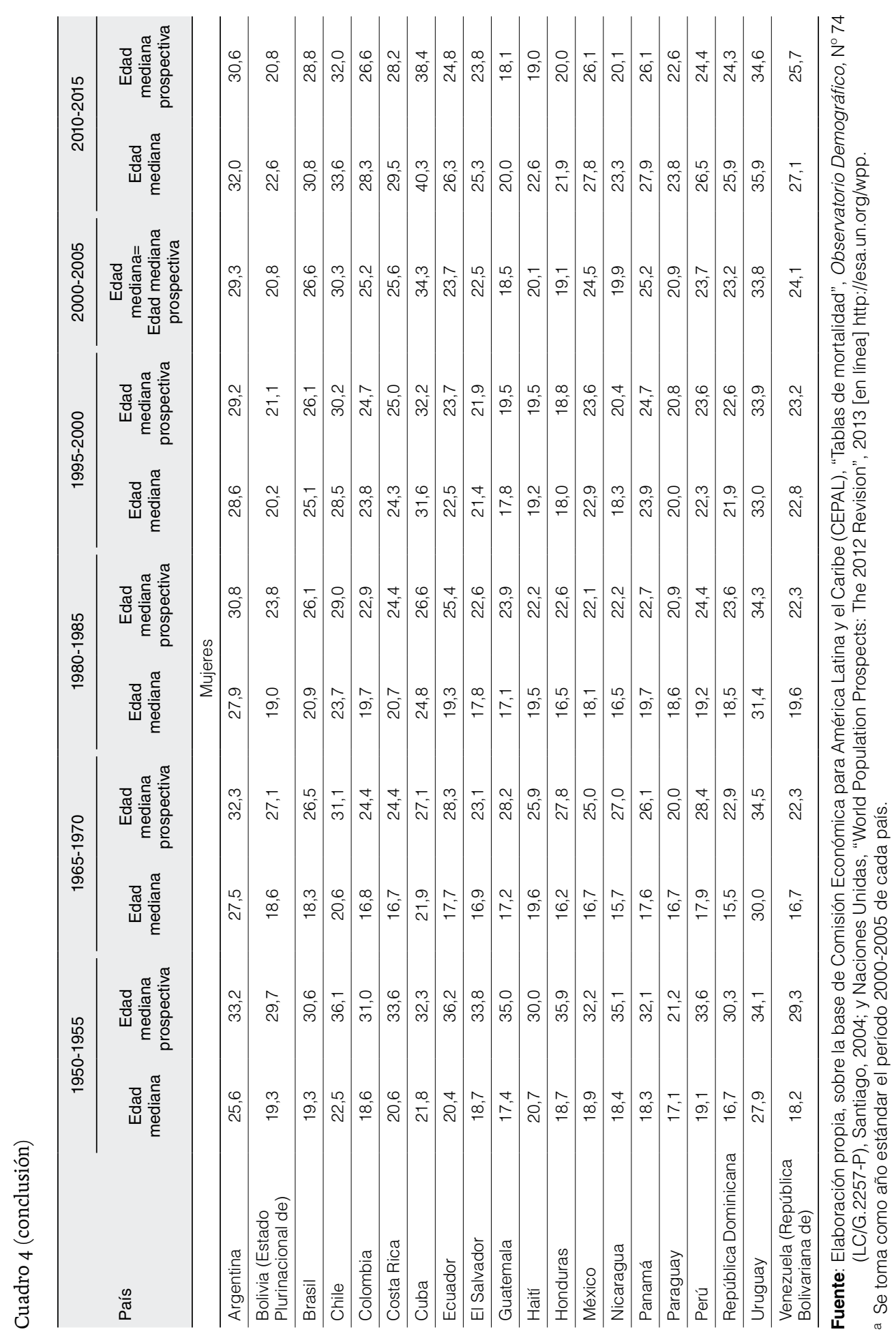


Por otro lado, Cuba es el país que experimenta los mayores cambios, tanto en la edad mediana como en la edad mediana prospectiva. A mediados del siglo XX, la edad mediana de la población cubana era de 22,6 para los hombres y 21,8 para las mujeres, y se incrementó a 39,2 y 40,3 años, respectivamente, en el período 2010-2015. El caso cubano corresponde al proceso de envejecimiento más rápido que se ha dado en la región. Si bien a mediados del siglo XX la edad mediana de la población cubana era similar a la de Costa Rica o Chile, el rápido envejecimiento que experimentó en las décadas siguientes lo ha llevado a ser el país con la mayor edad mediana dentro de la región, superando incluso a los países que han tenido una trayectoria más antigua de envejecimiento. Además de los factores habituales que originan el envejecimiento, en Cuba se añade el intenso proceso migratorio por el que ha pasado, que repercutió en la intensidad del envejecimiento desde la década de $1980^{18}$.

La prospectiva permite ver la historia del envejecimiento con una dimensión complementaria. La Argentina y el Uruguay, los dos casos precursores de la región, con las poblaciones de mayor edad mediana, experimentaron un descenso de la edad mediana prospectiva durante la segunda mitad del siglo XX. Sobre la base de la edad mediana prospectiva no pueden considerarse ejemplos excepcionales de población envejecida en la región. En este sentido, son una muestra de cómo la prospectiva enriquece el análisis de la historia del envejecimiento al integrarse con la mirada retrospectiva.

En cuanto a la tasa de dependencia de las personas mayores, los países latinoamericanos con mayor nivel de envejecimiento muestran un crecimiento constante desde mediados del siglo XX, que se ha intensificado desde la década de 1990 hasta la actualidad. No obstante, como se vio anteriormente, el establecimiento de los 65 años de edad como umbral fijo de la vejez ha demostrado ser una definición arbitraria en el pasado y anacrónica en el presente.

En este sentido, como ocurre en Chile, a nivel regional las mejoras en la esperanza de vida a lo largo de la transición demográfica, sobre todo las producidas en edades avanzadas, han tenido efectos sobre el comportamiento de las personas, haciendo necesario integrar estos cambios a la perspectiva con la cual se analiza el envejecimiento (véase el cuadro 5).

Como se observa en el cuadro 6, el umbral de envejecimiento móvil en los países que actualmente son los más envejecidos de la región se situó por debajo del umbral fijo (considerado aquí como los 65 años de edad) hasta mediados de la década de 1970 o 1980, dependiendo del país. Por otro lado, su crecimiento desde mediados del siglo XX ha sido constante, situándose hoy en día muy por encima del umbral fijo. Se espera que este umbral siga ampliándose, llegando incluso a los 75 años en Chile y Costa Rica a mediados del siglo XXI.

Aunque en la mayoría de los casos es incipiente, no cabe duda de que el envejecimiento es una realidad en la región, y se espera que se generalice e intensifique en los próximos años. La preocupación se centra en los importantes desafíos a los cuales se verán sometidos los países de la región en el futuro cercano, entre los que se cuentan el sistema de pensiones, el mercado laboral y el sistema sanitario. Sin embargo, considerando la prospectiva, no se prevé un incremento considerable de la TDMP, como sí ocurre con la TDM (véase el gráfico 8).

18 Desde la década de 1960, Cuba presenta un saldo migratorio negativo, lo que constituye un factor añadido al proceso de envejecimiento y centra la preocupación en el futuro (véase De Urrutia (1997)). 
Cuadro 5

América Latina (países seleccionados): umbral móvil de envejecimiento a , 1950-2050

(En años de edad)

\begin{tabular}{lcccccc}
\hline & Argentina & Brasil & Chile & Costa Rica & Cuba & Uruguay \\
\hline $1950-1955$ & 62,1 & 60,7 & 61,3 & 61,2 & 61,5 & 63,0 \\
\hline $1955-1960$ & 63,1 & 61,9 & 62,0 & 62,5 & 62,4 & 63,5 \\
\hline $1960-1965$ & 62,9 & 62,8 & 62,6 & 63,6 & 63,3 & 64,1 \\
\hline $1965-1970$ & 63,2 & 63,6 & 62,7 & 64,2 & 64,2 & 64,2 \\
\hline $1970-1975$ & 63,6 & 64,1 & 63,4 & 64,5 & 65,5 & 64,3 \\
\hline $1975-1980$ & 64,0 & 64,4 & 64,3 & 65,3 & 67,0 & 64,7 \\
\hline $1980-1985$ & 64,7 & 62,9 & 65,1 & 66,3 & 67,5 & 65,2 \\
\hline $1985-1990$ & 65,1 & 64,4 & 66,3 & 67,4 & 67,6 & 65,6 \\
\hline $1990-1995$ & 65,9 & 66,0 & 67,2 & 68,4 & 67,6 & 66,6 \\
\hline $1995-2000$ & 66,9 & 67,4 & 68,3 & 69,4 & 68,4 & 67,4 \\
\hline $2000-2005$ & 67,5 & 68,5 & 70,0 & 70,1 & 68,9 & 68,0 \\
\hline $2005-2010$ & 68,2 & 69,2 & 70,5 & 70,6 & 69,7 & 68,8 \\
\hline $2010-2015$ & 68,9 & 70,0 & 71,5 & 71,4 & 70,4 & 69,3 \\
\hline $2015-2020$ & 69,4 & 70,8 & 72,3 & 72,1 & 71,0 & 69,8 \\
\hline $2020-2025$ & 70,0 & 71,4 & 73,0 & 72,7 & 71,7 & 70,3 \\
\hline $2025-2030$ & 70,6 & 72,1 & 73,6 & 73,2 & 72,2 & 70,8 \\
\hline $2030-2035$ & 71,2 & 72,7 & 74,1 & 73,7 & 72,8 & 71,3 \\
\hline $2035-2040$ & 71,7 & 73,3 & 74,6 & 74,2 & 73,2 & 71,7 \\
\hline $2040-2045$ & 72,2 & 73,8 & 75,1 & 74,6 & 73,7 & 72,2 \\
\hline $2045-2050$ & 72,6 & 74,3 & 75,6 & 75,0 & 74,1 & 72,6 \\
\hline
\end{tabular}

Fuente: Elaboración propia, sobre la base de Comisión Económica para América Latina y el Caribe (CEPAL), "Tablas de mortalidad", Observatorio Demográfico, № 74 (LC/G.2257-P), Santiago, 2004

a Edad en la que la población tiene una esperanza de vida igual a 15 años.

Gráfico 8

\section{América Latina (países seleccionados): tasa de dependencia de las personas mayores (TDM)} $\mathrm{y}$ tasa de dependencia de las personas mayores prospectiva (TDMP), 1950-2050

(En número de dependientes por cada 100 personas en edad laboral)

\section{A. Argentina}

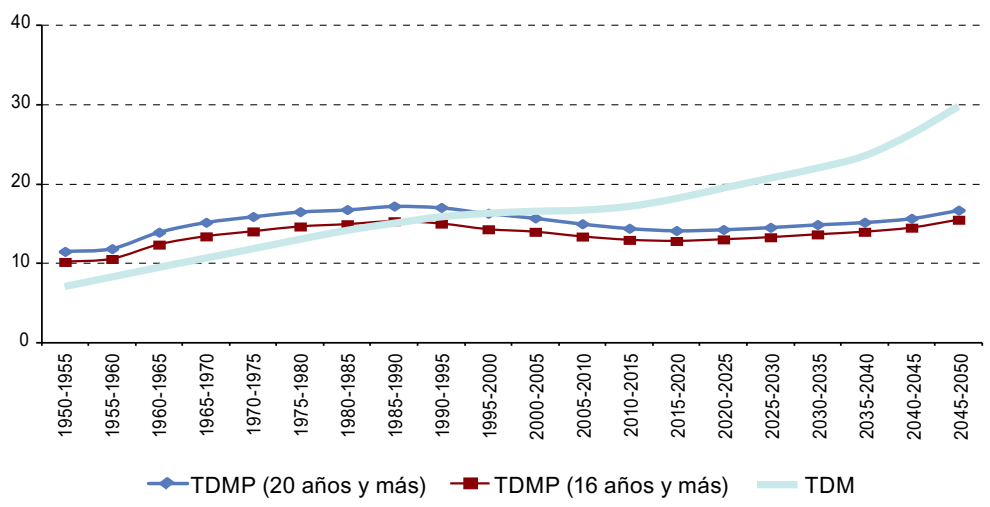


Gráfico 8 (continuación)

B. Brasil

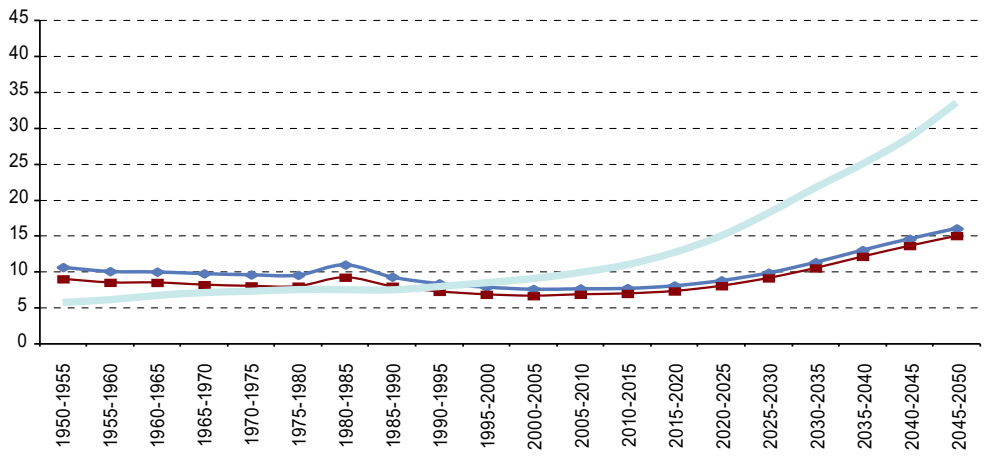

C. Costa Rica

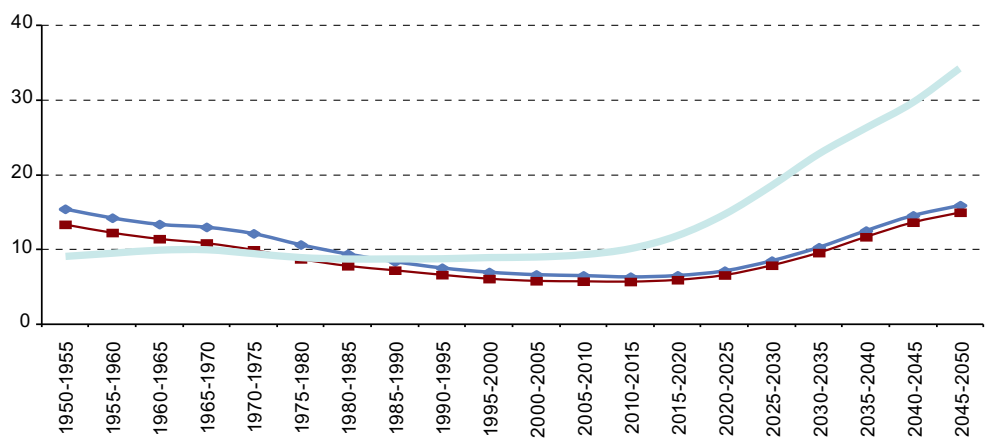

D. Cuba

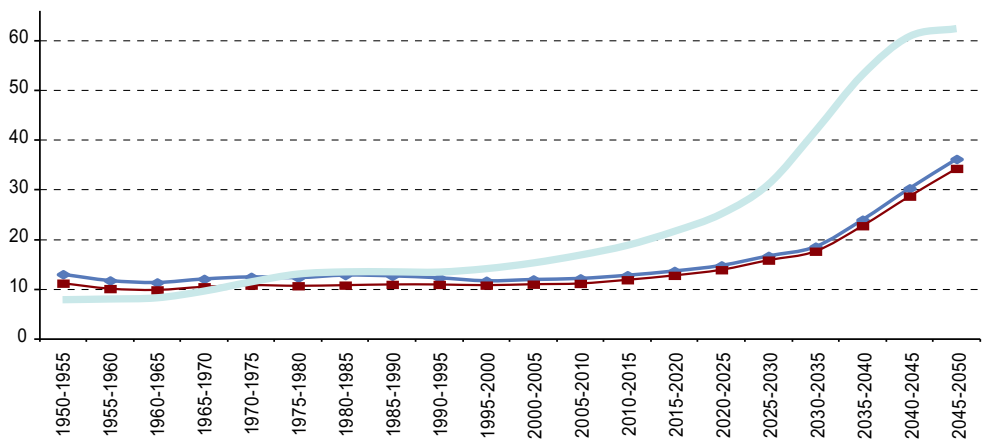

$\multimap$ TDMP (20 años y más) $\rightarrow$ TDMP (16 años y más) —TDM 
Gráfico 8 (conclusión)

E. Uruguay

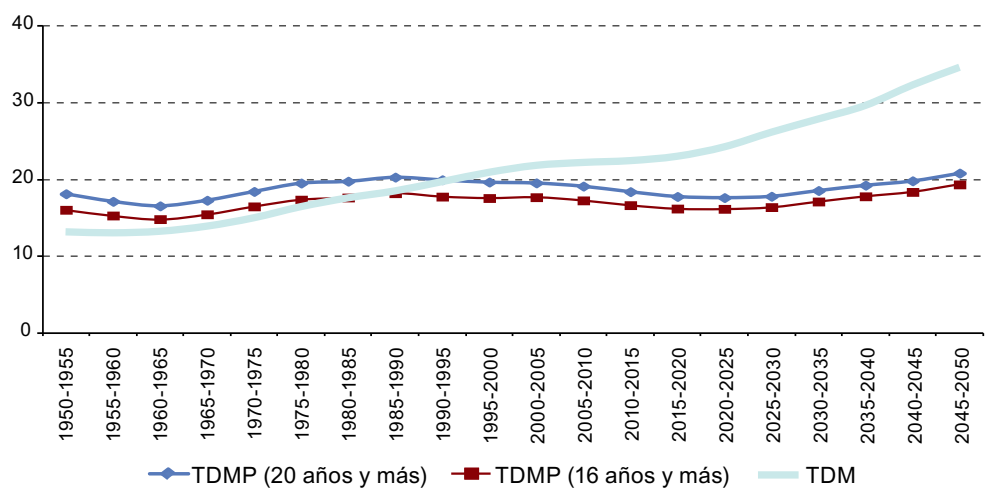

Fuente: Elaboración propia, sobre la base de Comisión Económica para América Latina y el Caribe (CEPAL), "Tablas de mortalidad", Observatorio Demográfico, No 74 (LC/G.2257-P), Santiago, 2004; y Naciones Unidas, "World Population Prospects: The 2012 Revision", 2013 [en línea] http://esa.un.org/wpp.

Puede observarse que en todos los casos existen diferencias entre la TDM y la TDMP. Dos hechos llaman especialmente la atención. Primero, como ocurre en Chile, en cuatro de los cinco países de la región analizados, se observa una TDMP inferior a la registrada en el pasado, a excepción de Cuba, que se mantiene prácticamente estable desde mediados del siglo XX hasta hoy. En segundo lugar, en todos los casos analizados se espera que en el futuro ambas tasas crezcan con mayor intensidad, aunque conservando sus diferencias de nivel.

\section{E. Conclusiones}

Hasta ahora, en los análisis sobre el envejecimiento en Chile y América Latina se tomó como base la proporción de personas mayores de 60065 años. Sin embargo, al medirlo según este umbral fijado por la edad, se obtiene una imagen que resulta anacrónica para el pasado e incompleta para el presente y el futuro. Como se señala en algunos de estos mismos estudios, este umbral no puede contemplar la multidimensionalidad de un estado que depende de muchos factores, en el que la edad por sí sola nada significa (Chackiel, 2000).

En este sentido, el enfoque prospectivo aporta una imagen más proporcional y a la vez coherente con los grandes avances producidos en la esperanza de vida a lo largo del tiempo y de la transición demográfica. Si se considera la edad de las personas no solo en términos de los años vividos, sino también en términos de los años que quedan por vivir, se concluye que la población mayor de 65 años ha rejuvenecido en términos prospectivos, pues los avances en términos de la esperanza de vida han sido considerables. 
Las mediciones tradicionales del envejecimiento de la población, como la edad mediana y la tasa de dependencia de las personas mayores, proporcionan una imagen incompleta del proceso de envejecimiento, pues se basan exclusivamente en una mirada retrospectiva de los cambios demográficos. En este sentido, al incorporar el enfoque prospectivo en los indicadores de envejecimiento, es posible observar grandes contrastes tanto en los niveles como en las tendencias del envejecimiento en el largo plazo.

En Chile, a diferencia del envejecimiento observado en la edad mediana a partir de la década de 1970 - precedido por un breve rejuvenecimiento-, mediante la edad mediana prospectiva se observa un rejuvenecimiento prolongado, que se extendió desde mediados del siglo XX hasta la década de 1990 . Detrás de este rejuvenecimiento en términos prospectivos, están las constantes mejoras en la esperanza de vida experimentadas por la población chilena.

Por otro lado, desde 1950 hasta mediados de la década de 1980, el umbral de envejecimiento móvil - fijado por la edad a la cual la esperanza de vida es igual a 15 añosse situó por debajo del umbral fijo - los 65 años de edad-, dando como resultado una TDMP superior a la TDM en ese período. Desde mediados de los años ochenta, la TDM supera a la TDMP debido a que las mejoras en esperanza de vida a edades avanzadas elevan el umbral de envejecimiento móvil por encima de los 65 años. En este sentido, las tendencias observadas en estas tasas entre 1970 y 2005 son radicalmente opuestas; mientras que la tasa de dependencia aumenta, la tasa de dependencia prospectiva disminuye. Con respecto al futuro, ambos indicadores coinciden en la tendencia al aumento del envejecimiento; no obstante, se aprecian diferencias significativas en los niveles esperados, por ejemplo, para el quinquenio $2045-2050$ se espera que la TDMP se ubique entre un $56 \%$ y un $60 \%$ por debajo de los niveles esperados de TDM. Esta diferencia tan marcada se debe a que la TDMP mantiene en condición de activos a importantes contingentes de población que, aunque superen los 65 años de edad, tendrán una esperanza de vida superior a 15 años.

Como ocurrió en Chile, el proceso de envejecimiento observado en América Latina a través de la edad mediana fue precedido por un breve rejuvenecimiento. Calculado a través de la edad mediana prospectiva, el rejuvenecimiento se prolonga en algunos países incluso hasta inicios del siglo XXI. En los casos de la Argentina y el Uruguay, se observa un rejuvenecimiento de la edad mediana prospectiva que no es apreciable por medio de la edad mediana. Por otro lado, en cuanto a los indicadores de TDM y TDMP, salvo el caso Cuba, se cumplen los mismos contrastes observados en Chile. Mientras que la TDM no deja de crecer, la TDMP experimenta caídas significativas que se prolongan hasta la década de 2020 , llegando a alcanzar niveles inferiores a los observados en el pasado.

En las próximas décadas, en la región se intensificará la acumulación de población en las edades avanzadas, lo que ha generado gran preocupación debido a los desafíos sociales y económicos que se asocian a esta dinámica. Estos desafíos previstos pueden enfrentarse mediante la implementación de políticas y programas que permitan el retiro de la vida laboral en condiciones dignas y, al mismo tiempo, permitan la permanencia como trabajadores activos a personas de 65 años y más que conserven las capacidades para ser autónomas y puedan prestar servicios útiles a la sociedad (Chackiel, 2000). La relevancia del 
enfoque prospectivo radica en la adopción del umbral de envejecimiento móvil, instrumento que permite distinguir entre los adultos mayores que conservan la capacidad de ser activos y los que no. El enfoque prospectivo contribuye a dar una proyección menos alarmista para los países que actualmente muestran un mayor nivel de envejecimiento en la región. La edad cronológica ha demostrado ser poco representativa del envejecimiento de las personas en el pasado y se prevé que ocurrirá lo mismo en el futuro.

\section{Bibliografía}

Andersson, B. (2001), "Scandinavian evidence on growth and age structure", Regional Studies, vol. 35, $\mathrm{N}^{\circ} 5$. Aranibar, P. (2001), "Acercamiento conceptual a la situación del adulto mayor en América Latina", serie Población y Desarrollo, N 21 (LC/L.1656-P), Santiago, Comisión Económica para América Latina y el Caribe (CEPAL).

Arthur, W. B. y G. McNicoll (1977), "Optimal time paths with age-dependence: a theory of population policy", The Review of Economic Studies, vol. 44, $\mathrm{N}^{\circ} 1$.

Bloom, D. E. y J. G. Williamson (1998), "Demographic transitions and economic miracles in emerging Asia", The World Bank Economic Review, vol. 12, $\mathrm{N}^{\circ} 3$.

Bloom, D.E., D. Canning y J. Sevilla (2003), The Demographic Dividend:A new perspective on the economic consequences of population change, Rand Corporation.

Bloom, D. E., D. Canning y G. Fink (2010), "Implications of population ageing for economic growth", Oxford Review of Economic Policy, vol. 26, $\mathrm{N}^{\circ} 4$.

Bongaarts, J. (2004), "Population aging and the rising cost of public pensions", Population and Development Review, vol. 30, $\mathrm{N}^{\circ} 1$.

Brander, J. A. y S. Dowrick (1994), "The role of fertility and population in economic growth", Journal of Population Economics, vol. 7, $\mathrm{N}^{\circ} 1$.

CEPAL (Comisión Económica para América Latina y el Caribe) (2004), "Tablas de mortalidad", Observatorio Demográfico, $\mathrm{N}^{\circ} 74$ (LC/G.2257-P), Santiago.

(2013), "América Latina: estimaciones y proyecciones de población a largo plazo 1950-2100: Revisión 2013", Centro Latinoamericano y Caribeño de Demografía (CELADE)-División de Población de la CEPAL [en línea] http://www.cepal.org/celade/proyecciones/basedatos_bd.htm [fecha de consulta: 16 de junio de 2015].

Cerda, R. A. (2008), “Cambios demográficos y sus impactos en Chile”, Estudios Públicos, № 110, Santiago. Chackiel, J. (2000), "El envejecimiento de la población latinoamericana: ¿hacia una relación de dependencia favorable?", serie Población y Desarrollo, No 4 (LC/L.1411-P), Santiago, Comisión Económica para América Latina y el Caribe (CEPAL).

(2004a), "La dinámica demográfica en América Latina", serie Población y Desarrollo, No 52 (LC/L.2127-P), Santiago, Centro Latinoamericano y Caribeño de Demografía (CELADE)-División de Población de la CEPAL.

(2004b), "La transición de la fecundidad en América Latina 1950-2000", Papeles de Población, № 41.

Chande, R. H. (2000), "Los umbrales del envejecimiento", Estudios Sociológicos, vol. 18, № 54.

Chesnais, J.C. (1986), «La transition démographique: étapes, formes, implications économiques. Etude de séries temporelles (1720-1984) relatives à 67 pays", Population.

(1990), El proceso de envejecimiento de la población, Santiago, Centro Latinoamericano y Caribeño de Demografía (CELADE). 
Coale, A. J. y E. M. Hoover (1958), "Population growth and economic development in low-income countries: a case study of India's prospects", The Milbank Memorial Fund Quarterly, vol. 37, N $^{\circ} 2$.

De Urrutia Barroso, L. (1997), "Aproximación a un análisis del proceso migratorio cubano", Papers: Revista de Sociología, $\mathrm{N}^{\circ} 52$.

Del Popolo, F. (2001), "Características sociodemográficas y socioeconómicas de las personas de edad en América Latina”, serie Población y Desarrollo, No 19 (LC/L.1640-P), Santiago, Comisión Económica para América Latina y el Caribe (CEPAL).

Desjardins, B. y J. Légaré (1984), «Le seuil de la vieillesse: quelques réflexions de démographes», Sociologie et sociétés, vol. 16, $\mathrm{N}^{\circ} 2$.

Díaz, J. P. (1998), "La demografía y el envejecimiento de las poblaciones", Enfermería Gerontológica, Ciudad de México, McGraw Hill.

Domínguez, O. (1987), "Estudios de las necesidades de la población adulta mayor de 60 años en Chile", documento presentado en el Simposio Internacional sobre el Envejecimiento ante el Fenómeno del Desarrollo, Santiago, Comisión Económica para América Latina y el Caribe (CEPAL).

Donoso, E. y J. Carvajal (2009), "Reducción de la fecundidad y envejecimiento de la población de mujeres chilenas en edad fértil: 1990-2004", Revista Médica de Chile, vol. 137, № 6 .

Doyle, Y. y otros (2009), "Meeting the challenge of population ageing", BMJ, vol. 339.

Gavrilov, L. A. y P. Heuveline (2003), "Aging of population", The Encyclopedia of Population, vol. 1.

Goldberger, A. (1973), "Dependency rates and savings rates: Further comment", American Economic Review, vol. 63, $\mathrm{N}^{\circ} 1$.

Gupta, K. L. (1971), "Dependency rates and savings rates: Comment", The American Economic Review, vol. $61, \mathrm{~N}^{\circ} 3$.

Guzmán, J. M. (2002), "Envejecimiento y desarrollo en América Latina y el Caribe”, serie Población y Desarrollo, $\mathrm{N}^{\circ} 28$ (LC/L.1737-P), Santiago, Comisión Económica para América Latina y el Caribe (CEPAL).

Higgins, M. y J. G. Williamson (1997), "Age structure dynamics in Asia and dependence on foreign capital", Population and Development Review, vol. $23, \mathrm{~N}^{\circ} 2$.

Huenchuan, S. y otros (2007), "Protección y participación en la vejez: escenarios futuros y políticas públicas para enfrentar el envejecimiento en Chile", Documentos de Proyecto (LC/W.139), Santiago, Comisión Económica para América Latina y el Caribe (CEPAL).

INE (Instituto Nacional de Estadísticas de Chile) (1970), XIV Censo de Población y III de Vivienda. Total pais, Santiago.

_ (2014), “Actualizacióndepoblación2002-2012yproyecciones2013-2020”[enlínea]http://www.ine.cl/ canales/chile_estadistico/familias/demograficas_vitales.php [fecha de consulta: 16 de junio de 2015].

Kelley, A. C. (1973), "Population growth, the dependency rate, and the pace of economic development", Population Studies, vol. 27, $\mathrm{N}^{\circ} 3$.

Lee, R.y G. Donehower (2010), "Elenvejecimiento dela población, las transferencias intergeneracionales y el crecimiento económico: América Latina en el contexto mundial", Notas de Población, $\mathrm{N}^{\circ} 90$ (LC/G.2469-P), Santiago, Comisión Económica para América Latina y el Caribe (CEPAL).

Leff, N. H. (1969), "Dependency rates and savings rates", The American Economic Review, vol. 61.

Leiva, A. X. (2010), "Reflexiones, debates y consensos en torno al envejecimiento, las transferencias y la protección social", Notas de Población, No 90 (LC/G.2469-P), Santiago, Comisión Económica para América Latina y el Caribe (CEPAL).

Lindh, T. y B. Malmberg (1999), "Age structure effects and growth in the OECD, 1950-1990", Journal of Population Economics, vol. 12, $\mathrm{N}^{\circ} 3$. 
Meza, J. S. (2003), "La transición demográfico-epidemiológica en Chile, 1960-2001", Revista Española de Salud Pública, vol. 77, $\mathrm{N}^{\circ} 5$.

Naciones Unidas (1948), Demographic Yearbook, Nueva York.

(1974), Demographic Yearbook, Nueva York.

_ (2013), "World Population Prospects: The 2012 Revision" [en línea] http://esa.un.org/wpp [fecha de consulta: 16 de junio de 2015].

Notestein, F. (1945), "Population: the long view", Food for the World, T. Schultz (ed.), Chicago.

Ortega Ordóñez, X. A. y F. J. Villamarín Martínez (2010), “Demographic transition: an empiric dimension of modernization in Nariño's Andes Region", Semestre Económico, vol. 13, № 27.

Ortiz Álvarez, M. I. y L. Gerónimo Mendoza (2008), "El envejecimiento en México. Aspectos territoriales y repercusiones sociales", Trayectorias: Revista de Ciencias Sociales de la Universidad Autónoma de Nuevo León, vol. 10, $\mathrm{N}^{\circ} 26$.

Parkin, T. G. (2003), Old Age in the Roman World:A cultural and social history, JHU Press.

Reher, D. S. (2004), "The demographic transition revisited as a global process", Population, Space and Place, vol. $10, \mathrm{~N}^{\circ} 1$.

_(2011), "Economic and social implications of the demographic transition", Population and Development Review, vol. $37, \mathrm{~N}^{\circ}$ s1.

Rivadeneira, L. y M. Villa (2000), "El proceso de envejecimiento de la población en América Latina y el Caribe: una expresión de la transición demográfica", Encuentro Latinoamericano y Caribeño sobre las Personas de Edad:ponencias, serie Seminarios y Conferencias, $\mathrm{N}^{\circ} 2$ (LC/L.1399-P), Santiago, Comisión Económica para América Latina y el Caribe (CEPAL).

Rosero Bixby, L. y P. Jiménez Fontana (2012), Retosy oportunidades del cambio demográfico para la política fiscal, San José, Centro Centroamericano de Población de la Universidad de Costa Rica.

Ryder, N.B. (1975), "Notes on stationary populations", Population Index, vol. 41, No 1.

Sanderson, W. y S. Scherbov (2010), "Remeasuring aging", Science (Washington), vol. 329, № 5997.

_ (2007), "A new perspective on population aging", Demographic Research, vol. 16, No 2.

_ (2005), "Average remaining lifetimes can increase as human populations age", Nature, vol. 435, $\mathrm{N}^{\circ} 7043$.

Saravia, F. F. (2012), "El bono demográfico en riesgo: una mirada desde las tendencias de pobreza, desigualdad e informalidad laboral", Población y Desarrollo-Argonautas y Caminantes, vol. 7,

Solari, A. E. (1957), "El fenómeno del "envejecimiento" en la población uruguaya", Revista Mexicana de Sociología, vol. $19, \mathrm{~N}^{\circ} 2$.

Spijker, J. y J. MacInnes (2013), "Population ageing: the timebomb that isn't?", BMJ, vol. 347.

Villa, M. y D. González (2004), "Dinámica demográfica de Chile y América Latina: una visión a vuelo de pájaro", Revista de Sociología, vol. 18.

Villalón, G. y S. Vera (2012), "Panorama demográfico en Chile contemporáneo: Desafíos para la sociedad del siglo XXI", Revista Anales de la Universidad de Chile, $\mathrm{N}^{\circ} 3$.

Weeks, J. (1984), Sociología de la población: introducción a los conceptos y cuestiones básicas, Alianza Editorial.

Wolf, D. A. y A. A. Amirkhanyan (2010), "Demographic change and its public sector consequences", Public Administration Review, vol. 70, $\mathrm{N}^{\circ}$ s1. 



\title{
Subutilización de las capacidades de los profesionales mexicanos de las ciencias y la tecnología y su vínculo con la migración a los Estados Unidos ${ }^{1}$
}

\author{
Fernando Lozano Ascencio² \\ Telésforo Ramírez-García ${ }^{3}$
}

\section{Resumen}

El presente artículo tiene como objetivo analizar el problema de la subutilización de las capacidades de la población profesional mexicana, tanto en su país de origen como en los Estados Unidos, con especial hincapié en aquellos formados en las áreas de las ciencias, la tecnología, las ingenierías y las matemáticas (CTIM). El argumento central es que la subutilización de las capacidades de esta población está estrechamente vinculada con la migración a los Estados Unidos. Sobre la base de los datos de

\footnotetext{
El presente trabajo ha sido realizado en el marco del proyecto Diásporas altamente calificadas y desarrollo científico y tecnológico de México y América Latina, que recibe financiamiento del Programa de Cátedras para Jóvenes Investigadores del Consejo Nacional de Ciencia y Tecnología (CONACYT) de México, y que se desarrolla en el Área de Estudios sobre Migraciones y Transformación Social del Centro Regional de Investigaciones Multidisciplinarias (CRIM) de la Universidad Nacional Autónoma de México (UNAM).

2 Investigador del CRIM-UNAM. Doctor en Sociología y Maestro en Demografía. Sus líneas de investigación incluyen: migración de México a los Estados Unidos, remesas, migración y desarrollo, migración de retorno y migración calificada en México y América Latina. Correo electrónico: flozano@correo.crim.unam.mx.

3 Catedrático del CONACYT, CRIM-UNAM. Doctor en Estudios de Población y Maestro en Demografía. Sus temas de investigación giran en torno a la migración internacional (remesas, migración de retorno, migración calificada), estudios sobre la familia y el envejecimiento demográfico. Correo electrónico: telex33@gmail.com.
} 
la Encuesta Nacional de Ocupación y Empleo (ENOE) de México y la American Community Survey (ACS) de los Estados Unidos (ambas de 2013) y a partir de una estrategia analítica que compara la situación laboral de esta población en México y en los Estados Unidos, los resultados muestran que los profesionales mexicanos de las áreas anteriormente citadas que se encuentran radicados en los Estados Unidos tienen una probabilidad mayor de participar en ocupaciones acordes con su formación y mejores remuneraciones salariales que aquellos que radican en México.

Palabras clave: migración calificada, mercados de trabajo, brain waste, Estados Unidos, México.

\begin{abstract}
This article analyses the underutilization of the skills of Mexican professionals, both in their home country and in the United States, focusing in particular on those who studied science, technology, engineering and mathematics (STEM). The central hypothesis is that the underutilization of the skills of this group is closely linked to migration to the United States. On the basis of data from the Mexican National Survey on Employment and Occupation (ENOE) and the American Community Survey (ACS) of the United States (both undertaken in 2013) and an analytical strategy that compares the employment situation of this group in Mexico and in the United States, our findings show that Mexican professionals in the aforementioned areas, who are settled in the United States, are more likely to work in jobs that correspond to their training and have better wages than those who remain in Mexico.
\end{abstract}

Keywords: skilled migration; labour markets; brain waste; United States; Mexico

\title{
Résumé
}

Cet article a pour but d'analyser le problème de la sous-utilisation des capacités des professionnels mexicains, aussi bien dans leur pays d'origine qu'aux ÉtatsUnis, notamment les professionnels formés dans les domaines de la science, de la technologie, des ingénieries et des mathématiques (CTIM). L'argument central est que la sous-utilisation des capacités de cette population est étroitement liée à la migration vers les États-Unis. Sur la base des données de l'enquête nationale d'occupation et d'emploi (ENOE) du Mexique et la American Community Survey (ACS) des États-Unis, toutes deux de 2013, et à partir d'une stratégie analytique qui compare la situation professionnelle de cette population au Mexique et aux États-Unis, les résultats démontrent que les professionnels mexicains des domaines mentionnés plus haut résidant aux États-Unis ont plus de chance d'exercer des fonctions plus conformes à leur formation et obtiennent de meilleures rémunérations que ceux qui résident au Mexique.

Mots clés: migration qualifiée, marché du travail, brain waste (gaspillage des compétences), États-Unis, Mexique. 


\section{Introducción}

La transición a la economía basada en el conocimiento ha traído consigo un incremento de la demanda de mano de obra calificada en todo el mundo (Beckhusen y otros, 2013), particularmente de profesionales formados en las áreas de las ciencias, la tecnología, las ingenierías y las matemáticas (CTIM). Para satisfacer tal demanda, los países más desarrollados han incrementado su gasto en educación e investigación con la finalidad de formar a los mejores y más brillantes profesionales en estos campos del conocimiento (Beckhusen y otros, 2013), dado que constituyen un recurso fundamental en los procesos de innovación e incremento de la productividad y que su trabajo está ligado a la generación de nuevas ideas, tecnologías, patentes, empresas e industrias (Lozano y Ramírez, 2015).

Asimismo, con el objeto de suplir la escasez de estos recursos humanos, aumentar su productividad y mantener el liderazgo en la economía del conocimiento, muchos países han desplegado diversas políticas para reclutar este tipo de mano de obra desde el extranjero. De ahí que, en los últimos años, se haya despertado una fuerte competencia entre naciones para atraer, retener y capacitar a migrantes calificados (Tuirán y Ávila, 2013; Beckhusen y otros, 2013). Destacan las políticas basadas en sistemas de puntos, que consisten en asignar a los migrantes calificados una preferencia en virtud de atributos de capital humano tales como la edad, el nivel educativo, el conocimiento de idiomas y la experiencia laboral (Duncan y Waldorf, 2010; Duncan, 2012; Reiner, 2010).

Un ejemplo que ilustra esta situación es la Acción Ejecutiva sobre Inmigración propuesta por el Presidente de los Estados Unidos Barack Obama y anunciada el 20 de noviembre de 2014, que incluye, entre otras medidas: a) proporcionar una autorización de trabajo a trabajadores altamente calificados que se encuentran en espera de la concesión de residencia legal, b) mejorar las opciones para empresarios extranjeros y c) capacitar y ampliar las oportunidades laborales para los profesionales formados en áreas CTIM y que se hayan graduado en universidades estadounidenses (Lozano y Ramírez, 2015). De esta forma, algunos países como los Estados Unidos se están convirtiendo en polos de atracción de población migrante altamente calificada.

Para muchos profesionales, la migración hacia países más desarrollados constituye una oportunidad para utilizar sus conocimientos en la generación de nuevas ideas o productos y participar en procesos de desarrollo e innovación; esto resulta especialmente atractivo para trabajadores calificados de países donde existen pocas oportunidades laborales, bajos ingresos y donde las carencias de la infraestructura científica y tecnológica limitan las posibilidades para su desarrollo profesional.

Si bien muchas personas calificadas han sido admitidas sobre la base de políticas de inmigración sumamente rígidas, cabe destacar que no todas logran colocarse en empleos acordes con su nivel de educación, experiencia laboral o capacitación y, con frecuencia, terminan en ocupaciones para las cuales están sobrecalificadas (Siar, 2013). Según Mattoo, Neaguy Özden (2008), esta situación representa un "desperdicio de habilidades" (brain waste), 
toda vez que existe un desajuste entre los requerimientos del empleo y los conocimientos, habilidades y destrezas adquiridas durante su formación educativa y desarrollo profesional. Ello lleva a que muchos profesionales inmigrantes a menudo se enfrenten a problemas de subempleo, desempleo y subutilización de sus capacidades, lo cual impacta negativamente en sus condiciones laborales y remuneraciones salariales.

Esta problemática ha sido ampliamente documentada en algunos países de destino, principalmente en aquellos de mayor tradición y volumen de inmigración, como Australia (Green, Kler y Leeves, 2007), el Canadá (Bauder, 2003; Salami y Nelson, 2014), España (Fernández y Ortega, 2008), los Estados Unidos (Mattoo, Neagu y Özden, 2008) y el Reino Unido (Lindley, 2009). A este respecto, los datos empíricos muestran que los inmigrantes calificados enfrentan diversas barreras para incorporarse al mercado de trabajo y dificultades para hacerlo en ocupaciones apropiadas para su nivel y área de formación educativa. A modo de ejemplo, Bauder (2003), apoyándose en el concepto del capital humano institucionalizado propuesto por Bourdieu (1986), da cuenta del desaprovechamiento de la calificación (de-skilling) que afecta a los inmigrantes calificados en el Canadá debido a la falta de reconocimiento de títulos y experiencia laboral por parte de las instituciones reguladoras, en particular las asociaciones profesionales y los empleadores, que suelen dar preferencia a los trabajadores nacidos y educados en ese país y de esta forma restringen el acceso de los inmigrantes a ocupaciones superiores del mercado laboral canadiense.

Para Bauder, estos inmigrantes experimentan una discriminación institucionalizada ya que, a pesar de contar con cualidades similares de educación y formación, no se sitúan en una posición de igualdad laboral con la población nativa calificada. Según este autor, dicha discriminación se produce, por un lado, debido a los criterios establecidos, con el respaldo del Estado, por las instituciones educativas encargadas de la validación de títulos o grados académicos obtenidos en el extranjero, y por otro, por la falta de experiencia laboral y el desconocimiento del mercado de trabajo por parte de los inmigrantes que han llegado recientemente al país, así como por otros factores como la falta de dominio del idioma y la no posesión de la ciudadanía, lo que contribuye a desplazar a los inmigrantes a los puestos más bajos y peor remunerados de la pirámide ocupacional.

Según esta misma perspectiva, Salami y Nelson (2014), apoyándose en información del Live-in Caregiver Program del Canadá, dan cuenta del desaprovechamiento de la calificación de enfermeras en el Canadá debido que estas dejan de ocupar empleos vinculados a la atención médica para desempeñarse en empleos temporales de atención domiciliaria a niños, ancianos o personas discapacitadas, que no demandan un uso cabal de sus conocimientos de enfermería, sino la realización de otras actividades propias del trabajo doméstico. Estos resultados concuerdan con los reportados por Browne, Braun y Arnsberger (2007) y por Bourgeault y otros (2010), quienes señalan la existencia de una sobrerrepresentación de las enfermeras en el trabajo doméstico y en el sector auxiliar de cuidados personales. Según estos investigadores, la migración internacional de enfermeras como trabajadoras de la salud es consecuencia del capitalismo global y refuerza las desigualdades raciales, de género y de clase. 
No obstante, cabe destacar que dicha problemática no es exclusiva de los países de destino, sino que, con distintos matices, también se presenta en los países de origen. En México, como en otros lugares, es común que las enfermeras y otros especialistas de la salud realicen trabajos de cuidado doméstico, situación que se da con mayor frecuencia entre quienes se encuentran en desempleados o subempleados o reciben salarios bajos en su empleo principal. Sobre este punto, Hernández, Solís y Stefanovich (2013), a través de un análisis del balance de la oferta y la demanda de mano de obra calificada mexicana, muestran que el problema del desaprovechamiento de la calificación afecta a los profesionales en mayor medida que el desempleo abierto. Según los autores, el porcentaje de profesionales mexicanos que se desempeñan en ocupaciones altamente calificadas disminuyó del $69 \%$ al $61 \%$ entre 2000 y 2009 , lo que originó un incremento de las ocupaciones medianamente profesionalizadas, del $19 \%$ al $23 \%$, y de las escasamente profesionalizadas, del $12 \%$ al $15 \%$. Esta tendencia, como se señala más adelante, guarda relación con el crecimiento de las instituciones de educación superior y del número de matrículas universitarias, que ha generado un aumento de la población de egresados con altos niveles de formación educativa sin ir acompañado del desarrollo de una estructura ocupacional que absorba esta mano de obra calificada (Hernández, Solís y Stefanovich, 2013). Esto podría incentivar la migración internacional entre algunos de estos trabajadores (Lozano, Gandini y Ramírez, 2015), en busca de mejores oportunidades, salarios y desarrollo profesional o para sacar partido de la creciente demanda de mano de obra calificada a nivel mundial, sobre todo en el caso de especialistas de las ciencias de la salud, la informática y las ingenierías.

Al respecto, Nowicka (2013) documenta que la falta de perspectivas de desarrollo profesional y la insuficiencia de ingresos son algunas de las causas que explican la migración de profesionales de Polonia al Reino Unido. Según la autora, antes de emigrar algunos migrantes calificados desempeñaban trabajos que no demandaban los conocimientos adquiridos durante su formación educativa, y otros ni siquiera habían intentado emplearse en el mercado laboral polaco, ya que consideraban que sus habilidades no serían valoradas adecuadamente en términos económicos y en consecuencia preferían emigrar. De igual forma, Hochschild (2002) encuentra que las profesionales filipinas deben decidir entre trabajar como profesoras, enfermeras o administradoras en su país de origen por 176 dólares al mes o emigrar a Norteamérica (los Estados Unidos o el Canadá) y realizar trabajos de menor calificación, como trabajadoras domésticas, niñeras o cuidadoras, por unos 1.400 dólares al mes.

Estos estudios muestran que la subutilización de capacidades o desaprovechamiento de la calificación es un problema que afecta a la población profesional tanto en el origen como en el destino, aunque de distinta forma. Sin embargo, existen pocas obras que aborden este desperdicio de la formación desde una perspectiva comparativa que permita comprender de manera simultánea sus causas y sus consecuencias, tanto en el origen como en el lugar de destino, con sus vínculos, manifestaciones y trasformaciones. Por ejemplo, en el caso de México, un país que en los últimos años ha presentado un incremento de la oferta de profesionales y a su vez un crecimiento de la migración de 
esta mano de obra a los Estados Unidos, cabe plantearse algunas preguntas: ¿ha logrado este contingente de profesionales mexicanos insertarse en el mercado de trabajo en México?, ¿en qué condiciones laborales lo ha hecho? y ¿qué factores sociodemográficos explican sus patrones de inserción ocupacional y las remuneraciones salariales que reciben por sus empleos?

Con el fin de responder a los interrogantes anteriormente planteados, el presente artículo tiene como objetivo analizar el problema de la subutilización de capacidades entre la población mexicana calificada, con especial atención al caso de los profesionales de áreas CTIM residentes en México y los Estados Unidos. Específicamente, se examinan tres aspectos: 1) la existencia de la subutilización de capacidades de la mano de obra mexicana calificada en el contexto mexicano y estadounidense, 2) los factores sociodemográficos vinculados a tal problemática y su efecto en el nivel de ingresos de los trabajadores en los dos países y 3) la exploración de posibles vínculos entre la situación laboral y la migración de los profesionales mexicanos a los Estados Unidos. El análisis se basa en los datos de la Encuesta Nacional de Ocupación y Empleo (ENOE) de México del segundo semestre de 2013 y la American Community Survey (ACS) de 2013.

Tras esta introducción, el documento está organizado en tres grandes apartados. En primer lugar, se presenta un análisis de los niveles y tendencias de la población mexicana calificada y de aquella formada específicamente en áreas CTIM que residía en México o los Estados Unidos en el período comprendido entre 1990 y 2013. A continuación, se analizan las condiciones laborales de los profesionales mexicanos en ambos países, específicamente en 2013, y se destacan aspectos referentes a los niveles de ocupación, desempleo y subutilización de sus capacidades. Posteriormente, se examinan las diferencias salariales y los factores determinantes del ingreso o la permanencia por trabajo en cada país. Por último, a modo de cierre, se destacan las principales conclusiones que se derivan de la investigación.

\section{A. Tendencias de la población calificada mexicana residente en México y en los Estados Unidos}

En México, al igual que en otros países de América Latina, la población con estudios terminados de licenciatura o posgrado (maestría o doctorado) ha experimentado un notorio crecimiento en los últimos años. Las estadísticas oficiales indican que, en conjunto, este segmento poblacional creció un 103,7\% entre 1990 y 2000, al pasar de 2,1 millones a 4,4 millones de personas. En este período, los profesionales con licenciatura aumentaron un $122,1 \%$, mientras que los que habían obtenido un título de maestría o doctorado incrementaron un $4,3 \%$. Durante la siguiente década, la población profesional mexicana siguió ascendiendo hasta alcanzar la cifra de 8,2 millones de personas en 2010; sin embargo, lo hizo a un ritmo inferior al decenio anterior (84,4\%). Entre 2000 y 2010, el cambio más novedoso fue el vertiginoso incremento que experimentó la población con estudios de 
posgrado, al pasar de 355.000 a 921.000 personas en el espacio de dicha década. Esto representó un aumento del 159,2\%, que supera con creces el registrado con relación a aquellos que solo habían terminado una licenciatura $(77,9 \%)$. De hecho, entre 2000 y 2013 , los posgraduados obtuvieron el mayor crecimiento (153,9\%) (véase el cuadro 1 ).

Cuadro 1

México: población calificada con formación profesional, por nivel educativo, $1990,2000,2010$ y 2013

\begin{tabular}{|c|c|c|c|c|c|c|c|}
\hline \multirow{2}{*}{$\begin{array}{l}\text { Nivel } \\
\text { educativo }\end{array}$} & \multicolumn{4}{|c|}{ Valores absolutos } & \multicolumn{3}{|c|}{ Variación porcentual } \\
\hline & 1990 & 2000 & 2010 & 2013 & $1990-2000$ & $2000-2010$ & $2000-2013$ \\
\hline Total & 2191370 & 4464793 & 8231822 & 10020035 & 103,7 & 84,4 & 124,4 \\
\hline Licenciatura & 1850630 & 4109571 & 7311013 & 9118008 & 122,1 & 77,9 & 121,9 \\
\hline Posgrado & 340740 & 355222 & 920809 & 902027 & 4,3 & 159,2 & 153,9 \\
\hline
\end{tabular}

Fuente: Elaboración propia sobre la base de Instituto Nacional de Estadística y Geografía (INEGI), muestras censales, 1990, 2000 y 2010; Encuesta Nacional de Ocupación y Empleo (ENOE), segundo trimestre de 2013.

El sólido crecimiento de la población profesional mexicana tiene su explicación en múltiples factores sociales, económicos e institucionales, entre los que se encuentran aquellos vinculados al cambio demográfico (Zúñiga y Molina, 2008; Hernández, Solís y Stefanovich, 2013; Gandini y Lozano, 2012). El elemento que más repercute en la dinámica demográfica nacional es el crecimiento de la población en edad de recibir educación superior (19 a 23 años). Ante este hecho, el Estado mexicano ha implementado una serie de políticas educativas y planes de desarrollo sexenales para la educación superior encaminados a ampliar la cobertura escolar, mejorar la calidad educativa y multiplicar las oportunidades para que un mayor número de jóvenes pueda acceder a la educación superior y culminarla (Hernández, Solís y Stefanovich, 2013). Por ejemplo, en el Programa Sectorial de Educación 2007-2012 se planteó como objetivo aumentar la cobertura de la educación superior a través de: 1) la ampliación de la oferta educativa de las instituciones, 2) la creación de nuevas universidades públicas y privadas y 3) la diversificación de los sistemas, áreas y carreras que integran la oferta educativa, incluidos programas de educación a distancia y semipresenciales (SEP, 2008). Como resultado de tales iniciativas, el número de matrículas de la educación superior creció un $45 \%$ entre 2000 y 2010 : un $41,4 \%$ en el caso de las licenciaturas y un $66,3 \%$ en el de los posgrados. En el año escolar 2009/10 existían más de 1.900 universidades en el país cuya oferta educativa contaba con 22.000 programas educativos distribuidos en 3.000 planteles (ANUIES, 2011).

Estos cambios también guardan una estrecha relación con la creciente demanda de mano de obra de mayor calificación y especialización por parte de las empresas e instituciones, sobre todo de aquellas orientadas a promover el desarrollo científico y tecnológico y la innovación en el país. De ahí que algunas carreras universitarias, especialidades y posgrados (maestrías y doctorados) en áreas CTIM hayan cobrado gran importancia en los últimos años. Al respecto, las estadísticas censales muestran que, entre 1990 y 2000, los profesionales de carreras CTIM experimentaron un crecimiento de $124,2 \%$, cifra ligeramente inferior a la 
de los estudios no relacionados con las áreas CTIM (129,1\%). Dentro de las especialidades CTIM, los graduados en ciencias de la computación y matemáticas crecieron a un ritmo superior al promedio general con un aumento del $737,0 \%$, seguidos por los de física y ciencias de la vida $(188,8 \%)$. Por nivel educativo, los datos revelan que en este período los licenciados en carreras CTIM crecieron un $138,5 \%$ y los posgraduados un $5,0 \%$. En ambos casos, los especialistas en computación y matemáticas presentaron las mayores tasas de crecimiento: $823,6 \%$ en el caso de los licenciados y $212,6 \%$ en el caso de los posgraduados (véase el cuadro 2).

Cuadro 2

México: población con formación profesional, por nivel educativo y área del conocimiento, 1990, 2000, 2010 y 2013

\begin{tabular}{|c|c|c|c|c|c|c|c|}
\hline \multirow{2}{*}{$\begin{array}{l}\text { Nivel educativo } \\
\text { y área del } \\
\text { conocimiento }\end{array}$} & \multicolumn{4}{|c|}{ Valores absolutos } & \multicolumn{3}{|c|}{ Variación porcentual } \\
\hline & 1990 & 2000 & 2010 & 2013 & $\begin{array}{l}1990- \\
2000\end{array}$ & $\begin{array}{c}2000- \\
2010\end{array}$ & $\begin{array}{c}2000- \\
2013\end{array}$ \\
\hline Total $^{a}$ & 1871120 & 4259218 & 7893696 & 10003039 & 127,6 & 85,3 & 134,9 \\
\hline CTIM ${ }^{b}$ & 565360 & 1267599 & 2025444 & 2785196 & 124,2 & 59,8 & 119,7 \\
\hline Computación y matemáticas & 22140 & 185310 & 312821 & 364766 & 737,0 & 68,8 & 96,8 \\
\hline Ingenierias & 360770 & 555387 & 1281701 & 1869022 & 53,9 & 130,8 & 236,5 \\
\hline Física y ciencias de la vida & 182450 & 526902 & 430922 & 551408 & 188,8 & $-18,2$ & 4,7 \\
\hline No CTIM & 1305760 & 2991619 & 5868252 & 7217843 & 129,1 & 96,2 & 141,3 \\
\hline Licenciatura $^{a}$ & 1627280 & 3941202 & 7094688 & 9102251 & 142,2 & 80,0 & 131,0 \\
\hline CTIM ${ }^{b}$ & 504710 & 1203893 & 1847411 & 2602394 & 138,5 & 53,5 & 116,2 \\
\hline Computación y matemáticas & 19000 & 175493 & 286177 & 343408 & 823,6 & 63,1 & 95,7 \\
\hline Ingenierias & 321730 & 531201 & 1186308 & 1774121 & 65,1 & 123,3 & 234,0 \\
\hline Física y ciencias de la vida & 163980 & 497199 & 374926 & 484865 & 203,2 & $-24,6$ & $-2,5$ \\
\hline No CTIM & 1122570 & 2737309 & 5247277 & 6499857 & 143,8 & 91,7 & 137,5 \\
\hline Posgrado $^{a}$ & 243840 & 318016 & 799008 & 900788 & 30,4 & 151,2 & 183,3 \\
\hline CTIM $^{b}$ & 60650 & 63706 & 178033 & 182802 & 5,0 & 179,5 & 186,9 \\
\hline Computación y matemáticas & 3140 & 9817 & 26644 & 21358 & 212,6 & 171,4 & 117,6 \\
\hline Ingenierias & 39040 & 24186 & 95393 & 94901 & $-38,0$ & 294,4 & 292,4 \\
\hline Física y ciencias de la vida & 18470 & 29703 & 55996 & 66543 & 60,8 & 88,5 & 124,0 \\
\hline No CTIM & 183190 & 254310 & 620975 & 717986 & 38,8 & 144,2 & 182,3 \\
\hline
\end{tabular}

Fuente: Elaboración propia sobre la base de Instituto Nacional de Estadística y Geografía (INEGI), muestras censales de 1990, 2000 y 2010; Encuesta Nacional de Ocupación y Empleo (ENOE), segundo trimestre de 2013.

a No incluye a la población que no declaró el nombre de la carrera o posgrado.

b Áreas de las ciencias, la tecnología, las ingenierías y las matemáticas.

No obstante, estas tendencias sufrieron un cambio radical en la década de 2000 . Aunque a nivel nacional se sumaron más de 757.000 estudiantes al número absoluto de graduados en carreras CTIM, con lo que se pasó de 1,2 millones a poco más de 2 millones, en términos relativos dicho crecimiento fue inferior al observado en el decenio anterior 
(59,8\%, con respecto al $124,2 \%$ anterior) y mucho menor que el reportado por los graduados en carreras que no son del área CTIM (96,2\%). Por área de especialidad, se observa que el crecimiento relativo de los profesionales en computación y matemáticas se redujo a un $68,8 \%$, lo que podría dar cuenta de una posible saturación de las carreras de computación tras varios años con ritmos de crecimiento muy elevados. Para los especialistas en física y ciencias de la vida el descenso fue todavía mayor, pues exhibieron un crecimiento negativo $(-18,2 \%)$. En cambio, los graduados en ingenierías crecieron un 130,8\%.

Al analizar estas tendencias en relación con los niveles educativos alcanzados (licenciatura o posgrado), entre 2000 y 2010 se observa que los licenciados en carreras CTIM crecieron a ritmos inferiores al promedio nacional (53,5\%) e incluso registraron un crecimiento menor que el de la maestrías y los doctorados. Estos últimos, por el contrario, presentaron un incremento extraordinariamente alto, del $179,5 \%$ en el período considerado. Por ejemplo, los ingenieros aumentaron un $294,4 \%$ y los formados en computación y matemáticas un $171,4 \%$. Asimismo, las tendencias observadas entre 2010 y 2013 corroboran un incremento de los profesionales con una carrera CTIM, especialmente en el caso de los ingenieros (véase el cuadro 2).

Estos cambios en el nivel y perfil educativo de la población mexicana se traducen en diversos retos y oportunidades. Por un lado, el aumento de la población con educación constituye una oportunidad para impulsar y contribuir al desarrollo nacional, ya que los saberes científico y tecnológico adquieren cada vez más centralidad en los diferentes ámbitos de la vida económica, social y cultural. Y por otro, representan un gran reto, no solo en lo que concierne a la incorporación de esta mano de obra al mercado laboral, sino también en la creación de empleos que permitan una utilización plena de los conocimientos, habilidades y competencias adquiridas durante su formación, es decir, garantizar que la inversión de cuatro o más años de estudios de licenciatura o posgrado se materialice en un empleo para el que se requiera dicha formación.

Sin embargo, como muestran estudios de otros países, como China, Italia, el Perú y el Reino Unido (Purcel, Wilton y Elias, 2002; Walker y Zhu, 2005; Dolton y Vignoles, 2000; Burga y Moreno, 2001) - y como se documenta en los siguientes apartados de este trabajo-, alcanzar un equilibrio entre la oferta y la demanda de mano de obra calificada, así como una sincronía entre las habilidades adquiridas por los profesionales y las requeridas por el mercado de trabajo, es un reto difícil de superar. Esta situación, que en muchos casos se manifiesta en mayores tasas de desempleo, subocupación y subutilización y, por consiguiente, en menores remuneraciones salariales (Lozano, Gandini y Ramírez, 2015), ha obligado a muchos profesionales mexicanos a emigrar a otros países, y a aquellos que se forman y residen en el extranjero, a no retornar al país (Tuirán y Ávila, 2013).

Las estadísticas estadounidenses señalan a México como el país latinoamericano con el mayor flujo de personal calificado hacia los Estados Unidos. Entre 1990 y 2000, el número de mexicanos con estudios de licenciatura o posgrado se duplicó con creces al pasar de 123.519 a 308.660 personas, lo que en términos relativos representa un incremento del $149,9 \%$. En este período, los inmigrantes mexicanos con una licenciatura terminada 
crecieron a un ritmo superior al total de los profesionales mexicanos (158,5\%), y por encima de los posgraduados $(136,9 \%)$. Durante la primera década del presente siglo, la población calificada mexicana se multiplicó por 1,8 hasta alcanzar la suma de 554.276 personas en 2010. Sin embargo, en estos años, la llegada de licenciados (113,2\%) y posgraduados $(24,2 \%)$ mexicanos a los Estados Unidos fue mucho menor que en el decenio anterior, posiblemente a consecuencia de la crisis económica de 2008, que afectó profundamente a la economía estadounidense. Ahora bien, dicho patrón migratorio también puede ser reflejo del descenso que experimentó la población mexicana calificada durante esta década, como mencionamos anteriormente. En 2013, el número de profesionales mexicanos en los Estados Unidos ascendió a 611.904 personas, lo que representó un aumento del 98,2\% en comparación con la registrada en 2000; este aumento corresponde a un $135,3 \%$ en el caso de los licenciados y a un $37,2 \%$ para los posgraduados. De continuar esta tendencia, supondría una posible recuperación de la migración mexicana calificada a los Estados Unidos en los próximos años (véase el cuadro 3).

Cuadro 3

Estados Unidos: población mexicana calificada residente, por nivel de estudios, 1990, 2000, 2010 y 2013

\begin{tabular}{|c|c|c|c|c|c|c|c|}
\hline \multirow{2}{*}{ Nivel de estudios } & \multicolumn{4}{|c|}{ Valores absolutos } & \multicolumn{3}{|c|}{ Variación porcentual } \\
\hline & 1990 & 2000 & 2010 & 2013 & $1990-2000$ & $2000-2010$ & $2000-2013$ \\
\hline Total & 123519 & 308660 & 554276 & 611904 & 149,9 & 79,6 & 98,2 \\
\hline Licenciatura $^{a}$ & 74333 & 192135 & 409560 & 452032 & 158,5 & 113,2 & 135,3 \\
\hline Posgrado $^{\text {b }}$ & 49186 & 116525 & 144716 & 159872 & 136,9 & 24,2 & 37,2 \\
\hline
\end{tabular}

Fuente: Elaboración propia sobre la base del proyecto sobre el uso público integrado de series de microdatos (IPUMS), muestras censales de 1990 y la American Community Survey (ACS), 2000, 2010 y 2013.

a Cuatro años terminados.

b Maestría, profesional y doctorado.

En 2013, del total de la mano de obra mexicana calificada presente en los Estados Unidos, el $24,2 \%$ había estudiado una carrera en algún área CTIM. Los ingenieros, que representaban un 58,9\% del total, constituían el grupo más grande, seguidos por los especialistas en ciencias de la computación y matemáticas $(21,4 \%)$ y, a continuación, los graduados en física y ciencias de la vida $(19,7 \%)^{4}$. Por nivel educativo, los datos dan cuenta de algunas diferencias. Una de ellas es que el porcentaje de personas con una carrera CTIM es mayor entre los posgraduados que entre los licenciados (un $28 \%$ frente a un $22,8 \%$ ), lo que confirma la existencia de una selectividad positiva hacia la mano de obra mexicana de mayor calificación. Otra diferencia es que entre los posgraduados predominan, además de los ingenieros, los especialistas en física y ciencias de la vida, mientras que entre los licenciados son mayoría los ingenieros y los profesionales en computación y matemáticas (véase el cuadro 4).

4 La clasificación de profesionales en áreas CTIM y no CTIM fue tomada del trabajo de Langdon y otros (2011). 
Cuadro 4

Estados Unidos: población mexicana residente, por nivel de estudios

y área del conocimiento, 2013

(En porcentajes y número de personas)

\begin{tabular}{lcccccc}
\hline Área del conocimiento & \multicolumn{2}{c}{ Total } & \multicolumn{2}{c}{ Licenciatura } & \multicolumn{2}{c}{ Posgrado } \\
\hline Total & 611904 & 100,0 & 452032 & 100,0 & 159872 & 100,0 \\
\hline CTIM $^{a}$ & 147946 & 24,2 & 103164 & 22,8 & 44782 & 28,0 \\
\hline Computación y matemáticas & 31618 & 21,4 & 24547 & 23,8 & 7071 & 15,8 \\
\hline Ingenierías & 87145 & 58,9 & 63200 & 61,3 & 23945 & 53,5 \\
\hline Física y ciencias de la vida & 29183 & 19,7 & 15417 & 14,9 & 13766 & 30,7 \\
\hline No CTIM & 463958 & 75,8 & 348868 & 77,2 & 115090 & 72,0 \\
\hline
\end{tabular}

Fuente: Elaboración propia sobre la base del proyecto sobre el uso público integrado de series de microdatos (IPUMS) y la American Community Survey (ACS), 2013.

a Áreas de las ciencias, la tecnología, las ingenierías y las matemáticas.

En suma, los datos hasta aquí expuestos muestran un aumento de la oferta de profesionales mexicanos, especialmente de aquellos que han terminado una carrera CTIM, pero también un crecimiento del número de trabajadores mexicanos formados en estos campos del conocimiento que se encuentran radicados en los Estados Unidos, lo que podría suponer la existencia de un vínculo entre la creciente oferta mexicana y la demanda estadounidense de trabajadores graduados en este tipo de carreras y posgrados universitarios. No obstante, queda por ver de qué forma se ha producido la incorporación de este grupo de profesionales mexicanos al mercado de trabajo y si se desempeñan en una ocupación acorde con su nivel y área de formación profesional. Asimismo, cabe preguntarse acerca de los factores sociodemográficos que determinan su participación económica, el tipo de trabajo que realizan, sus condiciones laborales y los salarios que reciben por su trabajo en ambos países.

\section{B. Condiciones laborales de la población mexicana calificada en México y en los Estados Unidos}

Desde la óptica de la teoría del capital humano se postula que contar con altas credenciales educativas representa, para cualquier persona y en cualquier país, una oportunidad para acceder a mejores condiciones laborales y salariales (Becker, 1964). Sin embargo, esta expectativa no siempre se cumple, pues la situación de los profesionales en el mercado laboral está determinada por una gran diversidad de factores demográficos, económicos, políticos, sociales e institucionales que impactan de forma distinta según el género, la clase social, la nacionalidad y la situación migratoria. Tomando en cuenta estas consideraciones, presentamos a continuación un análisis de las condiciones laborales de la población mexicana calificada residente en México y en los Estados Unidos, con el año 2013 como 
base. La estrategia analítica consiste en comparar las condiciones laborales de la población ocupada mexicana con estudios de licenciatura o de posgrado según su país de residencia, es decir, México o los Estados Unidos. Se trata de un colectivo de 8,2 millones de personas, de las cuales 462.230 (5,6\%) residen en los Estados Unidos y el resto en México.

\section{Ocupación, desempleo y subocupación entre los profesionales mexicanos}

Lo primero que destaca cuando se analizan los indicadores laborales de los profesionales mexicanos es su alta participación en el mercado laboral. Al respecto, los datos del cuadro 5 muestran que, en ambos países, la tasa de ocupación oscila entre el $94 \%$ y el $97 \%$, lo que indica que algo más de 9 de cada 10 profesionales mexicanos tanto radicados en México como en los Estados Unidos se encuentran insertos en el mercado laboral y desempeñan alguna actividad económica y productiva. Sin embargo, la información desagregada por área del conocimiento y nivel de estudios muestra la existencia de ligeras diferencias entre los países. De entrada, se advierte que la tasa de ocupación de los profesionales residentes en México es muy similar entre los que tienen una carrera en áreas CTIM y aquellos con estudios en áreas no CTIM (un 93,9\% frente a un 94,5\%). En cambio, entre los migrantes mexicanos calificados de los Estados Unidos dicho indicador es mayor en el caso de los formados en el área CTIM (95,9\%, frente al 95,0\% para otras áreas), y también es superior al registrado por los especialistas del ramo con residencia en México (véase el cuadro 5).

\section{Cuadro 5}

Tasas de ocupación de la población mexicana calificada, por nivel de estudios y área del conocimiento, según país de residencia, 2013

\begin{tabular}{|c|c|c|c|c|c|c|}
\hline \multirow{2}{*}{ Área del conocimiento } & \multicolumn{3}{|c|}{ México } & \multicolumn{3}{|c|}{ Estados Unidos } \\
\hline & Total & Licenciatura & Posgrado & Total & Licenciatura & Posgrado \\
\hline Población ocupada & 7758365 & 6999102 & 759263 & 462230 & 340692 & 121538 \\
\hline Tasa de ocupación total & 94,4 & 94,2 & 96,4 & 95,2 & 94,7 & 96,8 \\
\hline CTIM $^{a}$ & 93,9 & 93,6 & 97,4 & 95,9 & 94,7 & 98,7 \\
\hline Computación y matemáticas & 95,2 & 95,4 & 92,2 & 96,8 & 97,0 & 79,4 \\
\hline Ingenierías & 93,4 & 93,1 & 98,4 & 96,0 & 94,5 & 99,9 \\
\hline Física y ciencias de la vida & 94,7 & 94,3 & 97,6 & 94,6 & 91,8 & 97,6 \\
\hline No CTIM & 94,5 & 94,6 & 96,1 & 95,0 & 94,6 & 95,9 \\
\hline
\end{tabular}

Fuente: Elaboración propia sobre la base de Instituto Nacional de Estadística y Geografía (INEGI), Encuesta Nacional de Ocupación y Empleo (ENOE), segundo trimestre de 2013, y del proyecto sobre el uso público integrado de series de microdatos (IPUMS) y la American Community Survey (ACS), 2013.

a Áreas de las ciencias, la tecnología, las ingenierías y las matemáticas.

Cuando se analizan los datos por nivel de estudios se vislumbra un escenario similar: los profesionales formados en una carrera CTIM presentan una tasa de ocupación más alta, aún mayor entre los posgraduados que entre los licenciados, y la brecha entre ambos 
especialistas es más amplia en los Estados Unidos que en México. Esto indica que los mexicanos que cuentan con una maestría, un grado profesional o un doctorado en un área CTIM tienen mayores probabilidades de emplearse en los Estados Unidos, lo cual podría ser un aliciente para la migración de este segmento de mano de obra calificada, así como para el establecimiento permanente o definitivo de los mexicanos que se formaron en aquel país. Esto es especialmente pertinente en el caso de los que cuentan con un posgrado en ingeniería, entre los que la tasa de ocupación es del 99,9\%, o de física y ciencias de la vida, para los que la tasa es del 97,6\%, y también podría extenderse a los que poseen una licenciatura en ciencias de la computación y matemáticas, quienes presentan una de las tasas de ocupación más altas de los licenciados mexicanos en los Estados Unidos.

De acuerdo con los datos hasta aquí expuestos, podría parecer que el desempleo no es un problema que afecte a la población mexicana calificada radicada en uno de estos dos países. Sin embargo, si se considera la contraparte de las tasas de ocupación incluidas en el cuadro 5, esto es, las tasas de desempleo abierto, se observa que esta problemática atañe en mayor medida a los residentes en México, particularmente a los formados en las áreas de la computación, la tecnología, la informática y las matemáticas. Los datos presentados en el gráfico 1 revelan que la tasa de desempleo abierto entre los profesionales con una carrera CTIM que viven en México es del 6,1\%, mientras que entre sus connacionales con similares credenciales y títulos académicos radicados en los Estados Unidos es del 4,1\%, una diferencia de dos puntos porcentuales. En cambio, en el caso de los profesionales con carreras distintas a las CTIM la brecha entre las tasas de desempleo abierto es mínima o casi inexistente, con el 5,5\% en México y el 5,0\% en los Estados Unidos.

\section{Gráfico 1}

Tasas de desempleo abierto de la población mexicana calificada, por área del conocimiento y país de residencia, 2013

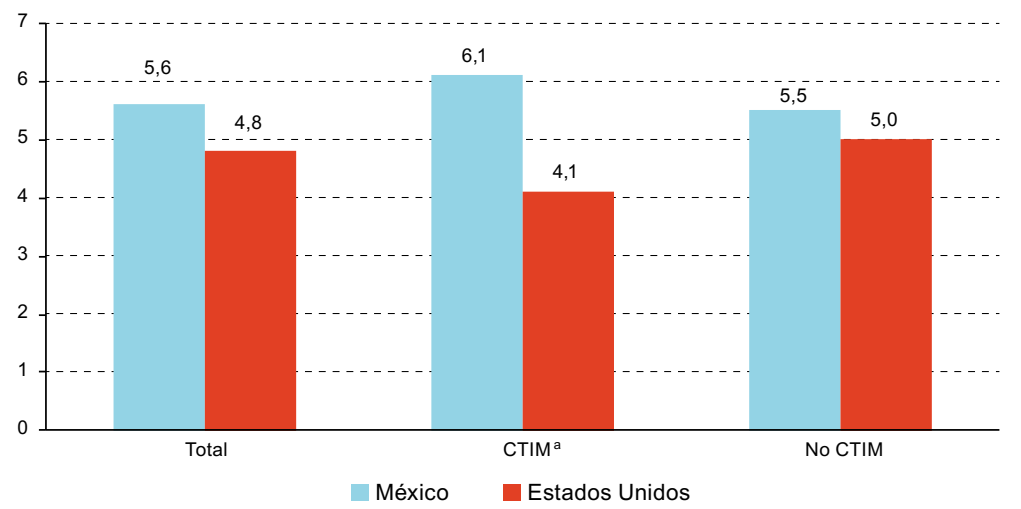

Fuente: Elaboración propia sobre la base de Instituto Nacional de Estadística y Geografía (INEGI), Encuesta Nacional de Ocupación y Empleo (ENOE), segundo trimestre de 2013, y del proyecto sobre el uso público integrado de series de microdatos (IPUMS) y la American Community Survey (ACS), 2013.

a Áreas de las ciencias, la tecnología, las ingenierías y las matemáticas. 
Ambas situaciones ilustran el impacto desigual del desempleo entre los profesionales mexicanos según su nivel de estudios, área del conocimiento y país de residencia. Sugieren además que en México un contingente considerable de la mano de obra calificada no se está incorporando al mercado laboral, lo que implica la existencia de un desequilibrio entre la oferta y la demanda de profesionales que se inclina a favor de la oferta. También podría estar gestándose una saturación del empleo para los graduados de determinadas carreras, como es el caso de los profesionales de áreas CTIM, debido a la falta de creación de nuevos puestos de trabajo que absorban a los recién graduados de las universidades y centros de educación superior que buscan un cargo que les proporcione un sustento económico y que les permita avanzar en su desarrollo profesional.

Además del desempleo, un punto central en el análisis de la inserción laboral de esta mano de obra es el estudio del nivel de correspondencia entre las habilidades y capacidades obtenidas por los profesionales durante su formación académica y los requisitos que exigen las ocupaciones para su correcto desempeño. Para llevar a cabo tal ejercicio se establecieron dos grupos de ocupaciones sobre la base de la tipología de Hernández, Solís y Stefanovich, (2013): 1) ocupaciones altamente calificadas, que requieren una utilización de las capacidades de los profesionales, al participar en labores acordes con su formación, y 2) ocupaciones de mediana y escasa calificación, que implican una subutilización de las capacidades, al tratarse de actividades que no tiene que desempeñar necesariamente un profesional o que requieren un menor nivel de educación 5 . Las estimaciones realizadas muestran que únicamente el 56,6\% de los profesionales mexicanos residentes en México y el 45,9\% de los radicados en los Estados Unidos se emplean en una ocupación altamente calificada, mientras que el resto desempeñan ocupaciones de mediana o escasa calificación (43,4\% en el caso de México y 54,1\% en el de los Estados Unidos), lo que implica que en ambos países existe una importante subutilización o devaluación de las capacidades de la mano de obra calificada mexicana.

Aunque en términos generales, el porcentaje de profesionales empleados en una ocupación altamente calificada es mayor entre las personas que viven en México que entre aquellas que se encuentran en los Estados Unidos - posiblemente debido a las barreras institucionales, culturales y migratorias a las que se enfrentan para acceder a puestos de trabajo acordes con sus credenciales educativas-, es posible enunciar algunos contrastes por país de residencia y área del conocimiento. En los Estados Unidos, por ejemplo, los profesionales con una licenciatura o un posgrado en áreas CTIM presentan una mayor participación en actividades altamente calificadas que los que se formaron en otro campo del conocimiento (un 48,0\% frente a un 45,2\%), mientras que en México la relación observada es la inversa. Es decir, en este caso, el porcentaje de profesionales que trabaja en una ocupación altamente calificada es significativamente mayor entre los que no se formaron en áreas CTIM que entre los que sí (un 59,6\% frente a un 49,0\%).

Las diferencias en este sentido indican que, el 27,7\% de los empleados los radicados en los Estados Unidos en una actividad laboral altamente calificada ha terminado una carrera universitaria o un posgrado en el área CTIM, mientras que en México solo el 24,6\% de los

5 Véase información más detallada sobre la tipología de ocupaciones en Hernández, Solís y Stefanovich, (2013, pág. 176). 
que trabajan en este tipo de ocupaciones se ha formado en este campo del conocimiento. De ahí que la proporción de profesionales de áreas CTIM que se emplean en una ocupación de mediana o escasa calificación sea más alta en México que en los Estados Unidos (un $33,5 \%$ frente a un $25,5 \%$ ) (véanse el cuadro 6 y el gráfico 2 ).

\section{Cuadro 6}

Distribución de la población mexicana calificada ocupada, por nivel de estudios y área de conocimiento, según país de residencia y tipo de educación, 2013

(En porcentajes)

\begin{tabular}{|c|c|c|c|c|c|c|}
\hline \multirow[b]{2}{*}{$\begin{array}{l}\text { Nivel y área } \\
\text { del conocimiento }\end{array}$} & \multicolumn{3}{|c|}{ México } & \multicolumn{3}{|c|}{ Estados Unidos } \\
\hline & Total & $\begin{array}{l}\text { Altamente } \\
\text { calificada }\end{array}$ & $\begin{array}{c}\text { Mediana y } \\
\text { escasamente } \\
\text { calificada }\end{array}$ & Total & $\begin{array}{l}\text { Altamente } \\
\text { calificada }\end{array}$ & $\begin{array}{c}\text { Mediana y } \\
\text { escasamente } \\
\text { calificada }\end{array}$ \\
\hline \multicolumn{7}{|c|}{ Porcentaje horizontal } \\
\hline Total & 100,0 & 56,6 & 43,4 & 100,0 & 45,9 & 54,1 \\
\hline CTIM $^{a}$ & 100,0 & 49,0 & 51,0 & 100,0 & 48,0 & 52,0 \\
\hline No CTIM & 100,0 & 59,6 & 40,4 & 100,0 & 45,2 & 54,8 \\
\hline \multicolumn{7}{|l|}{ Porcentaje vertical } \\
\hline Total & 100,0 & 100,0 & 100,0 & 100,0 & 100,0 & 100,0 \\
\hline $\mathrm{CTIM}^{\mathrm{a}}$ & 28,5 & 24,6 & 33,5 & 26,5 & 27,7 & 25,5 \\
\hline No CTIM & 71,5 & 75,4 & 66,5 & 73,5 & 72,3 & 74,5 \\
\hline
\end{tabular}

Fuente: Elaboración propia sobre la base de Instituto Nacional de Estadística y Geografía (INEGI), Encuesta Nacional de Ocupación y Empleo (ENOE), segundo trimestre de 2013, y del proyecto sobre el uso público integrado de series de microdatos (IPUMS) y la American Community Survey (ACS), 2013.

a Áreas de las ciencias, la tecnología, las ingenierías y las matemáticas.

Gráfico 2

\section{Población mexicana calificada en un área CTIM ${ }^{\mathrm{a}}$, por país de residencia y tipo de ocupación, 2013}

(En porcentajes)

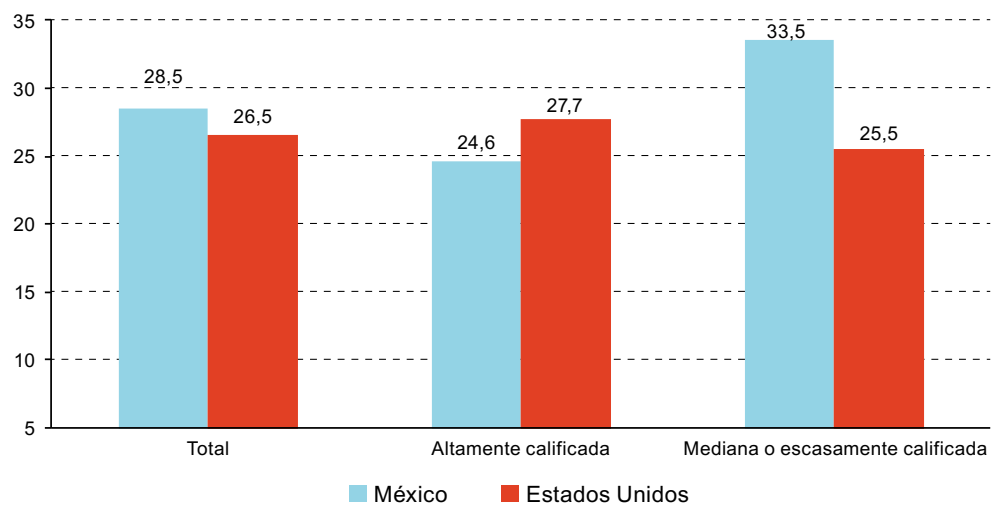

Fuente: Elaboración propia sobre la base de Instituto Nacional de Estadística y Geografía (INEGI), Encuesta Nacional de Ocupación y Empleo (ENOE), segundo trimestre de 2013, y del proyecto sobre el uso público integrado de series de microdatos (IPUMS) y la American Community Survey (ACS), 2013.

a Áreas de las ciencias, la tecnología, las ingenierías y las matemáticas. 
Estos resultados sugieren que la incidencia de la subutilización de la mano de obra calificada es mayor entre los profesionales en áreas CTIM radicados en México que entre los que viven en los Estados Unidos. Esta situación muestra sincronía con lo observado en las tasas de desempleo abierto, que también son mayores entre los radicados en México. Desde el punto de vista teórico del desaprovechamiento de la calificación y de la devaluación del trabajo, ambas situaciones dan cuenta de un fuerte desperdicio de recursos humanos calificados, toda vez que el mercado laboral mexicano no está generando empleos que garanticen una adecuada utilización de los conocimientos, habilidades y competencias de este tipo de profesionales. No obstante, como ya se anotó más arriba, esta problemática también afecta a un segmento importante de los profesionales mexicanos que han emigrado a los Estados Unidos. Si bien en este país existe una política explícita de atracción, contratación y retención de personal calificado, no todos los trabajadores inmigrantes calificados se colocan en ocupaciones acordes con su nivel educativo y área de especialización. Esto confirma el argumento de Bauder (2003) de que nos encontramos frente a una situación de "maltrato de cerebros" (brain abuse), debido a la falta de reconocimiento de las capacidades tanto en el país de origen como en el de destino.

Dado que el patrón ocupacional difiere por país de residencia y área de formación, conviene conocer el perfil sociodemográfico de los profesionales mexicanos que residen en México y en los Estados Unidos. De esta forma, podemos identificar los rasgos vinculados a una utilización plena de los conocimientos, habilidades y competencias adquiridas durante su formación educativa, así como a su experiencia y capacitación laboral (inserción en ocupaciones altamente calificadas), o bien vinculados a una subutilización de esas capacidades, al insertarse en ocupaciones de mediana y escasa calificación. Pero también hay que considerar que los empleos que se ofrecen en el mercado laboral exigen que el candidato responda a cierto perfil sociodemográfico y educativo. Consideramos que un análisis de este tipo puede aportar mayores elementos para ahondar en la problemática de la subutilización de capacidades de este grupo de profesionales mexicanos.

\section{Perfil sociodemográfico de los profesionales mexicanos por país de residencia}

En el cuadro 7 se presenta la distribución porcentual de la población calificada mexicana por país de residencia según distintas características sociodemográficas. De su lectura se desprende que, entre los residentes en México, los hombres presentan una mayor participación que las mujeres en ocupaciones altamente calificadas, mientras que en los Estados Unidos la participación en este tipo de trabajos tiende al equilibrio entre ambos sexos: en este país las posibilidades de emplearse en una ocupación acorde con el grado académico obtenido son iguales entre hombres y mujeres. Ellas presentan una mayor participación laboral en este tipo de empleos en los Estados Unidos que sus congéneres residentes en México, lo que sugiere que la subutilización de capacidades es un problema que impacta en mayor medida a las mujeres profesionales mexicanas no migrantes. 
Cuadro 7

Características sociodemográficas de la población mexicana calificada, por país de residencia y tipo de ocupación, 2013

(En porcentajes)

\begin{tabular}{|c|c|c|c|c|c|c|}
\hline \multirow{3}{*}{ Características } & \multicolumn{3}{|c|}{ México } & \multicolumn{3}{|c|}{ Estados Unidos } \\
\hline & \multicolumn{3}{|c|}{ Tipo de calificación de la ocupación } & \multicolumn{3}{|c|}{ Tipo de calificación de la ocupación } \\
\hline & Total & $\begin{array}{l}\text { Altamente } \\
\text { calificada }\end{array}$ & $\begin{array}{l}\text { Mediana o } \\
\text { escasamente } \\
\text { calificada }\end{array}$ & Total & $\begin{array}{l}\text { Altamente } \\
\text { calificada }\end{array}$ & $\begin{array}{c}\text { Mediana o } \\
\text { escasamente } \\
\text { calificada }\end{array}$ \\
\hline Sexo & 100,0 & 100,0 & 100,0 & 100,0 & 100,0 & 100,0 \\
\hline Hombre & 55,2 & 53,0 & 57,9 & 54,4 & 50,0 & 58,1 \\
\hline Mujer & 44,8 & 47,0 & 42,1 & 45,6 & 50,0 & 41,9 \\
\hline Grupos de edad & 100,0 & 100,0 & 100,0 & 100,0 & 100,0 & 100,0 \\
\hline Menor de 40 años & 57,7 & 53,6 & 63,0 & 45,5 & 48,1 & 43,4 \\
\hline 40 años o más & 42,3 & 46,4 & 37,0 & 54,5 & 51,9 & 56,6 \\
\hline Promedio de edad & 38,7 & 39,8 & 37,2 & 41,4 & 40,9 & 41,8 \\
\hline Estado civil & 100,0 & 100,0 & 100,0 & 100,0 & 100,0 & 100,0 \\
\hline Unido & 59,0 & 62,0 & 55,0 & 63,0 & 64,8 & 61,4 \\
\hline No unido & 41,0 & 38,0 & 45,0 & 37,0 & 35,2 & 38,6 \\
\hline Escolaridad & 100,0 & 100,0 & 100,0 & 100,0 & 100,0 & 100,0 \\
\hline Licenciatura & 90,2 & 86,2 & 95,4 & 73,7 & 64,9 & 81,2 \\
\hline Maestrría & 8,5 & 11,7 & 4,3 & 18,1 & 24,8 & 12,4 \\
\hline Doctorado & 1,3 & 2,1 & 0,3 & 2,4 & 3,9 & 1,2 \\
\hline Profesional & - & - & _- & 5,8 & 6,3 & 5,3 \\
\hline Tipo de carrera & 100,0 & 100,0 & 100,0 & 100,0 & 100,0 & 100,0 \\
\hline CTIM a & 28,5 & 24,6 & 33,5 & 26,5 & 27,7 & 25,5 \\
\hline No CTIM & 71,5 & 75,4 & 66,5 & 73,5 & 72,3 & 74,5 \\
\hline País de estudio & - & - & - & 100,0 & 100,0 & 100,0 \\
\hline Estados Unidos & - & - & - & 41,4 & 48,9 & 35,1 \\
\hline México & - & - & _- & 58,6 & 51,1 & 64,9 \\
\hline Ciudadanía estadounidense & - & - & - & 100,0 & 100,0 & 100,0 \\
\hline Sí & - & - & - & 53,2 & 63,0 & 44,8 \\
\hline No & - & - & - & 46,8 & 37,0 & 55,2 \\
\hline Habla inglés & & & & 100,0 & 100,0 & 100,0 \\
\hline Sí & & & & 84,5 & 93,5 & 76,9 \\
\hline No & & & & 15,5 & 6,5 & 23,1 \\
\hline
\end{tabular}

Fuente: Elaboración propia sobre la base de Instituto Nacional de Estadística y Geografía (INEGI), Encuesta Nacional de Ocupación y Empleo (ENOE), segundo trimestre de 2013, y del proyecto sobre el uso público integrado de series de microdatos (IPUMS) y la American Community Survey (ACS), 2013.

a Áreas de las ciencias, la tecnología, las ingenierías y las matemáticas.

En cuanto a la edad, los datos muestran que en general los profesionales en México son más jóvenes que los que viven en los Estados Unidos: el promedio es de 38,7 y 41,4 años, respectivamente. En ambos países un alto porcentaje de los que realizan actividades altamente calificadas son menores de 40 años. Cabe resaltar que, en el caso de México, 6 de cada 
10 profesionales (63\%) que se desempeñan en una ocupación de mediana o escasa calificación son también menores de 40 años, lo cual hace suponer que una parte importante de los jóvenes egresados de las universidades públicas y privadas del país no se están insertando en una actividad acorde con su nivel educativo. En los Estados Unidos, dicha proporción es de alrededor de 4 de cada 10 profesionales $(43,4 \%)$, lo que se traduce en una diferencia de casi 20 puntos porcentuales.

En lo que concierne a la situación familiar, la información muestra de manera palpable que tanto en México como en los Estados Unidos más de la mitad de los profesionales mexicanos están casados o en pareja, situación que se afianza entre los empleados en una ocupación altamente calificada: el 62\% en México y el 64,8\% en los Estados Unidos. Respecto al nivel de escolaridad, los datos indican que el $90,2 \%$ de los profesionales calificados en México tiene únicamente estudios de licenciatura y el 9,8\% tiene también un posgrado, en tanto que entre la comunidad mexicana calificada residente en los Estados Unidos un $73,7 \%$ cuenta solo con la licenciatura y el resto $(26,3 \%)$ ha obtenido además un posgrado. En consecuencia, el porcentaje de profesionales con estudios de maestría y doctorado empleados en una ocupación altamente calificada es significativamente mayor en los Estados Unidos que en México (un 35,0\% frente a un 13,8\%, en conjunto).

Estos datos revelan la existencia de una selectividad positiva hacia la mano de obra mexicana con mayores credenciales educativas, especialmente en el caso de los formados en áreas CTIM. Para estos profesionales, el porcentaje de empleados en una ocupación acorde a su nivel educativo (altamente calificada) es mayor entre los que viven en los Estados Unidos (27,7\%) que en México (24,6\%). Es más, como ya se apuntó anteriormente, de los profesionales calificados que radican en México y desempeñan una ocupación de mediana o escasa calificación, un 33,5\% son especialistas de áreas CTIM, lo que sugiere una subutilización de esta mano de obra mexicana, ya que están realizando actividades laborales que no demandan sus capacidades y conocimientos universitarios (véase el cuadro 7).

En lo que respecta a las características migratorias de los profesionales mexicanos radicados en los Estados Unidos, se observa que más de la mitad de ellos cursó sus estudios de licenciatura en México (58,6\%). De los profesionales mexicanos que ejercen una actividad altamente calificada en los Estados Unidos, el 51,1\% estudiaron en México, así como el $64,9 \%$ de los que se desempeñan en trabajos de mediana y escasa calificación ${ }^{6}$. La ciudadanía estadounidense también es un factor relevante en lo que concierne a la situación laboral. Únicamente el 53,2\% de los profesionales ocupados en los Estados Unidos posee la ciudadanía: el 63,0\% de los que se emplean en una ocupación altamente calificada cuentan con ese estatus migratorio, mientras que un alto porcentaje $(55,2 \%)$ de los que desempeñan una actividad profesional que no es acorde con los conocimientos adquiridos durante sus estudios universitarios no la tienen.

\footnotetext{
El lugar de estudio es una variable indirecta que determina en qué país (Estados Unidos o México) recibieron las personas su educación universitaria. Dicha variable se estableció según el año de llegada a los Estados Unidos, el año de la encuesta y la edad de la persona al momento de la entrevista. A partir de dicha variable se definió como educadas en México a las personas que ingresaron a los Estados Unidos con 21 años o más y que ya contaban con al menos una licenciatura en ese momento. Se consideró como educados en los Estados Unidos a los mexicanos que ingresaron a este país antes de los 21 años de edad y que habían completado como mínimo una licenciatura.
} 
Pese a que se trata de una población con estudios universitarios y capacitada, el 15,5\% de los profesionales mexicanos no habla o no domina el inglés, lo que indudablemente repercute en su inserción y en sus condiciones laborales: el 23,1\% de los profesionales mexicanos calificados que se emplean en una ocupación de mediana o escasa calificación en los Estados Unidos no habla inglés (véase el cuadro 7).

\section{Factores determinantes de la inserción laboral de los profesionales mexicanos}

Los resultados del análisis descriptivo permitieron identificar algunos rasgos sociodemográficos asociados con la participación laboral de la mano de obra mexicana en México y en los Estados Unidos. Sin embargo, es importante determinar en qué medida y en qué dirección dichas características influyen en la correspondencia entre el nivel educativo alcanzado y el tipo de ocupaciones ejercidas por los profesionales mexicanos. Para llevar a cabo tal evaluación se establecieron modelos de regresión logística binomial, que permitieron determinar el efecto que tiene el conjunto de variables anteriormente descritas sobre la propensión de un profesional mexicano a insertarse en una ocupación altamente calificada en estos dos países?.

En el cuadro 8 se presentan los resultados de los modelos logísticos por país de origen. En este cuadro se puede observar que todas las variables explicativas resultaron estadísticamente significativas a un $95 \%$ de confidencialidad ( $<<0,05)$. En cuanto al sexo, el odds ratio o razón de tasas indica que, al mantener constantes las demás variables incluidas en el modelo, en ambos países las mujeres son más propensas a insertarse en ocupaciones altamente calificadas que los hombres. Entre la población residente en México, la propensión de desempeñar una ocupación acorde con su nivel educativo en el caso de las mujeres es un $22 \%$ mayor que en el de los hombres, mientras que entre las radicadas en los Estados Unidos ese porcentaje asciende al 33\%. Estos resultados corroboran lo señalado en el análisis descriptivo, en el sentido de que las mexicanas se insertan cada vez más en ocupaciones altamente profesionalizadas y que las probabilidades de hacerlo son mayores en el mercado laboral estadounidense que en el mexicano.

En cuanto a la edad, los resultados del modelo muestran que el ser menor de 40 años incide en la propensión a trabajar en una actividad altamente calificada en comparación con los mayores de 40 años. Sin embargo, el efecto de dicha variable es diferente según el país de residencia, pues entre los profesionales residentes en México el ser menor de dicha

$7 \quad$ El modelo logístico estimado está conformado por una variable dependiente, que toma el valor de 1 si la persona se emplea en una ocupación altamente calificada y de o si lo hace en una de mediana o escasa calificación. En el modelo estimado para México, las variables independientes fueron: sexo, edad, estado civil, escolaridad y tipo de carrera, y en el caso de los Estados Unidos, además de estas variables, se incluyeron otros predictores como el país de obtención del título universitario, la condición de tenencia de la ciudadanía estadounidense y el dominio del idioma inglés. Cabe señalar que para la estimación de los modelos se realizaron pruebas de correlación a fin de evaluar la pertinencia de inclusión de todas las variables explicativas. Los resultados de las matrices de correlación obtenidas no detectaron problemas de correlación entre variables. De hecho, el coeficiente no fue superior a 0,5 en ninguna intercepción. 
edad disminuye un $27 \%$ la propensión a insertarse en una ocupación altamente calificada, mientras que entre sus connacionales residentes en los Estados Unidos tener menos de 40 años aumenta un $45 \%$ las posibilidades de emplearse en este tipo de ocupaciones.

\section{Cuadro 8}

\section{México y Estados Unidos: regresiones logísticas que predicen la probabilidad} de la población mexicana de insertarse en una ocupación altamente calificada, 2013

\begin{tabular}{|c|c|c|c|c|c|c|}
\hline \multirow{3}{*}{ Variables } & \multicolumn{3}{|c|}{ México } & \multicolumn{3}{|c|}{ Estados Unidos } \\
\hline & \multirow{2}{*}{$\operatorname{Exp}(B)$} & \multicolumn{2}{|c|}{$\begin{array}{l}\text { Intervalo de confianza } \\
95 \% \text { para } \operatorname{Exp}(B)\end{array}$} & \multirow{2}{*}{$\operatorname{Exp}(B)$} & \multicolumn{2}{|c|}{$\begin{array}{l}\text { Intervalo de confianza } \\
95 \% \text { para } \operatorname{Exp}(B)\end{array}$} \\
\hline & & $\begin{array}{l}\text { Límite } \\
\text { inferior }\end{array}$ & $\begin{array}{l}\text { Límite } \\
\text { superior }\end{array}$ & & $\begin{array}{l}\text { Límite } \\
\text { inferior }\end{array}$ & $\begin{array}{l}\text { Límite } \\
\text { superior }\end{array}$ \\
\hline \multicolumn{7}{|l|}{ Sexo } \\
\hline Hombre $^{a}$ & 1,000 & & & 1,000 & & \\
\hline Mujer & $1,227^{b}$ & 1,167 & 1,290 & $1,333^{b}$ & 1,156 & 1,536 \\
\hline \multicolumn{7}{|l|}{ Grupos de edad } \\
\hline 40 años o más a & 1,000 & & & 1,000 & & \\
\hline Menores de 40 años & $0,735^{b}$ & 0,698 & 0,773 & $1,456^{b}$ & 1,264 & 1,676 \\
\hline \multicolumn{7}{|l|}{ Estado civil } \\
\hline Unido $^{a}$ & 1,000 & & & 1,000 & & \\
\hline No unido & $0,805^{b}$ & 0,765 & 0,847 & $0,840^{b}$ & 0,729 & 0,968 \\
\hline \multicolumn{7}{|l|}{ Nivel de escolaridad } \\
\hline Maestría $^{a}$ & 1,000 & & & 1,000 & & \\
\hline Licenciatura & $0,360^{b}$ & 0,326 & 0,397 & $0,423^{b}$ & 0,354 & 0,505 \\
\hline Doctorado & $2,555^{b}$ & 1,800 & 3,627 & $1,679^{b}$ & 1,018 & 2,769 \\
\hline Profesional & & & & $0,764^{b}$ & 0,555 & 1,052 \\
\hline \multicolumn{7}{|l|}{ Tipo de carrera } \\
\hline No CTIMa & 1,000 & & & 1,000 & & \\
\hline $\mathrm{CTIM}^{\mathrm{ac}}$ & $0,695^{b}$ & 0,659 & 0,734 & $1,259^{b}$ & 1,072 & 1,479 \\
\hline \multicolumn{7}{|l|}{ Lugar de estudio } \\
\hline Estados Unidos ${ }^{a}$ & & & & 1,000 & & \\
\hline Otro país & & & & $0,707^{\mathrm{b}}$ & 0,610 & 0,820 \\
\hline \multicolumn{7}{|c|}{ Ciudadanía estadounidense } \\
\hline Sía & & & & 1,000 & & \\
\hline No & & & & $0,638^{b}$ & 0,549 & 0,740 \\
\hline \multicolumn{7}{|l|}{ Habla inglés } \\
\hline Sía & & & & 1,000 & & \\
\hline No & & & & $0,333^{b}$ & 0,266 & 0,417 \\
\hline Constante & 3,842 & & & 2,068 & 1,685 & 2,539 \\
\hline $\mathrm{R}^{2}$ & 0,060 & & & 0,086 & & \\
\hline $\mathrm{N}$ & 29608 & & & 3896 & & \\
\hline
\end{tabular}

Fuente: Elaboración propia sobre la base de información de Instituto Nacional de Estadística y Geografía (INEGI), Encuesta Nacional de Ocupación y Empleo (ENOE), segundo trimestre de 2013, y del proyecto sobre el uso público integrado de series de microdatos (IPUMS) y la American Community Survey (ACS), 2013.

a Categoría de referencia.

b $p<0,05$.

c Áreas de las ciencias, la tecnología, las ingenierías y las matemáticas. 
Respecto al estado civil, según el control a partir de las demás variables incluidas en el modelo, no encontrarse en unión disminuye la propensión de obtener un empleo de alta calificación. Así, en el caso de la población mexicana calificada que vive en México, no tener pareja reduce un $20 \%$ las posibilidades de emplearse en una ocupación adecuada para profesionales (altamente calificada); en el caso de los radicados en los Estados Unidos ese porcentaje es del $16 \%$.

Como era de esperar, contar con mayores credenciales educativas tiene un efecto positivo en la inserción laboral de los profesionales mexicanos. En el caso de México, poseer simplemente un título de licenciatura disminuye un $64 \%$ la propensión a insertarse en ocupaciones altamente calificadas en comparación con quienes tienen estudios de maestría. A su vez, la probabilidad de emplearse en ese tipo de ocupaciones entre los que cuentan con un doctorado es 1,5 veces superior a la de quienes tienen únicamente una maestría. Algo similar ocurre entre la diáspora mexicana calificada en los Estados Unidos: tener solo estudios de licenciatura o un grado profesional reduce casi un $58 \%$ (en el primero de los casos) o un $24 \%$ (en el caso del grado) la probabilidad de ocuparse en empleos altamente especializados. De igual forma, los que cuentan con un doctorado son un $67 \%$ más propensos a desempeñar una ocupación altamente calificada que los que tienen una maestría. Estos resultados confirman que los doctorados tienen un peso importante en el mercado laboral profesional en ambos países.

En lo que concierne al campo de formación universitaria, el odds ratio de los modelos estimados corrobora que los profesionales de carreras CTIM residentes en México tienen una menor propensión a obtener empleos altamente calificados (30\%) que los que estudiaron otras carreras universitarias. En cambio, entre los que viven en los Estados Unidos la relación es la inversa, es decir, los profesionales formados en áreas CTIM tienen un 25\% más de probabilidades de emplearse en ocupaciones altamente especializadas y de vanguardia, lo que hoy en día se conoce como la "economía del conocimiento". Este resultado ratifica la subutilización o desperdicio de esta mano de obra en México.

Sobre las características migratorias de los profesionales mexicanos residentes en los Estados Unidos se encontró que, si se mantenía constante el efecto de las demás variables incluidas en el modelo, el hecho de haber realizado estudios de licenciatura fuera de los Estados Unidos reducía un $30 \%$ la propensión a emplearse en ocupaciones altamente calificadas en comparación con los que habían estudiado en este país. Asimismo, no contar con la ciudadanía estadounidense y no hablar inglés demostró tener un efecto negativo en la calidad ocupacional de los profesionales mexicanos. El odds ratio indicó una reducción del $36 \%$ y del $67 \%$ de las probabilidades de acceder a una ocupación calificada, en comparación con la situación opuesta.

Estos resultados confirman la existencia de una discriminación institucionalizada hacia los migrantes mexicanos calificados en los Estados Unidos debida a la falta de reconocimiento de sus credenciales educativas, por el hecho de haber adquirido su formación profesional en otro país, ser extranjero no naturalizado o no tener un buen dominio del inglés, entre otros factores considerados en esta investigación (Bauder, 2003; Siar, 2013). A pesar de ello, la migración de talentos mexicanos a los Estados Unidos es un fenómeno social que ha venido 
creciendo en los últimos años, al igual que ocurre con otras corrientes migratorias que tienen su origen en diversos países de América Latina y regiones del mundo. Este fenómeno se debe, sin duda, a la falta de oportunidades laborales, los bajos ingresos y el limitado desarrollo científico y tecnológico de los países para emplear a licenciados y titulares de maestrías y doctorados en las áreas del conocimiento para las cuales fueron capacitados (Tuirán y Ávila, 2013). La diferenciación salarial, por ejemplo, es un factor que ha alentado y sostenido la centenaria migración mexicana a los Estados Unidos.

En este contexto, presentamos a continuación un análisis descriptivo y variado de las remuneraciones salariales y sus determinantes entre los profesionales mexicanos residentes en México y los Estados Unidos con la intención de profundizar en sus condiciones laborales, especialmente en el caso de los profesionales CTIM, e identificar posibles nexos con la migración internacional.

\section{Remuneraciones salariales de los profesionales mexicanos}

Como ya se señaló, la teoría del capital humano postula que contar con altas credenciales educativas aumenta las probabilidades de obtener mejores ocupaciones y mayores salarios (Becker, 1964). En la práctica dicha expectativa se cumple, es decir, los profesionales logran obtener mejores trabajos y mayores ingresos en comparación con los trabajadores con menores niveles educativos, pero cada vez es más difícil alcanzarla. Esto es debido a diversos problemas, como la insuficiente creación de empleos que demanden mano de obra altamente calificada (Hernández y Velázquez, 2003), la saturación de los puestos de trabajo para algunas carreras (ANUIES, 2003), el reconocimiento diferenciado de las profesiones según el área del conocimiento (Langdon y otros, 2011) y la no validación de títulos y grados académicos (Bauder, 2003). Esta última cuestión, por ejemplo, hace que en países receptores de mano de obra calificada los profesionales inmigrantes no tengan las mismas oportunidades laborales, retribuciones salariales y prestaciones sociales que los nativos.

\section{Diferencias en las remuneraciones salariales}

En el cuadro 9 se presenta el ingreso medio anual en 2013 de los profesionales mexicanos asalariados según el tipo de ocupación y el país de residencia. En él se puede observar que los residentes en los Estados Unidos obtienen retribuciones salariales significativamente mayores por su trabajo que los que viven en México. Entre los primeros, el ingreso medio anual es de 52.298 dólares, en tanto que entre los segundos es de 9.635 dólares. Al desglosar estos montos por tipo de ocupación se obtiene que, en ambos casos, quienes se emplean en una ocupación altamente calificada gozan de un ingreso más alto que aquellos que lo hacen en una actividad de mediana o escasa calificación. La brecha del ingreso medio entre 
ambos tipos de ocupaciones es del $28,5 \%$ en México y del 32,6\% en los Estados Unidos. Estos porcentajes indican que por cada dólar que gana un profesional que se emplea en una ocupación calificada en México y en los Estados Unidos, otro que lo hace en una de menor calificación gana 0,72 y 0,68 dólares, respectivamente.

Cuadro 9

Ingreso medio anual de la población mexicana calificada, por país de residencia y tipo de ocupación, 2013

(En dólares)

\begin{tabular}{|c|c|c|c|c|c|c|}
\hline \multirow[b]{2}{*}{ Ingreso } & \multicolumn{3}{|c|}{ México } & \multicolumn{3}{|c|}{ Estados Unidos } \\
\hline & Total & $\begin{array}{l}\text { Altamente } \\
\text { calificada }\end{array}$ & $\begin{array}{l}\text { Mediana y } \\
\text { escasamente } \\
\text { calificada }\end{array}$ & Total & $\begin{array}{l}\text { Altamente } \\
\text { calificada }\end{array}$ & $\begin{array}{l}\text { Mediana y } \\
\text { escasamente } \\
\text { calificada }\end{array}$ \\
\hline Ingreso medio anual & 9635 & 11045 & 7894 & 52298 & 63136 & 42581 \\
\hline Brecha salarial & & & 28,5 & & & 32,6 \\
\hline
\end{tabular}

Fuente: Elaboración propia sobre la base de Instituto Nacional de Estadística y Geografía (INEGI), Encuesta Nacional de Ocupación y Empleo (ENOE), segundo trimestre de 2013, y del proyecto sobre el uso público integrado de series de microdatos (IPUMS) y la American Community Survey (ACS), 2013.

La brecha del ingreso medio anual se ensancha cuando se mide por áreas del conocimiento. En México, en términos generales, los profesionales de las áreas CTIM perciben un ingreso medio anual ligeramente mayor que los graduados de otros campos del conocimiento. Sin embargo, las mayores diferencias salariales entre los que han estudiado carreras CTIM y los que han estudiado otro tipo de carreras se presentan en el caso de ocupaciones altamente calificadas, en las que la brecha salarial es de 2.490 dólares, es decir, del 19,2\% (véase el gráfico 3).

\section{Gráfico 3}

México: ingreso medio anual de la población mexicana calificada, por tipo de ocupación y área del conocimiento, 2013

(En miles de dólares)

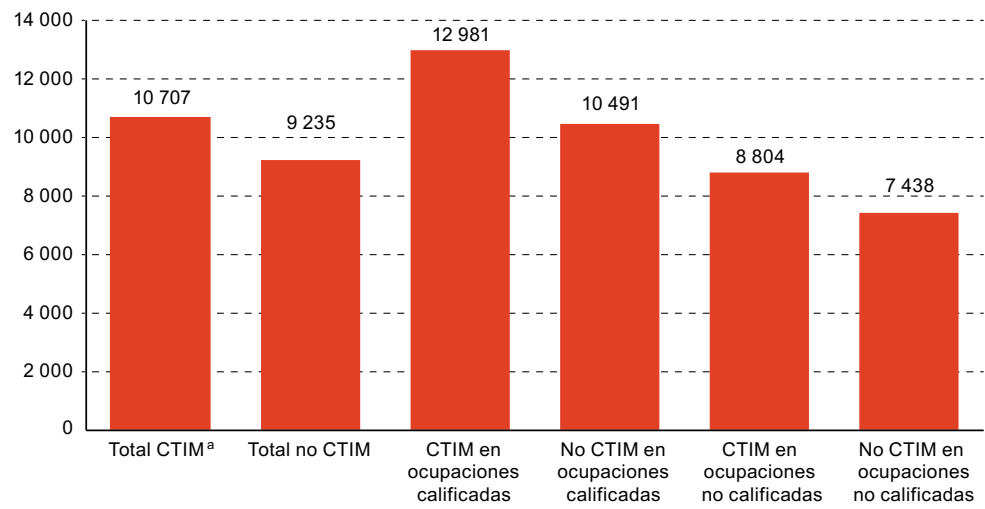

Fuente: Elaboración propia sobre la base de información del Instituto Nacional de Estadística y Geografía (INEGI) y la Encuesta Nacional de Ocupación y Empleo (ENOE), segundo trimestre de 2013.

a Áreas de las ciencias, la tecnología, las ingenierías y las matemáticas. 
En los Estados Unidos los profesionales CTIM también reciben mayores ingresos por su trabajo, pero las brechas salariales con sus pares no CTIM son más contundentes. Por ejemplo, la diferencia en el ingreso medio total es de alrededor de 18.281 dólares, una brecha salarial del $27,8 \%$, y entre los empleados en una ocupación altamente calificada, la diferencia es de 26.582 dólares al año (véase el gráfico 4). Estos datos ponen de manifiesto que el incentivo salarial por estudiar una carrera universitaria o posgrado en un campo CTIM es mayor en los Estados Unidos que en México, y se acrecienta cuando corresponde a un trabajo que demanda los conocimientos, habilidades y destrezas adquiridos en la universidad, así como experiencia y capacitación laboral. Esta diferencia salarial podría ser una de las razones que explican la creciente emigración de profesionales mexicanos a los Estados Unidos.

\section{Gráfico 4}

Estados Unidos: ingreso medio anual de la población mexicana calificada, por tipo de ocupación y área del conocimiento, 2013

(En miles de dólares)

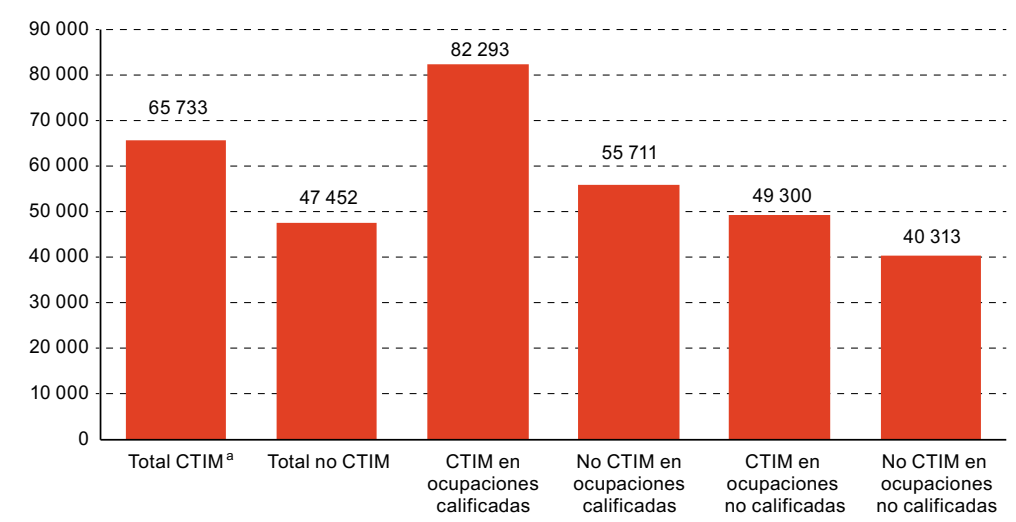

Fuente: Elaboración propia sobre la base del proyecto sobre el uso público integrado de series de microdatos (IPUMS) y la American Community Survey (ACS) de 2013.

a Áreas de las ciencias, la tecnología, las ingenierías y las matemáticas.

\section{Determinantes del ingreso por trabajo de los profesionales mexicanos}

Con el propósito de determinar el efecto de algunas variables sociodemográficas en el monto del salario de los profesionales mexicanos residentes en México y en los Estados Unidos, se utilizó un modelo de regresión lineal múltiple, en que la variable dependiente es el logaritmo natural del ingreso anual por trabajo, y como predictores explicativos se tomó el conjunto de variables analizadas en el apartado anterior (edad, sexo, estado civil, nivel de escolaridad, tipo de carrera, país de estudio, tenencia de la ciudadanía estadounidense y condición de hablar el idioma inglés). Al igual que en el ejercicio de la regresión logística, 
se estableció un modelo por país de residencia ${ }^{8}$, y se eligió la estrategia analítica de tipo comparativa entre países para los resultados estimados.

En el cuadro 10 se presentan los resultados estimados de los modelos. Se puede observar que todas las variables incluidas en el análisis resultaron ser determinantes para la retribución salarial anual de los profesionales mexicanos, a un nivel de significancia de $\mathrm{p}<0,05$. Con relación al sexo, los datos indican que, al mantener constantes las demás variables incluidas en el modelo, la condición de ser mujer presenta un efecto negativo en la retribución anual. Concretamente, las mujeres residentes en México reciben una retribución salarial un $17 \%$ menor que el ingreso de los hombres, y la retribución de las mujeres en los Estados Unidos es un 38\% inferior a la de los varones. También el ser menor de 40 años tiene un efecto negativo en el ingreso: los profesionales mexicanos menores de esta edad que viven en su país perciben una retribución un 17\% menor en comparación con los mayores, en tanto que en el caso de los que se encuentran en los Estados Unidos la diferencia es del $15 \%$ si se compara con los mayores de 40 años. Si bien en este último caso el efecto negativo es menor, concuerda con los resultados del modelo logístico.

Estar casado o en pareja aumenta ligeramente el ingreso anual por trabajo de los profesionales mexicanos: un 10\% entre los residentes en México y un $17 \%$ entre los que viven en los Estados Unidos, en comparación con los solteros. Asimismo, los resultados del modelo estimado validan la existencia de una relación positiva entre el nivel de escolaridad y los ingresos. En el caso de los profesionales que viven y trabajan en México, el hecho de contar con estudios de maestría o doctorado incrementa la remuneración un $30 \%$ y un $34 \%$, respectivamente, respecto a los que solo tienen estudios de licenciatura. En los Estados Unidos, dicho aumento es del 16\% cuando se tiene un grado profesional, del $18 \%$ en el caso de una maestría, y del $24 \%$ en el de un doctorado, si se compara con los profesionales que solo han completado estudios de licenciatura.

En lo que concierne al tipo de carrera estudiada, los coeficientes de los modelos estimados refuerzan la hipótesis enunciada a lo largo de este trabajo: contar con una carrera de Ciencias, Tecnología, Ingeniería y Matemáticas (CTIM) tiene un efecto positivo en la inserción laboral y en las retribuciones salariales en los Estados Unidos, mientras que en México el impacto, aunque también es positivo, es de menor magnitud. En otras palabras, en los Estados Unidos, tener una carrera CTIM incrementa la retribución salarial un 22\% en relación con los graduados de otras áreas del conocimiento, mientras que en México ser licenciado y posgraduado en un área CTIM solo acrecienta un 9\% el nivel de ingresos respecto a otros profesionales.

Desempeñarse en una ocupación altamente calificada aumenta significativamente el ingreso por trabajo de los profesionales en ambos países (un $34 \%$ en los Estados Unidos y un $31 \%$ en México) en relación con quienes se emplean en una ocupación de mediana o escasa calificación, es decir, en actividades para las cuales no siempre se requiere poseer un alto nivel de estudios o de calificación.

\footnotetext{
Todas las variables fueron incluidas como variables ficticias. Asimismo, se realizaron pruebas de correlación para evitar problemas de colinealidad y multicolinealidad, así como diversas pruebas (incluidas en el paquete estadístico de Stata) para evaluar la calidad del modelo.
} 
Cuadro 10

México y Estados Unidos: regresiones lineales múltiples del logaritmo natural
de la retribución anual salarial de la población mexicana calificada, 2013

\begin{tabular}{|c|c|c|c|c|c|c|}
\hline \multirow{3}{*}{ Variables } & \multicolumn{3}{|c|}{ México } & \multicolumn{3}{|c|}{ Estados Unidos } \\
\hline & \multirow{2}{*}{$\begin{array}{c}\text { Coeficiente } \\
\text { B }\end{array}$} & \multicolumn{2}{|c|}{$\begin{array}{c}\text { Intervalo de confianza } \\
95 \% \text { para B }\end{array}$} & \multirow{2}{*}{$\begin{array}{c}\text { Coeficiente } \\
\text { B }\end{array}$} & \multicolumn{2}{|c|}{$\begin{array}{c}\text { Intervalo de confianza } \\
95 \% \text { para B }\end{array}$} \\
\hline & & $\begin{array}{l}\text { Límite } \\
\text { inferior }\end{array}$ & $\begin{array}{l}\text { Límite } \\
\text { superior }\end{array}$ & & $\begin{array}{l}\text { Límite } \\
\text { inferior }\end{array}$ & $\begin{array}{l}\text { Límite } \\
\text { superior }\end{array}$ \\
\hline \multicolumn{7}{|l|}{ Sexo } \\
\hline \multicolumn{7}{|l|}{ Hombre $^{a}$} \\
\hline Mujer & $-0,174^{b}$ & $-0,195$ & $-0,153$ & $-0,382^{b}$ & $-0,443$ & $-0,321$ \\
\hline \multicolumn{7}{|l|}{ Grupos de edad } \\
\hline \multicolumn{7}{|l|}{40 años o más ${ }^{a}$} \\
\hline Menores de 40 años & $-0,178^{b}$ & $-0,199$ & $-0,157$ & $-0,154^{b}$ & $-0,215$ & $-0,093$ \\
\hline \multicolumn{7}{|l|}{ Estado civil } \\
\hline \multicolumn{7}{|l|}{ No unido ${ }^{a}$} \\
\hline Unido & $0,108^{b}$ & 0,087 & 0,130 & $0,172^{b}$ & 0,109 & 0,234 \\
\hline \multicolumn{7}{|l|}{ Nivel de escolaridad } \\
\hline \multicolumn{7}{|l|}{ Licenciatura $^{a}$} \\
\hline Maestría & $0,305^{b}$ & 0,269 & 0,342 & $0,180^{b}$ & 0,106 & 0,254 \\
\hline Doctorado & $0,347^{b}$ & 0,258 & 0,436 & $0,244^{b}$ & 0,068 & 0,421 \\
\hline Profesional & & & & $0,160^{b}$ & 0,036 & 0,284 \\
\hline \multicolumn{7}{|l|}{ Tipo de carrera } \\
\hline \multicolumn{7}{|l|}{ No CTIMa } \\
\hline CTIM ${ }^{a c}$ & $0,093^{b}$ & 0,070 & 0,117 & $0,223^{b}$ & 0,154 & 0,293 \\
\hline \multicolumn{7}{|l|}{ Tipo de ocupación } \\
\hline \multicolumn{7}{|l|}{$\begin{array}{l}\text { Mediana o escasamente } \\
\text { calificada }^{\text {a }}\end{array}$} \\
\hline Altamente calificada & $0,346^{b}$ & 0,325 & 0,366 & $0,316^{b}$ & 0,256 & 0,377 \\
\hline \multicolumn{7}{|l|}{ Lugar de estudio } \\
\hline \multicolumn{7}{|l|}{ Otro país ${ }^{a}$} \\
\hline Estados Unidos & & & & $0,198^{b}$ & 0,133 & 0,263 \\
\hline \multicolumn{7}{|c|}{ Ciudadanía estadounidense } \\
\hline \multicolumn{7}{|l|}{$\mathrm{No}^{\mathrm{a}}$} \\
\hline Sí & & & & $0,181^{b}$ & 0,114 & 0,247 \\
\hline \multicolumn{7}{|l|}{ Habla inglés } \\
\hline \multicolumn{7}{|l|}{ Sía } \\
\hline No & & & & $-0,312$ & $-0,402$ & $-0,222$ \\
\hline Constante & 8,789 & 8,761 & 8,818 & 10,207 & 10,117 & 10,297 \\
\hline$R^{2}$ & 0,142 & & & 0,177 & & \\
\hline $\mathrm{N}$ & 17408 & & & 3667 & & \\
\hline
\end{tabular}

Fuente: Elaboración propia sobre la base de información de Instituto Nacional de Estadística y Geografía (INEGI), la Encuesta Nacional de Ocupación y Empleo (ENOE), segundo trimestre de 2013, y del proyecto sobre el uso público integrado de series de microdatos (IPUMS) y la American Community Survey (ACS), 2013.

a Categoría omitida en el modelo.

b $p<0,05$.

c Áreas de las ciencias, la tecnología, las ingenierías y las matemáticas. 
Finalmente, en cuanto a las características migratorias de los profesionales mexicanos residentes en los Estados Unidos, los resultados indican que haber estudiado en este país aumenta un $19 \%$ el ingreso por trabajo en comparación con los profesionales que obtuvieron sus títulos en otros países. El coeficiente estimado para la variable de tenencia de la ciudadanía estadounidense apunta en ese mismo sentido: ser ciudadano aumenta el ingreso un $18 \%$ con relación a los que no se han naturalizado, mientras que no hablar inglés disminuye significativamente el ingreso de los profesionales (31\%) en comparación con los que sí dominan el idioma.

\section{Reflexiones finales}

Con la finalidad de profundizar en el análisis del desperdicio de las capacidades de los profesionales mexicanos y su vínculo con la migración a los Estados Unidos - realizado en un trabajo de investigación previo, cuyo universo de estudio fue la comunidad de posgraduados mexicanos (Lozano, Gandini y Ramírez, 2015)-, el presente artículo tuvo como objetivo principal analizar el problema de la subutilización de capacidades en un universo de estudio más amplio: se consideró a los profesionales con estudios de licenciatura o más graduados en carreras CTIM. Para ello, además de la información contenida en los censos mexicanos de población, se utilizó la Encuesta Nacional de Ocupación y Empleo de México (ENOE) del segundo trimestre de 2013 y se actualizaron los datos de la American Community Survey (ACS) de 2013, a fin de que el análisis de la situación laboral de esta población fuera lo más actualizado posible.

Los resultados del estudio, analizados desde una perspectiva comparativa, permitieron corroborar la existencia tanto en México como en los Estados Unidos de una discriminación institucionalizada que se materializa en altas tasas de desempleo abierto y en una subutilización de capacidades, lo que afecta de forma distinta a los profesionales mexicanos residentes en uno u otro país. En términos generales, los resultados indican que el problema del desempleo abierto y de la subutilización de capacidades afecta en mayor medida a los profesionales mexicanos que viven en México, y que dicha problemática toca a un número importante de profesionales con estudios de licenciatura y posgrados en áreas CTIM. El análisis estadístico multivariado confirmó, por ejemplo, que en México estos profesionales tienen menos probabilidades de insertarse en una ocupación altamente calificada, es decir, en un trabajo que demande los conocimientos y habilidades que han adquirido en su carrera universitaria, mientras que sus pares que residen en los Estados Unidos son más propensos a desempeñarse en este tipo de ocupaciones. Esto revela la importancia de esta mano de obra calificada para la economía del conocimiento estadounidense - se trata de profesionales que poseen conocimientos, habilidades y destrezas que son fundamentales en los procesos de desarrollo de nuevas empresas, industrias, patentes y productos-y confirma la existencia de una selectividad positiva hacia inmigrantes mexicanos con altos niveles de formación y especialización. 
Asimismo, los resultados muestran que en México los jóvenes (menores de 40 años) cuentan con menos oportunidades para acceder al mercado laboral en ocupaciones acordes con su nivel educativo que en los Estados Unidos, lo que hace suponer que en aquel país no se están generando los puestos de trabajo necesarios para incorporar a los miles de jóvenes que año tras año se gradúan en las universidades e instituciones de educación superior públicas y privadas. Esta situación podría estar incentivando la emigración de esta mano de obra mexicana, así como desincentivando el retorno de los jóvenes mexicanos que culminan sus estudios de licenciatura o posgrado en el país vecino del norte. Una situación similar se observa en el caso de las mujeres: en los Estados Unidos ellas tienen más oportunidades que en México de desarrollarse profesionalmente, es decir, de emplearse en una ocupación que demande el pleno uso de los conocimientos adquiridos durante su formación universitaria.

En lo concerniente al grado de formación de los profesionales mexicanos, los resultados coinciden con los postulados de la teoría del capital humano que rezan que cuanto más alto es el nivel de educación, mayor es la propensión a colocarse en un empleo altamente calificado. Específicamente, se comprobó que quienes poseen un título de doctorado tienen más posibilidades de emplearse en los puestos de trabajo más altos de la pirámide ocupacional y, por tanto, de recibir mayores retribuciones salariales en comparación con los que tienen únicamente estudios de licenciatura o maestría. Sin embargo, estos resultados también dan cuenta de lo que Bauder (2003) llama discriminación institucionalizada, ya vez que un sector importante de la mano de obra calificada, tanto en México como en los Estados Unidos, presenta dificultades para colocarse en el mercado de trabajo. En el caso de México, esto se deba posiblemente a la falta de creación de nuevos puestos de trabajo, así como a la falta de vinculación entre las políticas educativas y los requerimientos de mano de obra del mercado laboral mexicano. Por otro lado, en los Estados Unidos podrían pesar otros factores vinculados a su situación migratoria. Sobre este punto, los resultados obtenidos indican que tanto el hecho de no contar con la ciudadanía estadounidense como de haber estudiado en otro país y no hablar inglés tienen un impacto negativo en la inserción ocupacional y en el nivel de ingresos de los profesionales. Pese a ello, es evidente que en los Estados Unidos los profesionales mexicanos tienen mayores posibilidades de desarrollarse profesionalmente y acceder a mejores condiciones de vida que en México. No obstante, cabe preguntarse en qué condiciones laborales se emplean los profesionales mexicanos radicados en los Estados Unidos y en qué posición se encuentran frente a la población nativa y otras poblaciones inmigrantes residentes en ese país. Sin duda, estos son solo algunos interrogantes que surgen del análisis expuesto en estas páginas, que ameritan una mayor investigación en el futuro. 


\section{Bibliografía}

ANUIES (Asociación Nacional de Universidades e Instituciones de Educación Superior) (2011), Anuario Estadístico 2010: población escolar y personal docente en la educación media superior y superior, ciclo escolar 2009-2010, Ciudad de México.

(2003), Mercado laboral de profesionistas en México. Diagnóstico 1990-2000, Ciudad de México.

Bauder, H. (2003), "Brain abuse', or the devaluation of immigrant labour in Canada", Antipode, vol. $35, \mathrm{~N}^{\circ} 4$.

Becker, Gary S. (1964), Human Capital: a Theoretical and EmpiricalAnalysis with Special Reference to Education, Nueva York, Oficina Nacional de Investigaciones Económicas (NBER), Columbia University.

Beckhusen, Julia y otros (2013), "Attracting global talent and then what? Overeducated immigrants in the United States", Journal of Regional Science, vol. 53, $\mathrm{N}^{\circ} 5$.

Bourdieu, P. (1986), "The forms of capital", Handbook of Theory and Research for the Sociology of Education, J. Richardson (ed.), Nueva York, Greenwood.

Bourgeault, I.L. y otros (2010), Immigrant Care Workers in Aging Societies: The Canadian Context and Experience, Ottawa, Ontario Health Human Resource Research Network [en línea] http://www. healthworkermigration.com/images/stories/docs/immigrant-care-workers-report-2.pdf.

Browne, C, K. Braun y P. Arnsberger (2007), "Filipinas as residential long-term care providers: the role of culture, gender, and immigrant status", Journal of Gerontological Social Work, vol. 48.

Burga, C. y M. Moreno (2001), “Existe subempleo profesional en el Perú urbano?”, Investigaciones Breves, $\mathrm{N}^{\circ} 17$, Lima, Consorcio de Investigación Económica y Social.

Dolton, P y A. Vignoles (2000), "The incidence and the effects of overeducation in the UK graduate labour market", Economics of Education Review, vol. 19, $\mathrm{N}^{\circ} 2$.

Duncan, Natasha (2012), Immigration Policy in the Global Era: In Pursuit of Global Talent, Nueva York, Palgrave Macmillan.

Duncan, Natasha y Brigitte S. Waldorf (2010), "High skilled immigrant recruitment and the global economic crisis: the effects of immigration policies", Working Paper, $\mathrm{N}^{\circ} 10-1$. Departamento de Economía Agrícola, Universidad de Purdue [en línea] http://ageconsearch. umn.edu/ bitstream/58417/2/10-1.pdf.

Fernández, Christina y A. Carolina Ortega (2008), "Labor market assimilation of immigrants in Spain: employment at the expense of bad job-matches?", Spanish Economic Review, vol. 10.

Gandini, Luciana y Fernando Lozano Ascencio (2012), "La migración calificada en perspectiva comparada: el caso de los profesionistas con posgrado en Estados Unidos, 2001-2010", México ante los recientes desafíos de la migración internacional, Telésforo Ramírez-García y Manuel Ángel Castillo (coords.), Ciudad de México, Consejo Nacional de Población (CONAPO).

Green, Colin, Parvinder Kler y Gareth D. Leeves (2007), "Immigrant overeducation: evidence from recent arrivals to Australia", Economics of Education Review, vol. 26.

Hernández, Enrique y Jorge Velázquez (2003), Globalización, desigualdad y pobreza. Lecciones de la experiencia mexicana, Ciudad de México, Plaza y Valdés Editores.

Hernández, Enrique, Ricardo Solís y Ana Stefanovich (2013), Panorama del mercado laboral de profesionistas en México. Diagnóstico (2000-2009) y prospectiva (2010-2020). Informe final, Ciudad de México, Asociación Nacional de Universidades e Instituciones de Educación Superior (ANUIES).

Hochschild, A.R. (2002), "Love and gold", Global Woman: Nannies, Maids, and Sex Workers in the New Economy, B. Ehrenreich y A.R. Hochschild (eds.), Nueva York, Henry Holt and Company.

Langdon, David y otros (2011), "STEM: Good Jobs Now and for the Future", Departamento de Comercio de los Estados Unidos [en línea] http://www.esa.doc.gov/sites/default/files/stemfinalyjuly14_1.pdf. 
Lindley, Joanne (2009), "The over-education of U.K. immigrants and minority ethnic groups: evidence from the Labour Force Survey", Economics of Education Review, vol. 28.

Lozano Ascencio, Fernando y Telésforo Ramírez-García (2015), "Obama's immigration executive action and STEM workers", Voices of Mexico, Centro de Investigaciones sobre América del Norte (CISAN)/Universidad Nacional Autónoma de México (UNAM), en prensa.

Lozano Ascencio, Fernando, Luciana Gandini y Telésforo Ramírez-García (2015), "Devaluación del trabajo de posgraduados en México y su relación con la migración internacional: el caso de los profesionistas en ciencia y tecnología", La migración altamente calificada: elementos para una política nacional de ciencia y tecnología. Informe Técnico, Raúl Delgado Wise (coord.), Ciudad de México, Consejo Nacional de Ciencia y Tecnología (CONACYT)/Programa Gestión de las Transformaciones Sociales (MOST), Organización de las Naciones Unidas para la Educación, la Ciencia y la Cultura (UNESCO).

Mattoo, Aaditya, Ileana Neagu y Çaglar Özden (2008), "Brain waste? Educated immigrants in the U.S. Labor Market", Journal of Development Economics, vol. 87.

Nowicka, Magdalena (2013), "Migrating skills, skilled migrants and migration skills: the influence of contexts on the validation of migrants' skills", Migration Letters, vol. 11, $\mathrm{N}^{\circ} 2$.

Purcell, K., N. Wilton y P. Elias (2007), "Hard lessons for lifelong learners? Mature graduates and mass higher education", Higher Education Quarterly, vol. 61, $\mathrm{N}^{\circ} 1$.

Reiner, Christian (2010), "Brain competition policy as a new paradigm of regional policy: a European perspective", Papers in Regional Science, vol. 89.

Salami, B. y S. Nelson (2014), "The downward occupational mobility of internationally educated nurses to domestic workers", Nursing Inquiry, vol. 21, $\mathrm{N}^{\circ} 2$.

SEP (Secretaría de Educación Pública) (2010), Estadísticas ciclo escolar 2009-2010, Ciudad de México [en línea] http://www.sep.gob.mx/work/models/sep1/Resource/1899/1/images/principales_cifras_ 2009_2010.pdf.

(2008), Programa Sectorial de Educación 2007-2012, Ciudad de México, Secretaría de Educación Pública (SEP).

Siar, Sheila V. (2013), "From highly skilled to low skilled: revisiting the deskilling of migrant labor", Discussion Paper Series, $\mathrm{N}^{\circ}$ 2013-30, Instituto de Estudios para el Desarrollo de Filipinas.

Tuirán, Rodolfo y José Luis Ávila (2013), “De la fuga a la circulación de talentos?”, Este País, 25 de junio.

Walker, Ian y Yu Zhu (2010), "Differences by degree: evidence of the net financial rates of return to undergraduate study for England and Wales", IZA Discussion Papers, $\mathrm{N}^{\circ} 5254$, Institute for the Study of Labor (IZA).

Zúñiga, Elena y M. Molina (2008), Demographic Trends in Mexico: The Implications for Skilled Migration, Washington, D.C., Migration Policy Institute (MPI). 


\title{
La actitud positiva y el bienestar: un análisis del ciclo vital de la esperanza de vida sana y la esperanza de vida feliz a nivel individual en el Brasil y México
}

\author{
Gilvan R. Guedes ${ }^{1}$ \\ Cristina G. Rodrigues ${ }^{2}$ \\ Luisa P. Terra ${ }^{3}$
}

Recibido: 08/06/2015

Aceptado: 14/07/2015

\section{Resumen}

En este artículo se investiga la relación entre la actitud positiva y el tiempo vivido de manera sana y feliz durante todo el ciclo de vida en el Brasil y México. La medición empírica de la actitud multidimensional se basa en tres niveles de percepción: la autopercepción, las relaciones con las redes sociales y el entorno que rodea a la persona. Esta medición se utiliza para evaluar las diferencias en la esperanza de vida sana (EVS) y la esperanza de vida feliz (EVF) a lo largo del ciclo de vida de la persona

\footnotetext{
Doctor en Demografía del Centro de Desarrollo y Planificación Regional (CEDEPLAR) de la Universidad Federal de Minas Gerais (UFMG) del Brasil; Profesor Asociado del Departamento de Demografía de la UFMG. Correo electrónico: grguedes@cedeplar.ufmg.br.

2 Doctora en Demografía del Centro de Desarrollo y Planificación Regional (CEDEPLAR) de la Universidad Federal de Minas Gerais (UFMG) del Brasil; Profesora del Departamento de Ciencia Actuarial de la Fundación Instituto de Investigación Contable, Actuarial y Financiera de la Universidad de São Paulo (FIPECAFI/USP). Correo electrónico: guimaraes.cristina@gmail.com.

3 Maestría en Ciencias en Demografía del Centro de Desarrollo y Planificación Regional (CEDEPLAR) de la Universidad Federal de Minas Gerais (UFMG) del Brasil; Profesora Asistente del Departamento de Ciencia Actuarial de la Universidad Federal de Alfenas, Varginha (Brasil). Correo electrónico: luisaterra@yahoo.com.br.
} 
de acuerdo con el grado de actitud positiva y para descomponer los efectos del cambio observado en los efectos de prevalencia y mortalidad. La evidencia muestra que la actitud positiva está asociada con la EVS y la EVF en ambos países, siendo mayor en el Brasil, aunque en ese país la asociación no es lineal a lo largo del ciclo vital de cada persona en lo que respecta a la salud. Si bien los años restantes de vida de los brasileños son más sanos y felices que los de los mexicanos, sin importar la edad, la diferencia va disminuyendo con el tiempo.

Palabras clave: actitud multidimensional; esperanza de vida sana; esperanza de vida feliz; método de Sullivan; modelo de clases latentes.

\begin{abstract}
This article investigates the relationship between a positive attitude and the time lived happily and healthily over an individual's life cycle in Brazil and Mexico. The empirical measurement of multidimensional attitude is based on three levels of perception: selfawareness, relationship with social networks and the surrounding environment. This measurement is used to evaluate differences in healthy (HLE) and happy life expectancy (GLE) over an individual's life cycle according to the extent of the individual's positive attitude, and to decompose the observed change in prevalence and mortality effects. The evidence shows that positive attitude is associated with HLE and GLE in both countries, although it is higher in Brazil and the association is not linear over an individual's life cycle for health in that country. While Brazilians live more of their remaining years in health and happiness than Mexicans, regardless of age, the gap is closing over time.
\end{abstract}

Keywords: multidimensional attitude; healthy life expectancy; happy life expectancye; Sullivan method; latent class model.

\title{
Résumé
}

Dans cet article l'auteur étudie le rapport entre l'attitude positive et le temps vécu de manière saine et heureuse pendant tout le cycle de vie au Brésil et au Mexique. La mesure empirique de l'attitude multidimensionnelle est basée sur trois niveaux de perception : l'auto perception, les relations avec les réseaux sociaux et avec l'entourage de la personne. Cette mesure est utilisée pour évaluer les différences dans l'espérance de vie saine (EVS) et l'espérance de vie heureuse (EVH) tout au long du cycle de vie de la personne, en fonction du degré d'attitude positive et pour désagréger les effets du changement observé dans les effets de prévalence et de mortalité. Les faits démontrent que l'attitude positive est associée à l'EVS et à l'EVH dans les deux pays, de manière plus marquée au Brésil, même si, dans ce dernier pays, l'association n'est pas linéaire tout au long du cycle vital de chaque personne en termes de santé. Même si les années qui restent de vie des Brésiliens sont plus saines et heureuses que celles des mexicains, indépendamment de l'âge, cette différence s'estompe avec le temps.

Mots clés: attitude multidimensionnelle; espérance de vie saine; espérance de vie heureuse; méthode de Sullivan; modèle de classes latentes. 


\section{Introducción}

En los últimos tiempos, la felicidad ha recibido atención científica en las disciplinas de economía, demografía y otras ciencias sociales como indicador indirecto de la calidad de vida (Graham y Pettinatto, 2002; Easterlin, 2006; Margolis y Myrskyla, 2011). El creciente número de estudios fue posible gracias a la disponibilidad de datos de encuestas sobre felicidad en muy diversos contextos. Tal es el caso de la Encuesta Mundial sobre Valores, que permite a los investigadores empíricos demostrar la importancia que tiene ese concepto multidimensional para el bienestar de la persona4.

La felicidad es un concepto muy general y amplio, que representa un estado general de la vida, que a menudo no se relaciona directamente con condiciones materiales ni estructuras sociales específicas, como las relaciones familiares o la inserción en el mercado de trabajo. Según Bradburn (1969), la felicidad es el grado en que los sentimientos positivos superan los negativos. Así pues, la medición de ese saldo neto suele realizarse a partir de la evaluación de puntuaciones basadas en las respuestas de la persona sobre su satisfacción con la vida, los afectos positivos y negativos y los niveles de depresión. La Escala de Bienestar General (General Wellbeing Schedule) (Fazio, 1977), el Afectómetro 2 (Kamman y Flett, 1983), la Escala de Afectos Positivos y Negativos (PANAS) (Watson, Clark y Tellegen, 1988), y la Escala de Depresión-Felicidad (Joseph y Lewis, 1998) son algunos de los instrumentos más conocidos que se emplean en la esfera de la investigación y la recopilación de datos sobre la felicidad con el fin de abordar empíricamente dicho concepto.

Dado que la comprensión y la evaluación colectiva de la felicidad pueden variar de una sociedad a otra, Graham (2008) sugiere que la mejor forma de garantizar la comparabilidad intercontextual consiste en tratar de no imponer una definición precisa de lo que significa ser feliz. Según ese criterio, la felicidad tiene que ser un concepto elaborado sobre una base social y cultural. Independientemente de las especificidades culturales, la bibliografía empírica sobre datos de felicidad declarados por las propias personas pone de relieve su vínculo con la calidad de los valores y normas familiares, incluida la calidad de las uniones matrimoniales (Dush, Taylor y Kroeger, 2008), el estado de salud, la estabilidad financiera y laboral, además del nivel educativo, el estado civil, el sexo y la raza (Cantril, 1965).

En la bibliografía económica, las investigaciones sobre la felicidad se han centrado predominantemente en su asociación con el ingreso, el empleo y el crecimiento económico (Graham, 2005; Corbi y Menezes-Filho, 2006; Easterlin, 2013). La economía de la felicidad depende de conceptos más amplios de utilidad y bienestar como influencias racionales y no racionales en el comportamiento económico. Los economistas especializados en desarrollo han utilizado las mediciones de felicidad para comprender el comportamiento económico

\footnotetext{
El número creciente de estudios en esa esfera es resultado, al mismo tiempo, de la disponibilidad de datos y del interés cada vez mayor en las dimensiones no monetarias del bienestar (Easterlin, 2013). El propio aumento de la disponibilidad de datos puede interpretarse como una respuesta académica e institucional al creciente interés sobre el tema, que justifica los esfuerzos financieros e intelectuales encaminados a la recopilación, publicación y análisis de datos sobre la felicidad en el mundo entero.
} 
sobre la base del concepto de la preferencia revelada de Samuelson (Graham, 2005). El interés en la relación entre la felicidad y la economía surgió a partir de Easterlin (1974), quien observó que, en los países desarrollados, las personas de mayores recursos son más felices que las de menores recursos, pero al comparar entre sí distintos países y distintos períodos de tiempo, el nivel de felicidad no varía mucho con el ingreso. Esas conclusiones empíricas se conocen como "paradoja de Easterlin". De modo similar, el bienestar se mantiene más o menos constante teniendo en cuenta el ciclo vital, si bien las condiciones económicas mejoran con la edad. Según Easterlin, esa paradoja se plantea porque la mayoría de los estudios empíricos se basan en cortes transversales, que no tienen en cuenta las posibilidades de cambios en la relación entre las variables a lo largo del tiempo. En estudios recientes basados en datos longitudinales se ha concluido que el ingreso es un factor importante en la felicidad, aunque esa asociación parece ser débil, sobre todo entre las personas de edad avanzada.

Teniendo en cuenta la relación entre la salud y la felicidad, los resultados indican que los afectos positivos están relacionados con menores tasas de mortalidad en distintas poblaciones a nivel demográfico (Pressman y Cohen, 2005), así como con menores tasas de suicidio y depresión (Ditella, Macculloch y Oswald, 2003; Bray y Gunnell, 2006; Ostir y otros, 2001) y de enfermedades cardiovasculares (Ostir y otros, 2001; Blanchflower y Oswald, 2007). Al mismo tiempo, hay pruebas empíricas de una elevada correlación entre los datos de salud y felicidad declarados por las propias personas (Frey y Stutze, 2002). Sobre esa base, la bibliografía sobre el tema de la salud y la felicidad indica que las mediciones de felicidad son un indicador de salud mental a nivel demográfico, lo que representa una alternativa interesante a los índices tradicionales basados en perturbaciones psicológicas, que ponen de relieve la dimensión negativa de la salud (Bray y Gunnell, 2006).

En el caso del Brasil, un estudio reciente basado en datos de la Encuesta Mundial sobre Valores concluyó que los hombres tienen más probabilidades de ser felices que las mujeres (Corbi y Menezes-Filho, 2006). Si bien no existen series cronológicas sobre la felicidad en el país, los datos de los Estados Unidos dan a entender que la diferencia entre los sexos en cuanto a la felicidad disminuye con el tiempo (Easterlin, 2001). Desde la perspectiva del ciclo vital, las mujeres declaran ser más felices que los hombres en las etapas iniciales de la vida adulta, con una tendencia inversa en etapas posteriores del ciclo vital (Marcelli y Easterlin, 2007; Plagnol y Easterlin, 2008). Según los autores, esa diferencia entre los sexos dependiente de la edad puede deberse a las distintas aspiraciones relacionadas con la riqueza y la familia según el sexo. En promedio, las mujeres dan mayor peso a la consolidación de la familia, que normalmente tiene lugar en las etapas iniciales de la vida adulta, mientras que los hombres prefieren acumular riqueza, lo que constituye una función positiva de la edad (Plagnol y Easternin, 2008; Dush, Taylor y Kroeger, 2008).

Si se examina el patrón de edad de la felicidad, las estimaciones obtenidas mediante regresión sugieren una curva en forma de parábola, independientemente de los datos que se utilicen (Blanchflower y Oswald, 2007). En general, el punto más bajo de la curva corresponde a las personas de mediana edad, lo que probablemente refleja las contradicciones entre las tareas, las aspiraciones y los logros (Clark y Oswald, 1994; Gerlach y Stephan, 1996; Winkelmann y 
Winkelmann, 1998; Ditella, Macculloch y Oswald, 2001, 2003). En el Brasil, el nivel de felicidad más bajo se observó entre las personas de 53 a 54 años de edad (Corbi y Menezes-Filho, 2006), en comparación con el mayor nivel de infelicidad registrado entre las personas de 30 a 40 años en el caso de los estadounidenses y los británicos (Frey y Stutzer, 2000).

La mayoría de los estudios demográficos se centran en los factores determinantes de la salud y la felicidad pero, hasta donde se tiene conocimiento, ninguno aborda la relación entre la actitud y la vida sana en los países en desarrollo. A partir de teorías sobre la longevidad y la psicología social, el presente estudio es un intento de aportar pruebas empíricas sobre la forma en que la esperanza de vida feliz y la esperanza de vida sana pueden depender de la edad y la actitud en los países en desarrollo. Al combinar cifras de la Base de Datos sobre la Mortalidad Humana, el Instituto Brasileño de Geografía y Estadística (IBGE), la base de datos de mortalidad de la Comisión Económica para América Latina y el Caribe (CEPAL) y la Encuesta Mundial sobre Valores, en este documento se presentan estimaciones empíricas sobre la forma en que han evolucionado la esperanza de vida feliz y la esperanza de vida sana en el Brasil y México en años recientes. También se ha estimado hasta qué punto la actitud positiva de la persona influye en la proporción de sus años restantes de vida con felicidad y salud en cada país en dos momentos determinados. Por último, se ha estimado hasta qué punto el aumento observado en la proporción de años vividos con felicidad y salud se debe a las mejoras en lo que respecta a la mortalidad y a los cambios en la prevalencia de personas felices (sanas). Los autores creen que esos resultados podrían ser útiles para comprender la importancia de promover un entorno sano que contribuya al mantenimiento de una actitud más positiva hacia la vida como forma de aumentar el bienestar de la población.

\section{A. La actitud, el comportamiento y los resultados}

Los modelos de comportamiento sociopsicológicos, como el de la acción razonada y el de la acción planificada, predicen que las acciones responden a la influencia del control percibido del comportamiento, las normas sociales y la actitud relacionada con la voluntad de comportarse, lo que a su vez influye en la acción futura (Ajzen y Driver, 1991; Ajzen y Fishbein, 2000). Al mismo tiempo, los resultados se obtienen a partir de una combinación de acciones (comportamientos) y otros factores individuales y contextuales (Cacioppo y Hawkley, 2003, Cacioppo, Hawkley y Berntson, 2003) $)^{5}$. Por ejemplo, Albarracin y otros

Esos modelos se representa mediante las siguientes funciones relacionales:
$O_{i} \approx f\left(B_{0} ; Z_{i} ; Z\right)$
(1)
$B_{0} \approx f\left(I_{B} ; P B C\right)$
$I_{B} \approx f\left(A_{B} ; S N_{B} ; P B C\right)$

donde $O_{i}$ se refiere al resultado correspondiente a la persona $i$-nésima como función de factores relacionados con la acción (comportamiento) $\left(B_{O}\right)$, factores individuales $\left(Z_{i}\right)$ y factores contextuales $(Z)$. A su vez, la acción $B_{O}$ se ve influenciada por la intención $\left(I_{B}\right)$ de realizar el comportamiento concreto, $B o$, y por el control percibido $(P B C)$ sobre la acción $B_{O}$. Por último, la intención conductual $I_{B}$ se ve afectada por la evaluación de realizar la acción $\mathrm{B}\left(\mathrm{A}_{\mathrm{B}}\right)$, las normas sociales $\left(\mathrm{SN}_{\mathrm{B}}\right)$ que regulan las acciones y el control percibido sobre ellas. 
(2001), determinaron que la intención de utilizar condones guarda una relación importante con el control que la persona percibe sobre el uso en los 96 casos examinados en su estudio mediante procedimientos de metaanálisis. Las conclusiones de los autores dan a entender que, contrariamente a la predicción teórica, algunas actitudes directas y controles percibidos del comportamiento no influyen en el comportamiento concreto. La falta de influencias directas de la actitud y el control percibido del comportamiento apuntan a la relación no despreciable que, según algunos autores, existe entre la actitud y el comportamiento (Cacioppo, Gardner y Berntson, 1997). Es decir, independientemente de la influencia que ejerzan las normas sociales y de la capacidad de controlar el comportamiento, la acción se ve influenciada por el efecto que tienen distintas evaluaciones del comportamiento en la transformación de la intención en un comportamiento concreto (Cacioppo y Berntson, 1994).

En la bibliografía abundan las relaciones empíricas entre la actitud, el comportamiento y los resultados. Se ha determinado que la percepción y la evaluación de la experiencia de la vida y su propósito están asociados con el comportamiento sano y una menor frecuencia de síntomas médicos (Kass y otros, 1991), así como una mayor proporción de personas con buena o excelente salud según sus propias declaraciones (Idler, Hudson y Leventhal, 1999). Danner, Snowdon y Friesen (2001) también encontraron una asociación positiva entre la evaluación emocional positiva en las fases iniciales del ciclo vital y una mayor esperanza de vida en fases posteriores. Posadski y otros (2010) afirman que, mientras mayores sean el sentido de coherencia, el nivel de optimismo y la autonomía, más elevados serán los niveles de los indicadores de salud entre los adultos jóvenes, lo que valida el constructo relativo a la influencia de la actitud positiva en la salud.

La importancia de la actitud para la psicología social y las ciencias sociales en general es ampliamente reconocida en la bibliografía (Norris y otros, 2010; Greenwald y Banaji, 1995), entre otras razones, porque, 'las actitudes: i) son un aspecto dominante de la vida mental y social; ii) influyen en una amplia gama de decisiones y comportamientos; iii) proporcionan una estadística resumida sobre el conocimiento de los estímulos y las reacciones correspondientes, y iv) reducen el esfuerzo o el estrés de la toma de decisiones' (Cacioppo, Gardner y Berntson, 1997, pág. 4).

\section{Definición de actitud}

Tradicionalmente, la actitud se ha definido como el grado en que una persona tiene una evaluación positiva, en lugar de negativa, del comportamiento, medido a partir de escalas bipolares basadas en el diferencial semántico (Fishbein y Manfredo, 1992), con lo que la escala bipolar de valoración resulta opcional (Larsen, Norris y Cacioppo, 2003). Otros autores definen la actitud de forma algo diferente, pues no se centran en la evaluación del propio comportamiento, sino de una meta determinada. Aunque las definiciones de la actitud en relación con objetivos o metas se considera menos útiles para medir directamente el comportamiento (Eagly y Chaiken, 1993), tienen la ventaja de predecir comportamientos indirectos. 
Esta definición es importante al abordar la actitud como factor que influye en los resultados (por ejemplo, el estado de salud, la esperanza de vida sana) mediados por comportamientos no observables (como las consultas con médicos, los mayores niveles de integración social, la participación en actividades relacionadas con sus iguales, la contribución activa a satisfacer las necesidades de la comunidad). En el presente estudio se aborda la actitud como un fenómeno multidimensional, que tiene que ver con la percepción y con procesos evaluativos complejos en distintas esferas de influencia. Esa definición más amplia difiere del concepto de actitud como el grado en que una persona tiene una valoración positiva en lugar de negativa del comportamiento medido con escalas bipolares basadas en el diferencial semántico (Eagly y Chaiken, 1993), pues considera que la actitud debe verse como una serie continua de procesos evaluativos (Cacioppo y Berntson, 1994).

Además de abordar la actitud como resultado de interacciones recíprocas entre evaluaciones positivas y negativas, es importante saber en qué circunstancias se activan recíprocamente esos dos estados extremos para poder obtener un posible comportamiento (y resultado). Esas circunstancias tienen en cuenta la pluralidad de esferas en que se desarrollan las experiencias de la persona: el yo, las redes sociales y el entorno circundante (Norris y otros, 2010; Larson, Story y Nelson, 2009). Dichas esferas son parte activa de la identidad de la persona y definen directamente su forma de determinar cómo comportarse. Por consiguiente, según dan a entender las constataciones recientes en la psicología conductista, las actitudes positivas y negativas coexisten en distintas dimensiones e influyen en la forma en que las personas planifican sus acciones y experimentan el resultado de su comportamiento efectivo (Cacioppo y Hawkley, 2003).

La determinación de las condiciones para la activación de los procesos no es despreciable, pero han comenzado a surgir evidencias que dan a entender que la forma en que evaluamos las situaciones y procesos no solo depende de nuestra percepción del fenómeno sino de las normas sociales que median en él (Berntson y Cacioppo, 2008). Por ejemplo, Ankler, Feeley y Kim (2010) afirman que la capacidad de las actitudes de predecir patrones de comportamiento estables depende en gran medida de si se abordan correctamente las múltiples dimensiones de la actitud, entre las que figuran sus componentes cognitivos y afectivos. Sobre la base de las perspectivas de los autores, el presente estudio sostiene que la relación entre la actitud y los resultados, mediada por los comportamientos implícitos, puede vincularse con una compleja red de relaciones entre la percepción de la esfera inmediata de evaluación (el yo) y otras esferas jerárquicas de la percepción (las redes sociales y el entorno circundante).

\section{La actitud y el bienestar}

La influencia del contexto social en el bienestar ha ido recibiendo cada vez más atención y apoyo científico, sobre todo entre los expertos en genética molecular. Algunos estudios han demostrado que las personas que presentan una mayor susceptibilidad genética a determinadas enfermedades no siempre manifiestan esas patologías (Ryff y Singer, 2005). 
Como una de las explicaciones posibles, se ha planteado la hipótesis de que hay mecanismos sociales en funcionamiento que actúan como factores de protección. Las evidencias indican que los entornos negativos influyen en los procesos neurobiológicos y, a la postre, hacen que aumente el riesgo de dolencias crónicas y muerte causadas por enfermedades cardiovasculares (Burleson y otros, 2003).

El optimismo general también se asocia con mayores tasas de supervivencia (Danner, Snowdon y Friesen, 2001). Las autoevaluaciones positivas se traducen en mayores niveles de felicidad y altruismo, mayor disposición de participar en actividades sociales, mayores probabilidades de alcanzar las metas y menores niveles de depresión (Kwan y otros, 2003). Según algunos estudios, el mecanismo subyacente que vincula el optimismo con el bienestar puede relacionarse con las conexiones neuronales del cerebro humano. Por ejemplo, Urry y otros (2004) demuestran que el aumento del bienestar psicológico se asocia positivamente con el aumento de la actividad del hemisferio izquierdo del cerebro. Esa conclusión es pertinente porque la activación del funcionamiento del hemisferio izquierdo se asocia con la capacidad de recuperarse de episodios negativos y la facilidad de superar emociones negativas en sentido amplio.

Las conclusiones científicas antes descritas dan a entender que la relación entre la actitud y el bienestar opera mediante distintas esferas evaluativas. Al aplicar los enfoques de Ankler, Feeley y Kim (2010) y de Posadski y otros (2010) respecto de las díadas de la actitud y el comportamiento o resultado, se ha realizado un ejercicio empírico para medir la actitud multidimensional hacia las tres esferas evaluativas antes descritas. De este modo, se ha utilizado la medición empírica de la actitud multidimensional para analizar su relación con la esperanza de vida sana y la esperanza de vida feliz a lo largo de distintas etapas del ciclo vital de cada persona. Este ejercicio aporta pruebas descriptivas sobre la asociación entre la actitud y el bienestar, pero carece de base para argumentos de causalidad, pues solamente se aplican datos transversales.

\section{B. Comparación de los contextos del Brasil y México}

El Brasily México son países que presentan semejanzas en sus indicadores de bienestar, como el PIB, la satisfacción con la vida y la huella ecológica (Salomon y otros, 2012; Veenhoven, 2013). Según el Índice de Felicidad del Planeta, ambos están igualados en el puesto 21 (de un total de 151 países). El índice está compuesto por tres subíndices: la esperanza de vida, el bienestar experimentado y la huella de carbono, que permiten medir hasta qué punto los países proporcionan a su población una vida larga, feliz y sostenible. Representa la cantidad de vidas largas y felices que produce cada país por unidad de insumo ambiental. Los resultados correspondientes a 2012 muestran que ocho de los nueve países que ocupan los primeros lugares se encuentran en América Latina y están clasificados muy por delante de muchos países desarrollados (estimaciones de los autores basadas en los datos del Índice de Felicidad del Planeta). 
Mapa 1

Clasificación de los países con arreglo al Índice de Felicidad del Planeta en 2012
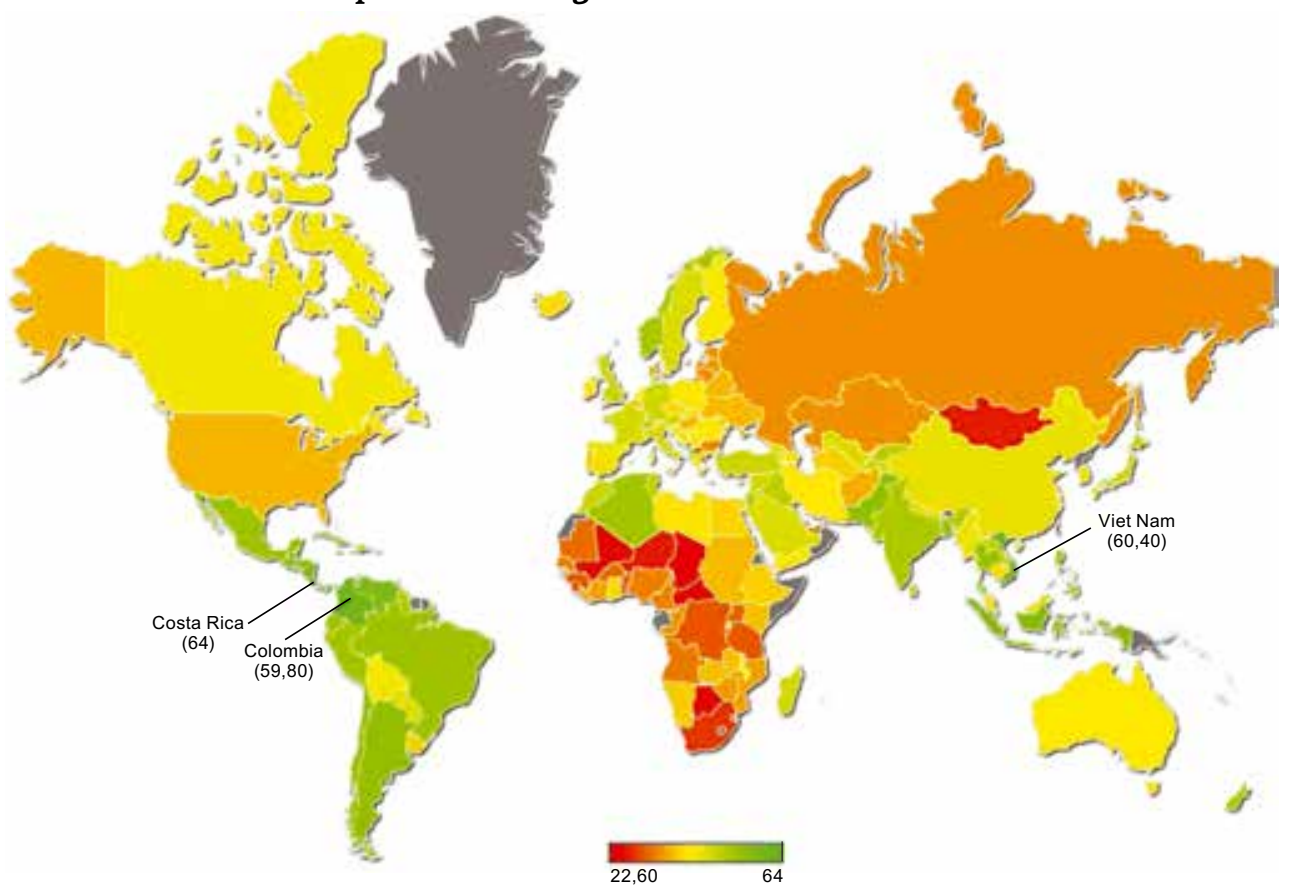

Fuente: Índice de Felicidad del Planeta, 2013.

Nota: Los límites y los nombres que figuran en este mapa no implican su apoyo o aceptación oficial por las Naciones Unidas.

Si se examinan más de cerca los índices que miden la satisfacción con la vida, ambos países siguen mostrando niveles muy similares. Por ejemplo, según la pregunta relativa a la escala de la vida en la encuesta mundial Gallup, el Brasil y México indican en promedio el mismo valor de 6,8 puntos en una escala de o a 10 (HPI, 2013). En el cuadro 1 se muestran diferentes indicadores de felicidad disponibles en la Base de Datos Mundial sobre la Felicidad (Veenhoven, 2013). A excepción de los años de vida feliz, todos los demás indicadores son muy similares.

Cuadro 1

Brasil y México: indicadores de felicidad

\begin{tabular}{lcccc}
\hline Felicidad & Felicidad media & Años de vida feliz & $\begin{array}{c}\text { Desigualdad de } \\
\text { la felicidad }\end{array}$ & $\begin{array}{c}\text { Felicidad ajustada } \\
\text { en función de } \\
\text { la desigualdad }\end{array}$ \\
\hline Intervalos posibles & 0 a 10 & 0 a 100 & 0 a 3,5 & 0 a 100 \\
\hline Puntuación superior & 8,5 Costa Rica & 66,7 Costa Rica & 1,42 Países Bajos & 73 Dinamarca \\
\hline Brasil & 7,5 & 53,5 & 2,19 & 61 \\
\hline México & 7,9 & 59,7 & 2,19 & 64 \\
\hline Puntuación inferior & 2,6 & 12,5 & 3,19 & 16 \\
\hline
\end{tabular}

Fuente: Elaboración propia sobre la base de R. Veenhoven, Happiness in Nations, World Database of Happiness, Erasmus University, Rotterdam (Países Bajos) [en línea] http://worlddatabaseofhappiness.eur.nl/hap_nat/ nat_fp.php?mode=1 [fecha de consulta: 13 de agosto de 2013] 
Los países también son similares en lo que se refiere a la esperanza de vida sana. Según un artículo publicado recientemente en la revista especializada The Lancet (Salomon y otros, 2012), el Brasil y México presentan niveles muy similares de esperanza de vida ajustada en función de la salud a los 50 años de edad en ambos sexos. Las diferencias (en años) entre la esperanza de vida y la esperanza de vida sana al nacer, así como entre la proporción de los años restantes de vida sana a los 50 años de edad (véase el cuadro 2), tampoco son muy grandes en comparación con la diferencia observada entre el Brasil (o México) y otros países de América Latina (Salomon y otros, 2012).

Cuadro 2

Brasil y México: esperanza de vida ajustada en función del estado de salud, por sexo y año

\begin{tabular}{|c|c|c|c|c|c|c|}
\hline \multirow[b]{2}{*}{ País } & \multicolumn{3}{|c|}{ Hombres } & \multicolumn{3}{|c|}{ Mujeres } \\
\hline & $e_{50}$ & $\% \mathrm{EVS}_{50}$ & $\begin{array}{c}\mathrm{e}_{50}-\mathrm{EVS}_{50} \\
\text { (número de años } \\
\text { sin salud) }\end{array}$ & $e_{50}$ & $\% \mathrm{EVS}_{50}$ & $\begin{array}{c}\mathrm{e}_{50}-\mathrm{EVS}_{50} \\
\text { (número de años } \\
\text { sin salud) }\end{array}$ \\
\hline & \multicolumn{6}{|c|}{1990} \\
\hline Brasil & 24,9 & 79,1 & 8,8 & 29 & 77,9 & 10,7 \\
\hline \multirow[t]{2}{*}{ México } & 26,9 & 81,4 & 7,8 & 30,6 & 80,7 & 9,4 \\
\hline & \multicolumn{6}{|c|}{2010} \\
\hline Brasil & 26,8 & 79,5 & 9,4 & 31,1 & 78,8 & 11,1 \\
\hline México & 28 & 82,5 & 7,8 & 31,4 & 81,8 & 9,3 \\
\hline
\end{tabular}

Fuente: Elaboración propia, sobre la base de J. A. Salomon y otros, "Healthy life expectancy for 187 countries, 1990-2010: a systematic analysis for the Global Burden Disease Study 2010", The Lancet, vol. 380, 2012.

A pesar de las similitudes entre los países en cuanto a los indicadores mundiales de bienestar, tanto objetivos como subjetivos, cabe preguntarse si la actitud individual presenta especificidades en cada país en relación con el bienestar. Como indican los resultados que se exponen más adelante, los gradientes de optimismo y actitud presentan una asociación más firme con las diferencias en cuanto al estado de vida sano en el Brasil, sobre todo en el caso de los jóvenes y los adultos. Respecto de la esperanza de vida feliz, se prevé que las personas que tienen mayores niveles de optimismo y actitud positiva experimentarán felicidad durante una proporción mayor de los años restantes de vida en ambos países, independientemente de la edad. Por último, los resultados del presente estudio también indican que, si bien los mexicanos tienen mayor esperanza de vida, presentan una menor proporción de años de vida restantes con salud y felicidad que los brasileños. Sin embargo, la diferencia entre los países tiende a disminuir, sobre todo en lo que se refiere a los indicadores de felicidad. En ambos casos, la mayor parte del aumento de los indicadores de bienestar se explica por el cambio en la prevalencia de los niveles positivos de salud y felicidad notificados. 


\section{Estrategia de modelización}

La definición conceptual de actitud utilizada en el presente estudio se basa en las relaciones multidimensionales de percepción y evaluación del yo, las redes sociales y el entorno circundante en que está inmersa la persona (Cacciopo y Berntson, 1994). Aquí se plantea que la influencia interactiva de las evaluaciones positivas y negativas no solo ocurre al mismo nivel de percepción de la persona, sino entre distintos niveles. Por ejemplo, una persona puede considerar que tiene un alto grado de control sobre su vida a pesar de sentirse aislada de las redes sociales. Las diversas posibilidades de evaluación entre los distintos niveles de percepción se corresponden con los supuestos de los modelos de variables latentes basados en la lógica difusa. Es decir, en lugar de clasificar simplemente como optimista o no optimista a una persona que tenga control sobre su vida y esté aislada de las redes sociales, es posible medir su grado de optimismo y utilizar ese parámetro como indicador empírico indirecto de la heterogeneidad de su actitud (Cacciopo y Berntson, 1994; Manton, Tolley y Woodbury, 1994).

De una amplia gama de técnicas de variables múltiples, en este caso se ha seleccionado el modelo basado en el grado de pertenencia (GP) debido a las razones siguientes: i) produce una medición empírica de la heterogeneidad entre las unidades de muestreo basadas en la asociación no observada entre categorías de variables; ii) dicha medición empírica, basada en conjuntos de datos difusos, expresa el grado de pertenencia para referenciar grupos de elementos, lo que, en modelos que solo tienen dos grupos (perfiles) extremos de referencia, puede traducirse en cierto grado de pertinencia con la actitud percibida multidimensional (multiescalar) general; iii) la medición de las estimaciones de heterogeneidad mejora con el número de variables y no es sensible a la relación endógena entre ellas, puesto que se trata de una técnica exploratoria, y iv) permite que una misma persona tenga respuestas positivas y negativas, pues mide la distancia entre la positividad y la negatividad de cada persona y los grupos de referencia positivos y negativos (Woodburry, Clive y Garson, 1978; Manton, Tolley y Woodbury, 1994).

El modelo GP representa una metodología matemática basada en la lógica difusa que se utiliza para delinear conglomerados de elementos dentro de un conjunto de datos heterogéneo y multidimensional. Se clasifica como técnica de conglomeración difusa porque permite que la misma persona tenga cierto nivel de pertinencia con múltiples conjuntos ${ }^{6}$. El modelo estima dos parámetros: un parámetro de ubicación, $\lambda_{\mathrm{kjl}}$, y un parámetro de partición difusa, $g_{\mathrm{ik}}$. El parámetro de ubicación se corresponde con la probabilidad condicional de respuesta para la categoría $l$, de la variable $j$, en un perfil de referencia (extremo) $k$. Es decir,

6 Esto se diferencia de la nítida lógica tradicional, en la que una persona o elemento tiene que clasificarse en uno de los conglomerados, independientemente de su grado de heterogeneidad en relación con el conglomerado en que se clasifica. La incapacidad de los modelos de conjuntos nítidos para modelizar explícitamente el nivel individual de heterogeneidad y de diferencia de cada conglomerado de referencia hace que la descripción de la heterogeneidad de las muestras sea más deficiente. Ese es uno de los principales atractivos técnicos de la utilización de modelos de conglomerados basados en la lógica difusa, pues permite que las personas se distingan de los conglomerados de referencia, y, en lugar de ello, mide cuán distinto es cada uno en comparación con cada conglomerado de referencia (Manton, Tolley y Woodbury, 1994; Vermunt, 2003). 
el parámetro $\lambda_{\text {kil }}$ mide las probabilidades que tiene una persona representativa de un grupo de referencia de responder en determinada categoría de una variable específica. La partición difusa mide el grado en que cada elemento (observación) $i$ manifiesta las características conjuntas del perfil de referencia $k$. Es decir, hasta qué punto las características de un perfil de referencia se manifiestan en una persona sobre la base de su patrón de respuestas en comparación con el patrón típico de respuestas de una persona que pertenece a ese perfil de referencia. Por consiguiente, el parámetro $g_{i k}$ se corresponde con la heterogeneidad a nivel individual basada en las funciones de pertenencia difusas. La variación de ambos parámetros se limita al rango de o a 1 (Manton, Tolley y Woodbury, 1994).

Para establecer el modelo empírico GP, se comenzó por seleccionar 20 variables relacionadas con las preferencias, la percepción, los valores y las actitudes notificados por personas de entre 18 y 84 años de edad de cada país. Las variables se explican a continuación. En el nivel del yo, las variables iniciales fueron: i) el nivel de satisfacción con la vida; ii) la importancia de tener una buena vida; iii) el grado de control de la persona sobre su vida y su destino; iv) el grado de control de la persona sobre su propia suerte, y v) cuán a menudo piensa en el propósito de su vida. En el nivel de las redes sociales, las variables iniciales fueron: i) la importancia de la familia en la vida de la persona; ii) la importancia de los amigos en la vida de la persona; iii) el reconocimiento de que la tolerancia y el respeto deben ser parte del carácter de los niños; iv) el reconocimiento de que la determinación y la perseverancia deben ser parte del carácter de los niños; v) el reconocimiento de que la generosidad debe ser parte del carácter de los niños; vi) hasta qué punto se puede confiar en otros; vii) hasta qué punto otras personas son justas con el encuestado; viii) cuán importante es ayudar al prójimo, y ix) la sensación de aislamiento social. En el nivel del entorno circundante, las variables iniciales fueron: i) cuáles deberían ser los objetivos del país de la persona; ii) la importancia de proteger el medio ambiente; iii) el reconocimiento de que el gobierno debería reducir la contaminación ambiental; iv) el reconocimiento de que el mundo es mejor gracias a la ciencia y la tecnología; v) el sentimiento de orgullo por ser brasileño o mexicano, y vi) el grado de interés del encuestado durante la encuesta.

Dado que el modelo GP, en la forma en que lo generan la mayoría de los programas informáticos disponibles (Stata, $\mathrm{R}$ o Windows) no ofrece una prueba estadística significativa con la que las variables seleccionadas organizarían realmente los datos observados en perfiles bien definidos o difusos, en el presente estudio se ha utilizado un modelo de conglomerados de clases latentes (CCL) con covariables activas (sexo y edad) a fin de analizar la asociación de variables múltiples significativas (de modalidades mixtas) entre los indicadores (Vermunt, 2003)7. Puede adoptarse un modelo paramétrico

$7 \quad$ El método semiparamétrico basado en grupos utiliza una estrategia de modelización polinómica para establecer la correspondencia de la caracterización de los grupos como clases latentes en los datos (Land, 2001). Dado que es improbable que toda la población corresponda a una de las clases de percepción y actitud, el método permite obtener resultados difusos al estimar las probabilidades posteriores de pertenencia a una clase respecto de las distintas clases para cada persona. La pertenencia a una clase específica se define como pertenencia modal, es decir, que la persona pertenece a la clase en la que presente una mayor probabilidad condicional posterior. 
CCL respecto del constructo de percepción y actitud, de la manera siguiente (Vermunt y Magidson, 2007):

$$
f\left(\mathbf{y}_{i} \mid \mathbf{z}_{i}^{\mathrm{cov}}\right)=\sum_{x=1}^{K} P\left(x \mid \mathbf{z}_{i}^{\mathrm{cov}}\right) \prod_{t=1}^{T} f\left(y_{i t} \mid x\right)
$$

En la ecuación (1), $\mathrm{P}(\mathrm{x} \mid \mathrm{z})$ representa la probabilidad de que determinada persona pertenezca a la clase $x$, en función de las covariables observadas. La clase $x$-nésima en el modelo CCL es análoga al perfil k-nésimo en el modelo GP. En el modelo utilizado, se han tenido en cuenta la edad y el sexo como covariables demográficas de control de la heterogeneidad observada. No se incluyeron otras covariables, pues los autores estaban más interesados en encontrar indicadores estadísticamente significativos del índice, y no tanto en determinar el tamaño de las clases ${ }^{8}$. Cada uno de los 20 indicadores seleccionados del cuadro 3 corresponde a $y_{i t}$ en la ecuación (1). O sea, el indicador t-nésimo y respecto de la persona i-nésima. La porción $f\left(y_{i t} \mid x\right)$ es la función de densidad condicional correspondiente a cada indicador, que se supone sea independiente en el indicador $t$, según la clase a que pertenezca (independencia local). Es decir, los modelos básicos de CCL presuponen que, una vez que se haya estimado la clase $x$, no debería existir ninguna otra relación entre los distintos indicadores. Ese supuesto puede moderarse con efectos directos del tipo indicadores-indicadores o covariable-indicador, utilizando los valores residuales bivariados mayores que 2 (Vermunt, 2003).

\section{Cuadro 3}

\section{Brasil y México: estadísticas de prueba para los indicadores de actitud} multidimensional en los modelos seleccionados

\begin{tabular}{lccccc}
\hline \multirow{2}{*}{ Indicador } & \multicolumn{2}{c}{ Brasil } & & México \\
\cline { 2 - 3 } \cline { 5 - 6 } & Prueba de Wald & Valor $\mathrm{p}$ & & Prueba de Wald & Valor $\mathrm{p}$ \\
\hline Importancia de la familia en su vida & 11,681 & 0,001 & & 9,113 & 0,011 \\
\hline Importancia de los amigos en su vida & 29,035 & 0,000 & & 26,725 & 0,000 \\
\hline Nivel de satisfacción con la vida & 15,395 & 0,000 & & 14,776 & 0,001 \\
\hline Importancia de pasarla bien & 12,847 & 0,000 & & 39,289 & 0,000 \\
\hline Importancia de ayudar al prójimo & 67,782 & 0,000 & & 47,318 & 0,000 \\
\hline Grado de control sobre su vida y destino & 5,902 & 0,015 & & 0,708 & 0,700 \\
\hline Cuán orgulloso se siente de su nacionalidad & 25,615 & 0,000 & & 22,634 & 0,000 \\
\hline Nivel de aislamiento de la persona & 22,008 & 0,000 & & 25,547 & 0,000 \\
\hline
\end{tabular}

Fuente: Elaboración propia, sobre la base de la Encuesta mundial de valores (Brasil, 2006; México, 2005).

Al aplicar un modelo CCL con covariables, se ejecuta una serie de modelos de 1 a 5 conglomerados o clases y se selecciona el modelo sobre la base de determinados criterios, entre los que figuran la adecuación general del modelo $\left(\mathrm{L}_{2}\right.$ estadística de prueba de

\footnotetext{
8 Como sugiere la ecuación anterior, los indicadores, yit, se ven afectados por la clase, pero no por las covariables, que
} solamente influyen en el tamaño estimado de las clases. 
ji al cuadrado $\mathrm{L}_{2}$ y valor p con la técnica bootstrap) y la adecuación del modelo de componentes (BIC-LL) y el análisis de los valores residuales (valores residuales bivariados)9. Los modelos se ejecutaron en el programa informático Latent Gold, versión 4.5 (Vermunt y Magidson, 2007). Debido a la escasez de datos (porque algunos indicadores son variables continuas y otros son variables categóricas), se utiliza la técnica bootstrap $\mathrm{L}^{2}$ para determinar la validez de los parámetros del modelo ${ }^{10}$. De conformidad con la significación de la técnica bootstrap $\mathrm{L}^{2}$, una variable de clases latentes que representa la actitud multidimensional tendría por lo menos dos clases o grupos de referencia (lo que indica la validez del modelo es un valor $\mathrm{p}$ no significativo). Entre los modelos que presentan un valor $\mathrm{L}^{2}$ no significativo $\mathrm{L}^{2}$, los autores han elegido el número de clases basadas en el criterio de información bayesiano (BIC). El menor criterio $\mathrm{BIC}$ con un valor $\mathrm{L}^{2}$ significativo es el mejor modelo para describir los datos. Del cuadro A.1 del anexo se deduce que un modelo de dos clases en el caso del Brasil y un modelo de tres clases en el caso de México son la mejor forma de describir la asociación observada entre los indicadores antes enumerados.

Después de esa preselección, los autores compararon las variables seleccionadas sugeridas por los modelos de clases latentes con las variables utilizadas en la bibliografía y luego descartaron las variables adicionales con el fin de obtener subdimensiones aproximadas más coherentes del constructo latente 'percepción y actitud multidimensional. En el cuadro 3 se incluye la prueba de Wald y el valor p asociado correspondiente a cada indicador final utilizado para crear la actitud multidimensional en los modelos seleccionados de clases latentes. En ambos países, prácticamente todos los indicadores presentan distintos parámetros logarítmicos lineales estadísticamente significativos en todas las clases de la variable latente. Los indicadores restantes que no se utilizaron en los modelos finales no pudieron explicarse mediante la clase latente y se excluyeron de las especificaciones finales.

Una vez que los modelos CCL validaron la significación estadística de los indicadores seleccionados, los autores aplicaron esos indicadores a un modelo GP de dos perfiles ${ }^{11}$. El modelo GP final correspondiente a cada país en cada año produjo dos grados de mediciones de la pertenencia, $g_{i_{1}}$ y $g_{i 2}$. El parámetro $g_{i 2}$ que se utilizó fue el grado de actitud positiva multidimensional. Mientras el valor de $g_{i 2}$ más se aproxima a 1 , más positiva será la actitud que tiene la persona.

A los efectos de este artículo, se considera que una persona tiene una actitud multidimensional positiva si pertenece al cuarto o quinto quintil del grado acumulativo

9 El análisis de los valores residuales bivariados es importante, porque indica si se ha violado o no el supuesto de la independencia local. Si esto ha sucedido (con valores residuales mayores que 2), es posible moderar esa restricción y permitir que haya efectos directos entre pares de indicadores, incluso después de estimar las clases $\mathrm{x}$. Esto constituye un reconocimiento empírico de que el modelo no es capaz de describir todo el patrón de asociaciones de covarianza solamente a partir de las clases latentes (Vermunt, 2003).

10 Cuando escasean los datos, L2 no sigue una distribución de ji al cuadrado, y el valor p calculado sería incorrecto (Vermunt y Magidson, 2007). Esto explica por qué se requiere un procedimiento basado en la técnica bootstrap para aplicar la prueba hipotética correcta correspondiente a un modelo de alcance limitado.

11 La estrategia de modelización en la que se utiliza el modelo GP con dos perfiles de referencia y una probabilidad fija sigue el procedimiento descrito en Guedes y otros (2012). Para evitar incluir detalles técnicos adicionales, se puede encontrar más información sobre el procedimiento en el artículo de los autores. 
de pertenencia $\left(g_{i 2}\right)$ al perfil de actitud positiva, y se considera que tiene una actitud multidimensional negativa si pertenece al primer o segundo quintil. Después de clasificar a las personas incluidas en la muestra según su actitud, los autores estimaron la proporción de personas de cada grupo de edad decenal que indicaron encontrarse con buena salud (buena o muy buena) o con mala salud (regular o mala) en función de su actitud. En el caso de la esperanza de vida feliz, los autores definen a la persona feliz como "muy feliz" o "bastante feliz" y a la personas infeliz como "no feliz" o "completamente infeliz".

\section{a) Medición de la esperanza de vida sana y la esperanza de vida feliz}

La esperanza de vida sana (EVS) y la esperanza de vida feliz (EVF) se calcularon con el método de Sullivan (Sullivan, 1971). Se utilizaron datos de la Encuesta Mundial sobre Valores correspondientes al Brasil (1997 y 2006) y México (1996 y 2005). Las tablas de mortalidad del Brasil fueron calculadas por el Instituto Brasileño de Geografía y Estadística (IBGE) ${ }^{12}$. En el caso de México, los autores calcularon sus propias tablas de mortalidad abreviadas ${ }^{13}$, para lo cual aplicaron los datos demográficos y de fallecimientos indicados por la Base de Datos de Mortalidad Humana Latinoamericana (LAHMD). Para obtener las estimaciones de la EVS y la EVF se aplicó la prevalencia del atributo (estado de salud o grado de felicidad con la vida) en intervalos decenales comenzando a los 15 años de edad. No es conveniente aplicar la prevalencia de un solo año debido a los problemas que plantea la utilización de un pequeño número de casos y a la influencia de las imprecisiones al indicar la edad (Preston, Heuvelline y Guillot, 2001). La esperanza de vida sana (feliz) $\left(\mathrm{EVS}_{\mathrm{a}} / \mathrm{EVF}_{\mathrm{a}}\right.$ ) y la esperanza de vida sin salud (ni felicidad) $\left(\mathrm{EVSI}_{\mathrm{a}}\right.$ / $\mathrm{EVFI}_{\mathrm{a}}$ ) se estiman con arreglo a las fórmulas siguientes:

$$
H L E_{a}=\frac{\sum_{a=15}^{75}\left({ }_{n} \pi_{a}{ }_{n} L_{a}\right)}{l_{a}} ; U H L E_{a}=\frac{\sum_{a=15}^{75}\left[\left(1-{ }_{n} \pi_{a}\right){ }_{n} L_{a} .\right.}{l_{a}}
$$

donde:

- ${ }_{n} \pi_{a}$ es la tasa de prevalencia de personas sanas (felices) desde la edad $a$ hasta $a+n$; - $\left(1-\pi_{n}\right)$ es la tasa de prevalencia de personas sin salud (infelices) en el mismo grupo de edad;

12 Para obtener las estimaciones de la EVSI y la EVFI correspondientes a 1997 en el caso de los brasileños se utiliza la tabla completa de mortalidad de 1998 en relación con ambos sexos. Es la primera tabla completa que se puede descargar de Internet, elaborada por el Instituto Brasileño de Geografía y Estadística (IBGE).

13 Se probaron distintos enfoques para estimar las tablas de mortalidad por períodos en el caso de México. Por ejemplo, se promedió el número de fallecimientos notificados durante un lapso de tres y cinco años a fin de reducir la aglomeración en los informes periódicos, y se utilizaron distintas estimaciones demográficas a mitad de año por edad (con datos de la CEPAL, y otros datos obtenidos directamente de los censos de 1990, 2000 y 2010 procesados por el proyecto IPUMS). La estimación de los años aportados por los fallecidos en cada grupo de edad, nax, se basó en el procedimiento iterativo sugerido por Preston y otros (2001). Para calibrar los resultados, se compararon las estimaciones obtenidas con la esperanza de vida al nacer notificadas por las Naciones Unidas en relación con México. En los datos de 1995, se apreció una diferencia de 0,1 años, así como una diferencia de 0,5 años en los de 2005. A los efectos del presente estudio, esas desviaciones se consideran menores. 
- $l_{a}$ es el número de sobrevivientes a la edad exacta $a$;

- $\sum\left({ }_{n} \pi_{a}{ }_{n}{ }_{n} L_{a}\right)$ es el número total de años vividos en condiciones de salud (felicidad) entre las edades $a$ y $a+n$ por una cohorte, $\mathrm{y}$

$-\sum\left[\left(1-{ }_{n} \pi_{a}\right){ }_{n} L_{a}\right]$ es el número total de años vividos sin salud (ni felicidad) en el grupo de edad $(a, a+n)$ por una cohorte.

Las fórmulas utilizadas para estimar entre $\operatorname{EVSI}_{a}\left(\operatorname{EVFI}_{a}\right)$ y $\operatorname{EVS}_{a}\left(\operatorname{EVF}_{a}\right)$ tienen dos componentes independientes: la mortalidad $\left({ }_{n} L_{a}\right)$ y la salud [felicidad] $\left(1_{n} \pi_{a}\right)$. Por último, se realizaron simulaciones de hipótesis estacionarias de mortalidad y prevalencia de salud [felicidad] con el fin de medir hasta qué punto el cambio observado en los valores \%EVS $\mathrm{y}$ $\% \mathrm{EVF}_{\mathrm{a}}$ desde el momento 1 hasta el momento 2 se debió al cambio de la prevalencia a lo largo del período. Debido a que no estaba disponible toda la información utilizada para crear la medición de la percepción multidimensional y la actitud en la primera fase de datos (1995 en el caso de México y 1997 en el caso del Brasil), solamente se aplicó la descomposición por edad de las mediciones de felicidad y salud. La muestra de descomposición analítica correspondiente al Brasil es de 1.496 observaciones en la fase de 2006 y de 1.148 observaciones en la fase de 1997, mientras que en el caso de México las cifras son 1.550 en la fase de 2005 y 2.310 en la fase de 1995.

\section{Constataciones}

\section{a) La actitud y la salud}

Se comenzó por examinar la prevalencia de personas sanas por grupo de edad y actitud. Como se indica en el cuadro 4, una pequeña proporción de la población se mantiene sana a medida que envejece, aunque dicha proporción suele ser más elevada entre las personas que muestran una actitud positiva en cualquier edad. La diferencia en las proporciones de personas sanas por actitud, del $1 \%$, resulta estadísticamente significativa en todos los grupos de edad. En general, esa diferencia aumenta con la edad entre los brasileños, pero no así entre los mexicanos. En promedio, el $89,1 \%$ de los brasileños que tienen actitud positiva también indicaron gozar de buena salud, en comparación con apenas el $65,4 \%$ entre los que tienen actitudes negativas. Entre los mexicanos, el 68,9\% de las personas que tienen actitud positiva se consideran saludables, en comparación con el $65,2 \%$ entre los que tienen actitudes negativas.

También se aprecia una tendencia ascendente en las edades más avanzadas en el caso de los brasileños. Si bien hay una tendencia decreciente en el caso de las personas sanas que tienen actitudes positivas a medida que envejecen, en el grupo de 65 años y más la proporción de personas sanas es aproximadamente de un $76,2 \%$, lo que supera el porcentaje correspondiente a las personas del grupo de 55 a 64 años de edad (65,0\%). El aumento de los 64 a 65 años de edad no es de sorprender, pues esa es aproximadamente la edad de jubilación en el Brasil. Se han realizado muchos estudios con la intención de analizar los efectos de la jubilación sobre la felicidad y el bienestar. Por ejemplo, mediante la utilización 
de datos longitudinales del estudio sobre salud y jubilación (Health and Retirement Study (HRS)) sobre adultos mayores estadounidenses y sus cónyuges de 1992 a 2004, Calvo, Haverstick y Sass (2008) demostraron que la manera en que las personas perciben su transición del mercado de trabajo a la jubilación (gradual o abrupta) es más importante para explicar las actitudes positivas de las personas hacia la jubilación que el propio tipo de jubilación (completa o parcial). Otros estudios demuestran que la llegada de la jubilación puede percibirse como una amenaza y dar paso a un período de depresión y, en general, a una sensación mermada de satisfacción con la vida (Huang y otros, 2011). Si bien no se han realizado muchos estudios en el Brasil con respecto a la jubilación y la felicidad, la edad media de jubilación en el país es de 54 años, lo que da a entender que, a los 65 años, las personas de edad avanzada ya han tenido suficiente tiempo para adaptar sus expectativas en relación con una vida mejor.

Cuadro 4

Brasil (2006) y México (2005): proporción de personas sanas por grupo de edad y actitud (En porcentajes)

\begin{tabular}{|c|c|c|c|c|}
\hline País & Grupo de edad & Actitud positiva & Actitud negativa & Valor $p^{2}$ \\
\hline \multirow{7}{*}{ Brasil } & 15 a 24 & 97,5 & 81,6 & 0,0000 \\
\hline & 25 a 34 & 95,0 & 80,7 & 0,0004 \\
\hline & 35 a 44 & 89,5 & 67,8 & 0,0000 \\
\hline & 45 a 54 & 86,3 & 53,8 & 0,0000 \\
\hline & 55 a 64 & 65,0 & 44,1 & 0,0252 \\
\hline & 65 y más & 76,2 & 33,3 & 0,0000 \\
\hline & Total & 89,1 & 65,4 & 0,0000 \\
\hline \multirow{7}{*}{ México } & 15 a 24 & 77,9 & 80,3 & 0,4916 \\
\hline & 25 a 34 & 76,6 & 71,9 & 0,0928 \\
\hline & 35 a 44 & 69,3 & 60,0 & 0,0372 \\
\hline & 45 a 54 & 74,7 & 59,0 & 0,0011 \\
\hline & 55 a 64 & 47,8 & 45,2 & 0,4295 \\
\hline & 65 y más & 40,9 & 38,5 & 0,4866 \\
\hline & Total & 68,9 & 65,2 & 0,0205 \\
\hline
\end{tabular}

Fuente: Elaboración propia, sobre la base de la Encuesta Mundial sobre Valores (Brasil, 2006; México, 2005).

a Prueba bilateral de proporciones entre grupos.

Cuando se combina la prevalencia con los niveles de mortalidad por edad, se observa una tendencia muy similar. En el Brasil, la diferencia entre la proporción de años de vida con salud según la actitud aumenta con la edad (véase el gráfico 1). De este modo, a medida que las personas envejecen, la actitud parece cobrar cada vez mayor importancia en lo que se refiere a vivir una vida más sana (partiendo de una perspectiva de cohorte ficticia). En México también se aprecia la asociación entre la vida sana y la actitud positiva pero, a medida que las personas envejecen, la actitud parece influir cada vez menos en el nivel de salud de la persona durante sus años restantes de vida (y en la duración de ese período). Por último, conviene señalar que el efecto de la actitud sobre la esperanza de vida sana es mayor 
entre los brasileños. Con este tipo de análisis (en que se utilizan datos transversales) resulta difícil determinar lo que va primero: si la actitud contribuye a mejorar la salud, o si sucede lo inverso. Por ejemplo, tal vez quienes tienen actitudes positivas hagan más ejercicios físicos y tengan relaciones sociales más sólidas que quienes tienen actitudes negativas. Al mismo tiempo, quienes gozan de mejor salud pueden sentirse más felices y más dispuestos a ayudar a otros.

\section{Gráfico 1}

Brasil y México: proporción de los años restantes de vida con buena salud según el nivel de actitud multidimensional, 2006

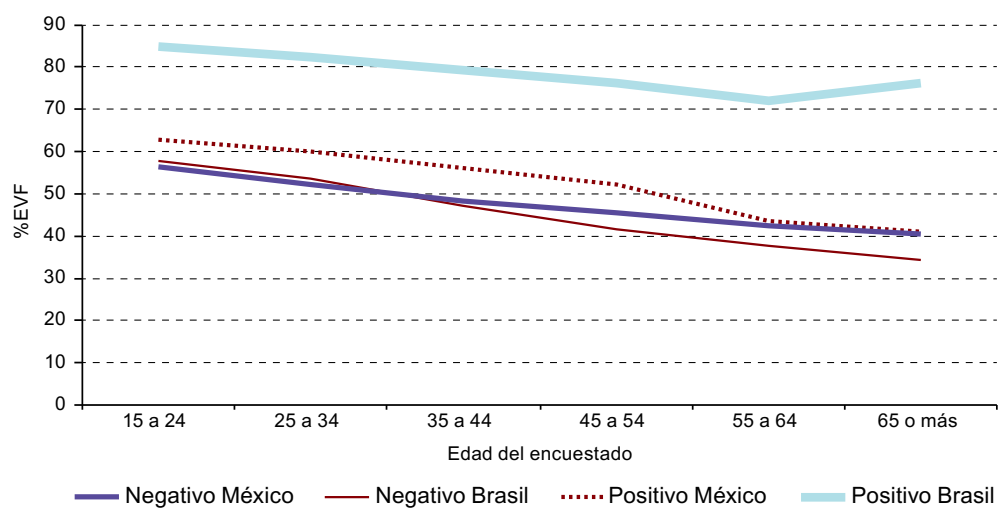

Fuente: Elaboración propia, sobre la base de la Encuesta Mundial sobre Valores (Brasil, 2006; México, 2005); datos del Instituto Brasileño de Geografía y Estadística (IBGE), 2006; y de la Comisión Económica para América Latina y el Caribe (CEPAL), 2005.

Algunas pruebas empíricas relacionadas con la felicidad y el comportamiento individual indican que la causalidad va de la actitud al comportamiento, aunque no esté directamente relacionada con la salud. Por ejemplo, la satisfacción con el trabajo puede ser un factor que prediga el abandono del empleo en el futuro (Clark, 2001). La felicidad también es uno de los predictores de la productividad en el entorno laboral (Oswald, Proto y Sgroi, 2009). Con todo, el vínculo entre la actitud y la salud no es concluyente. Un aspecto que merece atención es el papel de la actitud positiva para frenar el avance del cáncer y extender la vida de las personas a quienes se ha diagnosticado esa enfermedad. Coynes y Trennen (2010), por ejemplo, sugieren que, pese a las evidencias contradictorias en la bibliografía debido a la falta de datos y métodos coherentes, el sentido común parece indicar que "el espíritu de lucha" contribuye a retrasar el avance del cáncer o incluso a curarlo en sus etapas iniciales. A pesar de la orientación teórica limitada acerca del vínculo entre la actitud y la salud, e independientemente de la hipótesis altamente endógena descrita por el análisis transversal aquí expuesto, parece ser que los brasileños se benefician de la actitud positiva en mayor grado que los mexicanos. Es necesario realizar nuevos estudios, sobre todo con datos longitudinales, para validar dicha hipótesis. 


\section{b) La actitud y la felicidad}

A continuación se aborda el tema de la prevalencia de personas felices por grupo de edad y actitud. Como se indica en el cuadro 5 y el gráfico 2, la proporción de personas felices no varía significativamente a lo largo del ciclo vital, con un ligero descenso a medida que las personas envejecen. Resulta interesante señalar que las proporciones por edad entre los brasileños muestran una curva invertida en función de la actitud. Las personas que tienen actitudes positivas indican que son felices en una proporción creciente hasta los 55 años de edad y luego esa proporción disminuye; como reflejo inverso de esa tendencia, ocurre lo contrario entre las personas que tienen actitudes negativas. Si se analizan las personas de 65 años y más, hay un aumento significativo de la proporción notificada de personas felices, sobre todo entre las personas de edad avanzada que tienen actitudes negativas. La misma tendencia se observó anteriormente respecto de las personas sanas según la actitud en el artículo. Es probable que después de transcurridos algunos años de la decisión de jubilarse, las personas sientan sobre sí una menor presión al haber logrado la mayor parte de las metas de su vida. Las personas de edad avanzada disponen entonces de más tiempo para disfrutar de la vida, hacer ejercicios físicos y participar en actividades sociales, lo que promueve una sensación general de felicidad y bienestar (Calvo, Haverstick y Sass, 2008). Así pues, incluso para las personas que tienen actitudes negativas, la nueva fase podría representar una oportunidad de realizar actividades y desarrollar conexiones emocionales que producen felicidad (Clark, 2001; Calvo, Haverstick y Sass, 2008).

Cuadro 5

Brasil (2006) y México (2005): proporción de personas felices por grupo de edad y actitud

\begin{tabular}{|c|c|c|c|c|}
\hline País & Grupo de edad & Actitud positiva & Actitud negativa & Valor $p^{a}$ \\
\hline \multirow{7}{*}{ Brasil } & 15 a 24 & 97,5 & 86,4 & 0,0011 \\
\hline & 25 a 34 & 98,3 & 85,8 & 0,0003 \\
\hline & 35 a 44 & 99,1 & 84,2 & 0,0001 \\
\hline & 45 a 54 & 99,0 & 82,6 & 0,0001 \\
\hline & 55 a 64 & 95,0 & 84,3 & 0,0851 \\
\hline & 65 y más & 95,2 & 91,2 & 0,4417 \\
\hline & Total & 97,9 & 85,2 & 0,0000 \\
\hline \multirow{7}{*}{ México } & 15 a 24 & 97,9 & 92,6 & 0,0375 \\
\hline & 25 a 34 & 96,8 & 93,2 & 0,0762 \\
\hline & 35 a 44 & 95,0 & 84,7 & 0,0066 \\
\hline & 45 a 54 & 92,6 & 90,6 & 0,3102 \\
\hline & 55 a 64 & 92,5 & 78,4 & 0,0183 \\
\hline & 65 y más & 90,9 & 86,5 & 0,2641 \\
\hline & Total & 95,0 & 89,4 & 0,0003 \\
\hline
\end{tabular}

Fuente: Elaboración propia, sobre la base de la Encuesta Mundial sobre Valores (Brasil, 2006; México, 2005).

a Prueba bilateral de proporciones entre grupos. 
Gráfico 2

Brasil (2006) y México (2005): proporción del tiempo vivido con un gran nivel de felicidad en función de la actitud multidimensional

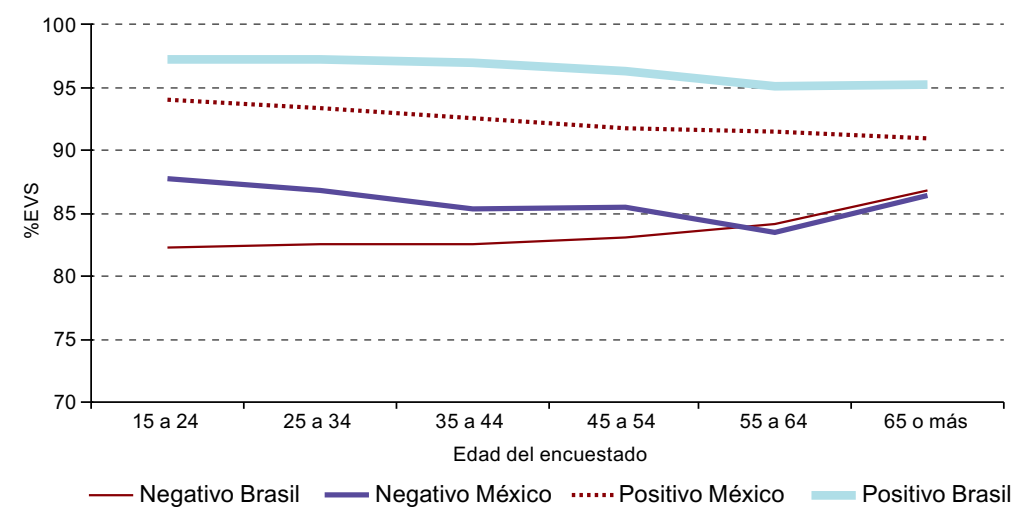

Fuente: Elaboración propia, sobre la base de la Encuesta Mundial sobre Valores (Brasil, 2006; México, 2005); datos del Instituto Brasileño de Geografía y Estadística (IBGE), 2006; y de la Comisión Económica para América Latina y el Caribe (CEPAL), 2005.

El patrón de edad por actitud observado entre los brasileños se distingue del observado entre los mexicanos. La proporción de mexicanos felices que tienen actitudes positivas disminuye ligeramente con la edad. En el caso de quienes tienen actitudes negativas, la tendencia de la edad es menos clara, aunque hay una disminución significativa de la felicidad entre quienes tienen actitudes negativas en torno a la edad de jubilación (del 90,6\% al 78,4\%). Las personas de 65 años y más son más felices que las de 55 a 64 años (del 78,4\% al 86,5\%). También se observó el mismo patrón que entre los brasileños de la misma edad que tienen actitudes negativas. Ese patrón de edad por actitud entre los mexicanos da a entender que la actitud positiva tal vez no sea suficiente para luchar contra la infelicidad a medida que las personas envejecen. Entre quienes tienen actitudes negativas, parece ser que el aumento en torno a la edad de jubilación reflejaría la reducción de la presión, lo que aliviaría el efecto sobre la felicidad, como se indicó anteriormente.

A pesar del pequeño gradiente general de la edad en relación con la felicidad, la diferencia por actitud resulta estadísticamente significativa en todas las edades entre los brasileños. En promedio, el $97,9 \%$ de los brasileños que tienen actitudes positivas también indicaron ser felices, en comparación con solamente el 85,2\% entre los que tienen actitudes negativas. Entre los mexicanos, la diferencia media es ligeramente menor (el 95,0\% entre los que tienen actitud positiva en comparación con el 89,4\% entre los que tienen actitud negativa). Una vez más, la felicidad parece ser más sensible a la actitud entre los brasileños, lo que se reflejará en la proporción de los años restantes de vida con felicidad y salud.

Cuando la prevalencia de la felicidad se combina con los niveles de mortalidad por edad, se observa una tendencia muy similar. Si bien la buena salud parece ser más 
sensible a los efectos de actitud del ciclo vital, la felicidad solamente responde a la actitud, y no a la edad. Quizás esto se puede relacionar con lo observado por Easterlin (1974), quien sugiere que el nivel de felicidad no es un efecto del ciclo vital debido al contrapeso que ejercen distintas aspiraciones según la edad. Al comparar los países, los brasileños parecen beneficiarse más de las actitudes positivas en lo que se refiere a la proporción de los años restantes de vida con felicidad en comparación con los mexicanos de todos los grupos de edad. A pesar de las diferencias entre los países en cuanto a la proporción de tiempo vivido con un gran nivel de felicidad en función de la actitud, la diferencia parece disminuir a medida que las personas alcanzan las edades de jubilación. Tal vez esto sea consecuencia de un efecto de selección, según el cual es probable que las personas que tienen actitudes negativas sean menos dependientes de las redes sociales para expresar felicidad. También podría ser un indicio de que, como consecuencia de la decisión de jubilarse, las personas sienten una disminución de la presión (Calvo, Haverstick y Sass, 2008), que sería particularmente amenazadora y difícil de abordar desde el punto de vista emocional para quienes tienen actitudes negativas (Clark, 2001).

\section{c) Cambio de la EVS y la EVF: ¿prueba de la compresión del bienestar por actitud?}

Seguidamente se aborda el tema de cómo la diferencia observada en la proporción de los años restantes de vida con salud y felicidad puede explicarse por dos efectos complementarios: el efecto de la mortalidad y el de la prevalencia. A fin de estimar dichos efectos, se han calculado la EVS y la EVF en función de la edad respecto de un cúmulo adicional de datos sobre cada país (correspondientes a 1995 en el caso de México y a 1997 en el caso del Brasil). Luego se aplicaron técnicas estándar de descomposición demográfica, presuponiendo hipótesis estacionarias de mortalidad y prevalencia (método de congelación de tasas), con el fin de aportar nuevas perspectivas sobre el bienestar en cada país (Watcher, 2014).

Como se puede apreciar en el cuadro 6, los habitantes de ambos países ahora viven más tiempo y presentan una mayor proporción de años restantes de vida con felicidad y salud. Por ejemplo, en 1995, la esperanza de vida de los mexicanos de 15 años de edad era de 59,5 años, de los cuales solamente 37,9 años correspondían a etapas felices. En 2005, la esperanza de vida de los mexicanos de la misma edad era de 62,5 años, de los cuales 55,7 años correspondían a etapas felices. En consecuencia, no solo vivían más tiempo, sino que tenían una proporción mayor de años restantes de vida con felicidad. La gran diferencia en la $\mathrm{EVF}_{15}$ en el caso de México de 1995 a 2005, por ejemplo, se debe principalmente al marcado aumento de la proporción de personas de 15 a 24 años de edad que indicaron haber sido felices durante ese decenio. Los datos correspondientes a México de la Encuesta Mundial sobre Valores indican que la proporción de mexicanos felices en ese intervalo de edad aumentó del 72,8\% al 93,6\% a lo largo de ese período. Ello explica el gran aumento de la EVF. Si bien el valor de la e $e_{15}$ aumentó en tres años de 1995 a 2005, el valor de la EVF $_{15}$ aumentó en 17,8 años. Ese resultado es coherente con los datos, porque el tiempo vivido sin felicidad disminuyó correspondientemente, de 21,6 años a 6,3 años, lo que representa 
una reducción de 15,3 años. Así pues: 17,8 - 15,3 = 3,4 años, es decir, el aumento exacto de la esperanza de vida para los mexicanos de 15 a 24 años en ese período. El mismo razonamiento se aplica a los otros grupos de edad del cuadro 6 en el caso de los brasileños y los mexicanos en relación con la $\mathrm{EVF}_{\mathrm{a}}$ y la $\mathrm{EVS}_{\mathrm{a}}$.

Cuadro 6

México $(1995,2005)$ y Brasil $(1997,2006)$ : esperanza de vida feliz y esperanza de vida sana (EVF y EVS) por edad ${ }^{a, b}$

\begin{tabular}{|c|c|c|c|c|c|c|c|c|c|c|c|}
\hline \multirow{2}{*}{ País } & \multirow{2}{*}{$\begin{array}{c}\text { Edad } \\
\text { exacta }(x)\end{array}$} & \multicolumn{2}{|c|}{$e_{x}$} & \multicolumn{2}{|c|}{$E V F_{x}$} & \multicolumn{2}{|c|}{$\% \mathrm{EVF}_{\mathrm{x}}$} & \multicolumn{2}{|c|}{$\mathrm{EVS}_{\mathrm{x}}$} & \multicolumn{2}{|c|}{$\%$ EVS $_{\mathrm{x}}$} \\
\hline & & $\mathrm{T} 1$ & T2 & $\mathrm{T} 1$ & T2 & $\mathrm{T} 1$ & T2 & $\mathrm{T} 1$ & T2 & $\mathrm{T} 1$ & T2 \\
\hline \multirow{6}{*}{ Brasil } & 15 & 56,3 & 59,7 & 47,2 & 54,2 & 83,9 & 90,7 & 36,7 & 41,1 & 65,3 & 68,9 \\
\hline & 25 & 47,0 & 50,5 & 39,6 & 45,7 & 84,2 & 90,5 & 29,3 & 32,8 & 62,4 & 65,0 \\
\hline & 35 & 38,0 & 41,5 & 32,3 & 37,6 & 85,0 & 90,6 & 21,9 & 25,0 & 57,6 & 60,3 \\
\hline & 45 & 29,3 & 32,8 & 25,1 & 29,7 & 85,5 & 90,5 & 15,9 & 18,1 & 54,3 & 55,3 \\
\hline & 55 & 21,3 & 24,7 & 18,3 & 22,4 & 86,0 & 90,9 & 10,8 & 12,4 & 50,8 & 50,5 \\
\hline & 65 & 14,1 & 17,5 & 12,3 & 16,2 & 86,8 & 92,6 & 7,8 & 8,7 & 55,3 & 50,0 \\
\hline \multirow{6}{*}{ México } & 15 & 59,5 & 62,5 & 37,9 & 55,7 & 63,7 & 89,2 & 29,5 & 36,4 & 49,6 & 58,2 \\
\hline & 25 & 50,0 & 53,0 & 31,0 & 46,8 & 61,9 & 88,4 & 22,8 & 28,8 & 45,6 & 54,3 \\
\hline & 35 & 40,8 & 43,6 & 24,8 & 37,9 & 60,9 & 87,0 & 17,2 & 21,8 & 42,2 & 50,1 \\
\hline & 45 & 31,8 & 34,5 & 18,6 & 29,5 & 58,5 & 85,5 & 12,1 & 16,0 & 38,1 & 46,4 \\
\hline & 55 & 23,3 & 25,9 & 13,1 & 21,7 & 56,0 & 83,8 & 8,5 & 10,3 & 36,6 & 39,8 \\
\hline & 65 & 15,6 & 18,3 & 7,8 & 15,3 & 50,0 & 83,7 & 5,4 & 7,1 & 34,3 & 38,8 \\
\hline
\end{tabular}

Fuente: Elaboración propia, sobre la base de datos del Instituto Brasileño de Geografía y Estadística (IBGE), "Tábua Completa de Mortalidade" [en línea] http://www.ibge.gov.br/home/estatistica/populacao/tabuadevida/ 2013/defaulttab_pdf.shtm [fecha de consulta: 10 de enero de 2013]; Base de Datos de Mortalidad Humana Latinoamericana (LAHMD), 2013; y Encuesta Mundial sobre Valores, 2013.

a Brasil (T1 = 1997; T2 = 2006); México (T1 = 1995; T2 = 2005).

b Tablas de mortalidad por períodos de vida de México basadas en el método de gradientes para determinar el promedio de años que vivieron los ya fallecidos. Las tablas de mortalidad del Brasil fueron estimadas por el IBGE $(1998,2006)$.

Aunque en promedio los mexicanos de todas las edades viven más tiempo que los brasileños, se prevé que en el caso de los mexicanos sea menor la proporción de años restantes de vida con felicidad. Con todo, la diferencia entre los países en cuanto a la felicidad va disminuyendo con el tiempo. Otra diferencia interesante entre ambos países consiste en que, si bien la proporción de EVF aumenta con la edad entre los brasileños, sucede lo contrario en el caso de los mexicanos. Así como para el caso de la felicidad, los brasileños viven, en promedio, una mayor proporción de tiempo con buena salud que los mexicanos. La diferencia entre los países también se va reduciendo con el paso del tiempo en todas las edades. En cuanto a la felicidad, los resultados dan a entender que existe compresión de la morbilidad, sobre todo en México. Esto no es de sorprender. Según el reciente Informe Mundial sobre la Felicidad de las Naciones Unidas (Helliwell, Layard y Sachs, 2015), los países de América Latina ocupaban los primeros lugares mundiales en lo que se refiere al aumento de la felicidad y la reducción de la desigualdad en esa materia. 
Esas tendencias se apreciaban sobre todo en países que antes presentaban menores niveles de felicidad en el plano regional, como México. El Brasil avanzó en menor grado, porque su punto de partida en el período de referencia correspondía a un alto nivel de felicidad. Esa tendencia es coherente con las conclusiones del presente estudio. Según el informe mencionado, los grandes avances en materia de felicidad entre los países de América Latina y el Caribe responden principalmente a la disminución de la desigualdad de la felicidad y a la percepción del público de que se han reducido los niveles de corrupción.

Si el cambio en la proporción de los años restantes de vida con felicidad y salud se descompone en los efectos de mortalidad y prevalencia, se observa que el aumento de la prevalencia de la felicidad y la buena salud es dominante en todas las edades (véase el cuadro 7). En el caso de México, el aumento de la supervivencia por edad haría disminuir efectivamente los indicadores de bienestar con el tiempo, si la prevalencia de la felicidad y la salud se mantuviera en los niveles observados en 1997. La explicación principal de por qué el aumento de la supervivencia redundaría en una disminución de la EVF y la EVS estaría relacionada con un estado de salud en deterioro y redes sociales más débiles entre las personas de edad avanzada (Huang y otros, 2011). La comparación de la compresión del bienestar partiendo de los indicadores declarados por las propias personas debe utilizarse con cautela, pues la interpretación subjetiva puede variar en las muestras probabilísticas transversales.

\section{Cuadro 7}

México $(1995,2005)$ y Brasil $(1997,2006)$ : descomposición de la proporción de la esperanza de vida sana y la esperanza de vida feliz por edad en efectos de prevalencia y mortalidad $(\Delta \%)^{\text {a }}$

\begin{tabular}{|c|c|c|c|c|c|c|c|}
\hline \multirow[b]{2}{*}{ Indicador } & \multirow{2}{*}{$\begin{array}{c}\text { Edad } \\
\text { exacta }(x)\end{array}$} & \multicolumn{3}{|c|}{ Brasil } & \multicolumn{3}{|c|}{ México } \\
\hline & & Efecto total & $\begin{array}{c}\text { Efecto de } \\
\text { prevalencia }\end{array}$ & $\begin{array}{l}\text { Efecto de } \\
\text { mortalidad }\end{array}$ & Efecto total & $\begin{array}{c}\text { Efecto de } \\
\text { prevalencia }\end{array}$ & $\begin{array}{l}\text { Efecto de } \\
\text { mortalidad }\end{array}$ \\
\hline \multirow{6}{*}{ EVF } & 15 & 6,8 & 6,6 & 0,2 & 25,5 & 26,1 & $-0,6$ \\
\hline & 25 & 6,3 & 6,1 & 0,2 & 26,5 & 27,1 & $-0,6$ \\
\hline & 35 & 5,6 & 5,4 & 0,1 & 26,1 & 26,7 & $-0,6$ \\
\hline & 45 & 5,1 & 5,0 & 0,1 & 27,0 & 27,7 & $-0,6$ \\
\hline & 55 & 4,8 & 4,7 & 0,1 & 27,8 & 28,4 & $-0,6$ \\
\hline & 65 & 5,7 & 5,7 & 0,0 & 33,7 & 33,7 & 0,0 \\
\hline \multirow{6}{*}{ EVS } & 15 & 3,6 & 4,1 & $-0,5$ & 8,7 & 9,3 & $-0,6$ \\
\hline & 25 & 2,7 & 3,1 & $-0,4$ & 8,7 & 9,2 & $-0,5$ \\
\hline & 35 & 2,8 & 3,0 & $-0,2$ & 7,9 & 8,3 & $-0,4$ \\
\hline & 45 & 1,0 & 1,0 & 0,0 & 8,3 & 8,6 & $-0,3$ \\
\hline & 55 & $-0,3$ & 0,3 & $-0,6$ & 3,2 & 3,5 & $-0,2$ \\
\hline & 65 & $-5,3$ & $-5,3$ & 0,0 & 4,5 & 4,5 & 0,0 \\
\hline
\end{tabular}

Fuente: Elaboración propia, sobre la base de datos del Instituto Brasileño de Geografía y Estadística (IBGE), "Tábua Completa de Mortalidade" [en línea] http://www.ibge.gov.br/home/estatistica/populacao/tabuadevida/ 2013/defaulttab_pdf.shtm [fecha de consulta: 10 de enero de 2013]; Base de Datos de Mortalidad Humana Latinoamericana (LAHMD), 2013; y Encuesta Mundial sobre Valores, 2013.

a Descomposición demográfica valiéndose de hipótesis estacionarias de mortalidad (con prevalencia variable) y de prevalencia (con mortalidad variable) entre los años 1 y 2. Brasil, 1997 a 2006. México, 1995 a 2005. 


\section{Conclusiones: la actitud, la salud y la felicidad en el Brasil y México}

En este documento se han estimado la esperanza de vida sana y la esperanza de vida feliz por edad y actitud multidimensional, utilizando los datos de la Encuesta Mundial sobre Valores correspondientes al Brasil y México. Mediante la combinación de distintos métodos los autores indagan si las personas que tienen actitudes positivas viven con más felicidad y mejor salud. Por último, al comparar las tendencias a lo largo del tiempo, se calcula la contribución de la mortalidad y la morbilidad al cambio observado en la proporción de tiempo vivido con felicidad y buena salud, lo que aporta más pruebas empíricas en cuanto a si esos dos países están experimentando contemporáneamente algún grado de compresión de la morbilidad.

La evidencia de la compresión de la morbilidad es de interés particular para los países en desarrollo, porque alivia la presión sobre el sistema de atención sanitaria y entraña un aumento de su bienestar general (Camargos, Machado y Rodrigues, 2008). A medida que países como el Brasil y México experimentan un rápido envejecimiento de la población debido a la rápida disminución contemporánea de la fecundidad y al aumento de la supervivencia, se plantea, desde el punto de vista de la salud pública y la política, la necesidad de determinar si los años de vida adicionales representan un tiempo adicional de calidad. Según las constataciones recientes en el caso del Brasil, los brasileños ahora viven más tiempo, pero hay una mayor proporción de personas que presentan discapacidad funcional (Nepomuceno y Turra, 2015). En vista de que un mayor nivel de educación hace reducir la morbilidad y que los niveles de educación han ido en aumento en el país (Guedes y otros, 2011), es de esperar que en el futuro próximo surjan pruebas de la compresión de la morbilidad entre los brasileños.

Se ha observado el mismo patrón en México en lo que se refiere a la morbilidad. Según Reyes-Beaman y otros (2005), la esperanza de vida activa disminuyó desde 26,9 años a los 6060 años de edad hasta 5,7 años a los 85 años. Además, los adultos mayores de zonas geográficas que presentan una mayor esperanza de vida se mantuvieron activos en una proporción menor de sus años de vida restantes. Estas pruebas empíricas dan a entender que la compresión de la mortalidad no se ha visto acompañada de la compresión de la morbilidad en ambos países. Teniendo en cuenta que la felicidad también es un factor que predice menores niveles de morbilidad, y que se han observado aumentos de la felicidad en los países de América Latina y el Caribe (Helliwell, Layard y Sachs, 2015), hay esperanzas para el futuro.

En el presente estudio se utilizaron datos sobre el estado de salud declarados por las propias personas en el Brasil y México para medir la esperanza de vida sana. A pesar de las críticas acerca del carácter subjetivo de ese tipo de información de salud a nivel demográfico, hay estudios que sugieren que los datos de salud declarados por las propias personas son un factor clave que predice la mortalidad futura (Shadbolt, Barresi y Craft, 
2002; Jylha, 2009). Las mediciones de felicidad en grandes encuestas son intrínsecamente subjetivas pero, en lo que se refiere a los datos de salud declarados por las propias personas, muchos estudios muestran una correlación coherente entre la felicidad, la mortalidad y la salud mental (Ryff y Singer, 2005; Bray y Gunnell, 2006; Easterlin, 2006; Ditella, Macculloch y Oswald, 2003). También hay pruebas de que la felicidad y la salud son tan importantes como los indicadores económicos para expresar eficientemente las funciones de insumoproducto en las sociedades modernas (HPI, 2013; Graham, 2008; Frey y Stutze, 2002; Ditella, Macculloch y Oswald, 2001).

Las estimaciones aquí expuestas sobre la esperanza de vida sana y la esperanza de vida feliz confirman lo que ya habían concluido Salomon y otros (2012), como se indica en el cuadro 2. Si bien en el presente estudio no se realizaron cálculos desglosados por sexo, se aprecian los mismos patrones generales detectados por esos autores: los mexicanos se benefician más que los brasileños en lo que se refiere a años adicionales con felicidad y salud a lo largo del tiempo. Las estimaciones aquí presentadas de felicidad y salud desglosadas por niveles de actitud multidimensional en el Brasil muestran evidencias descriptivas de una asociación positiva entre los índices vitales de actitud positiva y bienestar, lo que confirma las conclusiones estadísticas de Helliwell, Layard y Sachs (2015). Sin embargo, esa asociación no es lineal a lo largo del ciclo vital de una persona en lo que respecta a la salud: la diferencia en la proporción de años restantes de vida con buena salud aumenta con la edad al comparar a personas que tienen actitudes positivas y negativas hacia las tres dimensiones de la vida. Ocurre lo contrario en el caso de México. Una constatación curiosa es el punto de inflexión en la curva de la proporción de años que se vivirán con buena salud entre los brasileños que tienen actitudes positivas a los 60 años de edad. Cabe preguntarse si esto es reflejo de la reacción positiva de esas personas hacia acontecimientos del ciclo vital, tales como la jubilación (Calvo, Haverstick y Sass, 2008). Es decir, las personas que presentan altos niveles de optimismo y actitudes positivas ven la jubilación como una nueva oportunidad de cumplir aspiraciones personales que no podían lograr en etapas anteriores del ciclo vital debido a limitaciones de tiempo y de recursos (relacionadas, por ejemplo, con las largas horas de trabajo y la crianza de los hijos) (Clark, 2001). Esa tendencia es aun más pronunciada entre los mexicanos, sobre todo los que tienen actitudes negativas. En el caso de los mexicanos, cabe preguntarse si la jubilación refleja una disminución de la presión relacionada con las principales aspiraciones del ciclo vital, que pueden representar una mayor carga emocional para las personas que tienen actitudes negativas hacia la vida (Cacciopo y Berntson, 1994).

En vista de que solamente se han utilizado datos transversales, resulta difícil desligar la causalidad, pero podría afirmarse que, si bien hay un efecto acumulativo de la actitud sobre la salud a lo largo del ciclo vital entre los brasileños, la selección positiva parece dominar la cifra correspondiente a los mexicanos. En lo que respecta a la felicidad, las conclusiones de este estudio confirman lo que se ha documentado en la bibliografía internacional (Easterlin, 1974). Se aprecia una asociación plana entre la actitud positiva y la esperanza de vida feliz a lo largo del ciclo vital de cada persona en ambos países. No 
obstante, la proporción de años restantes de vida con felicidad es siempre mayor entre los brasileños, independientemente de la respuesta relacionada con la actitud. Una vez más, debido a la endogeneidad, resulta arriesgado extraer de los resultados inferencias de causalidad, pero al parecer la actitud positiva general de los brasileños influye más en su calidad de vida, mientras que entre los mexicanos la selectividad parece ser un factor latente (lo que explicaría por qué, a medida que envejecen, se reduce la diferencia en lo que respecta a la salud).

Una limitación del presente estudio se refiere a la falta de estimaciones desglosadas según el género. Esto respondió a la decisión de evitar los perfiles inestables desglosados por edad que se formarían debido a los problemas inherentes a la utilización de muestras pequeñas. Una vez que se realizaron los análisis en función de la esperanza de vida sana y la esperanza de vida feliz en comparación con la actitud, una desagregación adicional podría hacer que fuera menor el número de observaciones necesarias para realizar un análisis preciso. Los autores comprenden que ese tipo de análisis es muy importante y debe abordarse en estudios futuros, aunque en algunos estudios anteriores se ha determinado que las diferencias de género en las actitudes hacia la vida no son muy grandes. Diener y otros (1999), por ejemplo, concluyeron que, si bien las mujeres presentan un mayor grado de depresión que los hombres, también tienen más emociones positivas, lo que da a entender que las mujeres no van a la zaga de los hombres en lo que a felicidad se refiere.

En definitiva, los resultados del presente estudio indican que las personas que tienen actitudes positivas gozan de mejor salud y son más felices, de modo que experimentan más años de vida sin morbilidad. Incluso si los datos y los conocimientos actuales en la materia resultan paradójicos desde el punto de vista de las causalidades respecto de la relación entre la felicidad, la salud, los ingresos, el comportamiento en el mercado de trabajo y otras cuestiones (Carbonell, 2013), estas conclusiones dan a entender que las políticas que promuevan los componentes de la actitud positiva pueden crear un entorno propicio para que las personas se sientan motivadas a responder positivamente ante situaciones estresantes. Por último, en tales políticas públicas encaminadas a fomentar la afirmación positiva y la resiliencia mental se deberían tener en cuenta las diferencias entre los géneros, sobre todo porque incluyen la promoción de una vida más larga y sana para las personas que reaccionan de forma negativa ante factores externos. También convendría realizar estudios de cohortes a fin de desligar las cuestiones relacionadas con la causalidad necesarias para desarrollar la teoría de la actitud y el bienestar a lo largo del ciclo vital. 


\section{Bibliografía}

Ajzen, I. y B.L. Driver (1991), "Prediction of leisure participation from behavioral, normative, and control beliefs: An application of the theory of planned behavior", Leisure Sciences, vol. $13, \mathrm{~N}^{\circ} 3$.

Ajzen, I. y M. Fishbein (2000), "Attitudes and the attitude-behavior relation: reasoned and automatic processes", European Review of Social Psychology, vol. 11, № 1 .

Albarracin, D. y otros (2001), "Theories of reasoned action and planned behavior as models of condom use: a meta-analysis", Psychological Bulletin, vol. 127, $\mathrm{N}^{\circ} 1$.

Anker, A.E., T. H. Feeley y H. Kim (2010), "Examining the attitude-behavior relationship in prosocial donation domains", Journal of Applied Social Psychology, vol. 40, № 6.

Berntson, G. G. y J.T. Cacioppo (2008), "The neuroevolution of motivation". Handbook of Motivation Science, James Y. Shah y Wendi L. Gardner (eds.), Guilford Press.

Blanchflower, D. G. y A. J. Oswald (2007), "The rising well-being of the young", Youth Employment and Joblessness in Advanced Countries, D. G. Blanchflower y R. B. Freeman (eds.), Chicago, University of Chicago Press.

Bradburn, N. M. (1969), The Structure of Psychological Well-being, Chicago, Aldine.

Bray, I. y D. Gunnell (2006), "Suicide rates, life satisfaction and happiness as markers for population mental health", Social Psychiatry and Psychiatric Epidemiology, vol. 41, $\mathrm{N}^{\circ} 5$.

Burleson, M. H. y otros (2003), "Neuroendocrine and cardiovascular reactivity to stress in mid-aged and older women: Long-term temporal consistency of individual differences", Psychophysiology, vol. $40, \mathrm{~N}^{\circ} 3$.

Cacioppo, J. T. y G. G. Berntson (1994), "Relationship between attitudes and evaluative space: A critical review, with emphasis on the separability of positive and negative substrates", Psychological Bulletin, vol. $115, \mathrm{~N}^{\circ} 3$.

Cacioppo, J. T. y L.C. Hawkley (2003), "Social isolation and health, with an emphasis on underlying mechanisms", Perspectives in Biology and Medicine, vol. 46, $\mathrm{N}^{\circ} 3$.

Cacioppo, J. T., W.L. Gardner y G.G. Berntson (1997), "Beyond bipolar conceptualizations and measures: The case of attitudes and evaluative space", Personality and Social Psychology Review, vol. $1, \mathrm{~N}^{\circ} 1$.

Cacioppo, J. T., L.C. Hawkley y G.G. Berntson (2003), "The anatomy of loneliness", Current Directions in Psychological Science, vol. 12, $\mathrm{N}^{\circ} 3$.

Calvo, E., K. Haverstick y S.A. Sass (2008), "Gradual retirement, sense of control, and retirees happiness", Research on Aging, vol. 31, $\mathrm{N}^{\circ} 1$.

Camargos M. C. S., C. J. Machado y R.N. Rodrigues (2008), "Sex differences in healthy life expectancy from self-perceived assessments of health in the City of São Paulo, Brazil", Ageing and Society, vol. $28, \mathrm{~N}^{\circ} 1$.

Cantril, H. (1965), The Pattern of Human Concerns, New Brunswick, Rutgers University Press.

Carbonnel, A.F.I. (2013), "Happiness economics", Journal of the Spanish Economic Association, serie S., vol. 4.

Clark, A. E. (2001), "What really matters in a job? Hedonic measurement using quit data", Labor Economics, vol. 8.

Clark, A. E. y A. J. Oswald (1994), "Unhappiness and unemployment", The Economic Journal, vol. 104, $\mathrm{N}^{\circ} 424$.

Corbi, R. B. y N. A. Menezes-Filho (2006), "Os determinantes empíricos da felicidade no Brasil", Revista de Economía Política, vol. 26, $\mathrm{N}^{\circ} 4$.

Coynes, J.C. y H. Trennen (2010), "Positive psychology in cancer care: bad science, exaggerated claims, and unproven medicine", Annals of Behavioral Medicine, vol. 39. 
Danner, D. D., D.A. Snowdon y W.V. Friesen (2001), "Positive emotions in early life and longevity: findings from the nun study", Journal of Personality and Social Psychology, vol. 80, $\mathrm{N}^{\circ} 5$.

Diener, E. y otros (1999), "Subjective well-being: three decades of progress", Psychological Bulletin, vol. $125, \mathrm{~N}^{\circ} 2$.

Ditella, R., R. J. Macculloch y A. J. Oswald (2001), "Preferences over inflation and unemployment: evidence from surveys of happiness", American Economic Review, vol. 91, $\mathrm{N}^{\circ} 1$.

_(2003), "The macroeconomics of happiness", Review of Economics and Statistics, vol. 85, № 4 .

Dush, C. M. K., M. G. Taylor y R. A. Kroeger (2008), "Marital happiness and psychological well-being across the life course", Family Relations, vol. $57, \mathrm{~N}^{\circ} 2$.

Eagly, A. H. y S. Chaiken (1993), The Psychology of Attitudes, Harcourt Brace Jovanovich College Publishers.

Easterlin, R. A. (1974), "Does economic growth improve the human lot? Some empirical evidence", Nations and Households in Economic Growth: Essays in honour of Moses Abramowitz, P. A. David y M. W. Reder (eds.), Nueva York, Academic Press.

_ (2001), "Income and happiness: towards a unified theory", The Economic Journal, vol. 111, № 473. (2006), "Life cycle happiness and its sources: intersections of psychology, economics and demography", Journal of Economic Psychology, vol. 27, № 4 .

_ (2013), "Happiness, growth and public policy", IZA Discussion Paper, $\mathrm{N}^{\circ} 7234$.

Fazio, A. F. (1977), A Concurrent Validation Study of the NCHS' General Well-being Schedule, Hyattssville, US Government Printing Office, DHEW Publication.

Fishbein, M. y M. J. Manfredo (1992), "A theory of behavior change", Influencing Human Behavior.

Frey, B. S. y A. Stutze (2000), "Happiness: economy and institutions", The Economic Journal, vol. 110, $\mathrm{N}^{\circ} 446$.

_-(2002), Happiness and Economics, Princeton, Princeton Press.

Gerlach, K. y G. Stephan (1996), "A paper on unhappiness and unemployment in Germany", Economics Letters, vol. 52, $\mathrm{N}^{\circ} 3$.

Graham, C. (2005), "The economics of happiness", The New Palgrave Dictionary of Economics, S. Durlauf y L. Blume (eds.), The Brookings Institution.

_ (2008), "Measuring quality of life in Latin America: what happiness research can (and cannot) contribute", Research Department Working Paper, N 652, Washington, D.C., Banco Interamericano de Desarrollo (BID).

Graham, C. y S. Pettinato (2002), Happiness and Hardship: Opportunity and insecurity in new market economies, Washington, D.C., The Brookings Institution.

Greenwald, A. G. y M. R. Banaji (1995), "Implicit social cognition: attitudes, self-esteem, and stereotypes", Psychological Review, vol. 102, $\mathrm{N}^{\circ} 1$.

Guedes, G. R. y otros (2012), "Poverty and inequality in the rural Brazilian Amazon: a multidimensional approach", Human Ecology, vol. 40, $\mathrm{N}^{\circ} 1$.

(2011), "Educational and sex diferences in the funcional disability life expectancy of the elderly: Brazil 1998 and 2003", Caderno Saúde Coletiva, vol. 19, № 2.

Helliwell, J. F., R, Layard y J. Sachs (eds.) (2015), The 2015 World Happiness Report, Nueva York, Sustainable Development Solutions Network (SDSN).

HPI (Índice del Planteta Feliz) (2013), Happy Planet Index: 2012 Report. A global index of sustainable wellbeing [en línea] www.healthyplanetindex.org [fecha de consulta: 13 de agosto de 2013].

Huang, C.Q. y otros (2011), "Cognitive function and risk for depression and old age: a meta-analysis of published literature", International Psychogeriatric, vol. 23.

IBGE (Instituto Brasileño de Geografíay Estadística) (2013), "Tábua Completa de Mortalidade”[enlínea] http://www.ibge.gov.br/home/estatistica/populacao/tabuadevida/2013/defaulttab_pdf.shtm [fecha de consulta: 10 de enero de 2013]. 
Idler, E. L., S.V. Hudson y H. Leventhal (1999), "The meanings of self-ratings of health a qualitative and quantitative approach", Research on Aging, vol. 21, $\mathrm{N}^{\circ} 3$.

Joseph, S. y C. A. Lewis (1998), "The depression-happiness scale: reliability and validity of a bipolar self-report scale", Journal of Clinical Psychology, vol. 54, $\mathrm{N}^{\circ} 4$.

Jylha, M. (2009), "What is self-rated health and why does it predict mortality? Towards a unified conceptual model", Social Science and Medicine, vol. 69.

Kamman, R. y R. Flett (1983), "Affectometer 2: a scale to measure current level of general happiness", Australian of Journal of Psychology, vol. $35, \mathrm{~N}^{\circ} 2$.

Kass, J. D. y otros (1991), "Health outcomes and a new index of spiritual experience", Journal for the Scientific Study of Religion, vol. $30, \mathrm{~N}^{\circ} 2$.

Kwan, C. M. L. y otros (2003), "The role of self-enhancing evaluations in a successful life transition", Psychology and Aging, vol. 18, $\mathrm{N}^{\circ} 1$.

LAHMD (Base de Datos de Mortalidad Humana Latinoamericana) (2013), "MEX, Deaths by age and sex / MEX, Population by age, sex and region", Piedad Urdinola y Bernardo L. Queiroz [en línea] www.lamortalidad.org [Fecha de consulta: 13 de agosto de 2013].

Land, K. C. (2001), "Introduction to the special issue on finite mixture models", Sociological Methods and Research, vol. 29.

Larsen, J. T., C.J. Norris y J.T. Cacioppo (2003), "Effects of positive and negative affect on electromyographic activity over zygomaticus major and corrugator supercilii", Psychophysiology, vol. $40, \mathrm{~N}^{\circ} 5$.

Larson, N. I., M.T. Story y M.C. Nelson (2009), “Neighborhood environments: disparities in access to healthy foods in the US", American Journal of Preventive Medicine, vol. 36, $\mathrm{N}^{\circ} 1$.

Manton, K. G., H. D. Tolley y M. A. Woodbury (1994), Statistical Applications Using Fuzzy Sets, John Wiley \& Sons.

Marcelli, E. A. y R.A. Easterlin (2007), "The X-relation: Life cycle happiness of American women and men", University of Southern California, inédito.

Margolis, R. y M. Myrskyla (2011), "A global perspective on happiness and fertility", Population and Development Review, vol. $37, \mathrm{~N}^{\circ} 1$.

Nepomuceno, M. R. y C. M. Turra (2015), "Tendências da expectativa de vida saudável de idosas brasileiras, 1998-2008", Revista Saúde Pública, vol. 49, N 1.

Norris, C. J. y otros (2010), "The current status of research on the structure of evaluative space", Biological Psychology, vol. 84, $\mathrm{N}^{\circ} 3$.

Ostir, G. V. y otros (2001), "The association between emotional well-being and the incidence of stroke in older adults", Psychosomatic Medicine, vol. 63, $\mathrm{N}^{\circ} 2$.

Oswald, A.J., E. Proto y D. Sgroi (2009), "Happiness and productivity", IZA Discussion Paper, $\mathrm{N}^{\circ} 4645$.

Plagnol, A. C. y R. A. Easterlin (2008), "Aspirations, attainments, and satisfaction: life cycle differences between American women and men", Journal of Happiness Studies, vol. 9, № 4 .

Posadzki, P. y otros (2010), "A mixed-method approach to sense of coherence, health behaviors, selfefficacy and optimism: Towards the operationalization of positive health attitudes", Scandinavian Journal of Psychology, vol. 51, $\mathrm{N}^{\circ} 3$.

Pressman, S. D. y S. Cohen (2005), "Does positive affect influence Health?", Psychological Bulletin, vol. $131, \mathrm{~N}^{\circ} 6$.

Preston, S. H., P. Heuvelline y M. Guillot (2001), Demography:measuring and modeling population process, Malden: Blackwell Publishers.

Reyes-Beaman, S. y otros (2005), "Active life expectancy of older people in Mexico", Disability and Rehabilitation, vol. 27, $\mathrm{N}^{\circ} 5$. 
Ryff, C.D. y B. Singer (2005), "Social environments and the genetics of aging: Advancing knowledge of protective health mechanisms", Journal of Gerontology, vol. 60B, número especial.

Salomon, J. A. y otros (2012), "Healthy life expectancy for 187 countries, 1990-2010: a systematic analysis for the Global Burden Disease Study 2010", The Lancet, vol. 380.

Shadbolt, B., J. Barresi y P. Craft (2002), "Self-rated health as a predictor of survival among patients with advanced cancer", Journal of Clinical Oncology, vol. 20, $\mathrm{N}^{\circ} 10$.

Sullivan, D. F. (1971), "A single index of mortality and morbidity", HSMHA Health Rep, vol. 86.

Urry, H. L. y otros (2004), "Making a life worth living neural correlates of well-being", Psychological Science, vol. $15, \mathrm{~N}^{\circ} 6$.

Veenhoven, R. (2013), Happiness in Nations, World Database of Happiness, Erasmus University Rotterdam, The Netherlands [en línea] http://worlddatabaseofhappiness.eur.nl/hap_nat/nat_ fp.php?mode=1 [fecha de consulta: 13 de agosto de 2013].

Vermunt, J. K. (2003), "Multilevel Latent Class Models", Sociological Methodology, vol. 33, № 1.

Vermunt, J. K. y J. Magidson (2007), "Latent class analysis with sampling weights: A maximum likelihood approach", Sociological Methods and Research, vol. 36, $\mathrm{N}^{\circ} 1$.

Wachter, Kenneth W. (2014), Essential Demographic Methods, Harvard University Press.

Watson, D., L. A. Clark y A. Tellegen (1988), "Development and validation of brief measures of positive and negative affect: the PANAS scales", Journal of Personality and Social Psychology, vol. 54, № 6 .

Winkelmann, L. y R. Winkelmann (1998), "Why are unemployed people so unhappy? Evidence from Panel Data", Economica, vol. 65, No 257.

Woodbury, M. A., J. Clive y A. Garson (1978), "Mathematical typology: a grade of membership technique for obtaining disease definition", Computers and Biomedical Research, vol. 11, $\mathrm{N}^{\circ} 3$.

World Values Survey (2013), "WVS Database. Microdata for Brazil $(1995,2005)$ and Mexico (1997, 2006)" [en línea] http://www.worldvaluessurvey.org/WVSContents.jsp [fecha de consulta: 10 de enero de 2013]. 


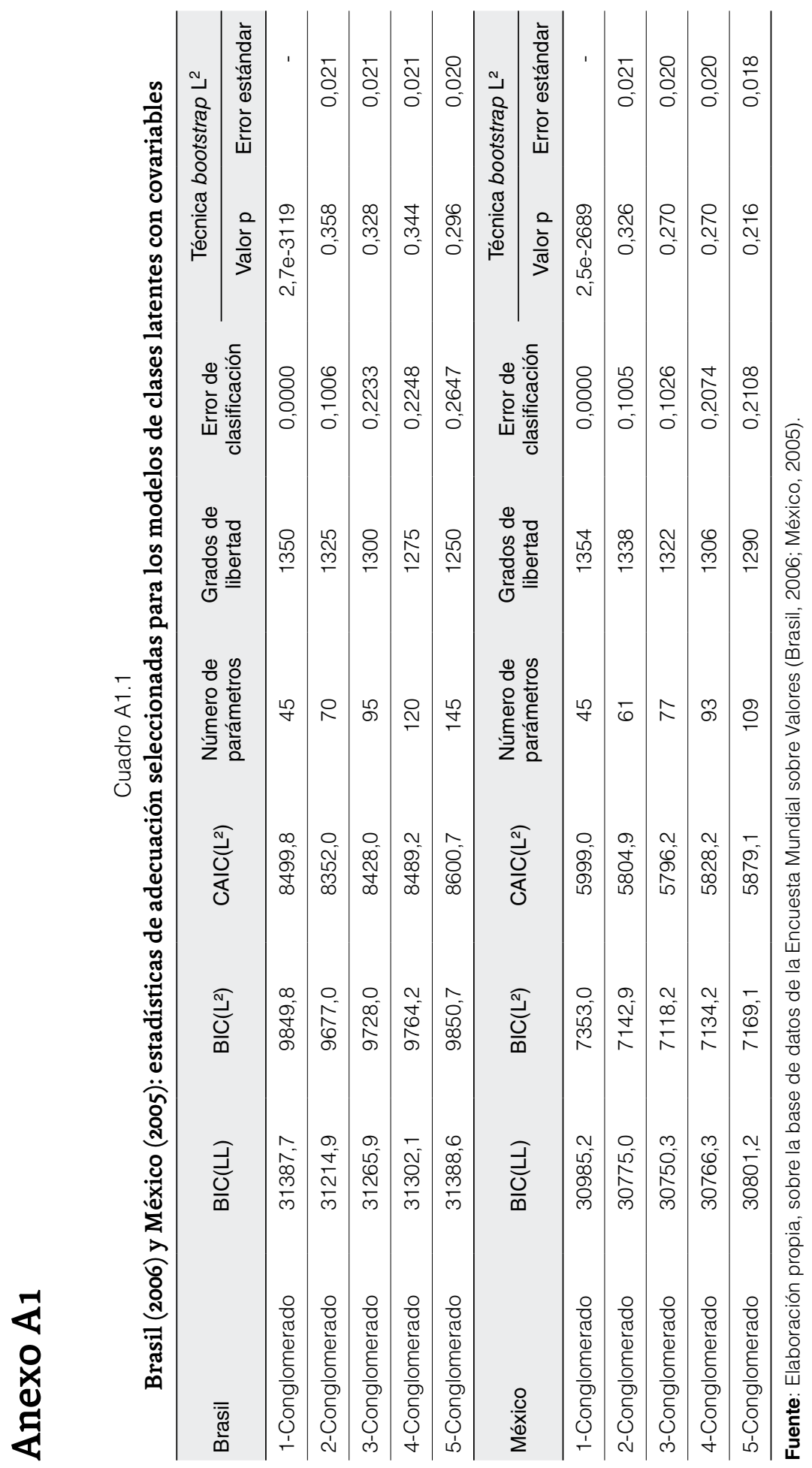





\title{
El yo y el otro: alteridad próxima en la declaración del color y la raza en preguntas abiertas

\author{
El caso de la Encuesta Mensual de Empleo del \\ Instituto Brasileño de Geografía y Estadística
}

\author{
Kaizô Iwakami Beltrão' \\ Moema De Poli Teixeira ${ }^{2}$
}

Recibido: 19/05/2015

Aceptado: 04/08/2015

Resumen

\begin{abstract}
Uno de los problemas de las encuestas de hogares consiste en que generalmente un único informante responde por todos los demás residentes. El objetivo de este artículo es comparar las respuestas a las preguntas abiertas y cerradas sobre color o raza según el informante, sobre la base del Suplemento de color y origen de la Encuesta Mensual de Empleo (PME) del Instituto Brasileño de Geografía y Estadística (IBGE).

Las categorías abiertas con matices adjetivos ("clara", "morena clara", "morena oscura" y "oscura") se utilizaron más con respecto a los otros que a sí mismo. También quedó en evidencia el uso regionalizado de los términos de clasificación del color y la raza.
\end{abstract}

\footnotetext{
Kaizô Iwakami Beltrão, Doctor en Estadística por la Universidad de Princeton, Profesor Titular de la Escuela Brasileña de Administración Pública y de Empresas (EBAPE) de la Fundación Getulio Vargas (FGV). Enseña e investiga en las áreas de demografía, políticas públicas (educación y previsión social) y color-raza. E-mail: kaizo. beltrao@fgv.br.

2 Moema De Poli Teixeira, Doctora en Antropología por el Museo Nacional (Universidad Federal de Río de Janeiro (UFRJ)), Investigadora Titular de la Escuela Nacional de Ciencias Estadísticas (ENCE) del IBGE. Enseña e investiga en las áreas de sociología y antropología de las relaciones interétnicas, políticas públicas e indicadores sociales. E-mail: moema.teixeira@ibge.gov.br.
} 
Los mayores niveles de coincidencia entre las respuestas espontáneas y las categorías cerradas del IBGE (90\%) se registraron con respecto a las categorías "blanca" (en todas las regiones metropolitanas) y "amarilla" (en São Paulo). Las demás combinaciones demostraron que las categorías cerradas del IBGE son, sin lugar a dudas, las más elegidas como opción abierta, con excepción de la categoría general "morena". Al tratarse de un término no descriptivo no puede utilizarse como alternativa cerrada.

Palabras clave: clasificación de color-raza; preguntas abiertas; preguntas cerradas; autoclasificación; hetero-clasificación.

\section{Abstract}

One of the problems found in household surveys is that a single informer answers the questionnaire for all members. This article compares answers to open and closed questions on colour/race contained in the supplement on colour and race in the Monthly Employment Survey conducted by the Brazilian Geographical and Statistical Institute (IBGE).

Open categories with adjectival content (e.g. "Clara"; "Morena Clara"; "Morena Escura" and "Escura") were used to describe others more often than self. A regional pattern in the use of the terms for colour/race also emerged from the analysis.

The highest levels of coincidence (90\%) between the spontaneous answers and the closed IBGE categories occurred for the "white" (branca) category in all metropolitan areas and "Asian" (Amarela) in São Paulo. All the other combinations showed that the categories proposed by IBGE are more often chosen, with the exception of the general category "Morena" (brunette). Since this term is non-descriptive and not a viable answer for analysis, it cannot be used for a closed question.

Keywords: ethnoracial classification; open questions; closed questions; self-classification; hetero-classification.

\section{Résumé}

Un des problèmes présentés par les enquêtes sur les ménages est que généralement un seul informateur répond pour tous les autres membres du ménage. L'objectif de cet article est de comparer les réponses apportées aux questions ouvertes et fermées sur la couleur ou la race, selon l'informateur, sur la base du Supplément sur la couleur et l'origine de l'Enquête mensuelle sur l'emploi (PME) de l'institut brésilien de géographie et de statistiques (IBGE).

Les catégories ouvertes nuancées par des adjectifs ( claire », "brun clair », " brun foncé " et "foncée ») ont été utilisées plus fréquemment par rapport aux autres qu'à soi-même. Il est également apparu que les termes de classification de la couleur et de la race ont différentes utilisations par région.

Les plus fortes coïncidences entre les réponses spontanées et les catégories fermées de I'IBGE (90\%) ont été enregistrées pour les catégories "blanche » (dans toute la région métropolitaine) et « jaune » » (à Sao Paulo). Les autres combinaisons ont démontré que les catégories fermées de l'IBGE sont, de toute évidence, les plus souvent choisies comme options ouvertes, à l'exception de la catégorie générale « brune ». S'agissant d'un terme non descriptif, il ne peut être utilisé comme options fermées.

Mots clés: classification de la couleur-race; questions ouvertes; questions fermées; auto classification; hétéro classification. 


\section{Introducción}

La raza y la etnia mantienen una fuerte correlación con la exclusión social en casi todos los países del mundo y en particular en América Latina y el Caribe, en función del proceso de colonización europea que subyugó a la población nativa y más tarde organizó la migración forzada de pueblos africanos. Debido a la hegemonía de la cultura europea local, los grupos dominados, no blancos, han estado siempre sobrerrepresentados en los estratos más pobres de la sociedad. Como bien señala Telles (2007), los datos disponibles sugieren que las personas de ascendencia africana e indígena tienen más probabilidades que sus pares de origen europeo de vivir en la pobreza, ser analfabetos, morir más jóvenes, vivir en hogares precarios y sufrir abuso policial. En consecuencia, las políticas públicas para promover la inclusión social deben tener en cuenta esta dimensión.

Por otra parte, las políticas públicas suponen actividades de planificación, implementación y control, para las cuales no se puede prescindir de estadísticas fiables que incluyan ese aspecto. Si bien en la guía de las Naciones Unidas para los censos de población (Naciones Unidas, 2010) se subraya esta necesidad, debido a la gran variedad de la composición étnico-cultural de los países, no se hace ninguna recomendación explícita sobre la manera de obtener esa información. En el Programa de Acción de Durban de la Conferencia Mundial contra el Racismo, la Discriminación Racial, la Xenofobia y las Formas Conexas de Intolerancia (Naciones Unidas, 2001) se insta a los Estados a que recojan, recopilen, analicen, difundan y publiquen datos estadísticos fidedignos que permitan evaluar la situación de los grupos discriminados. La experiencia de países históricamente similares constituye un aporte natural para ese tipo de encuestas. En ese sentido, organismos multilaterales como el Banco Interamericano de Desarrollo (BID), el Banco Mundial y el Centro Latinoamericano y Caribeño de Demografía - División de Población de la CEPAL han organizado seminarios y talleres, como "Todos Contamos" (Cartagena, Colombia, 2000 y Lima, Perú, 2002) y “Censos 2010 y la inclusión del enfoque étnico: hacia una construcción participativa con pueblos indígenas y afrodescendientes de América Latina" (Santiago, Chile, 2008), para promover el intercambio de experiencias en América Latina y el Caribe (CEPAL, 2008). Del Popolo y Schkolnik (2013) señalan el aumento de la visibilidad estadística de los pueblos indígenas y los afrodescendientes a partir de los cambios implementados en los cuestionarios de la ronda de censos de 2000 en América Latina. De acuerdo con Loveman (2014), el Informe sobre el Desarrollo Mundial publicado por el Banco Internacional de Reconstrucción y Fomento (BIRF), en el que se ignoraba casi por completo la importancia de la raza-etnia como condicionante de la pobreza, habría provocado el clamor en la comunidad científica, que a su vez promovió los programas para tomar conciencia de esta dimensión en las estadísticas oficiales. En ese contexto, en el presente trabajo se relata una experiencia de investigación de este aspecto en el Brasil mediante una pregunta de respuesta abierta y la distinción del encuestado. Si bien el período de referencia no es reciente, la información nunca se analizó desde este punto de vista y no existe en el Brasil otra investigación con la misma amplitud geográfica y el mismo objeto. 
Rallu, Piché y Simon (2001) destacan adecuadamente la importancia de estas encuestas. Los cuatro tipos de enfoque posibles para la enumeración étnica considerados por los autores son: la enumeración para luchar contra la discriminación (compterpour justifier l'action positive), la enumeración para el control político (compter pour dominer), la no enumeración en nombre de la integración nacional (ne pas compter au nom de lintégration nationale) y el discurso de la hibridación nacional (compter ou ne pas compter au nom de la mixité).

Uno de los problemas de las encuestas de hogares consiste en que por lo general un único informante responde al cuestionario. Como revelan las investigaciones de campo en el área de la construcción de las identidades étnico-raciales, esta situación es particularmente delicada en el caso de la variable color o raza, sobre todo con el aumento de la incidencia de los matrimonios interraciales. Los diversos estudios realizados sobre el tema demuestran en forma unánime la manera en que puede diferir la forma en que las personas se perciben y son percibidas en términos raciales, es decir que el proceso de clasificación racial es relacional (Teixeira Pacheco, 1987). Véase este ejemplo de Sheriff (2002, pág. 221):

\begin{abstract}
Durante mi estudio en la comunidad, también aprendí que algunas personas distinguían entre lo que parecían percibir como el "color verdadero" de la persona y las palabras convencionalmente usadas para hablar del color de una determinada persona. Cuando le pregunté a una muchacha cuál era su color, ella se rió y dijo: "La gente me dice blanca pero en realidad no lo soy. Yo soy, no sé, ¿morena?". En forma análoga, un hombre me dijo que su mujer era blanca, pero luego se rió y agregó: "Ella no lo es, pero decimos así". Una mujer de unos 40 años me dijo: "Yo soy negra. La gente me dice morena, pero yo creo que en realidad soy negra".
\end{abstract}

En principio, se pueden distinguir por lo menos cinco niveles de clasificación: i) la visión del individuo sobre sí mismo; ii) la visión del individuo sobre alguien cercano (por ejemplo un familiar); iii) la visión del individuo sobre un desconocido, basada exclusivamente en la apariencia de este último; iv) la visión de un individuo sobre la manera en que la sociedad en general lo percibe; y v) la visión que un individuo desea que tengan de él en un determinado contexto.

Esto puede ejemplificarse en el siguiente discurso transcrito por Teixeira Pacheco (1987):

Yo no soy racista. Tengo una hija clara, su padre es claro, yo soy oscura. Creo que mi color nunca estorbara (sic.) en nada. Creo que nunca lidié con personas que tuviera (sic.) racismo porque yo, con mi color, de la manera que soy, voy a cualquier lugar, me ambiento. No tengo y voy a enseñar a mi hija a no tener racismo también porque su madre es negra.

En este relato, la referencia al color o la raza de los familiares cercanos (hija y marido) es siempre relativa y con términos adjetivos (claro y oscuro) que atenúan la visión dicotómica entre blanco y negro. Al referirse a sí misma en dos momentos diferentes, la entrevistada utiliza distintas categorías de clasificación. Cuando habla en primera persona es oscura, dando continuidad al discurso sobre los familiares cercanos, pero cuando habla en tercera persona se vuelve negra. En el primer caso la categoría expresa la forma en que ella se ve y en el segundo caso la forma en que ella cree que es percibida socialmente. Es 
probable que los niveles (i) y (ii), objeto de esta investigación, estén más próximos entre sí en términos de categorías de atribución que los demás. Sin embargo, se considera que su análisis contribuirá en gran medida a evaluar las consecuencias de que una sola persona brinde la información sobre todas las personas del hogar.

En ese sentido, en el presente trabajo se analiza la variación entre las respuestas a la pregunta abierta y a la pregunta precodificada sobre el color a partir de la distinción del informante, que puede realizarse mediante el Suplemento de color y origen de la Encuesta Mensual de Empleo de julio de 1998. De las tres encuestas en las que se formulan preguntas abiertas y cerradas sobre color o raza (Encuesta Nacional de Hogares (PNAD 76), Encuesta Mensual de Empleo (PME 98) y Encuesta de las Características Étnico-Raciales de la Población (PCERP de 2008)), esta es la única que además de identificar al informante permite que la llamada "autoclasificación" sea realizada por otro. Cabe recordar que la PME es una encuesta de hogares realizada mensualmente por el IBGE en seis regiones metropolitanas. El carácter de muestra circular no afecta los datos ni el análisis pues el suplemento se realizó solamente en mes de julio de 1998 (IBGE, 2008, pág. 29), cuando se encuestó a 91.390 individuos en 30.161 hogares. En este análisis no se utilizan los factores de expansión de la muestra.

Cerca del 30,7\% de los datos corresponden al propio informante. Teniendo en cuenta que las familias eran en su mayoría razonablemente homogéneas con respecto al color o raza (es decir que los matrimonios interraciales no son la norma) y que las familias con individuos blancos y amarillos por lo general son menos numerosas, se esperaba encontrar una mayor proporción de autodeclaración en esos grupos. Los datos confirmaron esa previsión pues se registraron respectivamente el 31,4\% y el 33,7\% para esas dos categorías, en comparación con menos del $30 \%$ en el caso de negros y mulatos.

Para contribuir al debate sobre las categorías de color o raza que habrían de emplearse en el cuestionario del censo de 2000 se elaboró un suplemento en la PME con preguntas de respuestas abiertas y cerradas sobre el tema (véase el Anexo I de Teixeira Pacheco y Beltrão, 2008). En el suplemento se incluyeron también cuatro preguntas sobre diversas categorías de origen. Dos de ellas preveían respuestas abiertas libremente elegidas por el informante mientras que las otras dos, que eran equivalentes, tenían respuestas categorizadas y cerradas. La primera pregunta sobre el tema (pregunta 1) era “¿Cuál es el color o la raza de [nombre de la persona ${ }^{3}$ ]?" y preveía una sola respuesta posible, pero que admitía palabras compuestas. La pregunta equivalente con respuestas cerradas (pregunta 2) listaba las alternativas tradicionales de las encuestas del IBGE, a saber: blanca, preta (negra), amarilla, parda e indígena. En este caso se admitía solo una opción de respuesta. La otra pregunta con respuesta abierta (pregunta 3) abordaba la cuestión desde la perspectiva del origen - “¿Cuál(es) es(son) el (los) origen(es) que [nombre de la persona] considera que tiene?"-y admitía hasta tres respuestas posibles. La pregunta correspondiente con respuestas categorizadas (pregunta 4) incluía las siguientes opciones: africano, alemán, árabe, brasileño,

Antes de la entrevista propiamente dicha, el encuestador hace una lista nominal de todos los habitantes de ese hogar que serán objeto de las preguntas en la fase de la entrevista. 
español, indígena, italiano, japonés, judío, negro, portugués y otro. El encuestado podía elegir o no cada una de las 16 opciones listadas, con 65.536 combinaciones posibles.

Este trabajo es una ampliación reestructurada de una obra anterior de los autores (Teixeira Pacheco y Beltrão, 2008). Su principal objetivo es dar continuidad al diálogo con otras realidades nacionales de nuestro hemisferio sobre este tema, como hicieron por ejemplo los textos de Schkolnik (2009) y Paixão (2009). Con esto se procura ofrecer un aporte a la reformulación de la pregunta en encuestas de hogares futuras.

\section{A. Clasificación racial}

En varios estudios que trataron el tema de las relaciones raciales en el Brasil se abordaron los problemas inherentes a la clasificación étnico-racial de los individuos (Pierson, 1945; Wagley, 1952; Harris y Kottak, 1963; Nogueira, 1985). Si bien en algunos de ellos - como en el caso de Pierson - se refuerza la idea de democracia racial haciendo hincapié en el mestizaje y los casos de movilidad social de "elementos negros", al tratar las relaciones raciales como un aspecto de las relaciones sociales (Wagley, 1952, pág. 14) se plantean cuestiones importantes acerca de la clasificación racial de los individuos en los momentos de interacción social. En particular se concentran en el problema del "mulato" y constatan la ambigüedad de los términos utilizados por las poblaciones investigadas (Harris y Kottak, 1963, pág. 205).

Harris y Kottak (1963, pág. 203) enumeraron cerca de 40 tipos raciales diferentes en su trabajo de investigación en Arembepe (BA). De acuerdo con Harris (1964, pág. 57), en el Brasil se podrían reconocer alrededor de una docena de categorías según las combinaciones de color y textura del cabello, color de los ojos y de la piel. Hutchinson (1952, pág. 28) encontró y describió ocho categorías en Vila Recôncavo - negro o negro retinto, cabra (mestizo hijo de mulato y negra o viceversa), cabo verde (mestizo de negro e indio), oscuro, mulato (que podía ser tanto claro como oscuro), pardo, sarará (catire) y moreno-y llegó a la conclusión de que en esa localidad no se trataba simplemente de una cuestión de blanco y negro, sino de todas las gradaciones intermedias ${ }^{4}$.

Al estudiar los términos utilizados por un grupo de bajos ingresos en Río de Janeiro en los años ochenta, Teixeira Pacheco (1987) identificó ocho categorías - negro, preto, oscuro, caboclo, mulato, moreno, claro y blanco-consideradas importantes en algunos momentos de la interacción social, sobre todo en las ocasiones de conflicto o tensión, inclusión o exclusión, como por ejemplo en el momento de elegir al cónyuge.

En su trabajo en el Morro do Sangue Bom en Río de Janeiro, Sheriff (2002, pág. 219) hace una distinción entre lo que denomina "discurso de descripción" y lo que autores como Harris (1970) y Sanjek (1971) llaman "categorías raciales" e identifica tres tipos de discurso sobre los términos de raza y color: un estilo cotidiano en que las personas describen sus propias características físicas (el caso de los niveles (i) y (ii) citados en la introducción); un estilo

4 En el original: "...is not simply a matter of black and white, but of all the shades in between”. 
pragmático en el que las personas manipulan conscientemente ese vocabulario (nivel (v)); y por último, un estilo racial de discurso, que no hace hincapié en el color ni la apariencia, sino en un punto de vista bipolar o tripartito de identidad racial (el caso de los niveles (iii) y (iv)).

\section{B. El concepto de raza-color en las encuestas del IBGE}

La preocupación de carácter más antropológico por la adecuación de los términos referentes al color en las encuestas del IBGE surgió por primera vez en la década de 1970 (véase Araújo Costa, 1974). En ese trabajo se constata la necesidad de una investigación a nivel nacional de los términos de color utilizados por la población, conforme las recomendaciones de las Naciones Unidas. En documentos de la Organización fechados en la década de 1950 se argumentaba que en las encuestas sobre la composición étnica de sus poblaciones los países deberían utilizar las categorías que estas mismas empleaban para identificarse, porque estas permitirían un mejor uso de la información en términos de políticas públicas. Dentro del IBGE esa reflexión condujo a la inclusión de la pregunta con el formato de respuesta abierta en la PNAD de 1976, como base para el censo de 1980. El análisis de los resultados de la encuesta sirvió para afirmar, entre los 146 términos recogidos, las categorías tradicionalmente investigadas por la institución desde 1940.

\section{Censos 5}

Ya en el censo de 1872 se investigaron atributos referentes al color de la población ${ }^{6}$. Si bien la pregunta realizada se refería solamente al color, se utilizaba el término "caboclo" como opción de color junto a "blanco", "preto" y "pardo", lo que demostraba cierta ambigüedad en la definición del concepto. En la categoría "caboclo" se incluía, sin distinción de tribu, a toda la población indígena del país". No obstante la categoría "pardos" comprendiera nominalmente a todos los mestizos, se hacía hincapié en el mestizaje entre blancos y negros. Con el régimen esclavista aún en vigor, la población esclava solo fue clasificada, por el propietario o el encuestador, en dos categorías: preta y parda. Senra (2006) plantea como hipótesis la inexistencia de esclavos de otras categorías (blancos o caboclos) o una adaptación cultural o ideológica que negaría esas posibilidades. En 1890 el color "pardo" fue sustituido por la categoría "mestizo", una indicación más genérica, que incluía también los diversos resultados de la fusión con la población indígena. En los censos siguientes no se incluyeron preguntas sobre el color, que solo volvieron a aparecer en el cuestionario censal de 1940. De ahí surgió la clasificación de la población en tres grandes grupos - pretos, blancos y amarillos-y se estableció un grupo genérico bajo la designación de "pardos" para

Esta sección se basa principalmente en Beltrão y Teixeira (2005).

Si bien entendamos que el concepto pueda haber variado en el tiempo - véase Carvalho y otros (2004).

Costa Pereira (1975), apud Lima (1999), cita Teodoro da Silva para la etimología de caboclo como derivado del tupí caa-boc, "que viene del bosque". 
los que registraran otras declaraciones como "caboclo", "mulato" y "moreno", entre otras, o se limitaran a trazar una línea como se indicaba en las instrucciones. Solo en los casos de completa omisión de la respuesta se atribuyó la designación "color no declarado". En casi todas las tabulaciones las personas de "color no declarado" se sumaron a la categoría "pardos", en función del pequeño número de los que constituían el primero de esos grupos y porque la omisión de la respuesta traduciría, en muchos casos, una reserva a la declaración expresa del mestizaje (IBGE, 1940). Pese a que en el cuestionario se utilizaba solo el término "color", el análisis discursivo realizado en el capítulo del libro A Cultura Brasileira se titulaba O país e a raça (Azevedo, 1944, pág. 17-38). Después del relieve, la topología, la fauna, la flora, los recursos minerales y el clima del país se describen "...los orígenes del pueblo brasileño". El texto presenta un cierto sesgo, pues la raza predominante es la del blanco europeo y se tiene la certeza de un emblanquecimiento gradual fortalecido por la inmigración.

Con el tiempo, el aumento de la inmigración condujo a la inclusión de la categoría "amarilla" entre las respuestas posibles. No parecía haber instrucciones explícitas sobre la responsabilidad de la respuesta, es decir si la clasificación debía recaer en el encuestador o el encuestado. En el censo de 1950 la declaración se dejó al arbitrio del encuestado, dando así mayor precisión a los resultados, como se explicita en la publicación (IBGE, 1950). Si bien esto indica (por oposición) que en los censos anteriores la responsabilidad de la clasificación correspondía al encuestador, en la práctica se solía dejar el cuestionario para que el jefe del hogar, de ser alfabetizado, lo completara (IBGE, 1940). Con respecto al color, el censo de 1950 mantuvo la estructura del censo anterior, de modo que la población se distribuyó en cuatro grupos: blancos, pretos, amarillos y pardos. Este último incluía a los indios y a las personas que se declararan "mulatos", "caboclos" y "zambos", entre otros. En la introducción al informe del censo se indica que si bien no se habría censado completamente a toda la población aborigen, se obtuvo información indirecta e imparcial por medio de las declaraciones alusivas al color y a la lengua hablada. En el censo de 1960, como en el anterior, la población se dividió en blancos, pretos, amarillos y pardos. Los indígenas, en general, continuaron incluyéndose en este último grupo. Se creó una clase específica, "india", para aquellos que vivían en aldeas o asentamientos indígenas y que nunca fueron tabulados por separado ${ }^{8}$.

En el censo de 1960 se innovó desde dos puntos de vista: se definió una muestra con un cuestionario mayor en el que se incluía la pregunta sobre el color y se precodificó la pregunta sobre el color que anteriormente completaba en su totalidad el encuestador (o el encuestado). Es importante observar que la pregunta sobre el color no se incluyó en el censo de 1970. En su respuesta a la moción de 1976 de la Sociedad Brasileña para el Progreso de la Ciencia (SBPC) que pedía que se volviera a incluir la pregunta sobre color y raza en los censos, Kerstenetzky (1977), entonces presidente del IBGE, informó que tras la consulta de la Comisión Nacional del Censo a estudiosos y especialistas en el tema prevaleció el punto de vista de la inconveniencia de su inclusión hasta que no se realizara un estudio más específico. La PNAD de 1976 se utilizó para ese propósito mediante la presentación de

8 Las instrucciones eran: Solo deberán señalarse como "indios" los aborígenes que vivan en aldeas o asentamientos indígenas. Para los aborígenes que viven fuera de aldeas o asentamientos indígenas se deberá marcar el rectángulo número 27 (parda), así como para los que se declaren mulatos, caboclos y zambos, entre otros. (IBGE, 1960). 
un cuestionario con preguntas de respuestas abiertas y cerradas. Se concluyó que, incluso de forma espontánea, los términos más utilizados por la población coincidían con los propuestos por el IBGE o eran términos generales como "moreno", que no servían para una clasificación con fines estadísticos. Como se desprende del análisis que figura a continuación, este término ha sido empleado en mayor o menor grado por todas las categorías de color o raza tradicionalmente utilizadas por el IBGE.

En el censo de 1980 continuaron aplicándose las siguientes categorías de clasificación: blanca, preta, amarilla y parda. Esta última comprendía a mulatos, mestizos, indios, caboclos, mamelucos (mestizos) y zambos, entre otros (IBGE, 1980). Como en los casos anteriores, la pregunta figuraba solamente en el cuestionario de la muestra. Fue solo a partir del censo de 1991 que la población indígena pasó una vez más a enumerarse en forma separada de la parda, lo que posiblemente habría conducido, aunque de forma errónea, a la inclusión del término "raza" en la pregunta. Se admiten entonces las siguientes respuestas en relación con el color o la raza: blanca, preta, amarilla, parda (mulata, mestiza, cabocla, mameluca, zamba, entre otros) e indígena, clasificación que se aplica tanto a los habitantes de los asentamientos como a los que viven fuera de ellos. De acuerdo con el Manual do recenseador de 2000 (IBGE, 2000), se encuadran en la clasificación de raza amarilla las personas de origen japonés, chino y coreano, entre otros. En ese sentido, el Manual do recenseador del censo de 1991 (IBGE, 1991) es más explícito, pues añade la expresión "y sus descendientes" a la especificación anterior. Las muestras de los censos de 1960 a 1980 fueron sistemáticas dentro de cada sector censal y del $25 \%$ de la población. En 1991, la fracción de muestreo se redujo según el tamaño del municipio: se estableció el 20\% para los sectores de municipios con hasta 15.000 habitantes y el 10\% para los sectores de los demás municipios. Estas fracciones se mantuvieron en 2000. En el censo de 2010 se mantuvo la forma de la pregunta, pero se la incluyó también en el cuestionario del universo (IBGE, 2010). Si bien se utilizaron cinco fracciones de muestreo que variaban del $5 \%$ al 50\%, según el tamaño del municipio, esto no tuvo repercusiones en el análisis de la pregunta sobre color o raza, ya que esta figuraba también en el cuestionario del universo.

\section{Otras encuestas}

La pregunta sobre color o raza formulada en el Censo de Población comenzó a incorporarse regularmente en otras encuestas del IBGE, como la PNAD (a partir de 1987) y la PME (a partir de 2004). También se incorporó en algunas encuestas aisladas como el Recuento (Contagem) de 1996, la Encuesta sobre Condiciones de Vida (PPV) de 1997 y la Encuesta sobre Presupuestos Familiares (POF) de 2002-2003 y 2008-2009. Antes de 1987 se investigó el concepto en algunos suplementos de la PNAD, entre ellos los de educación (1982), fecundidad (1984), situación del menor (1985) y complementación alimentaria (1986). En 1976 se incluyó una pregunta abierta sobre el color en el suplemento de movilidad con el objetivo de verificar el grado de adecuación de los términos utilizados en la pregunta cerrada.

En 2008 el IBGE realizó una investigación-estudio sobre el tema del color y el origen, sin intención de representatividad nacional, denominada Encuesta de las Características 
Étnico-Raciales de la Población. Partiendo del principio que la alteridad próxima es un problema en las encuestas étnico-raciales, solo un único residente, elegido en forma aleatoria, respondió sobre sí mismo. En ese sentido, dicha investigación no constituye un aporte para el presente trabajo, en el que se examinan las diferentes respuestas cuando el encuestado se refiere a sí mismo y a una persona cercana (IBGE, 2011).

\section{Evidencias de los datos del suplemento de la PME de julio de 1998}

La pregunta 1 produjo 289 respuestas diferentes. Algunas de ellas correspondían a errores tipográficos, como por ejemplo "03morena", "blaanca" y "amrilla", que se sustituyeron respectivamente por "morena", "blanca" y "amarilla". Además de corregir los errores tipográficos, se optó por considerar equivalentes las categorías expresadas en las formas femeninas y masculinas, como por ejemplo, "moreno" y "morena", "blanco claro", "blanca claro" y "blanca clara", que se redujeron a la forma femenina, ya que tanto color como raza son palabras femeninas en portugués.

En una segunda etapa se planea evaluar las correlaciones existentes entre el género utilizado para brindar la información y el sexo de la persona a la que esta se refiere. Después de esta primera reclasificación se obtuvieron 142 categorías y se observó que las 11 más elegidas comprendían alrededor del $98,63 \%$ de la población de la muestra (la decimosegunda categoría corresponde a la no respuesta, con 241 casos) (véase el cuadro 1).

\section{Cuadro 1}

Categorías más elegidas como respuesta abierta a la pregunta 1

\begin{tabular}{lrrrrc}
\hline Categoría & Personas & $\begin{array}{c}\text { Porcentaje } \\
\text { del total }\end{array}$ & Porcentaje & $\begin{array}{c}\text { Porcentaje } \\
\text { acumulado del total }\end{array}$ & $\begin{array}{c}\text { Porcentaje } \\
\text { acumulado }\end{array}$ \\
\hline Blanca & 44560 & 48,76 & 48,89 & 48,76 & 48,89 \\
\hline Morena & 22194 & 24,28 & 24,35 & 73,04 & 73,24 \\
\hline Parda & 8971 & 9,82 & 9,84 & 82,86 & 83,08 \\
\hline Preta & 4189 & 4,58 & 4,60 & 87,44 & 87,67 \\
\hline Morena clara & 3723 & 4,07 & 4,08 & 91,52 & 91,76 \\
\hline Negra & 3132 & 3,43 & 3,44 & 94,94 & 95,19 \\
\hline Clara & 991 & 1,08 & 1,09 & 96,03 & 96,28 \\
\hline Mulata & 681 & 0,75 & 0,75 & 96,77 & 97,03 \\
\hline Morena oscura & 654 & 0,72 & 0,72 & 97,49 & 97,75 \\
\hline Amarilla & 582 & 0,64 & 0,64 & 98,13 & 98,39 \\
\hline Oscura & 464 & 0,51 & 0,51 & 98,63 & 98,89 \\
\hline No respondió & 240 & 0,26 & - & 98,89 & - \\
\hline Otras (inclusive ignorado) & 1012 & 1,11 & 1,11 & 100,00 & 100,0 \\
\hline Fura
\end{tabular}

Fuente: Instituto Brasileño de Geografía y Estadística (IBGE), sobre la base de datos de la Encuesta Mensual de Empleo, 1998.

9 El programa de entrada de datos solo aceptaba letras mayúsculas y por eso nuestras citas están en caja alta. 
En la literatura se menciona la existencia de términos regionales referentes al tema de la clasificación racial. En esta muestra, algunos términos se presentaron realmente circunscritos a algunas regiones metropolitanas. Fue el caso de "BUGRE/BUGRO" (indio salvaje), que se utilizó solo en Porto Alegre; "ALBO/ALBA", que apareció casi exclusivamente en Recife (una mención en Belo Horizonte de las 30 encontradas); "GALEGO/GALEGA", que se utilizó en las dos regiones metropolitanas del Nordeste (Recife y Salvador) y registró dos menciones en São Paulo (vista la ingente migración nordestina a São Paulo, sería razonable suponer que el término fue utilizado por migrantes pero lamentablemente la PME no incluye datos sobre el lugar de nacimiento, que permitirían verificar esa hipótesis); y "CABOCLO/CABOCLA", que se mencionaron 24 veces, tres cuartas partes de ellas también en el nordeste.

En la literatura también se plantea la posibilidad de que la atribución del color o la raza esté influenciada por la condición social del informante (Fernandes, 1978; Nogueira, 1985 y 1992; Azevedo, 1955; Costa Pinto, 1952). Debido a que esta posibilidad podría estar exacerbada si la información fuera proporcionada, por ejemplo, por la empleada doméstica, se verificó que estas fueron las informantes en poco menos del 10\% de los hogares con este tipo de empleadas. En el año de referencia, solo el 0,3\% de los hogares contaba con empleados domésticos residentes. Cabe señalar que, a diferencia de otras encuestas de hogares realizadas por el IBGE, en la PME no existe ninguna orientación específica para que el encuestador solicite que las declaraciones sean realizadas, preferiblemente, por el jefe (o la persona responsable) del hogar ${ }^{10}$. Por otra parte, existen instrucciones especiales en cuanto a la no interferencia del encuestador en las respuestas de los encuestados ${ }^{11}$.

También se planteó la hipótesis de que las discrepancias entre las respuestas abiertas y cerradas pudieran tener un componente relacionado con el color del encuestador. Se hizo entonces una tabulación por región metropolitana y número de entrevistador. Al no disponer de la información sobre el color de cada encuestador, debido a las modificaciones en el cuadro de personal contratado en el período transcurrido, se decidió descartar este aspecto.

En el cuadro 2 se presentan (sin los factores de expansión) los resultados que cruzan en las líneas las respuestas a la pregunta abierta (solo las 14 categorías más frecuentes) y en las columnas las respuestas a la pregunta cerrada (las cinco categorías cerradas). Los datos se desagregan con respecto al informante (si se refiere a sí mismo en la segunda sección del cuadro o a otro residente del hogar en la primera sección) y se refieren a la proporción de la columna, o sea, a la distribución de las respuestas en las preguntas con respuestas abiertas entre los que fueron clasificados en una determinada categoría en la pregunta con respuestas precodificadas. Se puede entonces verificar cuáles son las respuestas abiertas más comunes

10 Normalmente cada persona es el mejor informante con respecto a sus propias características, excepto en casos especiales o cuando se trata de niños. Sin embargo, algunas circunstancias pueden impedir o dificultar la realización de la entrevista con todos los residentes. En estos casos, el entrevistador debe verificar con criterio si entre los residentes presentes existen personas capacitadas para brindar, con seguridad, los datos relativos a las personas ausentes o que puedan contactarlas para obtenerlos (IBGE, 2008, pág. 38).

11 En ningún momento el entrevistador se debe dejar llevar por sus conceptos personales originados en otras encuestas o anteriormente aplicados a la encuesta. En caso de dificultad en la comprensión de las preguntas, el entrevistador debe aclararlas a los informantes, teniendo cuidado de no influir en las respuestas (IBGE, 2008, pág. 39). 
para una determinada clasificación cerrada. El valor modal para estas columnas se indica en color rojo. Los valores por encima del $75 \%$ se presentan en rojo y negrita. Los valores entre el 0,25\% y el 0,49\% aparecen en azul. En la tercera sección del cuadro se presenta la razón de las proporciones con la declaración relativa al otro en el numerador (tomada de la primera sección del cuadro) y a sí mismo en el denominador (tomada de la segunda sección del cuadro). Los valores mayores de 1,2 indican una mayor frecuencia de esa categoría en la descripción del otro que en la de sí mismo y se presentan en negrita verde. Por el contrario, los valores inferiores a o,8 indican una mayor frecuencia de esa categoría en la descripción de sí mismo que del otro y se presentan en rojo. No se incluyeron las razones alrededor de la unidad, más precisamente entre 0,8 y 1,2 , porque indicarían que no hay diferencias entre las clasificaciones del otro y de sí mismo. El cuadro 2 corresponde al total de la muestra. Los cuadros correspondientes a cada una de las regiones metropolitanas están disponibles en Teixeira Pacheco y Beltrão (2008). Por ejemplo, entre los individuos de toda la muestra (véase el cuadro 2) que al responder sobre sí mismos se clasificaron en la respuesta precodificada como de color "pardo", el 31,5\% también se describió como de color "pardo" en las respuestas abiertas. Al describir al otro esa proporción fue del 29,1\%. La razón entre estas dos proporciones es menor que la unidad pero mayor de 0,8 y por lo tanto no está presentada en el cuadro. En el caso de los encuestados que en la pregunta con respuestas precodificadas indicaron el color "preto", se observa que la razón entre las descripciones "moreno oscuro" y "oscuro" es, respectivamente, un $95 \%$ y un 50\% más frecuente cuando describían al otro que cuando se describían a sí mismos y están, por lo tanto, representadas en negrita verde. Mientras que en la penúltima línea se presenta el total de individuos que declararon la situación descrita en la columna, en la última se indica la representatividad de esa columna en el cuadro.

En la muestra en su conjunto (véase el cuadro 2), las declaraciones de color "blanco" de los encuestados fueron muy similares para sí mismos y para el otro y representaron la mayor proporción de coincidencia entre las dos clasificaciones: el 89\% de los que indicaron "blanco" en la pregunta con respuestas cerradas ya habían declarado "blanco" en la pregunta con respuesta abierta. "Moreno" y "moreno claro" fueron dos de las categorías abiertas que registraron proporciones significativas de declarantes, pero del mismo orden de magnitud en las descripciones del otro y de sí mismos entre los que declararon "blanco" en la pregunta precodificada: alrededor del 6,1\% y el 2,7\% respectivamente. La categoría "clara" apareció menos frecuentemente, pero con una incidencia un 49\% mayor para la descripción del otro, con valores del 1,9\% con respecto al otro y del 1,3\% con respecto a sí mismo.

Después de "blanca", la segunda mayor coincidencia de categorías se registró con respecto a los individuos que declararon la categoría "amarilla" en los dos tipos de pregunta, ligeramente por encima del 70\%, tanto para sí mismos como para el otro. Las discrepancias de tratamiento, entre el $5 \%$ y el 10\%, se referían a la categoría "blanca", que fue un $89 \%$ más frecuente para designar al otro que a sí mismo, y la categoría "morena", con equilibrio en los dos casos. Las categorías "clara", "morena clara" y "parda" también fueron opciones relevantes (con valores entre el $1 \%$ y el $7 \%$ de las respuestas de este grupo), pero usadas sobre todo para sí mismos. 


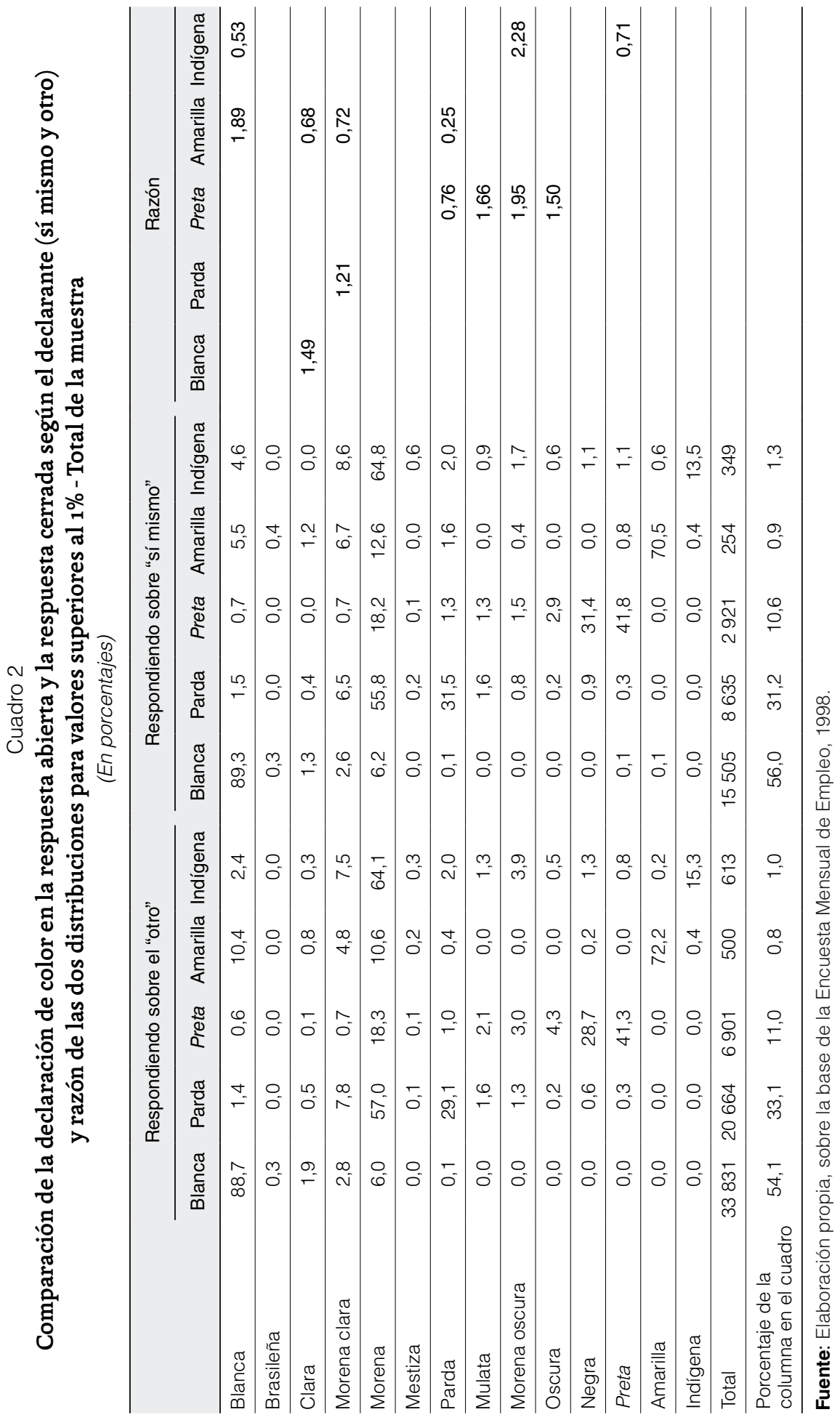


Llama la atención que la mayor parte (64,3\%) de los individuos categorizados como "indígena" en la pregunta precodificada declaró la categoría "morena" en la pregunta de respuesta abierta, con valores muy próximos para sí y para el otro. Si bien más del 60\% de las respuestas se concentran en una misma categoría abierta, es interesante notar que esta fue la categoría cerrada que se distribuyó en más clases relevantes en las respuestas abiertas: ocho categorías por encima del $1 \%$. Solo el 15,3\% de los encuestados declaró "indígena" para el otro y el $13,5 \%$ para sí mismo. Una proporción significativa -entre el 7\% y el 8\%- utilizó además la categoría "morena clara", en proporción similar con respecto a sí mismo y al otro. También fue relevante el grupo que declaró la categoría "morena oscura", que fue más frecuente con respecto al otro que a sí mismo. También aparecieron las categorías "blanca" y "parda", con valores alrededor del $2 \%$ al $4 \%$. La primera de ellas se empleó con más frecuencia en la descripción de sí mismo y la segunda en forma equilibrada en ambos casos.

Entre los que declararon "parda" en la pregunta precodificada, las opciones para la pregunta de respuesta abierta se concentraron sobre todo en dos categorías: "morena", con un $55,8 \%$ y un $57,0 \%$, respectivamente para sí mismo y para el otro, y "parda", con un $31,5 \%$ y un $29,1 \%$ respectivamente. Otra categoría relevante fue "morena clara", con el 6,5\% y el 7,8\% de las respuestas de este grupo, en una proporción más elevada en la declaración relativa al otro. "Mulata", "morena oscura" y "blanca" surgieron en proporciones similares, entre el $1,0 \%$ y el $1,5 \%$, aplicadas igualmente a sí mismo y al otro.

Los encuestados que indicaron "preta" en la pregunta precodificada se distribuyeron sobre todo en tres diferentes categorías abiertas: preta (41,4\%), negra (29,5\%) y morena $(18,2 \%)$, en proporciones similares en las declaraciones relativas a sí mismo y al otro. "Parda" se aplicó más a sí mismo en el 1,0\% de los casos. Las categorías "oscura", "morena oscura" y "mulata" aparecieron entre un 1,9\% y un 3,9\% más en la descripción del otro que de sí mismo. Se destaca que la categoría "negra" no fue la categoría modal en la pregunta de respuesta abierta como sostienen los movimientos negros. Teniendo en cuenta que la PME se realiza en regiones metropolitanas, donde debería haber un mayor nivel de información, era de esperar que -si el discurso de estos movimientos reflejara realmente el pensamiento de la población del grupo- la categoría "negra" suplantara a las demás, sobre todo a la categoría "preta", utilizada por el IBGE en los censos desde 1872 hasta hoy, y bastante criticada por los movimientos negros.

En cuanto a las diferencias en las declaraciones con respecto al otro y a sí mismo, se puede decir que en la muestra en su conjunto las categorías abiertas con matices adjetivos ("clara", "morena clara", "morena oscura" y "oscura") se aplicaron con mayor frecuencia al otro que a sí mismo, aunque en algunos casos con baja incidencia. 


\section{Resultados en las regiones metropolitanas}

\section{Control por la categoría cerrada}

En el cuadro 3 se presentan la incidencia y la categoría abierta modal correspondiente a cada categoría cerrada, sin la desagregación del informante, relativas a cada región metropolitana (línea) y al total de la muestra. Las únicas categorías abiertas que no tienen una equivalente cerrada son: morena $(\mathrm{M})$ y negra $(\mathrm{N})$. Todas las demás coinciden con una categoría cerrada: blanca (B), preta (P), amarilla (A), parda (Pa) e indígena (I). Por ejemplo, entre los entrevistados que optaron por la categoría "parda" en la pregunta cerrada, el 56,7\% (media ponderada del $57,0 \%$ y el 55,8\%, declarados respectivamente para el otro y para sí mismo) optaron también por "morena" (M) en la pregunta abierta (confrontar la línea "morena" y las columnas encabezadas por "parda" en la segunda y tercera secciones del cuadro 2).

\section{Cuadro 3}

Proporción de incidencia y categoría abierta modal de las respuestas abiertas para cada categoría de color-raza cerrada según la región metropolitana

(En porcentajes)

\begin{tabular}{llllll}
\hline Área & Blanca & Parda & Preta & Amarilla & Indígena \\
\hline Recife & $74,5 \mathrm{~B}$ & $82,0 \mathrm{M}$ & $60,5 \mathrm{M}$ & $29,1 \mathrm{~B}$ & $78,9 \mathrm{M}$ \\
\hline Salvador & $87,3 \mathrm{~B}$ & $47,2 \mathrm{~Pa}$ & $44,9 \mathrm{P}$ & $67,2 \mathrm{~A}$ & $44,7 \mathrm{M}$ \\
\hline Belo Horizonte & $75,6 \mathrm{~B}$ & $70,4 \mathrm{M}$ & $33,9 \mathrm{~N}$ & $40,0 \mathrm{~A}$ & $69,8 \mathrm{M}$ \\
\hline Río de Janeiro & $94,8 \mathrm{~B}$ & $52,4 \mathrm{~Pa}$ & $59,3 \mathrm{P}$ & $44,4 \mathrm{~A}$ & $68,6 \mathrm{M}$ \\
\hline São Paulo & $91,7 \mathrm{~B}$ & $59,2 \mathrm{M}$ & $42,7 \mathrm{~N}$ & $93,8 \mathrm{~A}$ & $61,5 \mathrm{M}$ \\
\hline Porto Alegre & $95,4 \mathrm{~B}$ & $52,5 \mathrm{~Pa}$ & $62,1 \mathrm{P}$ & $48,0 \mathrm{~A}$ & 41,8 I \\
\hline Total & $88,9 \mathrm{~B}$ & $56,7 \mathrm{M}$ & $41,4 \mathrm{P}$ & $71,6 \mathrm{~A}$ & $64,3 \mathrm{M}$ \\
\hline
\end{tabular}

Fuente: Elaboración propia, sobre la base de la Encuesta Mensual de Empleo, 1998.

Nota: $\mathrm{B}=$ blanca; $\mathrm{M}=$ morena; $\mathrm{Pa}=$ parda; $\mathrm{P}=$ preta; $\mathrm{N}=$ negra; $\mathrm{A}=$ amarilla; $\mathrm{I}=$ indígena.

La categoría cerrada "blanca" es la única que correspondió a la categoría abierta homónima como modal en todas las regiones metropolitanas. La proporción de concordancia varía del $74,5 \%$ (Recife) al $95,4 \%$ (Porto Alegre). En el extremo opuesto se encuentra la categoría cerrada "indígena", que solo corresponde a una categoría abierta modal homónima en Porto Alegre, e- incluso en ese caso presenta menos del 50\% de concordancia. En todas las demás regiones metropolitanas la categoría abierta modal para esa categoría cerrada es "morena", que llega a casi el 79\% de concordancia en Recife. Reforzando la idea de las reglas de etiqueta de las relaciones raciales en el Brasil (Teixeira, 2011; Azevedo, 1955; y Nogueira, 1992), "morena" es la categoría abierta predominante también para la población "parda". Solo en Salvador, Río de Janeiro y Porto Alegre la categoría abierta modal coincidió con la homónima, con valores que oscilaban entre el 47,2\% (Salvador) y el 52,5\% (Porto Alegre). En la muestra en su conjunto y en las regiones metropolitanas de Recife, Belo Horizonte y 
Porto Alegre, la clase modal es la homónima "parda", con valores que iban del 56,7\% para el total al 82,0\% en Recife.

Con excepción de Recife, la categoría modal de la categoría cerrada "amarilla" es la homónima, pero con concordancias que varían del 40,0\% (Belo Horizonte) al 93,8\% (São Paulo). El tema de la identidad-identificación se aborda más adelante junto con el análisis del gráfico 1.

En el caso de la categoría cerrada "preta", se observa que solo en dos regiones metropolitanas la opción abierta modal fue "negra": Belo Horizonte y São Paulo. Excepto por Recife, donde se optó sobre todo por "morena", la categoría abierta modal en las demás regiones metropolitanas fue "preta". En una encuesta más reciente realizada por el IBGE (IBGE, 2011), la opción abierta modal fue "negra", lo que señala un cambio en la percepción del término.

Cabe señalar que en la región metropolitana de Porto Alegre las categorías modales abiertas son siempre homónimas de las cerradas correspondientes y que en las regiones metropolitanas de Salvador y Río de Janeiro se registra una discrepancia solo con respecto a la población "indígena", que espontáneamente prefiere la categoría general "morena"12.

En el cuadro 4 se presentan las combinaciones de categorías cerradas y abiertas con desequilibrio entre las referencias del encuestado a sí mismo y al otro. Los matices adjetivos (clara y oscura) se señalan en cursiva. Por ejemplo, en Recife, para la población "preta" e "indígena" la clasificación abierta "morena oscura" fue más utilizada para describir al otro. Del cuadro se desprende que los matices adjetivos se utilizan más para clasificar al otro que a sí mismo.

Cuadro 4

\section{Correspondencia entre categorías cerradas y abiertas según el informante}

\begin{tabular}{|c|c|c|}
\hline Región metropolitana & Para sí & Para el otro \\
\hline Recife & $\mathrm{Pa} / \mathrm{Pa} \quad \mathrm{A} / \mathrm{Pa}$ & $\begin{array}{lllll}\mathrm{P} / \mathrm{MO} & \mathrm{I} / \mathrm{MO} & \mathrm{Pa} / \mathrm{B} & \mathrm{A} / \mathrm{B} & \mathrm{I} / \mathrm{B}\end{array}$ \\
\hline Salvador & $\mathrm{A} / \mathrm{B} \quad \mathrm{P} / \mathrm{M} \quad \mathrm{I} / \mathrm{O} \quad \mathrm{Pa} / \mathrm{N}$ & $\mathrm{B} / \mathrm{C} \mathrm{Pa} / \mathrm{MC} \mathrm{Pa} / \mathrm{MO} \mathrm{I} / \mathrm{MO} \mathrm{P} / O \quad \mathrm{~A} / \mathrm{A}$ \\
\hline Belo Horizonte & $\mathrm{Pa} / \mathrm{Pa}$ & $\mathrm{B} / \mathrm{CPa} / \mathrm{MC} \mathrm{A} / \mathrm{MC} \mathrm{Pa/MOP/MO} \mathrm{I} / \mathrm{MO} \mathrm{P} / \mathrm{O}$ \\
\hline Río de Janeiro & $\mathrm{I} / \mathrm{Mu} \quad \mathrm{A} / \mathrm{A}$ & $\mathrm{Pa} / \mathrm{MC} \quad \mathrm{I} / \mathrm{I}$ \\
\hline São Paulo & $\mathrm{B} / \mathrm{C} \quad \mathrm{B} / \mathrm{MC} \quad \mathrm{B} / \mathrm{M} \mathrm{P} / \mathrm{Pa}$ & $\mathrm{Pa} / \mathrm{MC} \quad \mathrm{P} / \mathrm{M}$ \\
\hline Porto Alegre & $\mathrm{A} / \mathrm{MC} \quad \mathrm{I} / \mathrm{Ms} \quad \mathrm{I} / \mathrm{Pa} \mathrm{Pa} / \mathrm{N}$ & $\mathrm{Pa} / \mathrm{MC} \quad \mathrm{I} / \mathrm{MC}$ \\
\hline Total & $\mathrm{A} / \mathrm{C} \quad \mathrm{A} / \mathrm{MC} \quad \mathrm{A} / \mathrm{Pa} \quad \mathrm{P} / \mathrm{Pa}$ & $\mathrm{A} / \mathrm{B} \quad \mathrm{B} / \mathrm{C} \mathrm{Pa} / \mathrm{MC} \mathrm{P} / \mathrm{Mu} \mathrm{P} / \mathrm{MO} \quad \mathrm{P} / \mathrm{O} \quad \mathrm{I} / \mathrm{MO}$ \\
\hline
\end{tabular}

Fuente: Elaboración propia, sobre la base de la Encuesta Mensual de Empleo, 1998.

Nota: La letra antes de la barra designa la categoría cerrada y la letra después de la barra la categoría abierta; $\mathrm{A}=$ Amarilla; $\mathrm{B}=$ Blanca; $\mathrm{P}=$ Preta; $\mathrm{Pa}=\mathrm{Parda} ; \mathrm{I}=$ Indígena; $\mathrm{MC}=$ Morena clara; $\mathrm{MO}=$ Morena oscura; $C=$ Clara; $O=$ Oscura; $\mathrm{Mu}=$ Mulata; $\mathrm{Ms}=$ Mestiza; $\mathrm{N}=$ Negra.

\section{Control por la categoría abierta}

En el cuadro 5 se presentan, para cada región metropolitana (columna) y para el total de la muestra, la incidencia y la categoría cerrada modal correspondiente a cada categoría abierta (línea), sin la desagregación del informante. El valor de la línea es igual al 100\%

12 Valle Silva (1996) reconoce esta propiedad de la categoría y su no especificidad para fines estadísticos. 
cuando para una determinada categoría abierta todas las respuestas cerradas se concentran en una única categoría. Es el caso de "oscura" en Recife, para la cual todos los encuestados optaron por la categoría cerrada "preta". Por ejemplo, entre los encuestados que señalaron "brasileña" en la pregunta abierta en la región metropolitana de Recife, el 66,7\% señaló también "blanca" en la pregunta cerrada. En el caso de las categorías abiertas "blanca", "parda", "negra", "preta" e "indígena" las proporciones de las categorías modales son altas y cercanas al $100 \%$ en todas las regiones metropolitanas. Para la categoría abierta "negra" la correspondencia se establece con la categoría cerrada "preta" y con la homónima para las demás. Las categorías abiertas "clara", "morena" y "amarilla" presentan valores un poco más bajos, pero que se refieren en forma consistente a la misma categoría cerrada, respectivamente, "blanca", "parda" y "amarilla".

\section{Cuadro 5}

Proporción de incidencia y categoría cerrada modal de las respuestas cerradas para cada categoría de color-raza abierta según la región metropolitana

(En porcentajes)

\begin{tabular}{lccccccc}
\hline & Recife & Salvador & $\begin{array}{c}\text { Belo } \\
\text { Horizonte }\end{array}$ & $\begin{array}{c}\text { Río de } \\
\text { Janeiro }\end{array}$ & São Paulo & $\begin{array}{c}\text { Porto } \\
\text { Alegre }\end{array}$ & Total \\
\hline Blanca & $95,7 \mathrm{~B}$ & $94,9 \mathrm{~B}$ & $98,8 \mathrm{~B}$ & $98,8 \mathrm{~B}$ & $98,4 \mathrm{~B}$ & $99,3 \mathrm{~B}$ & $98,4 \mathrm{~B}$ \\
\hline Brasileña & $66,7 \mathrm{~B}$ & $100,0 \mathrm{~Pa}$ & $100,0 \mathrm{~B}$ & $81,8 \mathrm{~B}$ & $87,5 \mathrm{~B}$ & $90,4 \mathrm{~B}$ & $89,0 \mathrm{~B}$ \\
\hline Clara & $88,5 \mathrm{~B}$ & $55,2 \mathrm{~B}$ & $88,4 \mathrm{~B}$ & $87,2 \mathrm{~B}$ & $90,1 \mathrm{~B}$ & $86,0 \mathrm{~B}$ & $85,4 \mathrm{~B}$ \\
\hline Morena clara & $57,1 \mathrm{~Pa}$ & $70,6 \mathrm{~Pa}$ & $59,8 \mathrm{~Pa}$ & $72,0 \mathrm{~Pa}$ & $50,1 \mathrm{~Pa}$ & $61,0 \mathrm{~B}$ & $58,5 \mathrm{~Pa}$ \\
\hline Morena & $68,5 \mathrm{~Pa}$ & $86,4 \mathrm{~Pa}$ & $74,9 \mathrm{~Pa}$ & $77,2 \mathrm{~Pa}$ & $80,7 \mathrm{~Pa}$ & $44,1 \mathrm{~Pa}$ & $74,8 \mathrm{~Pa}$ \\
\hline Mestiza & $66,7 \mathrm{~Pa}$ & $89,5 \mathrm{~Pa}$ & $83,3 \mathrm{~Pa}$ & $63,6 \mathrm{~Pa}$ & $60,0 \mathrm{P}$ & $55,0 \mathrm{~Pa}$ & $68,6 \mathrm{~Pa}$ \\
\hline Parda & $97,0 \mathrm{~Pa}$ & $98,4 \mathrm{~Pa}$ & $98,0 \mathrm{~Pa}$ & $96,4 \mathrm{~Pa}$ & $96,4 \mathrm{~Pa}$ & $98,0 \mathrm{~Pa}$ & $97,4 \mathrm{~Pa}$ \\
\hline Mulata & $62,1 \mathrm{~Pa}$ & $65,2 \mathrm{~Pa}$ & $56,1 \mathrm{~Pa}$ & $79,5 \mathrm{~Pa}$ & $52,2 \mathrm{P}$ & $55,9 \mathrm{~Pa}$ & $69,0 \mathrm{~Pa}$ \\
\hline Morena oscura & $56,6 \mathrm{P}$ & $67,5 \mathrm{~Pa}$ & $48,5 \mathrm{~Pa}$ & $64,3 \mathrm{~Pa}$ & $61,5 \mathrm{~Pa}$ & $66,7 \mathrm{~Pa}$ & $53,2 \mathrm{~Pa}$ \\
\hline Oscura & $100,0 \mathrm{P}$ & $79,1 \mathrm{P}$ & $89,0 \mathrm{P}$ & $79,8 \mathrm{P}$ & $66,7 \mathrm{P}$ & $100,0 \mathrm{~Pa}$ & $82,1 \mathrm{P}$ \\
\hline Negra & $93,9 \mathrm{P}$ & $92,3 \mathrm{P}$ & $93,8 \mathrm{P}$ & $90,9 \mathrm{P}$ & $92,0 \mathrm{P}$ & $92,2 \mathrm{P}$ & $92,5 \mathrm{P}$ \\
\hline Preta & $97,0 \mathrm{P}$ & $96,6 \mathrm{P}$ & $95,1 \mathrm{P}$ & $97,8 \mathrm{P}$ & $98,1 \mathrm{P}$ & $98,4 \mathrm{P}$ & $97,2 \mathrm{P}$ \\
\hline Amarilla & $81,8 \mathrm{~A}$ & $77,4 \mathrm{~A}$ & $92,9 \mathrm{~A}$ & $69,6 \mathrm{~A}$ & $97,8 \mathrm{~A}$ & $75,0 \mathrm{~A}$ & $92,8 \mathrm{~A}$ \\
\hline Indígena & $100,0 \mathrm{I}$ & $97,1 \mathrm{I}$ & $94,7 \mathrm{I}$ & $94,4 \mathrm{I}$ & $100,0 \mathrm{I}$ & 90,2 I & $94,6 \mathrm{I}$ \\
\hline Euente: & & & & &
\end{tabular}

Fuente: Elaboración propia, sobre la base de la Encuesta Mensual de Empleo, 1998.

Las demás categorías abiertas - morena clara, morena, mestiza, mulata, morena oscura y oscura - presentan clases modales de categorías cerradas con valores mayores y no homogéneos desde el punto de vista geográfico. "Morena clara" es sobre todo "blanca" $(61,0 \%)$ en Porto Alegre, pero principalmente "parda" en las demás regiones metropolitanas (con valores que van del 50,1\% en São Paulo al 72,0\% en Río de Janeiro). "Mestiza" es sobre todo "preta" $(60,0 \%)$ en São Paulo, pero por lo general "parda" en las otras regiones metropolitanas (con valores que varían del $55,0 \%$ en Porto Alegre al $89,5 \%$ en Salvador). "Mulata" presenta un patrón similar al de "mestiza", generalmente "preta" $(52,2 \%)$ en São 
Paulo, pero sobre todo "parda" en las otras regiones metropolitanas (con valores que oscilan entre el 55,9\% en Porto Alegre y el 79,5\% en Río de Janeiro). "Morena oscura" es sobre todo "preta" $(56,6 \%)$ en Recife, pero principalmente "parda" en las otras regiones metropolitanas (con valores que van del $48,5 \%$ en Belo Horizonte al $67,5 \%$ en Salvador). "Oscura" corresponde totalmente a "parda" $(100,0 \%)$ en Porto Alegre, pero sobre todo a "preta" en las otras regiones metropolitanas (con valores que varían del 66,7\% en São Paulo al $100,0 \%$ en Recife).

Se concluye que la opción abierta menos precisa en su acepción regional es sin lugar a dudas "morena" en Porto Alegre. Esta categoría tampoco presenta precisión en las demás regiones metropolitanas. "Morena clara" y "mulata" son también categorías poco precisas. Los términos que presentan en forma homogénea una correspondencia más precisa en las respuestas cerradas en todas las regiones son: blanca, parda, negra, preta e indígena.

En lo que se refiere específicamente a las coincidencias perfectas entre los términos de las categorías cerradas y la utilización de sus homónimos en la pregunta abierta (véase el cuadro 6), se observa que las categorías "blanca” en São Paulo, Río de Janeiro y Porto Alegre y "amarilla" en São Paulo son las que presentan el mayor porcentaje de coincidencia (todas por encima del 90\%). El grado de aceptación de las demás categorías por parte de la población es menor. El porcentaje más elevado de coincidencia de las categorías "preta" y "parda" se registra en las regiones metropolitanas de Río de Janeiro y Porto Alegre (alrededor del 60\% y el 52\% respectivamente).

Cuadro 6

Proporción de coincidencias entre las categorías cerradas y sus homónimas abiertas según las regiones metropolitanas

(En porcentajes)

\begin{tabular}{lrrrrc}
\hline & Blanca & Parda & Preta & Amarilla & Indígena \\
\hline Recife & 74,5 & 4,2 & 16,9 & 28,3 & 3,9 \\
\hline Salvador & 87,3 & 47,2 & 44,9 & 67,2 & 29,8 \\
\hline Belo Horizonte & 75,6 & 9,8 & 27,0 & 40,0 & 7,7 \\
\hline São Paulo & 91,7 & 33,0 & 41,6 & 93,8 & 15,6 \\
\hline Río de Janeiro & 94,8 & 52,4 & 59,3 & 44,4 & 14,0 \\
\hline Porto Alegre & 95,4 & 52,5 & 62,1 & 48,0 & 41,8 \\
\hline Total & 88,9 & 29,8 & 41,4 & 71,6 & 14,7 \\
\hline
\end{tabular}

Fuente: Elaboración propia, sobre la base de la Encuesta Mensual de Empleo, 1998.

Se planteó la hipótesis de que una mayor población de una determinada categoría debería reforzar su identidad. En las regiones metropolitanas estudiadas esto parece ocurrir en todas las categorías con excepción de la "parda", como evidencian las líneas de tendencia del gráfico 1. En este se presenta la proporción de las categorías cerradas en la población comparada con el porcentaje de coincidencia entre las categorías abiertas y cerradas según 
la región metropolitana. Este comportamiento de la población "parda" se observó también en otros países, entre ellos Jamaica. De acuerdo con Hall (1997), pese a que el $98 \%$ de la población de ese país era parda o preta nadie utilizaba el término "black" sino miles de otros.

Gráfico 1

Proporción de la categoría cerrada en la población y proporción de coincidencia
de las categorías abiertas y cerradas según la región metropolitana

(En porcentajes)

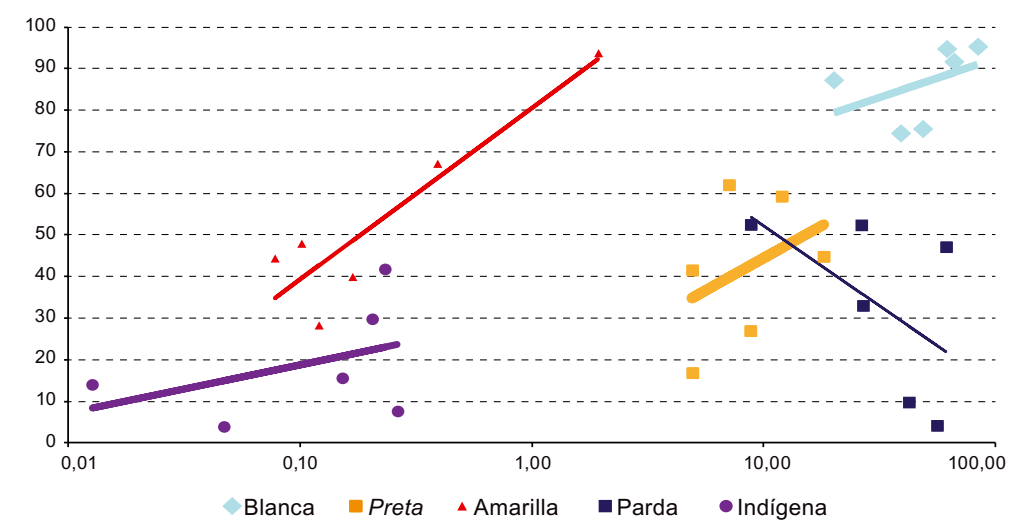

Fuente: Instituto Brasileño de Geografía y Estadística (IBGE), Microdados. PNAD 1998, Río de Janeiro, 1998; y Microdados. Pesquisa Mensal de Emprego. Julho 1998, Río de Janeiro, 1998.

Al analizar las categorías cerradas cuya opción espontánea preferencial no fue la homónima, se observa una dicotomía en la región metropolitana de Recife, pues dentro de la población clasificada como "blanca" o "morena", los individuos de piel amarilla serían agrupados preferentemente en la primera opción y los de todas las demás categorías cerradas en la segunda. Cabe notar la opción preferencial de los indígenas por la categoría abierta "morena" en todas las regiones metropolitanas con excepción de la de Porto Alegre (a pesar de que tanto la pregunta abierta como la cerrada hacen referencia a color o raza). En el otro extremo, para los individuos clasificados en la categoría cerrada "blanca" la opción abierta homónima es siempre modal. De los 14 casos en que no existe coincidencia entre las categorías abiertas y cerradas del cuadro 3, 11 se refieren a la opción abierta "morena", reforzando la opinión ya expresada por Valle Silva (1996) al analizar los datos de 1976. Las otras dos situaciones se refieren a la categoría abierta "negra" para la población que indicó la respuesta cerrada "preta".

Los resultados obtenidos no incentivan el debate acerca de una mejor opción para la categoría "preta" y su posible sustitución por la categoría "negra", pues los valores espontáneos de esta última en la respuesta abierta solo superaron a los de la primera en dos regiones metropolitanas. La situación contraria se observó en tres regiones metropolitanas, cifra que asciende a cuatro si el análisis no se limita únicamente a las categorías modales. 


\section{E. Comentarios y conclusiones}

La encuesta examinada en este trabajo permite hacer consideraciones interesantes en cuanto al uso regionalizado de los términos de clasificación del color o la raza, conforme ya señalado en la literatura. Los mayores niveles de coincidencia o aceptación de la categoría utilizada por el IBGE en la pregunta precodificada (alrededor del 90\%) corresponden a las categorías "blanca", en todas las regiones metropolitanas, y "amarilla", específicamente en São Paulo. Las demás combinaciones de color o raza y región metropolitana demostraron que las categorías cerradas del IBGE son, sin lugar a dudas, las más elegidas como opción abierta, con excepción de la categoría general "morena". Este término preferencial no es excluyente, de manera que el conjunto de la población brasileña al cual no se aplica es muy reducido. Como ya se comentó, este término ha sido empleado, en mayor o menor grado, por miembros de todas las categorías de color o raza tradicionalmente utilizadas por el IBGE y no serviría como alternativa cerrada viable en las encuestas. Este problema parece ser más agudo entre la población indígena, para la cual la opción "morena" fue la categoría modal en todas las regiones metropolitanas, con excepción de la de Porto Alegre. Esto nos remite a la necesidad de realizar nuevos estudios para discutir los usos y significados de los términos de identificación étnico-racial, con miras al perfeccionamiento de las formas de captación del fenómeno por parte de los órganos de estadística. Estas conclusiones llevaron al IBGE a mantener en el censo de 2000 las mismas categorías que permanecen intactas desde el censo de 1940. Sobre la base de los datos de la PCERP 2008 se llegó a conclusiones similares, que sirvieron para refrendar una vez más las categorías tradicionales utilizadas por el IBGE, de modo que tampoco se vio la necesidad de modificar los términos en el censo de 2010.

Para ello es necesario un debate sobre el concepto que se quiere medir con este tipo de pregunta. No cabe duda de que supone múltiples formas de identificación, que pueden referirse, entre otras cosas, al fenotipo, el genotipo, el origen familiar, la cultura y la ideología.

Un hecho que se desprende de la encuesta es que los resultados obtenidos no incentivan el debate acerca de una mejor opción para la categoría "preta" y su posible sustitución por la categoría "negra", pues los valores espontáneos de esta última en la respuesta abierta solo superaron a los de la primera en dos regiones metropolitanas. La situación contraria se observó en tres regiones metropolitanas, cifra que asciende a cuatro si el análisis no se limita únicamente a las categorías modales.

En cuanto a las diferencias en las declaraciones con respecto al otro y a sí mismo, se puede decir que en la muestra en su conjunto las categorías abiertas con matices adjetivos ("clara", "morena clara", "morena oscura" y "oscura") se aplicaron con mayor frecuencia al otro que a sí mismo, aunque en algunos casos con baja incidencia. Una encuesta con preguntas cerradas y una lista reducida de opciones debería minimizar este sesgo.

La pregunta de origen (que no se analizó en este trabajo) reveló que la población brasileña se remite, preferentemente, a la idea de nación o de pueblo, expresada en la categoría modal "brasileña", que fue elegida por más de tres cuartas partes de los entrevistados. 


\section{Bibliografía}

Araújo Costa, Teresa Cristina (1974), "O princípio classificatório 'cor', sua complexidade e implicações para um estudo censitário", Revista Brasileira de Geografia, vol. 36, N $^{\circ} 3$.

Azevedo, Fernando de (1944), A cultura brasileira: introdução ao estudo da cultura no Brasil", vol. 1, São Paulo, Companhia Editora Nacional.

Azevedo, Thales (1955), As elites de cor: um estudo de ascensão social, Brasilia, Companhia Editora Nacional.

Beltrão, Kaizô Iwakami y Moema De Poli Teixeira (2005), "O vermelho e o negro: viés de cor e gênero nas carreiras universitárias", Textos para Discussão, $\mathrm{N}^{\circ}$ 19, Río de Janeiro, Escuela Nacional de Ciencias Estadísticas (ENCE)/Instituto Brasileño de Geografía y Estadística (IBGE) [en línea] http://www.ence.ibge.gov.br/images/ence/doc/publicacoes/textos_para_discussao/texto_19.pdf.

Carvalho, José Alberto M. y otros (2004), "Estimating the stability of census-based racial/ethnic classifications: the case of Brazil", Population Studies: A Journal of Demography, vol. $58, \mathrm{~N}^{\circ} 3$, Taylor \& Francis.

CEPAL (Comisión Económica para América Latina y el Caribe) (2008), "Censos 2010 y la inclusión del enfoque étnico: hacia una construcción participativa con pueblos indígenas y afrodescendientes de América Latina", serie Seminarios y Conferencias, $\mathrm{N}^{\circ} 57$ (LC/L.3095-P), Santiago.

Costa Pereira, José Veríssimo da (1975), "Caboclo amazônico", Tipos e aspectos do Brasil, Río de Janeiro, Instituto Brasileño de Geografía y Estadístia (IBGE).

Costa Pinto, Luiz de A. (1952), O negro no Rio de Janeiro: relações de raças numa sociedade em mudança, São Paulo, Companhia Editora Nacional.

Del Popolo, Fabiana y Susana Schkolnik (2013), "Pueblos indígenas y afrodescendientes en los censos de población y vivienda de América Latina: avances y desafíos en el derecho a la información", Notas de Población, N 97 (LC/G.2598-P), Santiago, Comisión Económica para América Latina y el Caribe (CEPAL).

Fernandes, Florestan (1978), A integração do negro na sociedade de classes, São Paulo, Editora Ática.

Hall, Stuart (1997), "Old and new identities, old and new ethnicities", Culture, Globalization and the World-System: Contemporary Conditions for the Representation of Identity, A.D. King (ed.), Minneapolis, University of Minnesota Press.

Harris, Marvin (1970), "Referential ambiguity in the calculus of Brazilian racial identity", Southwestern Journal of Anthropology, vol. 26, $\mathrm{N}^{\circ} 1$.

(1964), Patterns of Race in the Americas, Nueva York, Walker and Company.

Harris, Marvin y Conrad Kottak (1963), "The structural significance of Brazilian racial categories", Sociología, vol. $25, \mathrm{~N}^{\circ} 3$.

Hutchinson, Harry W. (1952), "Race relations in a rural community of the bahian recôncavo", Race and Class in Rural Brazil, Charles Wagley (ed.), París, Organización de las Naciones Unidas para la Educación, la Ciencia y la Cultura (UNESCO).

IBGE (Instituto Brasileño de Geografía y Estadística) (2011), Características étnico-raciais da população -um estudo das categorias de classificação de cor ou raça 2008, Río de Janeiro.

(2010), Censo Demográfico 2010. Manual do recenseador CD - 1.09, Río de Janeiro.

(2008), PME. Manual de entrevista, Río de Janeiro.

(2000), XI Recenseamento geral do Brasil. Censo Demográfico 2000, Río de Janeiro.

(1998a), Microdados. Pesquisa Mensal de Emprego. Julho 1998, Río de Janeiro.

(1998b), Microdados. PNAD 1998, Río de Janeiro.

(1991), Censo Demográfico 1991. Manual do recenseador CD-1.09, Río de Janeiro. 
(1980), IX Recenseamento Geral do Brasil. Censo Demográfico. Manual do recenseador CD - 1.09, Río de Janeiro.

_(1960), Censo Demográfico. Instruções ao recenseador, Río de Janeiro.

_(1950), Recenseamento Geral de 1950, Censo Demográfico: instruções ao recenseador, Río de Janeiro.

_-(1940), Instruções ao agente recenseador. Recenseamento geral de 1940, Río de Janeiro.

Kerstenetzky, Isaac (1977), "Carta-resposta à moção da SBPC de 1976", Ciência e Cultura, vol. 29, № 4, São Paulo.

Lima, Deborah de M. (1999), "A construção histórica do termo caboclo: sobre estruturas e representações sociais no meio rural amazônico", Novos Cadernos NAEA, vol. 2, $\mathrm{N}^{\circ} 2$.

Loveman, Mara (2014), National Colors: Racial Classification and the State in Latin America, Oxford, Oxford University Press.

Maggie, Ivonne (1996), "Aqueles a quem foi negada a cor do dia: as categorias de cor e raça na cultura brasileira", Raça, ciência e sociedade, M.C. Maio y R.V. Santos (orgs.), Río de Janeiro, Centro Cultural Banco do Brasil/Fiocruz.

Naciones Unidas (2010), "Principios y recomendaciones para los censos de población y vivienda. Revisión 2", Informes Estadísticos Serie M, N ${ }^{\circ}$ 67/Rev.2 (ST/ESA/STAT/SER.M/67/Rev.2), Nueva York. _(2001), "Declaración y Programa de Acción de Durban", Informe de la Conferencia Mundial contra el Racismo, la Discriminación Racial, la Xenofogia y las Formas Conexas de Intolerancia (A/CONF.189/12), Nueva York.

Nogueira, Oracy (1992), Negro político, político negro, São Paulo, Editora da Universidade de São Paulo (EDUSP).

(1985), Tanto preto quanto branco: estudo de relações raciais, São Paulo, T.A. Queiroz Editor.

Paixão, Marcelo (2009), "La variable color o raza en los censos demográficos brasileños: historia y estimación reciente de las asimetrías", Notas de Población, No 89 (LC/G.2427-P), Santiago, Centro Latinoamericano y Caribeño de Demografía (CELADE)-División de Población de la CEPAL.

Pierson, Donald (1945), Brancos e pretos na Bahia: estudo de contacto racial, São Paulo, Companhia Editora Nacional.

Rallu, Jean-Louis, Victor Piché y Patrick Simon (2001), "Démographie et ethnicité: une relation ambiguë", Démographie: analyse et synthèse, Graziella Caselli, Jacques Vallin y Guillaume Wunsch (orgs.), París, Instituto Nacional de Estudios Demográficos (INED).

Sanjek, Roger (1971), "Brazilian racial terms: some aspects of meaning and learning", American Anthropologist, vol. 73, $\mathrm{N}^{\circ}$ 5, American Anthropological Association.

Schkolnik, Susana (2009), "La inclusión del enfoque étnico en los censos de población de América Latina", Notas de Población, No 89 (LC/G.2427-P), Santiago, Centro Latinoamericano y Caribeño de Demografía (CELADE)-División de Población de la CEPAL.

Senra, Nelson (2006), História das estatísticas brasileiras - Estatísticas desejadas (1822-c.1889), Río de Janeiro, Instituto Brasileño de Geografía y Estadística (IBGE).

Sheriff, Robin E. (2002), "Como os senhores chamavam os escravos: discursos sobre cor, raça e racismo num morro carioca”, Raça como retórica: a construção da diferença, Y. Maggie y C.B. Rezende (orgs.), Río de Janeiro, Civilização Brasileira.

Teixeira Pacheco, Moema De Poli (2011), Relações raciais na sociedade brasileira/Notas sobre a etiqueta das relações raciais no Brasil, vol. 6, Cuiabá, Editora da Universidade Federal de Mato Grosso.

(1987), "A questão da cor nas relações e representações de um grupo de baixa renda", Estudos Afro-Asiáticos, $\mathrm{N}^{\circ} 14$. 
Teixeira Pacheco, Moema De Poli y Kaizô Iwakami Beltrão (2008), "Eu e o outro: a alteridade próxima na declaração de cor no quesito aberto da PME 98", Textos para Discussão, $\mathrm{N}^{\circ} 24$, Río de Janeiro, Escuela Nacional de Ciencias Estadísticas (ENCE)/Instituto Brasileño de Geografía y Estadística (IBGE) [en línea] http://www.ence.ibge.gov.br/images/ence/doc/publicacoes/textos_para_ discussao/texto_24.pdf.

Telles, Edward E. (2007), "Incorporating race and ethnicity into the UN Millenium Development Goals", Inter-American Dialogue. Race Report [en línea] http://www.com.thedialogue.org/ PublicationFiles/telles.pdf.

Valle Silva, Nelson (1996), "Morenidade: modo de usar", Estudos Afro-Asiáticos, $\mathrm{N}^{\circ} 30$.

Wagley, Charles (1952), "Introduction", Race and Class in Rural Brazil, Charles Wagley (ed.), París, Organización de las Naciones Unidas para la Educación, la Ciencia y la Cultura (UNESCO). 



\section{Orientaciones para los autores}

\section{Procedimiento de selección}

En la revista Notas de Población se publican artículos originales e inéditos sobre estudios de población, con un enfoque multidisciplinario que abarca, además del ámbito específico de la demografía, las relaciones entre la dinámica demográfica, los fenómenos económicos y sociales y la sostenibilidad ambiental. Los artículos se deberán orientar de preferencia a América Latina y el Caribe, si bien en ocasiones podrán incluirse contribuciones relativas a otras regiones del mundo.

Los manuscritos deben estar escritos en español, aunque en algunos casos también podrán admitirse materiales en otros idiomas, que, de ser aceptados, serán traducidos al español para su publicación. Excepcionalmente y previo consentimiento del autor se publicarán traducciones de artículos ya publicados en otras lenguas.

Junto con el texto original, cada artículo debe incluir lo siguiente:

- Título.

- Datos del autor o los autores, entre los que deben figurar el nombre completo, una mención de los títulos académicos, la afiliación institucional, una sinopsis curricular, la dirección electrónica y el nombre del proyecto de investigación del que se deriva el artículo, si procede.

- Un mínimo de cinco palabras clave y un máximo de ocho.

- Un resumen de 160 palabras, como máximo.

- Bibliografía, de acuerdo con las normas editoriales de la revista.

- Una declaración concisa y clara de que el artículo es original, no ha sido publicado anteriormente y no se encuentra en proceso de revisión en ninguna otra publicación impresa o electrónica.

\section{Proceso de evaluación y dictamen}

Todos los artículos recibidos serán sometidos a una revisión inicial por parte del Comité Editorial, que verificará el cumplimiento de las normas editoriales básicas de la revista, la pertinencia temática y la adecuada estructuración del trabajo como artículo científico.

Los artículos aceptados en esta primera etapa serán sometidos al arbitraje de evaluadores externos por el sistema de doble ciego, conservándose el anonimato tanto de los autores como de los árbitros o dictaminadores.

Los árbitros evaluarán la pertinencia, relevancia y novedad del tema de acuerdo con la orientación de la revista, junto con la originalidad y el aporte conceptual o metodológico del artículo con respecto a los estudios de población.

Asimismo, analizarán si el trabajo se ha estructurado y ordenado adecuadamente, es decir, si se presentan con claridad los datos, la metodología, los objetivos y las hipótesis; si los cuadros, recuadros, gráficos, mapas y diagramas son ilustrativos y claros; si las referencias se encuentran actualizadas y correctamente citadas, y si existe coherencia entre los objetivos y los resultados del estudio.

Los evaluadores emitirán un dictamen que se concretará en una de las tres opciones siguientes: publicación con cambios menores, publicación con cambios mayores o rechazo del artículo. En caso de que el dictamen sea de publicación con cambios, los árbitros detallarán las modificaciones que consideren pertinentes para mejorar el artículo y estas serán comunicadas al autor, quien, previa aceptación, deberá enviar la versión definitiva dentro del plazo que el Comité Editorial establezca.

Si se produjeran divergencias en los dictámenes de los árbitros, el Comité Editorial de la revista determinará si el artículo debe someterse a una revisión adicional o cómo debe resolverse la controversia.

El Comité Editorial se reserva el derecho de efectuar modificaciones de forma al texto, los cuadros y recuadros y los elementos gráficos, con el fin de satisfacer las exigencias editoriales de la revista. 


\section{Política editorial}

Los autores se comprometerán a no presentar el material a ninguna otra revista durante tres meses, plazo dentro del cual recibirán respuesta confirmando o no la publicación del artículo. Los originales no serán devueltos en ningún caso. En los casos de no aprobación, las observaciones de los árbitros no se enviarán a los autores.

\section{Normas editoriales}

Extensión: El texto de los artículos no debe exceder las 10.000 palabras (incluidos cuadros, recuadros, gráficos, mapas, diagramas, notas y bibliografía).

Formato: El texto debe enviarse en un archivo electrónico de Word.

Cuadros: Deben insertarse en el archivo Word, como contenido editable, en el lugar que corresponda dentro del texto.

Gráficos: Deben insertarse en el archivo de Word, en forma de imagen, en el lugar que corresponda dentro del texto. Es indispensable adjuntar además un archivo de Excel que contenga todos los gráficos editables en el orden en que aparecen en el texto. En el archivo de Excel cada gráfico debe ocupar una hoja, en cuya pestaña se debe indicar el número del gráfico.

Diagramas: Deben insertarse en el archivo de Word, como contenido editable, en el lugar que corresponda dentro del texto.

Referencias a cuadros, recuadros y elementos gráficos: En el texto debe haber al menos una referencia a cada cuadro, recuadro, gráfico, mapa o diagrama. Asimismo, todos estos elementos deben incluir el título, la fuente y la unidad de medida de los datos presentados, si procede.

Fórmulas matemáticas: Se sugiere numerar las fórmulas matemáticas con cifras arábigas entre paréntesis y alineadas a la derecha.

Notas explicativas: Todas las notas deben insertarse a pie de página y estar numeradas correlativamente.

Referencias bibliográficas: Cada referencia bibliográfica mencionada en el texto debe incluir, entre paréntesis, el apellido del autor y el año de publicación.

Bibliografía: Debe figurar al final del texto. Los registros bibliográficos se presentarán en orden alfabético por el apellido del autor, seguido del nombre de pila, el año de publicación entre paréntesis, el título completo, la ciudad de publicación y la editorial.

\section{Ejemplos:}

\section{Libro con dos autores}

Auerbach, A. y L. Kotlikoff (1987), Dynamic Fiscal Policy, Cambridge, Cambridge University Press.

\section{Artículo con tres autores}

Auerbach, A., J. Gokhale y L. Kotlikoff (1994), "Generational accounting: a meaningful way to evaluate fiscal policy", Journal of Economic Perspectives, vol. 8, № 1.

(1991), "Generational accounts: a meaningful alternative to deficit accounting", Tax Policy and the Economy, vol. 5, David Bradford (ed.), The MIT Press.

\section{Publicación electrónica con más de tres autores}

Mason, A. y otros (2009), "National Transfer Accounts Manual. Draft Version 1.0" [en línea] http://www. ntaccounts.org/doc/repository/NTA\%20Manual\%20V1\%20Draft.pdf.

\section{Autor institucional:}

CEPAL (Comisión Económica para América Latina y el Caribe) (2009), Panorama Social de América Latina, 2008 (LC/G.2402-P/E), Santiago de Chile. Publicación de las Naciones Unidas, Nº de venta: S.08.II.G.89.

\section{Mismo autor, mismo año:}

Lee, R. (1994a), "The formal demography of population aging, transfers, and the economic life cycle", Demography of Aging, Linda G. Martin y Samuel H. Preston (eds.), Washington, D.C., National Academy Press. _ (1994b), "Population age structure, intergenerational transfers, and wealth: a new approach, with applications to the U.S.", Journal of Human Resources, vol. 29, № 4, número especial. 


\section{Guidelines for authors}

\section{Selection procedure}

The journal Notas de Población publishes original, unpublished articles on population studies, and has a multidisciplinary approach that covers not only the field of demography but also the links between demographic trends and economic and social phenomena and environmental sustainability. Articles should relate preferably to Latin America and the Caribbean, although contributions relating to other regions may on occasion be included.

Manuscripts must be drafted in Spanish, although in certain cases material may be submitted in other languages. If accepted for publication, the article would be translated into Spanish. Exceptionally, translations into other languages may be published with the author's permission.

Along with the original text, articles must contain the following:

- Title.

- Details of the author(s), including full name, academic qualifications, institutional affiliation, career synopsis, e-mail address, and the name of the research project with which the article is associated, if applicable.

- Between five and eight key words.

- An abstract of up to 160 words.

- A bibliography, prepared in accordance with the editorial rules applicable to the journal.

- A concise and clear declaration stating that the article is original, has not been published before and is not currently being reviewed by any other print or electronic publication.

\section{Review and evaluation process}

All articles received are reviewed initially by the Editorial Committee, which looks at whether they comply with the journal's basic editorial rules, the relevance of the subject matter, and whether the structure of the text is appropriate for a scientific article.

Articles that pass this initial stage are then reviewed by external assessors using a double-blind review system, in which both the author and the referees or reviewers remain anonymous.

The referees will first of all consider the pertinence, relevance and novelty of the subject matter, with reference to the journal's editorial stance, as well as the article's potential contribution to population studies in terms of its originality, concept and methodology.

They will then assess whether the work has been properly structured and organized, that is, whether the data, methodology, objectives and hypotheses have been clearly set out; whether the tables, boxes, figures, maps and diagrams are illustrative and clear; whether the references are up to date and correctly cited; and whether the objectives are consistent with the results of the study.

The assessors will make one of the following recommendations: publication with minor changes; publication with major changes; or rejection of the article. In the event that the referees decide the article should be published with changes, they will list the alterations they deem necessary to improve the article and notify the author accordingly. Should the author accept, the final version must be submitted by the deadline stipulated by the Editorial Committee.

If there are differences of opinion among the referees, the Editorial Committee will decide whether the article must undergo a second review or how this can be resolved.

The Editorial Committee reserves the right to make non-substantive changes to the text, tables, boxes and figures in order to satisfy the journal's editorial requirements. 


\section{Editorial policy}

Authors must undertake not to submit their material to any other publication for a period of three months, during which time they will be notified of the outcome of the review process. Please note that originals cannot be returned. If an article is not accepted, referees' comments will not be sent to the authors.

\section{Editorial rules}

Length: Articles must be no longer than 10,000 words (including tables, figures, maps, diagrams, notes and the bibliography).

Format: The text must be submitted in an electronic Word file.

Tables: These must be in an editable format and inserted in the Word file in the appropriate place.

Figures: These must be in image format and inserted in the Word file in the appropriate place. An Excel file must also be submitted containing editable versions of all the figures in the order in which they appear in the text. Each figure must appear on a separate sheet of the Excel file, and the number of the figure should be indicated on the tab.

Diagrams: These must be in an editable format and inserted in the Word file in the appropriate place.

References to tables, boxes and figures: There must be at least one reference to each table, box, figure, map and diagram within the body of the text. Each one must also have a title, source, and unit of measurement where appropriate.

Mathematical formulae: Mathematical formulae should be numbered using Arabic numerals in brackets and right aligned.

Explanatory notes: All notes must be inserted as footnotes and numbered sequentially.

Bibliographical references: Bibliographical references in the body of the text must contain the last name of the author and the year of publication in brackets.

Bibliography: This should appear at the end of the article. Bibliographical entries must be presented in alphabetical order by author's last name, followed by their first initial, year of publication in brackets, full title, city of publication and the publisher's name.

\section{Examples:}

\section{A book with two authors:}

Auerbach, A. and L. Kotlikoff (1987), Dynamic Fiscal Policy, Cambridge, Cambridge University Press.

\section{A paper with three authors}

Auerbach, A., J. Gokhale and L. Kotlikoff (1994), "Generational accounting: a meaningful way to evaluate fiscal policy", Journal of Economic Perspectives, vol. 8, No. 1.

(1991), "Generational accounts: a meaningful alternative to deficit accounting", Tax Policy and the Economy, vol. 5, David Bradford (ed.), The MIT Press.

\section{An e-publication with more than three authors:}

Mason, A. and others (2009), "National Transfer Accounts Manual. Draft Version 1.0" [online] http://www. ntaccounts.org/doc/repository/NTA\%20Manual\%20V1\%20Draft.pdf.

\section{An institutional author:}

ECLAC (Economic Commission for Latin America and the Caribbean) (2009), Social Panorama of Latin America, 2008 (LC/G.2402-P/E), Santiago, Chile. United Nations publication, Sales No: ES.08.II.G.89.

Same author, same year:

Lee, R. (1994a), "The formal demography of population aging, transfers, and the economic life cycle", Demography of Aging, Linda G. Martin y Samuel H. Preston (eds.), Washington, D.C., National Academy Press. (1994b), "Population age structure, intergenerational transfers, and wealth: a new approach, with applications to the U.S.", Journal of Human Resources, vol. 29, No. 4, special issue. 


\section{Publicaciones recientes de la CEPAL ECLAC recent publications}

\section{www.cepal.org/publicaciones}

\section{Informes periódicos / Annual reports}

\section{También disponibles para años anteriores / Issues for previous years also available}

- Estudio Económico de América Latina y el Caribe 2015, 204 p. Economic Survey of Latin America and the Caribbean 2015, 196 p.

- La Inversión Extranjera Directa en América Latina y el Caribe 2015, 150 p. Foreign Direct Investment in Latin America and the Caribbean 2015, 140 p.

- Anuario Estadístico de América Latina y el Caribe 2014 / Statistical Yearbook for Latin America and the Caribbean 2014, 238 p.

- Balance Preliminar de las Economías de América Latina y el Caribe 2014, 92 p. Preliminary Overview of the Economies of Latin America and the Caribbean 2014, 92 p.

- Panorama Social de América Latina 2014, 296 p. Social Panorama of Latin America 2014, 284 p.

- Panorama de la Inserción Internacional de América Latina y el Caribe 2014, 148 p. Latin America and the Caribbean in the World Economy 2014, 140 p.

\section{Libros y documentos institucionales / Institutional books and documents}

- La nueva revolución digital: de la Internet del consumo a la Internet de la producción, 2015, 98 p. The new digital revolution: From the consumer Internet to the industrial Internet, 2015, 98 p.

- Panorama fiscal de América Latina y el Caribe 2015: dilemas y espacios de políticas, 2015, 128 p. Fiscal Panorama of Latin America and the Caribbean 2015: Policy space and dilemmas. Executive Summary, 2015, $14 p$.

- La economía del cambio climático en América Latina y el Caribe: paradojas y desafíos del desarrollo sostenible, 2014, $96 \mathrm{p}$.

The economics of climate change in Latin America and the Caribbean: Paradoxes and challenges of sustainable development, 2014, 92 p.

- El desafío de la sostenibilidad ambiental en América Latina y el Caribe: textos seleccionados de la CEPAL 2012-2014, 2015, 148 p.

- Los pueblos indígenas en América Latina: avances en el último decenio y retos pendientes para la garantía de sus derechos, 2014, 410 p.

- Pactos para la igualdad: hacia un futuro sostenible, 2014, $340 \mathrm{p}$. Covenants for Equality: Towards a sustainable future, 2014, 330 p.

- Integración regional: hacia una estrategia de cadenas de valor inclusivas, 2014, 226 p. Regional Integration: Towards an inclusive value chain strategy, 2014, 218 p. Integração regional: por uma estratégia de cadeias de valor inclusivas, 2014, 226 p.

- Prospectiva y desarrollo: el clima de la igualdad en América Latina y el Caribe a 2020, 2013, 72 p. 
- Comercio internacional y desarrollo inclusivo: construyendo sinergias, 2013, $210 \mathrm{p}$.

International trade and inclusive development: Building synergies, 2013, 200 p.

- Cambio estructural para la igualdad: una visión integrada del desarrollo, 2012, $330 \mathrm{p}$.

Structural Change for Equality: An integrated approach to development, 2012, 308 p.

- La hora de la igualdad: brechas por cerrar, caminos por abrir, 2010, $290 \mathrm{p}$.

Time for Equality: Closing gaps, opening trails, 2010, 270 p.

A Hora da Igualdade: Brechas por fechar, caminhos por abrir, 2010, 268 p.

\section{Libros de la CEPAL / ECLAC books}

136 Instrumentos de protección social: caminos latinoamericanos hacia la universalización, Simone Cecchini, Fernando Filgueira, Rodrigo Martínez, Cecilia Rossel (eds.), 2015, 510 p.

135 Rising concentration in Asia-Latin American value chains: Can small firms turn the tide? Osvaldo Rosales, Osvaldo, Keiji Inoue, Nanno Mulder (eds.), 2015, 282 p.

134 Desigualdad, concentración del ingreso y tributación sobre las altas rentas en América Latina, Juan Pablo Jiménez (ed.), 2015, 172 p.

133 Desigualdad e informalidad: un análisis de cinco experiencias latinoamericanas, Verónica Amarante, Rodrigo Arim (eds.), 2015, $526 \mathrm{p}$.

132 Neoestructuralismo y corrientes heterodoxas en América Latina y el Caribe a inicios del siglo XXI, Alicia Bárcena, Antonio Prado (eds.), 2014, 452 p.

131 El nuevo paradigma productivo y tecnólogico: la necesidad de políticas para la autonomía económica de las mujeres, Lucía Scuro, Néstor Bercovich (eds.), 2014, 188 p.

130 Políticas públicas para la igualdad de género: un aporte a la autonomía de las mujeres, María Cristina Benavente, Alejandra Valdés, 2014, 134 p.

\section{Copublicaciones / Co-publications}

- Gobernanza global y desarrollo: nuevos desafíos y prioridades de la cooperación internacional, José Antonio Ocampo (ed.), CEPAL/Siglo Veintiuno, Argentina, 2015, 286 p.

- Decentralization and Reform in Latin America: Improving Intergovernmental Relations, Giorgio Brosio and Juan Pablo Jiménez (eds.), ECLAC / Edward Elgar Publishing, United Kingdom, 2012, $450 \mathrm{p}$.

- Sentido de pertenencia en sociedades fragmentadas: América Latina desde una perspectiva global, Martín Hopenhayn y Ana Sojo (comps.), CEPAL / Siglo Veintiuno, Argentina, 2011, 350 p.

\section{Coediciones / Co-editions}

- Perspectivas económicas de América Latina 2015: educación, competencias e innovación para el desarrollo, CEPAL/OCDE, 2014, $200 \mathrm{p}$.

Latin American Economic Outlook 2015: Education, skills and innovation for development, ECLAC,/ CAF/OECD, 2014, $188 \mathrm{p}$.

- Regional Perspectives on Sustainable Development: Advancing Integration of its Three Dimensions through Regional Action, ECLAC-ECE-ESCAP-ESCWA, 2014, 114 p.

- Perspectivas de la agricultura y del desarrollo rural en las Américas: una mirada hacia América Latina y el Caribe 2014, CEPAL / FAO / IICA, 2013, 220 p. 


\section{Cuadernos de la CEPAL}

101 Redistribuir el cuidado: el desafío de las políticas, Coral Calderón Magaña (coord.), 2013, 460 p.

101 Redistributing care: The policy challenge, Coral Calderón Magaña (coord.), 2013, 420 p.

\section{Documentos de proyecto / Project documents}

- La economía del cambio climático en el Perú, 2014, 152 p.

- La economía del cambio climático en la Argentina: primera aproximación, 2014, 240 p.

- La economía del cambio climático en el Ecuador 2012, 2012, 206 p.

\section{Cuadernos estadísticos de la CEPAL}

42 Resultados del Programa de Comparación Internacional (PCI) de 2011 para América Latina y el Caribe. Solo disponible en CD, 2015.

41 Los cuadros de oferta y utilización, las matrices de insumo-producto y las matrices de empleo. Solo disponible en CD, 2013.

\section{Series de la CEPAL / ECLAC Series}

Asuntos de Género / Comercio Internacional / Desarrollo Productivo / Desarrollo Territorial / Estudios Estadísticos / Estudios y Perspectivas (Bogotá, Brasilia, Buenos Aires, México, Montevideo) / Studies and Perspectives (The Caribbean, Washington) / Financiamiento del Desarrollo/ Gestión Pública / Informes y Estudios Especiales / Macroeconomía del Desarrollo / Manuales / Medio Ambiente y Desarrollo / Población y Desarrollo/ Política Fiscal / Políticas Sociales / Recursos Naturales e Infraestructura / Seminarios y Conferencias.

\section{Revista CEPAL / CEPAL Review}

La Revista se inició en 1976, con el propósito de contribuir al examen de los problemas del desarrollo socioeconómico de la región. La Revista CEPAL se publica en español e inglés tres veces por año.

CEPAL Review first appeared in 1976, its aim being to make a contribution to the study of the economic and social development problems of the region. CEPAL Review is published in Spanish and English versions three times a year.

\section{Observatorio demográfico / Demographic Observatory}

Edición bilingüe (español e inglés) que proporciona información estadística actualizada, referente a estimaciones y proyecciones de población de los países de América Latina y el Caribe. Desde 2013 el Observatorio aparece una vez al año.

Bilingual publication (Spanish and English) proving up-to-date estimates and projections of the populations of the Latin American and Caribbean countries. Since 2013, the Observatory appears once a year. 


\section{Notas de población}

Revista especializada que publica artículos e informes acerca de las investigaciones más recientes sobre la dinámica demográfica en la región. También incluye información sobre actividades científicas y profesionales en el campo de población.

La revista se publica desde 1973 y aparece dos veces al año, en junio y diciembre.

Specialized journal which publishes articles and reports on recent studies of demographic dynamics in the region. Also includes information on scientific and professional activities in the field of population. Published since 1973, the journal appears twice a year in June and December.

Las publicaciones de la CEPAL están disponibles en: ECLAC publications are available at:

\section{www.cepal.org/publicaciones}

También se pueden adquirir a través de: They can also be ordered through:

www.un.org/publications

United Nations Publications

PO Box 960

Herndon, VA 20172

USA

Tel. (1-888)254-4286

Fax (1-800)338-4550

Contacto / Contact. publications@un.org

Pedidos / Orders: order@un.org 
